Purdue University

October 2015

\title{
Member-Level Redundancy of Built-Up Steel Girders Subjected to Flexure
}

Matthew H. Hebdon

Virginia Tech, mhebdon@vt.edu

Cem Korkmaz

Purdue University, ckorkmaz@purdue.edu

Francisco Javier Bonachera Martín

Purdue University, fbonache@purdue.edu

Robert J. Connor

Purdue University, rconnor@purdue.edu 


\section{RECOMMENDED CITATION}

Hebdon, M. H., Korkmaz, C., Martín, F. J., \& Connor, R. J. (2015). Member-level redundancy of built-up steel girders subjected to flexure. West Lafayette, IN: Purdue University. https://doi.org/10.5703/1288284316728

\section{AUTHORS}

Matthew H. Hebdon, Ph.D., P.E.

Assistant Professor of Civil Engineering

Virginia Tech

(540) 231-6753

mhebdon@vt.edu

\section{Cem Korkmaz}

Ph.D. Candidate

Purdue University

ckorkmaz@purdue.edu

\section{Francisco Javier Bonachera Martín}

$\mathrm{Ph} . \mathrm{D}$. Candidate

Purdue University

fbonache@purdue.edu

\section{Robert J. Connor, Ph.D.}

Associate Professor of Civil Engineering

Director of S-BRITE Center

Purdue University

(765) 496-8272

rconnor@purdue.edu

Corresponding Author

\section{ACKNOWLEDGMENTS}

This project was funded by the Transportation Pooled Fund (Study Number TPF-5(253)). Participating agencies include: Federal Highway Administration, Indiana Department of Transportation, Iowa Department of Transportation, Minnesota Department of Transportation, New York State Department of Transportation, Oregon Department of Transportation, Wisconsin Department of Transportation, Wyoming Department of Transportation, and the Army Corps of Engineers. This project benefitted from substantial material and fabrication donations provided by Steel Dynamics Inc., Hirschfeld Industries Bridge Division, Nucor Fastener Division, and the Tennessee Valley Authority. Specific training was provided by Vern Mesler of VJM Metal Craftsman in the art of hot riveting steel built up girders. In addition, we acknowledge the essential contributions from staff professionals and graduate students at Purdue University throughout this research. 
TABLE OF CONTENTS

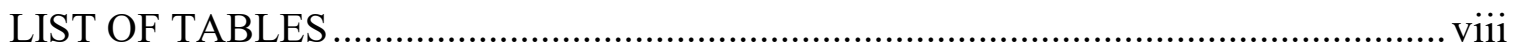

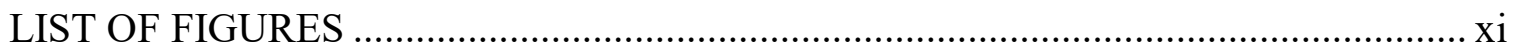

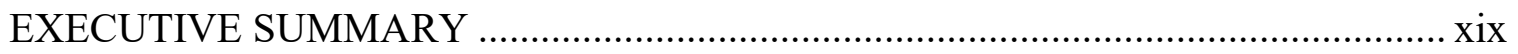

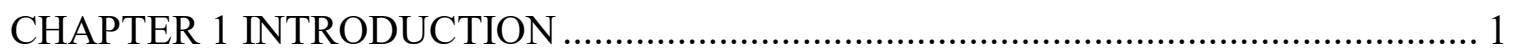

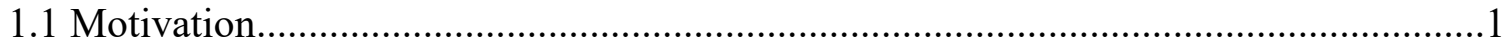

1.2 Construction Practices ................................................................................. 2

1.3 Development of the Fracture Critical Inspection Requirements ............................... 3

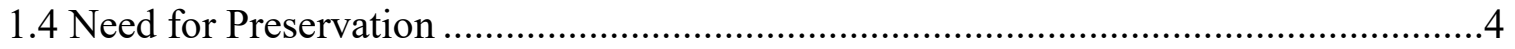

CHAPTER 2 PRIOR RESEARCH AND BACKGROUND ........................................... 5

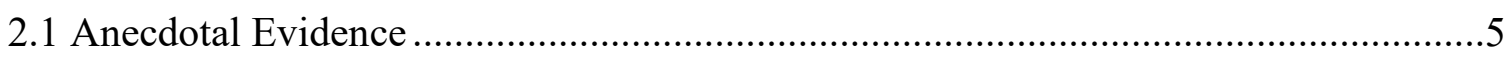

2.1.1 North Fork Mollala River Bridge, Clackamas County, Oregon ........................ 5

2.1.2 University of Texas Research Project............................................................. 7

2.1.3 Hastings Bridge, Minnesota..................................................................... 9

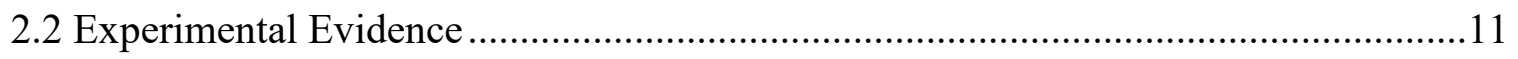

2.2.1 Cha, Lyrenmann, Connor, \& Varma (2014) - Milton Madison Bridge ........... 12

2.2.2 Fisher, Yen, Wang, \& Mann (1987) - NCHRP Project 12-25 ........................ 14

2.2.3 Out (1984) - Fatigue Strength of Weathered and Deteriorated Riveted

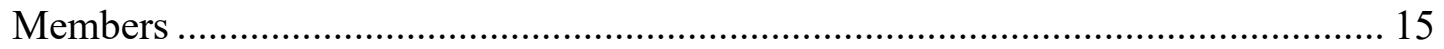

2.2.4 Åkesson (2010) - Fatigue Life of Riveted Steel Bridges ............................. 17

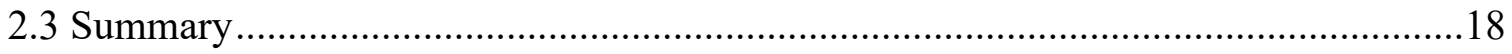

CHAPTER 3 EXPERIMENTAL RESEARCH PROGRAM ....................................... 20

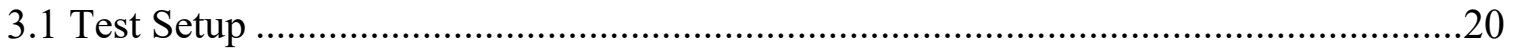

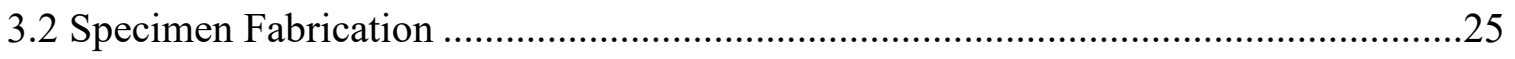




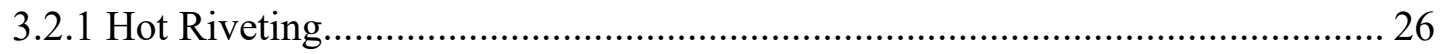

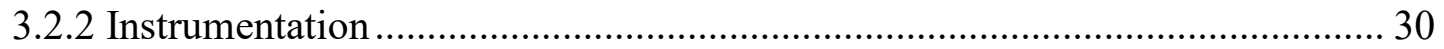

3.2.3 Notched Components.................................................................................. 33

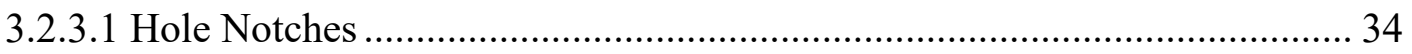

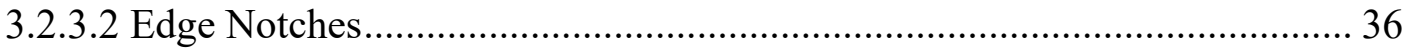

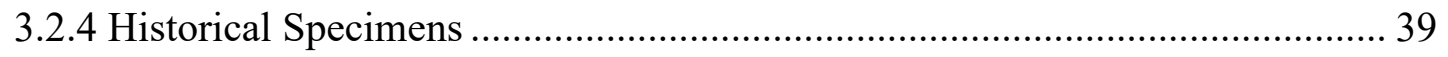

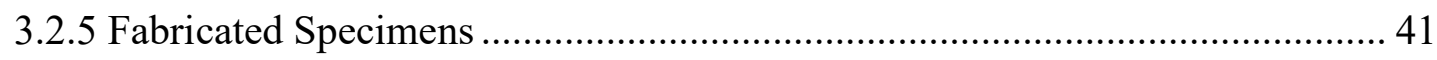

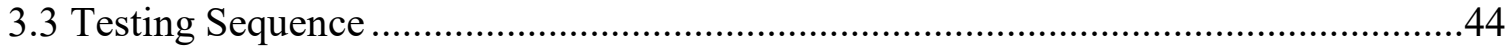

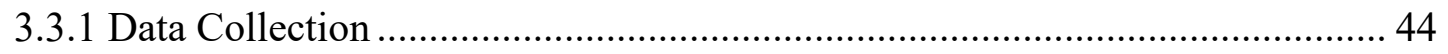

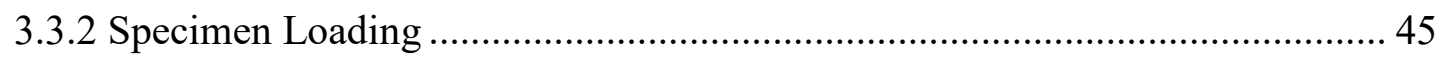

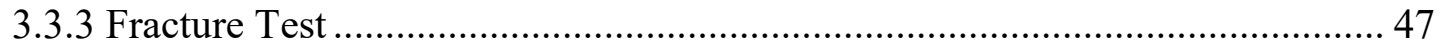

3.3.3.1 Temperature Chamber ......................................................................... 48

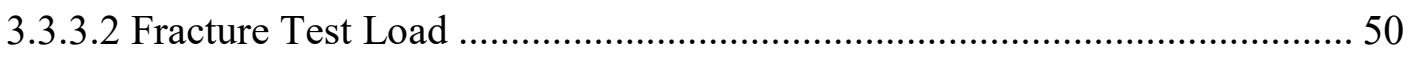

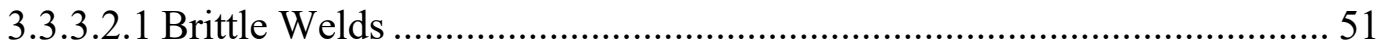

3.3.3.2.2 Driven Wedge Method ...................................................................... 54

3.3.4 After-Failure Fatigue Test ..................................................................... 58

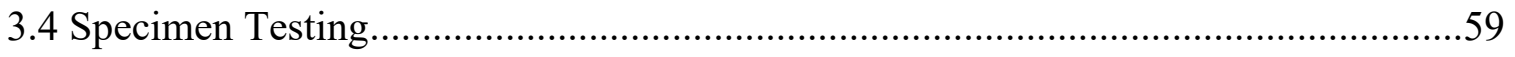

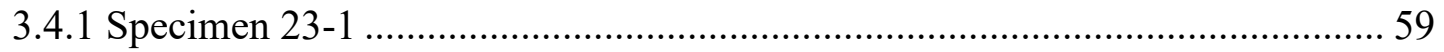

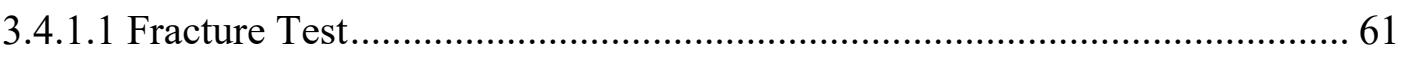

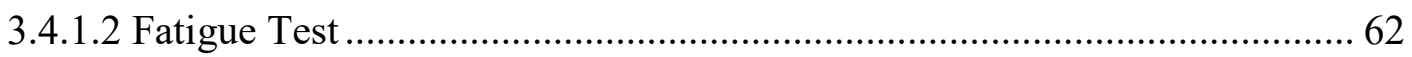

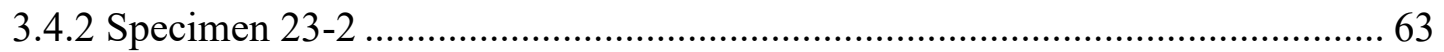

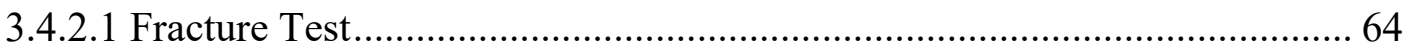

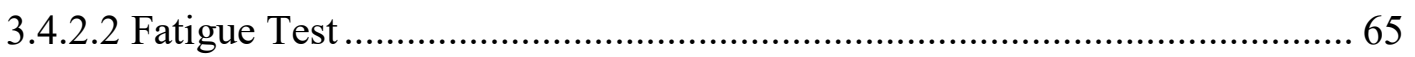

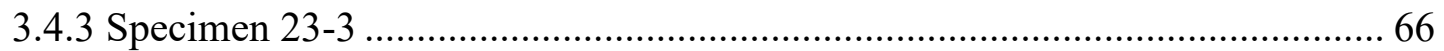

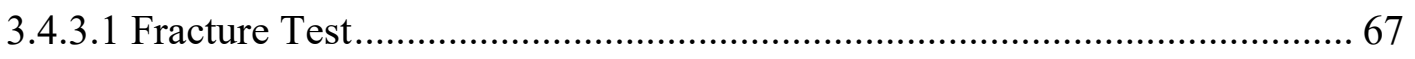

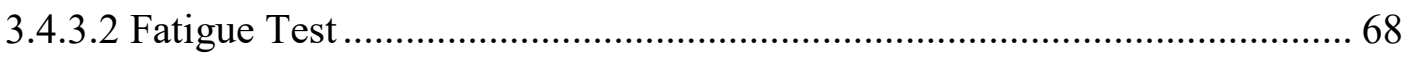

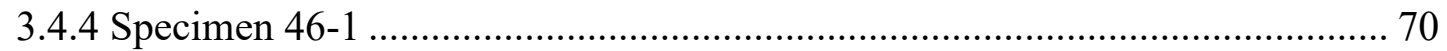

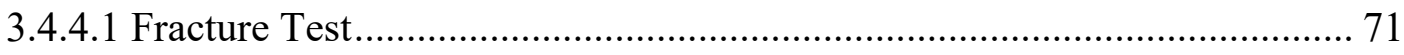

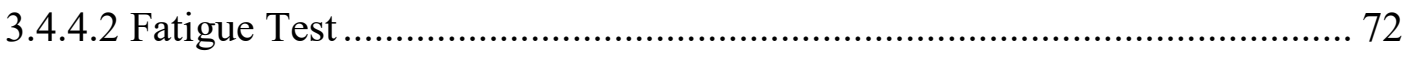

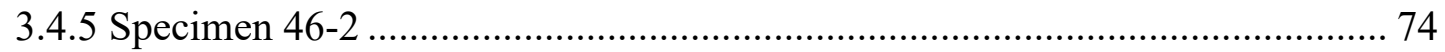




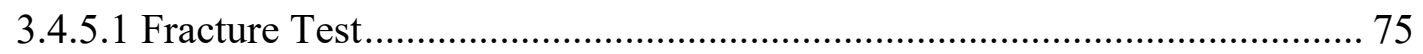

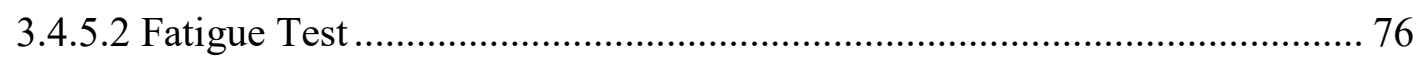

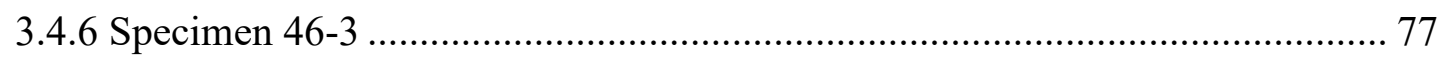

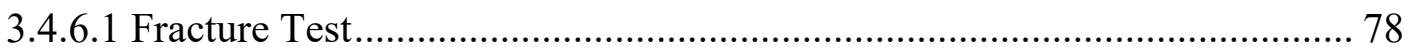

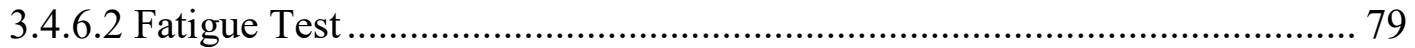

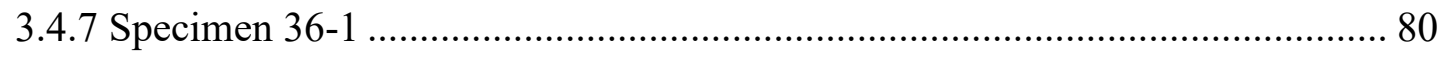

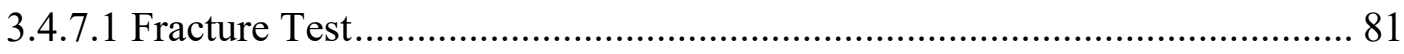

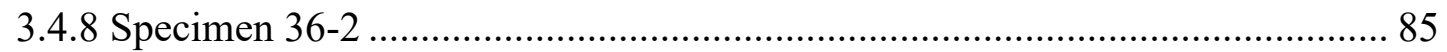

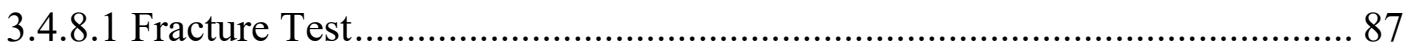

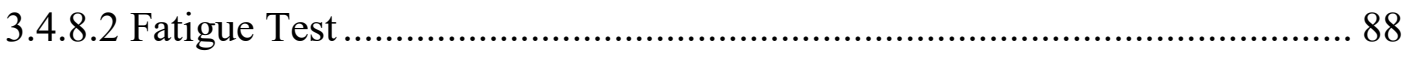

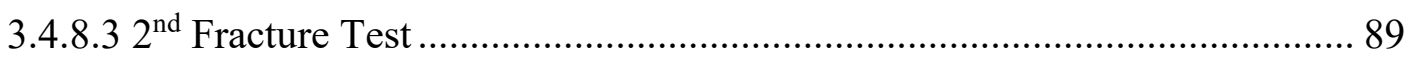

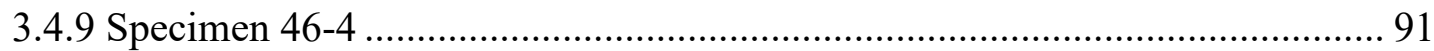

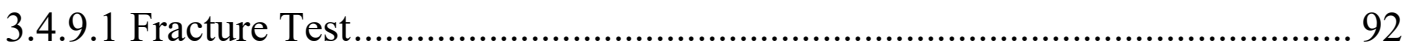

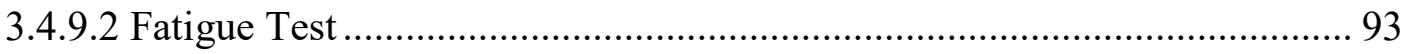

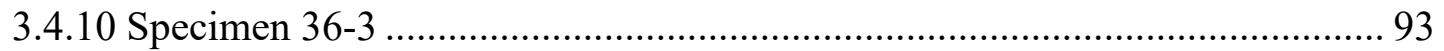

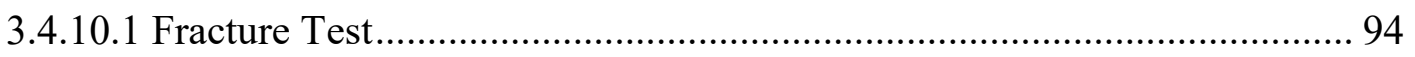

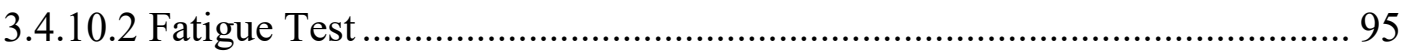

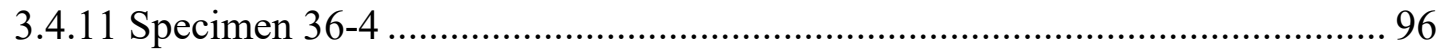

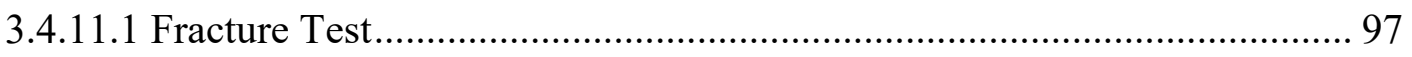

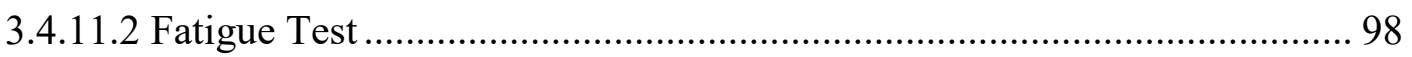

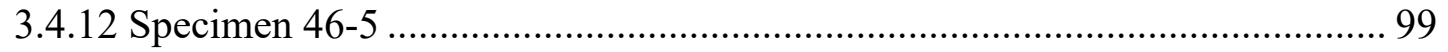

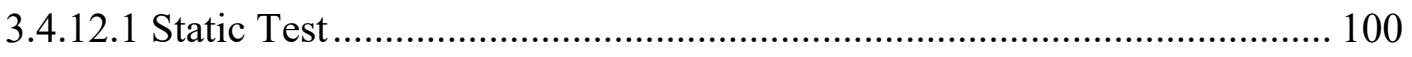

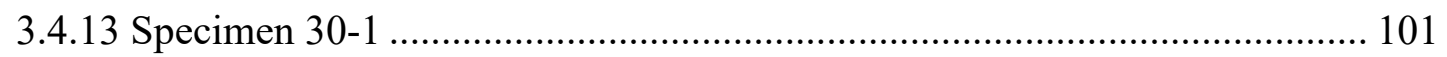

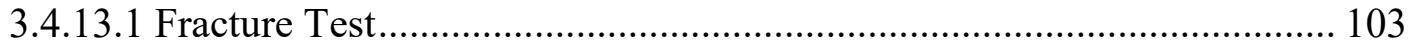

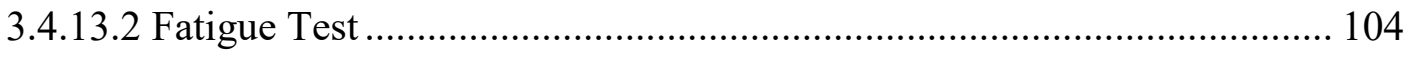

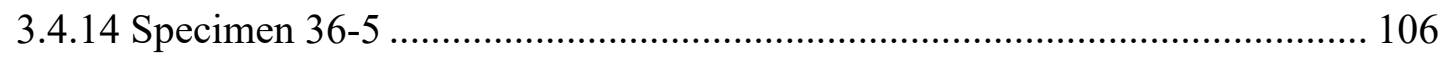

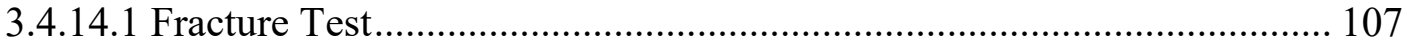

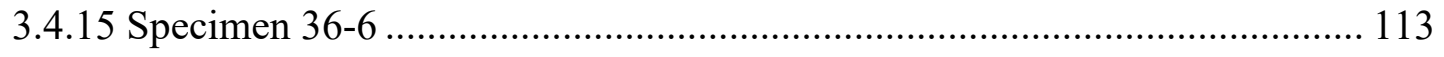

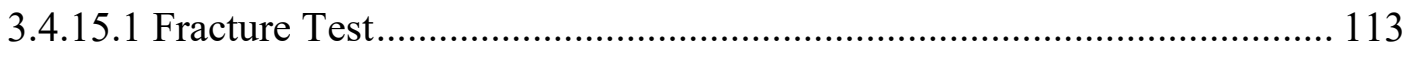

3.5 Experimental Results ..................................................................................115 


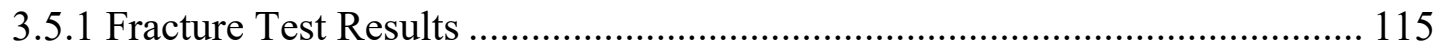

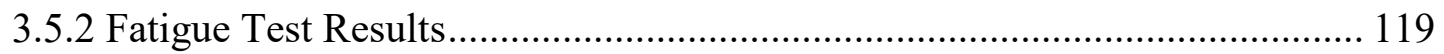

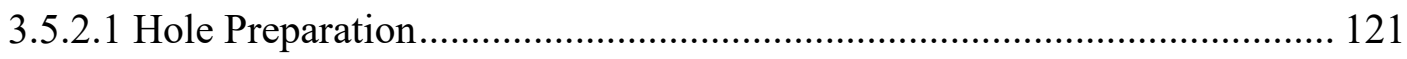

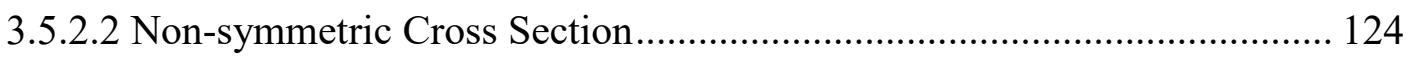

3.5.2.3 Friction Contribution.......................................................................... 125

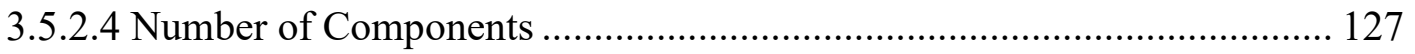

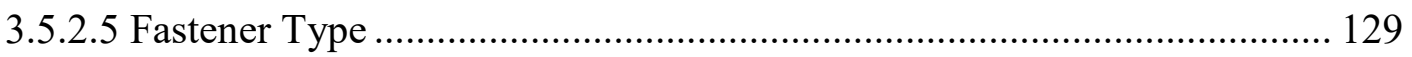

CHAPTER 4 ANALYTICAL RESEARCH PROGRAM ............................................. 132

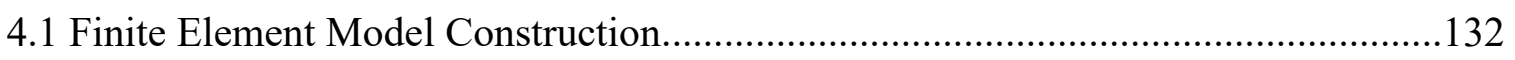

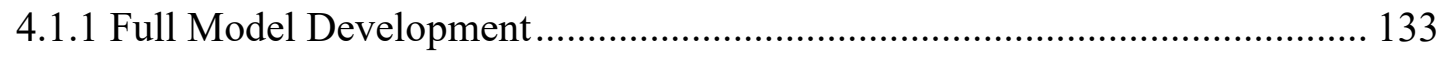

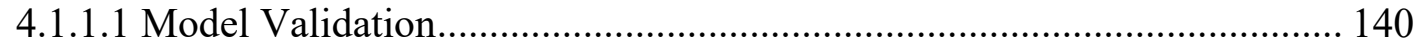

4.1.2 Quarter Model Development .................................................................... 143

4.1.3 Axial Model Development ........................................................................ 145

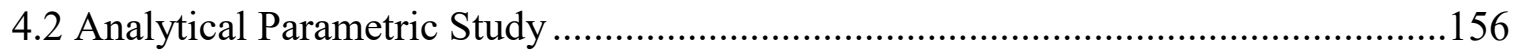

4.2.1 Parametric Model Development .............................................................. 157

4.2.2 Non-symmetric Cross-section ................................................................. 160

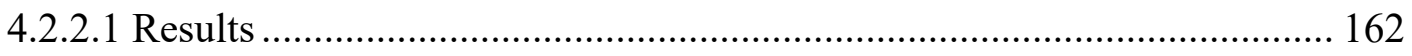

4.2.3 Tension Flange Unbraced Length................................................................ 168

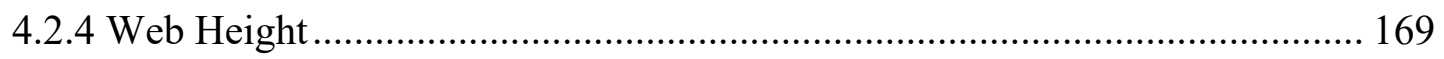

4.2.5 Multiple Flange Components ........................................................................ 171

4.2.6 Parametric Study Summary ……………………….................................... 182

CHAPTER 5 STRESS REDISTRIBUTION EVALUATION METHODOLOGY ....... 184

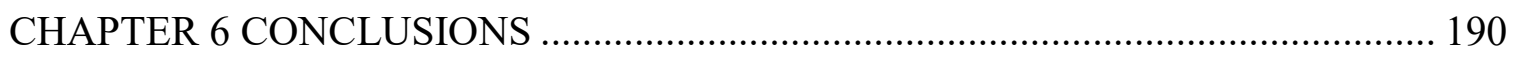

6.1 Summary of Primary Findings...............................................................................190

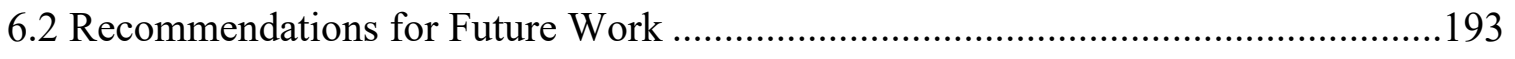

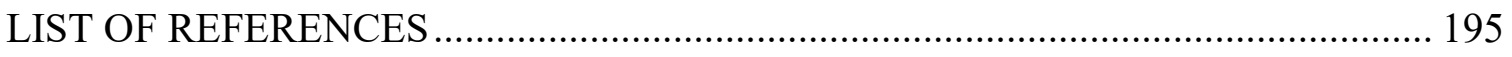

APPENDIX A WILSON DAM BASCULE BRIDGE DESIGN PLANS....................... 201

APPENDIX B HISTORICAL SPECIMEN DESIGN DRAWINGS .............................. 207

APPENDIX C FABRICATED SPECIMEN DESIGN DRAWINGS …………............ 210

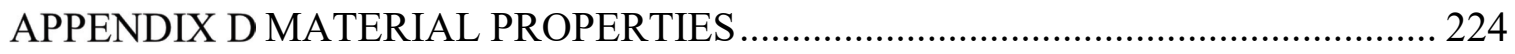


APPENDIX E STRAIN GAGE DRAWINGS ……………........................................ 286

APPENDIX F TABULAR DATA FOR PLASTIC MATERIAL DEFINITION ........... 332 


\section{LIST OF TABLES}

Table

Page

Table 3-1 Specimen 36-5 flange angles accumulated fatigue cycles ......................... 108

Table 3-2 Summary of fracture attempts per specimen ......................................... 117

Table 3-3 Summary of fatigue test data ............................................................. 121

Table 4-1 Stress comparison (FE full model vs. experimental data) ............................ 142

Table 4-2 Stress comparison (FE quarter model vs. experimental data) ...................... 144

Table 4-3 Axial model flange angle mesh refinement parameters ............................. 151

Table 4-4 After-failure net-section stress comparison - failure plane vs. $1^{\text {st }}$ hole ........ 162

Table 4-5 Out-of-plane stress redistribution (20" CP - partial cover plate failure) ....... 165

Table 4-6 Out-of-plane stress redistribution (26" CP - partial cover plate failure) ....... 167

Table 4-7 Web height parameter stress redistribution ............................................ 171

Table 4-8 Longitudinal stress in component adjacent to failed component .................. 174

Table 4-9 Net-section stress comparison (FE model vs. calculated) .......................... 180

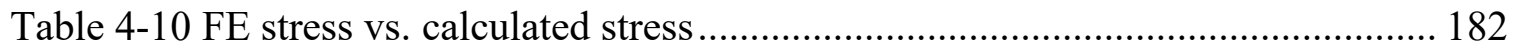

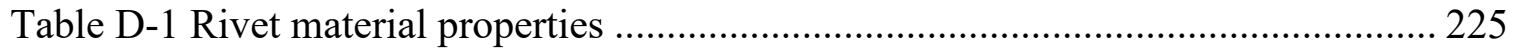

Table D-2 Specimen 23-1 material properties ................................................... 226

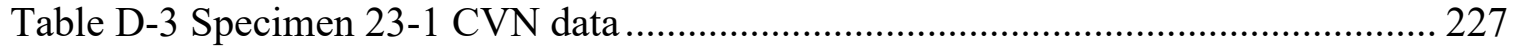

Table D-4 Specimen 23-2 material properties ...................................................... 229 


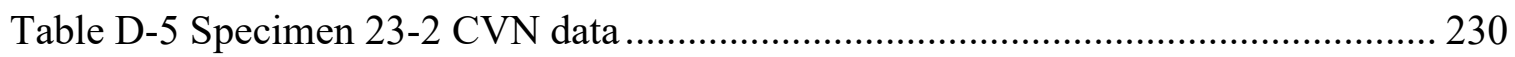

Table D-6 Specimen 23-3 material properties ...................................................... 232

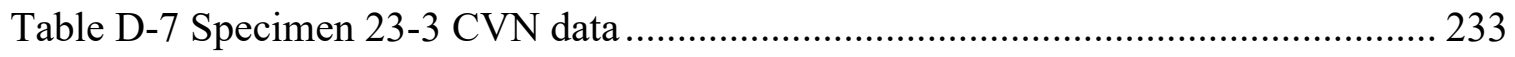

Table D-8 Specimen $30-1$ material properties ........................................................ 235

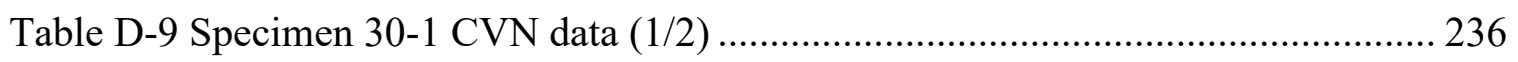

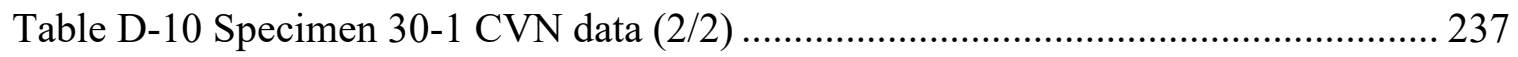

Table D-11 Specimen 36-1 material properties .................................................... 240

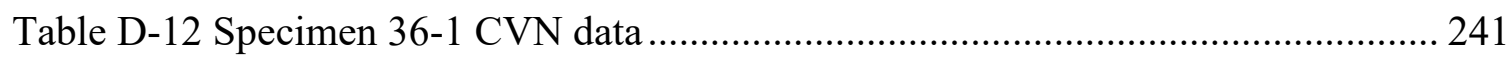

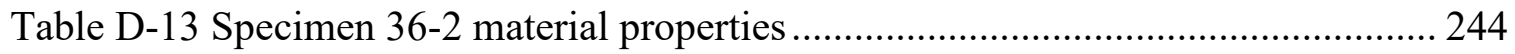

Table D-14 Specimen 36-2 CVN data .............................................................. 245

Table D-15 Specimen 36-3 material properties .................................................... 248

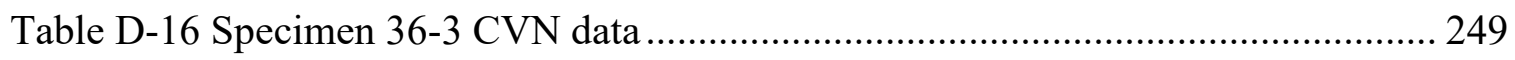

Table D-17 Specimen 36-4 material properties ................................................. 252

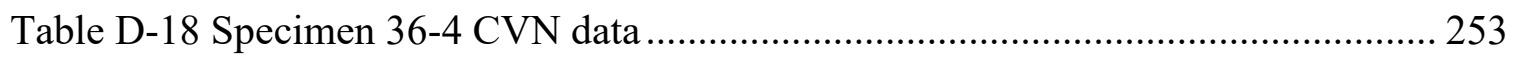

Table D-19 Specimen 36-5 material properties .................................................. 256

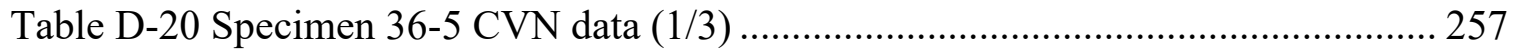

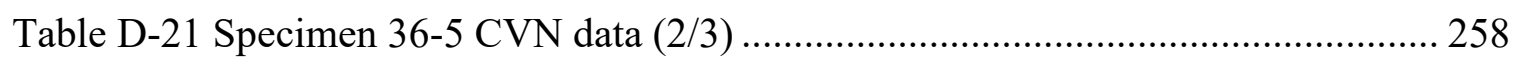

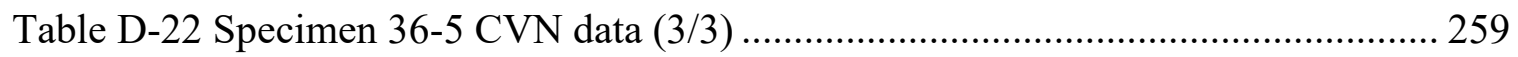

Table D-23 Specimen 36-6 material properties ................................................. 261

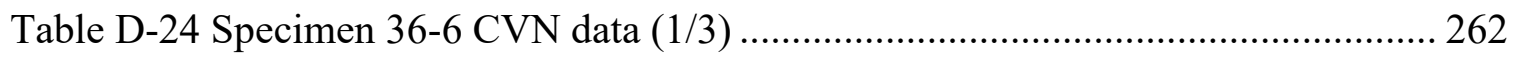

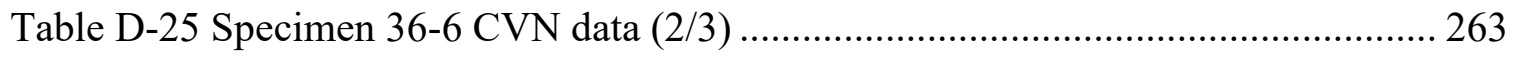

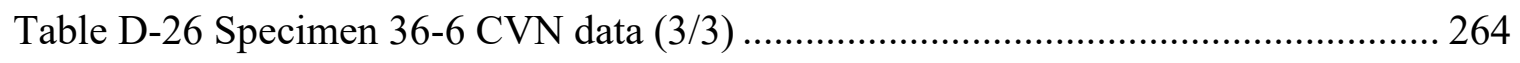

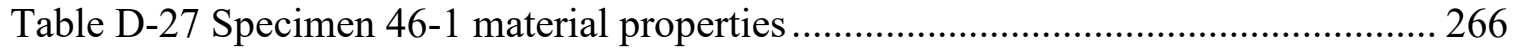




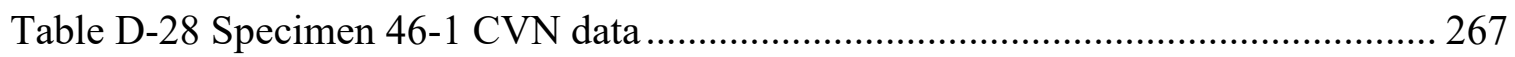

Table D-29 Specimen 46-2 material properties ................................................... 270

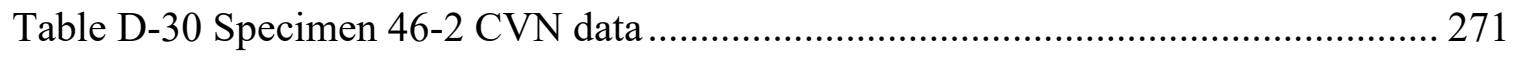

Table D-31 Specimen 46-3 material properties ...................................................... 274

Table D-32 Specimen 46-3 CVN data ................................................................. 275

Table D-33 Specimen 46-4 material properties .................................................... 278

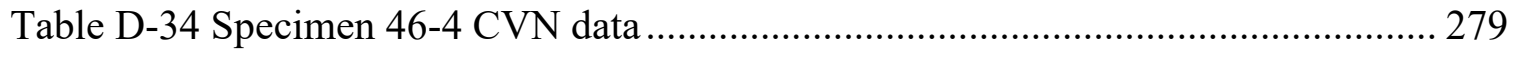

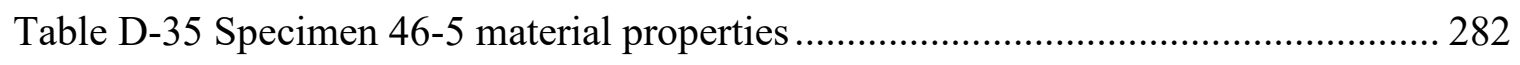

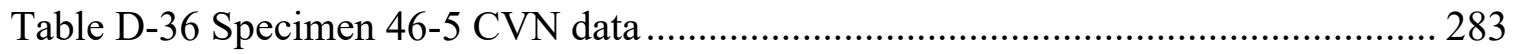

Table F-1 Tabular data for material definition ..................................................... 333 


\section{LIST OF FIGURES}

Figure

Figure 2-1 North Fork Mollala River Bridge, Oregon (OBEC, 2012) ........................... 6

Figure 2-2 Interior view of fractured flange angle (Lovejoy, 2001)............................. 7

Figure 2-3 Elevation view of Texas Research Project Bridge (Fasl, 2013).................... 8

Figure 2-4 Cracked top flange angle (Fasl, 2013) ................................................... 9

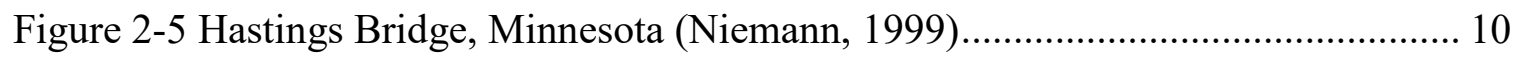

Figure 2-6 Fractured tie girder plate, Hastings Bridge (Niemann, 1999) ....................... 10

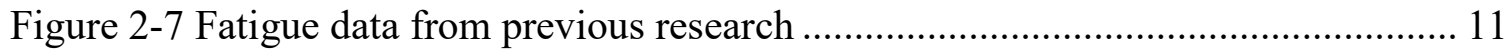

Figure 2-8 Approach span of Milton Madison Bridge, Indiana................................... 13

Figure 2-9 Partially severed bottom chord, Milton Madison Bridge approach span........ 14

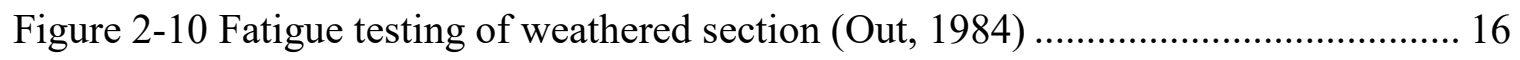

Figure 2-11 Fatigue testing of historical built-up stringers (Åkesson, 2010) .................. 17

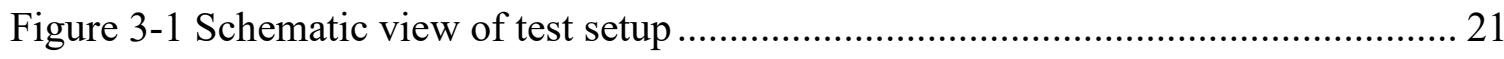

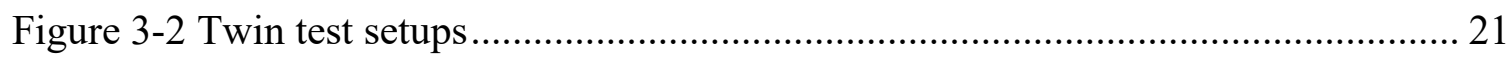

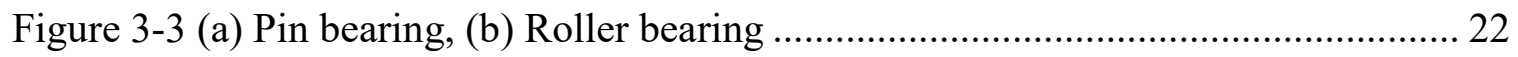

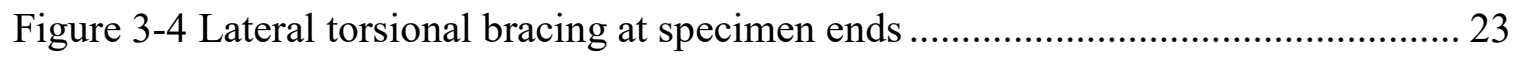

Figure 3-5 Lateral torsional buckling bracing (half-round slider plate method) ............. 24

Figure 3-6 Lateral torsional buckling bracing (thin plate method) .............................. 25 
Figure 3-7 Chicago Pneumatic CP-80RB Rivet Buster.............................................. 27

Figure 3-8 Chicago Pneumatic CP-AA-Offset holder-on........................................... 27

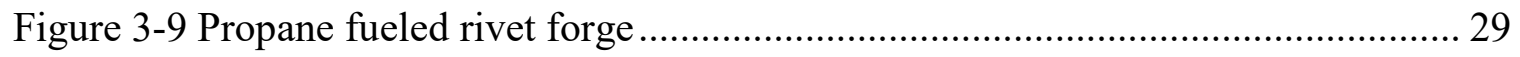

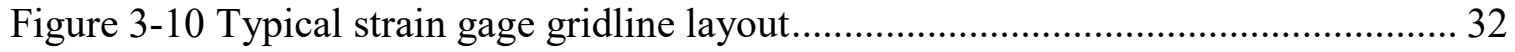

Figure 3-11 Typical 36 inch specimen bottom flange instrumentation .......................... 33

Figure 3-12 Typical hole notch with Dremel 409 cutting wheel .................................. 35

Figure 3-13 Typical edge notch geometry …...................................................... 38

Figure 3-14 Wilson Dam Bascule Bridge in raised position in the background, 1958

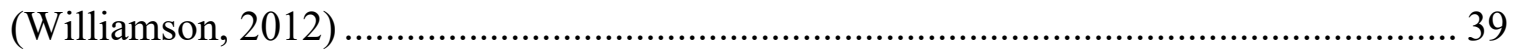

Figure 3-15 Wilson Dam Bascule Bridge specimens ........................................... 40

Figure 3-16 Cover plate installation on historical specimens ................................... 41

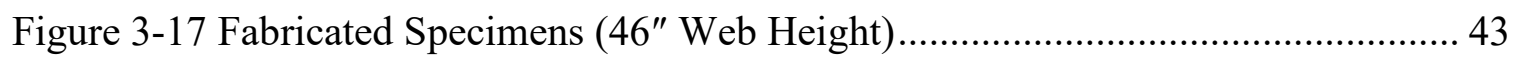

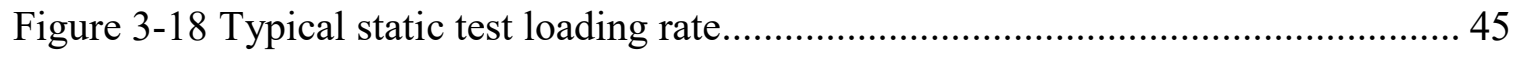

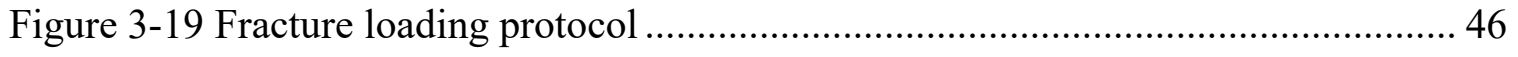

Figure 3-20 Crack growth from notch at a hole (Specimen 46-3) .............................. 48

Figure 3-21 Temperature chamber installed on beam (side view) .............................. 49

Figure 3-22 Temperature chamber installed on beam (end view) .............................. 49

Figure 3-23 Transverse cracks in Wearshield ME weld metal .................................... 52

Figure 3-24 Edge notch with Wearshield ME weld at notch tip................................. 53

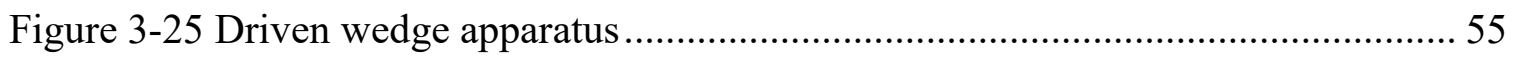

Figure 3-26 Driven wedge apparatus installed on Specimen 36-2 .............................. 56

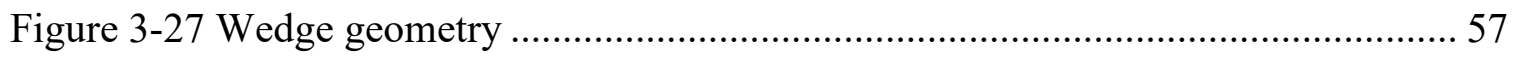

Figure 3-28 Stress intensity vs. number of fasteners removed .................................. 58 
Figure 3-29 Specimen 23-1 application of grease between components........................ 60

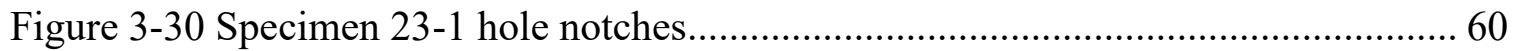

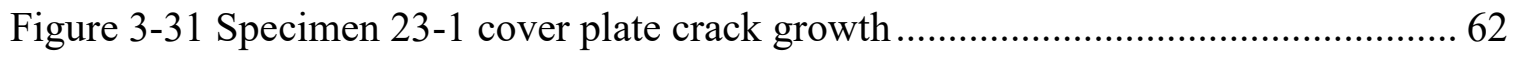

Figure 3-32 Specimen 23-1 failed flange angle and cover plate ................................. 63

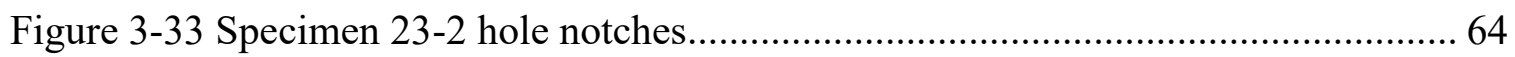

Figure 3-34 Specimen 23-2 crack growth in east flange angle................................... 65

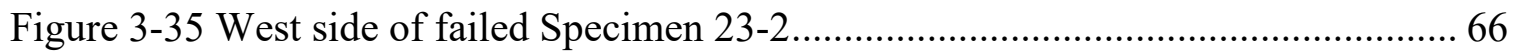

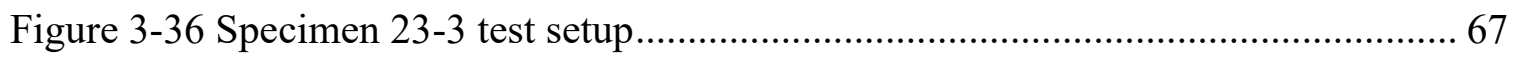

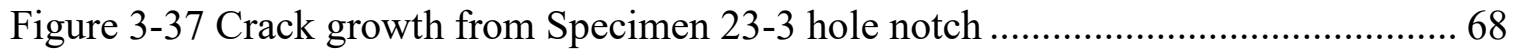

Figure 3-38 Cracks in Specimen 23-3; (a) East side, (b) West side ............................ 70

Figure 3-39 Specimen 46-1 cover plate hole notches ............................................ 71

Figure 3-40 Specimen 46-1 cracked flange angles; (a) East, (b) West........................... 73

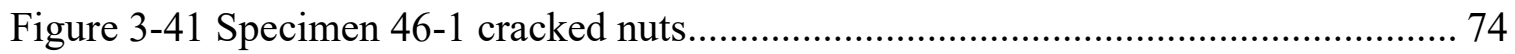

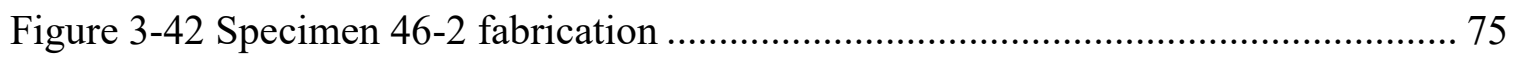

Figure 3-43 Specimen 46-2 cracked flange angles; (a) West, (b) East.......................... 77

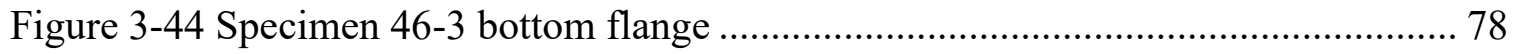

Figure 3-45 Specimen 46-3 fractured cover plate (from below) ................................ 79

Figure 3-46 Specimen 46-3 cracked flange angles; (a) West, (b) East.......................... 80

Figure 3-47 Specimen 36-1 crack detection gages; (a) Preparation (b) Installed............ 81

Figure 3-48 Specimen 36-1 crack growth and fracture attempts ............................... 83

Figure 3-49 Specimen 36-1 fractured bottom flange components (east side) ................. 84

Figure 3-50 Specimen 36-1 fractured bottom flange components (bottom view)........... 85

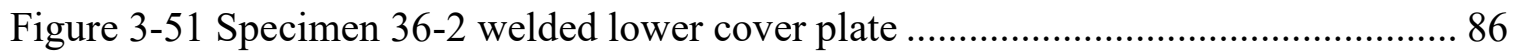




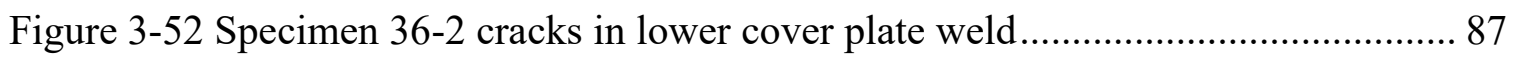

Figure 3-53 Specimen 36-2 lower cover plate failure surfaces ................................. 88

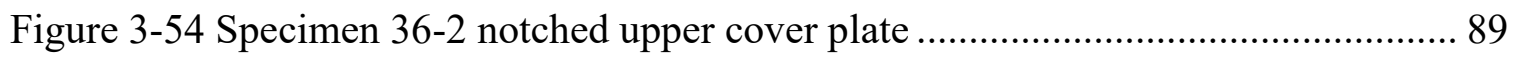

Figure 3-55 Specimen 36-2 upper cover plate notches (a) $2^{\text {nd }}$ attempt (b) $3^{\text {rd }}$ attempt.... 90

Figure 3-56 Specimen 36-2 failed upper cover plate (from below)............................. 91

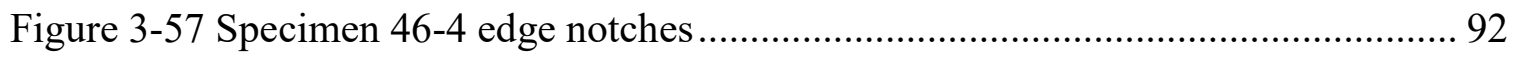

Figure 3-58 Specimen 46-4 fractured cover plate................................................. 93

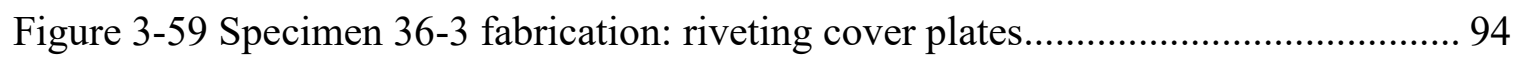

Figure 3-60 Specimen 36-3 fractured lower cover plate ......................................... 95

Figure 3-61 Specimen 36-4 cold worked top flange .............................................. 97

Figure 3-62 Specimen 36-4 fractured cover plate..................................................... 98

Figure 3-63 Specimen 46-5 severed flange angle................................................. 99

Figure 3-64 Specimen 46-5 string potentiometers............................................... 100

Figure 3-65 Specimen 46-5 out-of-plane stress gradient ....................................... 101

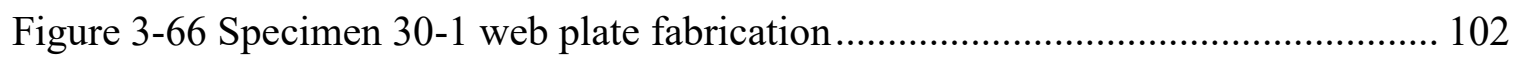

Figure 3-67 Specimen 30-1 fractured cover plate................................................. 104

Figure 3-68 Specimen 30-1 flange angle crack in hole ......................................... 105

Figure 3-69 Specimen 30-1 fractured west flange angle ........................................ 106

Figure 3-70 Specimen 36-5 notched cover plate …........................................... 107

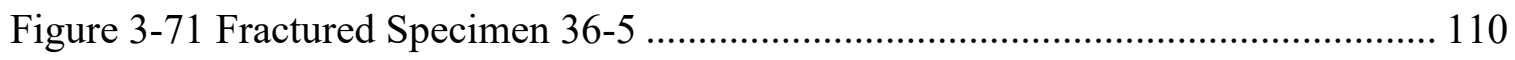

Figure 3-72 Specimen $36-5$ south fracture surfaces .......................................... 111

Figure 3-73 Specimen 36-5 rivet hole fatigue cracks ........................................... 112

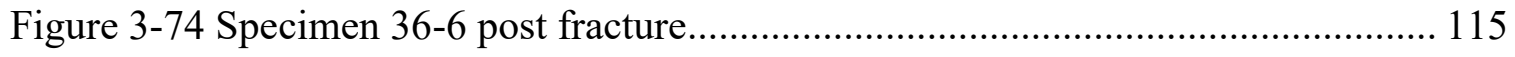


Figure 3-75 Fatigue data for specimens with punched holes.................................... 123

Figure 3-76 Fatigue data for specimens with drilled holes ...................................... 123

Figure 3-77 Fatigue data for specimens with non-symmetric cross sections ............... 124

Figure 3-78 Fatigue data for specimens with symmetric cross sections...................... 125

Figure 3-79 Fatigue data for specimens with low-friction between components .......... 126

Figure 3-80 Fatigue data for specimens with typical friction between components ...... 127

Figure 3-81 Fatigue data for specimens with 1 cover plate .................................... 128

Figure 3-82 Fatigue data for specimens with 2 cover plates ................................... 129

Figure 3-83 Fatigue data for specimens with rivets............................................. 130

Figure 3-84 Fatigue data for specimens with bolts ............................................. 131

Figure 4-1 (a) Mesh at fastener hole; (b) Rivet mesh ............................................... 134

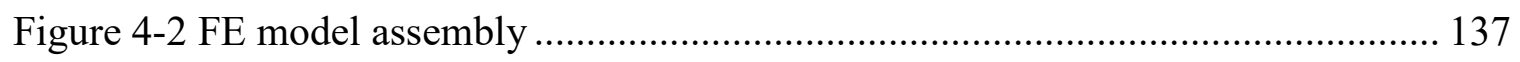

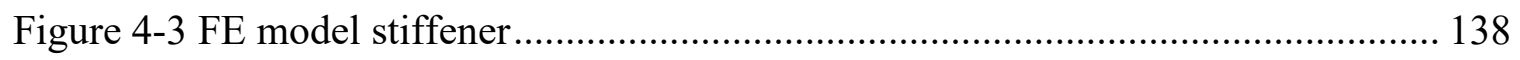

Figure 4-4 Full model: stress in cover plate at mid-span ....................................... 139

Figure 4-5 Full model - stress paths at cover plate and flange angle .......................... 141

Figure 4-6 Stress comparison (FE full model vs. experimental data).......................... 141

Figure 4-7 Stress comparison (FE quarter model vs. experimental data)..................... 143

Figure 4-8 Axial model symmetry planes........................................................... 146

Figure 4-9 Full model - linear elastic vs. elastic plastic ....................................... 147

Figure 4-10 Axial model - modeled and simulated rivets.................................... 148

Figure 4-11 Axial model - trapezoidal load distribution ...................................... 150

Figure 4-12 (a) Hole mesh seeding location, (b) Hole mesh .................................... 151

Figure 4-13 Axial model (with refined versions) vs. full model .............................. 152 
Figure 4-14 Axial model - stress paths through horizontal leg of flange angle 154

Figure 4-15 Axial model - stress gradient through flange angle thickness. 155

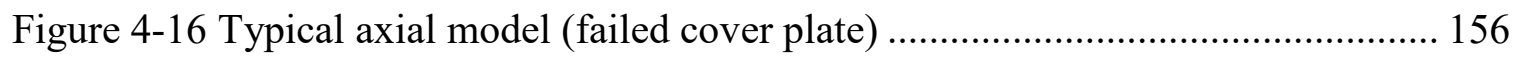

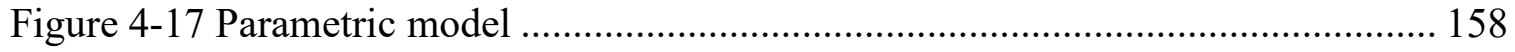

Figure 4-18 Stress transfer in (a) Flange angles, (b) Cover plate ............................... 160

Figure 4-19 Non-symmetric cross-section models ................................................ 161

Figure 4-20 Stress comparison - No failure vs. 100\% cover plate failure ................... 163

Figure 4-21 Stress comparison - No failure vs. 100\% flange angle failure .................. 164

Figure 4-22 Stress comparison - No failure vs. $25 \%, 50 \%, 75 \%$ cover plate failure..... 165

Figure 4-23 Out-of-plane stress redistribution $\left(20^{\prime \prime} \mathrm{CP}\right.$ - partial cover plate failure) .... 166

Figure 4-24 Out-of-plane stress redistribution (26" CP - partial cover plate failure) .... 167

Figure 4-25 Unbraced length parameter model geometries..................................... 169

Figure 4-26 Web height parameter model geometries.......................................... 170

Figure 4-27 Cover plate quantity parameter model geometries............................... 172

Figure 4-28 Model with 3 cover plates - lower cover plate failed ............................ 173

Figure 4-29 Model w/ two cover plates - stresses at 3 stages of cover plate failure...... 174

Figure 4-30 Stress increase in girders with multiple cover plates ............................ 175

Figure 4-31 Stress increase in components of girders with multiple cover plates (16", 20",

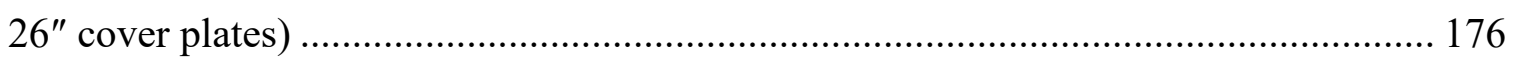

Figure 4-32 Stress concentration at cracked plate ............................................... 177

Figure 4-33 Stress increase in models with multiple cover plates.............................. 178

Figure 4-34 Net-section stress comparison (FE model vs. calculated) ........................ 181

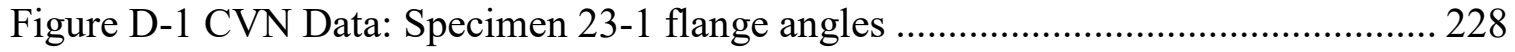


Figure D-2 CVN Data: Specimen 23-1 cover plate .............................................. 228

Figure D-3 CVN Data: Specimen 23-2 flange angles ............................................ 231

Figure D-4 CVN Data: Specimen 23-2 cover plate .............................................. 231

Figure D-5 CVN Data: Specimen 23-3 flange angles ............................................ 234

Figure D-6 CVN Data: Specimen 23-3 cover plate ................................................ 234

Figure D-7 CVN Data: Specimen 30-1 web plate ................................................. 238

Figure D-8 CVN Data: Specimen 30-1 flange angles ......................................... 238

Figure D-9 CVN Data: Specimen 30-1 cover plate ................................................. 239

Figure D-10 CVN Data: Specimen 30-1 cover plate fuse ....................................... 239

Figure D-11 CVN Data: Specimen 36-1 web plate ............................................. 242

Figure D-12 CVN Data: Specimen 36-1 flange angles ......................................... 242

Figure D-13 CVN Data: Specimen 36-1 upper, lower cover plates ........................... 243

Figure D-14 CVN Data: Specimen 36-2 web plate ................................................ 246

Figure D-15 CVN Data: Specimen 36-2 flange angles ....................................... 246

Figure D-16 CVN Data: Specimen 36-2 upper, lower cover plates .......................... 247

Figure D-17 CVN Data: Specimen 36-3 web plate ............................................. 250

Figure D-18 CVN Data: Specimen 36-3 flange angles ........................................ 250

Figure D-19 CVN Data: Specimen 36-3 upper, lower cover plates ........................... 251

Figure D-20 CVN Data: Specimen 36-4 web plate ........................................... 254

Figure D-21 CVN Data: Specimen 36-4 flange angles ......................................... 254

Figure D-22 CVN Data: Specimen 36-4 upper cover plate ................................... 255

Figure D-23 CVN Data: Specimen 36-4 lower cover plate ..................................... 255

Figure D-24 CVN Data: Specimen 36-5 web plate ............................................... 259 
Figure D-25 CVN Data: Specimen 36-5 flange angles ............................................. 260

Figure D-26 CVN Data: Specimen 36-5 cover plate .................................................. 260

Figure D-27 CVN Data: Specimen 36-6 web plate ……………………………...... 264

Figure D-28 CVN Data: Specimen 36-6 flange angles …………................................. 265

Figure D-29 CVN Data: Specimen 36-6 cover plate ................................................... 265

Figure D-30 CVN Data: Specimen 46-1 web plate …………………….................... 268

Figure D-31 CVN Data: Specimen 46-1 flange angles ………...................................... 268

Figure D-32 CVN Data: Specimen 46-1 cover plate ................................................... 269

Figure D-33 CVN Data: Specimen 46-2 web plate …………………….................. 272

Figure D-34 CVN Data: Specimen 46-2 flange angles ............................................... 272

Figure D-35 CVN Data: Specimen 46-2 cover plate _............................................... 273

Figure D-36 CVN Data: Specimen 46-3 web plate .................................................... 276

Figure D-37 CVN Data: Specimen 46-3 flange angles …………………………...... 276

Figure D-38 CVN Data: Specimen 46-3 cover plate ..................................................... 277

Figure D-39 CVN Data: Specimen 46-4 web plate …………………….................. 280

Figure D-40 CVN Data: Specimen 46-4 flange angles ............................................... 280

Figure D-41 CVN Data: Specimen 46-4 cover plate .................................................. 281

Figure D-42 CVN Data: Specimen 46-5 web plate ………………………………...... 284

Figure D-43 CVN Data: Specimen 46-5 flange angles ................................................ 284

Figure D-44 CVN Data: Specimen 46-5 cover plate _................................................ 285 


\section{EXECUTIVE SUMMARY}

\section{MEMBER-LEVEL REDUNDANCY OF BUILT-UP STEEL GIRDERS}

\section{Introduction}

There is a large number of bridges in the inventory having built-up steel construction. The majority of these bridges were constructed prior to the $1960 \mathrm{~s}$. This means that most of these bridges are approaching, or have surpassed, their original design life. It is widely accepted in the engineering community that built-up members possess internal member-level redundancy due to the number of different load paths created by the fastening of multiple components together with rivets or high-strength bolts. However, there is very little experimental research which addresses the capacity of builtup girders after a component failure.

The purpose of this research was to describe the behavior of mechanically fastened built-up girders in a partially failed condition. This was achieved by testing large-scale riveted and high-strength bolted built-up specimens to determine their fracture resilience at low temperatures and their fatigue capacity after a single component was failed. Additionally, a finite element parametric study was performed to understand the behavior of built-up girders and to better describe the load distribution that occurs locally in the region adjacent to a failed component. 


\section{Summary of Findings}

1. The fracture of a component was found to be highly unlikely due to the constraint created by fasteners in a stitch pattern along the length of a built-up steel girder.

2. Substantial fatigue life remains in a built-up steel girder with a failed component.

3. The presence of more than one cover plate increases the remaining fatigue life of a built-up steel girder with a single component failed due to the redistribution of stresses into multiple components.

4. The resulting longitudinal stresses in a component adjacent to a failed component can be conservatively estimated by amplifying the calculated stress of the remaining cross-section obtained from mechanics of materials $(\mathrm{My} / \mathrm{I})$ with an amplification factor, $\beta_{\mathrm{AF}}$.

\section{Implementation}

A methodology is described to determine the remaining fatigue life of a built-up girder with a single component failed. The remaining fatigue life is based on any prior fatigue damage (using Miner's Rule) and an adjusted net-section stress range which accounts for the localized stress increase adjacent to a component failure. 


\section{CHAPTER 1 INTRODUCTION}

\subsection{Motivation}

Currently, the inspection period for fracture critical bridges in the United States (U.S.) is mandated to be a maximum of 24 months (23 CFR $\S 650.311,2013)$. Bridges containing fracture critical members (FCMs) require a "hands-on" inspection, meaning the inspector must be within an arm's length of any fracture critical component (AASHTO, 2011). The cost associated with performing this level of inspection can be tremendous due to the time required, traffic control, and equipment required (Connor, Dexter, \& Mahmoud, 2005). While these inspections are intended to improve safety, it is noted that the increased time the inspectors are on site also increases the risk of injury to both the public and inspection personnel.

Through a search of the Indiana Bridge Inspection Application Service (BIAS) and the National Bridge Inventory (NBI), it is estimated that there are currently 13,000 bridges with riveted and bolted built-up-members in the national inventory. A large number of these bridges contain members requiring fracture critical inspection, such as found in older 2-girder bridges, tied arches, and truss bridges. While the structural engineering community has recognized that members comprised of plates and angles attached using mechanical fasteners possess internal redundancy or multiple load paths (AREMA, 2012; FHWA, 2012), there has been little documentation on the subject. To 
the author's knowledge, no research has been performed to quantify the load redistribution and redundancy of built-up steel members. Due to a lack of experimental evidence, the Federal Highway Administration (FHWA) does not recognize mechanically fastened built-up members as having adequate redundancy to reduce the inspection rigor from that of a fracture critical inspection. Documented experimental and analytical data on the utilization of multiple load paths and fatigue life of mechanically fastened built-up members will provide needed insight into their behavior. The data will be used in developing safe and rational guidelines for assessing redundancy and inspection intervals for bridges containing steel built-up members traditionally classified as fracture critical. It is noted that throughout this document, the term 'built-up member' refers to members comprised of plates and angles attached with mechanical fasteners, such as bolt or rivets.

\subsection{Construction Practices}

Mechanically fastened built-up steel girders are fabricated from a combination of steel plates and angles fastened together to create a member with section properties tailored to the requirements of a structure (e.g., increased section modulus). The use of built-up steel members in bridge construction began in the 1870's with the advent of rolled steel mills (Friedman, 2009). The components of these early built-up members were fastened together using structural rivets until the mid-1950's when high-strength bolts began to replace rivets as the primary fastener type. In the early 1960's, welding technology and quality evolved to a point where welded plate members replaced mechanically fastened built-up members as the primary bridge fabrication method. This was driven by reduced fabrication costs associated with welded members. 


\subsection{Development of the Fracture Critical Inspection Requirements}

As a result of the Silver Bridge collapse at Point Pleasant, West Virginia, in 1967, the safety of bridges became a national concern. Following this event, the United States Congress passed the first requirements for the formulation of a national bridge inspection standard (Federal Aid Highway Act of 1968, 1968). The original requirements were implemented through the first National Bridge Inspection Standards (NBIS) ("National Bridge Inspection Standards,” 1971).

In 1983, a span of the Mianus River Bridge in Connecticut collapsed. As a result, the 1988 NBIS was modified to require bridges in the U.S. having fracture critical members to be identified and inspection procedures developed at a state level ("National Bridge Inspection Standards," 1988). Most notably, the hands-on inspection requirement was added for bridges containing fracture critical members.

In 2012, the Federal Highway Administration (FHWA) issued a memorandum clarifying the definition of fracture critical members found in bridges and specified three different types of redundancy found therein (load path, structural, and internal member) (FHWA, 2012). While recognizing the existence and likely benefit of internal member redundancy (through built-up member detailing), the memorandum does not allow its use in demonstrating such members need not be classified as fracture critical. Additionally, it states all steel members fabricated prior to the introduction of the Fracture Control Plan (FCP) in 1978 are excluded from having the 'fracture critical' designation removed. Finally, the memorandum recognizes that current research is being performed on internally redundant members and that there are benefits to improving fracture 
propagation resistance (FHWA, 2012). It is the goal of this research project to generate adequate evidence to establish rational inspection intervals for riveted built-up members subjected to bending while still maintaining public safety. Ongoing research at Purdue University focused on tension members and bolted built-up members is being conducted by others.

\subsection{Need for Preservation}

Most of the bridges in the U.S. containing steel built-up members were constructed prior to the prevalence of welded plate girders in the early 1960's. Due to competing demands on funding sources and the large financial burden of replacing aged bridges, there is a need to maintain existing structures for longer periods of service. Additionally, due to the historic nature of many older bridges containing riveted built-up members, there is an effort to maintain them as working pieces of history. 


\section{CHAPTER 2 PRIOR RESEARCH AND BACKGROUND}

\subsection{Anecdotal Evidence}

The greatest testament to built-up member-level redundancy lies in observed and documented performance. Connor et al. (2005) reported that, during a period surveyed from 1960 to 2005, no fracture critical bridge with built-up members is known to have failed due to the fracture of one single component propagating a fracture to an adjacent component. In contrast, there are examples of several highway and railroad bridges containing component failures (i.e., failures of one component of a built-up member, such as an angle or plate) which continued to sustain service loads in the 'failed' state. A few selected examples follow.

\subsubsection{North Fork Mollala River Bridge, Clackamas County, Oregon}

Located in Clackamas County, Oregon, the North Fork Mollala River Bridge was a built-up riveted, two-girder fracture critical bridge built in 1966 (Figure 2-1). In 2001, during a fracture critical inspection, both flange angles of a riveted built-up steel girder (with no cover plate) were found to be fractured (Lovejoy, 2001). One of the main girders had sustained both fractures near a flange splice (see Figure 2-2). It was determined that the fractures had both initiated at fabrication defects resulting from punched holes. The corrosion product on each surface implied that the fractures occurred 
at separate unrelated times. While the fracture dates were not able to be determined, the bridge clearly carried service loads until the time of inspection and repairs were made. While plastic deformation was observed in the web directly above the fractures, no web cracks were found.

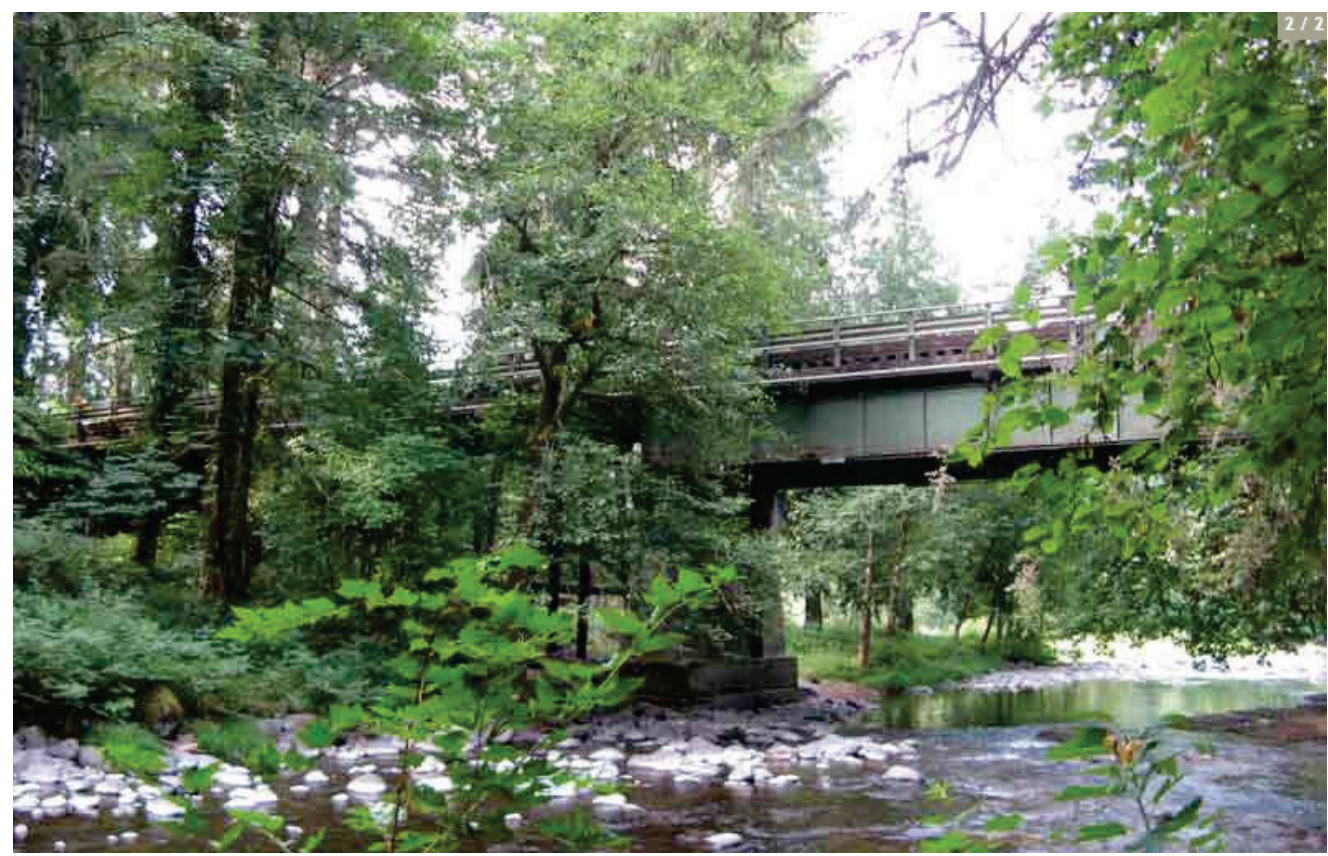

Figure 2-1 North Fork Mollala River Bridge, Oregon (OBEC, 2012) 


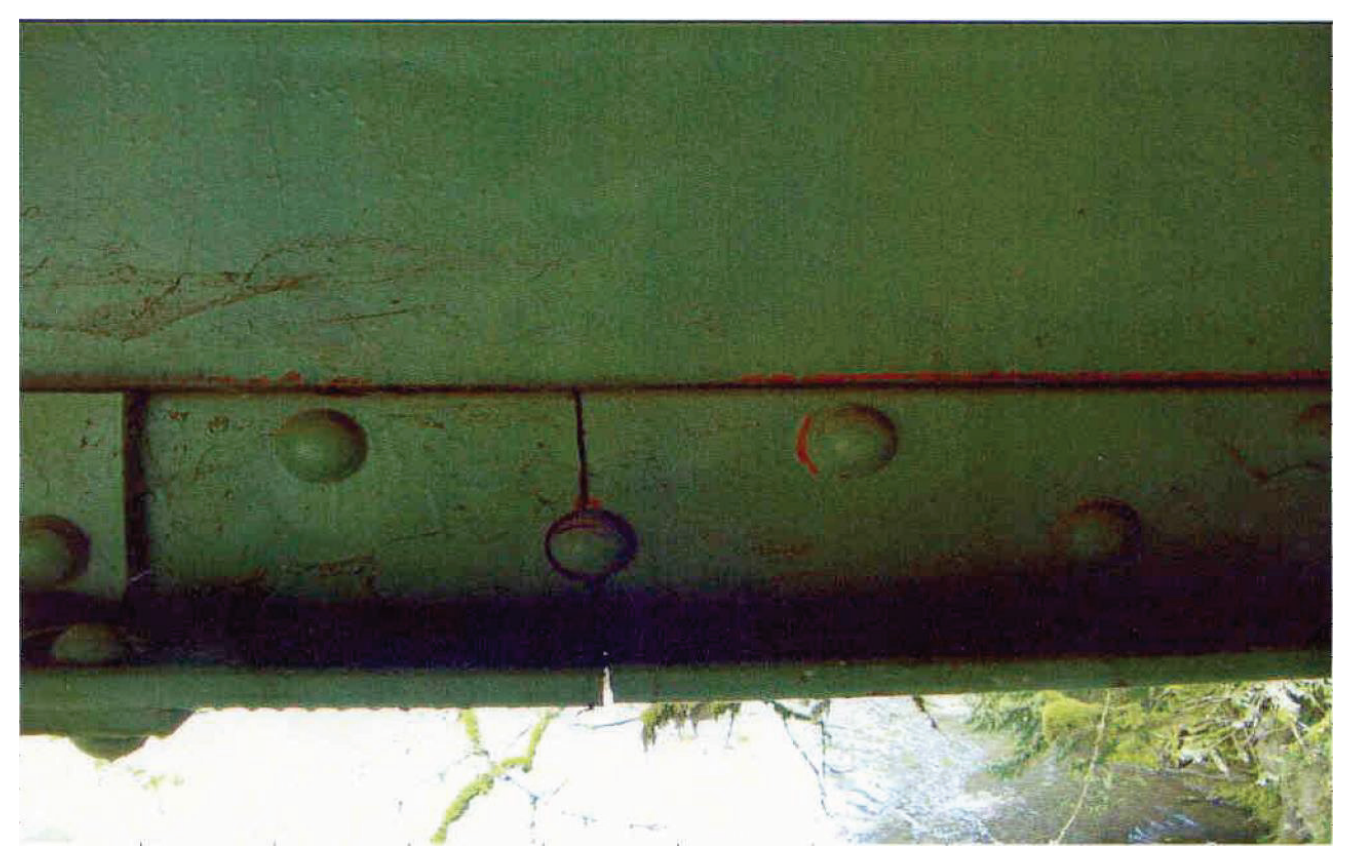

Figure 2-2 Interior view of fractured flange angle (Lovejoy, 2001)

\subsubsection{University of Texas Research Project}

A three-span, two-girder, non-composite, riveted built-up bridge was monitored by researchers at the University of Texas at Austin as part of a research project investigating wireless data acquisition systems (see Figure 2-3). The age and location of the bridge were not made available per the owner's request. The two longitudinal girders are continuous over the interior supports and extend approximately one-quarter of the center span to where the center section is suspended by hangers. The longitudinal girders are haunched and cover plated over the interior supports. 


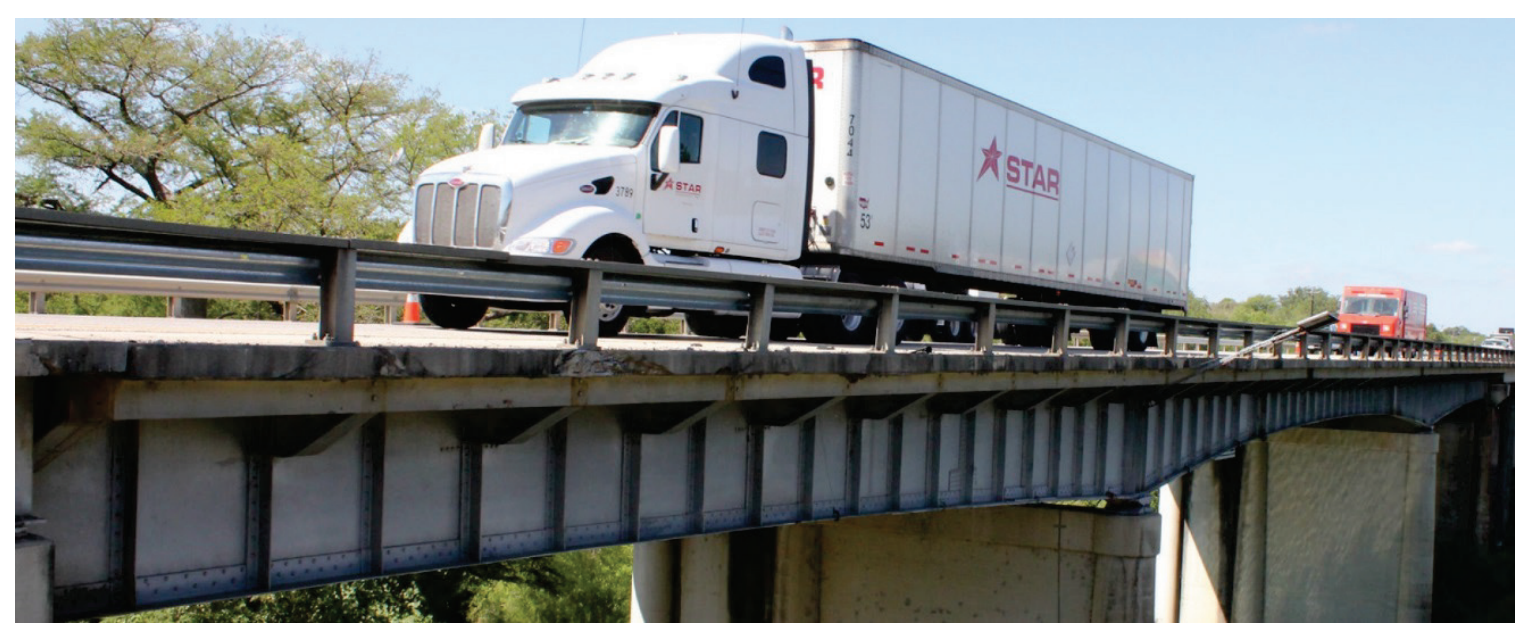

Figure 2-3 Elevation view of Texas Research Project Bridge (Fasl, 2013)

Approximately 40 years after construction, as part of a bridge widening project, transverse cantilever floor beams were added. These floor beams were riveted to transverse stiffeners and welded at the top and bottom flanges. The welded top flange connection resulted in a Category $\mathrm{E}$ fatigue detail. Cracks were later found during fracture critical inspections. Initiating at the weld toe of the cantilever floor beam, the cracks had grown the entire width of one of the top flange angles. Similar cracks were found at several locations along the length of the main girder. The cracks were clearly visible during a retrofit effort in which the concrete deck was removed (see Figure 2-4). The discontinuities between components of the built-up member (providing memberlevel redundancy) was credited with preventing the cracks from growing into the remaining top flange angle or the web plate (Fasl, 2013) 


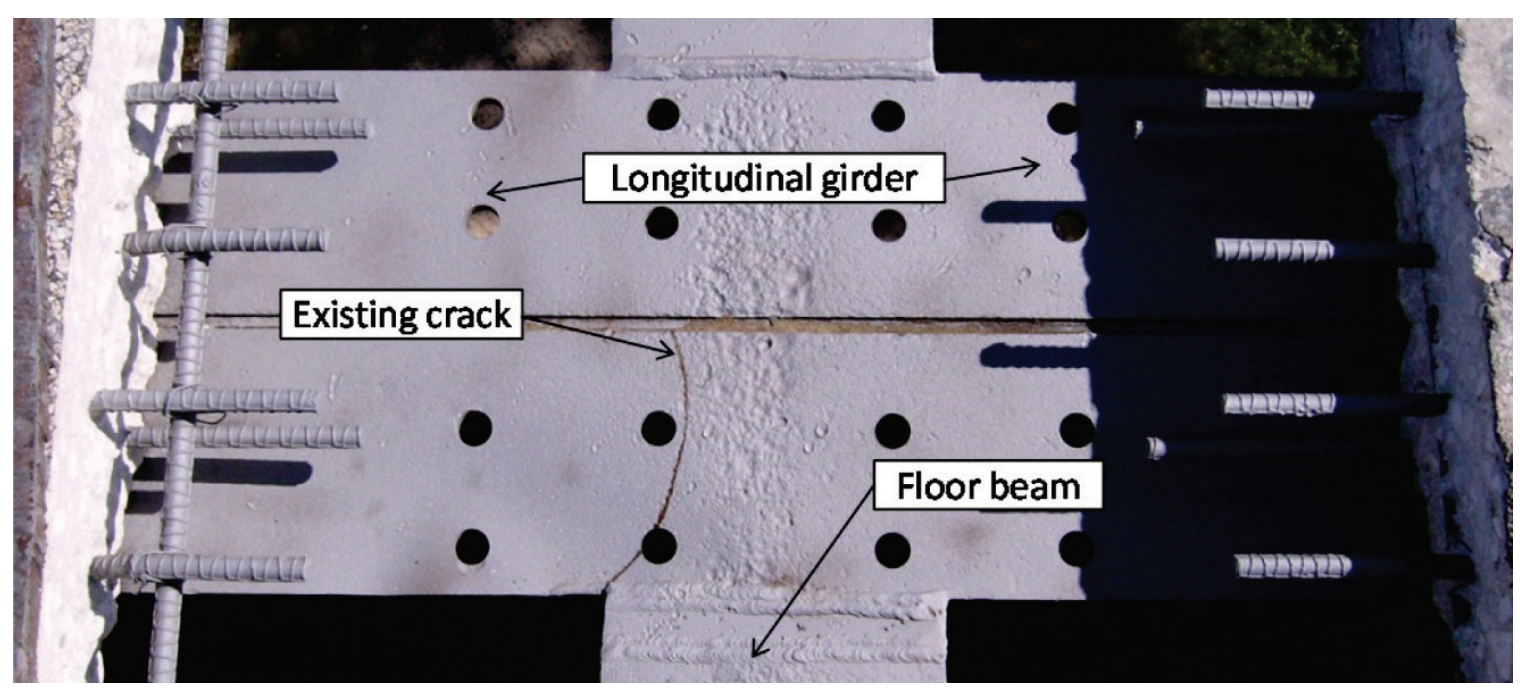

Figure 2-4 Cracked top flange angle (Fasl, 2013)

\subsubsection{Hastings Bridge, Minnesota}

Two separate fracture critical inspections revealed two partial member fractures on the Hastings Bridge in Minnesota in 1997 and 1998. The bridge is a tied-arch through truss bridge built in 1949 with riveted built-up members (see Figure 2-5). Both fractures occurred in the same plate of the tie girder. While the first fracture arrested in adjacent rivet holes, the second fracture propagated through the entire tie girder web plate (see Figure 2-6). Initiating, at a tack weld used to improve fabrication adjacent to a floor beam gusset plate, the second fracture ran the entire length of the web plate. It was determined that a single plate used in the fabrication of the tie girder had very low toughness causing each of these fractures to occur (Niemann, 1999). The internal member redundancy of the built-up members prevented the fracture from propagating into adjacent components. 


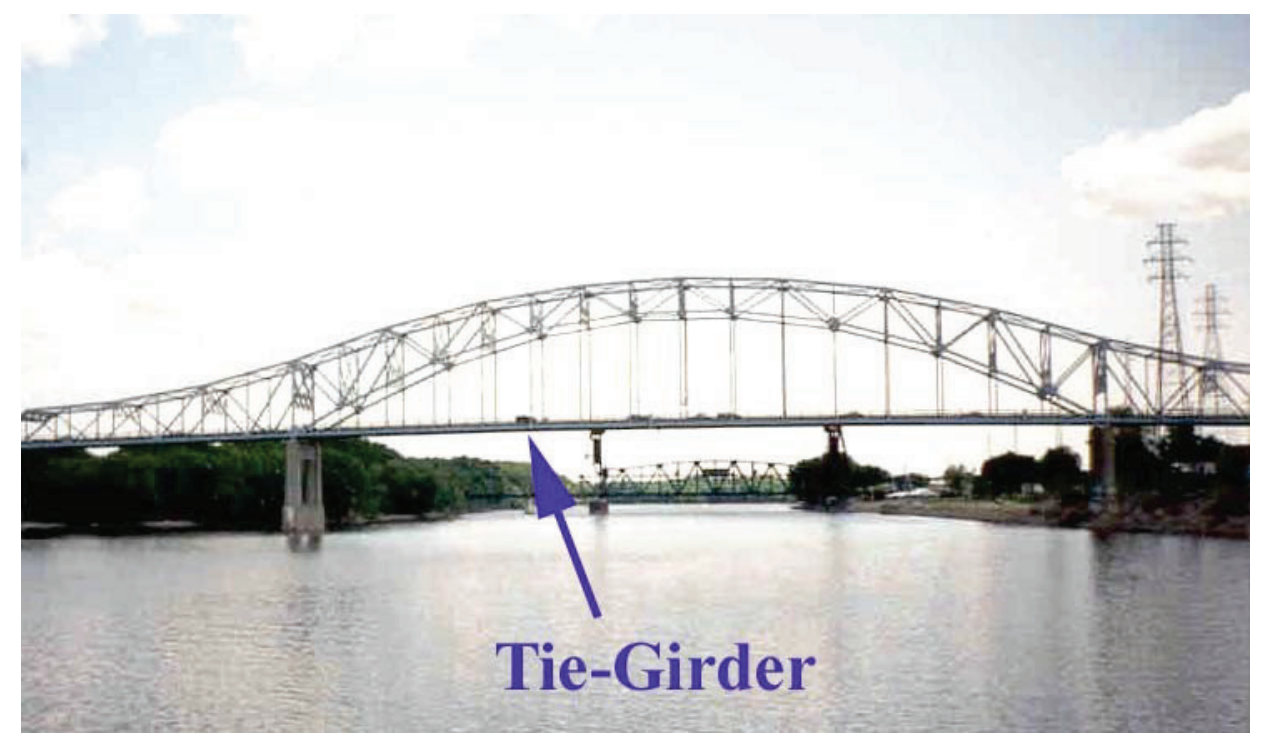

Figure 2-5 Hastings Bridge, Minnesota (Niemann, 1999)

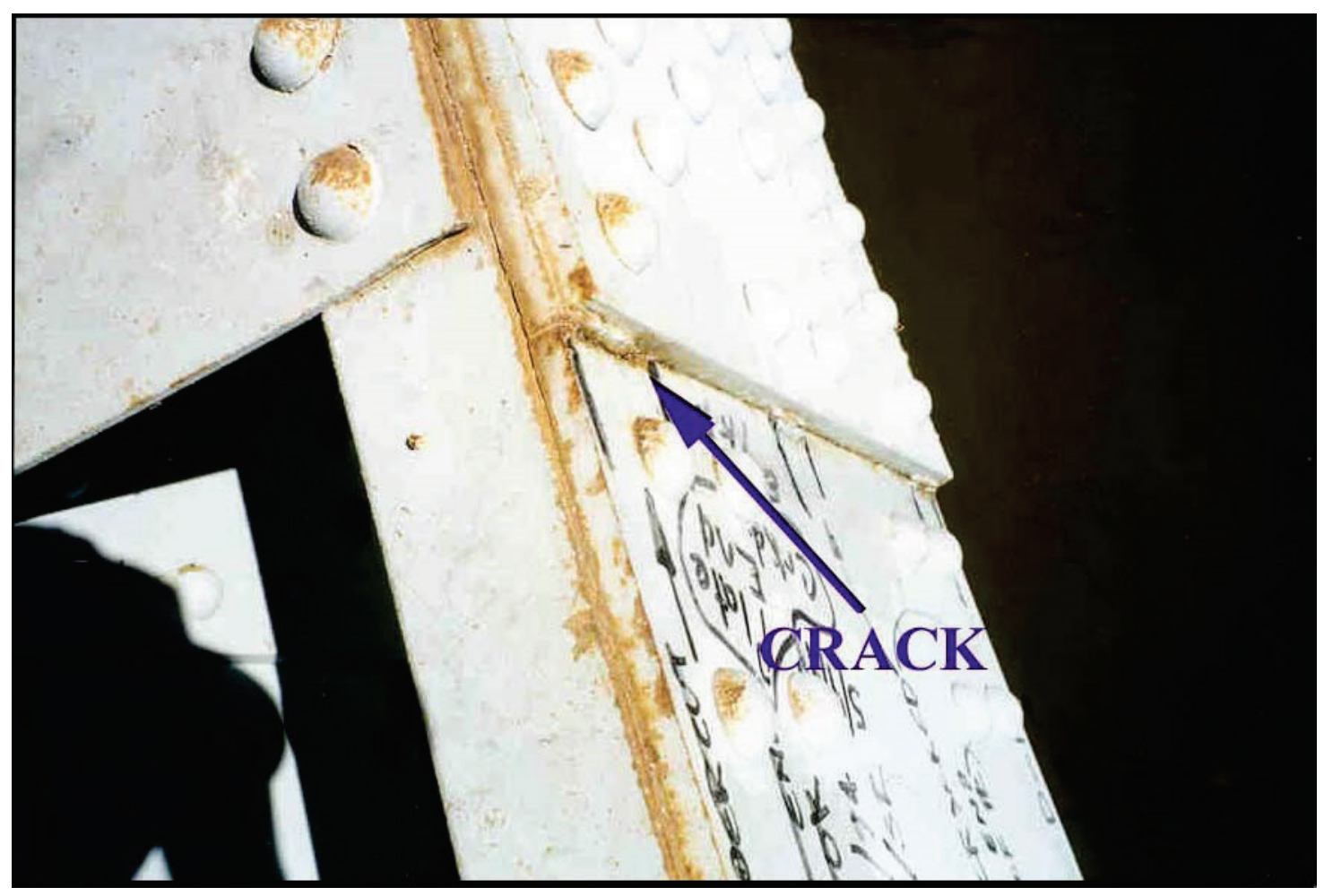

Figure 2-6 Fractured tie girder plate, Hastings Bridge (Niemann, 1999) 


\subsection{Experimental Evidence}

A thorough literature review was made to determine the extent of fatigue tests on riveted members that have been performed. The majority of testing, however, focuses on the initial fatigue life of riveted members, most commonly defined as the number of cycles until a single component is completely cracked. Figure 2-7 shows a compiled summary of the fatigue life of specimens tested and found in the following documents: Adamson \& Kulak, 1995; Åkesson, 2010; Baker \& Kulak, 1982, 1985; Baron, Larson, \& Kenworthy, 1955; Brühwiler, Smith, \& Hirt, 1990; DiBattista \& Kulak, 1995; Fisher, Yen, Wang, \& Mann, 1987; Out, Fisher, \& Yen, 1984; Parola, Chesson, \& Munse, 1965; Reemsnyder, 1975; Seong, 1983; Wilson \& Thomas, 1938; Zhou, 1994.

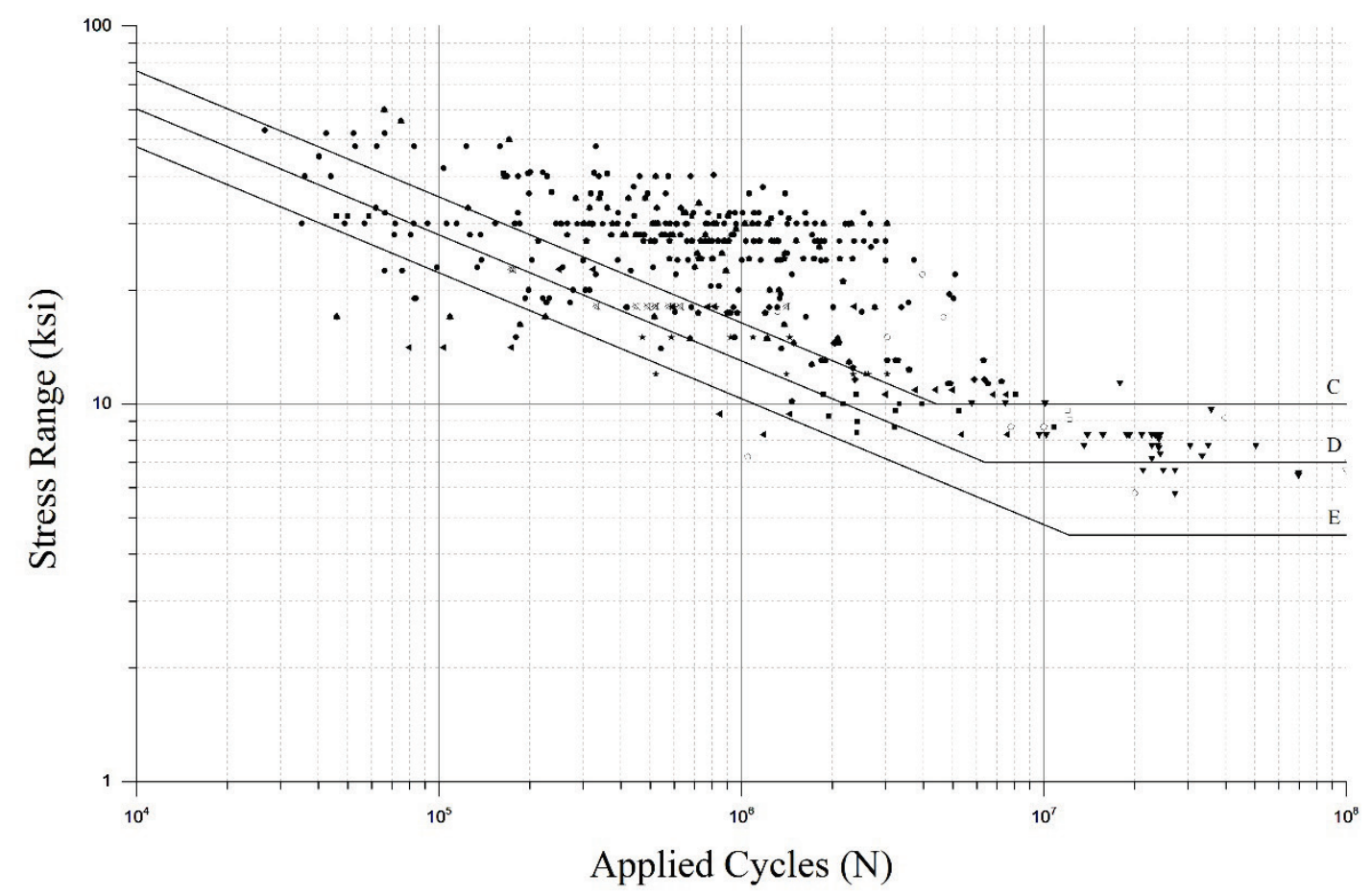

Figure 2-7 Fatigue data from previous research 
Few experimental studies have been performed investigating the behavior of members with partially failed components. The limited available data, however, indicates members with multiple components mechanically fastened together are able to resist total member failure through stress redistribution (as described in the following section). Additionally, the separation between individual components has been shown to extend the total member fatigue life by preventing crack propagation from one component into another.

\subsubsection{Cha, Lyrenmann, Connor, \& Varma (2014) - Milton Madison Bridge}

Construction of a new bridge to replace the structurally deficient and functionally obsolete Milton Madison Bridge began in 2010. The bridge was originally built in 1929 as a riveted built-up cantilevered through-truss crossing the Ohio River. As part of the demolition of the old bridge, a study was conducted to investigate both member-level and system-level redundancy. A Pratt Truss approach span was selected for the test due to its accessibility and geometry (see Figure 2-8). The span was instrumented, and then loaded with sand to simulate a loading condition greater than any seen on the bridge during longterm monitoring. After an analysis of the bridge members, the bottom chord at the center panel of the span was selected to be severed in two locations to measure member-level redundancy and system-level redundancy of the bridge. The bottom chord of the truss consisted of two built-up channel shapes connected with lattice. The lattice of the double built-up channel bottom chord was removed adjacent to the simulated fracture locations as well as the outstanding legs of the built-up channel. Two shape charges were used to sever the remaining components. The first shape charge was detonated, cutting through 
one of the built-up $\mathrm{C}$ shaped components to evaluate member-level redundancy (see Figure 2-9). The detonation of half of the cross-sectional area represented an extreme amount of section loss. The resulting stress increase in the remaining bottom chord builtup channel approximately doubled as expected. However, even with the energy release of the fracture, coupled with the energy imposed on the system due to the shape charge, the second bottom chord channel did not fracture or exhibit signs of any other cracks in adjacent components. Later the second shape charge was detonated in the remaining web plate, testing system level redundancy (Diggelmann, 2012).

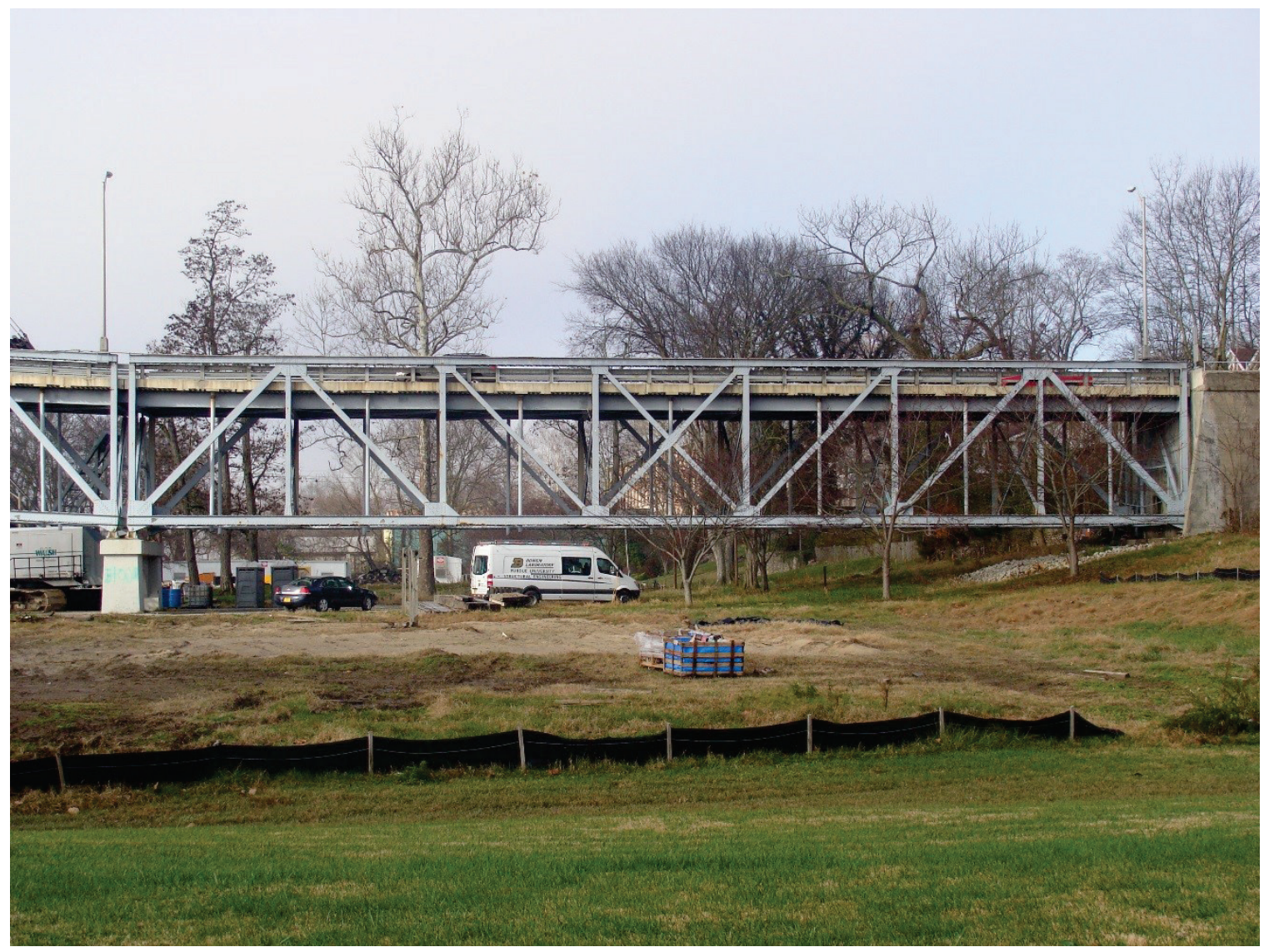

Figure 2-8 Approach span of Milton Madison Bridge, Indiana 


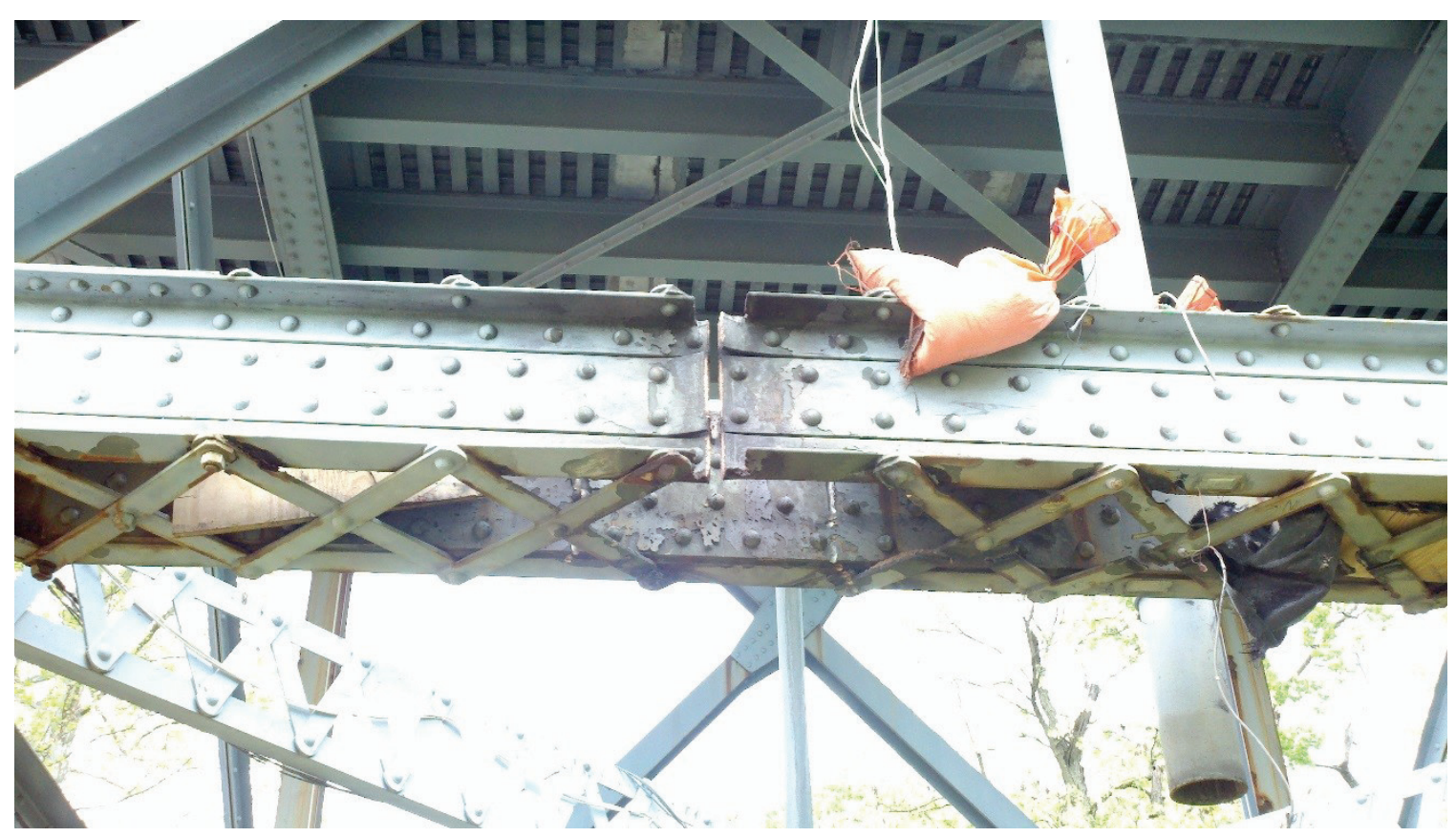

Figure 2-9 Partially severed bottom chord, Milton Madison Bridge approach span

\subsubsection{Fisher, Yen, Wang, \& Mann (1987) - NCHRP Project 12-25}

As part of NCHRP Project 12-25 (as reported in NCHRP Report 302 - Fatigue and Fracture Evaluation for Rating Riveted Bridges) a series of fourteen full-scale girder tests were performed on riveted girders removed from in-service bridges. It was reported, at the time of publication in 1987, the general practice of bridge owners was to ignore fatigue damage in the primary members of riveted built-up bridges because no adverse fatigue damage had been observed, and stress ranges of in-service bridges were unlikely to exceed the Category D fatigue limit. Seven of the fourteen specimens cycled in fatigue were also cooled to low temperatures and then attempted to initiate a fracture. The test specimens were obtained from three different bridges. Twelve of the specimens were in generally good condition, while the remaining two were heavily corroded. 
The research project was seeking to determine the ultimate fatigue life of the specimens. The member-level redundancy of the specimens was an integral aspect of the results. In general, for any of the fracture tests, with less than $50 \%$ of a component cracked, the loading protocol at the reduced temperature (between $-40^{\circ} \mathrm{F}$ and $-60^{\circ} \mathrm{F}$ ) did not result in a brittle fracture. Material testing resulted in $\mathrm{CVN}$ values between $4 \mathrm{ft}-\mathrm{lbs}$ to $7 \mathrm{ft}$-lbs at these temperatures. Additionally, specimens with large cracks in all tension components were still capable of withstanding the maximum test load (stresses ranging from 14 to $20 \mathrm{ksi}$ of the original, uncracked cross section) without fracturing (at the reduced temperature). In terms of fatigue capacity, an additional 200,000 to $1,000,000$ cycles beyond initial component failure was observed before complete specimen failure (Fisher et al., 1987).

\subsubsection{Out (1984) - Fatigue Strength of Weathered and Deteriorated Riveted Members}

A study performed under the direction of the FHWA Office of Research by researchers at Lehigh University found significant redundant behavior in deteriorated steel built-up girders. Six riveted built-up stringer specimens with top and bottom flanges consisting of two flange angles (no cover plates), which had been removed from an existing railroad bridge, were tested in fatigue to determine their fatigue capacity. The specimens had components with a reduced area of $5 \%$ to $40 \%$ due to advanced corrosion. Two of the specimens were cycled at reduced temperatures in an attempt to induce a fracture. Of these two specimens, only one sustained a component fracture. However, cracks of significant length were present in both flange angles and the web plate when all 
remaining portions of the flange angles and the majority of the web fractured. The other specimen had a flange angle with a fatigue crack through $95 \%$ of the cross section but still did not fracture. After dismantling the failed specimens, it was determined that the holes for the rivets had likely been punched. For two specimens the number of cycles were recorded between the first component failure and the final specimen failure. Before complete member failure of the specimens, 590,000 and 600,000 fatigue cycles at an original, uncracked net section stress range of $10.9 \mathrm{ksi}$ and $9.4 \mathrm{ksi}$ (respectively) were noted (Out et al., 1984).

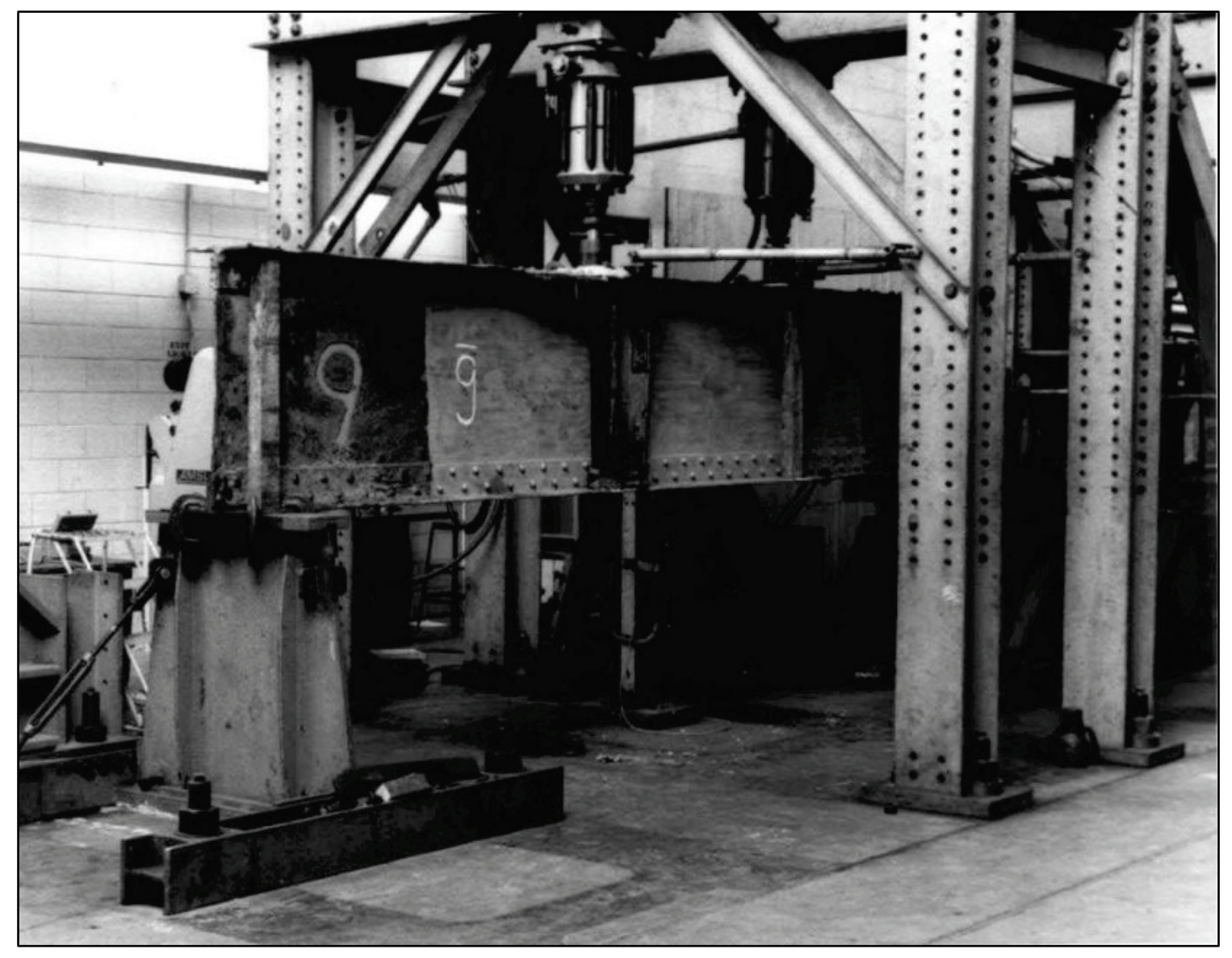

Figure 2-10 Fatigue testing of weathered section (Out, 1984) 


\subsection{4 Åkesson (2010) - Fatigue Life of Riveted Steel Bridges}

Nine built-up riveted stringers were tested in fatigue as part of this research study. The specimens were removed from a railway bridge over the Vindel River in Vännäsby, Sweden in 1993. The arch truss bridge was originally built in 1896, but, at the time of demolition, was deemed functionally obsolete. The specimens consisted of a top and bottom flange consisting of two flange angles (see Figure 2-11). Rivet holes were found to be punched.

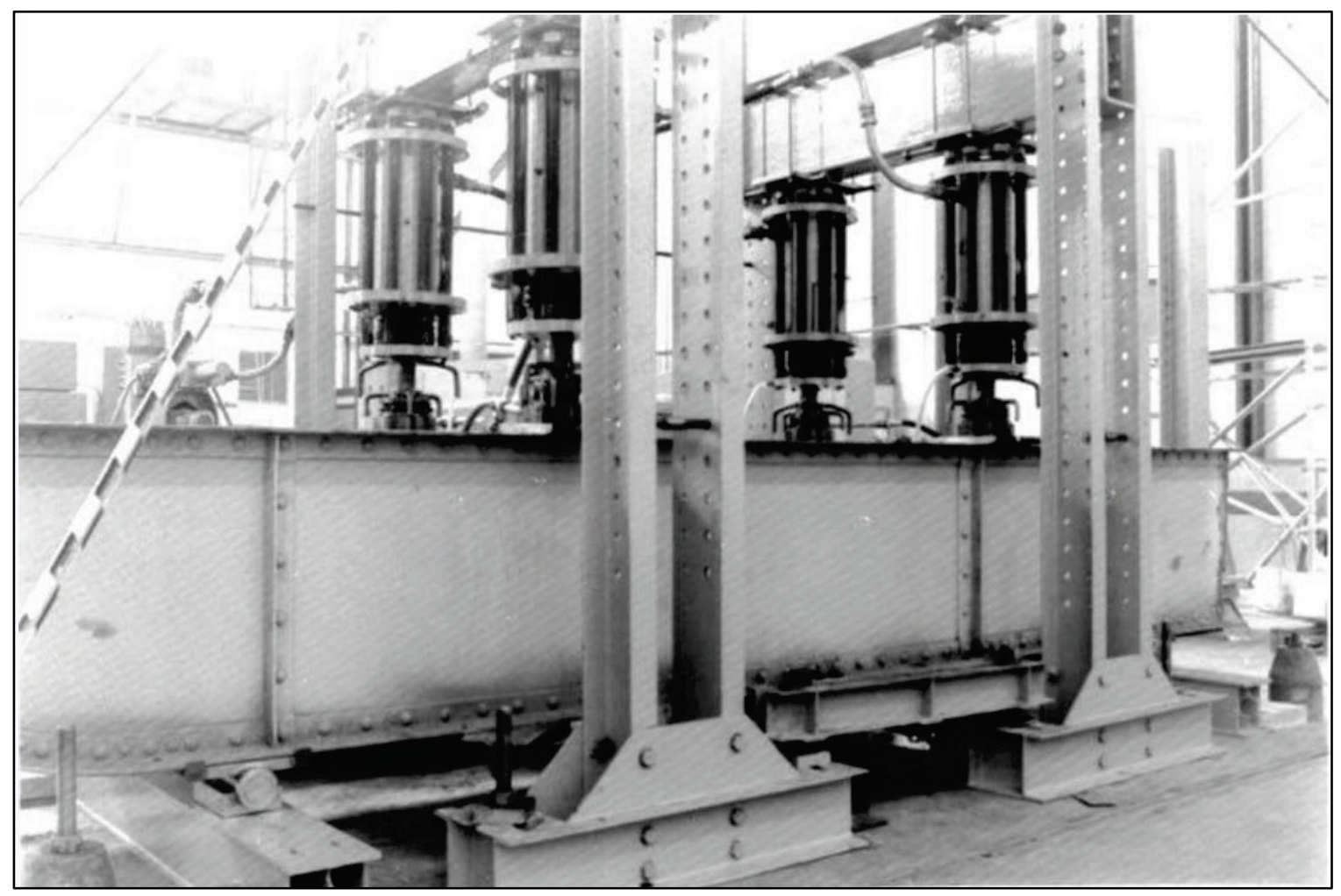

Figure 2-11 Fatigue testing of historical built-up stringers (Åkesson, 2010)

Each specimen was cyclically loaded to determine its fatigue life. The failure of each specimen was determined when both flange angles had failed. Three of the specimens (two of which were tested at a calculated net-section stress range of $5.8 \mathrm{ksi}$ 
and one which was tested at a net-section stress range of $8.7 \mathrm{ksi}$ ) were discontinued after a large number of cycles (20 million, and 10 million respectively) resulted in no observed crack initiation. The remaining six specimens were tested at higher net-section stress ranges and resulted in flange angle failures. Åkesson notes that a significant number of cycles passed after the first flange angle failed until cracks were detected in a second flange angle (between 44,000 and 143,000 at stress ranges between $11.6 \mathrm{ksi}$ and 14.5 ksi). Additionally, prior to the failure of the second flange angle failure, each specimen was capable of carrying the full test load. It is also noted that, while the fatigue propagation rate was rapid in the final stages of the flange failure, no brittle fracture occurred.

\subsection{Summary}

Evidence of in-service bridges exhibiting member-level redundancy of built-up steel components through the redistribution of loads has been illustrated. Three different bridges were described in which the failure of a single component did not immediately result in a catastrophic failure of the member. Additionally, four research projects were cited which, while not an intentional outcome of the test, illustrated the member-level redundancy of built-up girders tested in both fatigue and fracture.

It is clear, from the observations made, that built-up girders are resistant to catastrophic failure due to their inherent separation between components. Additionally, the examples provided illustrate that there is a significant fatigue life of built-up steel girders after a single component failure. 
Through the current research, it will be shown that mechanically fastened built-up steel girders are resistant to total member fracture - even in extreme conditions (critical crack lengths at low temperatures). Furthermore, the duration of the fatigue life of partially failed built-up girders will be measured which will quantify the remaining life beyond first component failure. The results of this research project will extend the current understanding of the behavior of built-up steel girders which will aid in the development of rational inspection periods for bridges with members of this composition. 


\section{CHAPTER 3 EXPERIMENTAL RESEARCH PROGRAM}

\subsection{Test Setup}

Due to the need to obtain data for large, full-scale bridge members, a load frame capable of maximizing the available laboratory equipment was designed (see Figure 3-1) and fabricated. Two 220 kip MTS 244.51 Servo hydraulic actuators were used to apply load to a single specimen in four-point bending. Each actuator was equipped with a 72103 Moog valve having a capacity of 60 gallons per minute (gpm). The actuators were controlled with an MTS 293.22 Hydraulic Service Manifold (100 gpm capacity) which was supplied by an MTS 505.120 Hydraulic Power Unit (HPU) pump with a pressure capacity of $3000 \mathrm{psi}$ and a flow capacity of $120 \mathrm{gpm}$. The actuators were spaced at $8^{\prime}-0^{\prime \prime}$ centered on the specimen to create a constant moment region. This resulted in a distance of constant stress in unflawed specimens that facilitated the measurement of stress redistribution during specimen degradation. A separate load frame supported each individual actuator and was braced to prevent lateral movement. Each load frame and brace was post-tensioned to the laboratory strong-floor to react against the actuator forces. Two separate test setups were fabricated and erected to allow two specimens to be tested simultaneously (see Figure 3-2). 


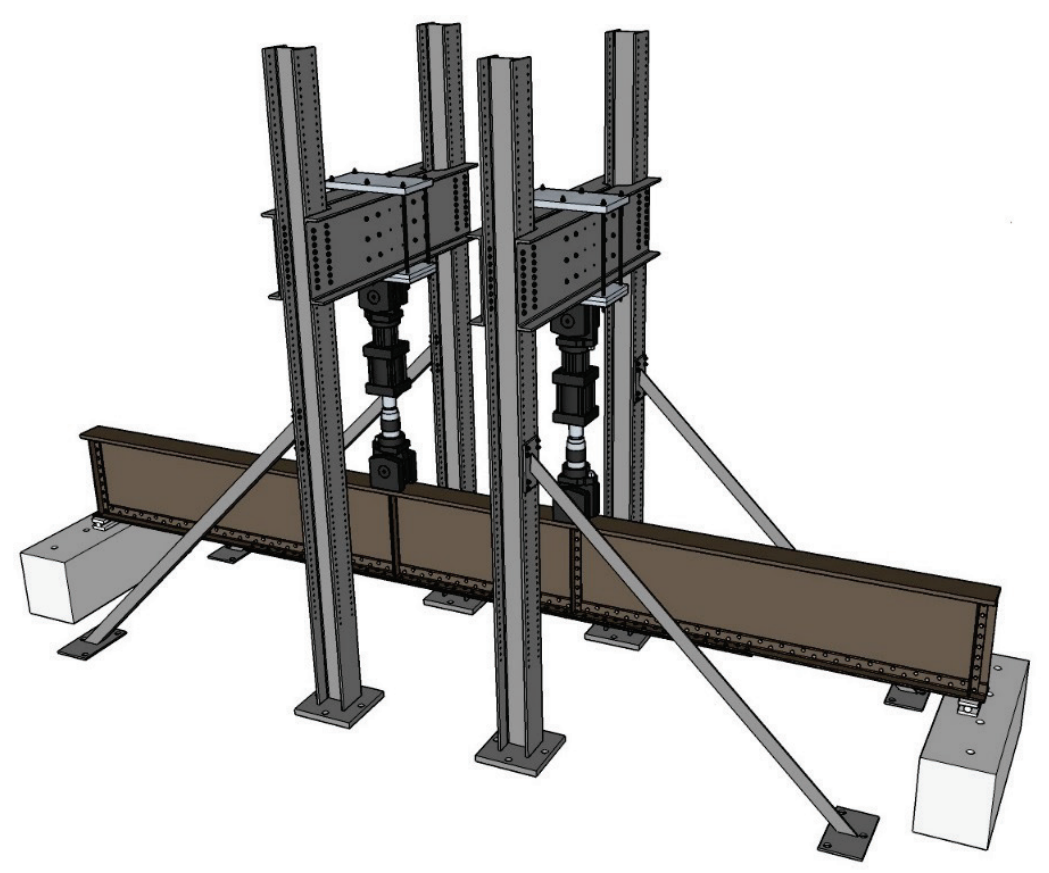

Figure 3-1 Schematic view of test setup

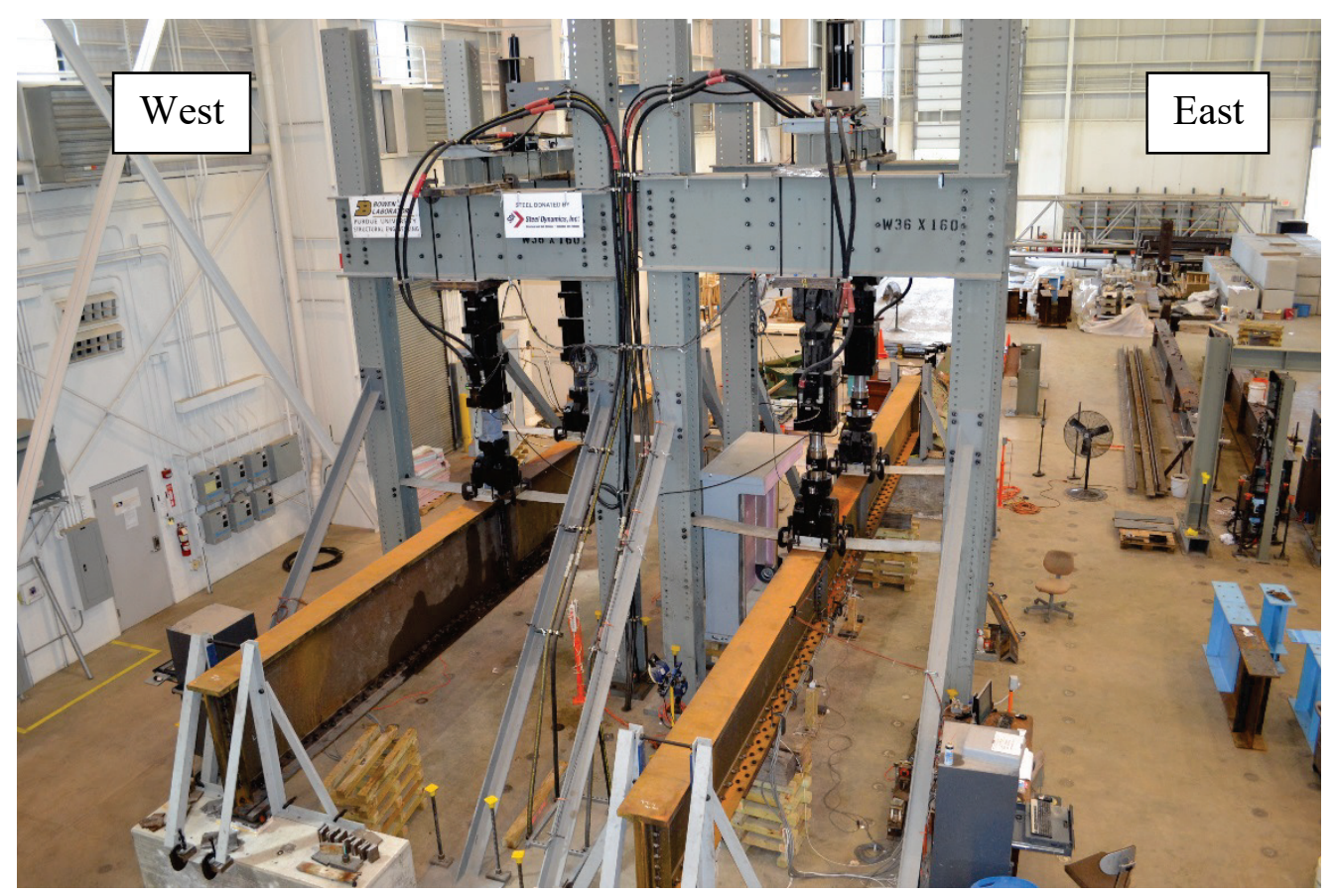

Figure 3-2 Twin test setups 
Specimens were supported at each end by steel bearings placed on concrete reaction blocks having a height of 36 inches to allow adequate room for inspection below the specimen. As shown in Figure 3-3, a pin bearing was used on the south end of each specimen and a roller bearing was used on the north end of each specimen to allow longitudinal movement resulting from actuator loading and subsequent displacement.

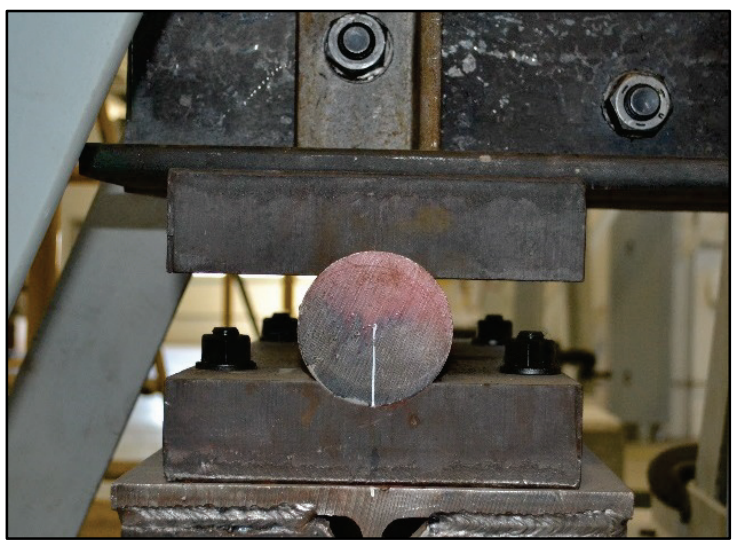

(a)

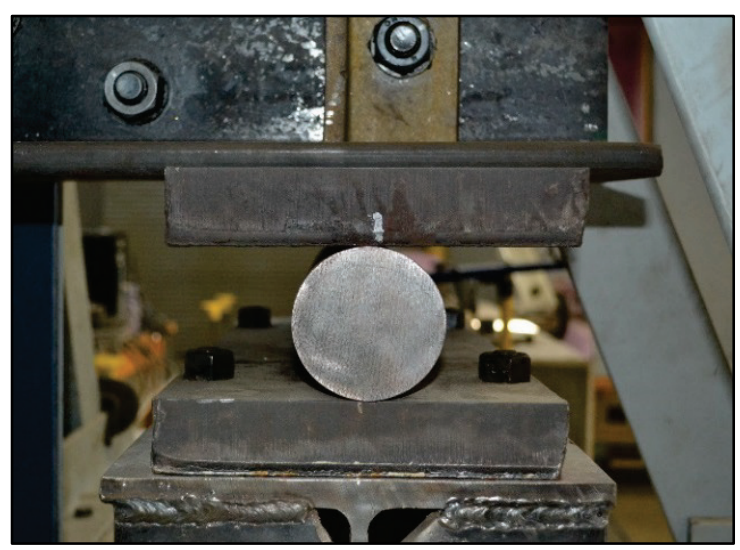

(b)

Figure 3-3 (a) Pin bearing, (b) Roller bearing

Bracing was used at discrete locations along the length of the beam to prevent out-of-plane bending and to prevent instability of the test setup. At each end of the specimen 4 " $\times 4$ " $\times 1 / 2$ " L's with an abrasion resistant UHMW Polyethylene bearing shim (to allow longitudinal rotational movement) were fastened at the top flange of the specimen and braced against an angle attached to the concrete reaction block with expansion anchors (see Figure 3-4). An additional angle was attached in the longitudinal direction to the reaction block which resulted in the stiffening of the end bracing. 

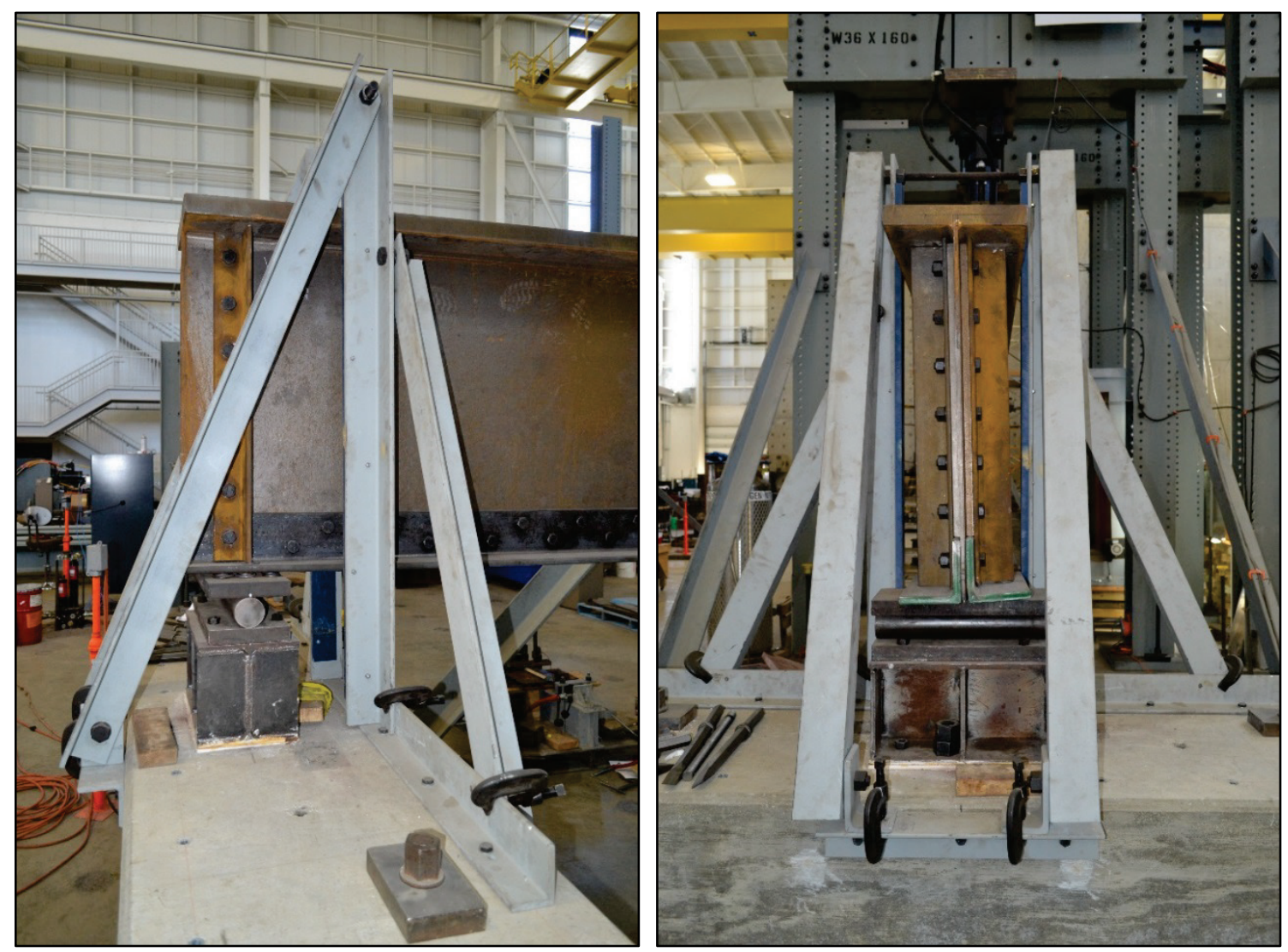

Figure 3-4 Lateral torsional bracing at specimen ends

The top flange of each specimen was also braced at the location of each actuator to prevent compression flange buckling. The first specimen (Specimen 23-1) was braced with stationary half-round slider plates attached to the load frame allowing the specimen to deflect vertically but preventing lateral movement (see Figure 3-5). Each half-round slider plate was greased to allow the specimen to deflect vertically with minimal friction. However due to the required frequency of lubricating the bearing plates and the resulting loud noise created as the specimen skidded along the slider plate, an alternate bracing method was devised for subsequent specimens. A $12^{\prime \prime} \times 1 / 8^{\prime \prime}$ plate was attached from the load frame column to the actuator bearing plate on each side of the specimen (see Figure 3-6). The plate was designed to resist any lateral forces from out-of-plane bending 
through tension from one side of the plate while allowing buckling of the brace on the opposite side. The thickness of the plate provided negligible stiffness in the vertical direction and therefore did not diminish the load applied to the specimen from the actuators.

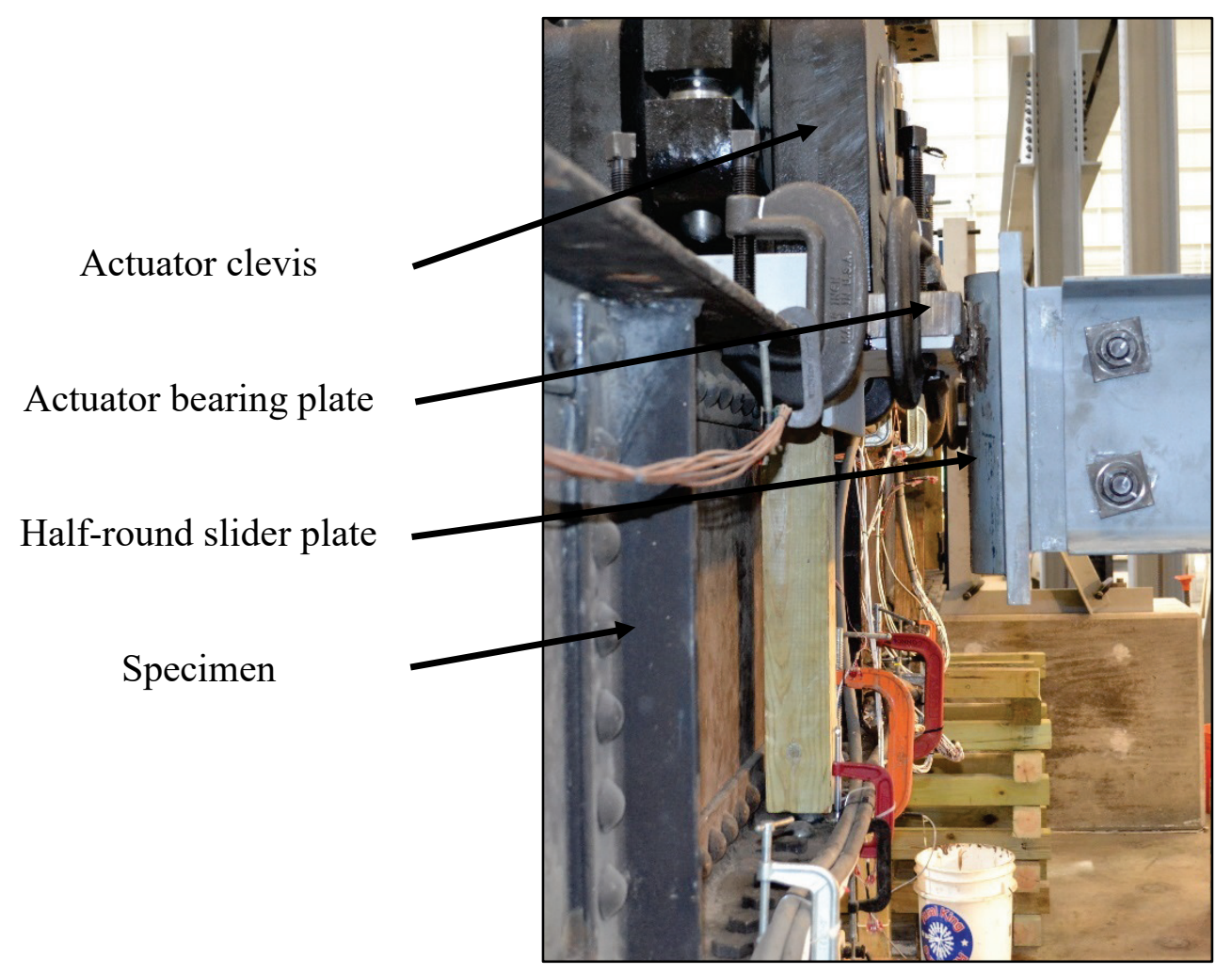

Figure 3-5 Lateral torsional buckling bracing (half-round slider plate method) 


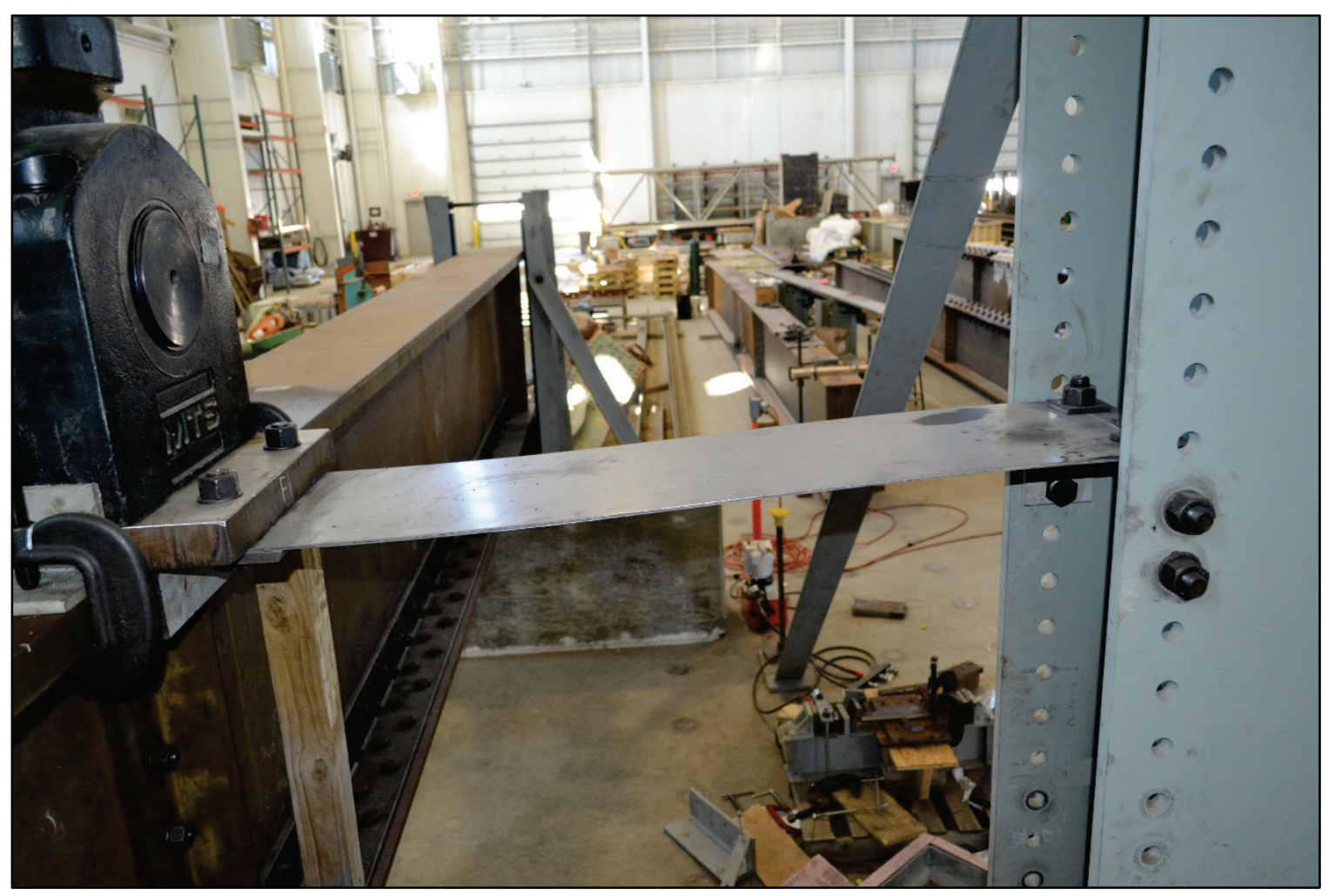

Figure 3-6 Lateral torsional buckling bracing (thin plate method)

\subsection{Specimen Fabrication}

Two different types of specimens were used, historical specimens, and newly fabricated specimens. Efforts were made to replicate conditions seen on historical bridges typical of built-up fabrication methods. This section describes the hot riveting process used in the fabrication of specimens, instrumentation for collection of data, the methods used to control the crack location, then describes the modifications made to the historical specimens, and finally details the fabrication of the remaining specimens. 


\subsubsection{Hot Riveting}

Due to the evolution of steel fabrication, the vast majority of bridges in the inventory contain built-up shapes with hot-driven rivets connecting each of the steel components. Because some newer structures utilizing built-up members contain highstrength bolted fasteners (as well as some retrofits and repairs of historical structures), both rivets and high-strength bolts were compared. Due to the lower clamping stresses obtained from riveted connections, as opposed to high-strength bolted connections, the conservatism created by using primarily riveted specimens was beneficial in creating a lower bound of specimen behavior.

Since the use of riveting is considered largely outdated and obsolete by the structural steel industry, few experts in the area remain with which to consult on proper techniques. Consultation and training was given by Vern Mesler of Lansing Community College in an effort to produce similar quality riveted connections as would have been made on historical structures. Mesler is a recognized expert on historical steel bridge restoration and rehabilitation (National Center for Preservation Technology and Training, 2010).

Refurbished rivet driving equipment from the late 1950s was purchased from Michigan Pneumatic Tool to drive the rivets. A Chicago Pneumatic CP-80RB rivet buster was used to drive the rivets (see Figure 3-7). This rivet buster is a long stroke boyer valve style rivet hammer capable of driving rivets up to $1-1 / 8^{\prime \prime}$ in diameter (Webster, 1920). A Chicago Pneumatic CP-AA-Offset holder-on was used to hold the shop head of the rivet in place during driving (see Figure 3-8). The holder-on works as a 
pneumatic piston designed to react against a sturdy object (typically the opposite interior flange of an I-shaped beam).

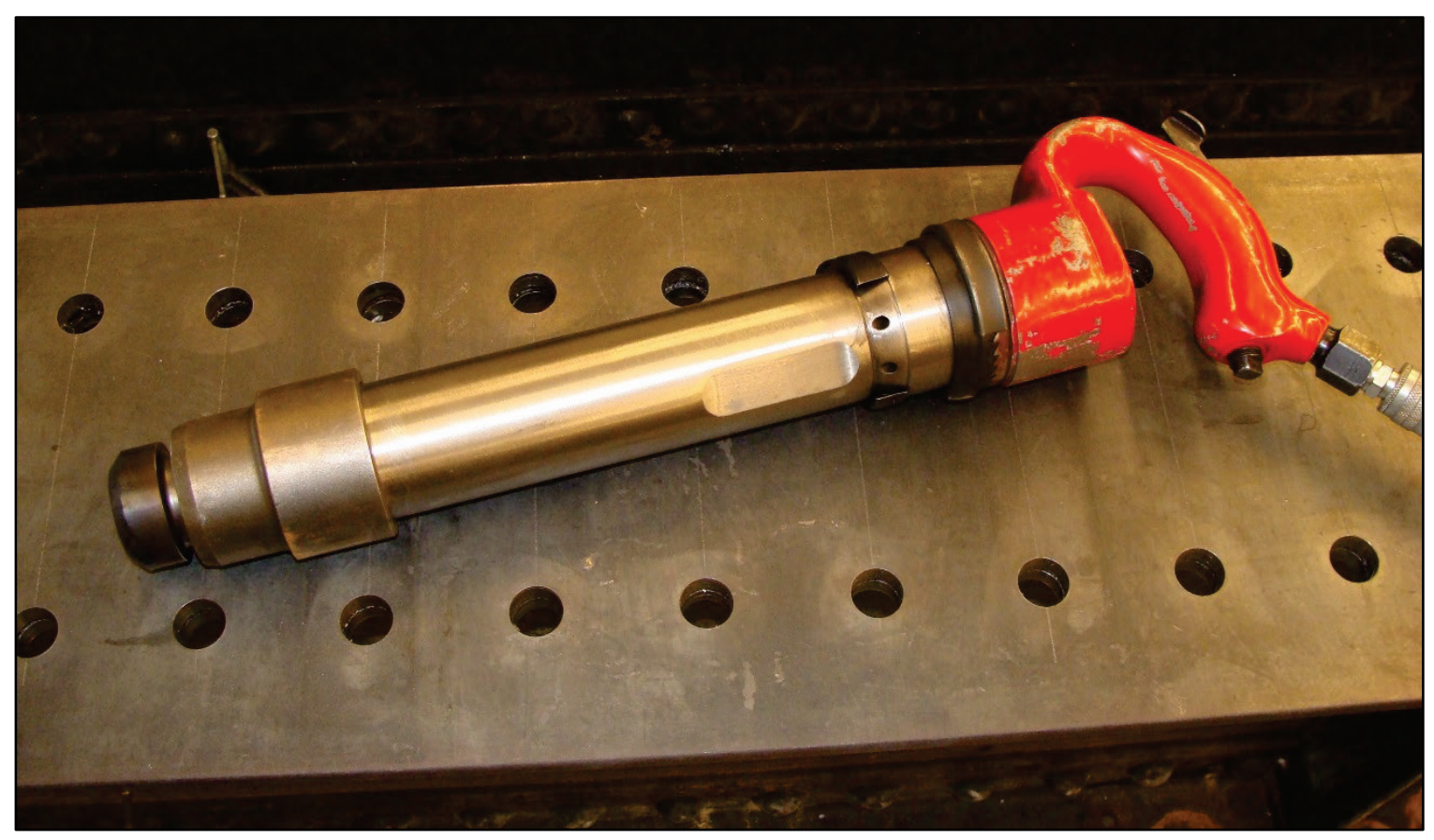

Figure 3-7 Chicago Pneumatic CP-80RB Rivet Buster

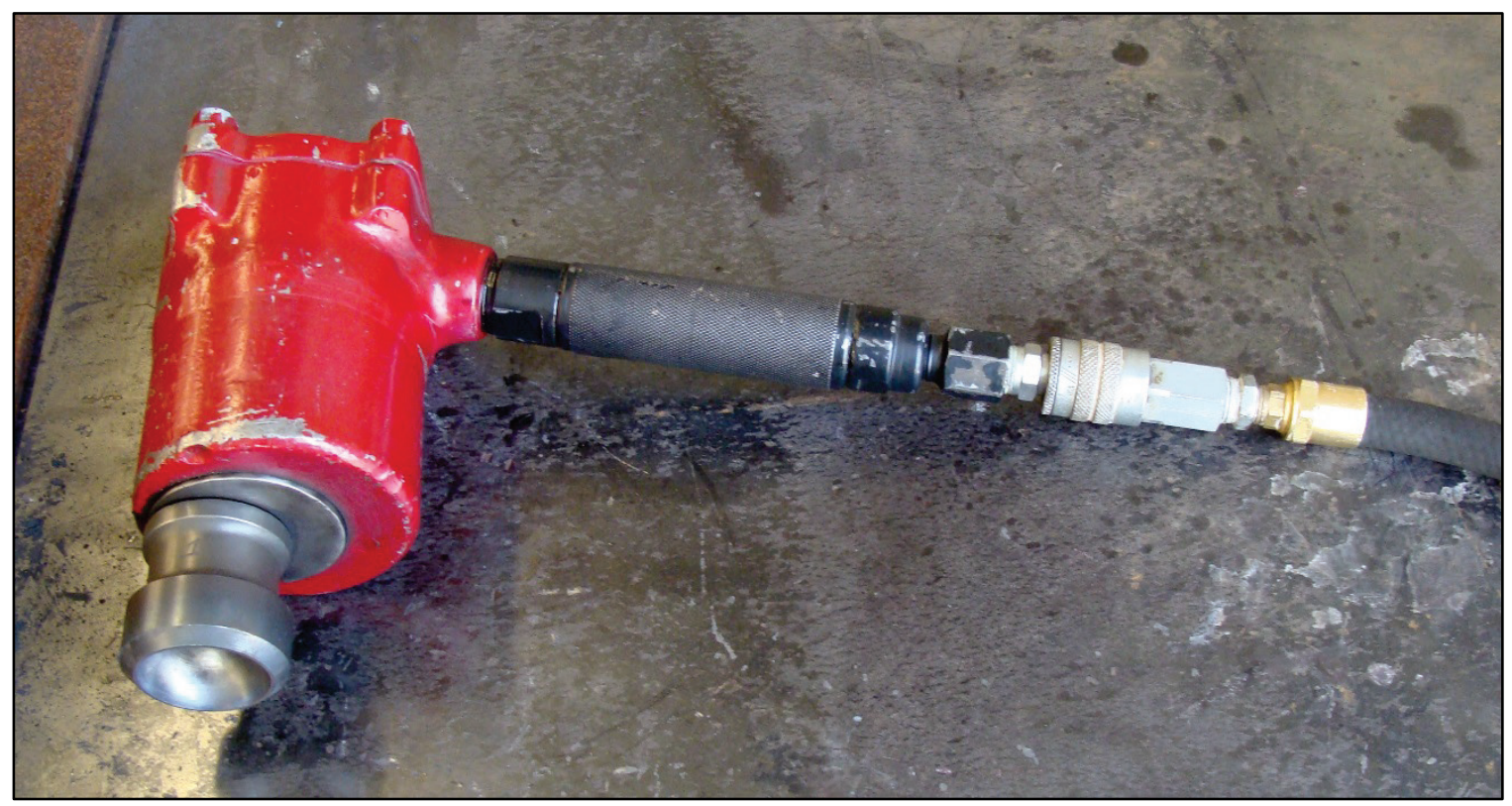

Figure 3-8 Chicago Pneumatic CP-AA-Offset holder-on 
Rivets were heated in a propane fuel forge until they reached approximately $1900^{\circ} \mathrm{F}-2100^{\circ} \mathrm{F}$ as measured by an Omega HH802U thermometer with a type $\mathrm{K}$ thermocouple probe placed adjacent to the heating rivets. This temperature correlated to a bright orange color. While little recorded guidance was found on the proper methods of heating and driving rivets, those references found on the subject suggest that during historical fabrication a bright cherry red to bright orange color was typically desired to ensure proper rivet heating (Champion, 1914; Hechtman, 1948). The author found that it was nearly impossible to pneumatically drive rivets that are only heated to a cherry red color since they are still too stiff at such a temperature. Instead, the rivets were driven at a bright orange color which resulted in proper forming of the rivet heads. During specimen fabrication, both temperature and color were monitored to ensure consistent quality rivets were driven. All rivets used for the current research were C1018 steel. The material properties can be found in APPENDIX D. 


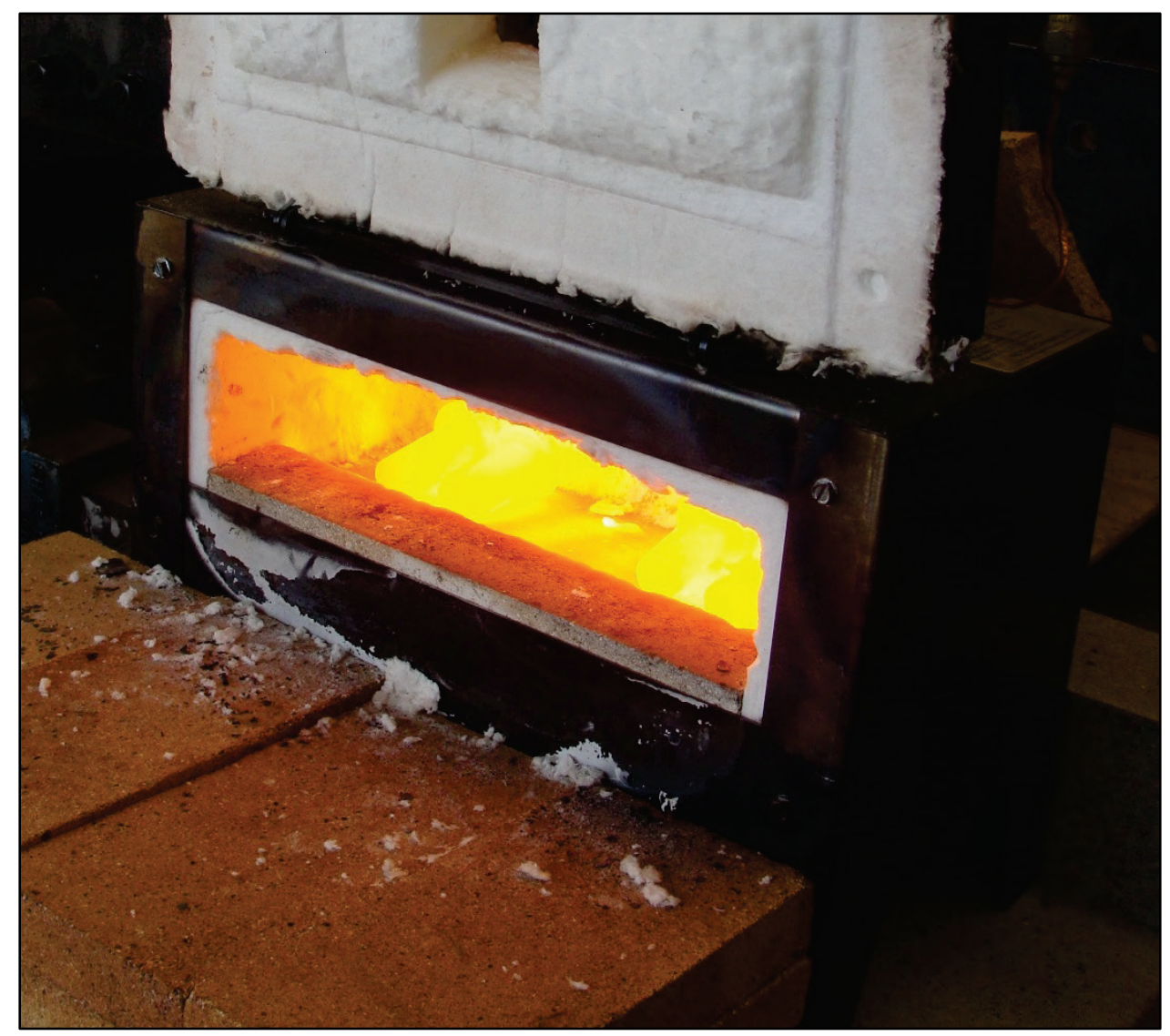

Figure 3-9 Propane fueled rivet forge

Traditionally, rivets were driven either in the field or in the shop. Shop driven rivets were driven using a hydraulic rivet press. Field rivets were driven using a four person driving crew consisting of a Heater, Sticker-in, Bucker-up, and Riveter. The Heater was responsible for tending the forge and tossing the rivet to the Sticker-in who would catch the rivet and place it in the hole. The Bucker-up would place a holder-on against the shop side of the rivet and the riveter would drive the rivet with a pneumatic rivet hammer. A similar crew was used for the specimen preparation during the fabrication of test specimens except that the Heater and Sticker-in were combined to form a three person crew. 


\subsubsection{Instrumentation}

A variety of measurement devices were used in the testing of each specimen. Displacement, force, temperature, and strain data were all measured and collected simultaneously using a Campbell Scientific CR9000X data acquisition base system (DAQ) outfitted with CR9050 cards. Data was collected at 20 samples per second for each specimen during most of the testing (a sampling that more than doubled the loading frequency to prevent aliasing of data).

Displacement was measured using two different methods. Analog data was fed from the linear variable displacement transducer (LVDT) within the MTS hydraulic actuator into the DAQ. Additionally, string potentiometers were attached to each specimen beneath each actuator (to avoid the inclusion of potential load frame deflection - as measured by the LVDT) and at the centerline of the beam. During the testing of later specimens the string potentiometer at the centerline of the beam was omitted to provide better inspection access of cracked sections.

Force was measured using analog data fed from the load cells attached to the MTS hydraulic actuator to the DAQ. Each load cell on the East setup was an MTS model 661.31E-01 with 220 kip capacity. Each load cell used on the actuators of the West setup was a Honeywell model 3129-112-300K with a 300 kip capacity.

Twelve different type $\mathrm{J}$ thermocouples were used to measure the temperature of the each specimen during cooling, prior to a fracture attempt. The thermocouples were arranged in a grid fashion with four thermocouples on each flange and the web. The purpose of the thermocouple distribution was to monitor temperatures across the entire 
specimen within the temperature chamber to minimize any temperature gradients. Two of the twelve thermocouples (one on the top flange and one on the bottom flange) were required to control each zone of an Omega CN79000 dual zone controller connected to two separate solenoid valves metering liquid nitrogen into the top and bottom of the temperature chamber.

Two different strain gage manufacturers were used throughout the testing program - Vishay Micro Measurements CEA-06-250UN-350/P2 and Texas Measurements FLA-6-350-11. Strain gages were adhered to each specimen per instructions published by Vishay Micro-Measurements (2005). All strain gages had a resistance of $350 \Omega$. For the purposes of this research program, all strain measurements were converted to stresses using the reported strain gage factor (used through a multiplier in the DAQ) and are reported as stress in the raw data.

Strain gages were applied to each specimen in an effort to collect meaningful data which could accurately describe the global behavior of the specimen both before, during, and after a component failure. Strain gages were located based on previous analytical work performed by Bonachera Martin (2014) in which the stress distribution of riveted and bolted plates with partial failures was studied. As illustrated in Figure 3-10, strain gages were organized in a three dimensional grid (longitudinal location, transverse location, and vertical location) to determine stress distribution at discrete points throughout the degradation of specimen components. Letter gridlines (A, B, C, etc.) were used along the longitudinal axis of the specimens. The grid numbering started at 'A' approximately one beam depth from the centerline of the specimen, and increased incrementally to the centerline of the beam. Only half of the longitudinal length of the 
specimen was instrumented due to the symmetry of the loading conditions. Numerical gridlines $(1,2,3$, etc.) were used along the transverse length of the specimen. Numbering started with ' 1 ' at the west end of each component and progressed to the east and vertically (e.g. for a specimen with a single cover plate, gridlines: 1, 2, 3 were on the cover plate; gridlines 4, 5, 6 were on the flange angle; gridlines $8,9,10$ were on the web plate). Figure 3-10 shows the typical gridlines used for most specimens. Strain gages were given names with a combination of gridlines (e.g. A1, A2, B1, B2, etc.). Figure 3-11 shows a typical gage plan for the bottom flange (flange angles and two cover plates) of the 36 inch specimens. Initial specimens had more strain gages than later specimens as some of the strain gages on the initial specimens were found to be redundant or less relevant.

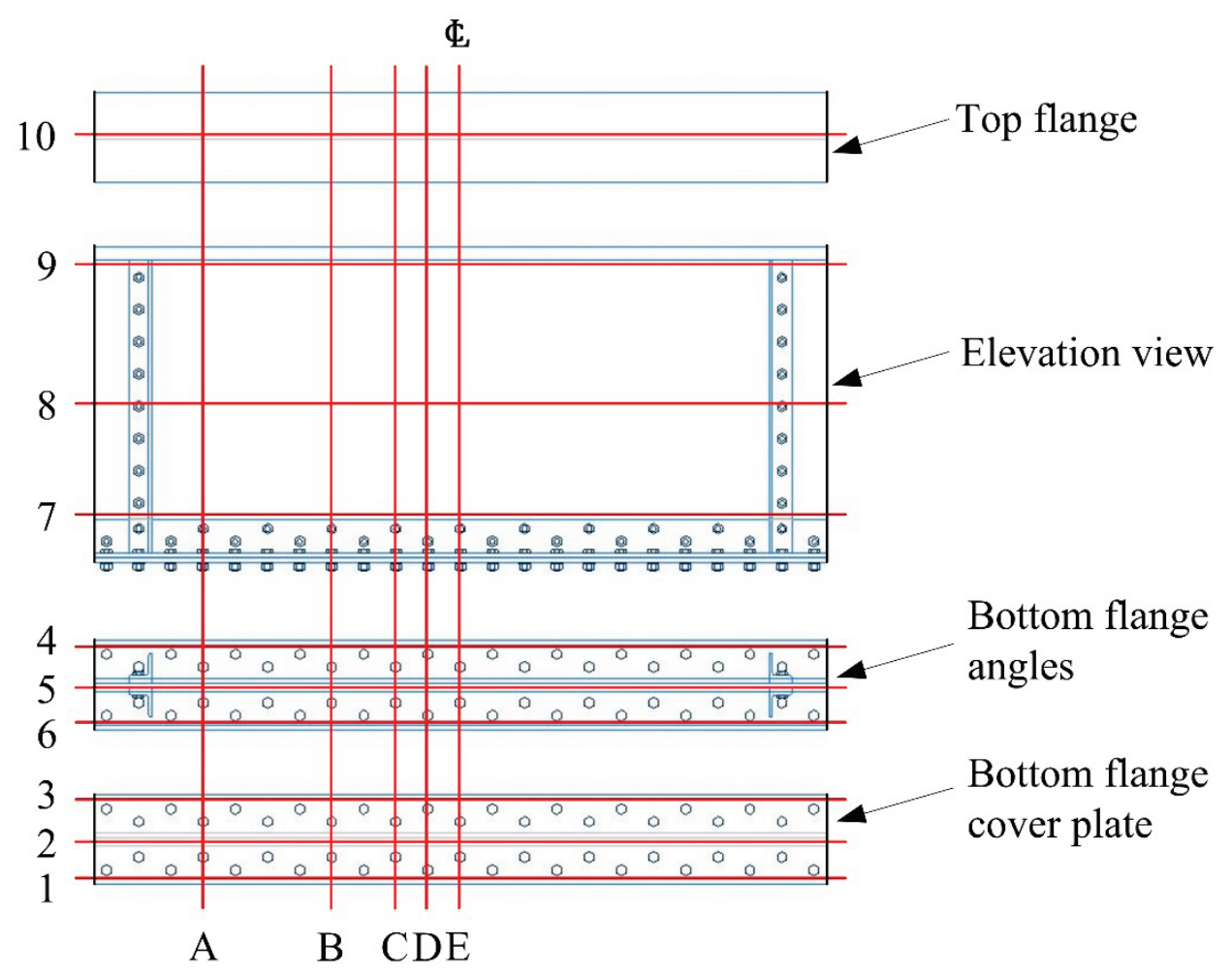

Figure 3-10 Typical strain gage gridline layout 


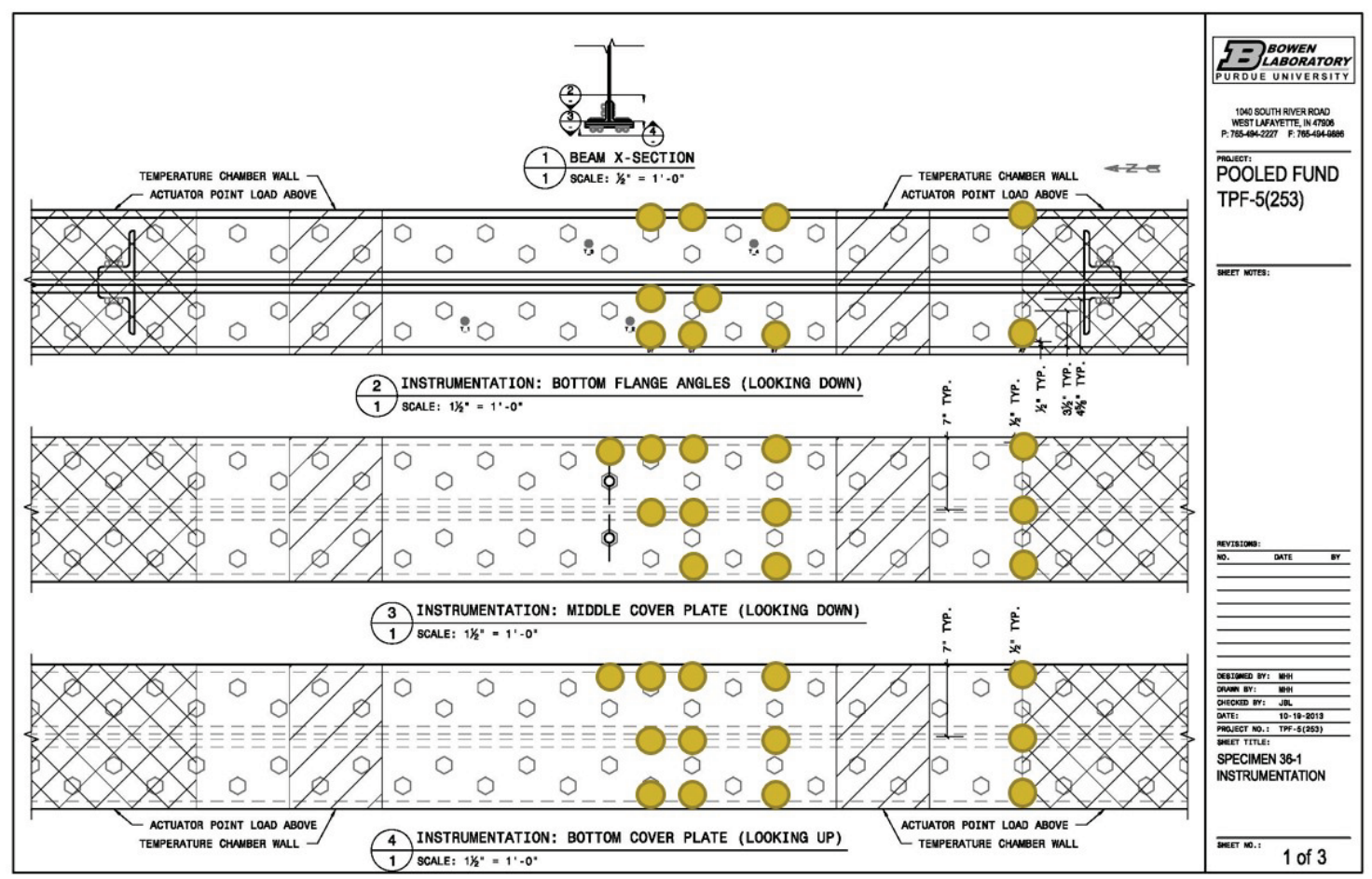

Figure 3-11 Typical 36 inch specimen bottom flange instrumentation

\subsubsection{Notched Components}

Throughout the test program two different methods were employed to initiate both fatigue cracks and fractures. The purpose of controlling the location of flaws was to ensure that strain gages were located in strategic locations to measure stress distributions and their changes throughout the degradation of components. This section will describe the two different methods of controlling crack location, namely hole notches and edge notches as well as their respective loading methods. 


\subsubsection{Hole Notches}

Initially notches were made in fastener holes at the centerline of the beam within the constant moment region. Notches were put in the holes to simulate the likely scenario of fatigue cracks growing from holes due to the localized stress concentration and any imperfections resulting from hole preparation (Zhou, 1994; Brown, Lubitz, Cekov, Frank, \& Keating, 2007).

A study was made to determine the most effective method for creating notches at holes. Due to the limited access required to cut notches at the interior portion of a hole a Dremel 409 cutting wheel was selected as the best method. The 409 cutting wheel had a thickness of $0.025^{\prime \prime}$ and a diameter of $15 / 16^{\prime \prime}$. A thin wheel was most desirable to create as sharp a notch as possible to increase the stress concentration (see Figure 3-12 for resulting notch). A small diameter cutting wheel was selected in order to minimize the length of the cut while still cutting as deep through the thickness as possible. While initial specimen notches were created as short as possible, notches in later specimens were cut to be slightly shorter than the critical crack length calculated from linear elastic fracture mechanics. 


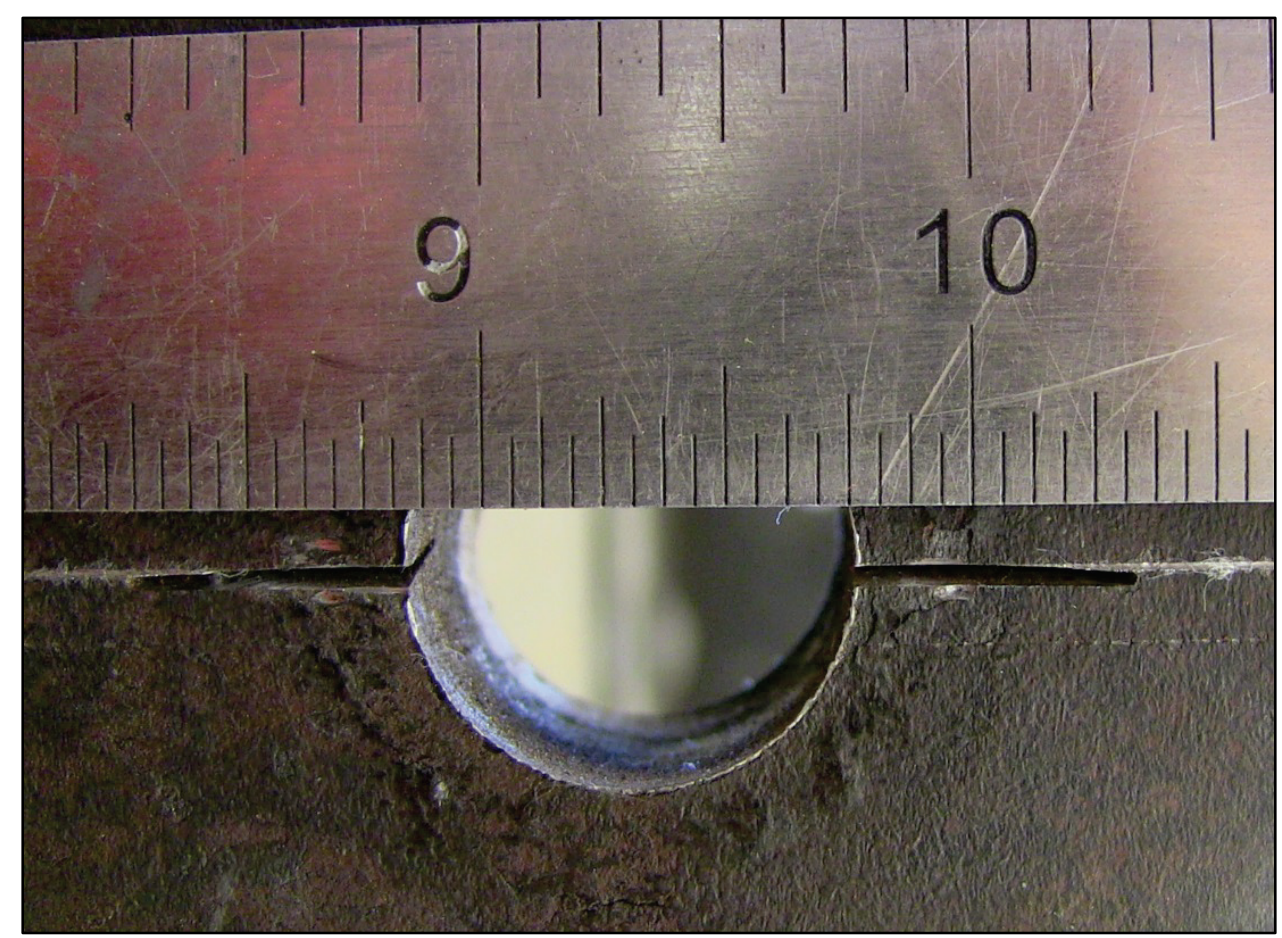

Figure 3-12 Typical hole notch with Dremel 409 cutting wheel

In order to calculate the critical crack length of a hole with two cracks, linear elastic fracture mechanics were employed. A target fracture stress of $0.55 \mathrm{~F}_{\mathrm{y}}$ was used to simulate the full design load used in older structures. This was similar to the loading protocol used by Wright (2003). The following equation was used to calculate the critical fracture toughness.

Where:

$$
K_{I c}=\sigma_{\text {frac }} \sqrt{\pi * a_{c}} * \beta
$$

$$
\begin{aligned}
& \mathrm{K}_{\mathrm{Ic}}=\text { Critical fracture toughness } \\
& \sigma_{\text {frac }}=\text { Stress at fracture } \\
& \mathrm{a}_{\mathrm{c}}=\text { Critical crack length } \\
& \beta=\text { Geometry factor }
\end{aligned}
$$


In order to calculate the geometry factor, only half of the cover plate was considered. The symmetry of the cover plate allowed the use of a geometry factor of a finite width plate with a crack on either side of a single hole. The geometry factor for two cracks in a hole in a plate with infinite width plate application was presented by Grandt (1975).

Where:

$$
\beta=\frac{0.6865}{2.772+\frac{a}{R}}+0.9439
$$

$$
\begin{aligned}
& \mathrm{a}=\text { crack length } \\
& \mathrm{R}=\text { Hole radius }
\end{aligned}
$$

Empirical data was presented by Newman (1971) who described the geometry factor for cracks emanating from a circular hole in a plate with finite width. The empirical data was a result of studies investigating the relationship between hole size and plate width, as well as the relationship between crack length and plate width. Grandt's (1975) geometry factor function was used for approximate values and later, Newman's empirical geometry factors were used to determine a more precise critical crack length of hole notched specimens.

\subsubsection{Edge Notches}

After testing six specimens (Specimens 23-1, 23-2, 23-3, 46-1, 46-2, and 46-3) it was decided that a higher energy release would be desirable to illustrate the resilience of built-up members in their resistance to fracture propagation. In order to gain a higher fracture energy release, a larger fracture surface was targeted (i.e. one where holes were 
not present). Additionally, since the cover plates with notches in the holes created four different crack tips resulting in three different potential fracture surfaces, it was felt that a worst case scenario could be obtained by limiting the fracture to a single crack surface. This eliminated the possibility of a specimen with notched holes only partially fracturing a component due to a crack arresting in a hole.

It was found to be much easier to fabricate notches at the edge of a component than at holes. Access to the exterior edge of plate allowed more flexibility in the tools that could cut the notch as well as increased control throughout the notching process. After an evaluation of several different methods a combination notch was made with a grinding wheel and a cutoff wheel on a $4 \frac{1}{2}$ " angle grinder. A $3 / 4^{\prime \prime}$ deep notch was cut into the edge of the plate with the grinding wheel which was $3 / 16^{\prime \prime}$ thick. Next a $1 / 4$ " deep notch was cut at the center of the first notch using the cutoff wheel which had a thickness of $0.04 "$. Figure 3-13 shows a plan view of the end result after both the grinding wheel and cutoff wheel were used. 


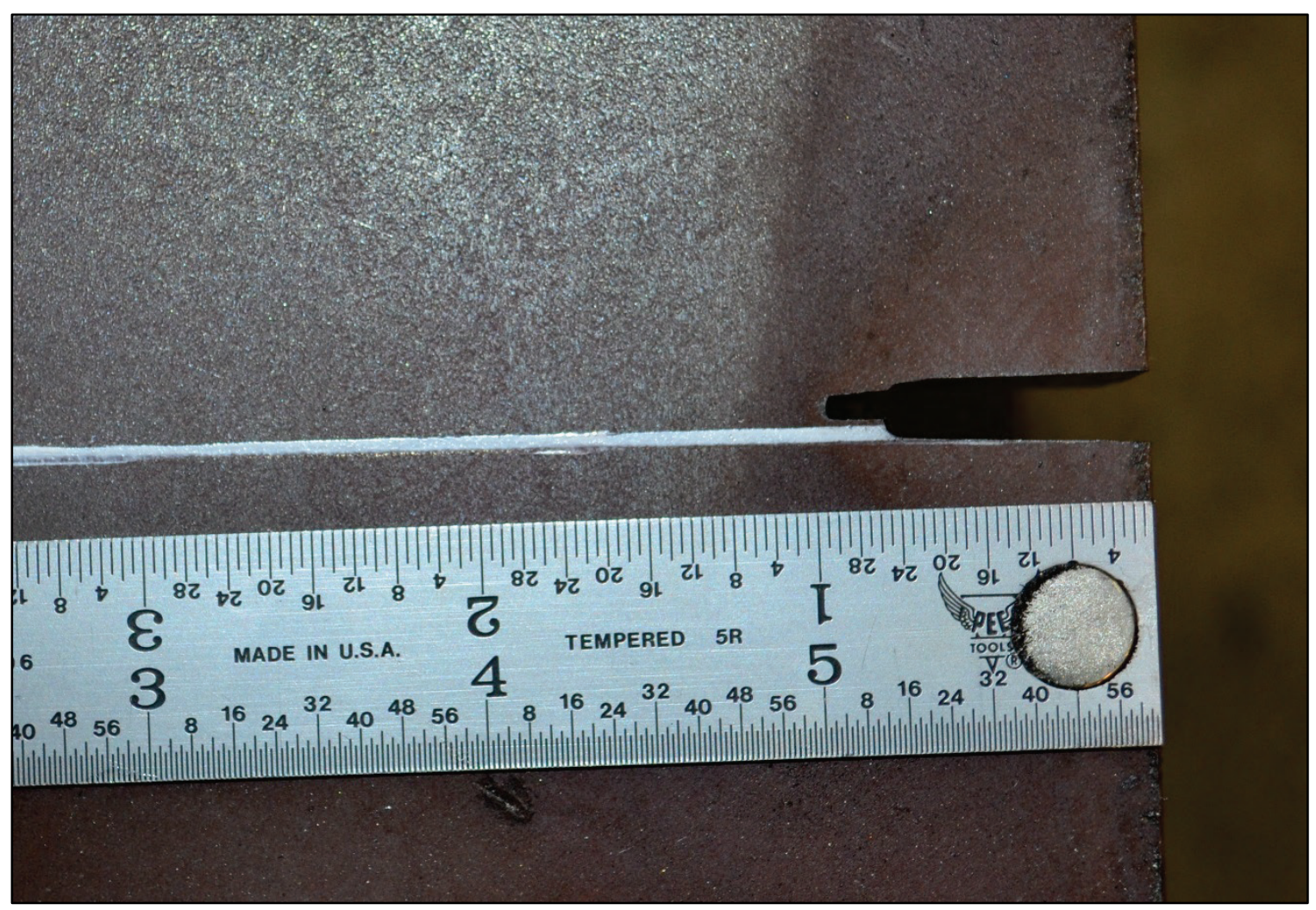

Figure 3-13 Typical edge notch geometry

By using edge notches rather than hole notches, the initial cracked portion (prior to the fracture attempt) of the component was reduced (approximately $64 \%$ for specimen cover plates) at the critical crack length. The geometry factor which was used for a finite width plate with two edge notches per Tada, Paris, \& Irwin, (2000) was:

$$
\beta=\frac{1.122-0.561\left(\frac{a}{b}\right)-0.205\left(\frac{a}{b}\right)^{2}+0.471\left(\frac{a}{b}\right)^{3}-0.190\left(\frac{a}{b}\right)^{4}}{\sqrt{1-\frac{a}{b}}}
$$

Where:

$$
\begin{aligned}
& a=\text { Crack length } \\
& b=1 / 2 \text { of the plate width }
\end{aligned}
$$




\subsubsection{Historical Specimens}

The 23 inch tall specimens (labeled 23-xx) were obtained from the Wilson Dam Bascule Bridge (Figure 3-14), which was removed from service in 2012. The specimens were riveted built-up steel beams with a usable span of $22^{\prime}-0$ "' (after removal). The bridge was built in 1926 as an access route over the lock at Wilson Dam, in Lauderdale County, Alabama on the Tennessee River (Williamson, 2012). Selected original design drawings of the bridge and floor beams can be found in APPENDIX A. The specimens were used as floor beams spanning between the bascule girders of the bridge.

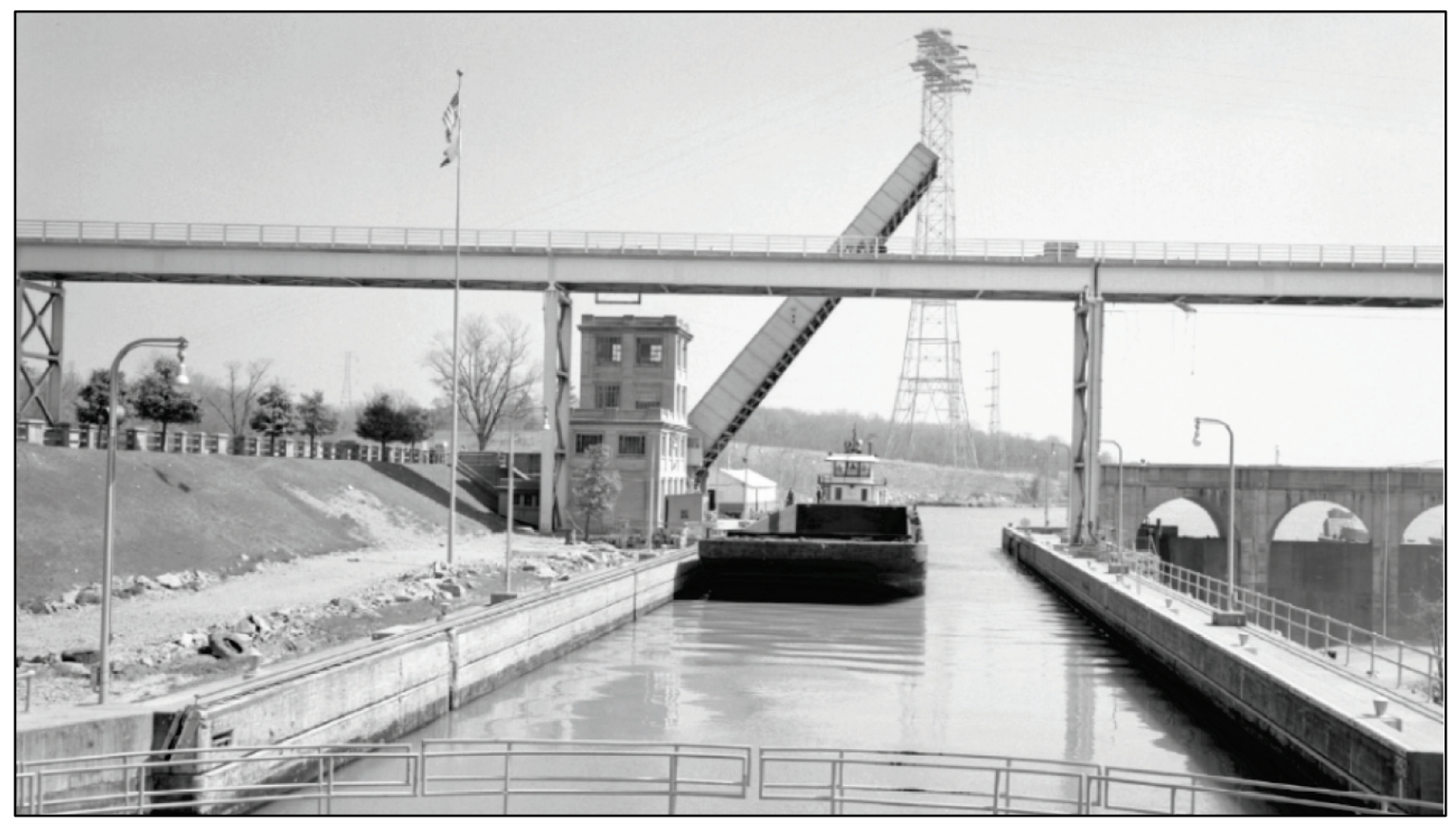

Figure 3-14 Wilson Dam Bascule Bridge in raised position in the background, 1958 (Williamson, 2012)

The cross section of the floor beams was composed of a $23^{\prime \prime} \times 3 / 8^{\prime \prime}$ web plate riveted to two $5^{\prime \prime} \times 3^{1 / 2} 2^{\prime \prime} \times 7 / 16^{\prime \prime}$ flange angles (long legs horizontal) on the top and bottom flange (see Figure 3-15). A cover plate was added to the bottom flange of each specimen 
for the purposes of the current research test. Holes were drilled in the horizontal leg of the flange angles as well as the cover plate. New rivets were driven in the holes connecting the cover plate to the flange angles (see Figure 3-16). Design drawings of the modified sections can be seen in APPENDIX A.

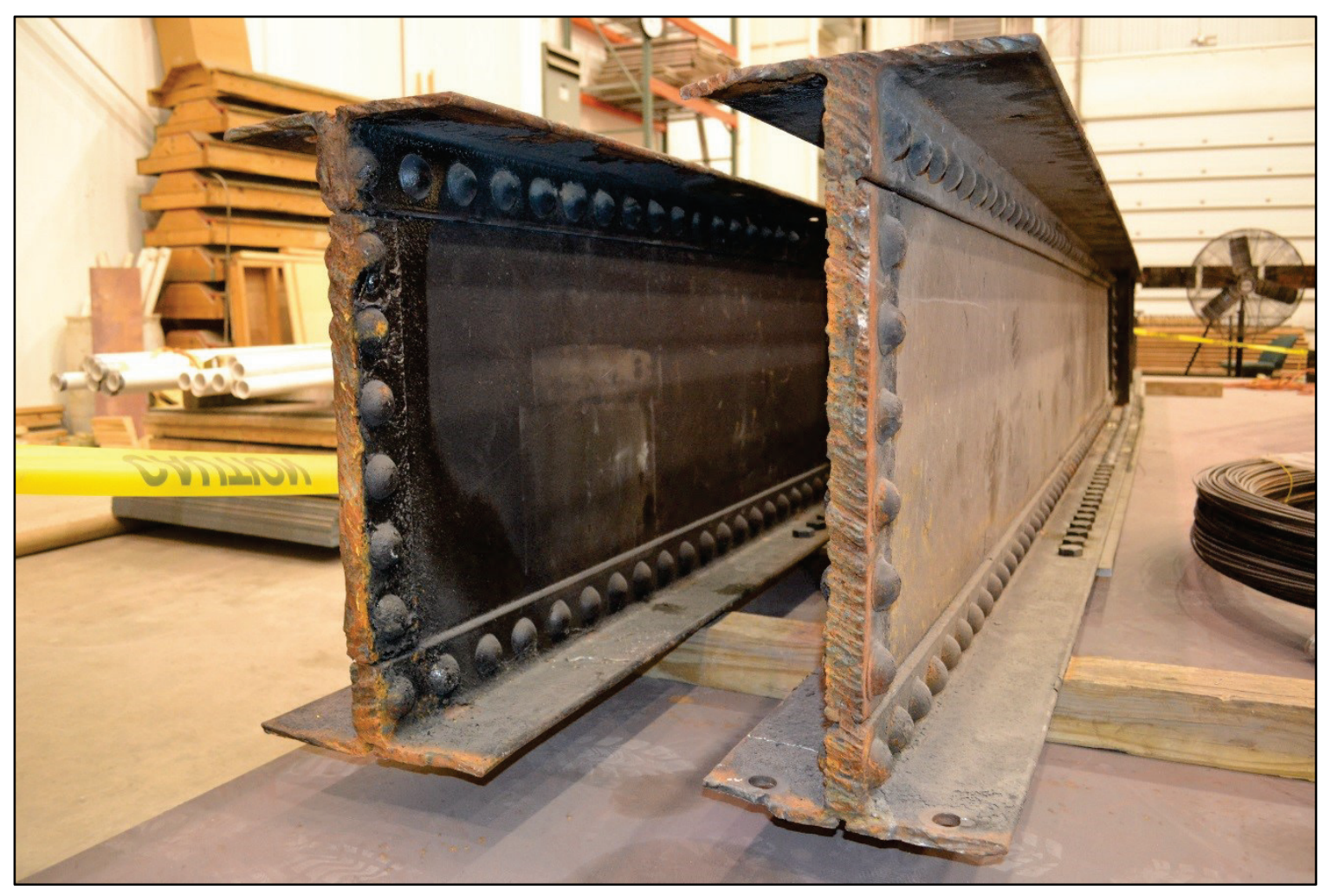

Figure 3-15 Wilson Dam Bascule Bridge specimens 


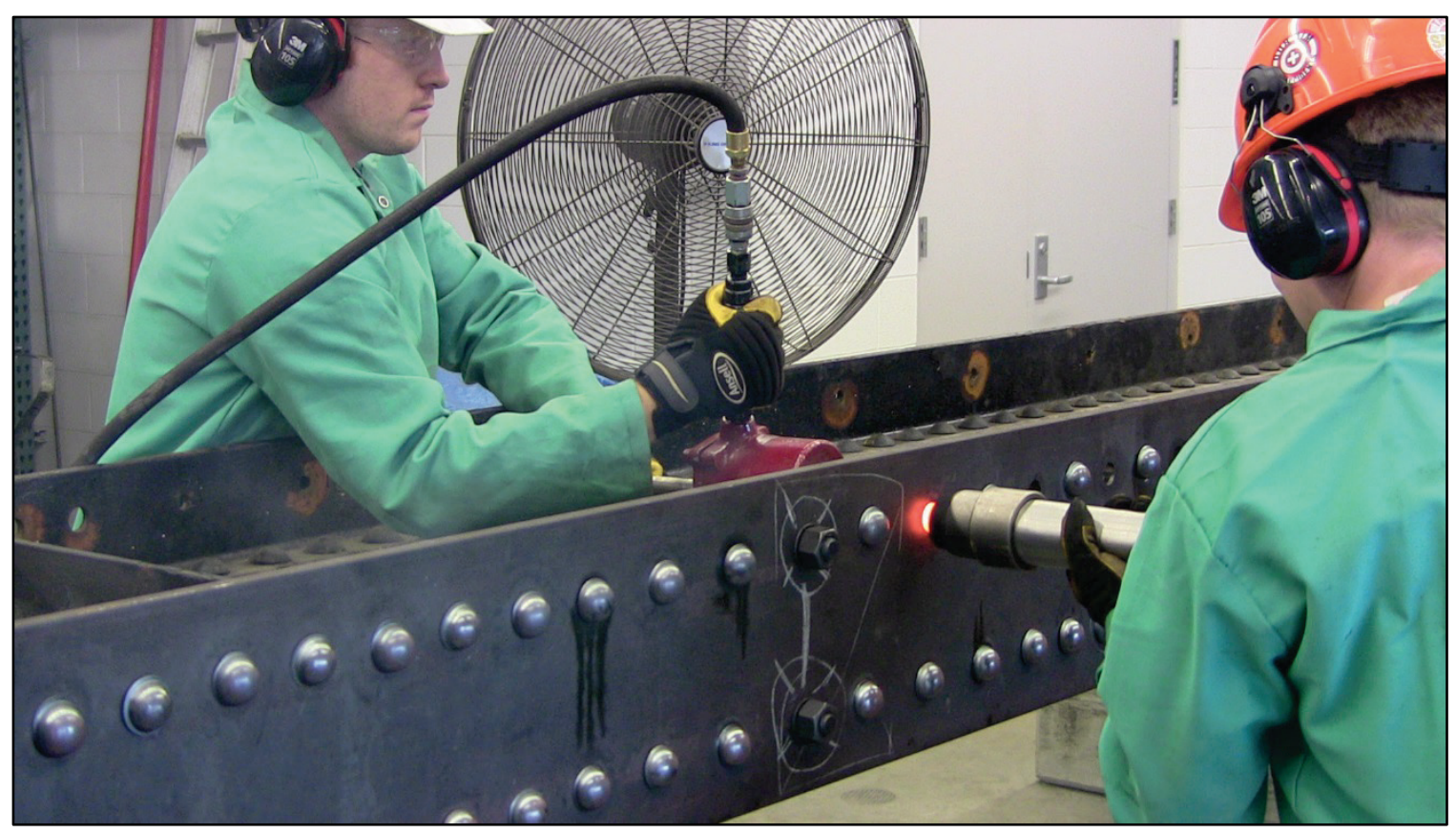

Figure 3-16 Cover plate installation on historical specimens

\subsubsection{Fabricated Specimens}

The design of the new specimens (labeled 46-xx, 36-xx, and 30-xx) was intended to maximize the loading capacity of the laboratory and test setup, while using appropriate sizes, thickness, shape, and proportions as those used on in-service built-up girder bridges. Each specimen was designed to reach $0.55 \mathrm{~F}_{\mathrm{y}}$ at approximately 200 kips (a $90 \%$ of the maximum force of the actuator) to maximize specimen size and simulate full-scale bridge girders. The specimens were designed to meet AASHTO design requirements (AASHTO, 2010). The maximum test stress of $0.55 \mathrm{~F}_{\mathrm{y}}$ was selected to correlate with historical allowable stress design capacity loads.

As the focus of this research project is on fracture critical sections, it was determined that the emphasis needed to be on the tension flange of the specimens. To minimize fabrication cost, the upper (compression) flange was fabricated using a 2" plate 
welded to the web (see Figure 3-17 for typical fabrication). Bottom flange angles were fabricated using $6 " \times 6 " \times 3 / 4^{\prime \prime}$ L's and attached to both the web plate and the $14^{\prime \prime} \times 3 / 4^{\prime \prime}$ cover plate(s) with $7 / 8^{\prime \prime} \varnothing$ bolts or rivets (depending on the specimen). The $30^{\prime \prime}$ and $46^{\prime \prime}$ specimens were fabricated with a single cover plate on the bottom flange which was stepped at the location where the bending moment required a larger section modulus. Similarly, the $36^{\prime \prime}$ specimens were fabricated with two cover plates on the bottom flange which were also stepped to meet bending moment demand. Web plates were $1 / 2$ " thick with heights of $30^{\prime \prime}, 36^{\prime \prime}$, and $46^{\prime \prime}$ for the three different specimens. The span length of the newly fabricated specimens was $39^{\prime}-0^{\prime \prime}$ from centerline to centerline of bearings. The girders extended an additional 6 inches beyond the centerline of the bearing for an overall specimen length of $40^{\prime}-0^{\prime \prime}$. See APPENDIX C for detailed design drawings of the specimens. 


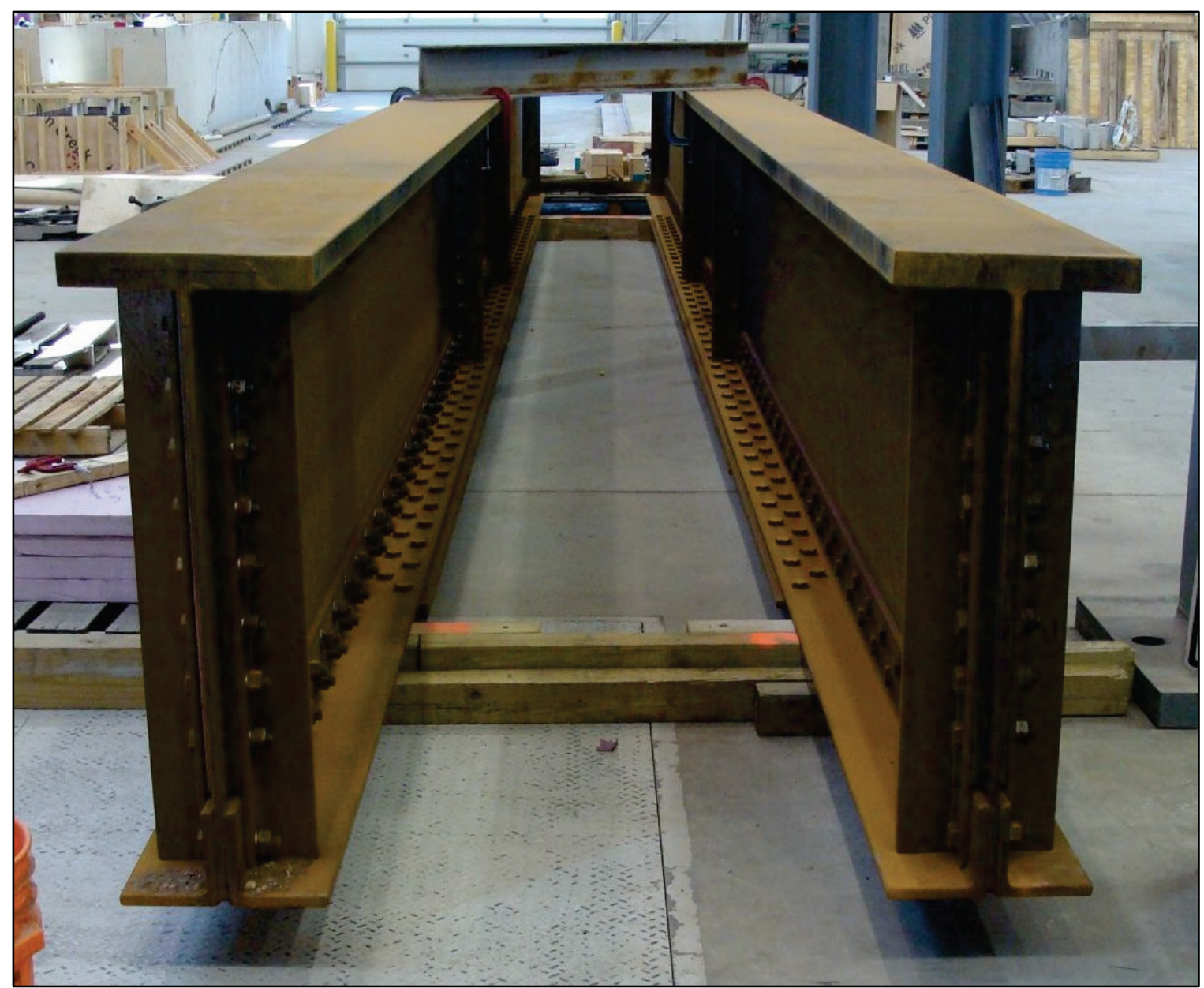

Figure 3-17 Fabricated Specimens (46" Web Height)

Initially, four new specimens were fabricated by Hirschfeld Industries Bridge Division. Each of these specimens was requested to be fabricated with punched holes to simulate the expected worst-case fatigue scenario based on previous research (Brown et al., 2007). Due to fabricator limitations, only the flange angles were punched. This was deemed acceptable for the purposes of this experiment because the location of the initial flaw for these specimens was selected to be the cover plate(s). This meant the remaining components with the highest stresses would be the flange angles where the holes would be most susceptible to fatigue. 
For riveted specimens, new rivets were driven in the constant moment region using a pneumatic riveting hammer. As per (Bowman, Fu, Zhou, Connor, \& Godbole, 2012) a snug tightened bolt had similar clamping stresses to the average stresses measured at a riveted connection. Therefore, all other holes (outside the constant moment region, the area of interest) were fastened with snug-tightened bolts.

\subsection{Testing Sequence}

After specimens were fabricated, notched, and instrumented, they were placed in the test setup for the two phases of testing: fracture resilience, and fatigue performance with a failed component. In the following section the typical testing sequence will be described.

\subsubsection{Data Collection}

Data was collected at several points throughout the test process. The primary data that was evaluated was measured during static tests performed at discrete times or after a significant event. A typical example of the static test can be seen in Figure 3-18 in which the load was incrementally increased, then decreased, from 0 kips to 200 kips. 


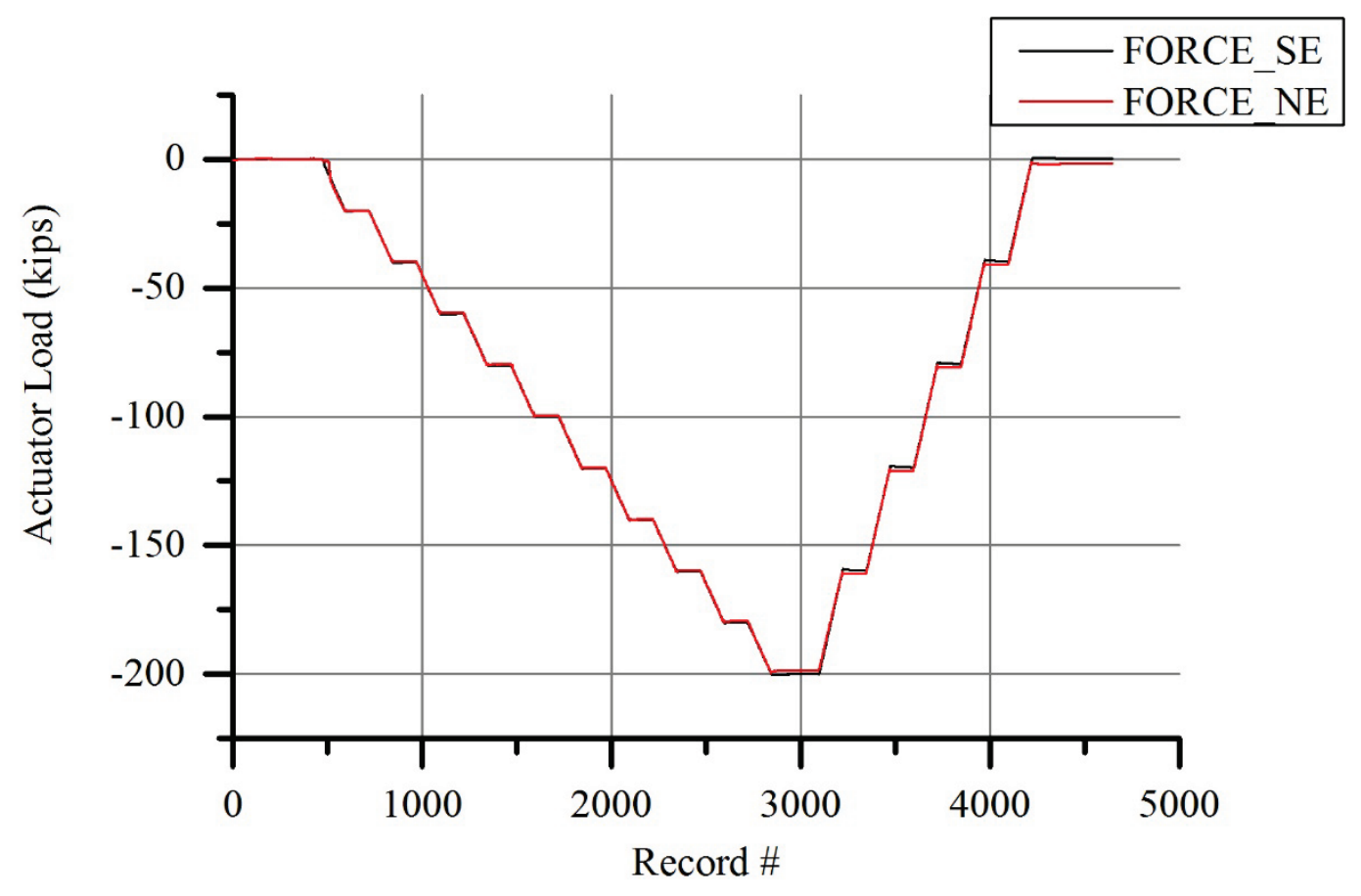

Figure 3-18 Typical static test loading rate

\subsubsection{Specimen Loading}

To approximate dead load conditions seen on in-service bridges, a minimum static load was targeted during the testing. Since dead load is never removed from in-service bridge members, initial attempts were made to keep dead load on the girder for all phases of testing. However, this proved to be impossible due to external laboratory conditions and the duration of the testing (multiple months per specimen). Hence, the dead load was removed between some phases of the testing for all specimens. Maximum stresses of approximately $0.55 \mathrm{~F}_{\mathrm{y}}-0.6 \mathrm{~F}_{\mathrm{y}}$ were targeted for both fracture testing as well as the largest of the fatigue stress ranges tested to represent the maximum stresses in the bottom flange under a typical design load. 
Figure 3-19 illustrates the loading protocol of the test. The specimens were first cyclically loaded to create a sharp crack tip, and then loaded with an impulse load to induce a brittle fracture, similar to the loading protocol used in the work performed by Wright (2003), who was testing fracture resistance of high-performance steel girders. As is described further in Section 3.3.3, each specimen was cooled to low temperatures prior to the application of load. An impulse load creating a stress corresponding to $0.55 \mathrm{~F}_{\mathrm{y}}$ was applied as fast as the actuators were able to apply the load (approximately 0.5-0.75 seconds). The load was held at this point for 2 seconds and then the actuators were cycled between $90 \%$ and $100 \%$ of the maximum load for 25 cycles to represent secondary vibration that could occur during a traffic loading condition. This further increased the likelihood of fracture under the applied loading. The general approach described by Wright was believed to be a reasonable approach.

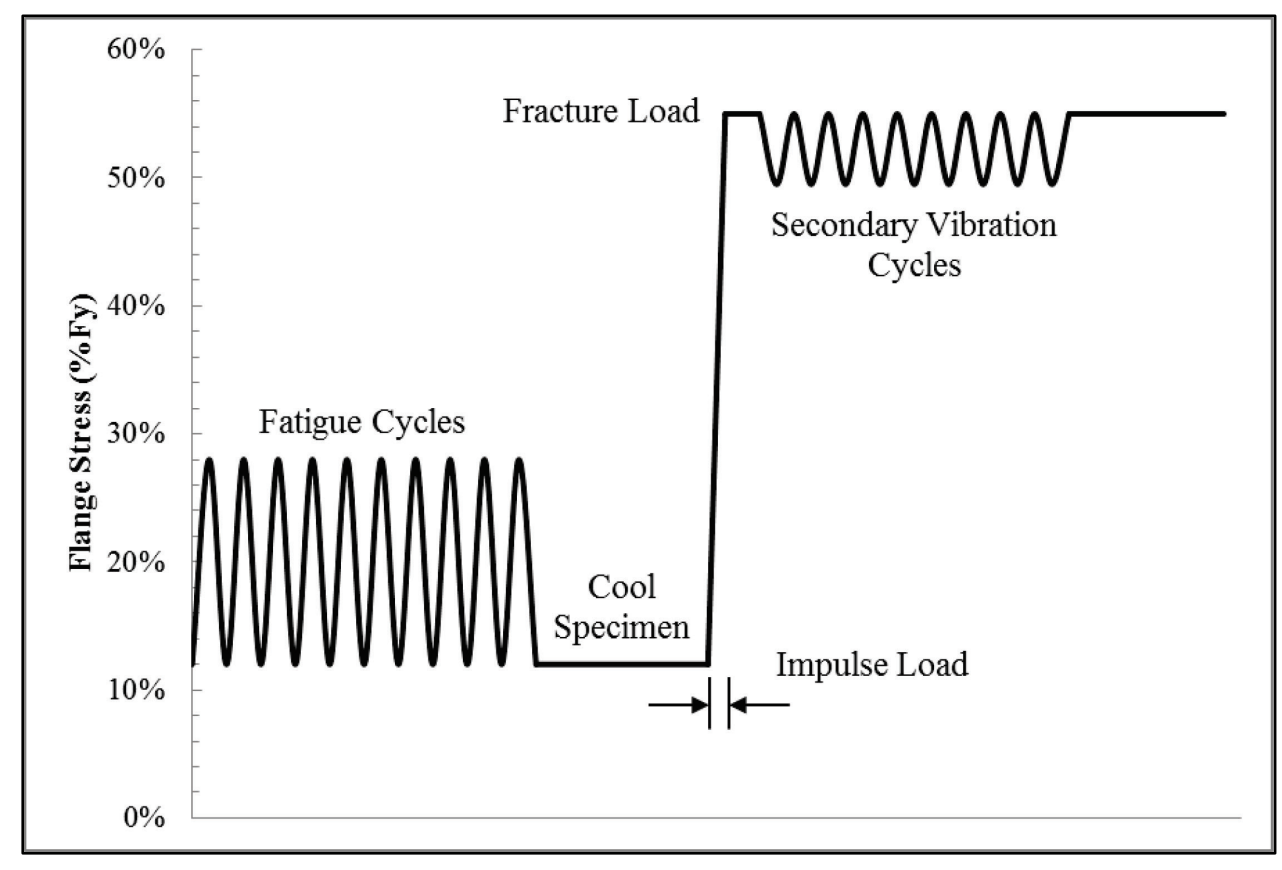

Figure 3-19 Fracture loading protocol 
After the fracture test, the specimen was cyclically loaded to determine its post failure fatigue life. The fatigue loading was varied with different specimens. Each specimen was cyclically loaded at a predetermined stress range. The stress ranges were varied in order to obtain data that would result in a broad spectrum to create an understanding of the overall fatigue behavior of partially failed built-up sections. The frequency of the testing varied with the applied stress range and the hydraulic actuator loading. The stiffness of the specimen, and consequently the displacement of the actuator, determined the maximum frequency of cyclic loading. The loading frequency was limited by the capacity of the hydraulic system and its ability to meet the targeted loads. Care was taken to keep the actuators in phase and ensure that the targeted loads were met through tuning of the loading frequency.

\subsubsection{Fracture Test}

In order to measure the fracture resilience, each specimen was prepared by creating a sharp crack tip to create a high stress concentration at the desired location. Two different methods were evaluated and used to create a sharp crack tip: fatigue cycling, and brittle welds (as described in Section 3.3.3.2.1).

For the fatigue cycling method a specimen was first notched by one of the methods described in Section 3.2.3. Then the specimen was cyclically loaded to create a fatigue crack at the notch location. Notches were created at close to the calculated critical crack length to minimize the required time to have the crack reach its critical length and thereby decrease the duration of the specimen testing. A typical fatigue crack grown from a notch at a hole can be seen in Figure 3-20. 


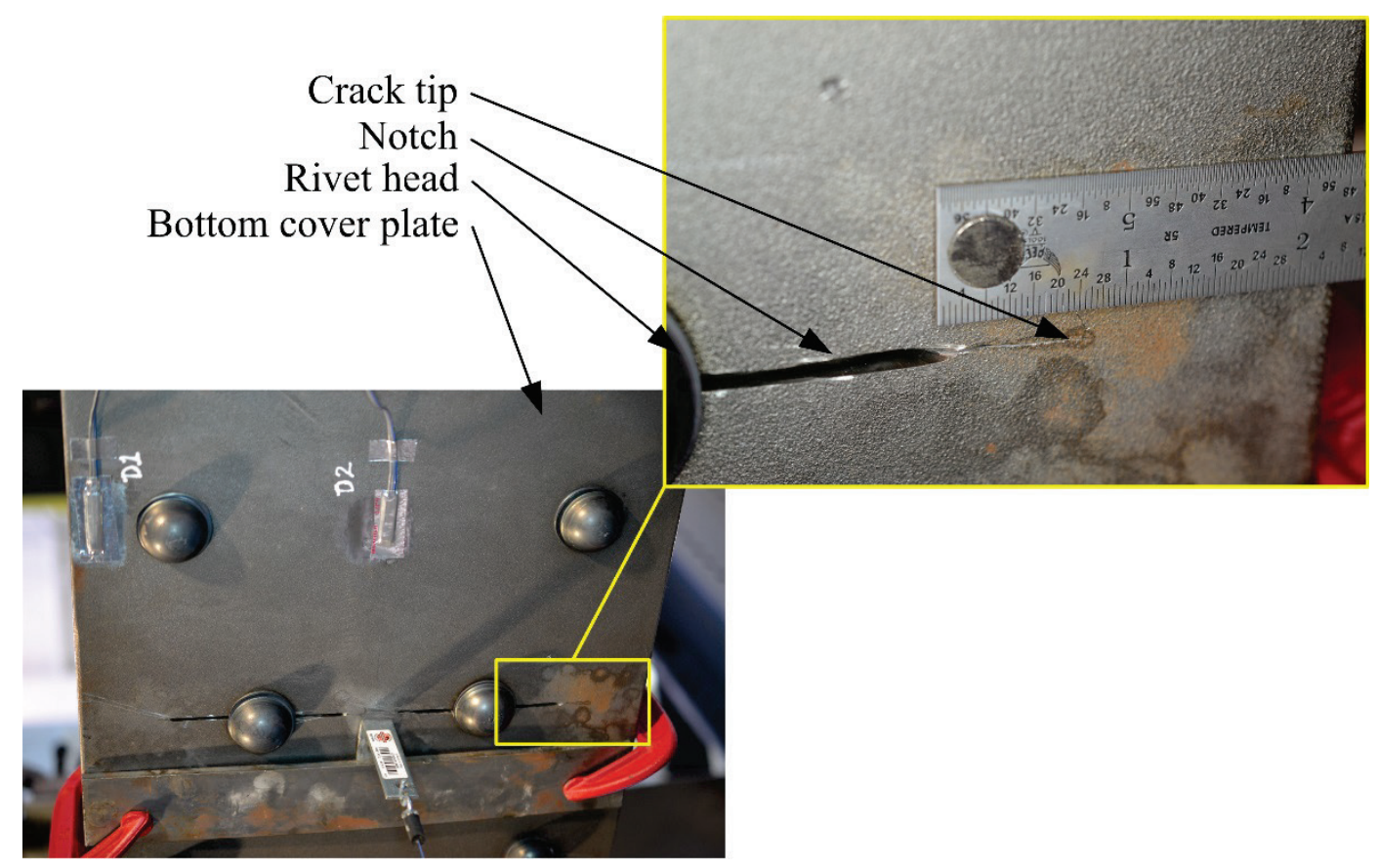

Figure 3-20 Crack growth from notch at a hole (Specimen 46-3)

\subsubsection{Temperature Chamber}

When the calculated critical crack length was reached the specimen was prepared for the fracture test. The majority of the specimens were cooled to a target temperature below $-60^{\circ} \mathrm{F}$, the AASHTO Zone III lowest anticipated service temperature (LAST). Some specimens were cooled to temperatures below $-60^{\circ} \mathrm{F}$ in order to reach lower shelf brittle conditions of the bottom flange components. As can be seen in the CVN curves found in APPENDIX D, each of the critical components (flange angles and cover plates) was at or near brittle (bottom shelf) behavior at these test temperatures. The cooling was performed using a temperature chamber covering the majority of the constant moment region (see Figure 3-21, Figure 3-22). The temperature chamber was constructed to enable quick installation and removal to facilitate testing. Fast removal of the chamber 
was necessary so that the chamber could be quickly removed, and the specimen could be tested while maintaining a temperature near the target.

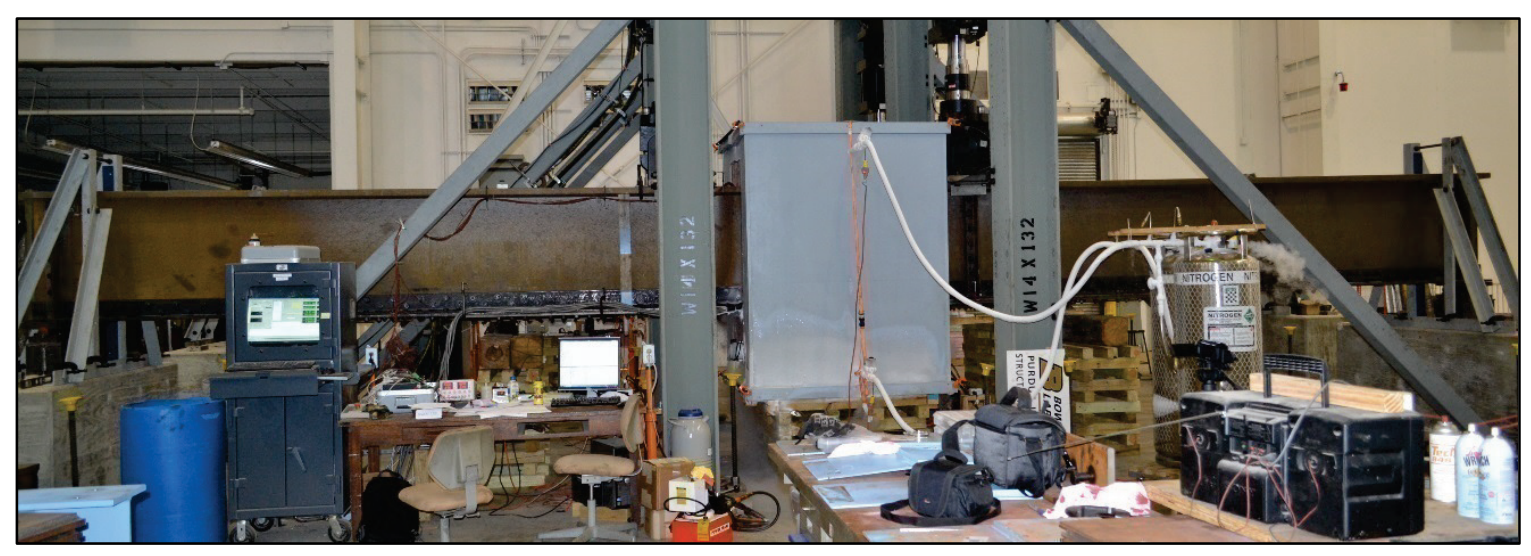

Figure 3-21 Temperature chamber installed on beam (side view)

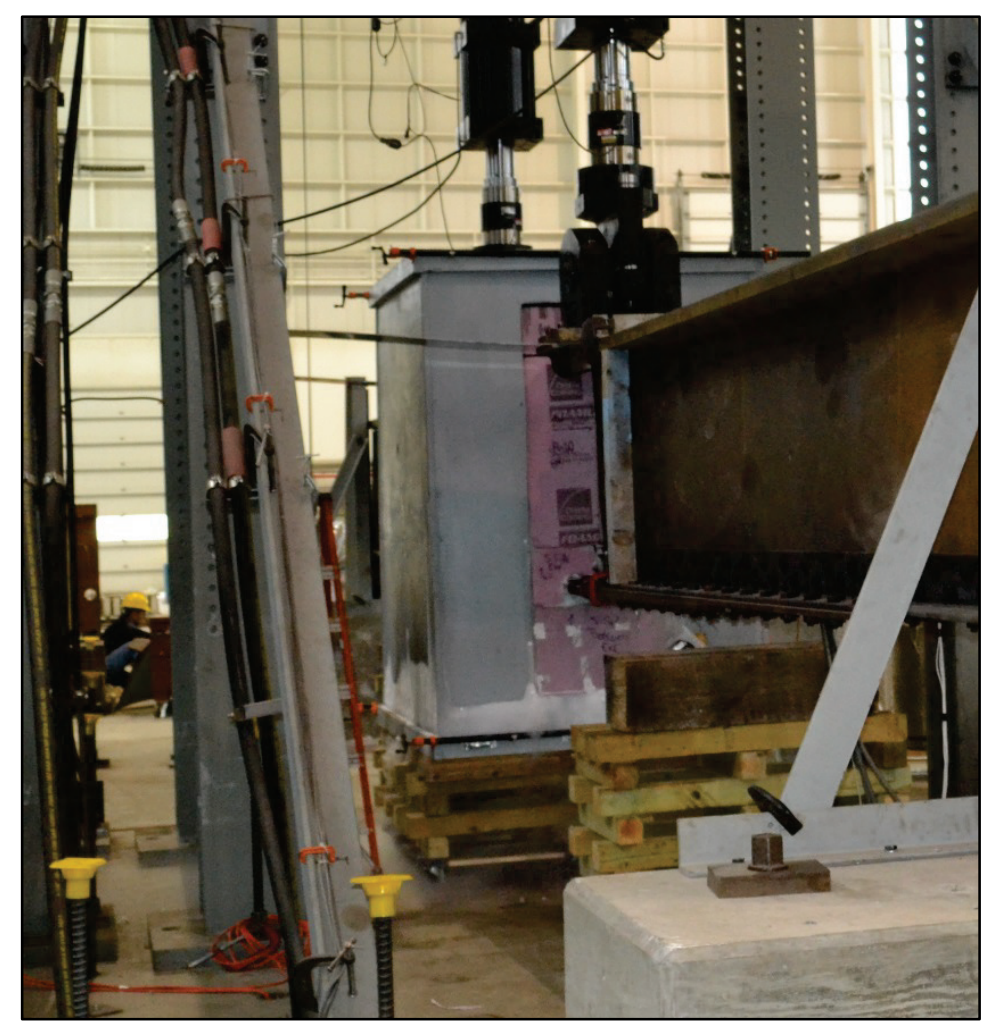

Figure 3-22 Temperature chamber installed on beam (end view) 
The chamber was constructed in a clamshell fashion with two halves on either side of the specimen. Each half of the clamshell was constructed with four layers of 2 " rigid insulation to insulate the specimen during cooling. Two layers of 2 " rigid insulation was used at the two longitudinal ends where the specimen emerged from the chamber. At this location the rigid insulation was custom cut for each specimen to ensure proper fit-up and minimal leakage.

Liquid nitrogen was pumped into the top and the bottom of the chamber and distributed through $3 / 4^{\prime \prime}$ copper pipe with small holes spaced approximately 8 " on center along the longitudinal length of the box. The liquid nitrogen was controlled with a solenoid valve and thermocouples as described in Section 3.2.2 to control and minimize the thermal gradient over the height and length of the chamber.

\subsubsection{Fracture Test Load}

When the temperature of the specimen reached the LAST, the temperature was maintained for a minimum of 30 minutes to create a constant temperature throughout the thickness of the steel components. The duration of the soaking time was based on experiments conducted using various girders and plates placed in the cooling chamber. Once the target temperature was reached, the chamber was then quickly removed and the loading protocol was started for the fracture test as described in Section 3.3.2. The removal of the temperature chamber and the loading protocol was completed in less than 2 minutes to maintain the temperature of the specimen. While this loading was applied to a girder with a component having cracks at or beyond their critical length (as calculated by linear elastic fracture mechanics), it was rare that a fracture was produced solely 
through this procedure. If a fracture did not occur, the specimen was allowed to warm up to ambient temperature and then fatigue loading was performed to grow the $\operatorname{crack}(\mathrm{s})$ another $1 / 4^{\prime \prime}-1 / 2 "$ in length. At this point the fracture test would be reattempted using the same method previously discussed. This cycle was repeated until the cracked component was completely failed (whether by fracture or through fatigue).

After several specimens had been tested in this manner without producing a brittle fracture in a notched component, it was decided that alternate methods would need to be employed to initiate a fracture. It was at this time that the edge notched specimens (as described in Section 3.2.3.2) were developed. This method also did not result in the brittle fracture of a component with cracks beyond their critical length. Additional methods were researched and developed to create a fracture event. These are described in the following sections.

\subsection{Brittle Welds}

Welds were first investigated as a method to increase the likelihood of creating a fracture. Specifically, poor welding techniques were attempted to create a fuse like element that was expected to fracture easily at the LAST. However it was found through testing that the reduced capacity of a poor weld resulted in stress distribution to more stiff components. Ultimately the poor welding alone did not result in a feasible fracture method for this test. However it was in this study that the ability to place hardfacing weld metal resulting in brittle welds were discovered and which was later utilized to create sharp crack tips in specimens to avoid having to initiate cracks through fatigue load cycles. 
Hardfacing welding rod, used to build up wearing faces typically found in heavy machinery, was investigated due to its brittle behavior. Lincoln Electric's Wearshield ME is a heavily alloyed hardfacing rod specifically designed for heavy abrasion. The weld material has a Rockwell $\mathrm{C}$ hardness of up to 59 when deposited in multiple layers (The Lincoln Electric Company, 2012). The weld metal is designed to cross crack (transverse to the direction of the weld axis) in order to relieve stresses and minimize distortion (The Lincoln Electric Company, 2014) as shown in Figure 3-23. The Wearshield ME welding rod was investigated as a source for creating sharp crack tips in specimens due to the cross cracking.

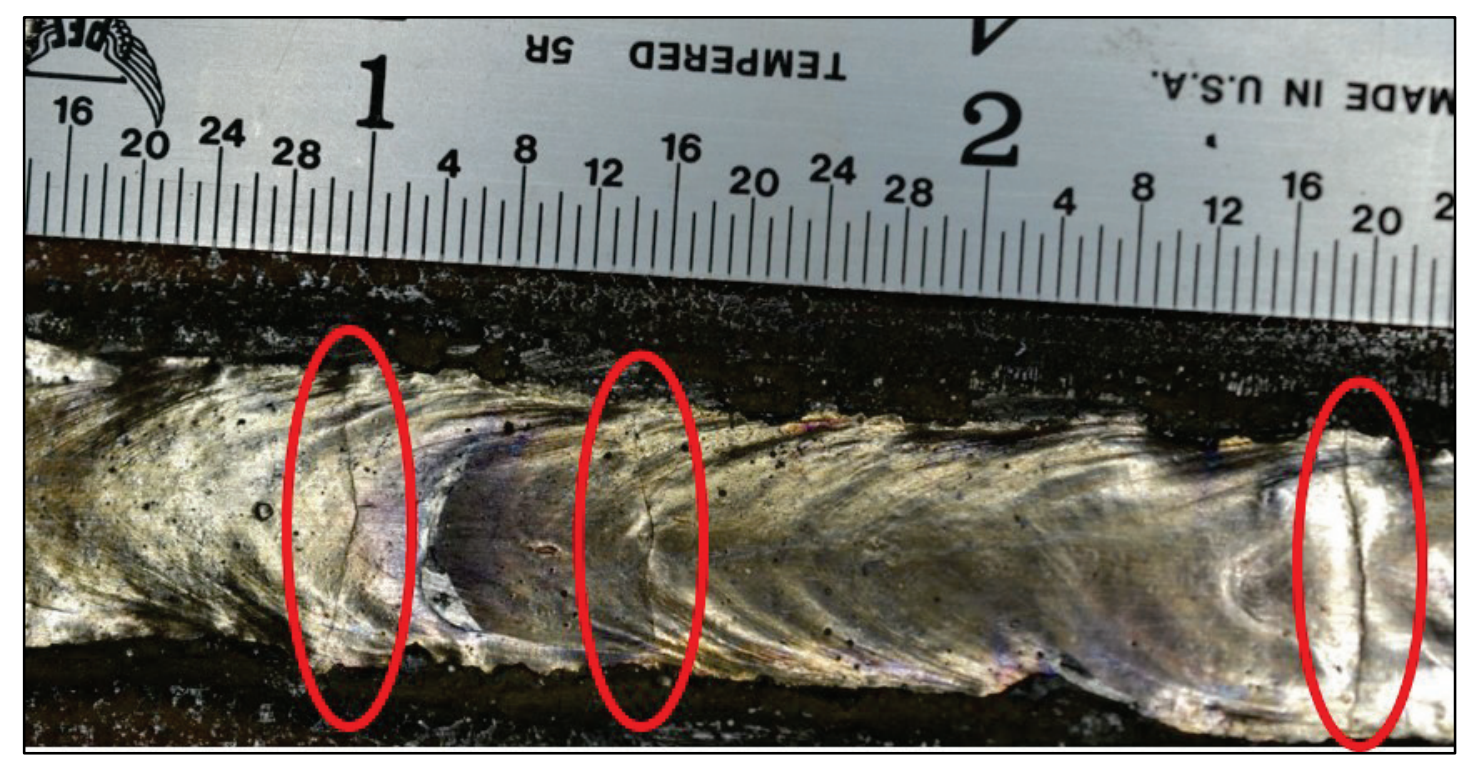

Figure 3-23 Transverse cracks in Wearshield ME weld metal

Many small scale specimens were created to investigate different methods of welding with the hardfacing welding rod to create cracks. It was found that the cracks would pop into the weld as the weld cooled. In some cases it was observed that the crack had some penetration into the base metal. The crack tips created from these welds were 
not found to be a reliable method for creating fractures. However, they were found to be an advantageous method in producing a sharp crack tip at the tip of a notch with no fatigue cracking required. They were utilized in conjunction with the wedge method as described in Section 3.3.3.2.2. Two beads of Wearshield ME were placed orthogonal to an edge notch as shown in Figure 3-24. The beads were placed at the top and bottom of each plate face as well as on each side. In order to allow proper fit-up of adjacent components a groove was ground into the interior face of a component which was subsequently filled with the hardfacing weld rod.

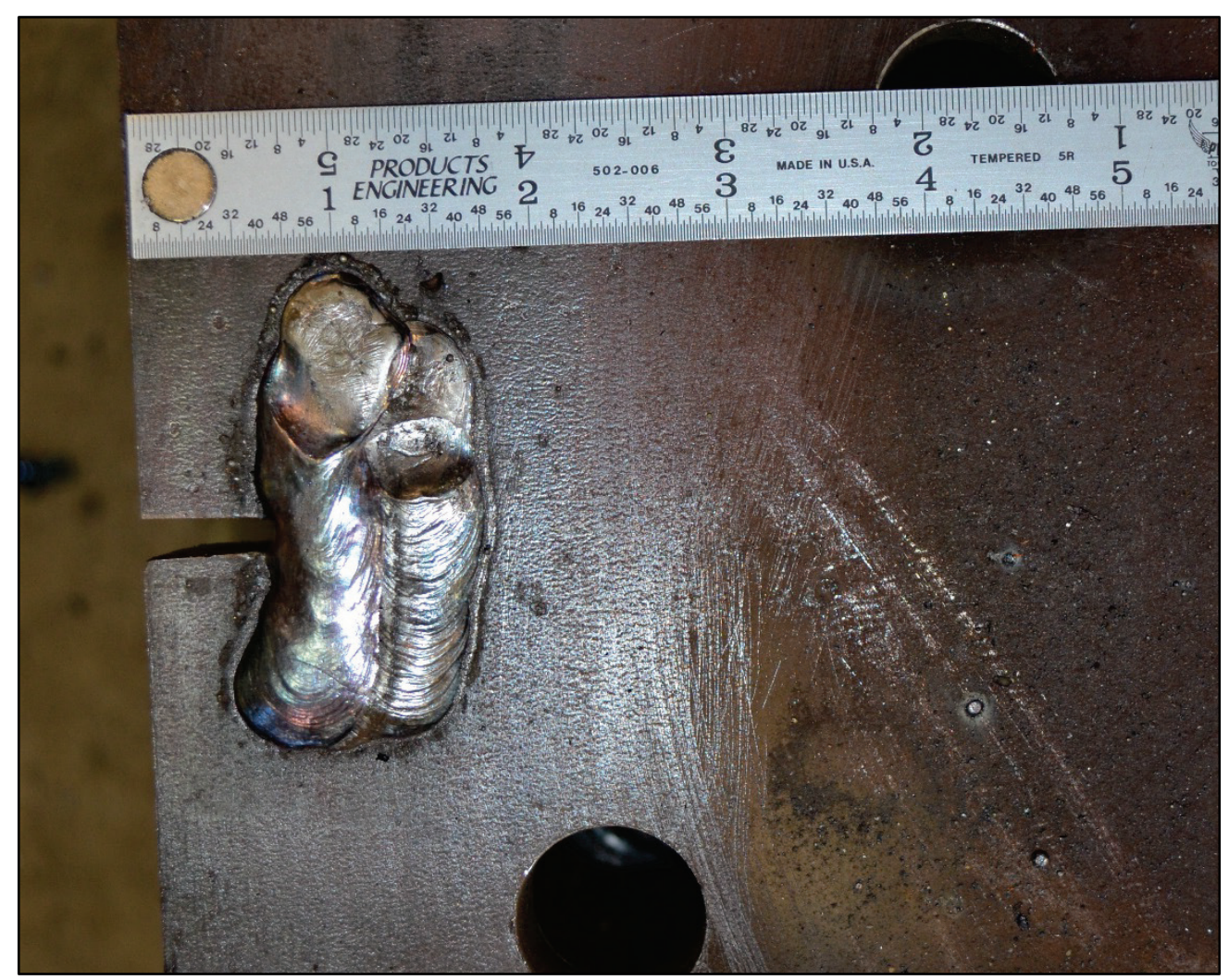

Figure 3-24 Edge notch with Wearshield ME weld at notch tip 


\subsection{Driven Wedge Method}

Prior to the development of this method, several attempts to fracture different specimens at predicted loads, critical crack lengths, and geometries were found unreliable. Due to the test configuration and hydraulic capacity it was not possible to increase the stresses beyond the targeted $0.55 \mathrm{~F}_{\mathrm{y}}$ in the bottom flange of the alreadyfabricated specimens. In order to create a brittle fracture with a relatively small crack length a method was devised to increase the stress concentration at the crack tip. After several evolutions in configuration and through much small scale testing to verify the validity of the method, a reliable solution emerged in the form of wedges driven into the notches of an edge-notched specimen with brittle welds at the notch tip.

The concept was derived and modified from brittle fracture testing on wide structural steel plates (Lazar \& Hall, 1957; Hall, Mosborg, \& McDonald, 1957; Rolfe \& Hall, 1958) in which a wedge was fired into a notch using a gas-operated piston device. The wedge was driven with an impact load to initiate a fracture in plates that were unable to initiate under static loading conditions. The method was modified significantly to meet the demands of the current test.

Due to the required displacement of the specimen, it was decided that a selfreacting assembly attached directly to the specimen would allow the appropriate movement without affecting the capacity during a test. A small steel beam was constructed with gusset reinforced reaction angles welded to the top flange (see Figure 3-25). The purpose of the beam was to span the transverse distance of the cover plates with additional space for wedges and loading equipment. Web stiffeners were added to 
increase the shear capacity of the beam. A 20 ton hydraulic ram (Power Team RSS202) with $13 / 4^{\prime \prime}$ stroke was used to drive a wedge on one side of the bottom flange, while the wedge on the opposite side of the flange reacted solely against the reaction angle attached to the beam. The beam was allowed to move in the transverse direction so that equal loads were applied to each wedge. Bracing angles were clamped to the bottom flange of the web to ensure movement of the bracing beam was restrained to the transverse direction of the specimen (see Figure 3-26).

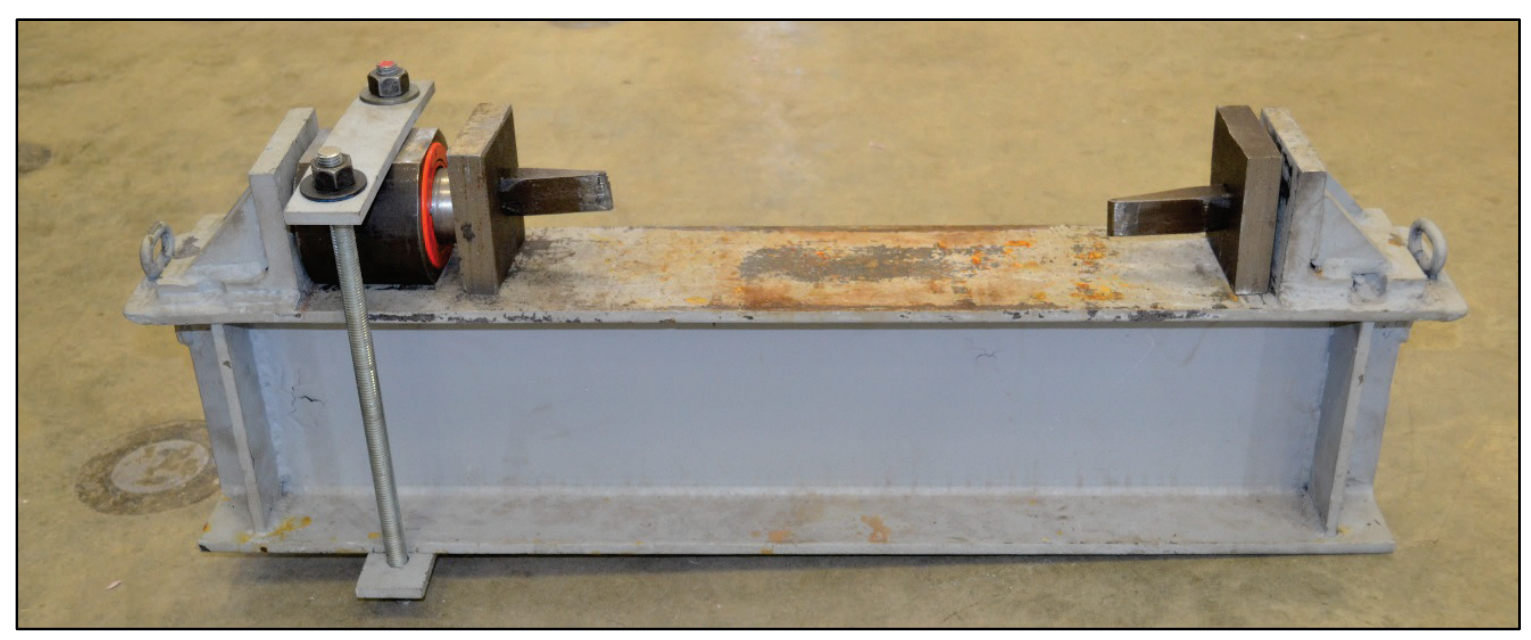

Figure 3-25 Driven wedge apparatus 


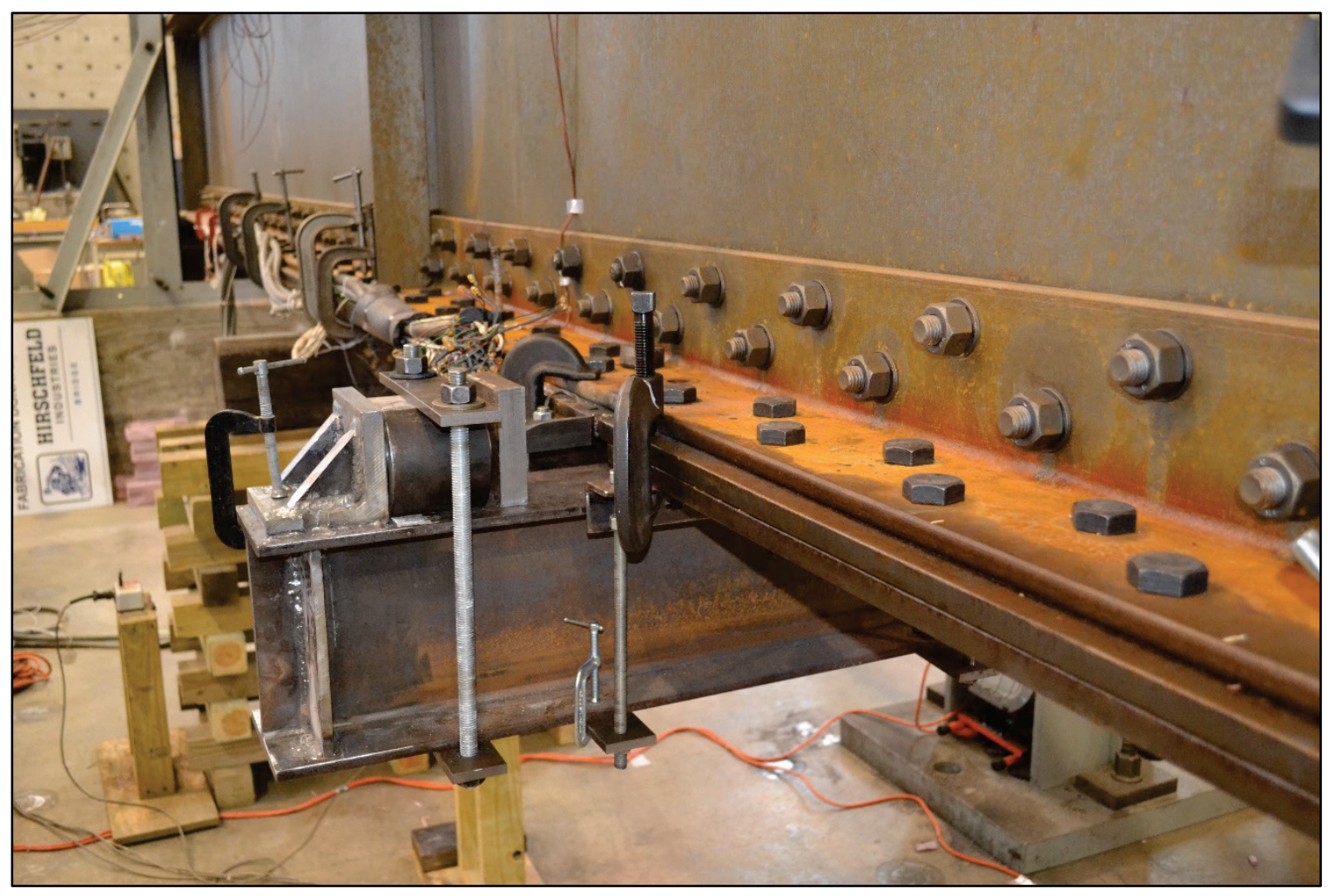

Figure 3-26 Driven wedge apparatus installed on Specimen 36-2

Wedges with small and angular tips were desired to maximize the mechanical advantage, force applied to the edges of the notch, and thereby increase the stress concentration. Wedges were made by cutting the ends from $1-1 / 8^{\prime \prime} \times 6^{\prime \prime} \times 14^{\prime \prime}$ standard demolition chisels. A side and top view of the chisels can be seen in Figure 3-27 The

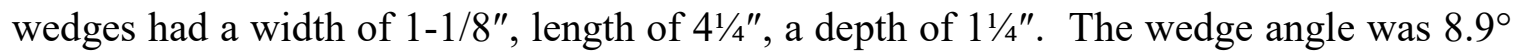
and a mechanical advantage of 3.2. This resulted in a maximum force (at full hydraulic pressure) of 128 kips applied longitudinally to the notch faces. The resulting load was applied in the longitudinal axis of the specimen, which significantly increased the stress concentration at the notch tip. 


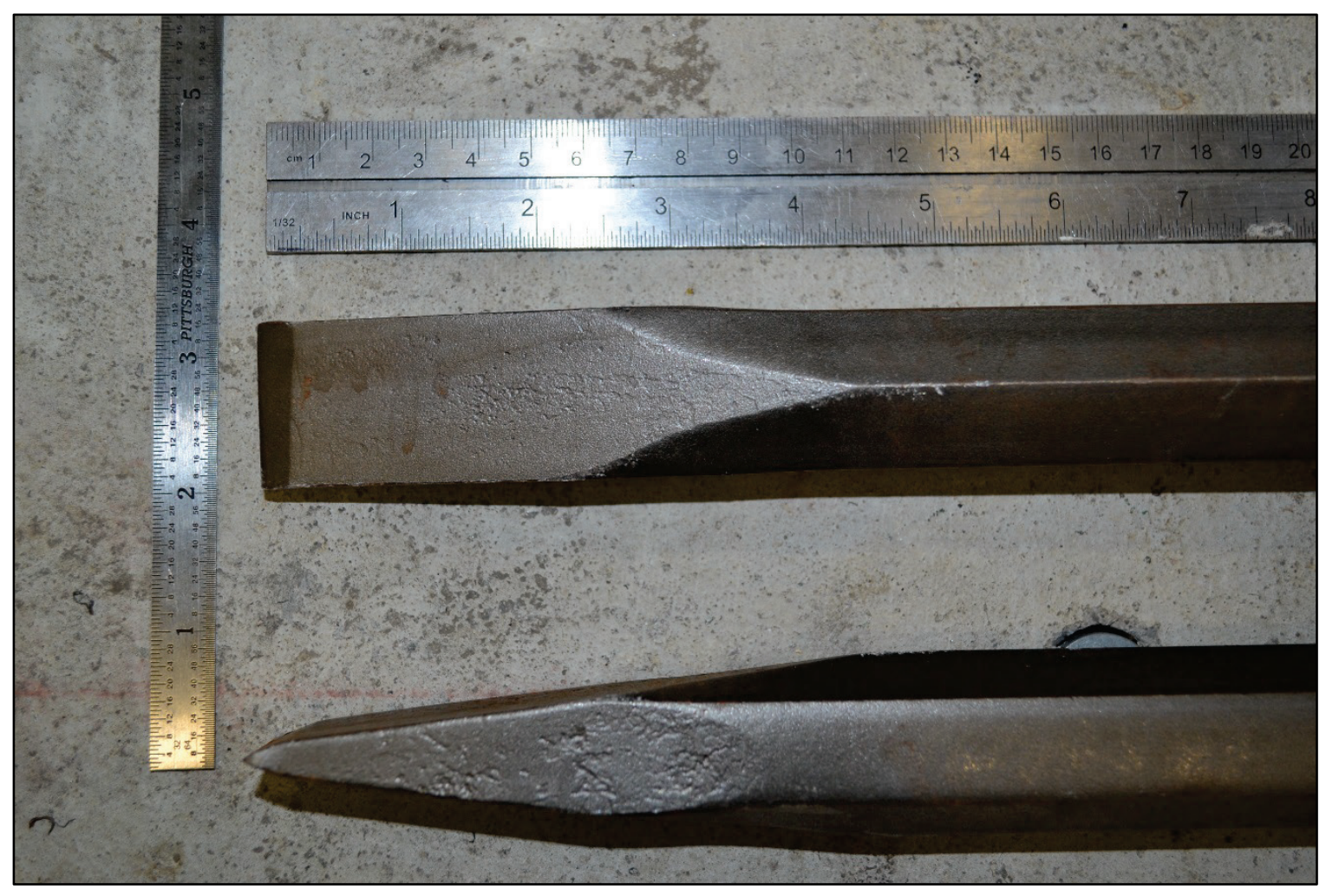

Figure 3-27 Wedge geometry

After initial attempts using the driven wedge method were found to be inconsistent, it was discovered that the constraint of nearby fasteners played a large role in the fracture of a built-up specimen component. The constraint and proximity of fasteners was investigated. A small finite element parametric study was made to determine the effect of the constraint of local fasteners to the stress intensity at the crack tip for two different notch lengths $\left(2^{1 / 2^{\prime \prime}}\right.$ and $\left.1^{1 / 2} 2^{\prime \prime}\right)$. A $14^{\prime \prime} \times 3 / 4^{\prime \prime}$ plate was modeled using half symmetry. Fasteners were spaced in the plate with the same dimensions (pitch, and gage) as the $36^{\prime \prime}$ specimens. The first model was constructed with all required fasteners. In subsequent models fasteners were removed two at a time (one on each side of the notch plane). Figure 3-28 shows the results of the study. The stress intensity was 
affected by removing up to six bolts (three on either side of the notch plane) after which

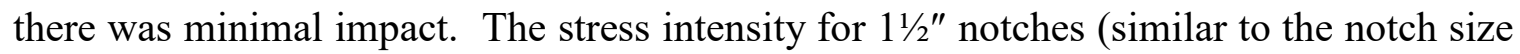
used in the test setup) increased by approximately $17 \%$. Based on the outcomes of this study, two fasteners were removed from the remaining specimens during the fracture phase of the test. This resulted in much more reliable and predictable fractures.

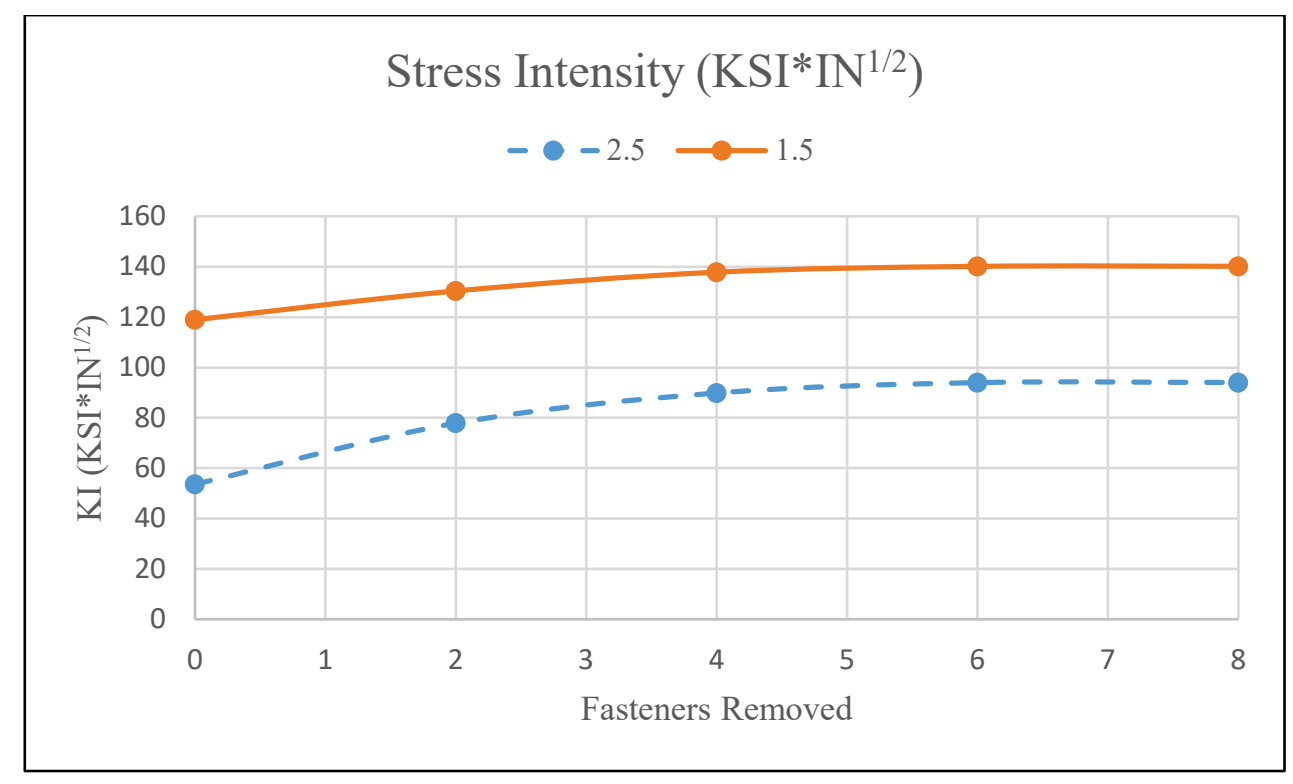

Figure 3-28 Stress intensity vs. number of fasteners removed

\subsubsection{After-Failure Fatigue Test}

Following the failure of a component specimens were allowed to return to ambient temperature in preparation for the fatigue portion of the test. Resulting fatigue stress ranges were intentionally varied in order to quantify the fatigue behavior. The tests were run at constant amplitude. After the initial component failure, each specimen was tested in fatigue until the failure of a second component. In cases where there was no failure, the test was stopped after it was determined that a crack was unlikely to form due 
to the probability that the stress range was within the 'infinite life' region of the AASHTO fatigue curves.

\subsection{Specimen Testing}

The following sections describe fabrication and preparation specifics of each specimen. In addition, details of each specimen throughout the testing of each of the test phases are reported. Each specimen is reported chronologically in the order in which it was tested. Specimens were oriented longitudinally from North to South. Cardinal directions are used to describe component and crack locations.

\subsubsection{Specimen 23-1}

Specimen 23-1 was the first specimen prepared and tested. Prior to testing, a $5 / 8^{\prime \prime} \times 12^{\prime \prime}$ A36 bottom flange cover plate was attached to the original cross section with hot-driven rivets in order to increase the number of bottom flange components and thereby increase the amount of redundancy of the specimen. Prior to the installation of the cover plate, a thin layer of packing grease was applied to create low-friction between the components (see Figure 3-29). Notches were cut into the cover plate at both hole locations adjacent to the beam centerline from the bottom of the cover plate (see Figure 3-30). Because the notches were cut after the cover plate was riveted to the flange angles the notches were on the exterior face of the plate only. The notches were $0.573^{\prime \prime}, 0.698^{\prime \prime}$, 0.796", and $0.764 "$ in length from the edge of the hole to the tip of the notch (measured from the west-to-east on the plate). Material properties for each of the components of the 
beam can be found in APPENDIX D. The strain gage plans can be found in APPENDIX

E.

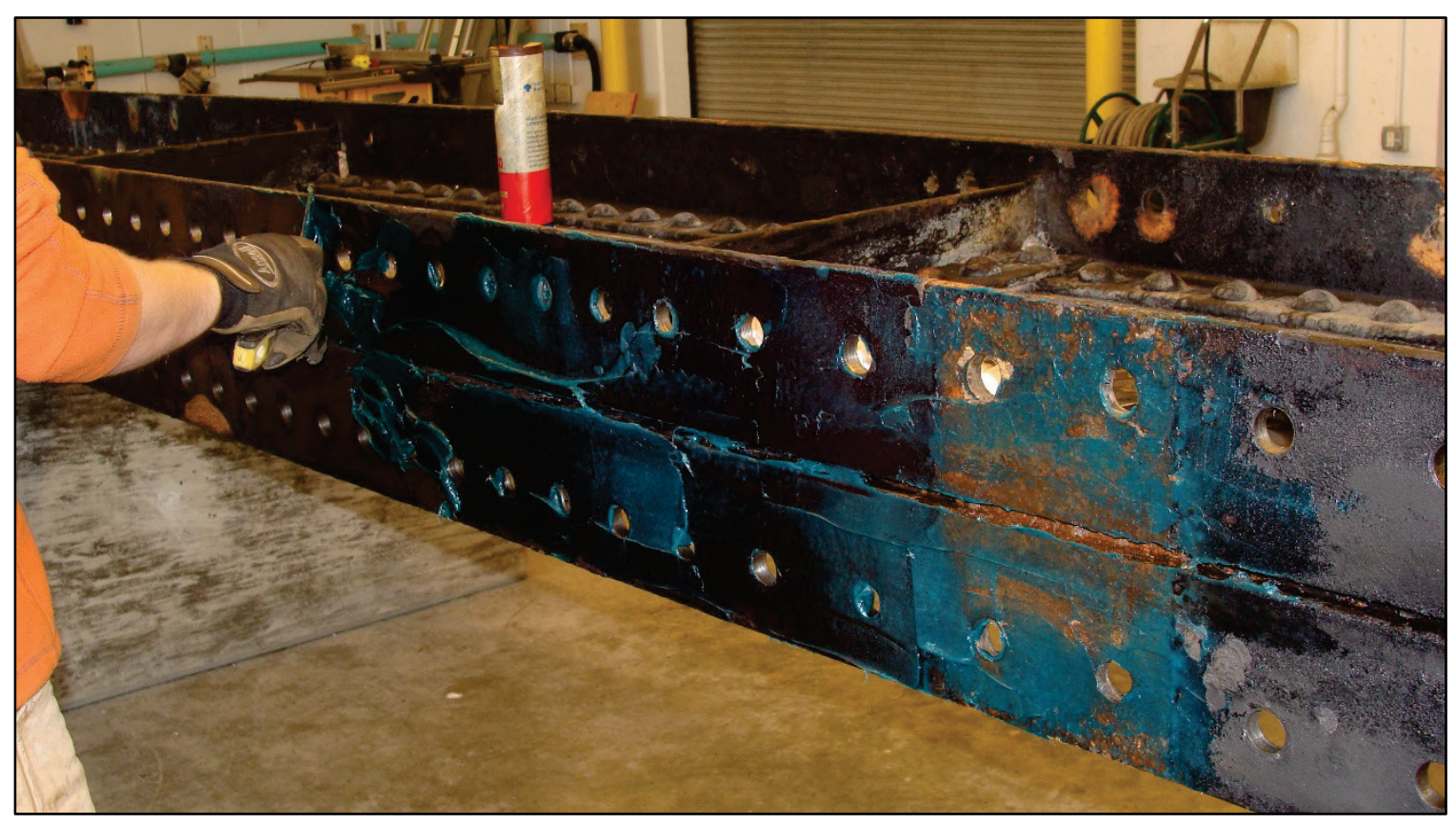

Figure 3-29 Specimen 23-1 application of grease between components

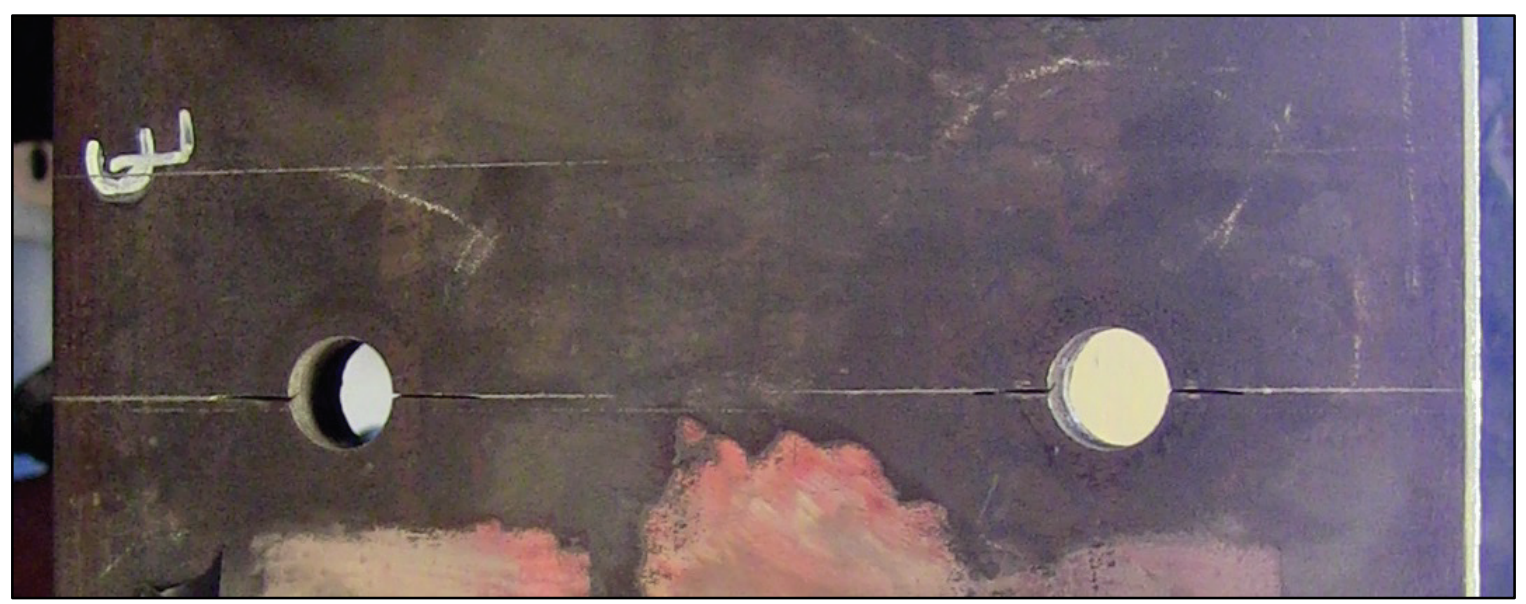

Figure 3-30 Specimen 23-1 hole notches 
Prior to testing, the specimen was loaded in a static test to determine initial stress distribution between the different components. The beam was loaded from a net section stress in the bottom cover plate of $0 \mathrm{ksi}$ (no load on the actuators) to a calculated net section stress of $18.9 \mathrm{ksi}$ (50 kips on each actuator) in 5 kip increments. The beam was then cyclically loaded from 15 kips to 50 kips at each actuator resulting in a calculated net-section stress (of the unfailed cross-section) of $13.3 \mathrm{ksi}$. The fatigue loading frequency was $1.9 \mathrm{~Hz}$. After approximately 1.57 Million cycles cracks were detected in three of the four notches. When the specimen had experienced approximately 1.85 Million cycles the specimen was prepared for the fracture test.

\subsubsection{Fracture Test}

At 1.85 Million cycles the cracks in the notches were measured to be at 1.18", $1.12^{\prime \prime}, 1.01 "$, and 1.05" (from west-to-east) measured from the edge of the hole to the tip of the crack. Using an assumed fracture toughness (as material testing had not been performed at this stage) the cracks were near the critical crack length. Later, material testing showed that the critical crack length for the plates was approximately $0.8^{\prime \prime}$ in length based on linear elastic fracture mechanics and the stress intensity factor found per Newman (1971). An attempt was made to fracture the specimen using the protocol described in Section 3.3.3 at a bottom flange temperature of $-66^{\circ} \mathrm{F}$, however no fracture occurred. The specimen was allowed to warm back up to ambient temperature and then cycled further to extend the crack lengths. Three more attempts were made to fracture the bottom cover plate at increasing crack lengths. The temperature at the three additional fracture attempts was $-79^{\circ} \mathrm{F},-75^{\circ} \mathrm{F}$, and $-11^{\circ} \mathrm{F}$ (due to a depletion of the 
liquid nitrogen). Figure 3-31 shows the notch lengths and crack lengths at each of the four fracture attempts. In the image, ' $\mathrm{N}$ ' represents the original notch length, and each of the numbers (1-4) represent the crack length at each fracture attempt. During the fatigue cycling of the specimen, after the fourth fracture attempt, the cover plate failed. The total number of cycles applied to the specimen was 2.14 million cycles.

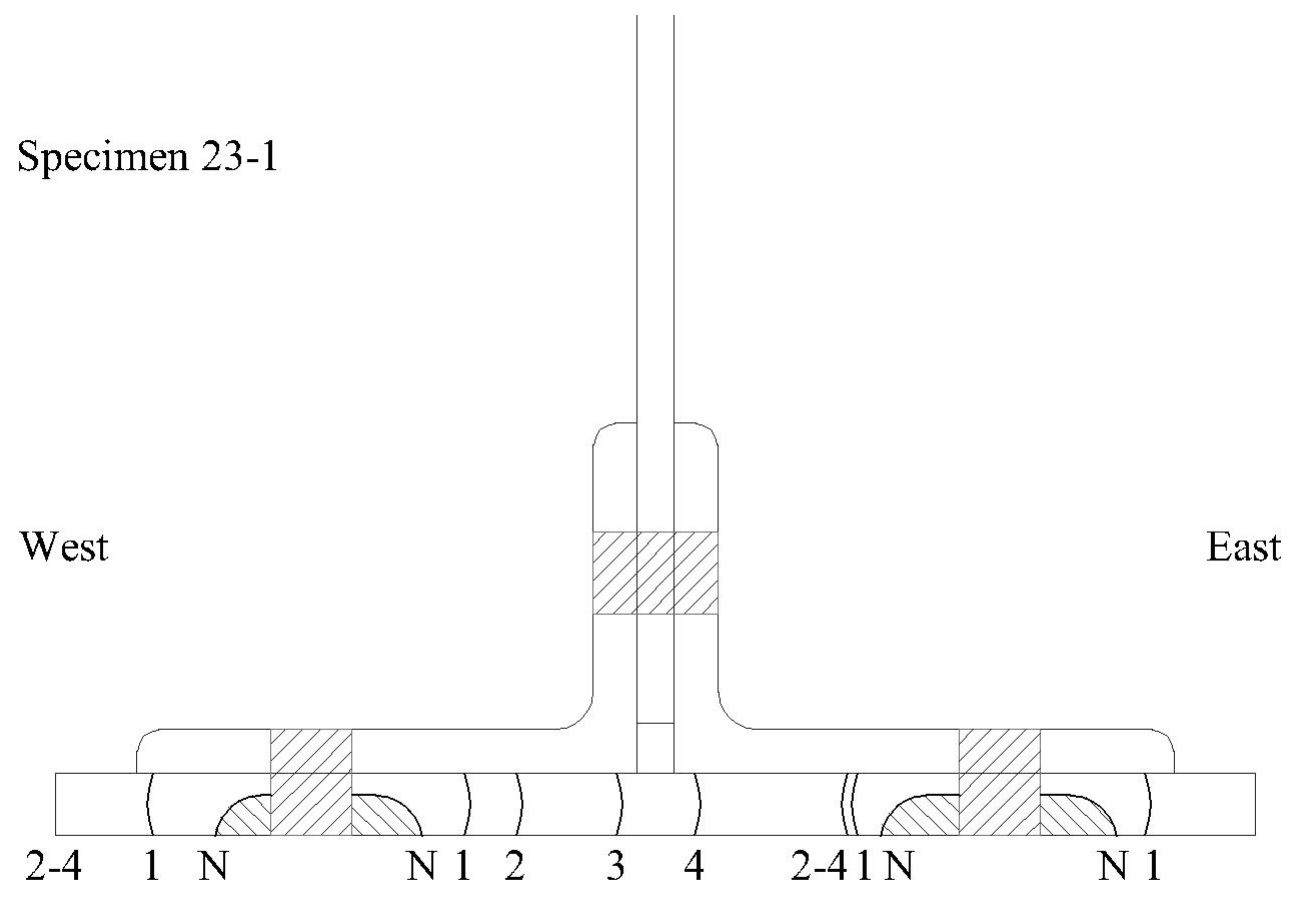

Figure 3-31 Specimen 23-1 cover plate crack growth

\subsubsection{Fatigue Test}

Following the fracture test, the fatigue portion of the test was started. The specimen was loaded from 15 kips to 50 kips on each actuator. This resulted in a calculated net section stress of $5.7 \mathrm{ksi}$ (simulated dead load) to $18.9 \mathrm{ksi}$ (simulated live load) of the original net section, and a calculated net-section stress of $11.0 \mathrm{ksi}$ to $36.6 \mathrm{ksi}$ 
of the net section after the failure of the cover plate. The calculated net section stress range of the remaining net section was $25.6 \mathrm{ksi}$. After cycling for 355,000 cycles, the east flange angle failed (one hole north of the crack in the failed cover plate) and the test was stopped (see Figure 3-32). The fatigue data can be seen plotted with other test results in Section 3.5.2.

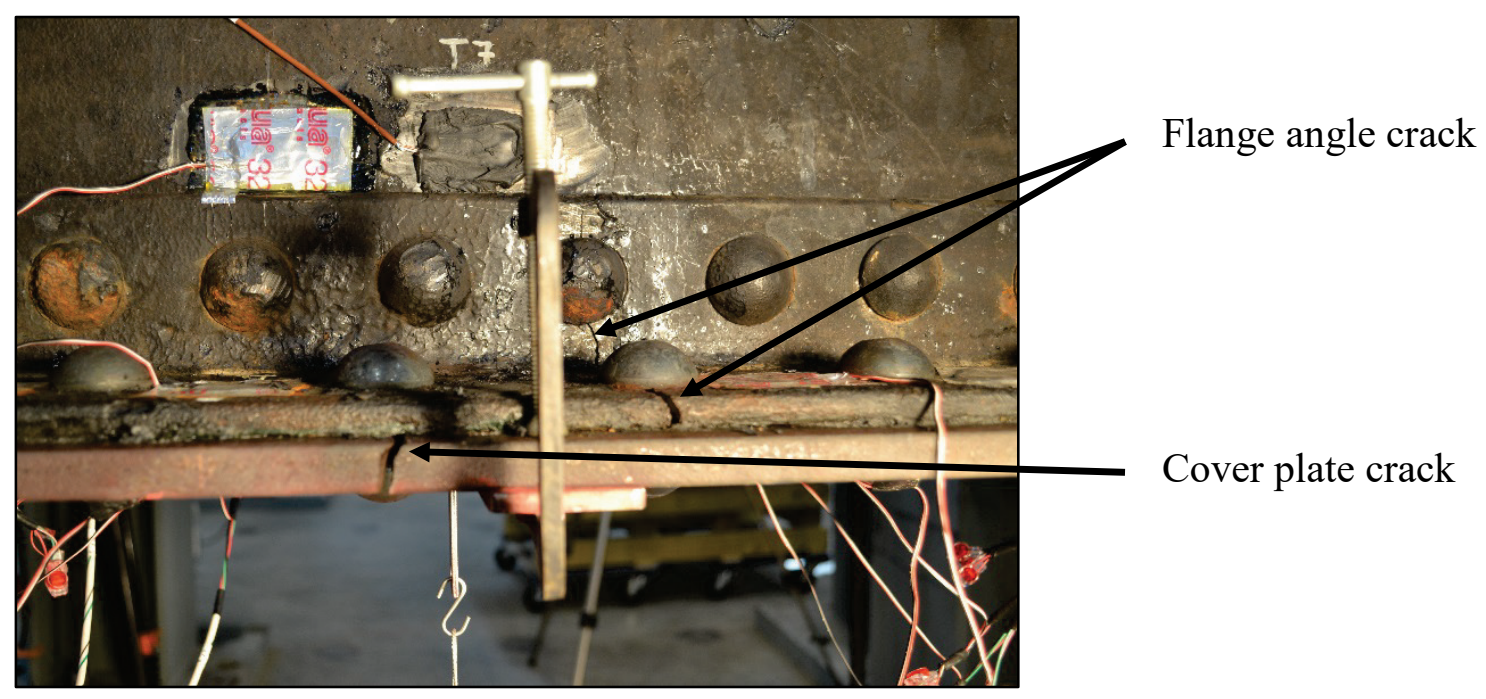

Figure 3-32 Specimen 23-1 failed flange angle and cover plate

\subsubsection{Specimen 23-2}

The east flange angle of Specimen 23-2 was notched at a rivet hole (see Figure 3-33) to investigate the behavior of a beam when the cross section was asymmetrical resulting from a component failure. A $12^{\prime \prime} \times 1 / 2 "$ A36 steel cover plate was attached to the bottom flange of the specimen with hot driven rivets. The cover plate was covered with a thin layer of packing grease prior to the installation in order to minimize the friction contribution to stress transfer between the components. The material properties of each component are reported in APPENDIX D. The notches were cut prior to the addition of 
the cover plate and were cut from the bottom and the top of the angle giving each notch a quarter circle shape at each face of the angle leg.

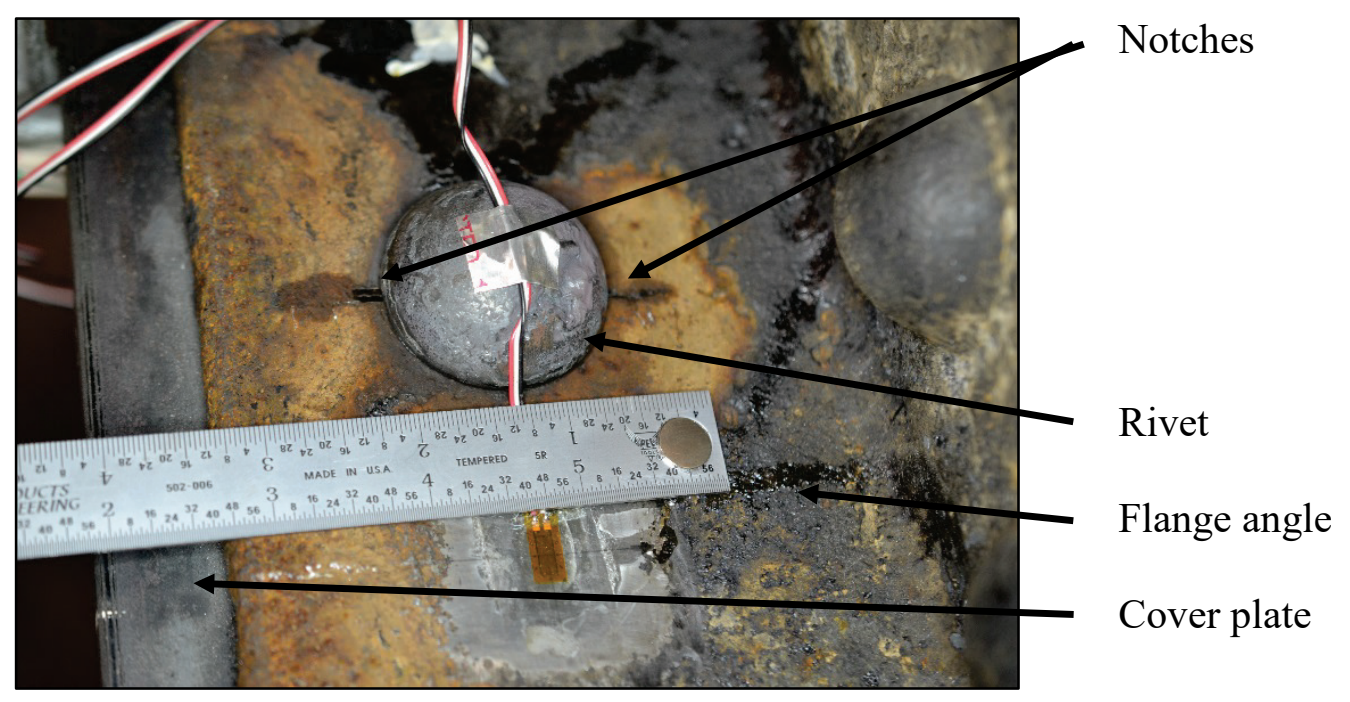

Figure 3-33 Specimen 23-2 hole notches

\subsubsection{Fracture Test}

The calculated critical crack length for Specimen 23-2 was 0.25 ", less than the original notch lengths. However, in order to create a sharp crack tip at each notch the cracks were grown in fatigue. After 319,000 cycles, cracks had grown from the notches on both sides of the rivet hole in the east flange angle. The specimen was cooled in the temperature chamber to $-74^{\circ} \mathrm{F}$ and an attempt was made to fracture the flange angle. Since the specimen did not fracture, it was allowed to warm and cycled in fatigue to increase the length of the crack. The specimen was tested for fracture two additional times at temperatures of $-66^{\circ} \mathrm{F}$ and $-64^{\circ} \mathrm{F}$ (see Figure 3-34 for crack lengths at different attempts) with no fracture occurring in the flange angle. 


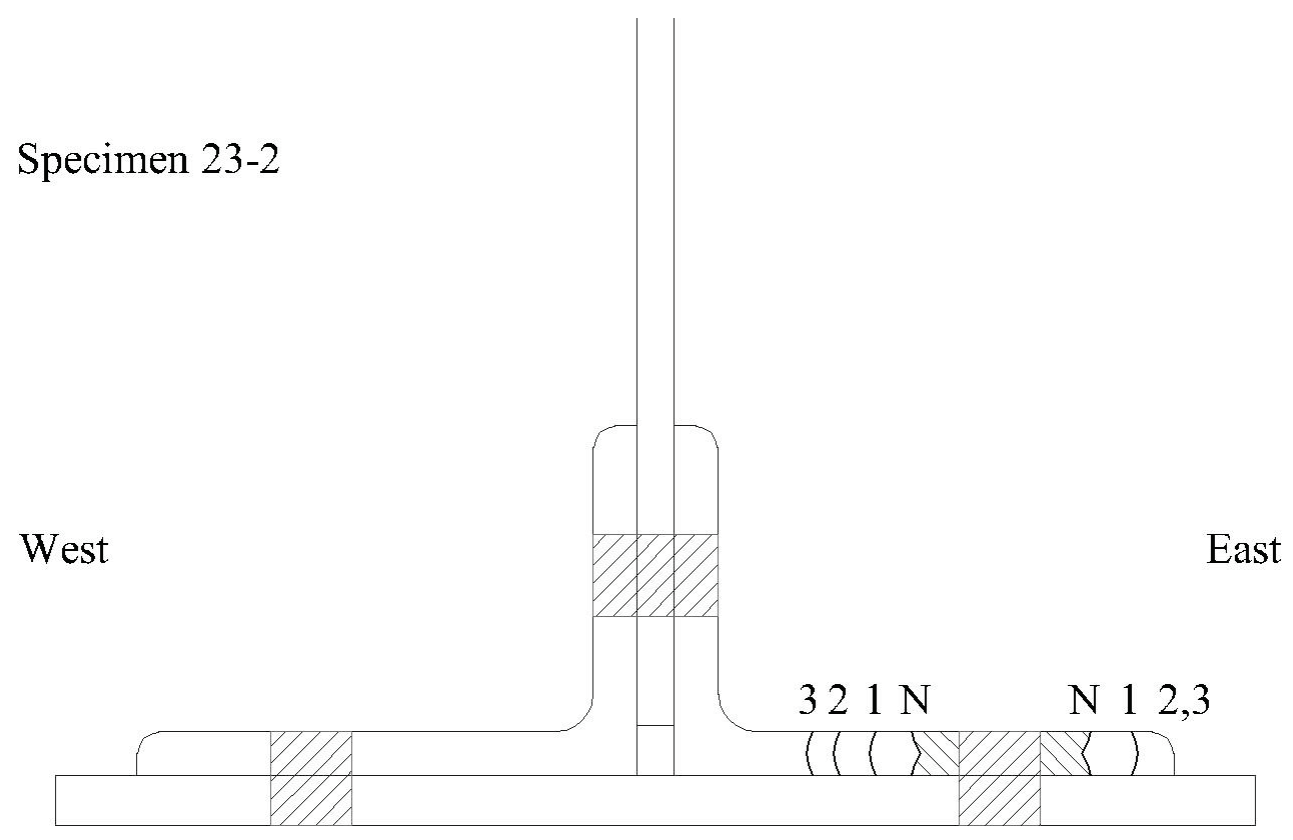

Figure 3-34 Specimen 23-2 crack growth in east flange angle

\subsubsection{Fatigue Test}

After the crack had grown through the remaining portion of the horizontal leg of the angle (at 535,000 cycles) the fatigue portion of the test was initiated to determine the fatigue life until the next component failure. The actuators were cycled from 15 kips to 50 kips which created calculated stresses from $6.3 \mathrm{ksi}$ to $21.1 \mathrm{ksi}$ in the original net section. The resulting stresses of the partially failed net-section were between $6.9 \mathrm{ksi}$ to $23.0 \mathrm{ksi}$ with a stress range of $16.1 \mathrm{ksi}$. Cracks were detected in the cover plate on the east side (below the failed flange angle) one hole south of the flange angle crack 1.3 million cycles after the initial component failure. Within another 50,000 cycles the cracks had grown through $86 \%$ of the cover plate. At this point, because cracks were 
detected in the vertical angle of the west flange angle as well as the web plate (Figure 3-35), the test was stopped. The compiled fatigue data is described in Section 3.5.2.

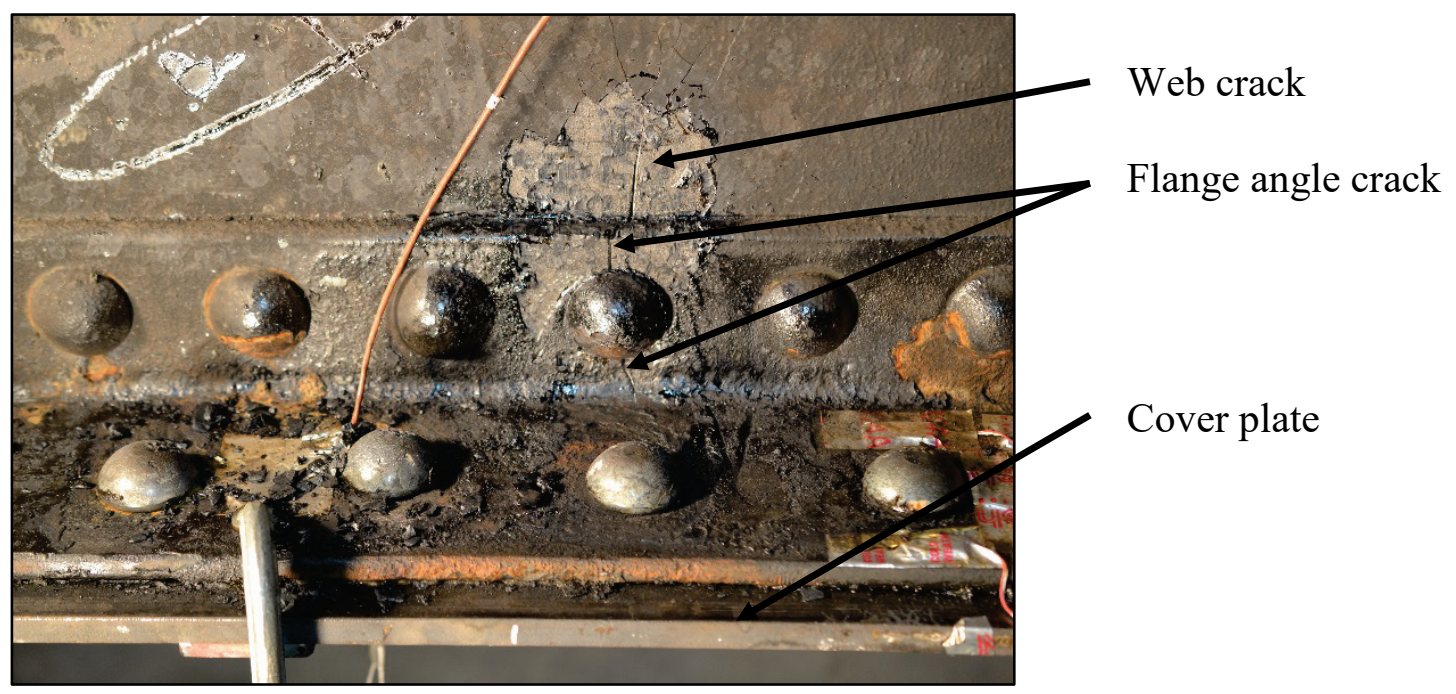

Figure 3-35 West side of failed Specimen 23-2

\subsubsection{Specimen 23-3}

Specimen 23-3 was fabricated with the same components and notched in the same location as Specimen $23-2\left(12^{\prime \prime} \times 1 / 2 "\right.$ A36 cover plate riveted to the historical floor beam with packing grease between the cover plate and bottom flange angles). APPENDIX D lists the material properties. Figure 3-36 shows Specimen 23-3 in the test setup. The hole notches in the east flange angle were $0.64 "$ and $0.39 "$ (from west to east) and were cut from the top and bottom of the angle. 


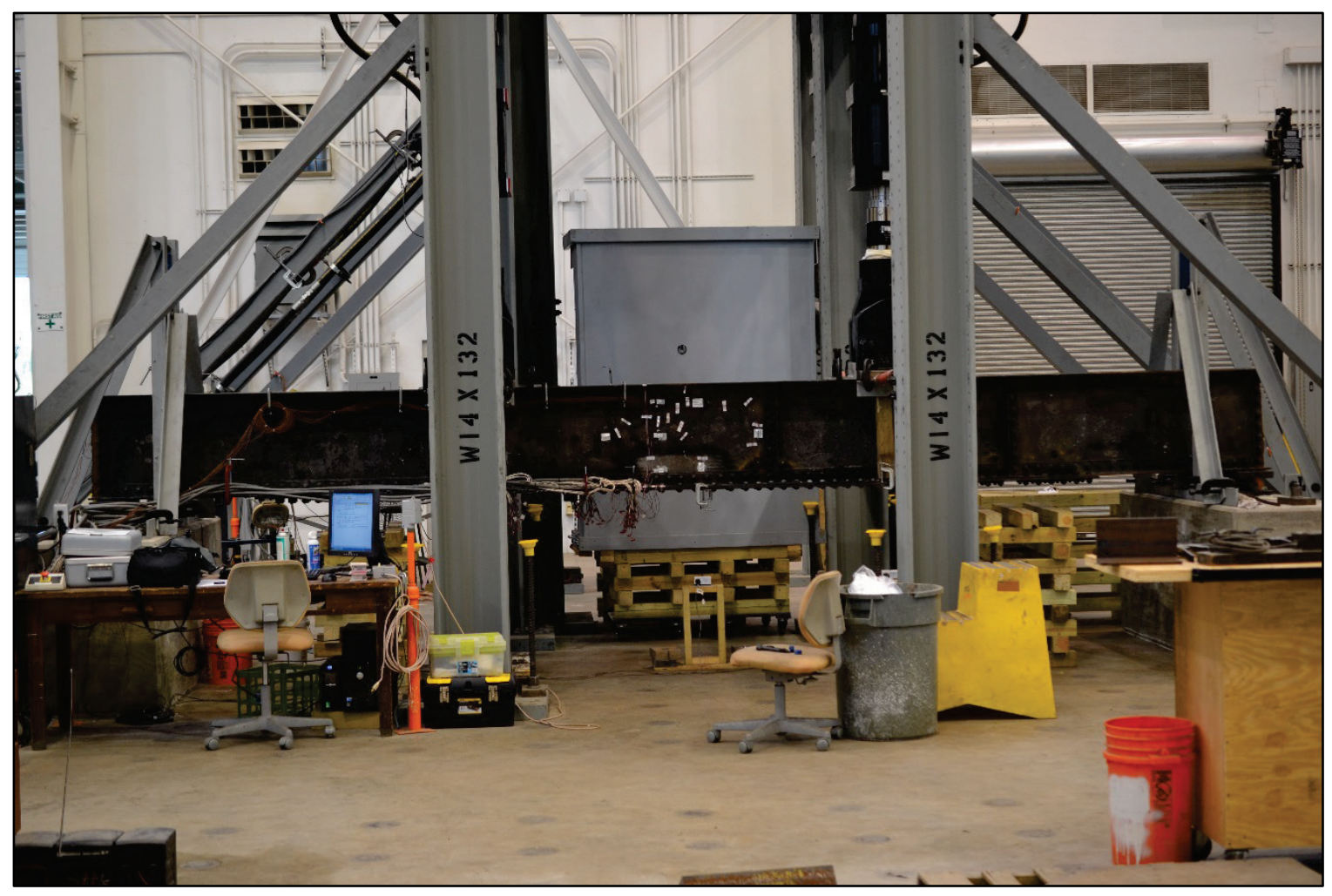

Figure 3-36 Specimen 23-3 test setup

\subsubsection{Fracture Test}

The specimen was again cycled in fatigue to create a sharp crack tip at the hole notches in the flange angle (Figure 3-37). Based on the results of Specimen 23-1 and Specimen 23-2, the cracks were allowed to grow further (prior to the fracture test being attempted) with the hope of inducing a fracture. Cracks were detected in both notches of the flange angle after 383,000 cycles. The crack grew quicker than expected through the exterior edge of the angle. At this point the total length of the crack was 3.6" (measured from the edge of angle through the hole) and the specimen was prepared for the fracture phase of the test. The specimen was first cooled to $-77^{\circ} \mathrm{F}$ and then the actuators were loaded to 50 kips each (resulting in a calculated net section stress of $21.1 \mathrm{ksi}$ in the 
bottom flange). No fracture occurred during the test. The specimen was allowed to warm up to ambient air temperature and then cyclic loads were continued to grow the crack length. The crack quickly grew through the remaining portion of the horizontal leg of the east flange angle. At this point, since no brittle fracture occurred, the fatigue portion of the test was begun.

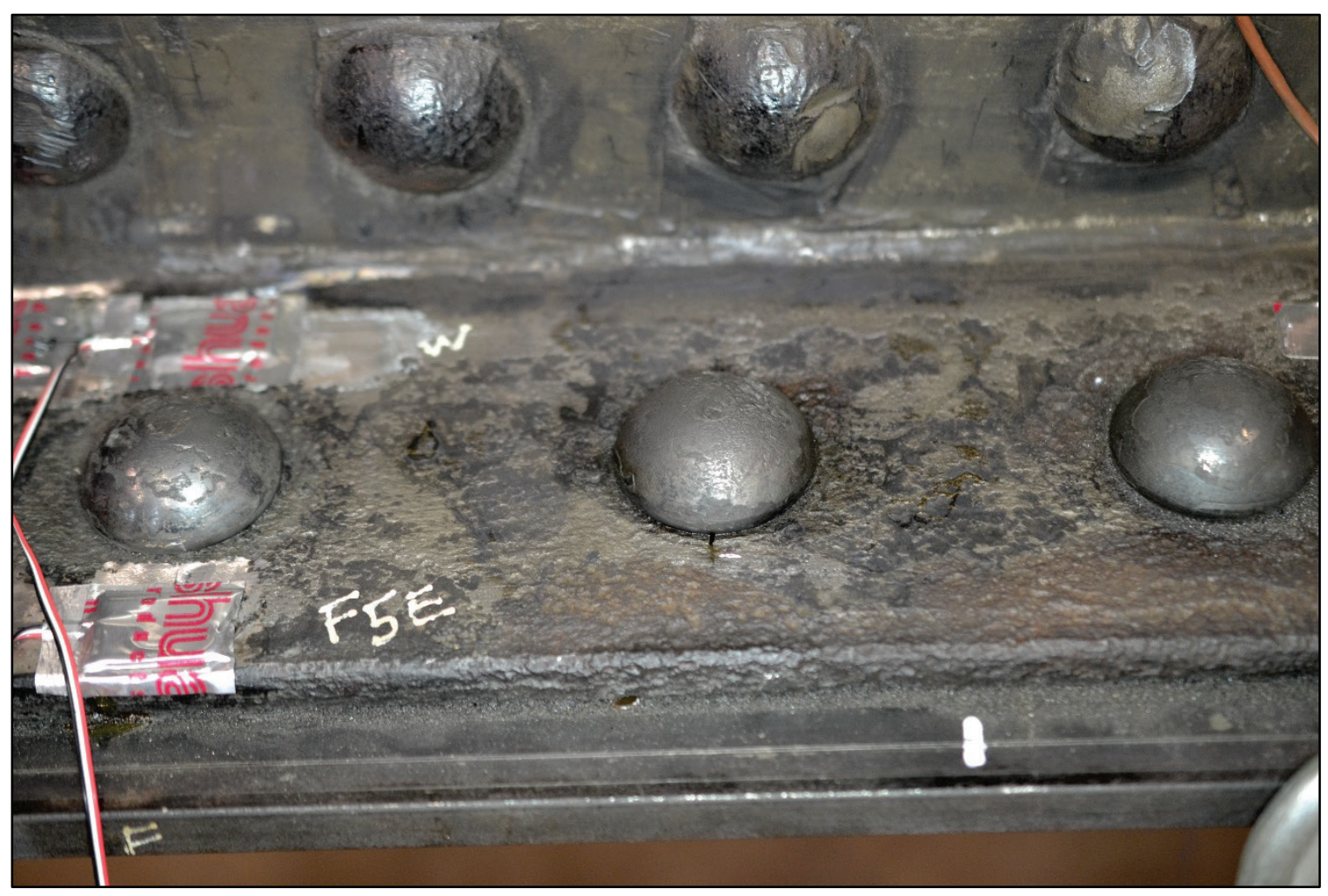

Figure 3-37 Crack growth from Specimen 23-3 hole notch

\subsubsection{Fatigue Test}

The cyclic loading applied to the actuators was between 15 kips and 50 kips on each jack. This load equated to a calculated net section stress range of $16.1 \mathrm{ksi}$ in the bottom cover plate. After 3.31 million cycles, cracks were detected in the cover plate on the east side. The cracks were located one hole south of the original crack location in the 
east flange angle. Shortly thereafter (52,000 cycles) a crack was detected growing in the web plate (directly above the original flange angle crack). Cracks were detected 184,000 cycles later in the vertical leg of the west flange angle in the same longitudinal location as the original east flange angle cracks. After another 237,000 cycles the test was stopped. At this point the east flange angle was completely cracked, the cover plate had a crack running from the east side, through the east rivet hole and had arrested in the west rivet hole. Additionally, the west flange angle had a crack through the entire vertical leg and had arrested in the rivet hole of the horizontal leg, and the web plate had a 7.2" crack. Figure 3-38 shows the extents of the cracks (under load) at the end of the test. A total of 3.78 million cycles were accumulated between the failure of the horizontal leg of the east flange angle and the time that the test was stopped. 


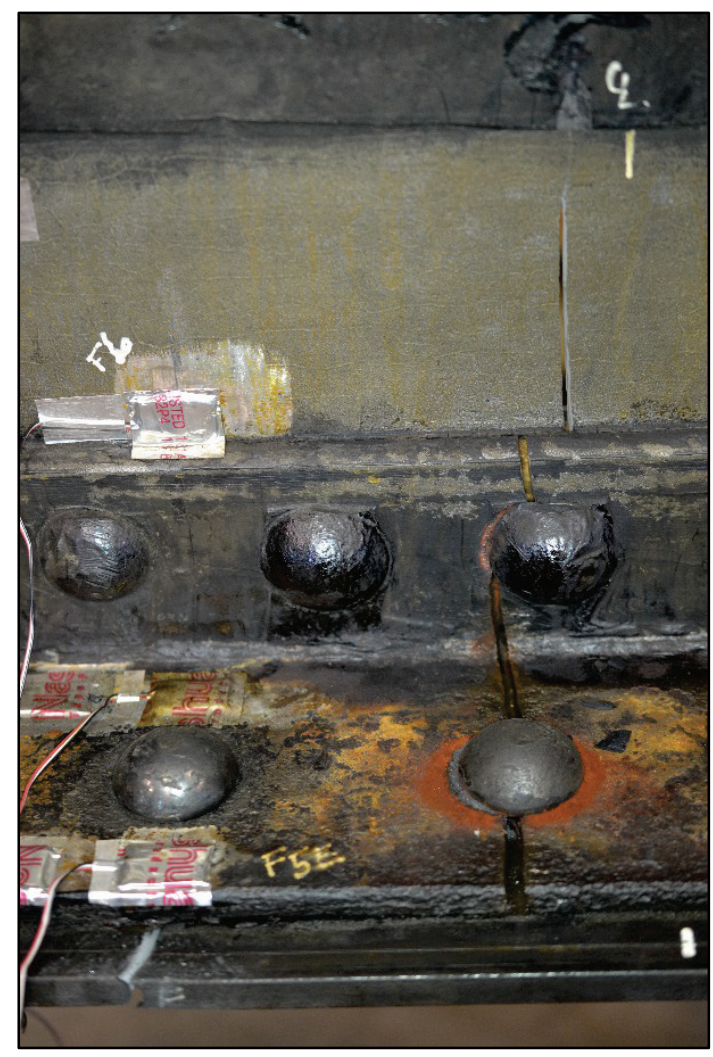

(a)

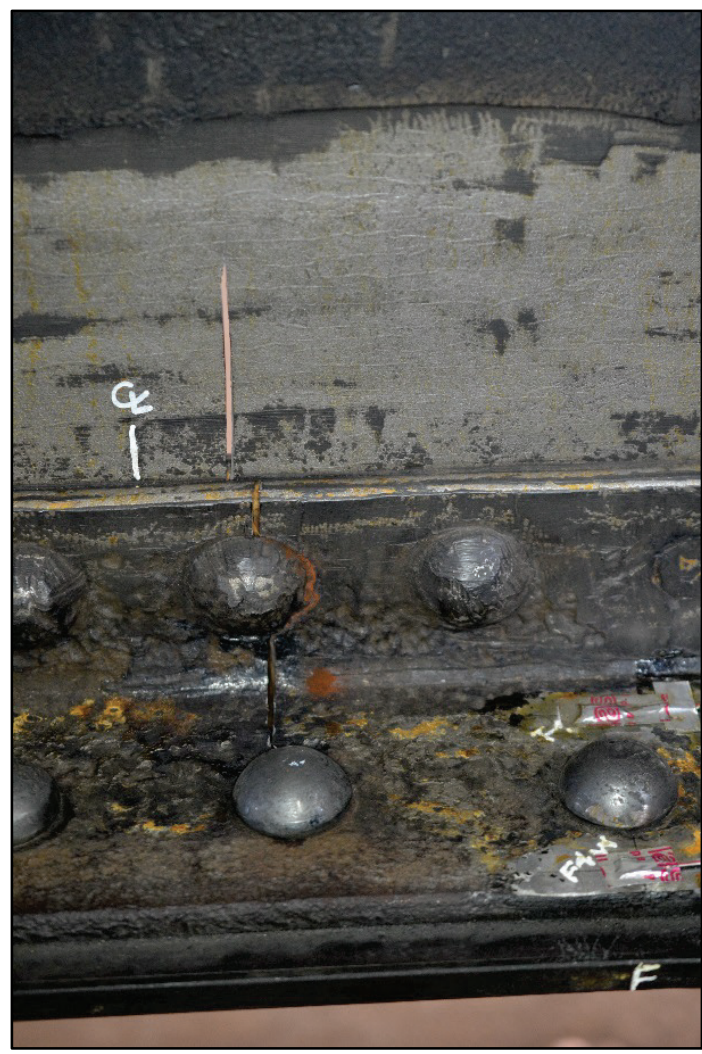

(b)

Figure 3-38 Cracks in Specimen 23-3; (a) East side, (b) West side

\subsubsection{Specimen 46-1}

Specimen 46-1 was the first of the 'new' fabricated specimens to be tested. All components of this specimen were fabricated by Hirschfeld Industries Bridge. The holes in the flange angles were punched, however all other holes were drilled. The components were connected with A325 bolts which were fully pretensioned by the turn-of nut method (RCSC, 2009). A thin layer of packing grease was applied to the contact surface between the cover plate and flange angles to simulate a low friction condition and investigate the impact of friction in the stress transfer between components. The material properties can be seen in APPENDIX D. The cover plate holes were prepared with 1.75" long notches 
at the centerline of the specimen (as shown in Figure 3-39) prior to connecting the cover plate and flange angles.

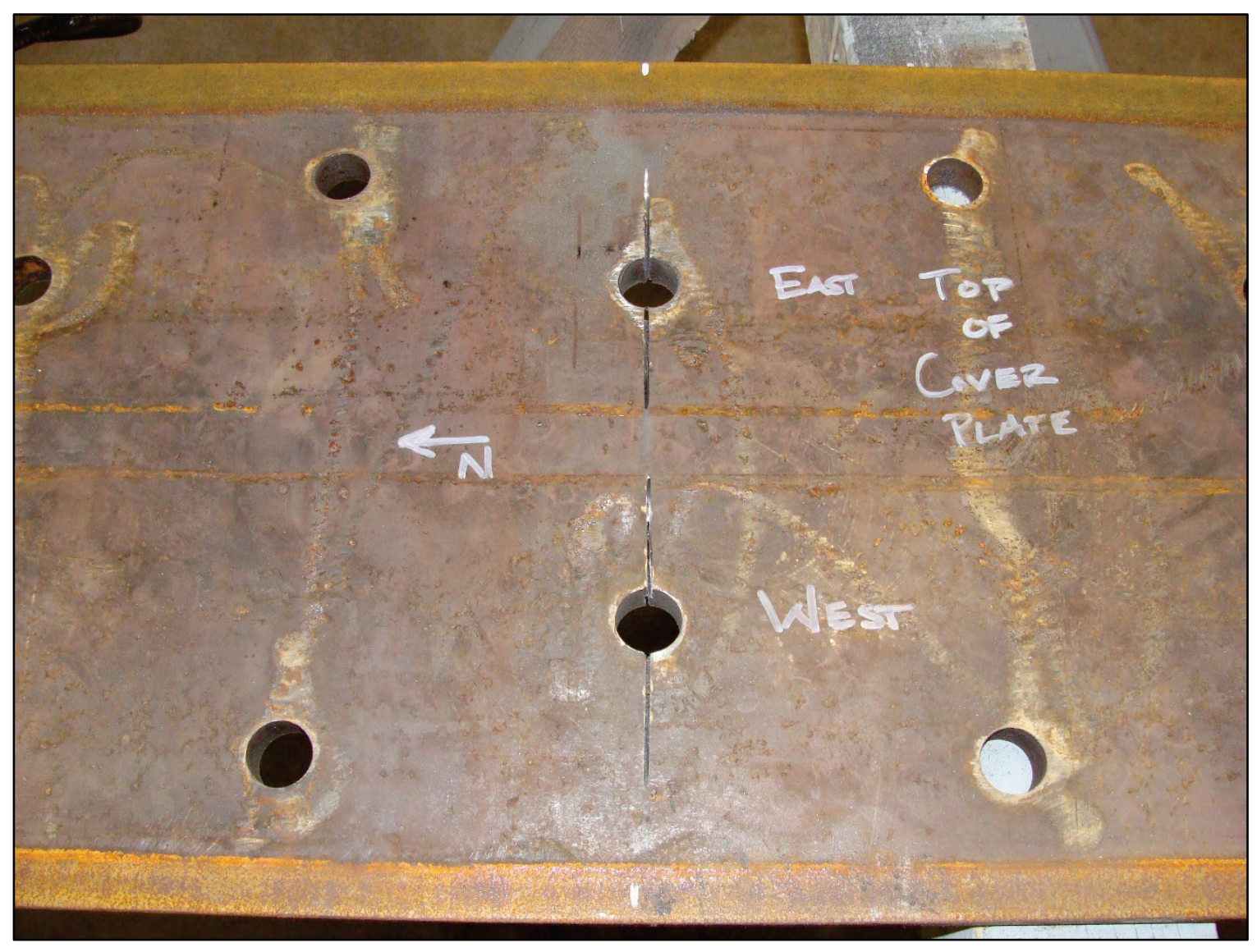

Figure 3-39 Specimen 46-1 cover plate hole notches

\subsubsection{Fracture Test}

Specimen 46-1 was cycled in fatigue from a load of 80 kips to 180 kips which equated to a calculated net section stress range of $16.8 \mathrm{ksi}$ at a rate of $1.5 \mathrm{~Hz}$. The first cracks were detected after 145,000 cycles. At this point a crack had already grown connecting the two notches at the center portion of the cover plate. Cracks were also visible at the exterior notches of the cover plate. These cracks had a length (including the notch) of $1.9^{\prime \prime}$ and $2.0^{\prime \prime}$ (west-to-east). The base load of 80 kips was maintained and the 
specimen was prepared for a fracture test. The specimen was cooled to $-71^{\circ} \mathrm{F}$ and loaded to 180 kips (following the protocol described in Section 3.3.2), however no fracture occurred. The specimen was allowed to warm to ambient temperature and fatigue cycles were reinitiated to grow the crack further before attempting another fracture test. However, the cracks quickly grew through the edges of the cover plate at this stress range and no fracture test was conducted.

\subsubsection{Fatigue Test}

The specimen was cyclically loaded from 80 kips to 180 kips to measure the fatigue life of the remaining components. The test was kept continuously running throughout the day and night to decrease the duration of the test. The east flange angle was found completely cracked through one morning. Additional cracks were also found in the hole of the horizontal leg of the west flange angle. Based on the cyclic load frequency and the data collected, it was calculated that the east flange angle had failed after approximately 74,400 cycles at a calculated net section stress range of $24.2 \mathrm{ksi}$. Figure 3-40 shows the cracked flange angles and cover plate on the east and west side of the specimen. 


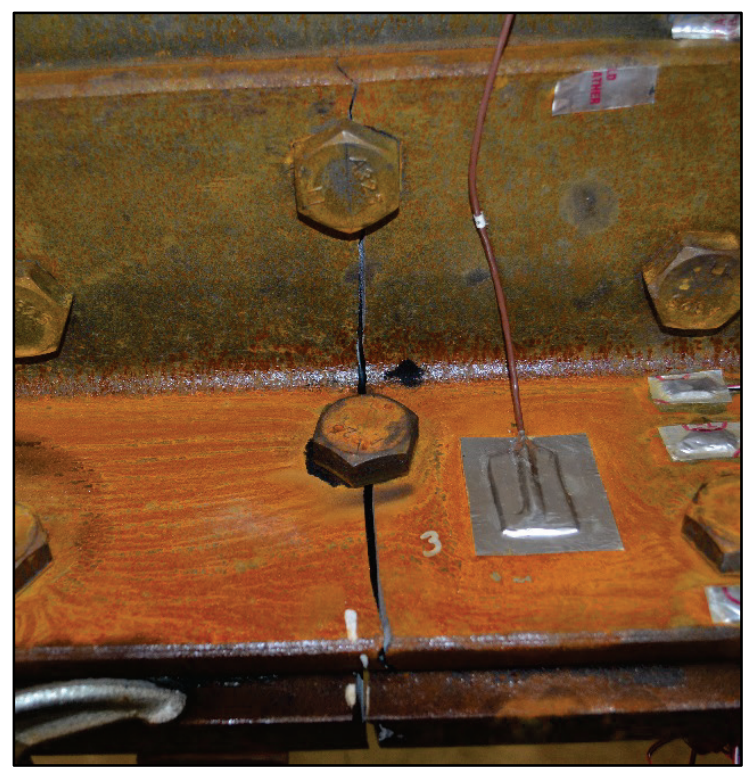

(a)

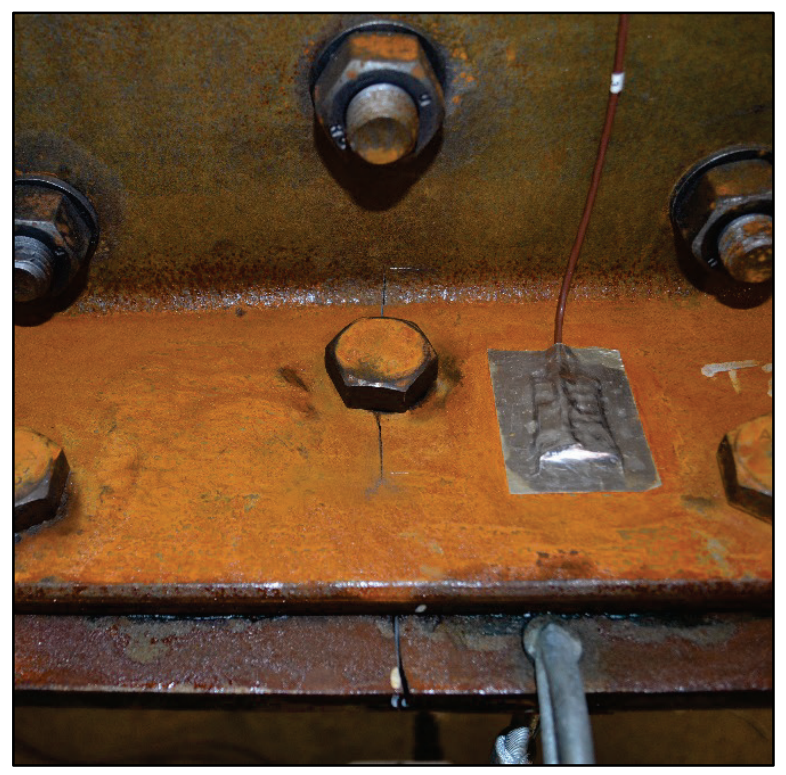

(b)

Figure 3-40 Specimen 46-1 cracked flange angles; (a) East, (b) West

Both the high-strength nuts and washers that were attached to the bolts at the location of the cover plate notch were found to have significant fatigue cracks (see Figure 3-41). As the specimen was cyclically loaded it went through a cyclic displacement which resulted in a gap opening of the failed cover plate. It was believed that the frictional force between the nut, washer, and cover plates (which was caused by the pretension in the fastener) resulted in cyclic axial forces (out-of-plane for both the bolt and washer) which resulted in the fatigue of the washers and bolts. 

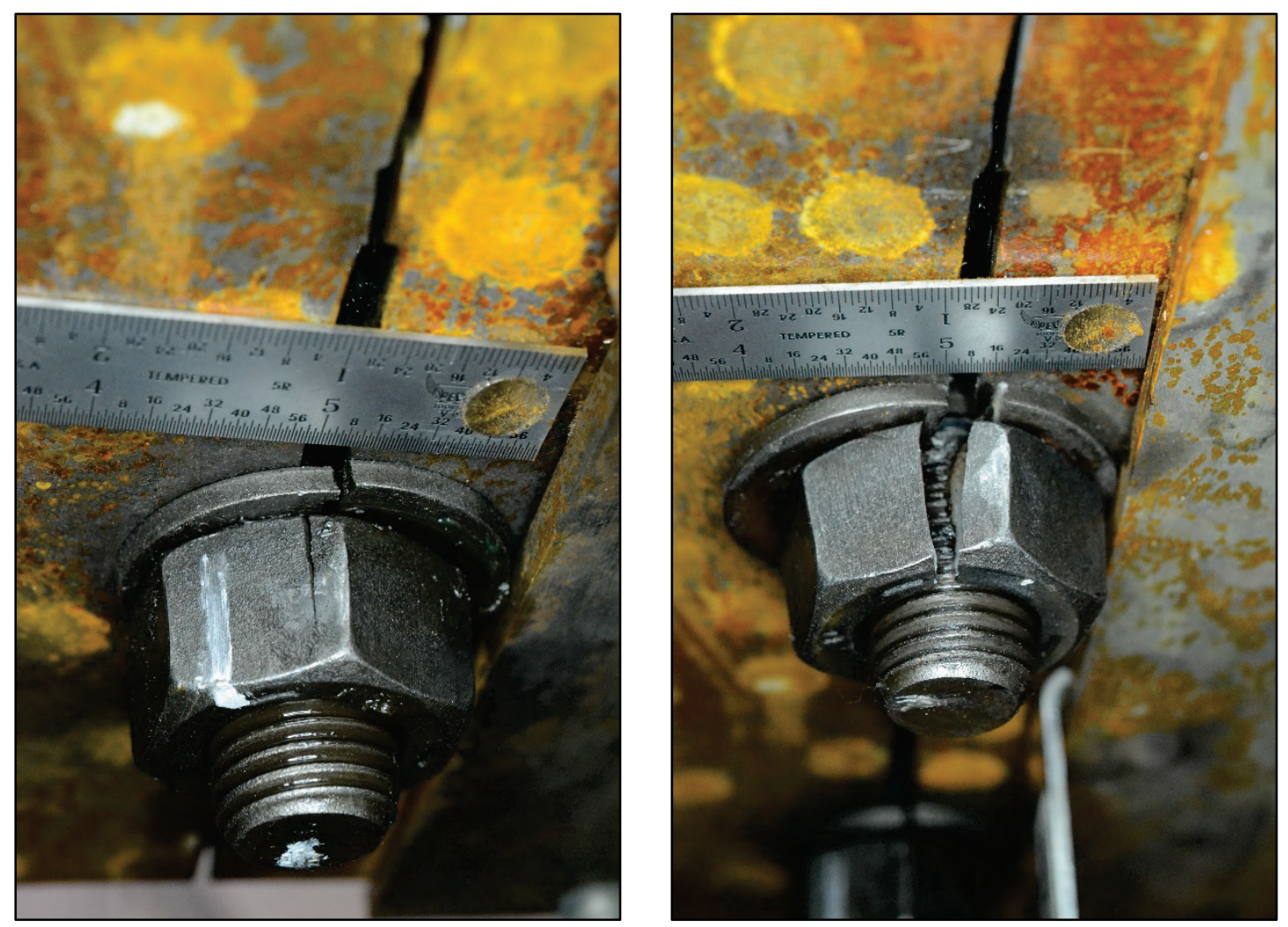

Figure 3-41 Specimen 46-1 cracked nuts

\subsubsection{Specimen 46-2}

Specimen 46-2 was assembled in much the same way as Specimen 46-1. Holes in the flange angles were punched but all others were drilled. However, no grease was used between the cover plate and angles to investigate a more realistic condition where friction would play a role in the stress transfer between components. High-strength bolts with the turn-of-nut tightening procedure were used to fasten the cover plate, angles, and web together. Figure 3-42 shows the specimen after the cover plate was notched and prior to it being bolted to the beam. 


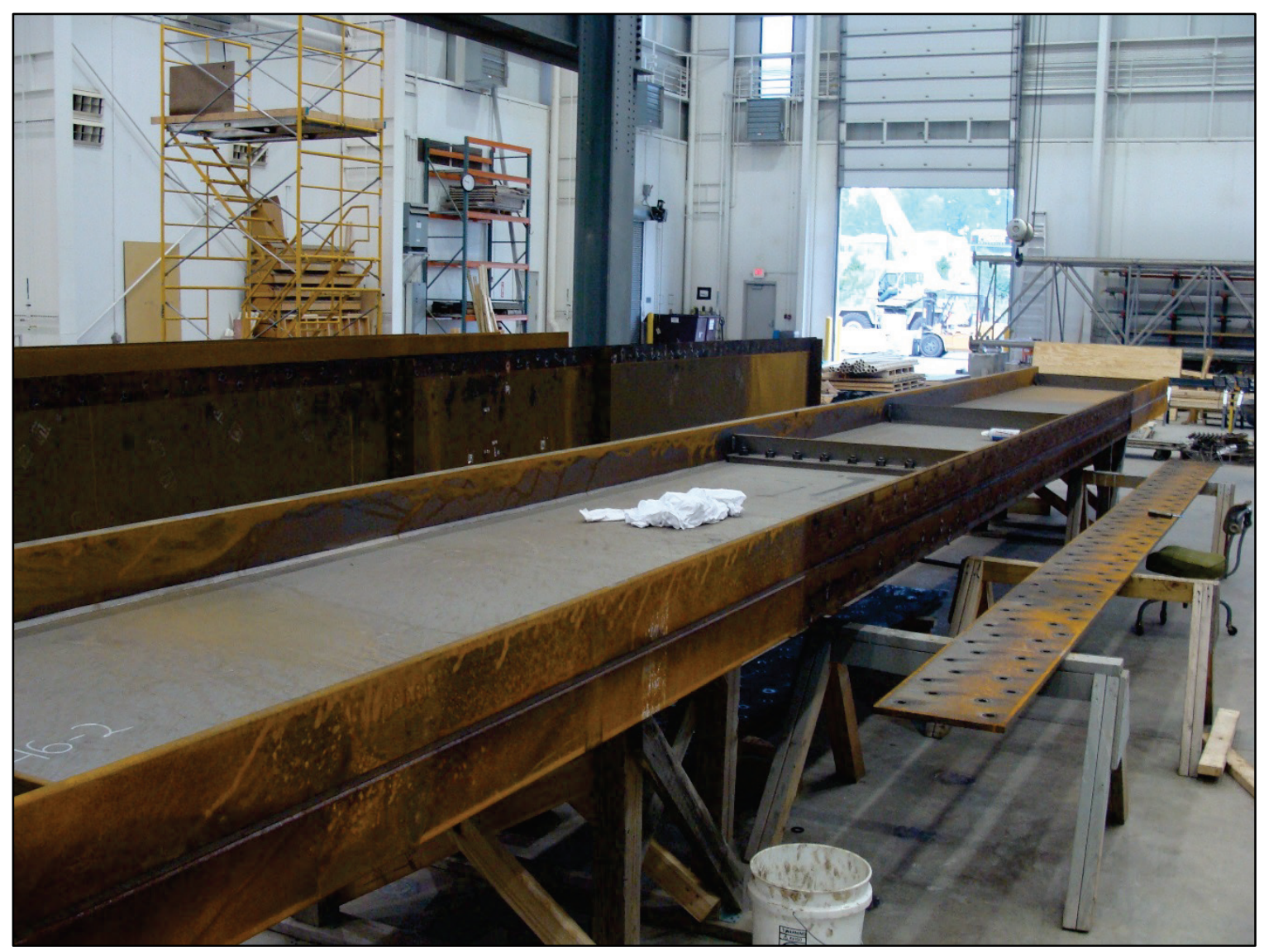

Figure 3-42 Specimen 46-2 fabrication

\subsubsection{Fracture Test}

Specimen 46-2 was first cycled in the test setup between 80 kips and 180 kips (a calculated net section stress range of $16.8 \mathrm{ksi})$. Cracks were detected emerging from both notches at the center portion of the cover plate after 47,000 cycles. After another 11,000 cycles cracks were detected at both exterior notches. At this point the cracks were 1.97", 2.10", 2.11", and 1.97" (from west to east). The specimen was cooled to $-82^{\circ} \mathrm{F}$ and a fracture was attempted. The specimen did not fracture and was allowed to warm to ambient temperature. The specimen was cyclically loaded further until a total of 139,000 cycles when the cover plate had completely failed due to fatigue. 


\subsubsection{Fatigue Test}

The specimen was loaded cyclically at the same magnitude which created a calculated net section stress range of $24.2 \mathrm{ksi}$ on the remaining bottom flange components. After 21,000 cycles cracks were detected in both the east and west flange angles as well as the nut on the east side at the location of the cracked cover plate. After a total of 31,200 cycles, cracks had grown through the entire length of the horizontal leg of the west flange angle and the test was stopped (see Figure 3-43). At this point $56 \%$ of the horizontal leg of the east flange angle was also cracked. The fatigue data is presented along with other specimens in Section 3.5.2. The nuts and washers on the bolts at the location of the cover plate crack initiated fatigue cracks in this specimen, similar to Specimen 46-1. 


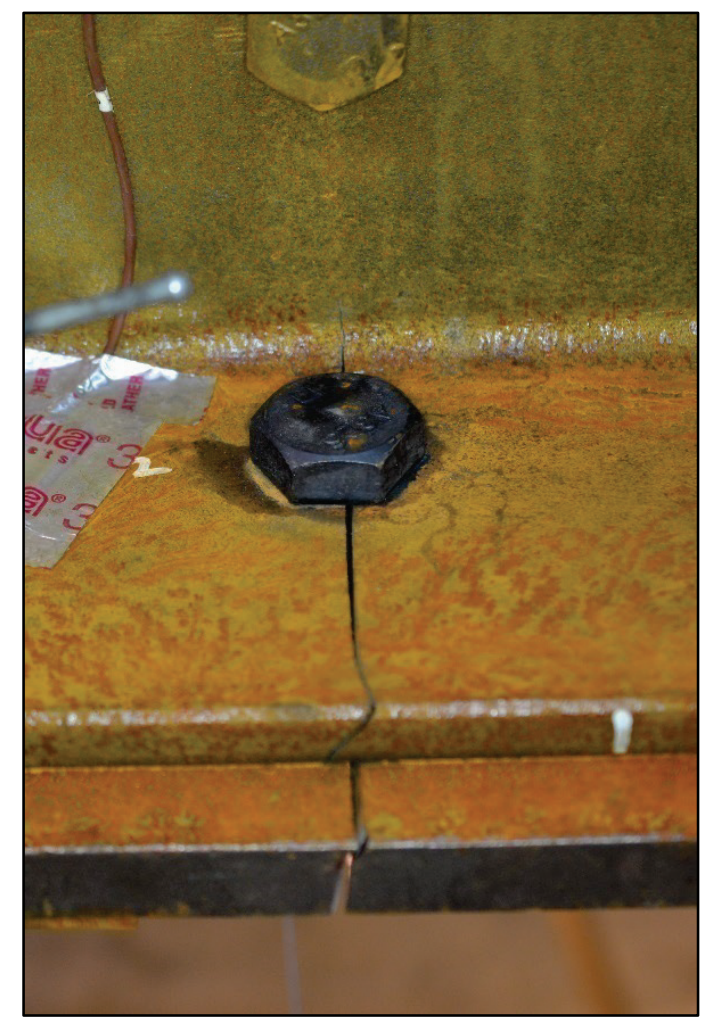

(a)

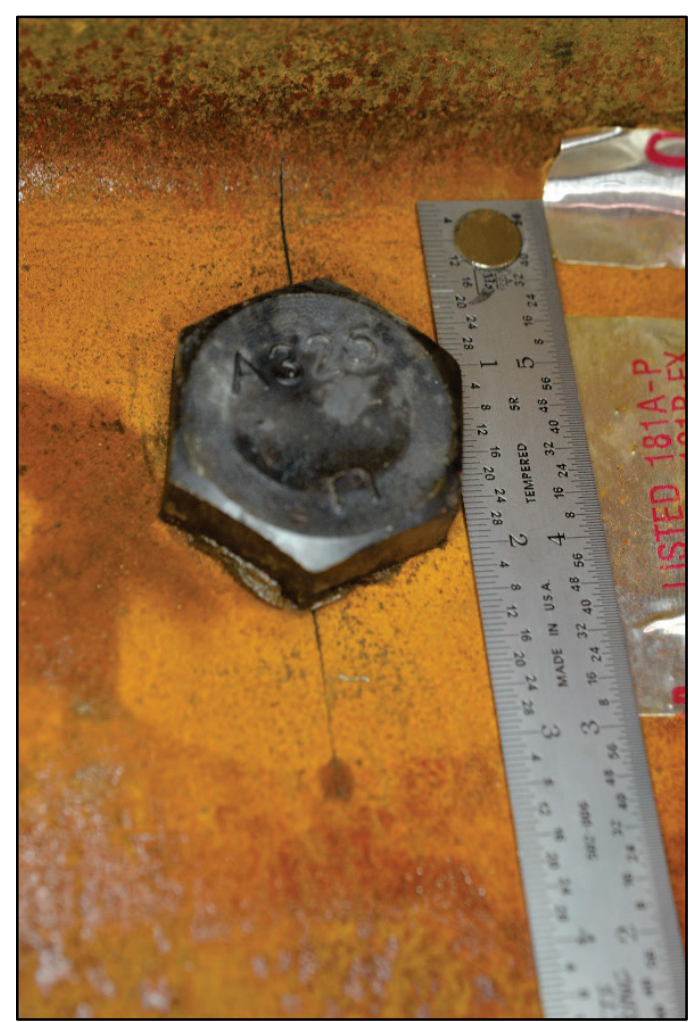

(b)

Figure 3-43 Specimen 46-2 cracked flange angles; (a) West, (b) East

\subsubsection{Specimen 46-3}

Specimen 46-3 used the same web plate and top flange as Specimen 46-1. The holes in the flange angles were punched. All holes in the other components were drilled. The holes at the centerline of Specimen 46-3 were notched to a length of $1.75^{\prime \prime}$. The bottom flange angles, cover plate, and web were riveted together in the constant moment region (see Figure 3-44). All other holes were fastened with snug tightened bolts to simulate the pretension resulting from rivets. No grease was applied to the cover plate. 


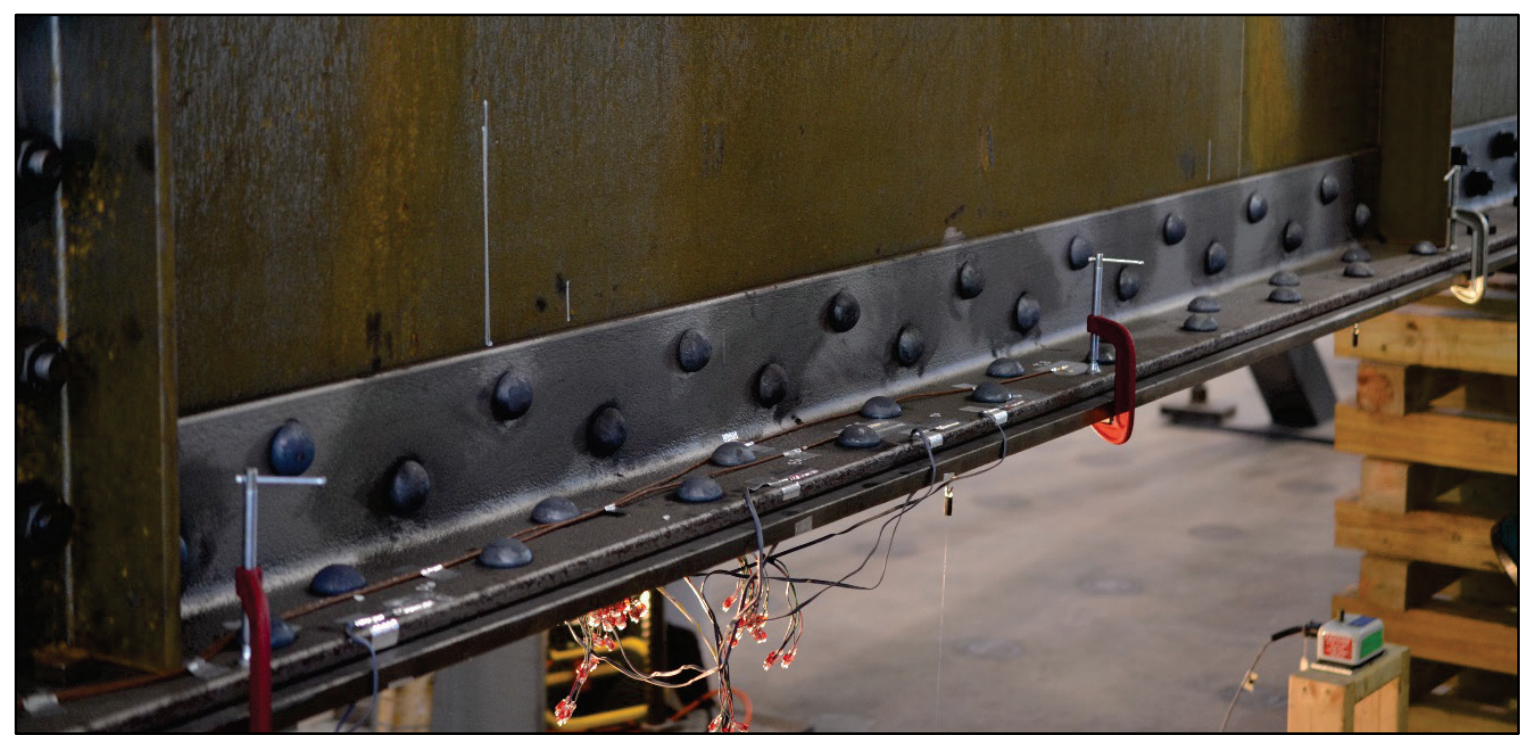

Figure 3-44 Specimen 46-3 bottom flange

\subsubsection{Fracture Test}

Prior to the fracture test, the specimen was cycled in fatigue between 80 kips and 180 kips with a calculated stress range in the bottom flange cover plate of $16.8 \mathrm{ksi}$. After 37,000 cycles cracks were detected at both interior notches and the east exterior notch of the cover plate. After an additional 3,000 cycles were applied, a crack was detected which had just started growing out of the west side notch. At this point the cracks growing at the interior portion of the cover plate had grown together. The total lengths of the cracks were 1.84", 2.21", 2.55", and 2.39" (from west-to-east). The specimen was prepared for the fracture test by cooling to a temperature of $-75^{\circ} \mathrm{F}$. A load of $200 \mathrm{kips}$ was applied on each actuator. At this point the cover plate of the specimen fractured. After a thorough inspection, no other cracks were found in any of the other components. Figure 3-45 shows the cover plate of the specimen after the fracture (from below). 


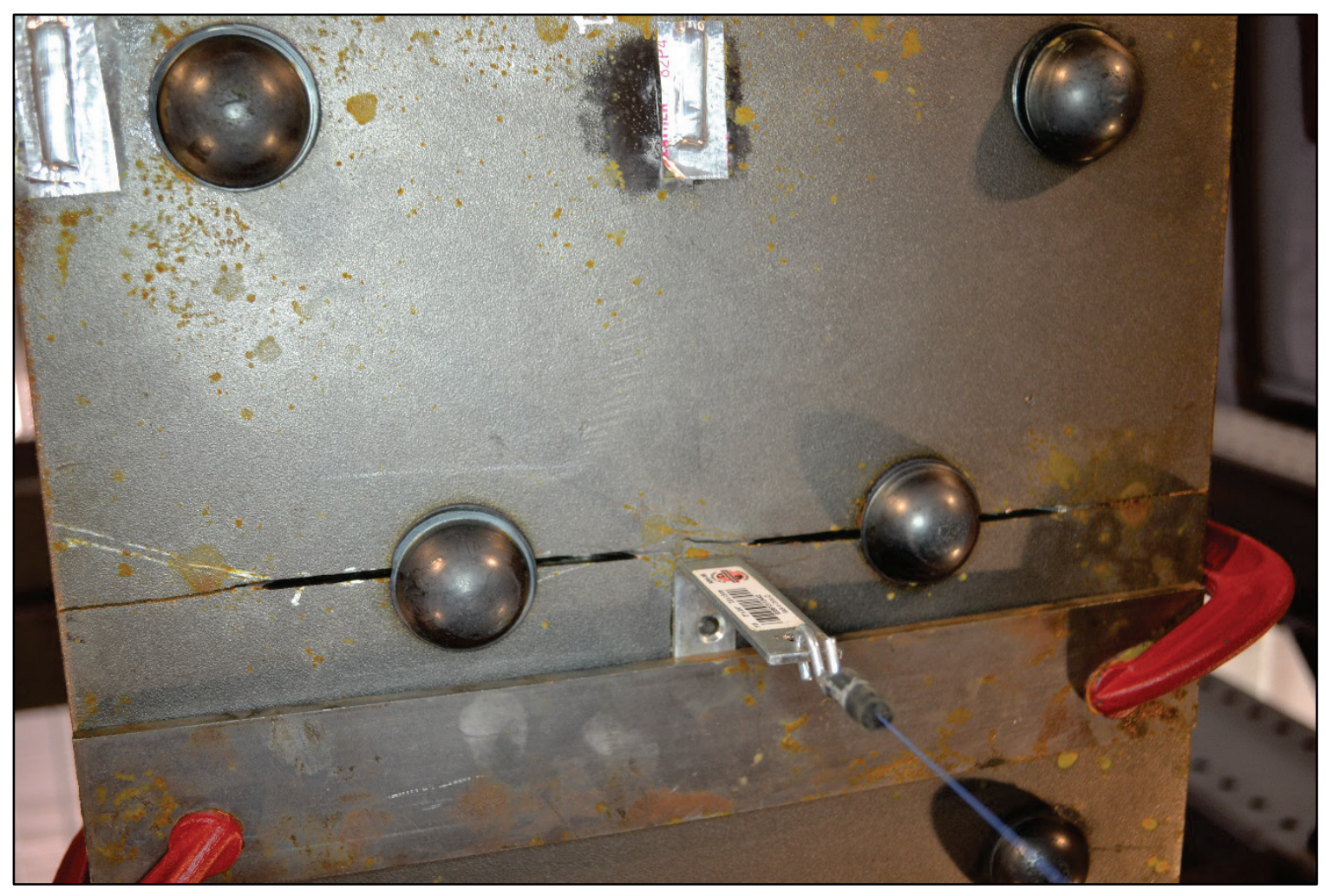

Figure 3-45 Specimen 46-3 fractured cover plate (from below)

\subsubsection{Fatigue Test}

Following the fracture test, Specimen 46-3 was cyclically loaded from 80 kips to 180 kips which resulted in a calculated net section stress range of $24.2 \mathrm{ksi}$ (of the remaining cross section). The first crack was detected after 92,000 cycles in the horizontal leg of the west flange angle. After another 58,000 cycles, cracks were detected on both sides of the rivet hole in the horizontal leg of the east flange angle. The crack growth rate increased due to the increased length of the crack. When the total cracked portion of the horizontal leg of the east flange angle was $80 \%$, the test was stopped to prevent damage to the web of the specimen (to allow its use for further 
specimens). The total number of cycles from the time the cover plate fractured until the test was stopped was 153,000 .

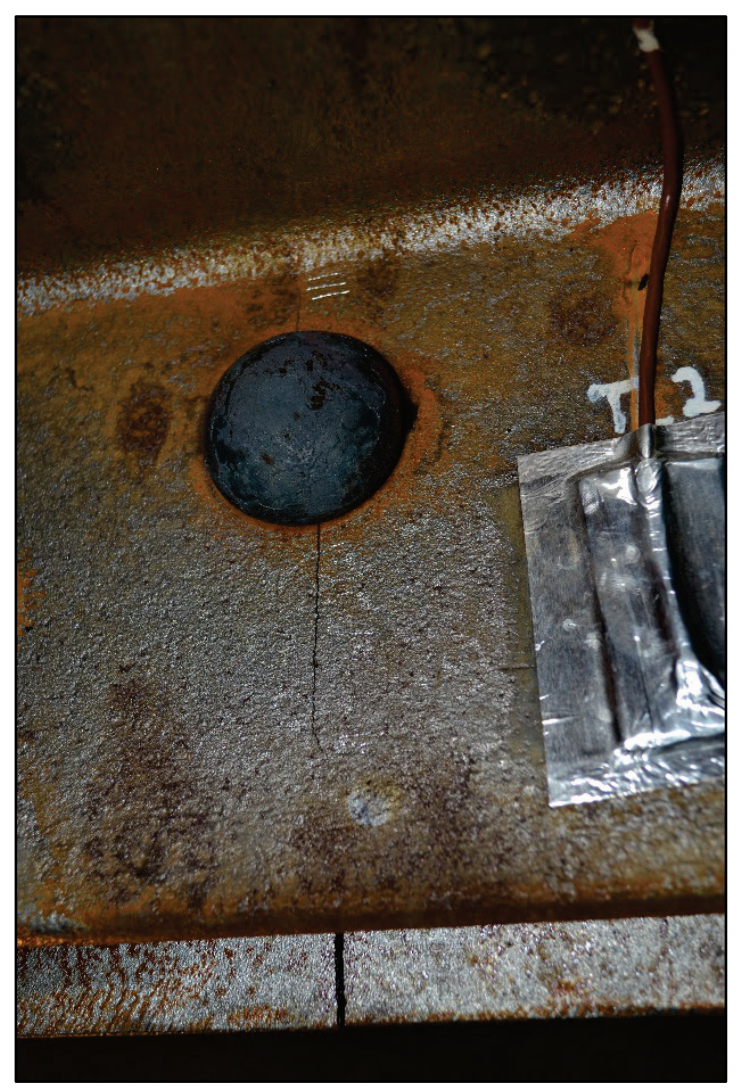

(a)

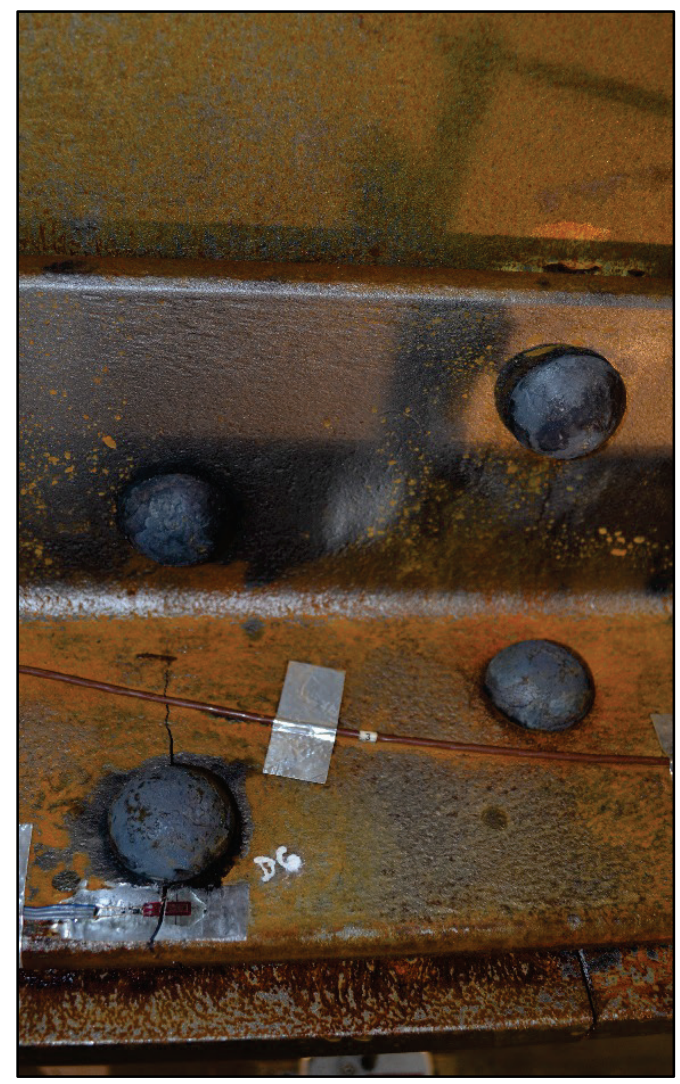

(b)

Figure 3-46 Specimen 46-3 cracked flange angles; (a) West, (b) East

\subsubsection{Specimen 36-1}

Specimen 36-1 was the first specimen tested with multiple cover plates. All components of the specimen were fabricated and sent from Hirschfeld Industries Bridge at the same time. The flange angles were the only components that were punched, all others were drilled. The upper cover plate was notched so that the lower cover plate would have the highest stress due to the distance from the neutral axis. Additionally, it allowed for easier inspection during the crack growth phase of the fatigue test. 
Because the notches on the upper plate were completely hidden by the flange angles and lower cover plate, it was impossible to visually detect when the upper cover plate had started to crack. Crack detection gages installed perpendicular to the notches were used in order to determine when each crack had reached its critical crack length. Using a grinder, a small area was dished out of the cover plate to allow the installation of the crack detection gages and their lead wires without interfering with the mating surface of the two cover plates. The dished out area was smoothed to minimize stress risers at their location. Figure 3-47 shows the preparation and installation of the crack detection gages on the upper cover plate.

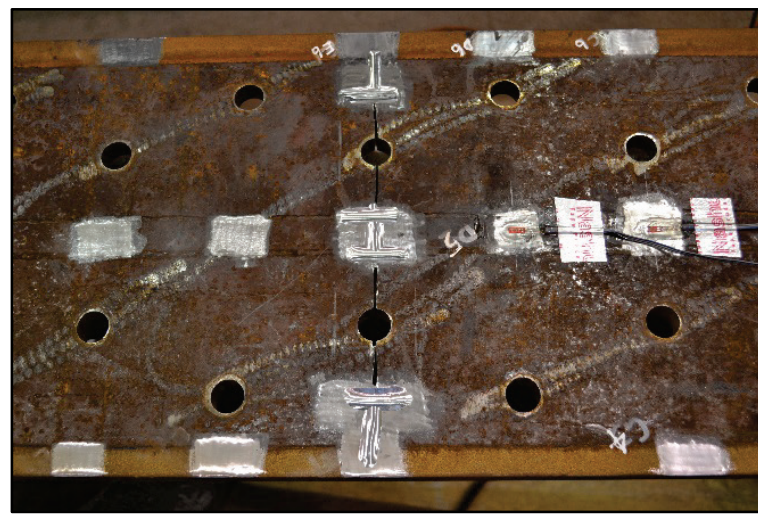

(a)

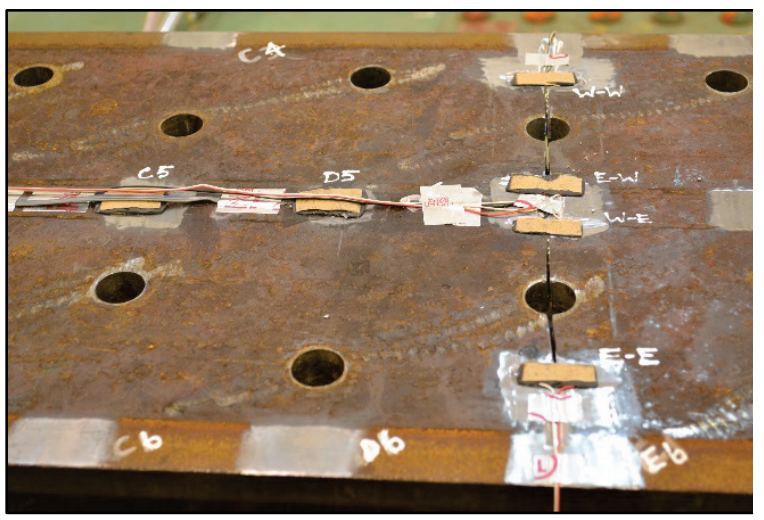

(b)

Figure 3-47 Specimen 36-1 crack detection gages; (a) Preparation (b) Installed

\subsubsection{Fracture Test}

The specimen was cyclically loaded between 80 kips and 180 kips which resulted in a calculated net section stress range of $16.8 \mathrm{ksi}$ in the upper cover plate. The crack detection gages were checked prior to the initiation of any fatigue cycles and one gage at an interior notch was found to be faulty. However, due to the location, it was impossible to correct the issue without dismantling the specimen and was therefore abandoned. 
After 116,000 cycles, the second interior crack detection gage was triggered. In another 94,000 cycles the west exterior crack detection gage was triggered. Due to previous failed attempts to fracture specimens, the test was continued to cycle to attempt to get all four crack tips to a critical length prior to the fracture test. After a total of 404,000 cycles, the fourth crack detection gage stopped working. It was at this point, however, that cracks were also detected in both flange angles and the lower cover plate (cracks were present in all bottom flange components). The specimen was then cooled to $-65^{\circ} \mathrm{F}$ and prepared for the fracture test. No fracture occurred at this point. The specimen was allowed to warm to ambient temperature, the cracks were grown through cyclic loading, and the fracture was reattempted three more times at temperatures of $-72^{\circ} \mathrm{F},-70^{\circ} \mathrm{F}$, and $64^{\circ} \mathrm{F}$. Figure 3-48 shows the notch locations in the upper cover plate as well as the crack lengths at each of the four different fracture attempts. 


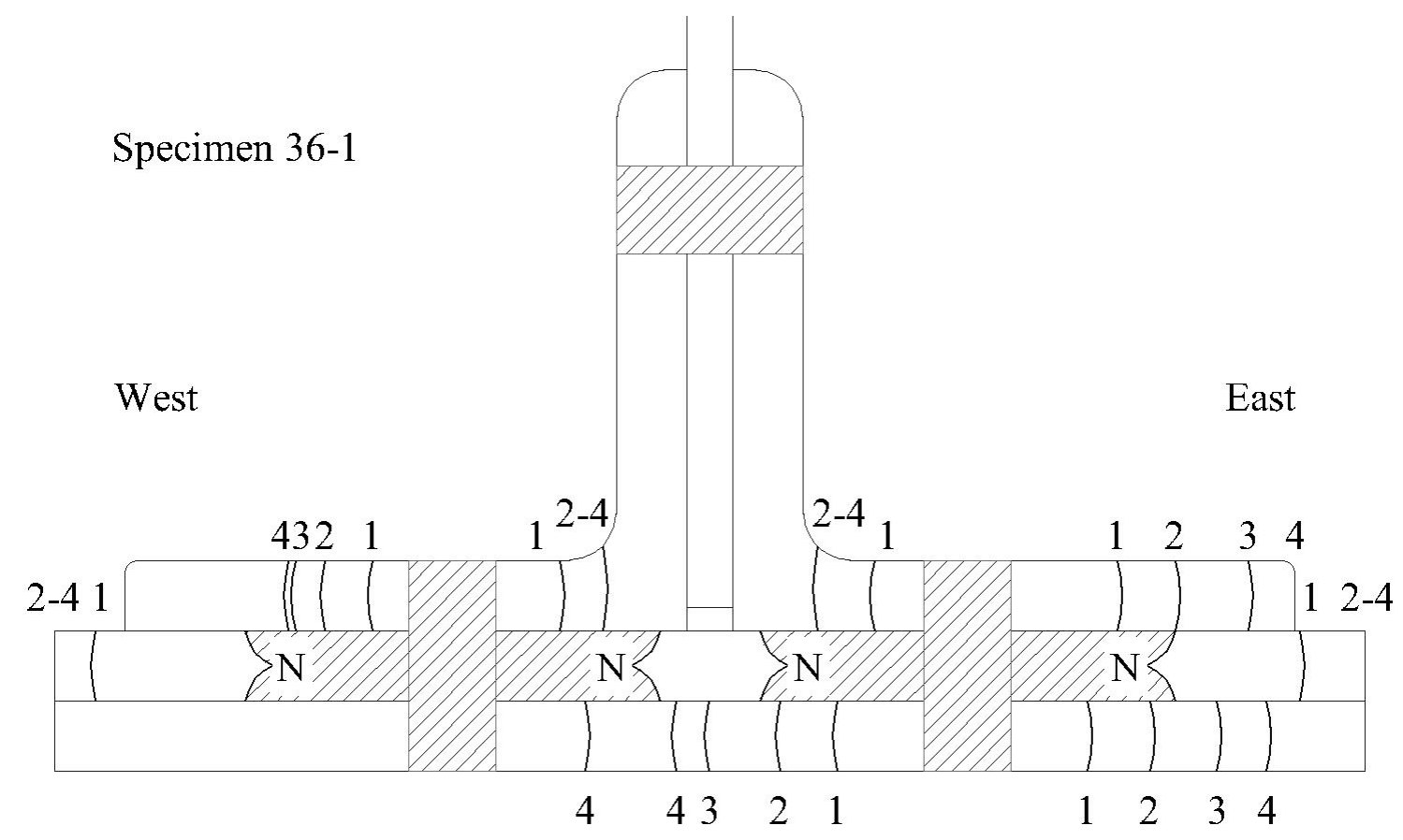

Figure 3-48 Specimen 36-1 crack growth and fracture attempts

Prior to the fourth fracture attempt, the cracks had grown completely through the upper cover plate, and completely through the horizontal leg of the east flange angle. Thirty four percent (34\%) of the lower cover plate and $29 \%$ of the west flange angle were all that remained of the bottom flange at the centerline. With such a large portion of the cross section cracked, the resulting calculated net section stress was $37 \%$ above yield. The stresses in the remaining portions of the bottom flange components were also greater than the nominal allowable yield stress during the second, third, and fourth fracture attempts.

When the fracture load was applied during the fourth fracture attempt, each of the remaining portions of the bottom flange components fractured (both flange angles, and the lower cover plate). The web yielded at the location of the fractures, but did not 
fracture. Due to the localized reduced stiffness, the actuators reached a deflection interlock in the MTS hydraulic software and the hydraulic pressure was shut off for the test. Figure 3-49 shows the east flange angle and both cover plates in the failed condition. Figure 3-50 shows the failure surface of the lower cover plate after disassembly.

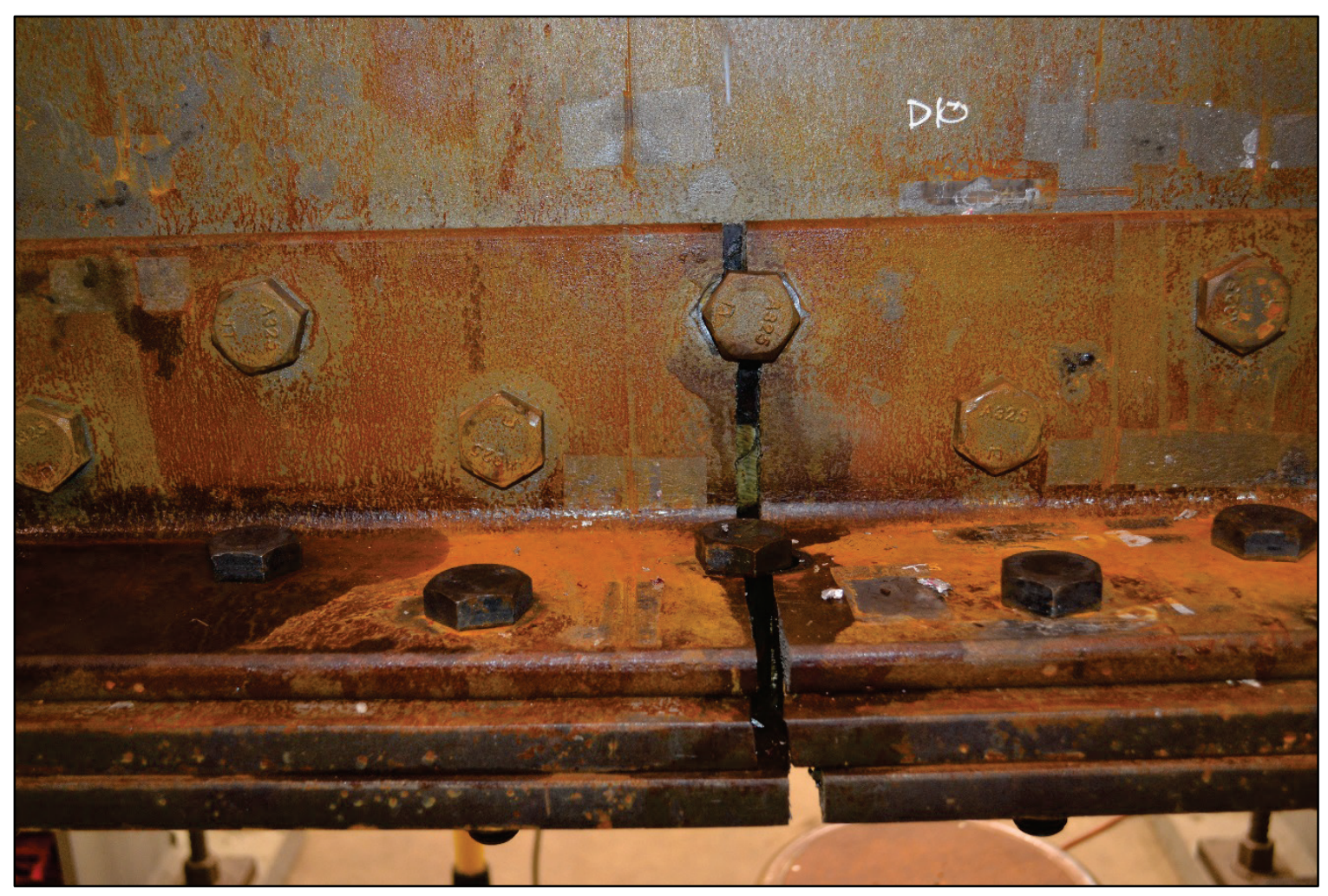

Figure 3-49 Specimen 36-1 fractured bottom flange components (east side) 


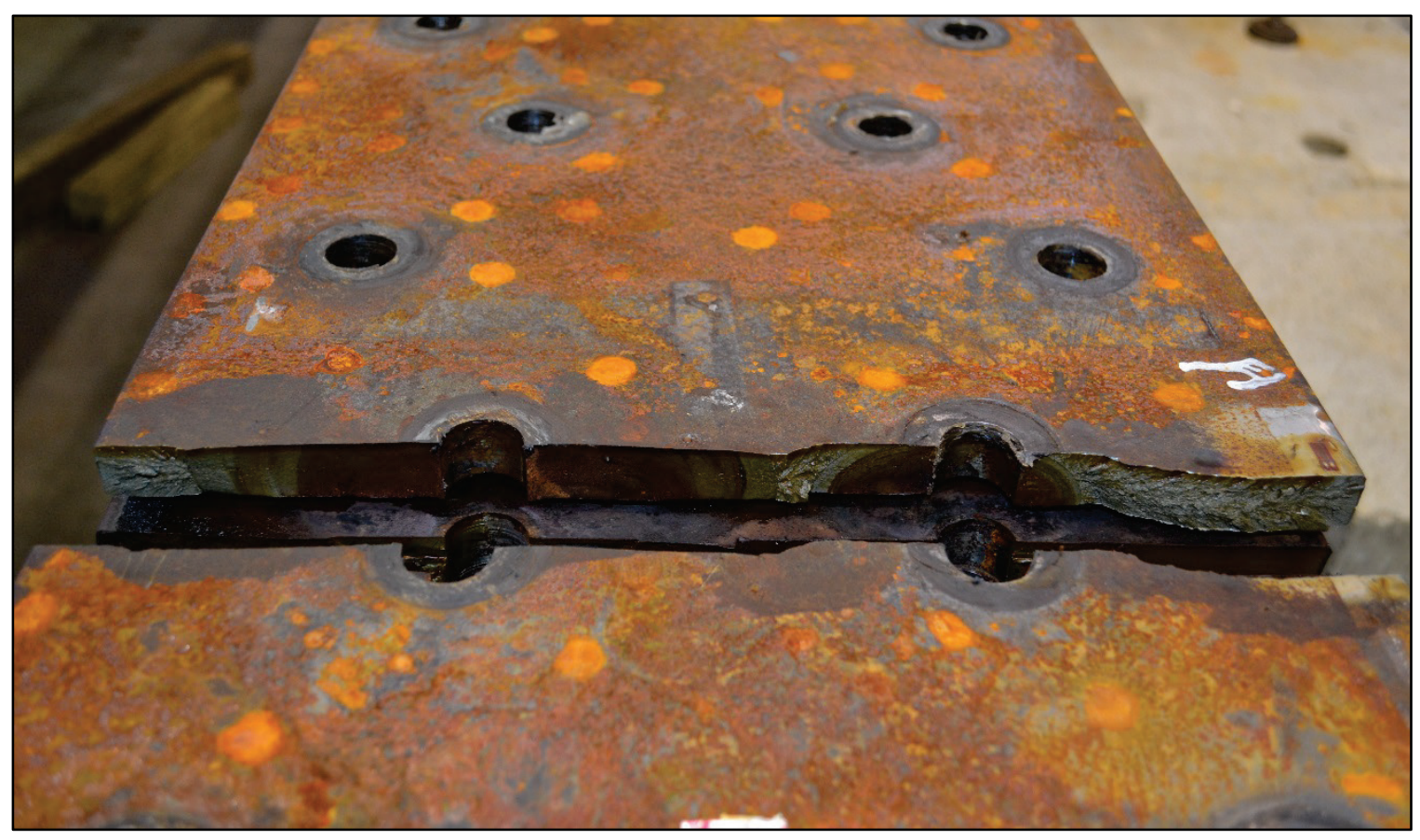

Figure 3-50 Specimen 36-1 fractured bottom flange components (bottom view)

\subsubsection{Specimen 36-2}

Specimen 36-2 was constructed by components received from Hirschfeld

Industries Bridge. The flange angles were punched, but all other components were drilled. All components were connected with high-strength A325 bolts which were tensioned using the turn-of-nut procedure. The lower cover plate was constructed from the failed lower cover plate from Specimen 36-1. The lower cover plate was welded back together and used as the initial component to fail. The failure surface of the cover plate was ground to a double bevel and welded with a full penetration weld (see Figure 3-51). 


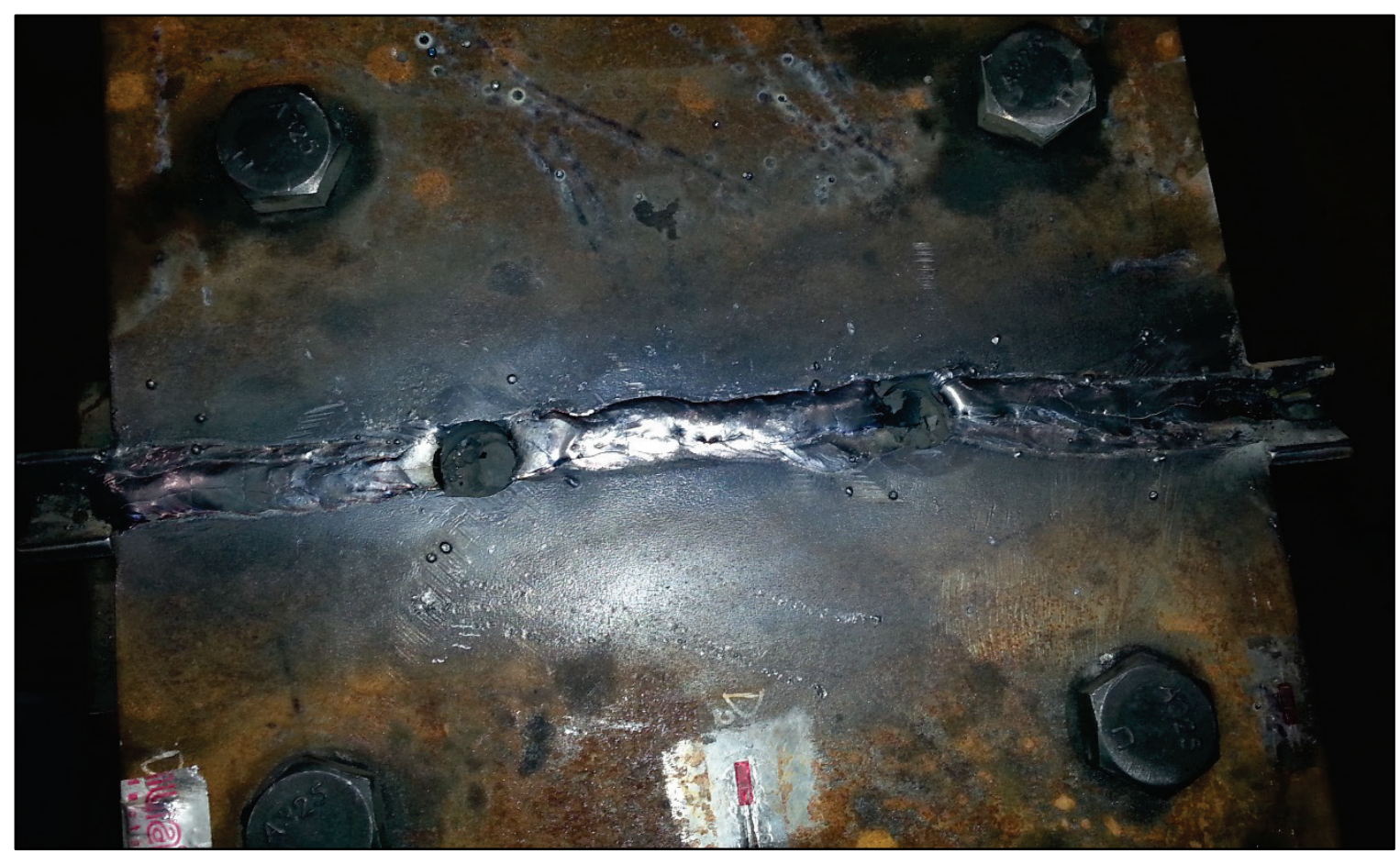

Figure 3-51 Specimen 36-2 welded lower cover plate

The weld was composed of Lincoln Electric Excalibur 7018 MR welding rod layered with Lincoln Electric Wearshield ME hardfacing welding rod. The intention was to create a 'bad' weld by layering the two weld metals together which would be used as a fuse element to increase the likelihood of a fracture. Figure 3-52 shows the substandard weld with many cracks which were expected to initiate a fracture. It was found that after three layers of the hardfacing weld were laid, the quality of the joint quickly decreased, creating multiple types of flaws including porosity and longitudinal cracks (in conjunction with the transverse cracks). 


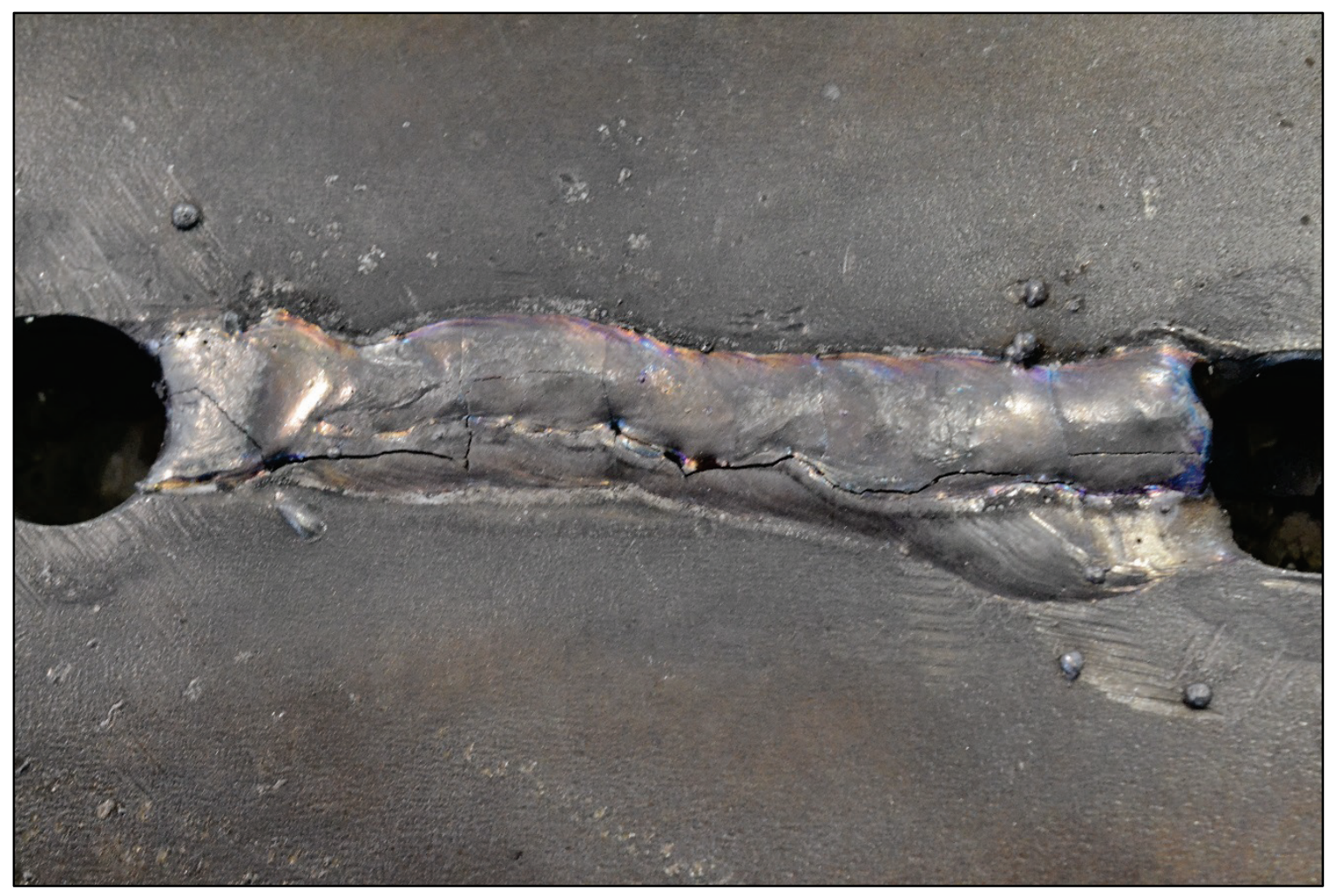

Figure 3-52 Specimen 36-2 cracks in lower cover plate weld

\subsubsection{Fracture Test}

Due to the substantial visible flaws in the welds at the centerline of the cover plate, no notches were cut into Specimen 36-2. The flaws were a result of the layering of the hardfacing weld material with $70 \mathrm{ksi}$ weld material. The specimen was first loaded to the fracture load of 180 kips at an ambient temperature of $57^{\circ} \mathrm{F}$ (due to the apparent large flaws in the welds). However no fracture occurred. A second fracture attempt was made after cooling the specimen to $-65^{\circ} \mathrm{F}$, with no results. The specimen was then allowed to warm to ambient temperature and cycled between 80 kips and 180 kips. This cyclic loading was an attempt to create a full depth crack tip through flaw coalescence, and then reattempt the fracture test. However, after only 9,500 cycles the entire lower cover plate 
had failed. Figure 3-53 shows the two failure surfaces of the lower cover plate after removal from the specimen. The weld defects are readily apparent in the photograph.

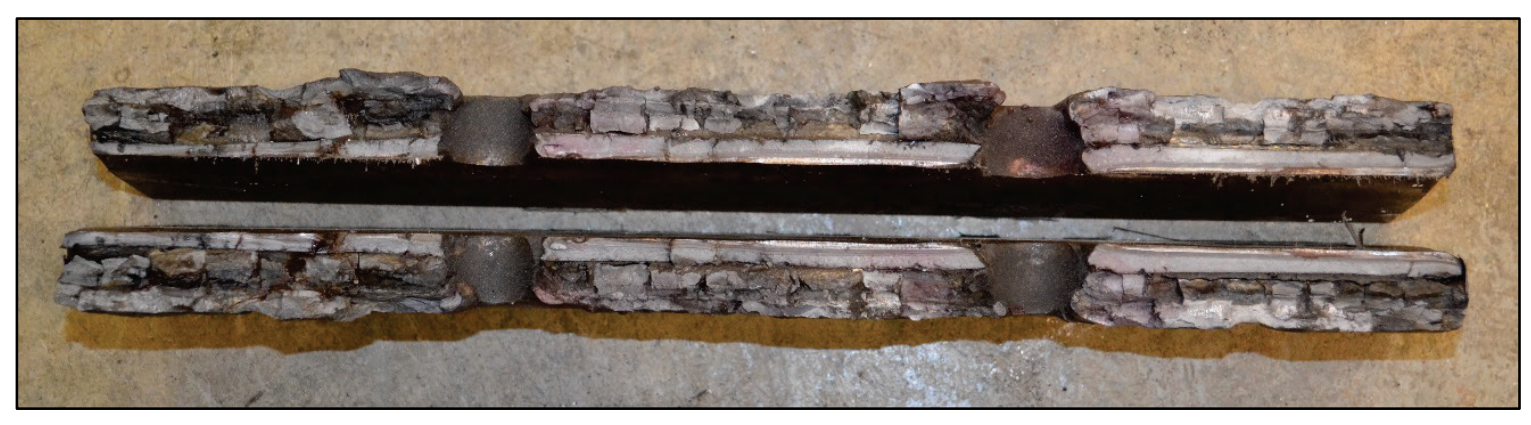

Figure 3-53 Specimen 36-2 lower cover plate failure surfaces

\subsubsection{Fatigue Test}

After the lower cover plate had failed, the specimen was tested to determine the fatigue life of the remaining bottom flange components. The specimen was loaded between 80 kips and 110 kips resulting in a calculated net section stress range of 6.6 ksi. The stress range was intentionally kept low to study the effects of stress range on the fatigue life. Further, such stress ranges more reasonably approximate in-situ stress ranges on highway bridges. Previous tests had focused on larger stress ranges which decreased the total number of cycles until failure. It was thought that the specimen would behave similar to the AASHTO Category D fatigue curve. Therefore, the loading was targeted to result in a stress range near the Category D CAFL ( $7 \mathrm{ksi})$. The specimen was cycled for a total of 20,000,000 cycles at this stress range with no observed cracks in any of the remaining bottom flange components. 


\subsubsection{3 $2^{\text {nd }}$ Fracture Test}

Following the termination of the fatigue portion of the test it was decided to further test this specimen by determining the effect of a second cover plate failure. Several bolts were removed connecting the bottom flange angles with the cover plates, and wedges were inserted to allow access to the cover plates without compromising the flange angles. A portion of the lower cover plate was removed (at the previously failed location). In addition, the upper cover plate was notched to allow the driven wedge method of fracture initiation (see Figure 3-54).

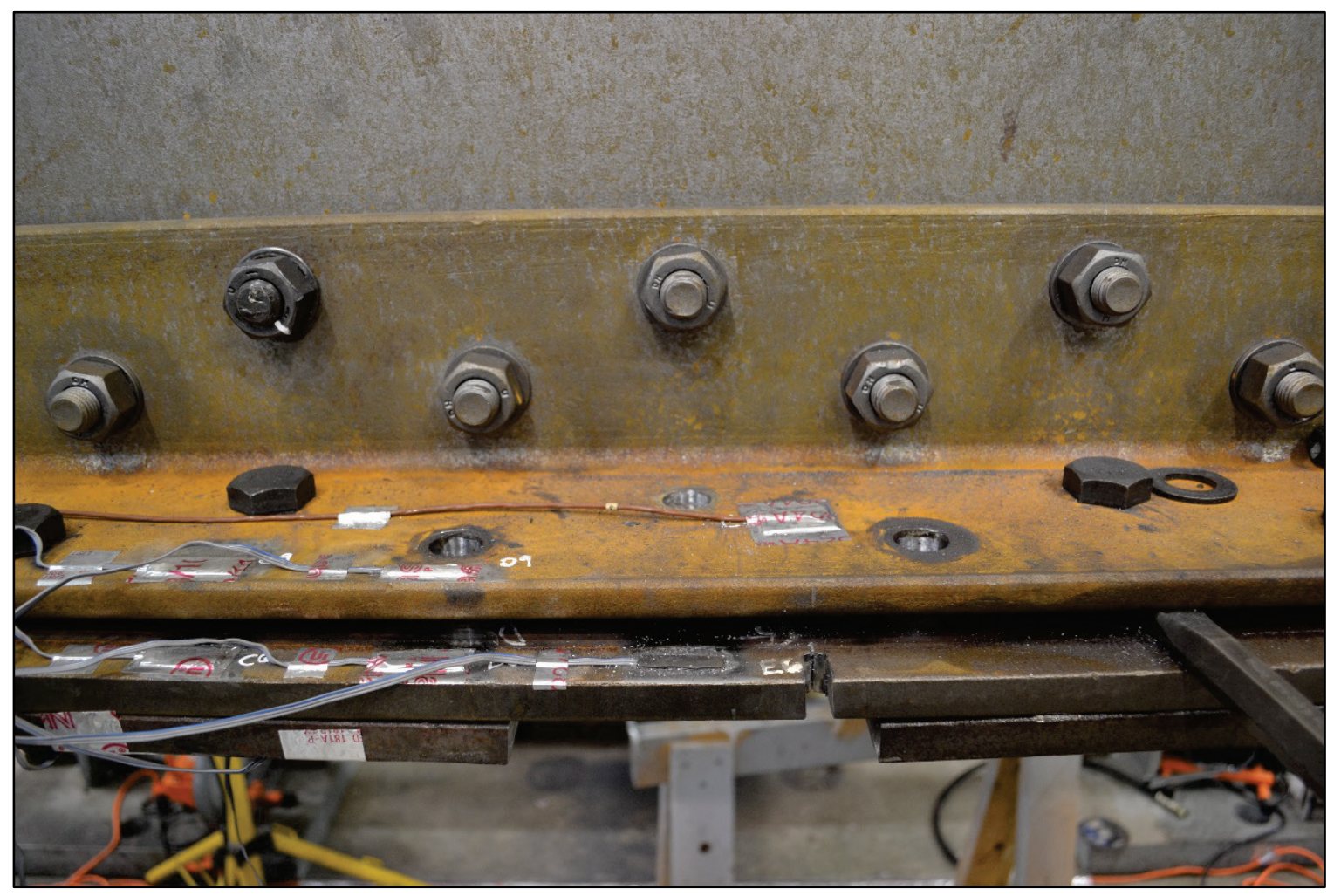

Figure 3-54 Specimen 36-2 notched upper cover plate

The high-strength bolts were reinserted and retightened to connect the holes. The specimen was then prepared for a second fracture test. The specimen was cooled to $-109^{\circ}$ 
F, the actuators were loaded to 180 kips, and the upper cover plate was loaded using the driven wedge (with a load of 40 kips on the wedges). The specimen did not fracture, so it was allowed to warm up to ambient temperature. Due to the localized deformation at the notch edge it was necessary to close the gap before further use of the wedge. Weld material was added to the notches to decrease the gap so that the wedge could be reused on the same notch (see Figure 3-55a). In addition, hardfacing weld material was used at the notch edges to introduce a sharp crack tip (due to the cross-cracking). The specimen was then cyclically loaded from 80 kips to 180 kips (a stress range of $21.8 \mathrm{ksi}$ ). After 71,000 cycles, cracks were detected at each notch tip. The specimen was again cooled to $-110^{\circ} \mathrm{F}$ and a fracture was attempted using the same loads as the previous attempt. The specimen did not fracture. It was decided that the notch geometry was a large factor in the failure of the wedge method. The notch was ground out and completely filled with weld metal, then a new notch was cut into the specimen (see Figure 3-55b).

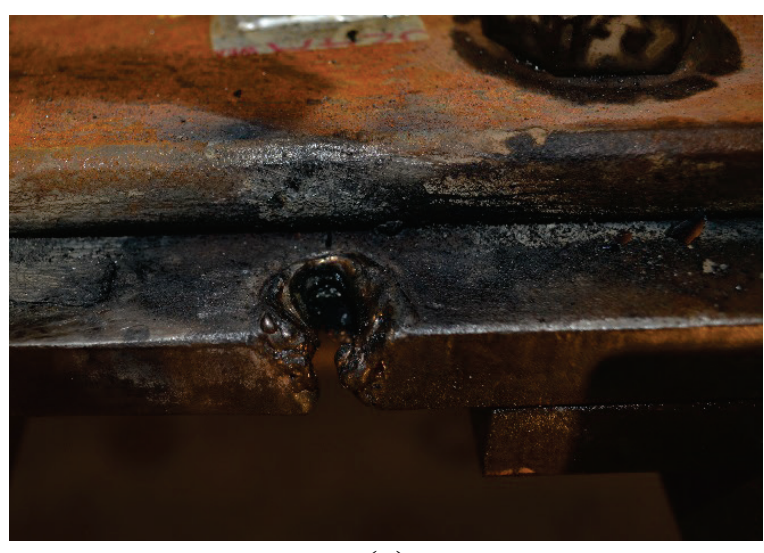

(a)

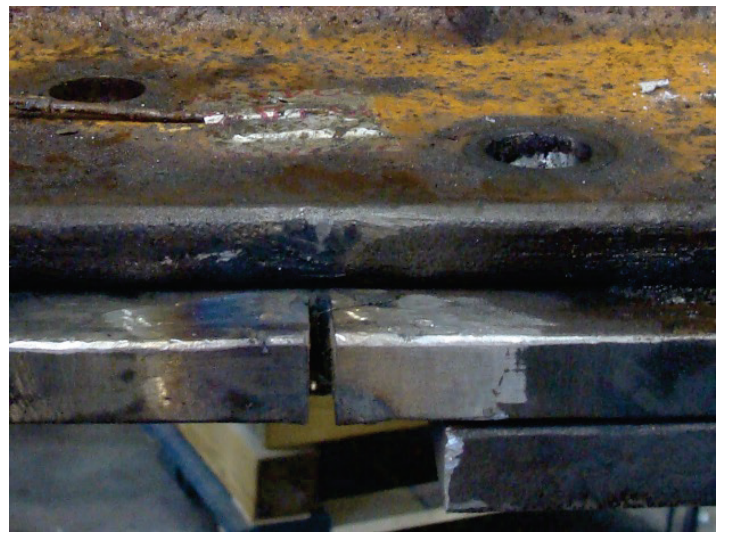

(b)

Figure 3-55 Specimen 36-2 upper cover plate notches (a) $2^{\text {nd }}$ attempt (b) $3^{\text {rd }}$ attempt

The specimen was then cooled to $-65^{\circ} \mathrm{F}$ and loaded to 180 kips with each actuator. This resulted in a calculated net section stress of $39.3 \mathrm{ksi}$. When no fracture 
occurred, the wedges were driven with a force of 40 kips at the notches. This stress concentration increase resulting from the wedges resulted in the fracture of the upper cover plate (see Figure 3-56). No other components (the remaining flange angles and web) were found to have cracks. Additionally, the specimen resisted the total load until it was manually removed and the test terminated.

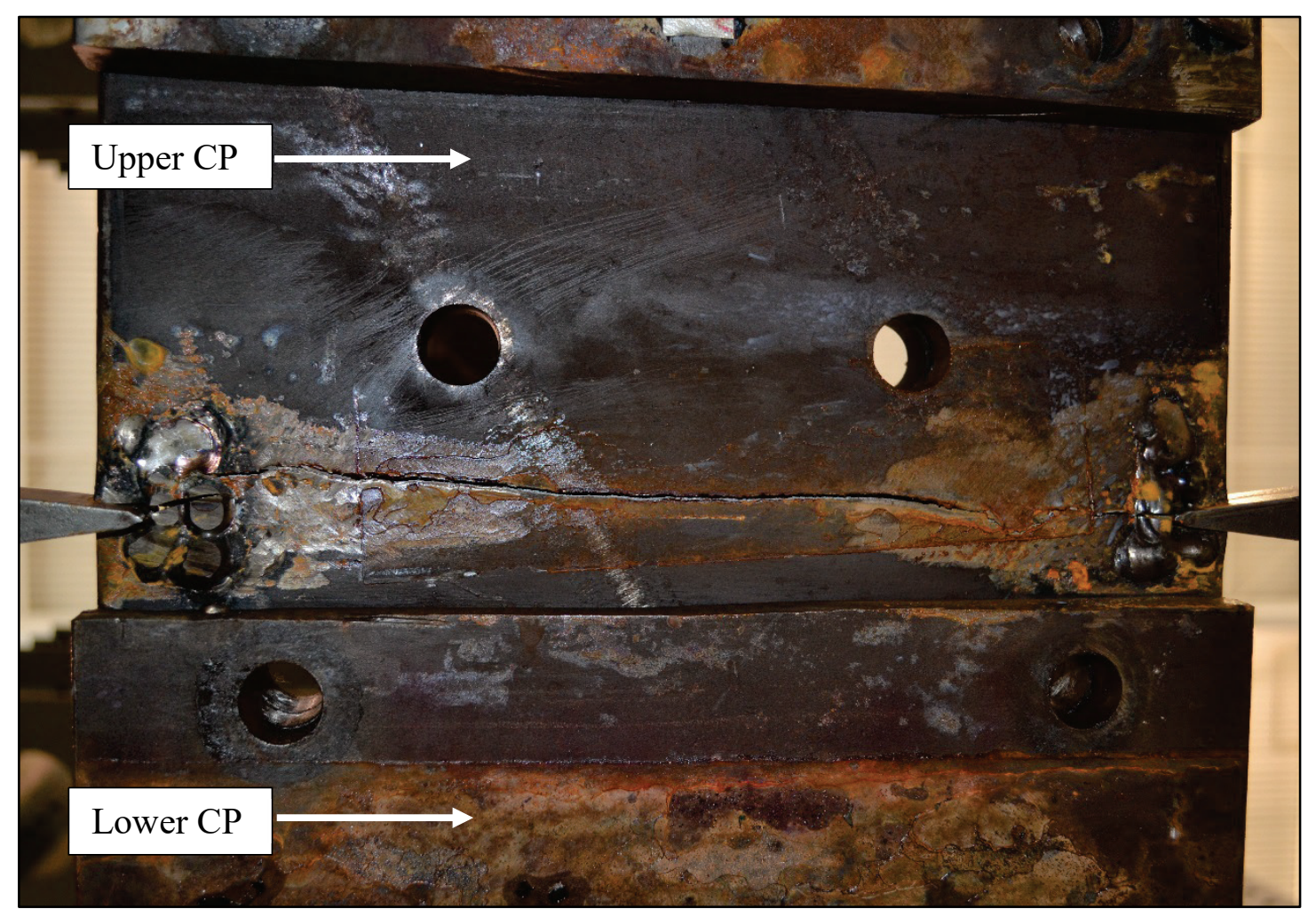

Figure 3-56 Specimen 36-2 failed upper cover plate (from below)

\subsubsection{Specimen 46-4}

Specimen 46-4 was fabricated from the web plate and the top flange originally used in Specimen 46-2. The cover plate and flange angles were obtained from Hirschfeld Industries Bridge and were fabricated identical to the original ones except that all holes were drilled in all components. High-strength A325 bolts were used to connect all 
components and were tightened by the turn-of-nut procedure. Notches were cut into the cover plate $2.5^{\prime \prime}$ from the centerline of the beam (see Figure 3-57). Two layers of hardfacing weld were placed at each notch tip to create a sharp crack tip at the notch tip.

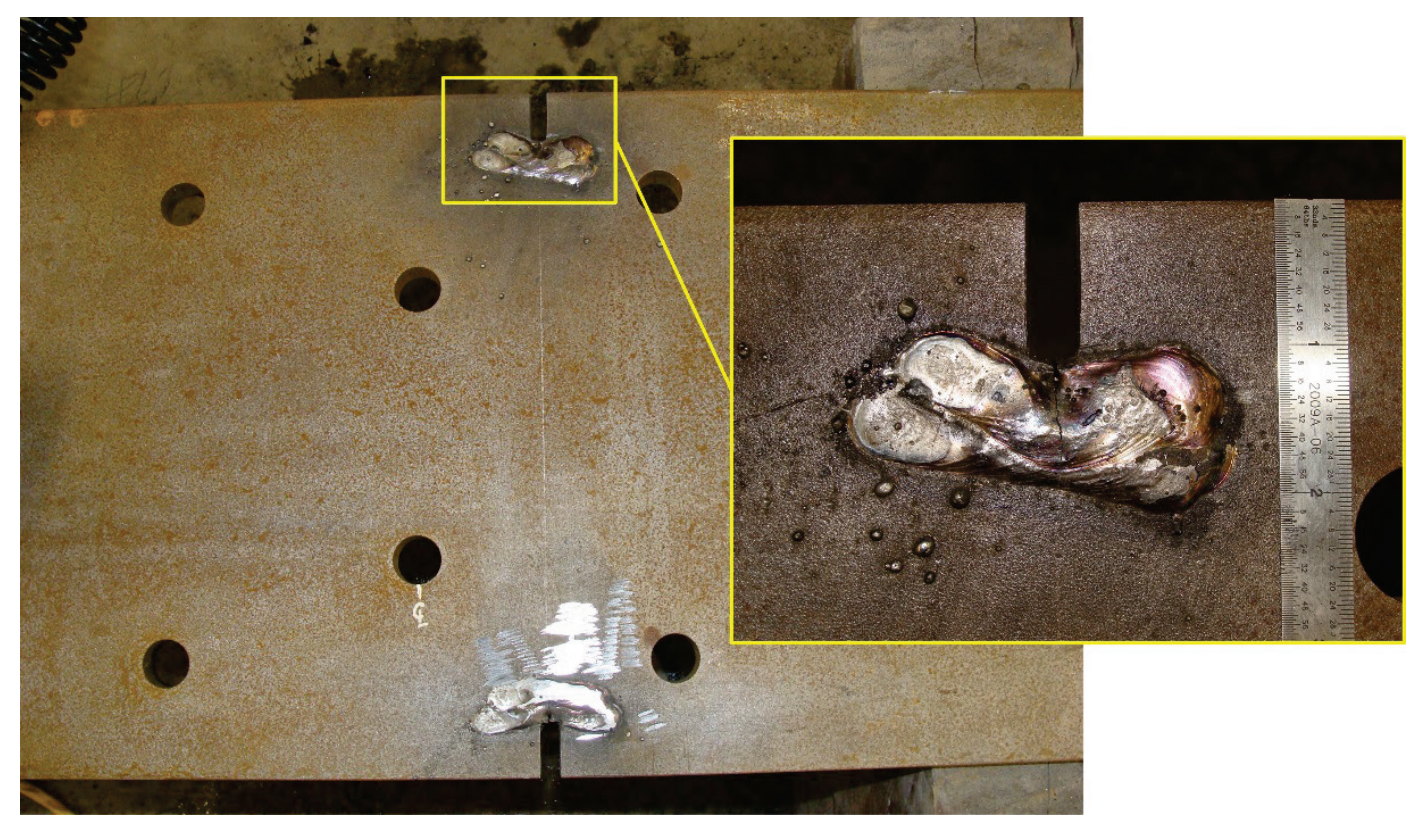

Figure 3-57 Specimen 46-4 edge notches

\subsubsection{Fracture Test}

After an initial static test to determine the original stress distribution, the specimen was cooled to $-117^{\circ} \mathrm{F}$. The actuators were then loaded to 180 kips with no resulting fracture. The wedges were driven into the notches with 40 kips. Three separate attempts were made to fracture the girder in this way. Modifications were made to the driven wedge setup to improve alignment and stability. On the third attempt the cover plate of the specimen fractured (see Figure 3-58). A thorough visual inspection of the specimen indicated that no other components had cracked. 


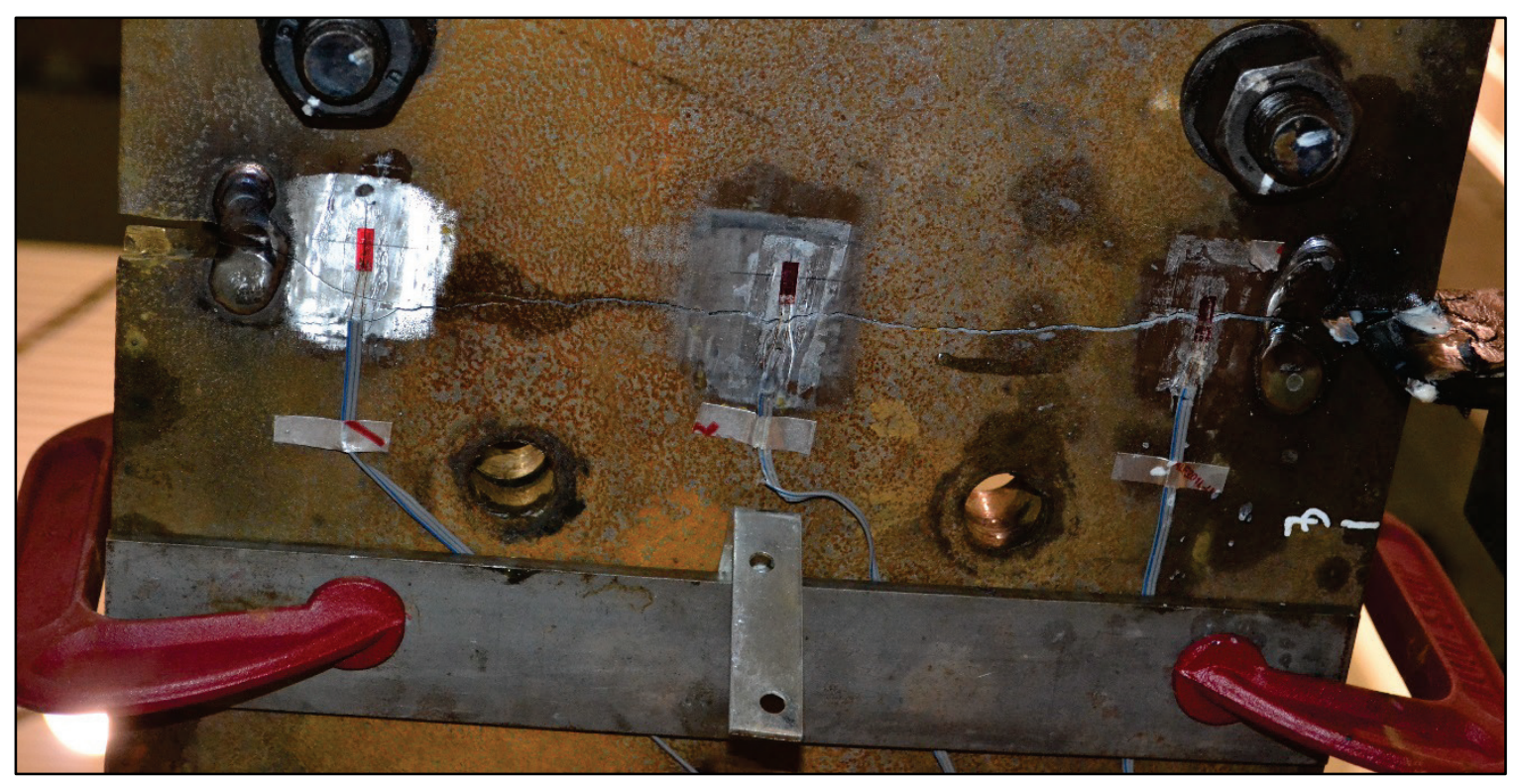

Figure 3-58 Specimen 46-4 fractured cover plate

\subsubsection{Fatigue Test}

Specimen 46-4 was next cyclically loaded to determine the fatigue life of the remaining bottom flange components. The specimen was loaded from 80 kips to 110 kips which resulted in a calculated net section stress range of $7.3 \mathrm{ksi}$. The specimen was cycled for 20,200,000 cycles with no evidence of other cracks. The specimen was inspected twice daily for the duration of the test (54 days). Due to the extensive number of cycles without any apparent cracking, the test was stopped. The fatigue data can be seen plotted with the results from other specimens in Section 3.5.2.

\subsubsection{Specimen 36-3}

Specimen 36-3 was fabricated from the web plate and top flange used in Specimen 36-2. The flange angles were obtained from Hirschfeld Industries Bridge and 
were drilled. The cover plates were purchased as flat plate and then were drilled by staff at the laboratory. Hot driven rivets were used to connect the bottom flange components in the constant moment region (see Figure 3-59). Outside the constant moment region A325 snug tightened bolts were used to simulate the pretension of rivets. Edge notches were cut into the lower cover plate and then two layers of hardfacing weld were applied at the notch tips.

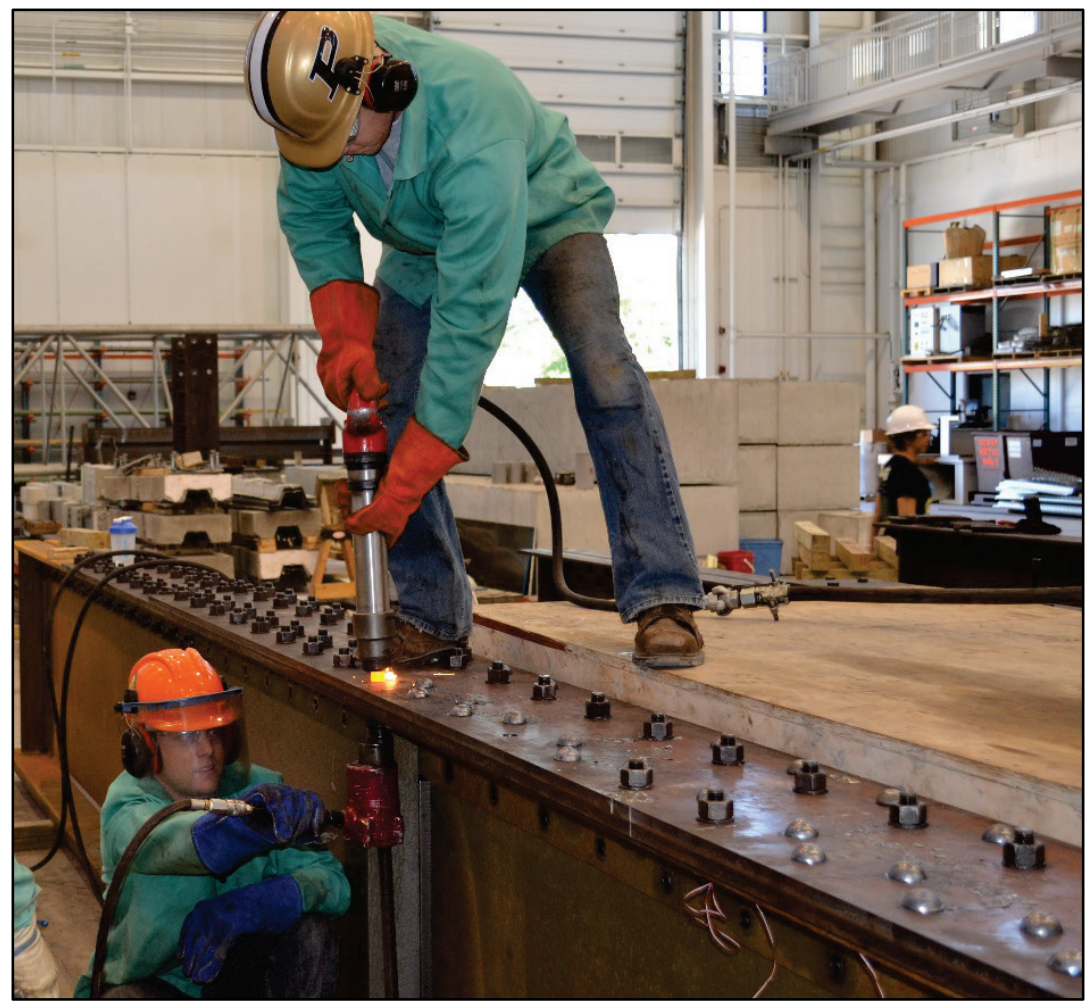

Figure 3-59 Specimen 36-3 fabrication: riveting cover plates

\subsubsection{Fracture Test}

The specimen was initially loaded from 80 kips to 180 kips for 200 cycles to allow any shifting and settling of the fastened components prior to the fracture test. Based on previous tests it was hypothesized that fasteners adjacent to the fracture were 
constraining the crack and preventing any crack from propagating through the notched component. As described in Section 3.3.3, a small parametric study verified this hypothesis. To minimize the possibility of this occurring on this specimen eight rivets were left out (two rows of two on either side of the notch location). The specimen was cooled to $-81^{\circ} \mathrm{F}$. The actuators were loaded to 200 kips which resulted in a stress of 33.5 ksi. Because no fracture occurred with the actuator loads, the wedges were then driven with 40 kips into the notches which resulted in the fracture of the lower cover plate (see Figure 3-60). A visual inspection did not find any cracks in any of the remaining components.

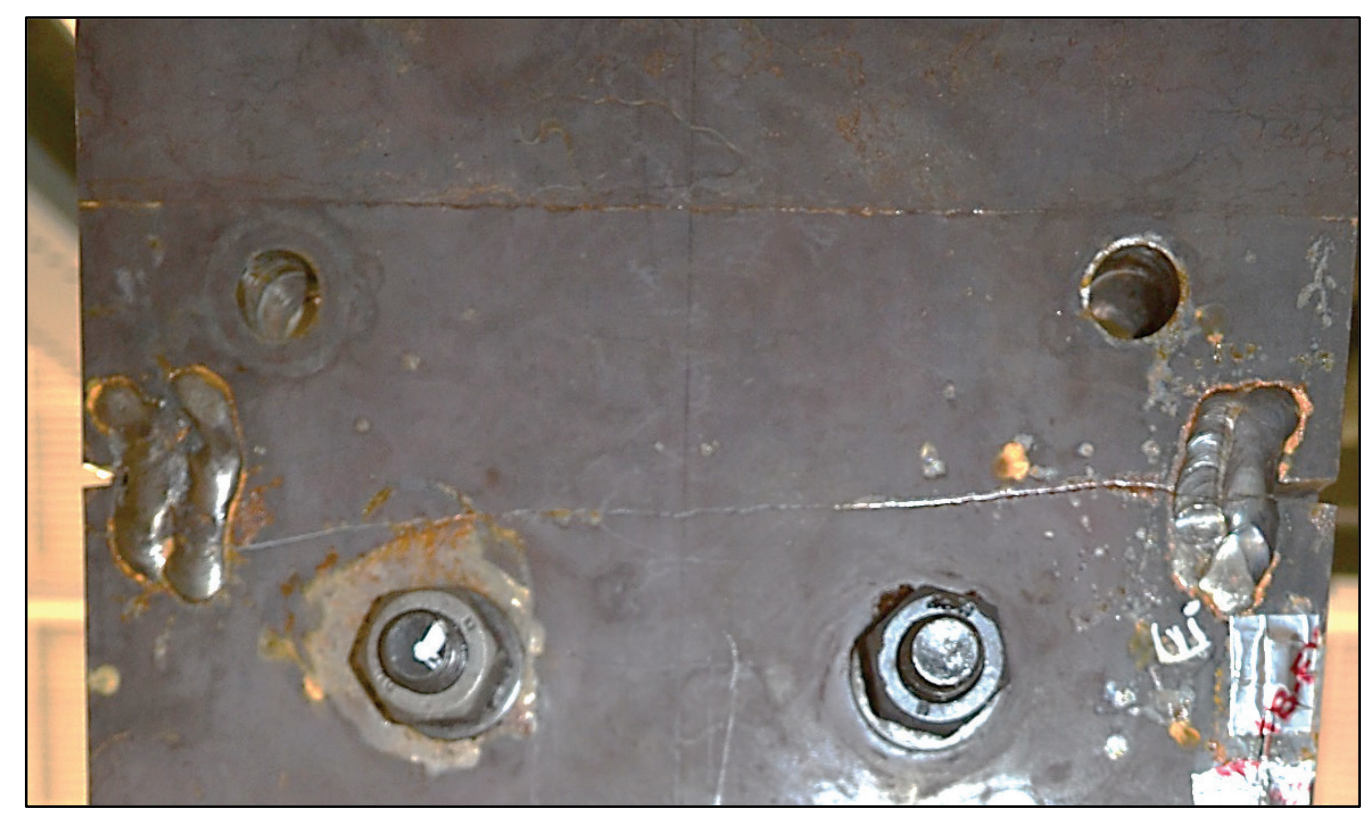

Figure 3-60 Specimen 36-3 fractured lower cover plate

\subsubsection{Fatigue Test}

After the fracture test six bolts were installed on the specimen adjacent to the fracture. The A325 bolts were snug tightened to simulate the pretension from a rivet. 
Two holes were left open to match the other specimens in which no stress transfer occurred at the fasteners located at the fracture line due to the crack opening. Specimen 36-3 was cyclically loaded from 80 kips to 124 kips which resulted in a calculated net section fatigue stress range of $9.6 \mathrm{ksi}$. This stress range was slightly higher than the Category D CAFL ( $7 \mathrm{ksi}$ ) and was targeted because the original net section stress (of the unfailed cross section) was $7 \mathrm{ksi}$. The specimen was cyclically loaded for 10 million cycles with no further cracks developing. At this point the test was stopped because the data plotted on the AASHTO fatigue curve was well beyond the Category D curve.

\subsubsection{Specimen 36-4}

The web plate and top flange that had been used for Specimen 46-1 and Specimen 46-3 was cut down to $36^{\prime \prime}$ with a track torch in order to fabricate Specimen 36-4. All holes in all components were drilled. The bottom flange components were hot riveted together in the constant moment region. Eight rivets (two rows of two on each side of the notch) were not installed so that the constraint of the fasteners would not prevent a fracture from propagating. Snug tightened A325 bolts were used outside the constant moment region. Prior to the fracture test a static test was performed to record the initial stress distribution in the bottom flange components. During this static test, at the peak load of $200 \mathrm{kips}$, the lateral torsional buckling bracing at the actuator loading points failed and the specimen buckled laterally before the hydraulic interlocks were triggered.

Due to the lateral buckling force the top flange of the specimen had a residual outof-plane sweep of $1-5 / 8^{\prime \prime}$. In order to remove the sweep so that the specimen could be tested, the specimen was removed from the test setup to be straightened. The specimen 
was laid with the weak axis parallel to the ground and blocked up approximately 12 ". A beam was then set up to span across the specimen which reacted to dwydag bars running through the strong floor. A hydraulic jack was used to cold work the top flange back to its original position. Figure 3-61 shows the jack at its peak displacement during the cold working of the specimen. The specimen was then reinstalled into the test setup and prepared for the fracture test.

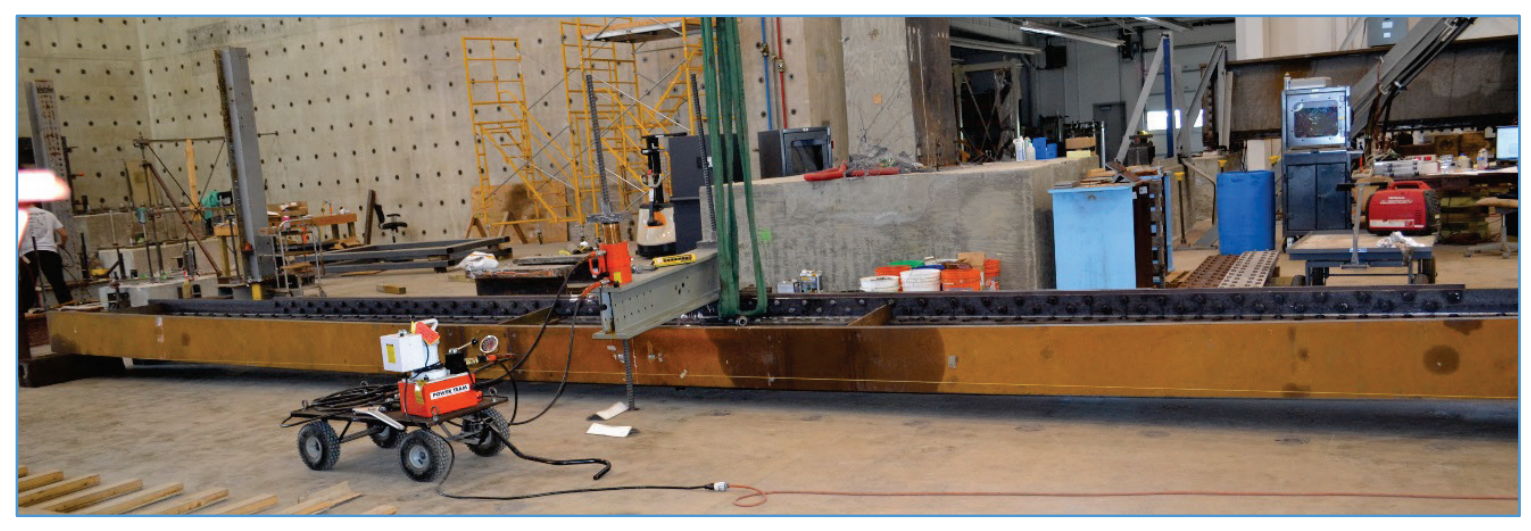

Figure 3-61 Specimen 36-4 cold worked top flange

\subsubsection{Fracture Test}

Specimen 36-4 was prepared with edge notches and two layers of hardfacing weld material at the tip of each notch. The specimen was cyclically loaded from 80 to 180 kips for 200 cycles to settle the components. The specimen was then cooled to $-103^{\circ} \mathrm{F}$ in the temperature chamber in preparation for the fracture test. A load of 200 kips was applied to each actuator. Wedges were driven into each notch with a force of $40 \mathrm{kips}$. This resulted in a fracture of the lower cover plate (see Figure 3-63). No cracks were found in any other components. 


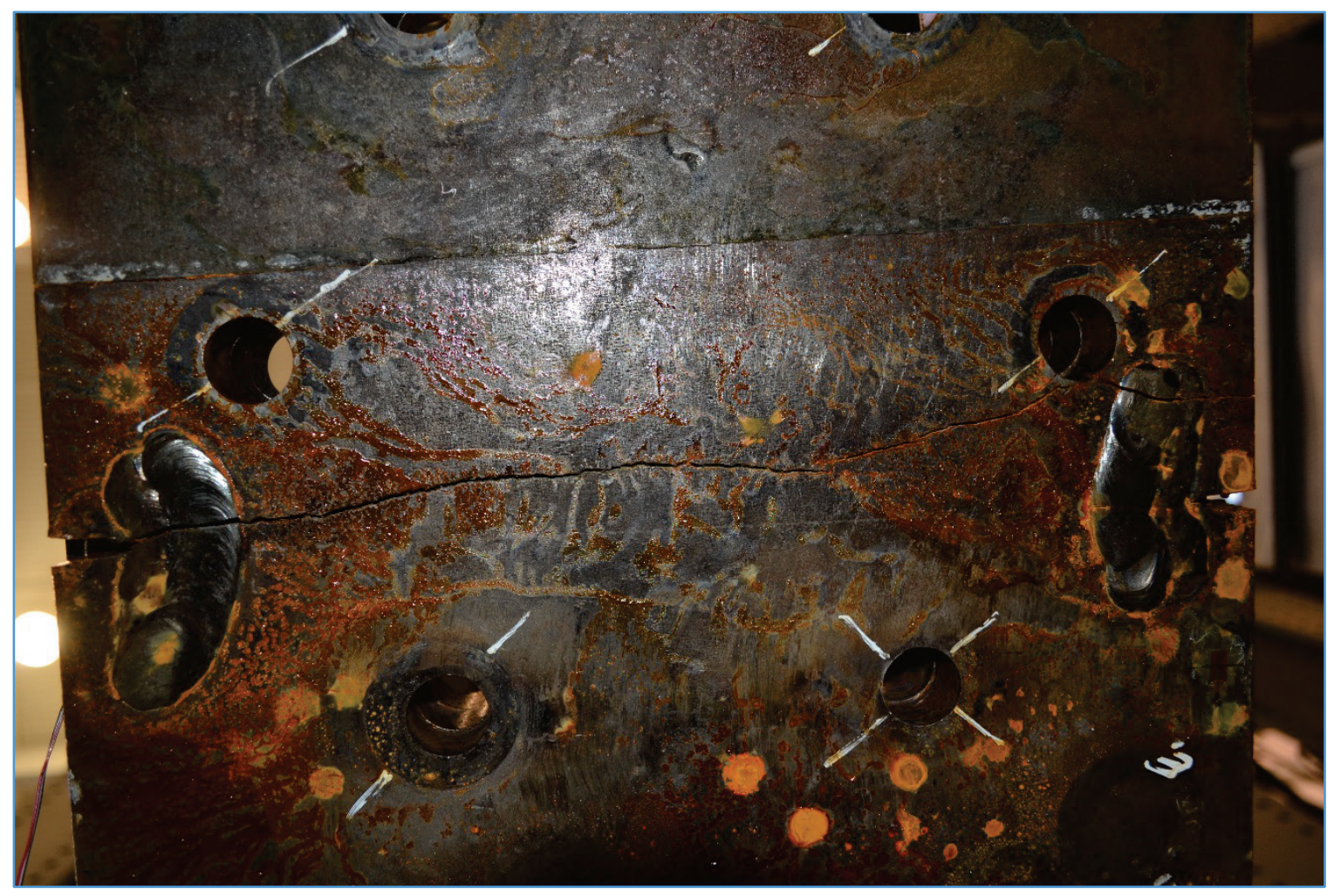

Figure 3-62 Specimen 36-4 fractured cover plate

\subsubsection{Fatigue Test}

Following the fracture test, 6 bolts ( 3 rows of 2 ) were replaced in the holes adjacent to the fracture and snug tightened. Two bolts on the north side of the crack were left out to be consistent with previous tests. The specimen was loaded from 80 kips to 124 kips which correlated with a stress range of $7 \mathrm{ksi}$ of the original net section and a stress range of $9.6 \mathrm{ksi}$ of the partially failed net section. The specimen was loaded for $12,000,000$ cycles with no evidence of crack initiation in other components. The test was stopped because the specimen had surpassed the AASHTO Category D fatigue curve. 


\subsubsection{Specimen 46-5}

Specimen 46-5 was fabricated from the same web plate and top flange as Specimen 46-2 and Specimen 46-4. The bottom flange angles and cover plate were obtained from Hirschfeld Industries Bridge and were all drilled. Fully pretensioned A325 bolts were used to fasten the bottom flange components. The east flange angle was entirely cut (see Figure 3-63) prior to the test to measure out-of-plane effects of nonsymmetrical failure in a cross section. A string potentiometer was installed at the top flange and another at the bottom flange at the centerline of the specimen to measure any out-of-plane horizontal deflection (see Figure 3-64).

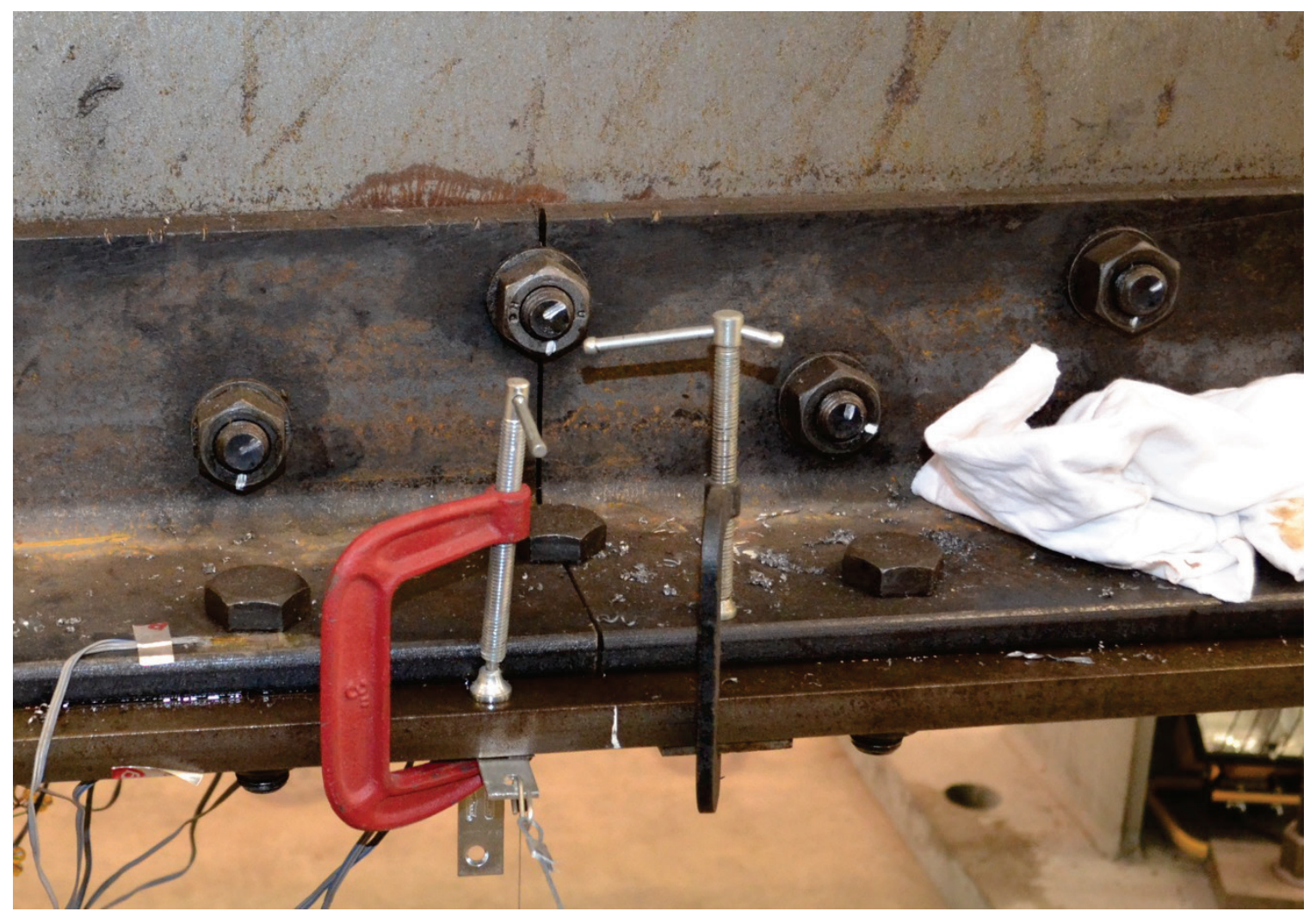

Figure 3-63 Specimen 46-5 severed flange angle 


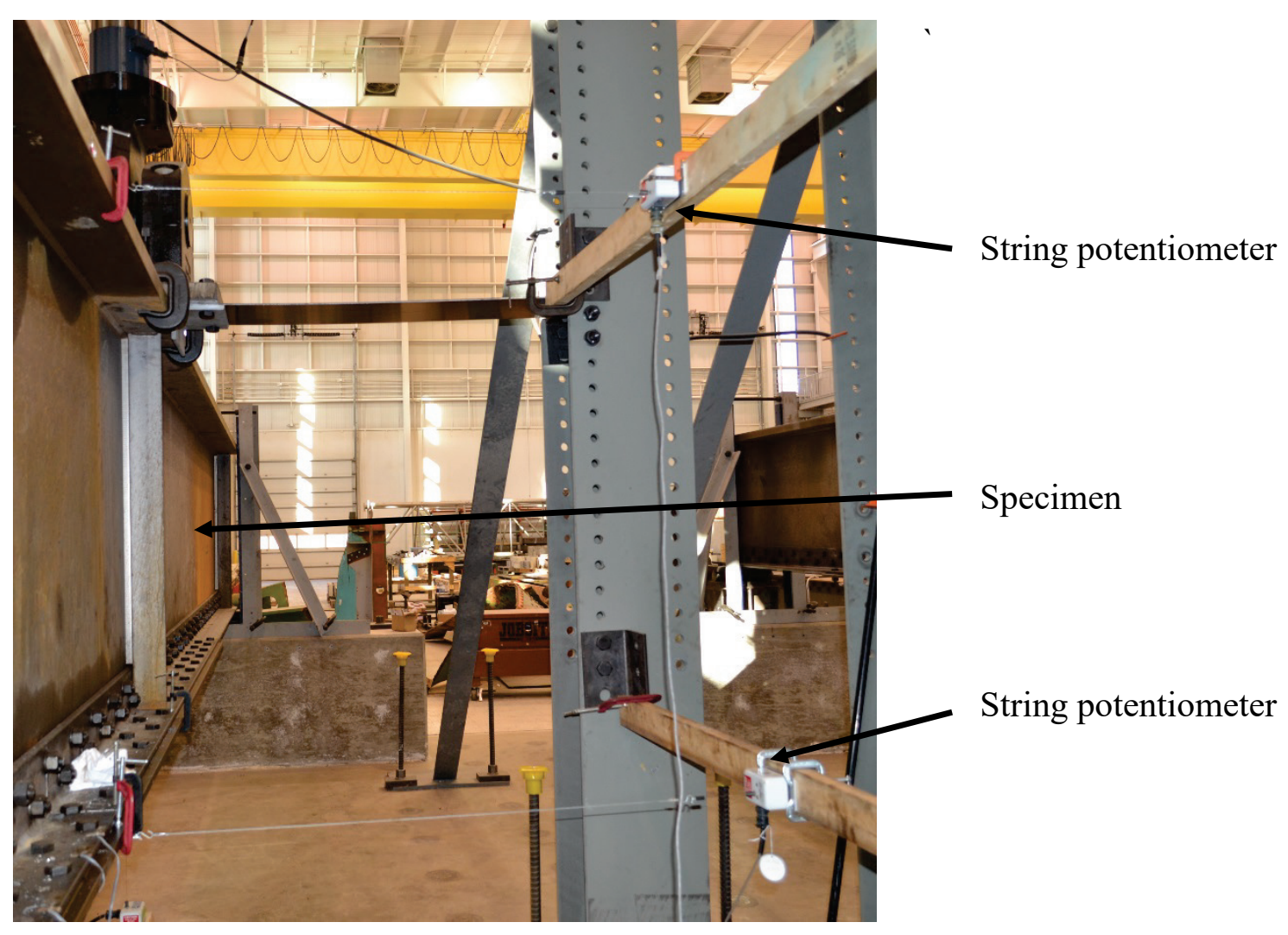

Figure 3-64 Specimen 46-5 string potentiometers

\subsubsection{Static Test}

Prior to the static test the specimen was cycled from 80 kips to 180 kips (which resulted in a calculated net section stress range of $19.9 \mathrm{ksi}$ ) for 1,100 cycles to settle the components of the bottom flange. The specimen was then statically loaded from 0 kips to 180 kips in increments of 20 kips. The out-of-plane deflection of the top and the bottom flange were both $0.035^{\prime \prime}$ at the peak load. A stress gradient of $15 \mathrm{ksi}$ was measured across the cover plate at the centerline location of the severed flange angle (see Figure 3-65). 


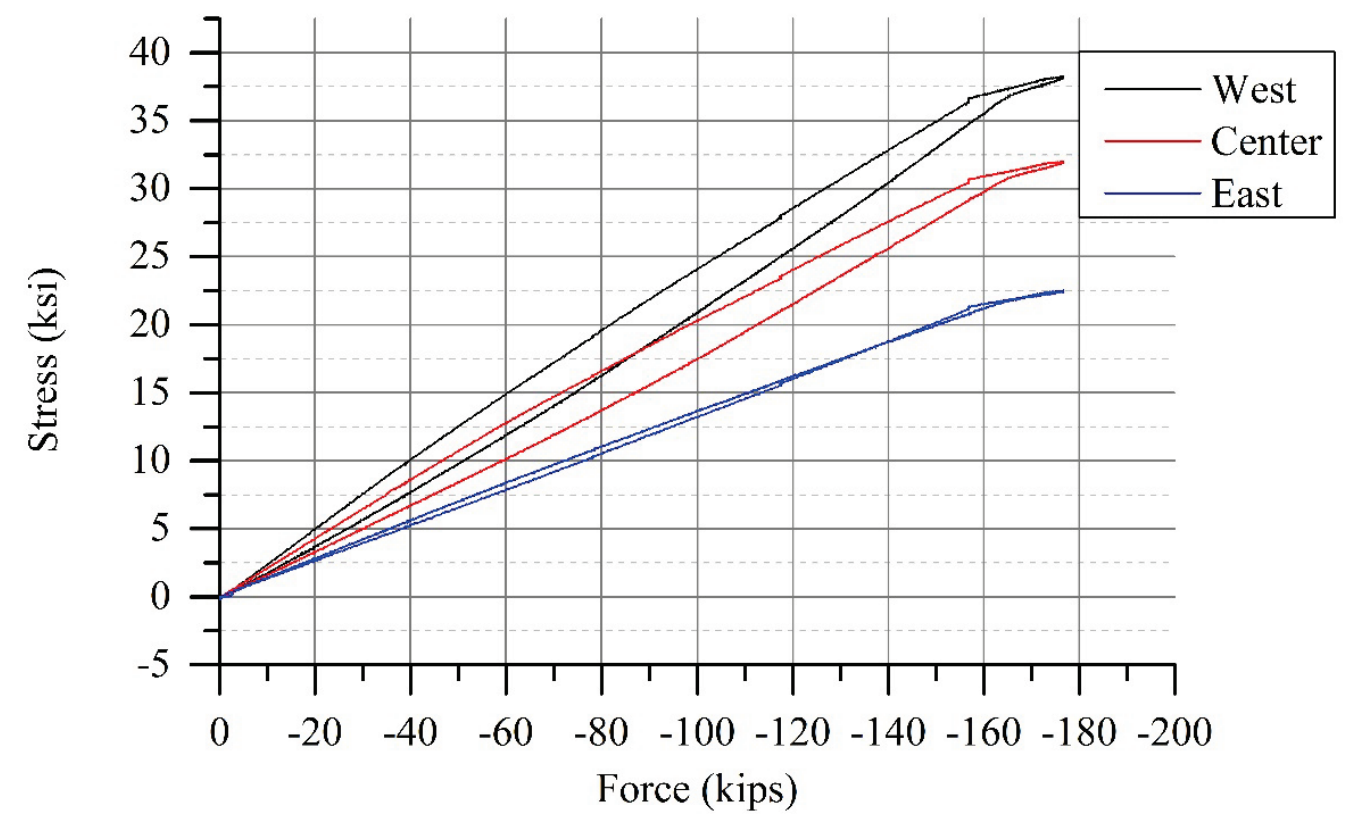

Figure 3-65 Specimen 46-5 out-of-plane stress gradient

\subsubsection{Specimen 30-1}

Specimen 30-1 was fabricated from the web plate and top flange that was originally used for Specimen 36-1. Due to the yielding of the web plate during the fracture test of Specimen 36-1, the specimen was left with a deflected shape of approximately $13 / 4 "$ at the beam mid-span. The web plate was cut with a track torch (as shown in Figure 3-66) to have a straight profile and new holes were drilled to meet the spacing requirements of the flange angles. The flange angles and cover plate were drilled by staff at the laboratory. A $14^{\prime \prime} \times 1 "$ cover plate was used to determine whether the fracture of a component with a larger area could potentially have enough energy to initiate and propagate a fracture in adjacent components. The components within the constant moment region were hot riveted together. All components were fastened with 
snug tightened A325 bolts outside the constant moment region to simulate the pretension of rivets.

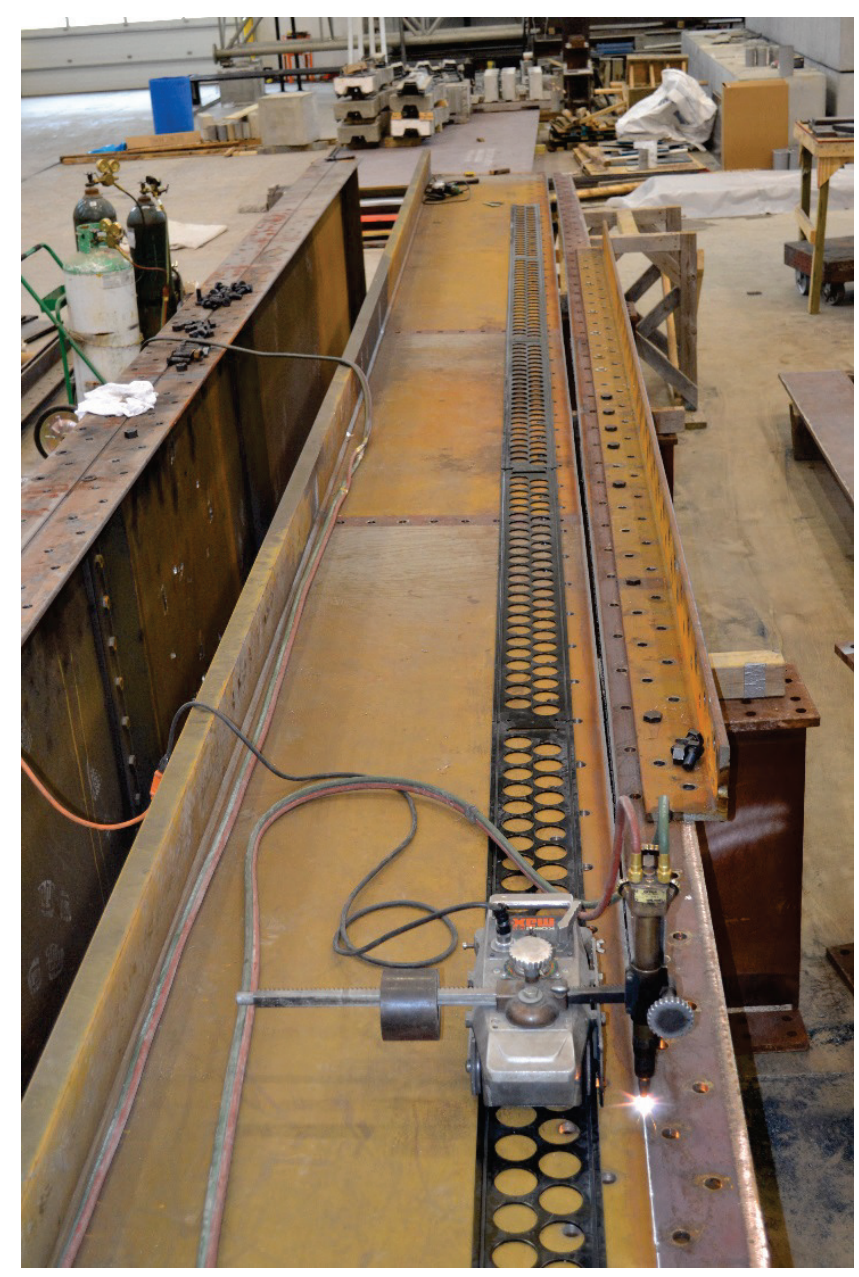

Figure 3-66 Specimen 30-1 web plate fabrication

The 1" cover plate obtained had a much higher toughness than previous components which caused concern whether the test parameters could cause a fracture with the desired loads. Therefore, a fuse element with very low fracture toughness was devised to be used at the mid-span. A $1^{\prime \prime}$ thick eyebar was obtained from a railroad bridge built in the 1890 's. A 4 " $\times 14^{\prime \prime}$ piece of the 1 " thick eyebar was welded into the center of the cover plate to be used as the fuse element. Edge notches were cut into the 
fuse element. Based on the low fracture toughness, it was thought that a fracture would occur without the need for hardfacing welds at the notch tips, and so these were omitted. The material properties of the eyebar can be found in APPENDIX D.

\subsubsection{Fracture Test}

The specimen was cooled to $-53^{\circ} \mathrm{F}$. This temperature corresponded to a lower shelf behavior of both the flange angles and the cover plate fuse element. The actuators were loaded to $130 \mathrm{kips}$. This equated to a stress of $36.7 \mathrm{ksi}$ in the cover plate. Wedges were then driven into the prepared notches with a force of 40 kips. No fracture occurred. The specimen was then allowed to warm up to ambient temperature prior to any modifications.

Eight rivets were removed from the cover plate-to-flange angle connection directly adjacent to the notches so that constraint would not prevent the fracture from occurring. Due to the plastic deformation at the notch edges (which resulted from the driven wedges during the first failed fracture attempt), welds were used to fill the notch prior to the notch being ground back out to create a new seat for the wedges. The specimen was then placed back in the temperature chamber and cooled to $-44^{\circ} \mathrm{F}$. The actuators were loaded to 130 kips and the wedges loaded to 40 kips. The cover plate of the specimen then fractured (see Figure 3-67). No other components were found to have cracks. 


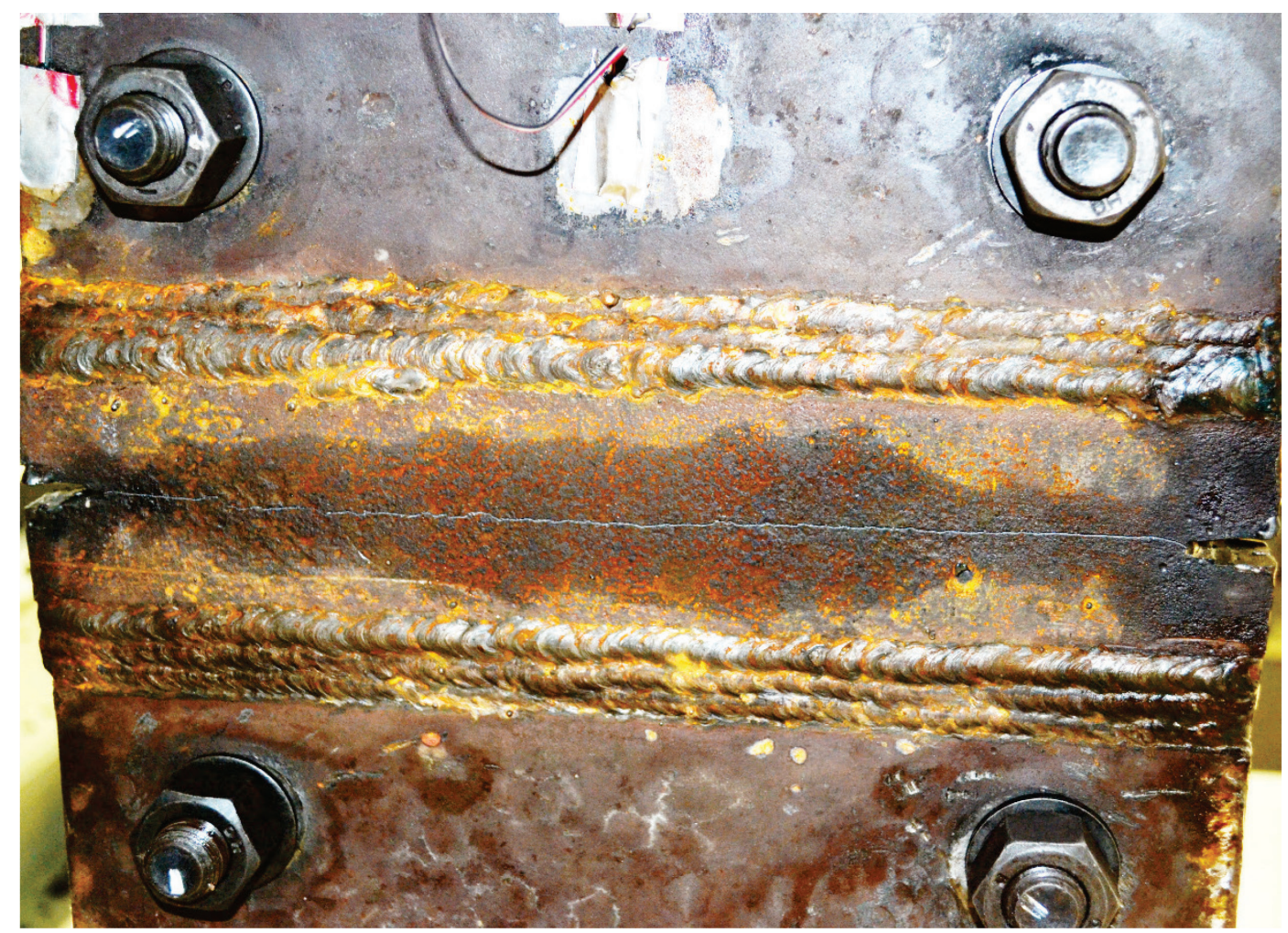

Figure 3-67 Specimen 30-1 fractured cover plate

\subsubsection{Fatigue Test}

The specimen was cyclically loaded from 80 kips to 110 kips. This was equal to a calculated net section stress range of $8.3 \mathrm{ksi}$ of the original section and $12.6 \mathrm{ksi}$ of the partially failed section. After 820,000 cycles, a crack (with length of $0.125^{\prime \prime}$ ) was detected at the bottom of the hole of the horizontal flange of the west flange angle directly above the fractured cover plate. Figure 3-68 shows the crack after some small growth while still inside the hole. After another 430,000 cycles the crack had grown across the interior region of the flange angle and had started up the vertical leg. At a total of 1.3 million cycles a crack was detected in the opposite side of the same hole of the horizontal flange of the west flange angle. When the specimen had reached 1.4 million 
cycles the remaining portion of the west flange angle fractured. At this point, the crack on the east side of the hole had grown through the entire horizontal portion and an additional 1.0" into the vertical leg of the flange angle (measured from the top face of the horizontal leg), and the crack on the west side of the hole had grown 0.875". Figure 3-69 shows the west flange angle after the fracture had occurred.

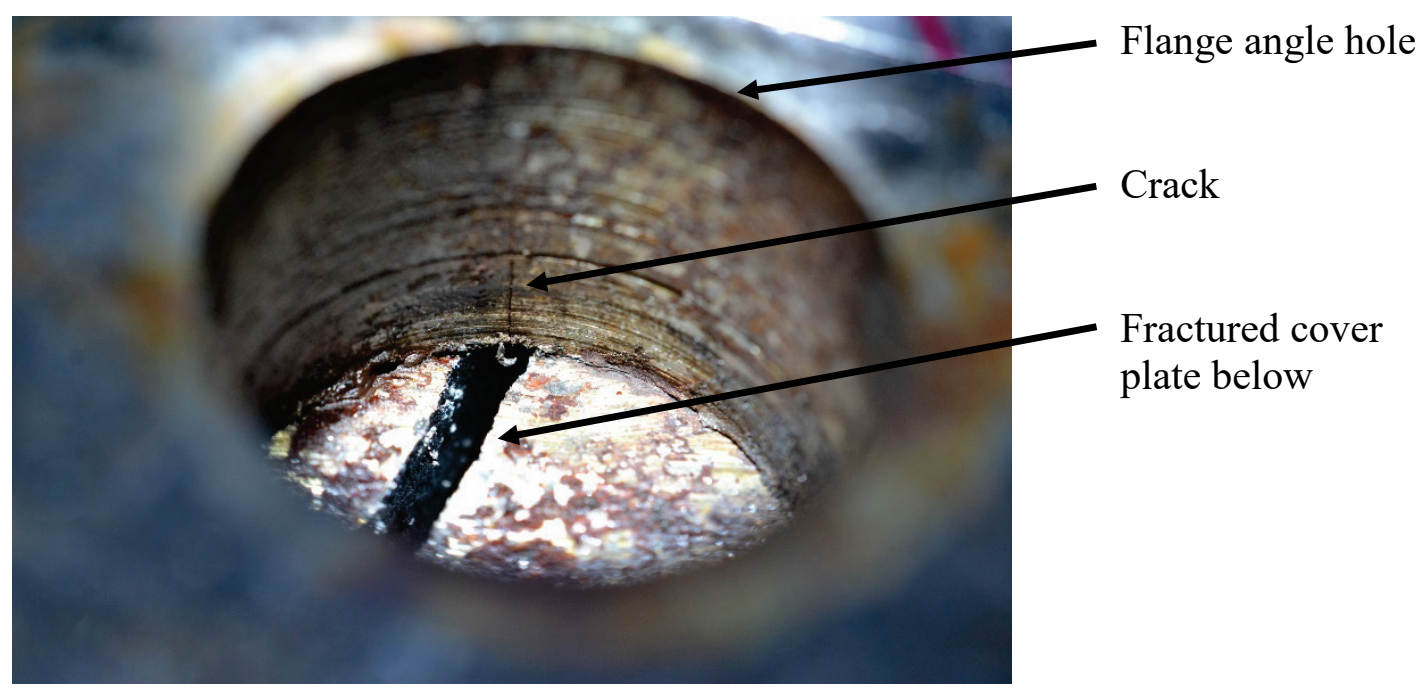

Figure 3-68 Specimen 30-1 flange angle crack in hole 


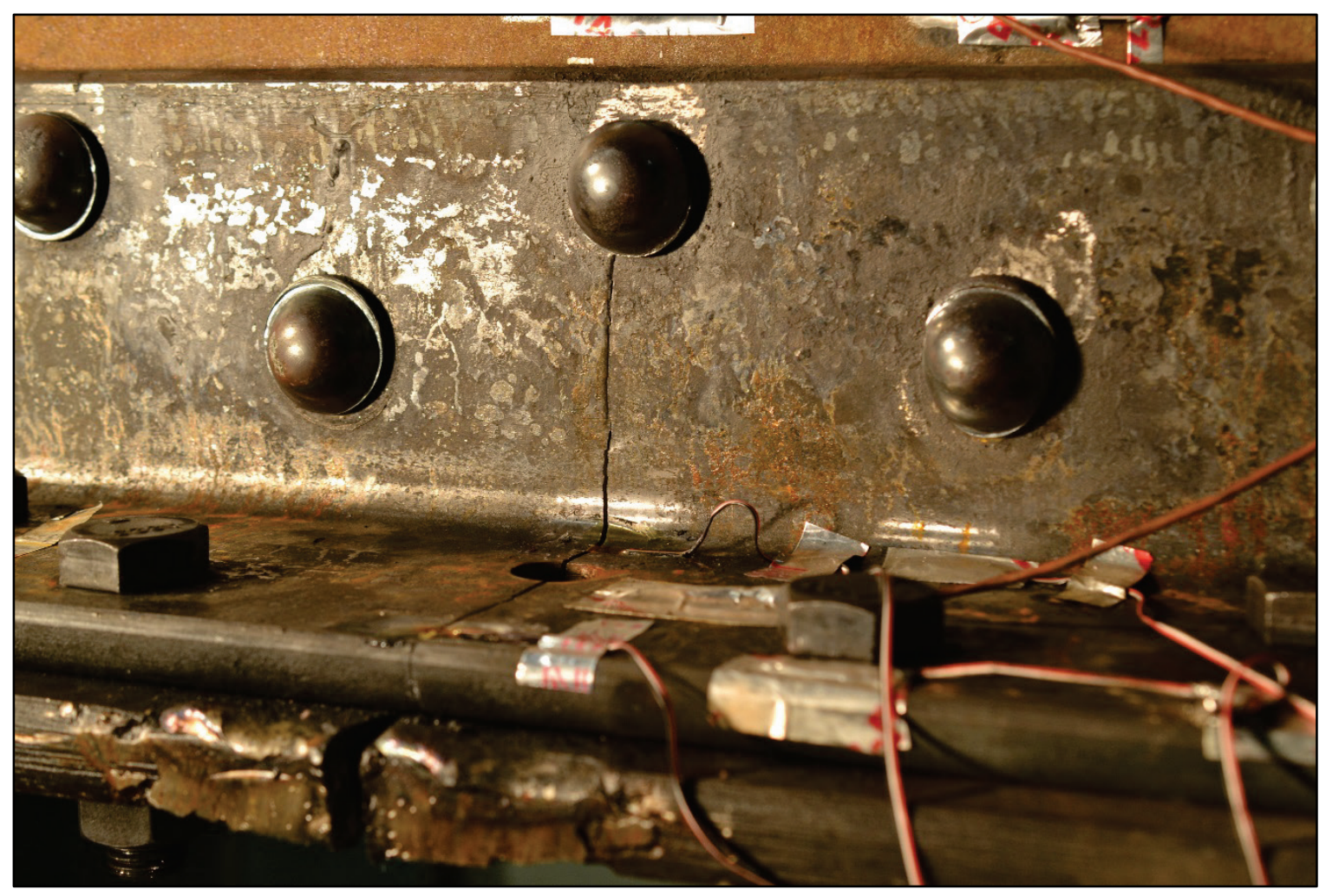

Figure 3-69 Specimen 30-1 fractured west flange angle

\subsubsection{Specimen 36-5}

Specimen 36-5 was fabricated using the top flange, web plate, and flange angles that had previously been used during the fracture testing and subsequent cyclic fatigue testing of Specimens $36-2$, and $36-3$. A new $14^{\prime \prime} \times 1 \frac{1}{2}{ }^{\prime \prime}$ cover plate was cut to size and drilled by the laboratory staff to match the hole configuration of the flange angles. The purpose of the thicker cover plate was to observe the ability of the remaining components to redistribute the load when a large component (representing a major portion of the force carried by the bottom flange) was subjected to a fracture. Fully pretensioned A325 bolts were used to connect each of the different components. A notch was cut into either side 
of the cover plate near the mid-span (see Figure 3-70). No hardfacing welds were placed at the notch tip.

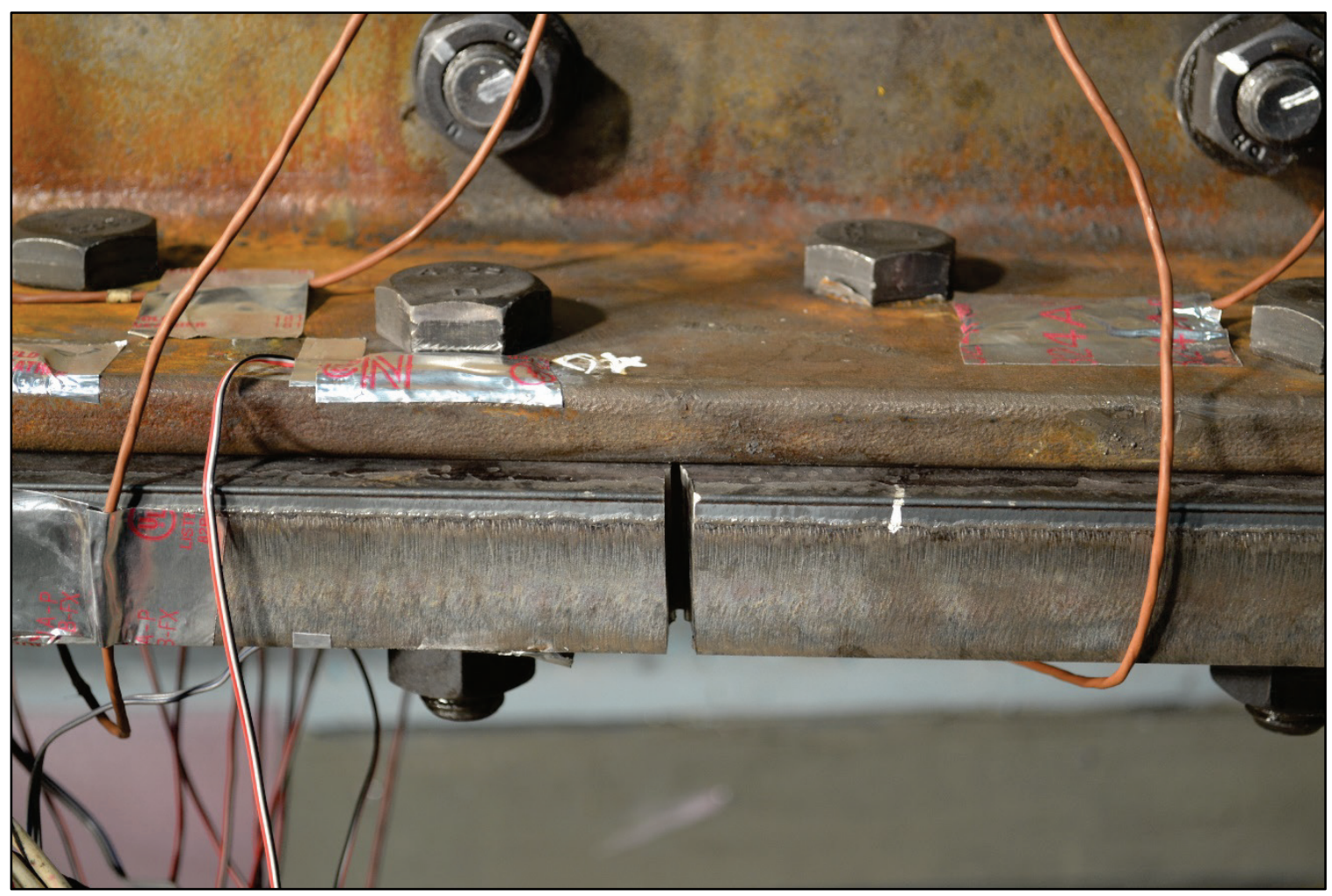

Figure 3-70 Specimen 36-5 notched cover plate

\subsubsection{Fracture Test}

Prior to the fracture test the top flange, web, and bottom flange angles of Specimen 36-5 were subjected to many fatigue cycles during the testing of Specimen 362 and 36-3. During the fatigue testing of Specimen 36-2, 23.5 million cycles were applied with stress ranges between 6.3 and $20.9 \mathrm{ksi}$ (see Section 3.4.8.2). Additionally, as these components were tested with Specimen 36-3, 10 million cycles were applied at a stress range of $9.2 \mathrm{ksi}$ (see Section 3.4.10.2). After Specimen 36-5 had been fabricated, it was cyclically loaded from 10 kips to 80 kips resulting in net-section stresses of $1.7 \mathrm{ksi}$ to 
$13.4 \mathrm{ksi}$ and a net-section stress range of $11.7 \mathrm{ksi}$ for 156,000 cycles. A summary of the cumulative fatigue history that the angles had already been subjected to can be seen in Table 3-1. Based on the Manual for Bridge Evaluation (2011) an equivalent stress range of $7.6 \mathrm{ksi}$ was calculated resulting in a Category D mean life of 10.2 million cycles. The total number of cycles at the equivalent stress range was 3.3 times ( 23.45 million cycles) greater than the calculated mean life at the time that the fracture test was performed. Thus, cracks were likely emanating from the fastener holes, though none were visible using basic visible inspection when this specimen was fabricted.

Table 3-1 Specimen 36-5 flange angles accumulated fatigue cycles

\begin{tabular}{|c|c|c|c|c|c|c|c|c|}
\hline \multirow{2}{*}{ Specimen } & \multirow{2}{*}{ Test Phase } & \multirow{2}{*}{ \# of Cycles } & \multirow{2}{*}{ Failed Components } & \multicolumn{2}{|c|}{ Load (kips) } & \multicolumn{3}{|c|}{ FE Net-section Stress (ksi) } \\
\hline & & & & Low & $\mathbf{H i}$ & Low & Hi & $\mathbf{S}_{\mathbf{r}}$ \\
\hline \multirow{3}{*}{$36-2$} & Initial Fatigue & 9,495 & None & 80 & 180 & 13.39 & 30.14 & 16.8 \\
\hline & After Lower CP failure & $23,388,151$ & Lower CP & 80 & 110 & 16.75 & 23.02 & 6.3 \\
\hline & Prior to fracture of upper $\mathrm{CP}$ & 71,401 & Lower CP & 80 & 180 & 16.75 & 37.65 & 20.9 \\
\hline $36-3$ & After Lower CP failure & $10,022,808$ & Lower CP & 80 & 124 & 16.75 & 25.95 & 9.2 \\
\hline \multirow[t]{2}{*}{$36-5$} & Prior to fracture of $\mathrm{CP}$ & 156,000 & None & 10 & 80 & 1.67 & 13.39 & 11.7 \\
\hline & Total & $33,647,855$ & & & & & & \\
\hline
\end{tabular}

In addition, the flange angles and web of Specimen 36-5 had been subjected to six different fracture attempts. Two fracture attempts were made on the lower cover plate of Specimen 36-2 with the cooling and loading protocol described in Section 3.3.3. In each of these attempts no fracture occurred (see Section 3.4.8.1). Subsequently three more attempts were made to fracture the upper cover plate, with the final attempt resulting in fracture (see Section 3.4.8.3). However no failure occurred in the bottom flange angles or web plate. These same components were then used for Specimen 36-3. A fracture of the lower cover plate occurred with no further failure in remaining components (see 
Section 3.4.10.1). Inspections of the bottom flange components were performed during each specimen fabrication as well as at regular intervals during the fatigue testing phase of each test. No fatigue cracks were found during these inspections.

With the fatigue cycle accumulation and the number of fracture attempts that the flange angles and web had experienced, it was felt this was certainly representative of a girder at a more vulnerable state and hence, was at a much higher risk for a fracture to occur in adjacent components after the fracture of a cover plate. This was compounded due to the thickness of the cover plate $\left(1^{1 / 2} 2^{\prime \prime}\right)$ in relation to the adjacent flange angles $\left(3 / 4^{\prime \prime}\right)$. The purpose in testing this specimen having components with advanced fatigue life and multiple fracture attempts was to evaluate a member which had been subjected to a long history of loading which would be expected to have resulted in fatigue cracks. Thus, it was likely that fracture of the remaining components would occur when the large 1.5 inch thick cover plate fracture.

Based on previous fractures of other specimens, two bolts on either side of the notch were removed to minimize constraint near the notches. Specimen 36-5 was cooled to a temperature of $-74^{\circ} \mathrm{F}$ in the temperature chamber. A load of 150 kips from each actuator was applied to the specimen. No fracture occurred at this load. At this point the wedges were driven into the notches with a 20 ton hydraulic ram. This resulted in a fracture of the cover plate. Subsequent fracture of the remaining components occurred almost simultaneously, as expected. Both of the flange angles as well as the web plate and the top flange plate were all fractured (see Figure 3-71). The cover plate fractured at the location of the notches. The west flange angle fractured at the nearest hole to the south of the notches. The east flange angle as well as the web plate and the top flange 
plate all fractured in the same plane which correlated to the fastener hole which was one hole south of the fracture which occurred in the west flange angle (see Figure 3-72).

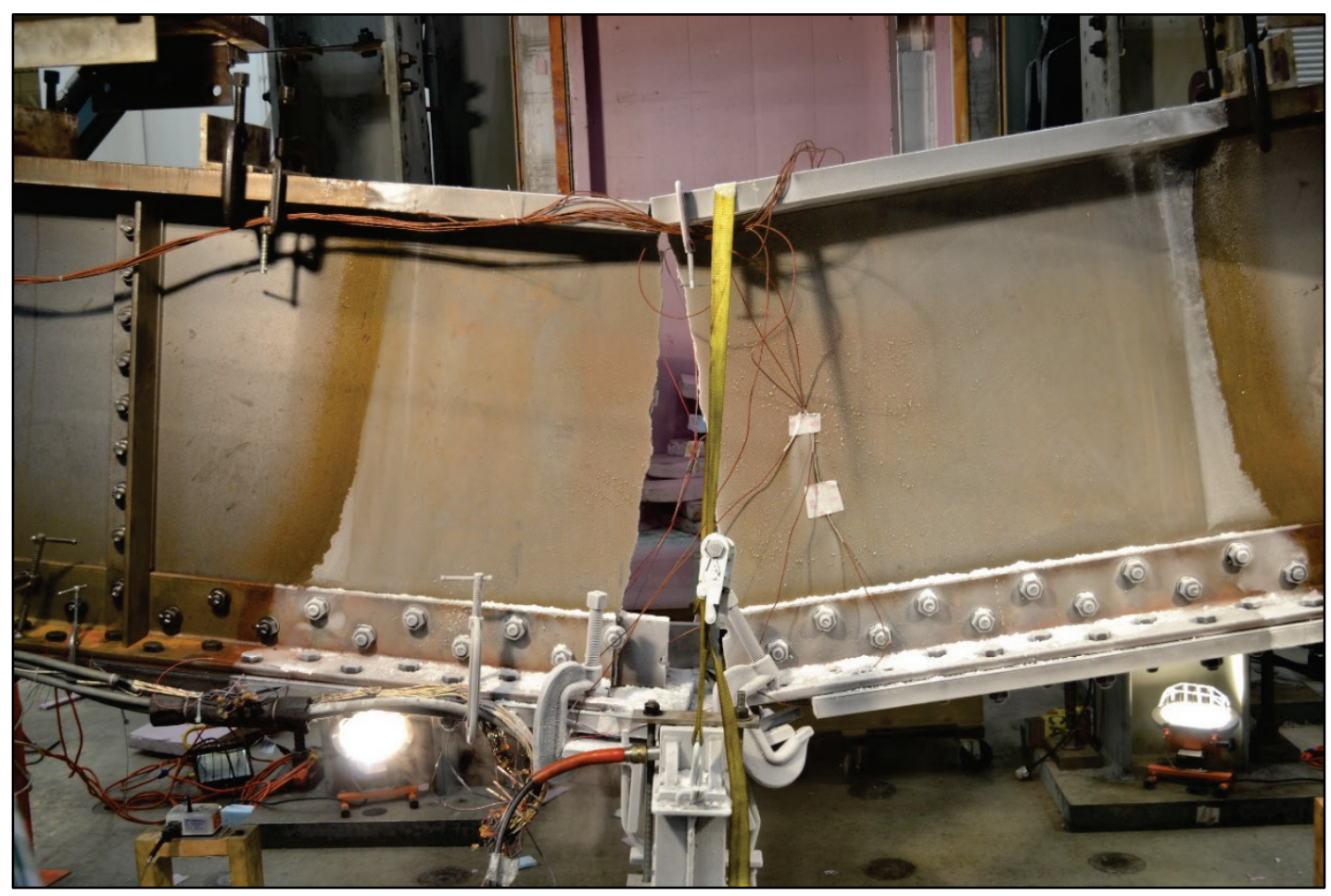

Figure 3-71 Fractured Specimen 36-5 


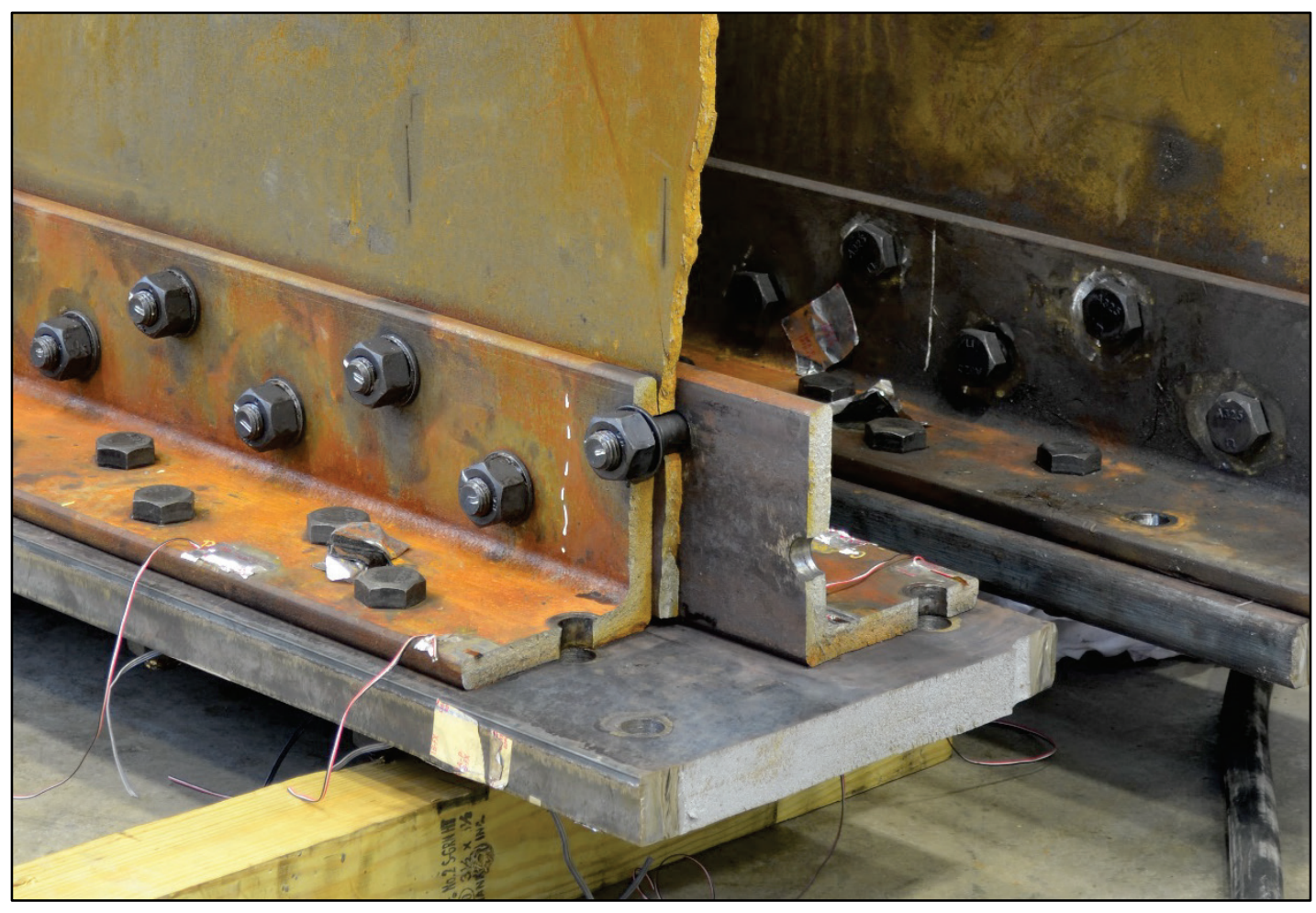

Figure 3-72 Specimen 36-5 south fracture surfaces

Upon removal of the specimen, a detailed inspection was performed to determine the cause of the fracture in the flange angles and in the web. A small fatigue crack was located at a rivet hole in the horizontal leg of the west flange angle (see Figure 3-73). The cracks were very small and contained within the hole and were visually hidden by the head of the fastener. It is very unlikely that they would have been detected with any NDE techniques, such as UT. However they served as initiation points for a fracture which resulted in the fracture of all of the remaining specimen components as there was simply not enough of the flange remaining to carry the load once the angle failed. 


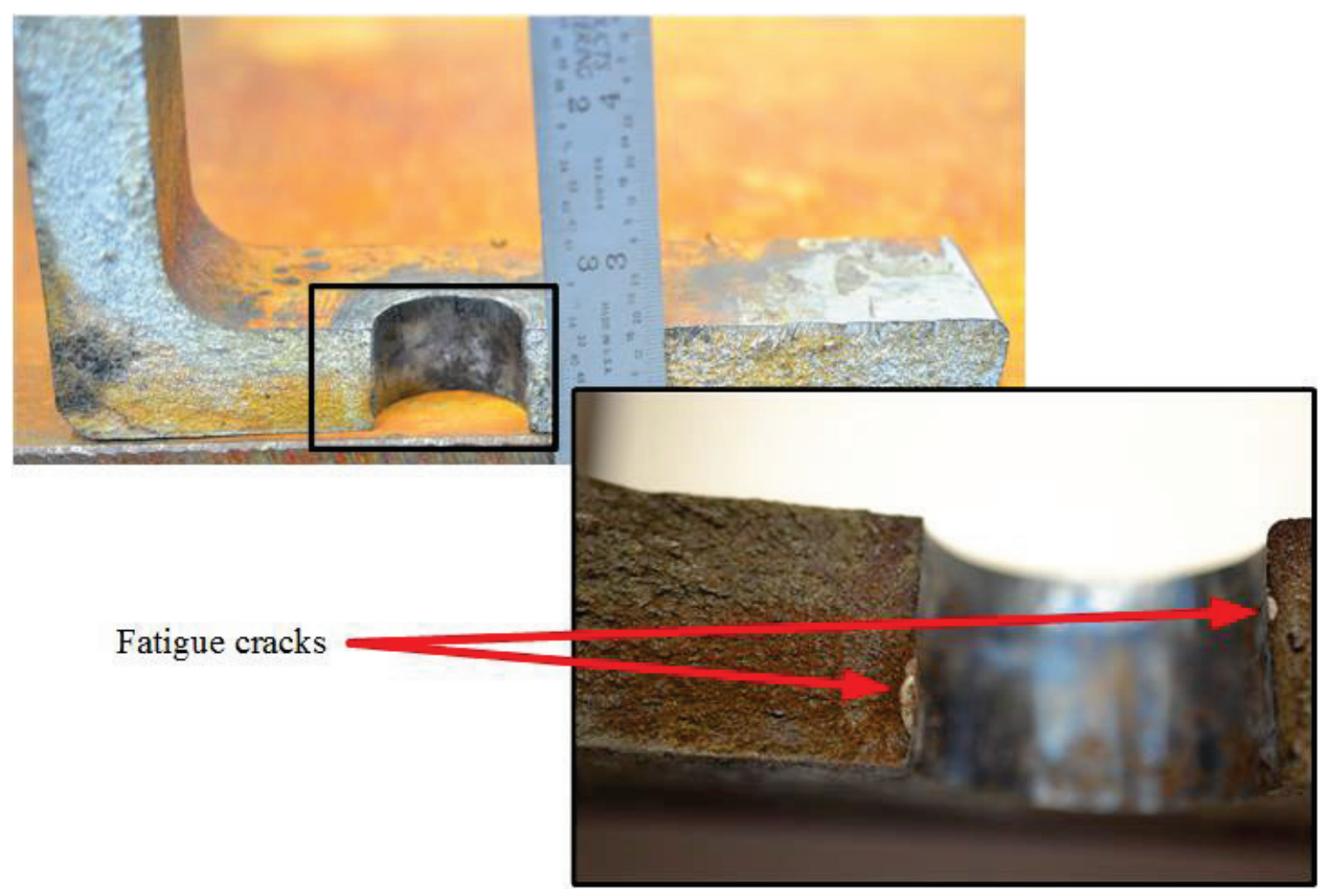

Figure 3-73 Specimen 36-5 rivet hole fatigue cracks

The resulting fracture of the remaining components of Specimen 36-5 illustrate suggested that there are two separate parameters which will affect the ability of a built-up steel member to resist fracture. The first is the proportional area of each of the tension flange components, and the second is the presence of damage (fatigue or otherwise) in components adjacent to the component which fails. In the case of Specimen 36-5 it is hypothesized that a combination of these two parameters led to the catastrophic failure of the entire beam cross-section. To verify this theory, Specimen 36-6 was tested with similar material properties and dimensions except that no prior fatigue history was applied to the flange angles (i.e. there were no fatigue cracks in the remaining angles). 


\subsubsection{Specimen 36-6}

Specimen 36-6 was fabricated using the top flange, and web plate which were used previously in the both the fracture attempts and the fatigue testing of Specimens 46$2,46-4$ and $46-5$. Because the previous specimens had a web plate depth of $46^{\prime \prime}$, the web plate was cut using a track torch to a depth of $36^{\prime \prime}$. The cut edge was then ground smooth with an angle grinder. Two new $6^{\prime \prime} \times 6^{\prime \prime} \times 3 / 4 "$ flange angles were obtained from Hirschfeld Industries Bridge Division which had the same fastener gage and spacing as was used in the web plate on previous $36^{\prime \prime}$ specimens. As with Specimen $36-5$, a new $14^{\prime \prime} \times 11^{1 / 2}$ cover plate was cut to size and drilled by the laboratory staff to match the hole configuration of the flange angles. The purpose of repeating the test with the same component dimensions as used on Specimen 36-5 was to determine whether the influence of components with an extensive fatigue history was a contributing factor in the failure of Specimen 36-5. As with the test of Specimen 36-5, the use of a thicker cover plate was intended to observe the ability of the remaining components to redistribute the load when a large component (representing a large portion of the stress in the bottom flange) was subjected to a fracture. Fully pretensioned A325 bolts were used to connect the bottom flange components. A notch was cut into either side of the cover plate approximately $1 \frac{1}{2}$ half of a hole length from the mid-span.

\subsubsection{Fracture Test}

Prior to the fracture test, Specimen 36-6 was loaded cyclically until cracks had initiated at each of the two notches cut into the cover plate. The specimen was first 
cycled at a calculated net-section stress range of $11.7 \mathrm{ksi}$ (from 10 kips to 80 kips) for 363,000 cycles. When no cracking had initiated at either notch, the calculated net-section stress range was increased to $17.4 \mathrm{ksi}$ (from 10 kips to 120 kips). After an additional 12,000 cycles at this stress range, a crack of 3/16" length was visible from the east notch tip, and a crack appeared to be initiating at the west notch tip. The specimen was then cooled with liquid nitrogen using the cooling procedure outlined in Section 3.3.3 to an average bottom flange temperature of $-83^{\circ} \mathrm{F}$ to ensure all material was on the lower shelf. At this point each of the actuators was loaded to 150 kips and then, following the protocol outlined in Section 3.3.2, cyclically loaded between $90 \%$ and $100 \%$ of this load. No fracture of the bottom cover plate occurred during this loading. Wedges were then driven into the notches of the lower cover plate with a 20 ton hydraulic ram to increase the stress concentration as described in Section 3.3.3.2.2. This resulted in the fracture of the lower cover plate. However the fracture did not propagate into any other components of the built-up specimen and the remaining net-cross section (in the partially-failed state) was capable of supporting the load of 150 kips from both of the hydraulic actuators. This load correlated to a calculated net-section stress in the remaining flange angles of $50 \mathrm{ksi}$. Figure 3-74 shows the bottom flange of the partially failed specimen. 


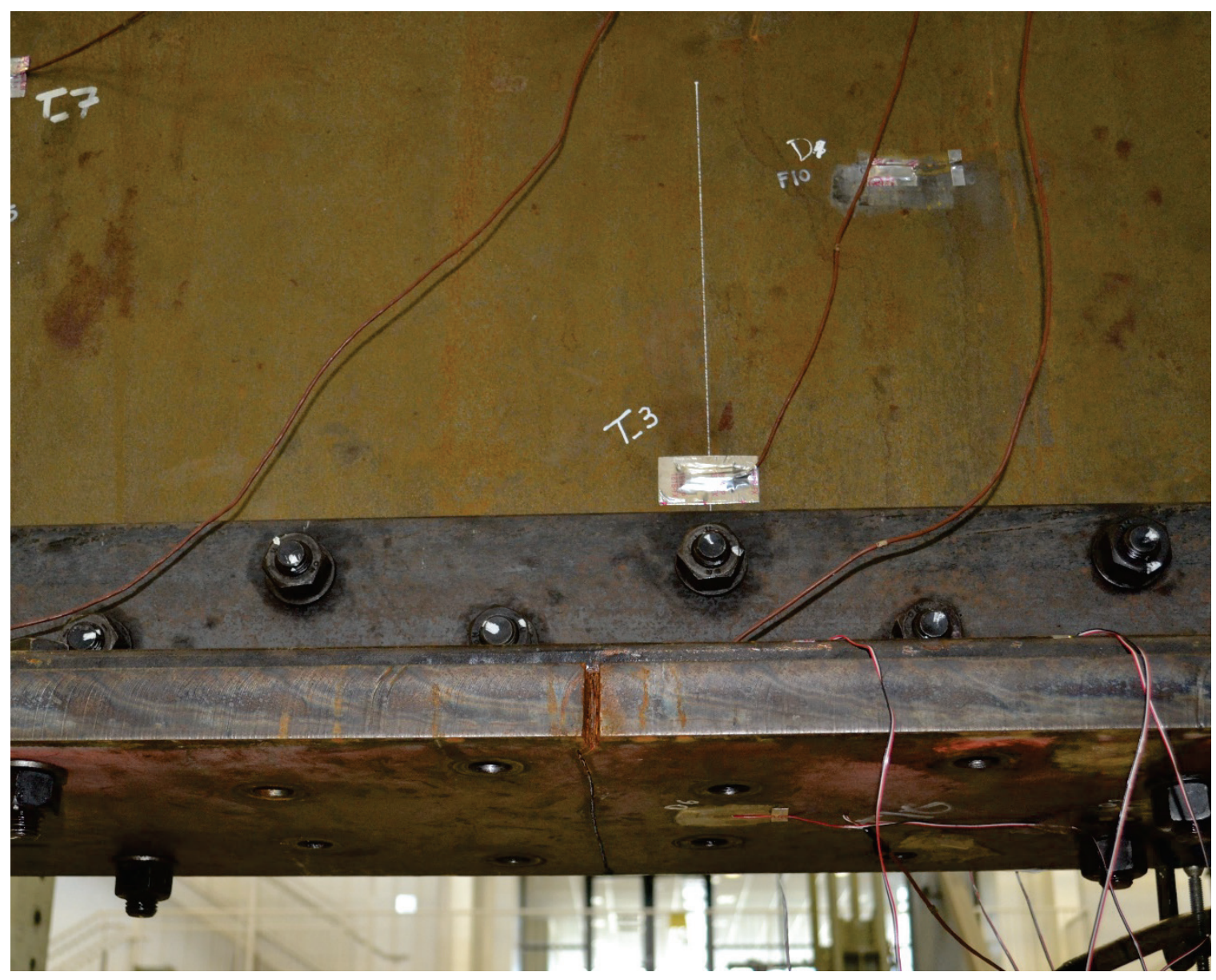

Figure 3-74 Specimen 36-6 post fracture

\subsection{Experimental Results}

The following section contains a summary of the experimental results of the different types of testing. In addition, conclusions are drawn based on the behavior of the built-up steel members subjected to both fracture and fatigue tests.

\subsubsection{Fracture Test Results}

Fifteen specimens were tested to determine if fracture of one component could lead to instantaneous fracture in one or more remaining components (one specimen was 
tested in two different configurations). Thirteen of the specimens were tested with components which were proportionally sized similar to historical built-up girders. Two of the specimens had larger cover plates which were intended to simulate extreme cases with unlikely proportions. Table 3-2 shows the different specimens that were tested, and indicates which tests resulted in a fracture of the first component. Twenty seven fracture tests were attempted while only eight of those were successful in creating a fracture. Three different methods were used to create the brittle fracture of a component: fatigue crack growth of components with notched holes, welded fuses with brittle welds, and wedges driven into edge notched components. The driven wedge method was the most consistent and reliable in producing fractures. 
Table 3-2 Summary of fracture attempts per specimen

\begin{tabular}{|c|c|c|c|c|}
\hline Specimen & Crack Prep Method & \begin{tabular}{|c|}
$\begin{array}{c}\text { \# of Fracture } \\
\text { Attempts }\end{array}$ \\
\end{tabular} & \begin{tabular}{|c|} 
Failure Mode of \\
1st Component \\
\end{tabular} & \begin{tabular}{|c|} 
Test Temp \\
$\left({ }^{\circ} \mathbf{F}\right)$ \\
\end{tabular} \\
\hline \multirow{4}{*}{$23-1$} & \multirow{4}{*}{ Fatigue Crack Growth } & \multirow{4}{*}{ 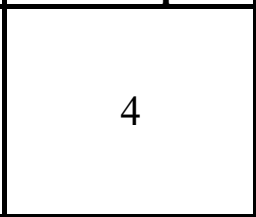 } & \multirow{4}{*}{ Fatigue } & -66 \\
\hline & & & & -79 \\
\hline & & & & -75 \\
\hline & & & & -11 \\
\hline \multirow{3}{*}{$23-2$} & \multirow{3}{*}{ Fatigue Crack Growth } & \multirow{3}{*}{3} & \multirow{3}{*}{ Fatigue } & -74 \\
\hline & & & & -66 \\
\hline & & & & -64 \\
\hline $23-3$ & Fatigue Crack Growth & 1 & Fatigue & -77 \\
\hline \multirow{2}{*}{$30-1$} & \multirow{2}{*}{ Driven Wedges } & \multirow{2}{*}{2} & \multirow{2}{*}{ Fracture } & -53 \\
\hline & & & & -44 \\
\hline \multirow{4}{*}{$36-1$} & \multirow{4}{*}{ Fatigue Crack Growth } & \multirow{4}{*}{4} & \multirow{4}{*}{ Fatigue } & -65 \\
\hline & & & & -72 \\
\hline & & & & -70 \\
\hline & & & & -64 \\
\hline \multirow{2}{*}{$36-2$} & \multirow{2}{*}{ Hardfacing Weld Fuse } & \multirow{2}{*}{2} & \multirow{2}{*}{ Fatigue } & 57 \\
\hline & & & & -65 \\
\hline \multirow{3}{*}{$36-2 b$} & \multirow{3}{*}{ Driven Wedges } & \multirow{3}{*}{3} & \multirow{3}{*}{ Fracture } & -109 \\
\hline & & & & -110 \\
\hline & & & & -65 \\
\hline $36-3$ & Driven Wedges & 1 & Fracture & -81 \\
\hline $36-4$ & Driven Wedges & 1 & Fracture & -103 \\
\hline $36-5$ & Driven Wedges & 1 & Fracture & -74 \\
\hline $36-6$ & Driven Wedges & 1 & Fracture & -83 \\
\hline $46-1$ & Fatigue Crack Growth & 1 & Fatigue & -71 \\
\hline $46-2$ & Fatigue Crack Growth & 1 & Fatigue & -82 \\
\hline $46-3$ & \begin{tabular}{|l} 
Fatigue Crack Growth \\
\end{tabular} & 1 & Fracture & -75 \\
\hline $46-4$ & Driven Wedges & 1 & Fracture & -117 \\
\hline
\end{tabular}

The difficulty in producing fractures in components of built-up steel specimens is encouraging in regards to their use as bridge members in the current inventory. Many specimens did not fracture at high stresses and with moderate to large cracks. These cracks were all expected to fracture based solely on simple linear elastic fracture mechanics solutions. Only one specimen (Specimen 46-3) fractured without the aid of a 
method to increase the stress concentration (the driven wedge method) at a crack tip. Additionally, three of the seven specimens which fractured due to the driven wedge method required multiple attempts before successfully fracturing a component. All seven specimens that were fractured using the driven wedge method also required the removal of fasteners adjacent to the notches so that the constraint would not prevent a brittle fracture from occurring. These results indicate that a fracture of a component of a builtup section, while possible, appears to be highly unlikely.

The ability of built-up members to prevent catastrophic failure of an entire crosssection was illustrated with the fracture tests. In all of the specimens which were proportioned following typical standards, not one brittle fracture of a specimen component propagated into an adjacent component. Additionally, each of the partially fractured specimens resisted the full experimental load of $0.55 \mathrm{~F}_{\mathrm{y}}$. Only two specimens (Specimen 36-1, and 36-5) resulted in simultaneous fractures of multiple components. For Specimen 36-1 however, this was expected to occur due to the number and size of cracks in each of the components prior to the fracture test. The extent of the cracks resulted in a remaining section modulus that was not capable of carrying the applied load. Even if brittle fracture did not occur at the low test temperature, the section would have failed by ductile fracture as the applied load was well in excess of the capacity of the section. In this case, however, even after the fracture of the remaining bottom flange components, the fracture did not propagate into the web plate. Instead, at the test temperature of $-64^{\circ} \mathrm{F}$, the web plate, which had no cracks, yielded. Specimen 36-6, the other specimen which experienced fracture of multiple components had bottom flange components which were all more than 3 times beyond their expected fatigue life and were 
thought to potentially have existing fatigue cracks. In addition, due to the proportions of the cover plate in relation to the flange angles, a much larger fracture energy occurred than would be expected with typical built-up girders. This test was performed to understand at what point a built-up member can no longer be expected to successfully prevent total member failure. Through the testing of these 15 specimens, fracture resilience of built-up girders subjected to flexure was successfully illustrated throughout the experimental testing phase of this research project.

\subsubsection{Fatigue Test Results}

Twelve of the specimens were subjected to cyclic loads to determine the fatigue life of a partially failed section. Initial fatigue life was not investigated in this study. Much research has previously been performed to determine the initial fatigue life of mechanically fastened structural components as described in Section 2.2. In previous studies, the fatigue life was calculated as the number of cycles until the failure of the first component. In this research project, the fatigue life of a partially failed cross section was measured as the number of cycles after the first component failure (whether by fatigue or fracture) until the second component failure. However, it is noted that the failure of two components also did not immediately result in a catastrophic failure of the section. The intent was to investigate the stress redistribution and examine how the resulting increase in stress of a component adjacent to a failed component affected the fatigue life.

Specimens were tested at a variety of different stress ranges. Previous research has established that fatigue life can be characterized linearly on a logarithmic scale when the number of cycles until failure is plotted versus the stress range (Weibull, 1961; 
ASTM, 1964). The intent of this research program was to evaluate the fatigue life at different stress ranges in order to establish a fatigue curve for partially failed built-up sections, as well as to compare with previously established trends. Table 3-3 gives a summary of the fatigue life in number of cycles from the first component failure until the second component failure. Two different constant amplitude stress ranges of the partially failed cross-section are given in the table: Calculated, and Amplified. The calculated stress range was obtained from mechanics of materials calculations (My/I). However, as is described in Section 4.2.5, the longitudinal stress in a partially failed cross-section experiences a localized stress increase near a failed component. This stress increase results in a stress range which is larger than that calculated by mechanics of materials, and is reported as the "amplified" stress range in Table 3-3. Both stress ranges are given for comparison. In addition, both the calculated and amplified net-section stresses are shown in the fatigue curve plots shown in the following sections which compare the fatigue life of specimens with similar parameters. 
Table 3-3 Summary of fatigue test data

\begin{tabular}{|c|c|c|c|c|c|}
\hline \multirow{2}{*}{ Specimen } & \multicolumn{2}{|c|}{$\begin{array}{c}\text { Cracked Section } \\
\text { Stress Range }-\mathrm{S}_{\mathrm{r}}(\mathrm{ksi})\end{array}$} & \begin{tabular}{c} 
Cycles @ \\
2nd \\
Component \\
\cline { 2 - 5 }
\end{tabular} & $\begin{array}{c}\text { 1st Component } \\
\text { Falculed }\end{array}$ & $\begin{array}{c}\text { 2nd Component } \\
\text { Failed }\end{array}$ \\
\hline $23-1$ & 25.6 & 30.5 & 355,190 & Cover Plate & Flange Angle \\
\hline $23-2$ & 16.1 & 19.2 & $1,340,642$ & Flange Angle & Cover Plate \\
\hline $23-3$ & 16.1 & 19.2 & $3,783,919$ & Flange Angle & Cover Plate \\
\hline $30-1$ & 12.6 & 15.0 & $1,408,195$ & Cover Plate & Flange Angle \\
\hline $36-2$ & 6.6 & 7.8 & $20,037,897$ & Lower Cover Plate & N/A (Test Stopped) \\
\hline $36-3$ & 9.6 & 11.4 & $10,022,808$ & Lower Cover Plate & N/A (Test Stopped) \\
\hline $36-4$ & 9.6 & 11.4 & $12,020,096$ & Lower Cover Plate & N/A (Test Stopped) \\
\hline $46-1$ & 24.2 & 28.8 & 74,420 & Cover Plate & Flange Angle \\
\hline $46-2$ & 24.2 & 28.8 & 31,158 & Cover Plate & Flange Angle \\
\hline $46-3$ & 24.2 & 28.8 & 153,123 & Cover Plate & Flange Angle \\
\hline $46-4$ & 7.3 & 8.6 & $20,160,536$ & Cover Plate & N/A (Test Stopped) \\
\hline $46-5$ & 10.2 & 12.2 & $3,547,474$ & Flange Angle & N/A (Test Stopped) \\
\hline
\end{tabular}

\subsubsection{Hole Preparation}

Two types of hole preparation were used over the course of the tests resulting in a noticeable difference in results. Punched holes were used on three of the specimens (Specimens 46-1, 46-2, and 46-3). The holes in the flange angles were punched, while the remainder of the holes (web plate, and cover plate) were drilled due to fabricator limitations. This was deemed acceptable because the flange angles of each of these three specimens were the components most susceptible to fatigue cracking (after the failure of the cover plate) due to their location on the bottom flange, and the configuration of the specimen (having only one cover plate). The components of all other specimens (Specimens 23-1, 23-2, 23-3, 30-1, 36-2, 36-3, 36-4, 46-4, and 46-5) were drilled in all locations. 
Figure 3-75 and Figure 3-76 show the number of cycles until the end of test on the $\mathrm{x}$-axis and the calculated net-section stress range (of the partially failed cross-section) on the y-axis for each of the hole preparation types. As illustrated in Figure 3-75 the specimens with punched holes exceeded the Category E' fatigue resistance curve at the time of a second component failure. Each of the three specimens tested, however, had experienced a large number of cycles at an initial stress range (of the unfailed net section) of $16.8 \mathrm{ksi}$. This is a much higher stress range than has typically been found in built-up member bridges (Fisher et al., 1987). Because the total number of cycles reported for this research is only counted after the failure of the first component, it is likely that a substantial portion of the fatigue life of the second components occurred during the phase of the test attempting to fracture the first component. As shown in Figure 3-76, the fatigue life, using the amplified net-section stress as a result of the localized stress increase, of specimens with drilled holes exceeds the Category $\mathrm{C}$ fatigue resistance curve at the time of failure of the second component or at the time the test was stopped. As a comparison, the fatigue life, using the calculated net-section stress, indicates that the Category D fatigue resistance curve is a reasonable lower bound. 


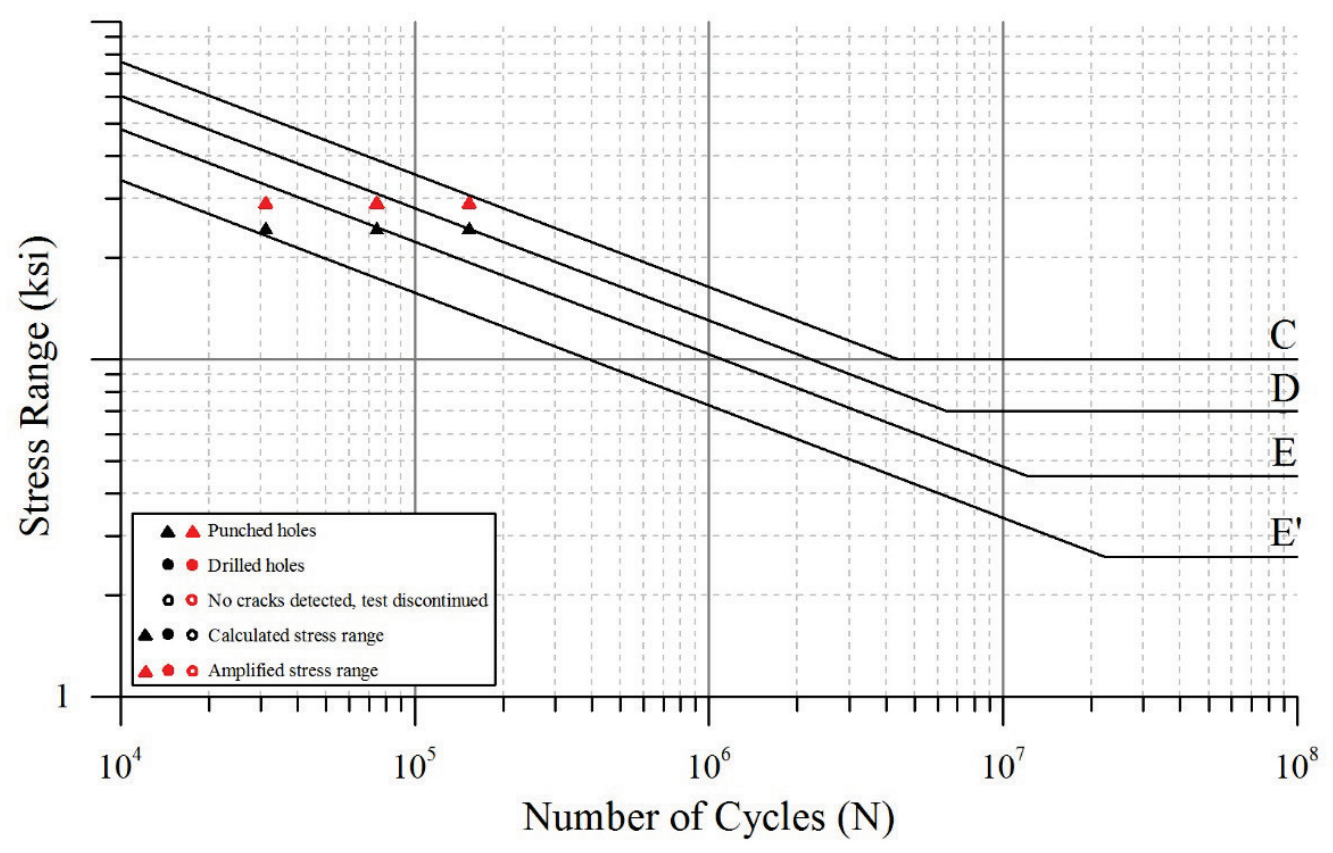

Figure 3-75 Fatigue data for specimens with punched holes

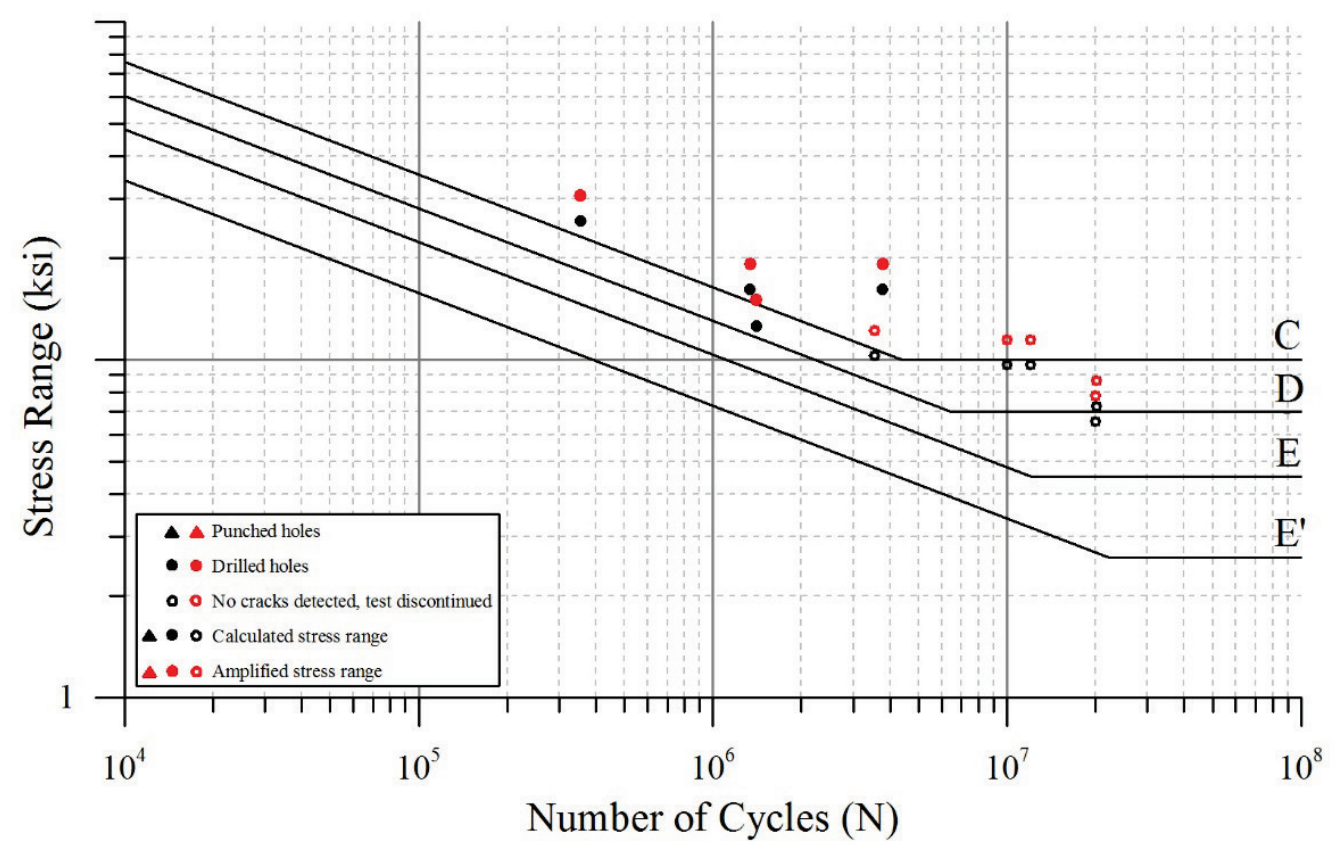

Figure 3-76 Fatigue data for specimens with drilled holes 


\subsubsection{Non-symmetric Cross Section}

Three specimens were tested in fatigue with non-symmetric cross sections (Specimens 23-2, 23-3, 46-5) resulting from the initial failure of a flange angle. All other specimens had a symmetric cross section at the initiation of the fatigue testing (due to the failure of a cover plate). The fatigue data for non-symmetric cross sections is presented in Figure 3-77, and the fatigue data for symmetric cross sections is shown in Figure 3-78. The specimens with non-symmetrical cross sections performed similarly to those with symmetrical cross sections. There was no evident decrease in fatigue life due to out-ofplane stresses resulting from a failed flange angle.

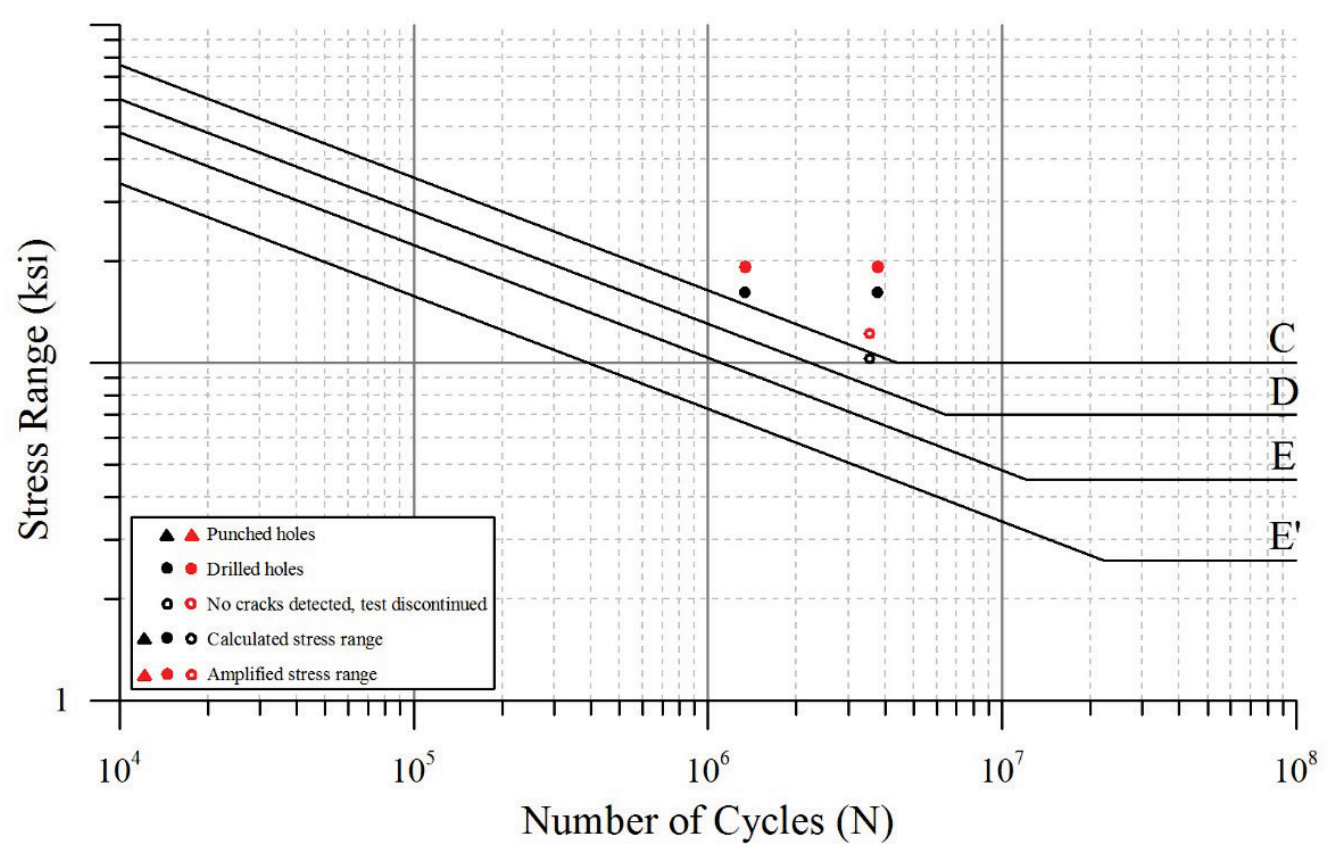

Figure 3-77 Fatigue data for specimens with non-symmetric cross sections 


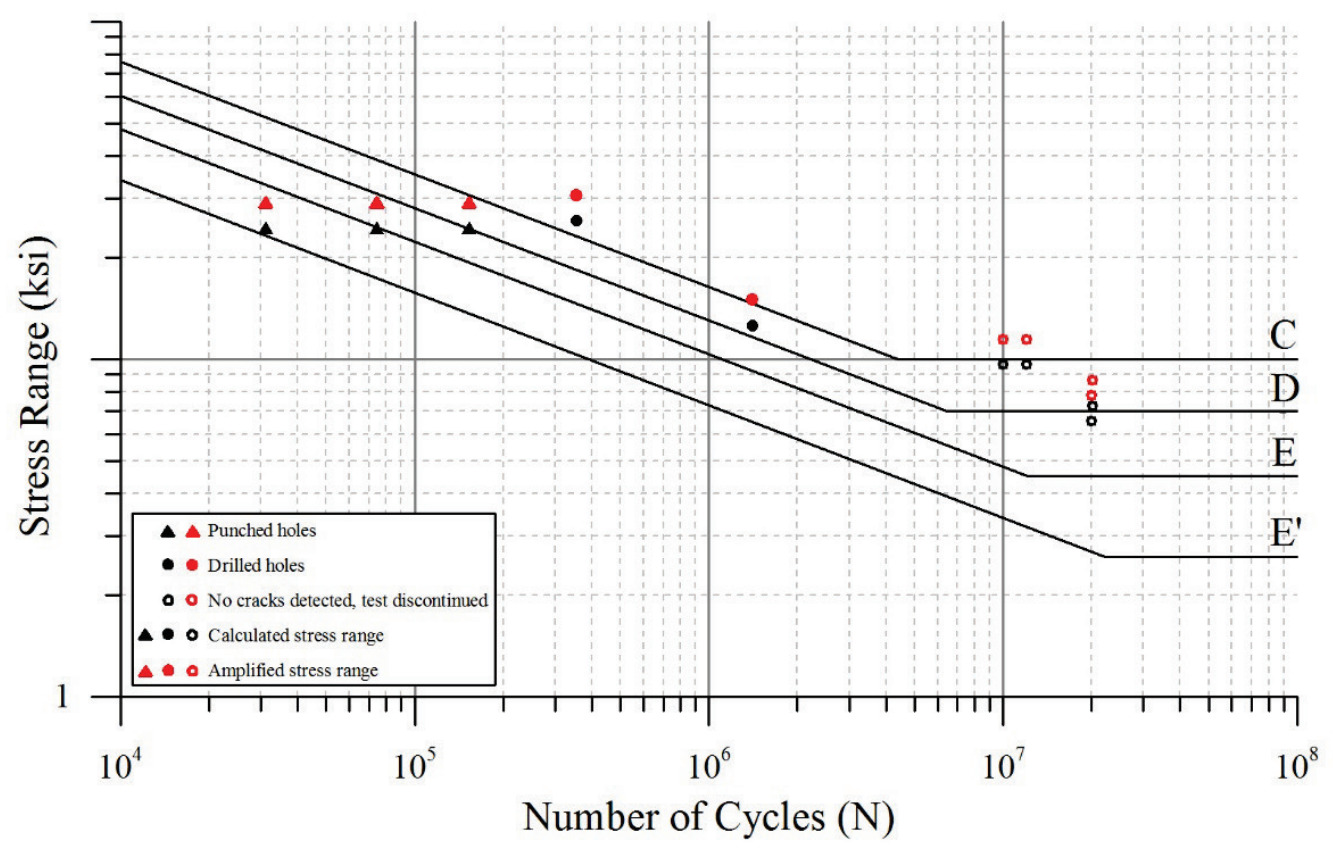

Figure 3-78 Fatigue data for specimens with symmetric cross sections

\subsubsection{Friction Contribution}

Four specimens (Specimens 23-1, 23-2, 23-3, and 46-1) were fabricated with a thin layer of packing grease between the cover plate and the flange angles to simulate a low friction (worse case) condition where the fasteners were relied upon to transmit the majority of the stresses between components. Each of these specimens consisted of only one cover plate attached to the bottom flange angles. The fatigue data for specimens with low friction is shown in Figure 3-79 and that of specimens with unprepared surfaces (expected to represent typical fabrication) is shown in Figure 3-80. No clear trend was noted between the two types of specimens. However, this may have been the result of the hot riveting process. During the fabrication of the specimens, as each rivet was being driven, a flame was observed at the hole. It was a result of the grease igniting when 
coming in contact with the rivet which had just been removed from the propane forge. It was not clear how much of the grease was burned off, however, since the frictional forces contributing to the transfer of stresses is expected to be highest adjacent to the hole where the fastener clamping applies the greatest normal force, the results were deemed inconclusive.

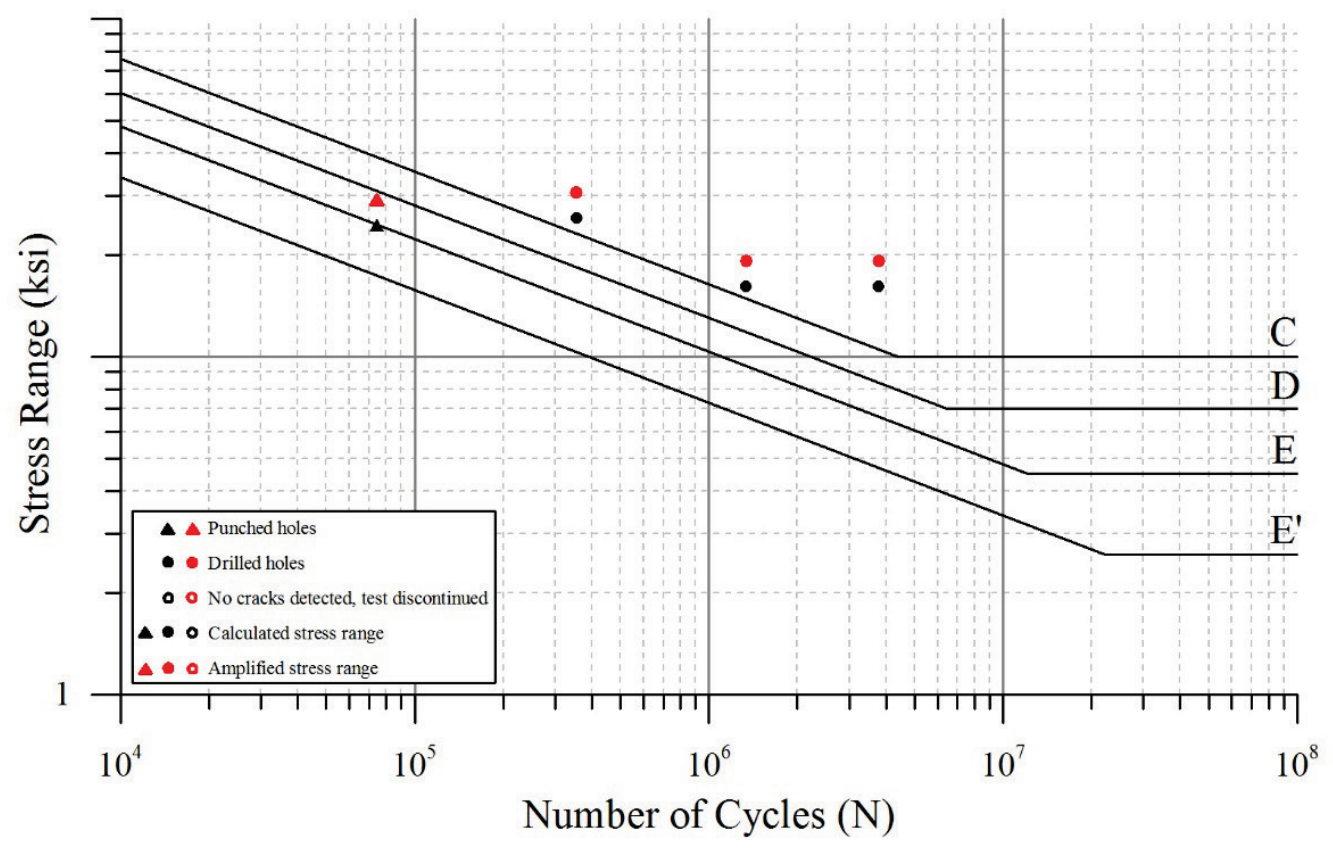

Figure 3-79 Fatigue data for specimens with low-friction between components 


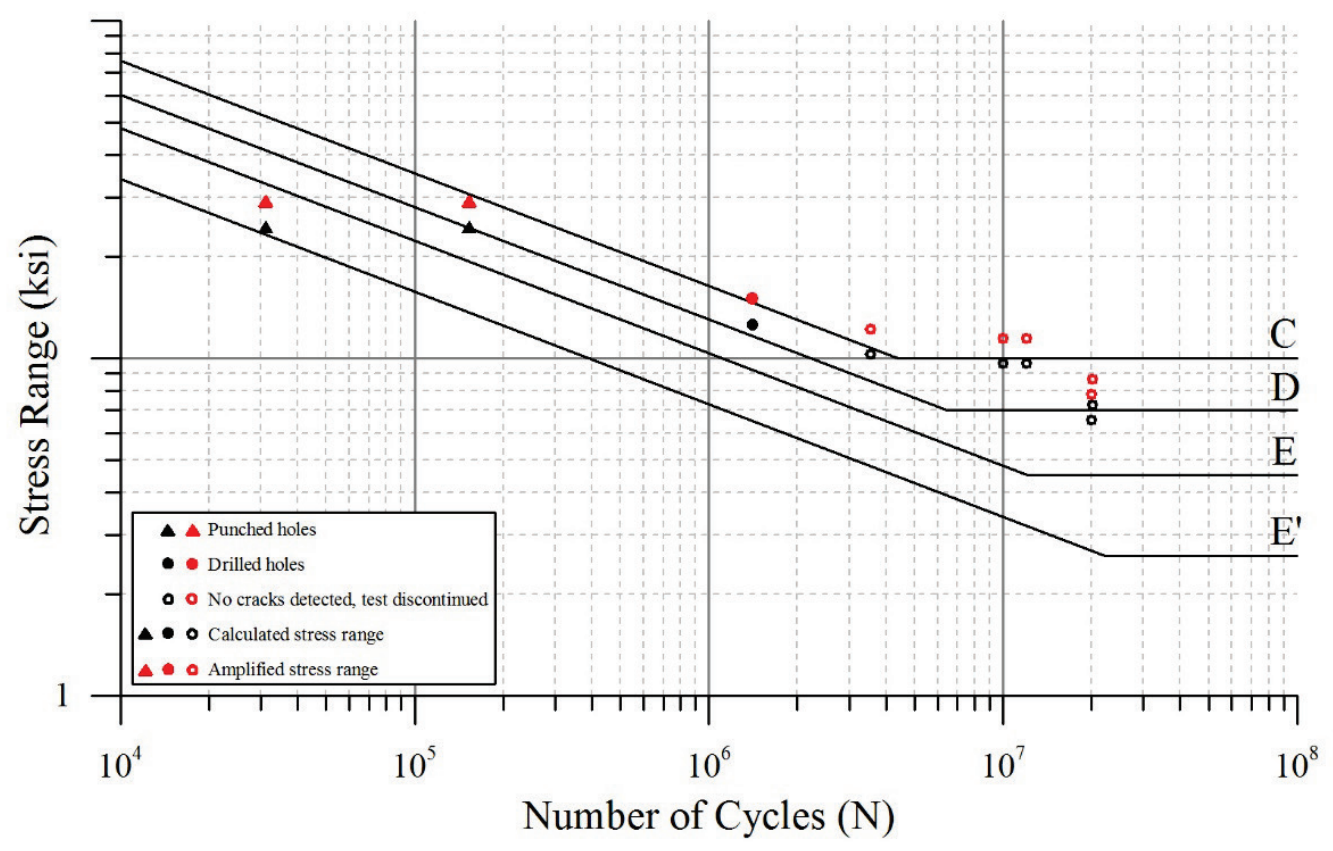

Figure 3-80 Fatigue data for specimens with typical friction between components

\subsubsection{Number of Components}

Three specimens were tested which had two cover plates (Specimens 36-2, 36-3, and 36-4) connected to the bottom flange angles. All other specimens consisted of one cover plate connected to the bottom flange angles. The intent of this parameter was to determine whether the number of components affected the fatigue life of the specimen. The number of cycles were still counted from the time of failure of the first specimen until the failure of the second specimen. Figure 3-81 shows the fatigue data for specimens having one cover plate and Figure 3-82 shows the fatigue data for specimens having two cover plates. The specimens containing two cover plates were all stopped due to a large number of accumulated fatigue cycles with no detection of cracks. Each of these specimens was tested at a net section stress range (both amplified and calculated) of 
the partially failed section which was on the lower end of the spectrum of stress ranges tested. The fatigue data is not conclusive on whether specimens with multiple cover plates had a longer fatigue life than that of a single cover plate due to insufficient data at higher stress ranges.

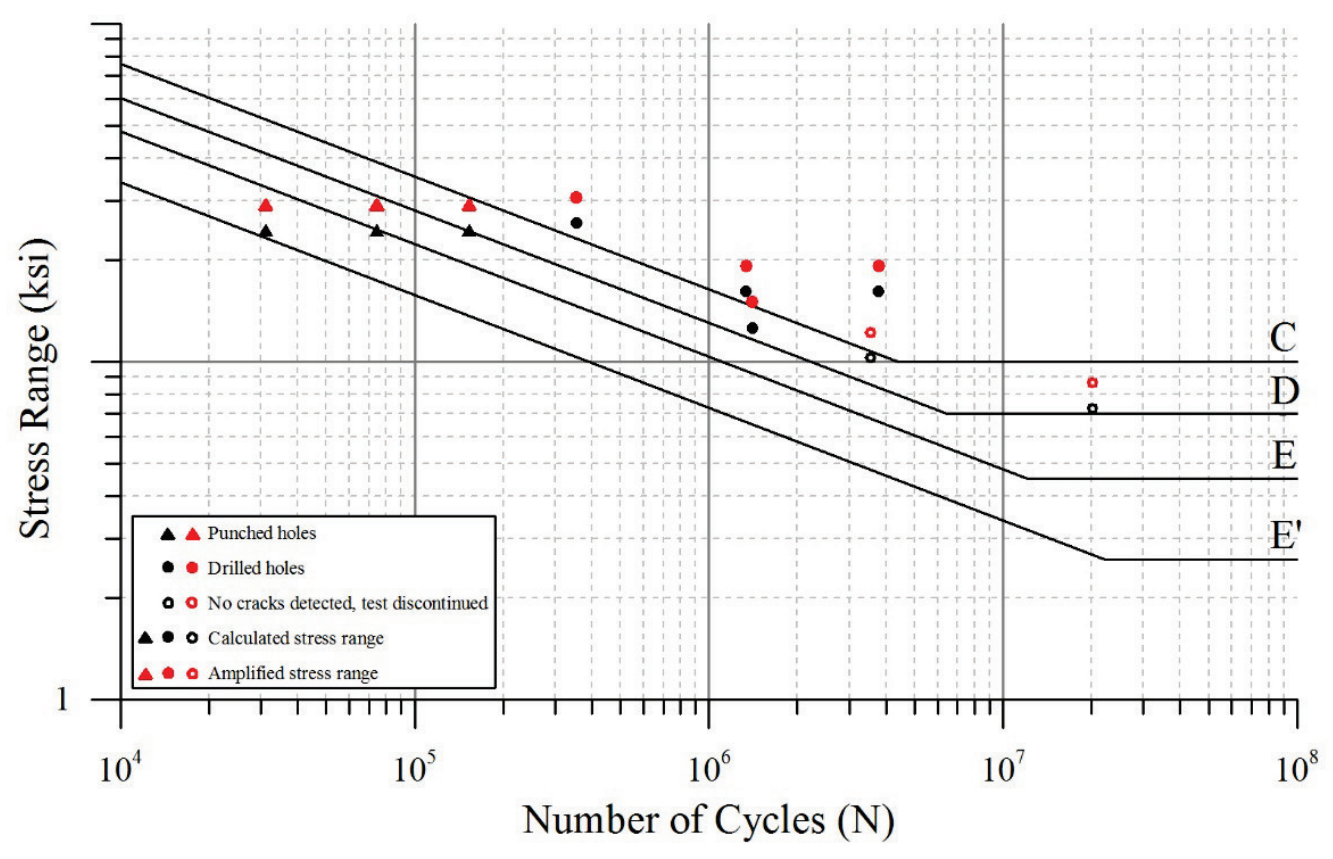

Figure 3-81 Fatigue data for specimens with 1 cover plate 


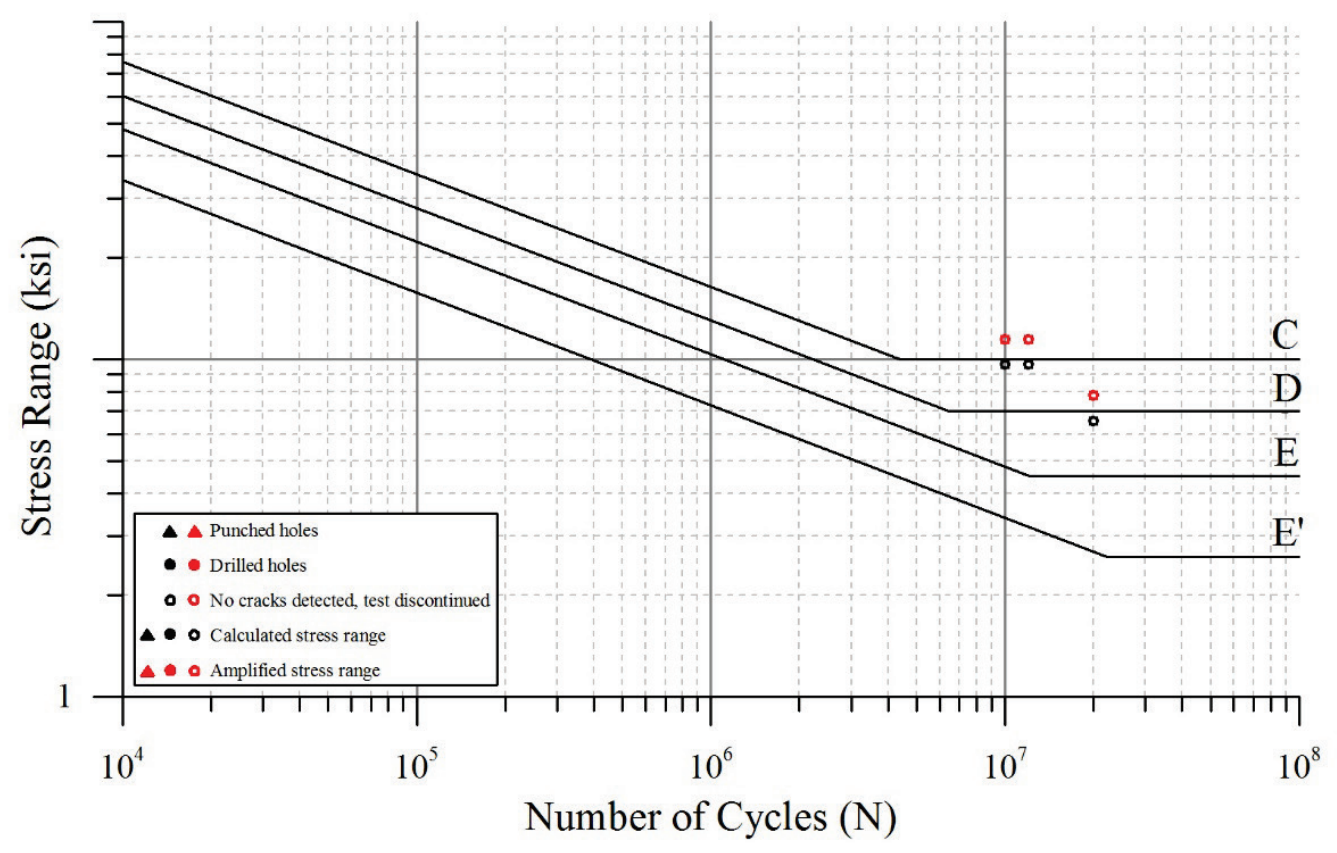

Figure 3-82 Fatigue data for specimens with 2 cover plates

\subsubsection{Fastener Type}

Five specimens were tested in fatigue with high-strength A325 bolts (fully pretensioned) connecting the bottom flange components (Specimens 36-2, 46-1, 46-2, 464, and 46-5). All other specimens used rivets to connect the bottom flange components. Some specimens connected with rivets used snug tightened A325 bolts to simulate the tension force applied by a rivet. The fatigue data for specimens with rivets is presented in Figure 3-83 and the fatigue data for specimens connected with high-strength tensioned bolts is shown in Figure 3-84. No noticeable difference in fatigue life was observed between specimens constructed with fully pretensioned high-strength bolts and those constructed with rivets. This behavior resulted because of the similarities of the resulting detail after a component failure. It was observed that when a component of a specimen 
with high-strength bolts was failed, the pretension was minimized due to fretting, or the fatigue of the washer and/or the nut. After the pretension of the bolt was lost, the fatigue detail was essentially that of a plate with a hole (having a loose fastener in it).

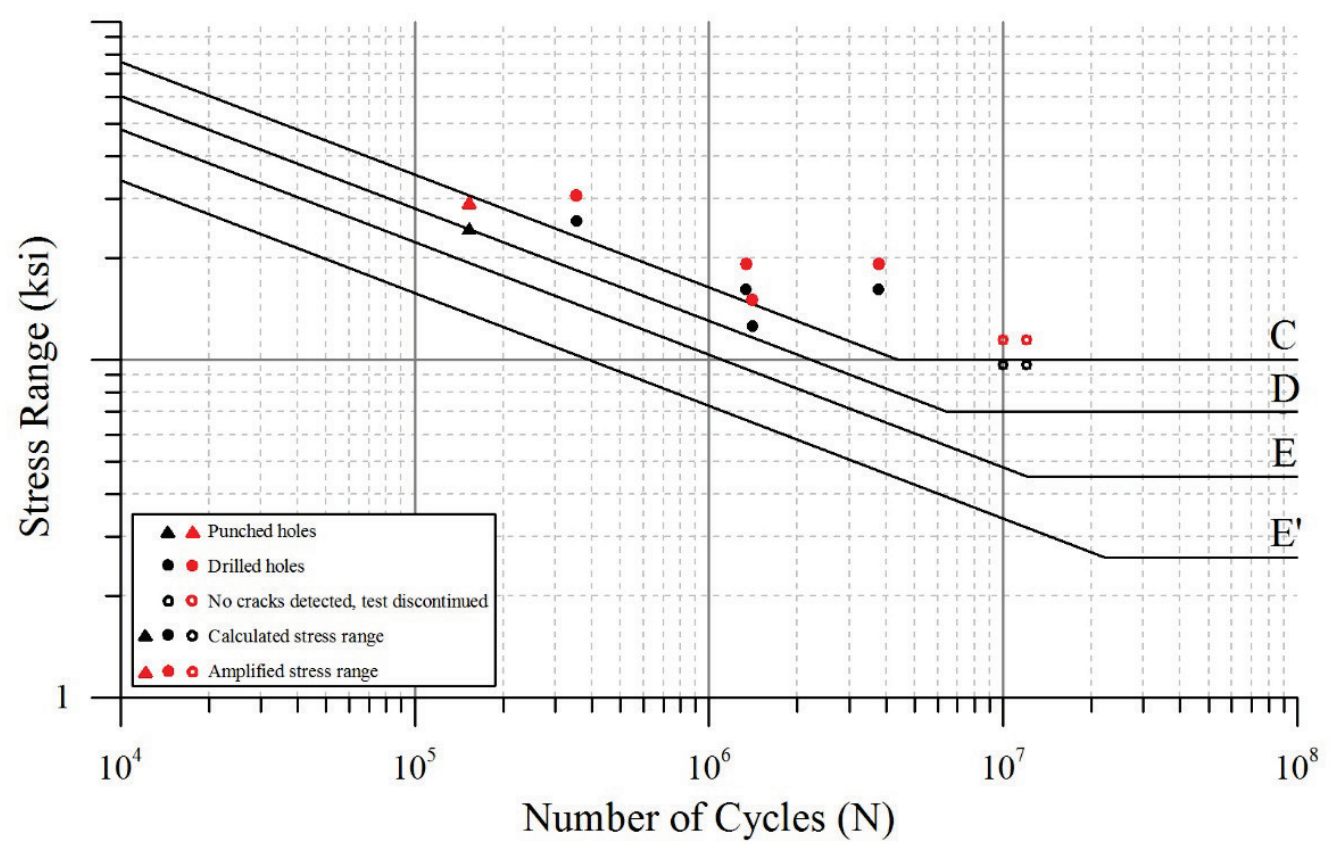

Figure 3-83 Fatigue data for specimens with rivets 


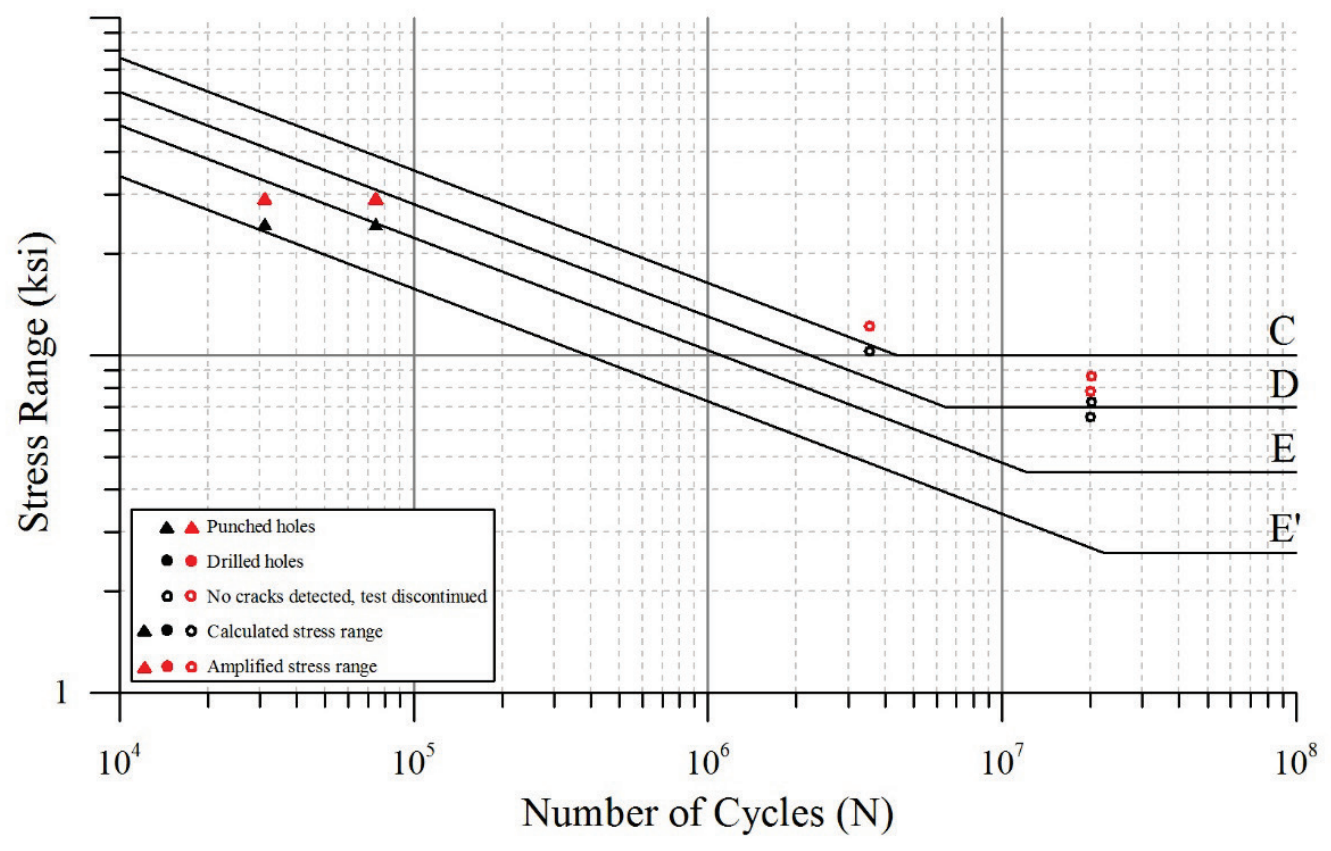

Figure 3-84 Fatigue data for specimens with bolts 


\section{CHAPTER 4 ANALYTICAL RESEARCH PROGRAM}

In order to better understand the behavior of built-up members in bending during various stages of component failure, finite element models of several girder geometries were developed. The models were benchmarked with strain data at discrete locations obtained from the experimental phase of this research program where possible. Once a benchmarked modeling approach was developed a parametric study was performed. This chapter describes the model development, construction, and parametric study.

\subsection{Finite Element Model Construction}

Bonachera Martin, (2014) investigated the behavior of mechanically fastened axially loaded plates and developed an experimentally correlated finite element methodology to study the effects of longitudinal stress distribution. Much of these findings were used during initial phases of built-up steel beam model development discussed herein. During the initial stages of the analytical phase of this project, full size models (with no symmetry) were created using Bonachera Martins methodology to examine the behavior of riveted built-up members subjected to 4-point bending as tested in the experimental phase of the project. While several iterations of models were made throughout the analytical phase of this research, only models which accurately represented the behavior of built-up steel girders in bending will be described herein. 


\subsubsection{Full Model Development}

The Abaqus CAE version 6.13 software produced by Dassault Systemes Simulia Corp. was used for all finite element modeling in this study. A Dynamic Explicit type model was used to construct the complete 'full' model of girders used in the experimental program due to the number of components and because of the computational requirements associated with modeling friction, fastener preload, and contact. Non-linear geometry was used due to the expected deformation of the failed components.

Each of the built-up components was created as an individual part composed of three dimensional deformable solid elements. The cross section of each longitudinal component was created and then extruded to the required length. Rivets were created by drawing half of a cross section and extruding the profile along a radial sweep. 8-noded linear brick elements with reduced integration and hourglass control (C3D8R) were used with a structured hex mesh. The global seed size was set to 0.5 inches for all longitudinal components except the top flange which was set to 2.0 inches due to its distance from the area of interest (the bottom flange). Local seeds were created at the holes to refine the mesh near the interaction with the fasteners (see Figure 4-1a). The global seed size of the rivets was set to 0.25 inches (see Figure 4-1b). 


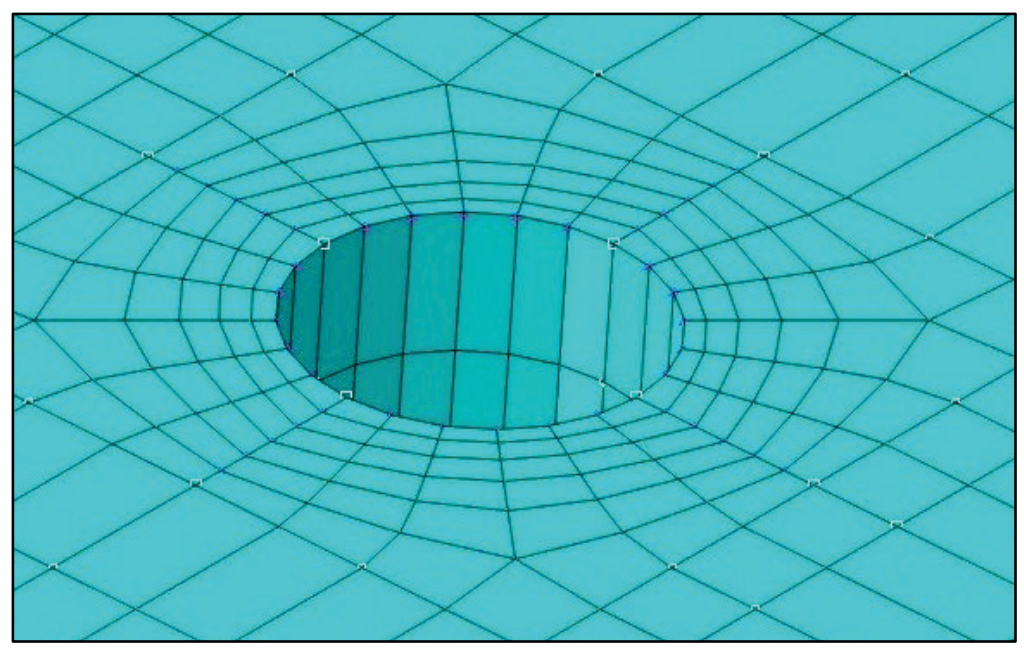

(a)

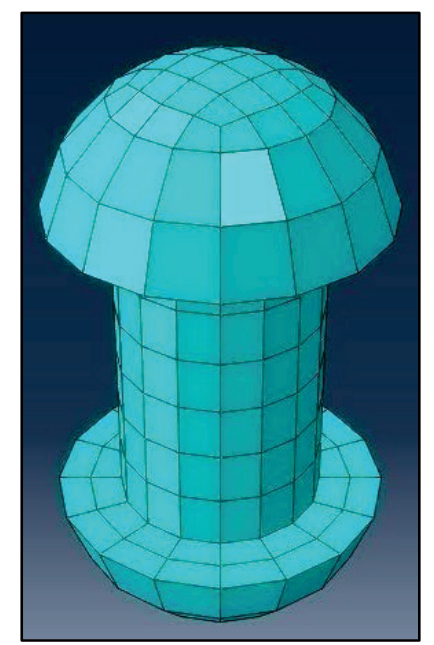

(b)

Figure 4-1 (a) Mesh at fastener hole; (b) Rivet mesh

The material properties for all longitudinal members was defined as linear elastic, with a modulus of elasticity of 29,000 ksi and Poisson's ratio of 0.3 . A density of $7.4 \times 10^{-7} \mathrm{kip} \mathrm{s}^{2} / \mathrm{in}^{4}\left(490 \mathrm{lb} / \mathrm{ft}^{3}\right)$ was used. After post-processing data from initial models, significant low cycle vibration was observed in the dynamic explicit models. As discussed by Bonachera Martin (2014) mass proportional damping was calculated using the following equation to reduce the vibration:

$$
\alpha_{\mathrm{R}}=2 \omega_{\min } \xi
$$

Where:

$$
\begin{aligned}
& \omega_{\min }=\text { natural frequency of the system } \\
& \xi=\text { desired damping ratio }(0.8)
\end{aligned}
$$

A resulting mass proportional damping of 485.519 was used. As explained by Bonachera Martin (2014) the inelastic portion of the stress-strain curve was defined by fitting a Ramberg-Osgood equation to the yield stress, ultimate stress, and maximum strain of the 
region beyond the linear elastic portion of the stress-strain curve: The tabular data used for the stress-strain relationship for the full models can be found in APPENDIX E.

The rivets were assigned the same damping and density as that used in the other parts. In order to apply a pretension load on the rivets, a temperature field and corresponding specification of thermal expansion was used as described by Bonachera Martin (2014). The elastic material properties were defined as orthotropic with elastic stiffness matrix as follows:

Where:

$$
\left[\begin{array}{c}
D_{1111} \\
D_{1122} \\
D_{2222} \\
D_{1133} \\
D_{2233} \\
D_{3333} \\
D_{1212} \\
D_{1313} \\
D_{2323}
\end{array}\right]=\left[\begin{array}{c}
2 \mu+\lambda \\
\lambda \\
2 \mu+\lambda \\
\lambda \\
\lambda \\
2 \mu+\lambda \\
\mu \\
\mu \\
\mu
\end{array}\right]=\left[\begin{array}{c}
38002.95 \\
15522.33 \\
38002.95 \\
15522.33 \\
15522.33 \\
38002.95 \\
11240.31 \\
11240.31 \\
11240.31
\end{array}\right]
$$

$$
\begin{aligned}
& \lambda=\frac{E v}{(1+v)(1-2 v)} \\
& \mu=\frac{E}{2(1+v)} \\
& \mathrm{E}=\text { Modulus of elasticity }(29,000 \mathrm{ksi}) \\
& \nu=\text { Poisson's Ratio }(0.3)
\end{aligned}
$$

Clamping force provided by each rivet was simulated by applying a tension stress of 15 ksi, to match values reported by Zhou (1994). This was achieved by selecting each rivet shank (no rivet heads were selected) and creating a predefined field. An orthotropic expansion value of $1 \times 10^{-5}\left(1 /{ }^{\circ} \mathrm{F}\right)$ for the longitudinal rivet axis was used. A predefined 
temperature field of $94\left({ }^{\circ} \mathrm{F}\right)$ in the initial step of the job was selected. The temperature field was then changing in the subsequent step to 0 to simulate the rivet tension.

Based on the work of Bonachera Martin (2014), the parts were assembled with "Hard Contact" Normal Behavior and Penalty Tangential Behavior having a friction coefficient of 0.5 to simulate the friction between the riveted components (web plate, flange angles, and cover plate). Figure 4-2 shows a typical assembled model with top flange, web plate, flange angles, cover plate, and rivets. The connection between the top flange and the web plate was simulated by using a mesh tie constraint. A pin bearing was modeled 6" from one end of the model by using a boundary condition displacement in the vertical and longitudinal direction. A roller was modeled 6" from the opposite end using a boundary condition preventing displacement in the vertical direction only. Lateral torsional buckling bracing was simulated by applying a boundary condition restricting movement in the transverse direction at nodes on either face of the top flange where the centerline of the actuator was located. 


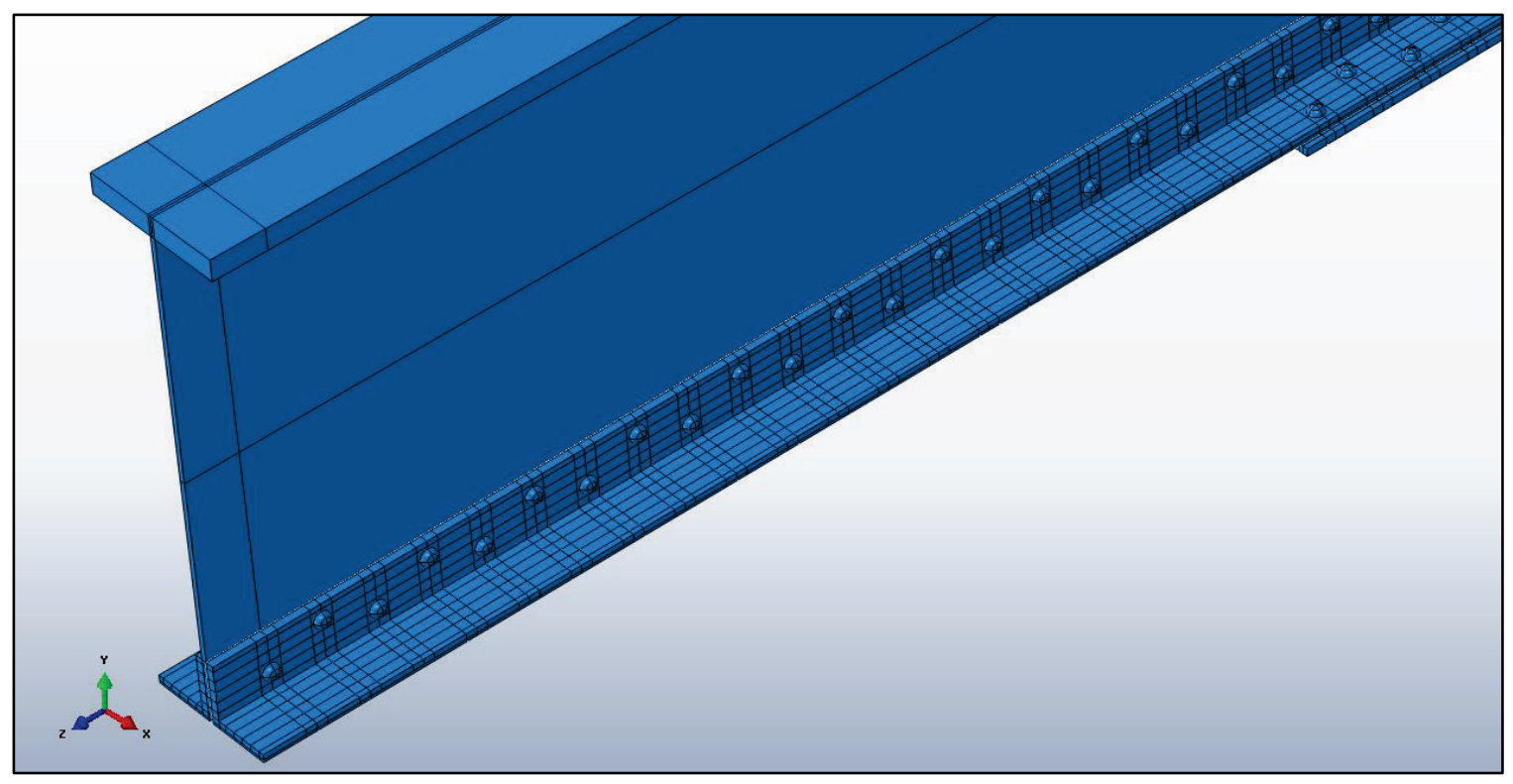

Figure 4-2 FE model assembly

Stiffeners were modeled by using a rigid kinematic coupling (see Figure 4-3). The master node was selected at mid-height of the web plate. Linear nodal regions along the top flange, web plate, and bottom flange (in the vertical plane) were selected as the slave regions. The U1, U2, and U3 degrees of freedom were all constrained. 


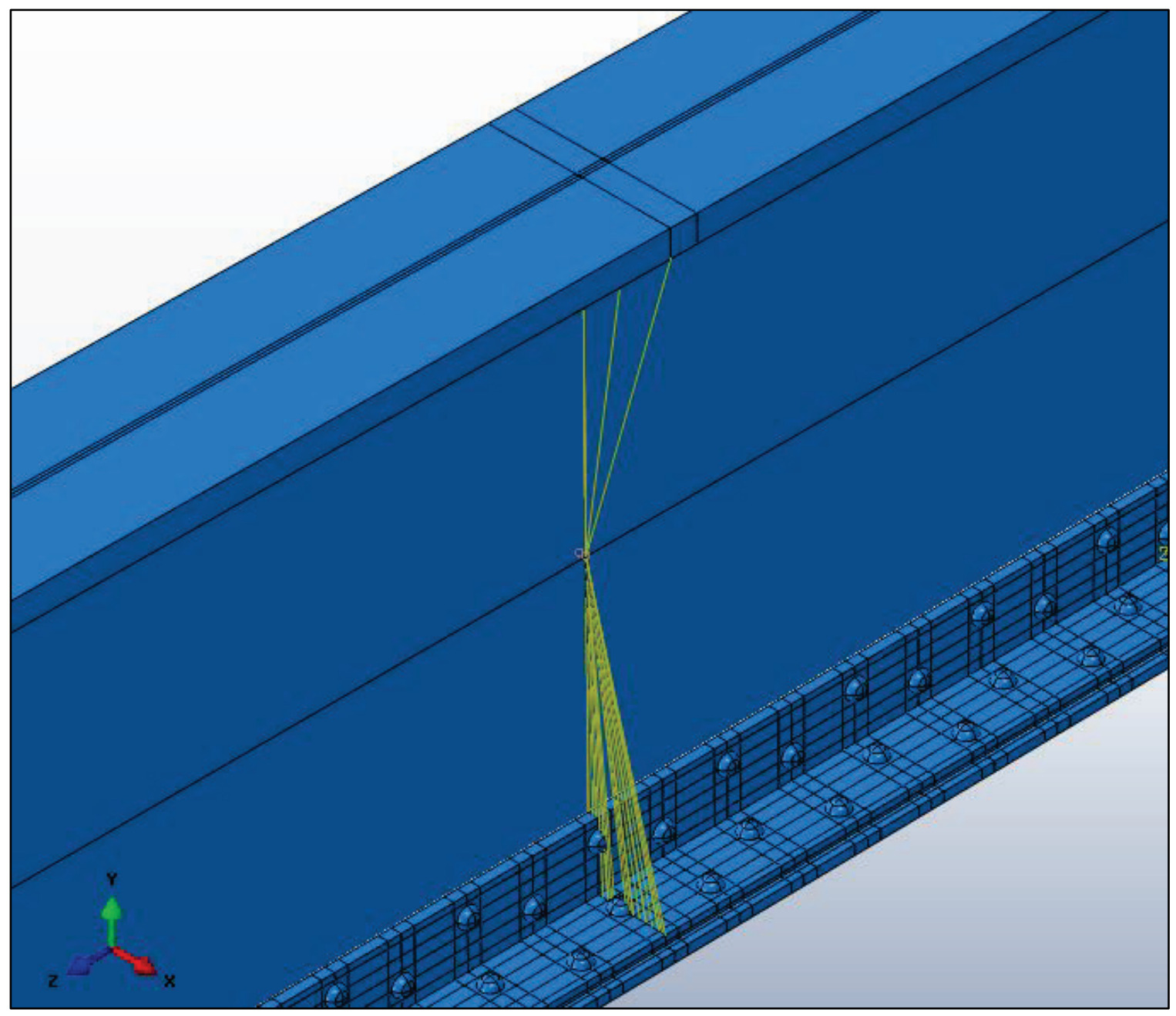

Figure 4-3 FE model stiffener

Because of the experimental program and the goals of the research, there was no experimental data available from a completely flaw free specimen (all specimens were notched prior to experimental test setup). The experimental data that was used to validate the full model was from an edge notched specimen (i.e., specimen 46-4). Notches in the cover plate were modeled using the seam function in the crack options.

Loading was applied as a concentrated force at each node located at the center of the top flange corresponding to the center of the actuators along the beam. Two steps 
were created for the loading - the first was to apply the dead load, and the second to apply the live load. A smooth step (with NLGEOM set to on) was created for the loading to reduce vibration in the model. Figure 4-4 shows the longitudinal stress of the cover plate in the constant moment region resulting from the full edge-notched model. The cover plate shown has notches at the center of the image, in line with the fastener holes. The stress range in the plot is between $0 \mathrm{ksi}-30 \mathrm{ksi}$ in order to illustrate the stress distribution in the component and concentrations around fastener holes (maximum stresses tensile and compressive stresses are shown beyond the range of the plot). Other components (flange angles and web plate) have similar stress distributions around the fastener holes.

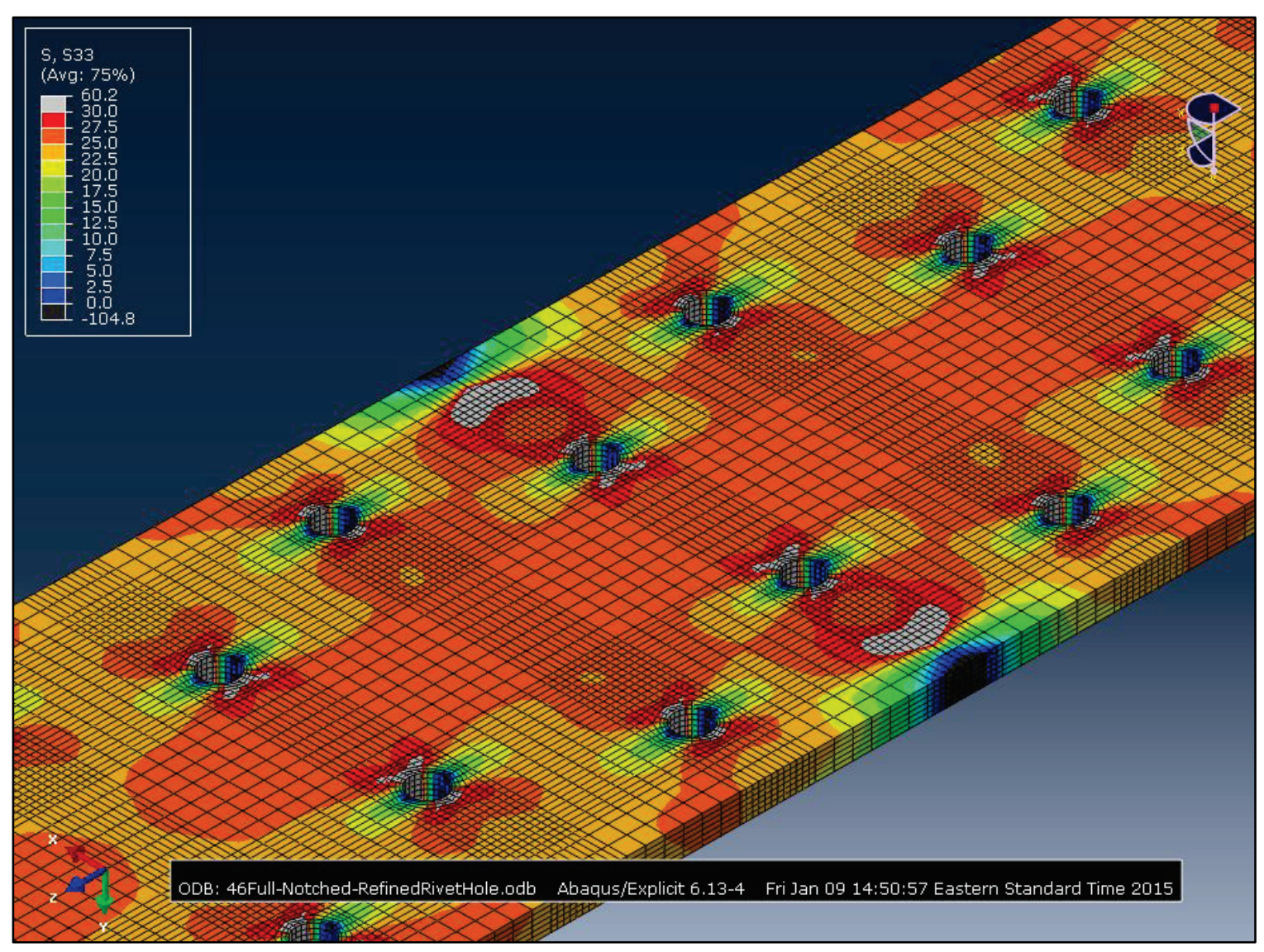

Figure 4-4 Full model: stress in cover plate at mid-span 


\subsubsection{Model Validation}

After the model was run, the resulting longitudinal stresses were plotted in both the longitudinal and transverse directions of the bottom flange angles and cover plate. Discrete paths were selected which correlated with the grid line locations of the strain gages used on the experimental specimens. It was determined that the best representation of the effects of stress concentrations were found through a comparison of stresses at a given transverse cross-section. Additionally, in order to benchmark the model, the stress values were obtained at each gage location (i.e. the top face of the flange angle, and the bottom face of the cover plate). An illustration of the paths (yellow lines) along which the stresses were measured for the purposes of benchmarking the models is shown in Figure 4-5. Figure 4-6 shows the longitudinal stresses obtained from the full model compared with the experimental data recorded from Specimen 46-4 prior to cover plate degradation. The stress is plotted as a function of the transverse distance along the top of the flange angle to represent the overall stress distribution at the cross section. The stress from both the model and the experimental results for all strain gages on the bottom flange are shown in Table 4-1. The model showed good correlation with the behavior of the experimental specimen as illustrated by an average of $1.11 \mathrm{ksi}$ difference between longitudinal stress values at the location of the strain gages. 


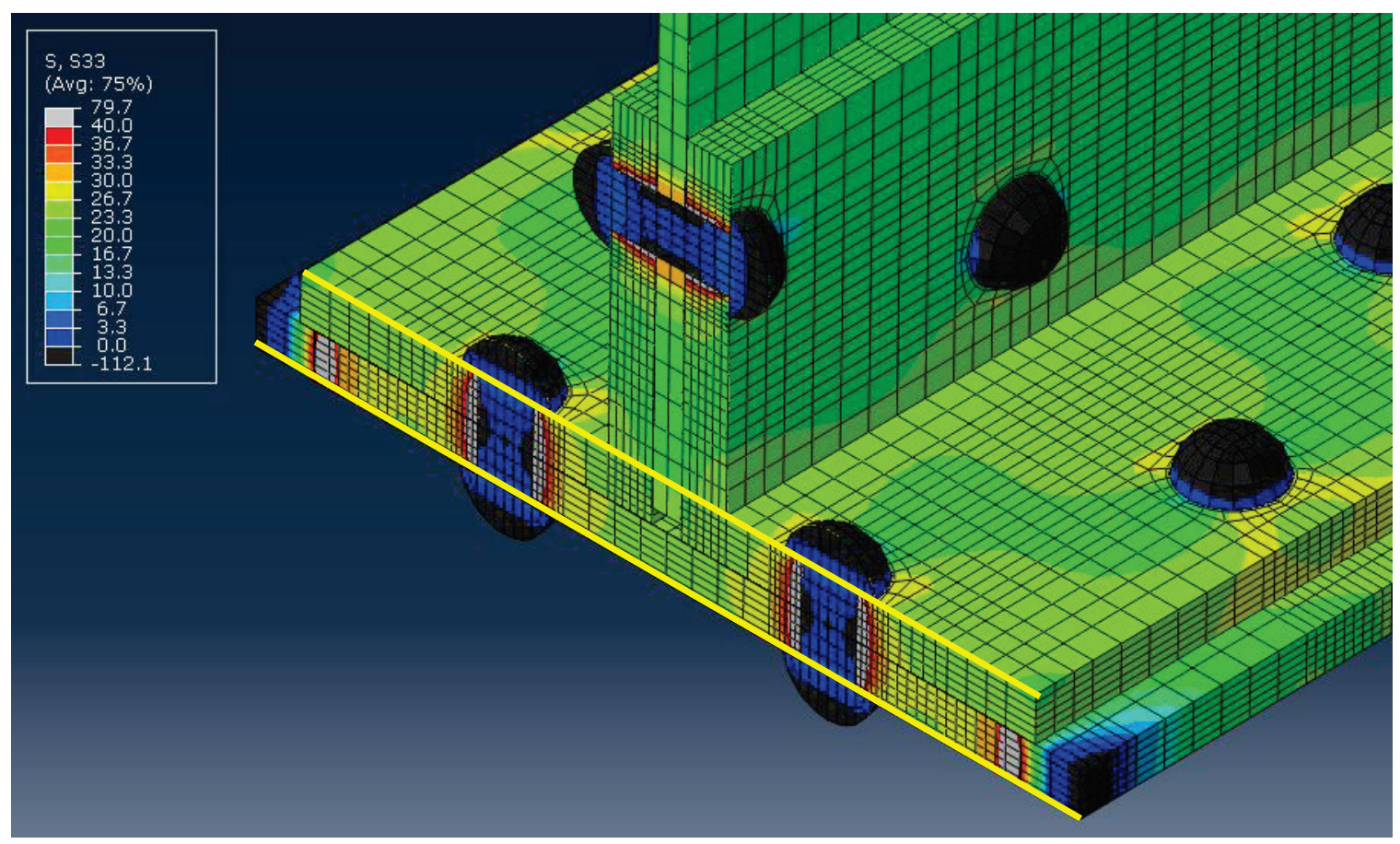

Figure 4-5 Full model - stress paths at cover plate and flange angle

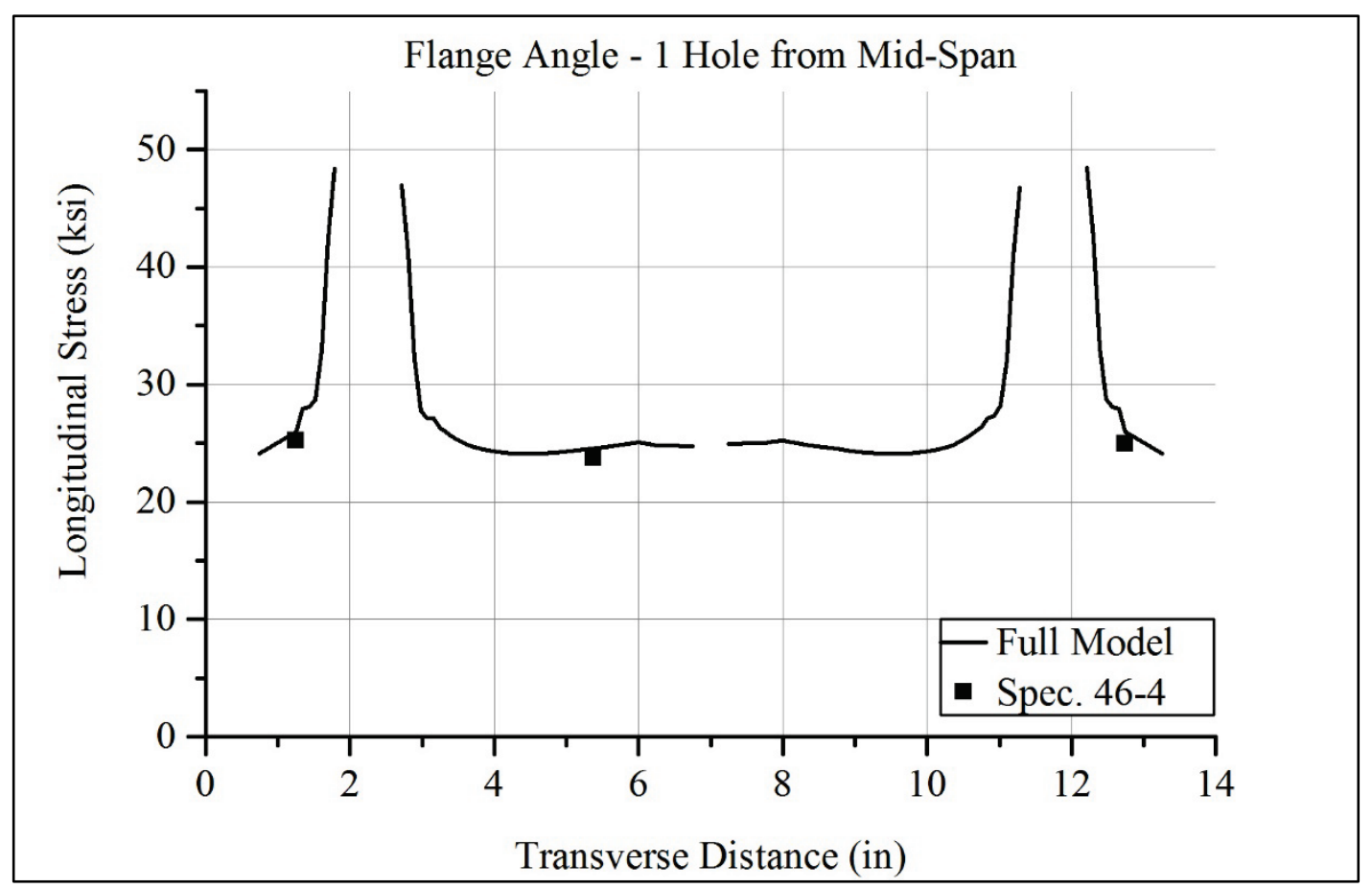

Figure 4-6 Stress comparison (FE full model vs. experimental data) 
Table 4-1 Stress comparison (FE full model vs. experimental data)

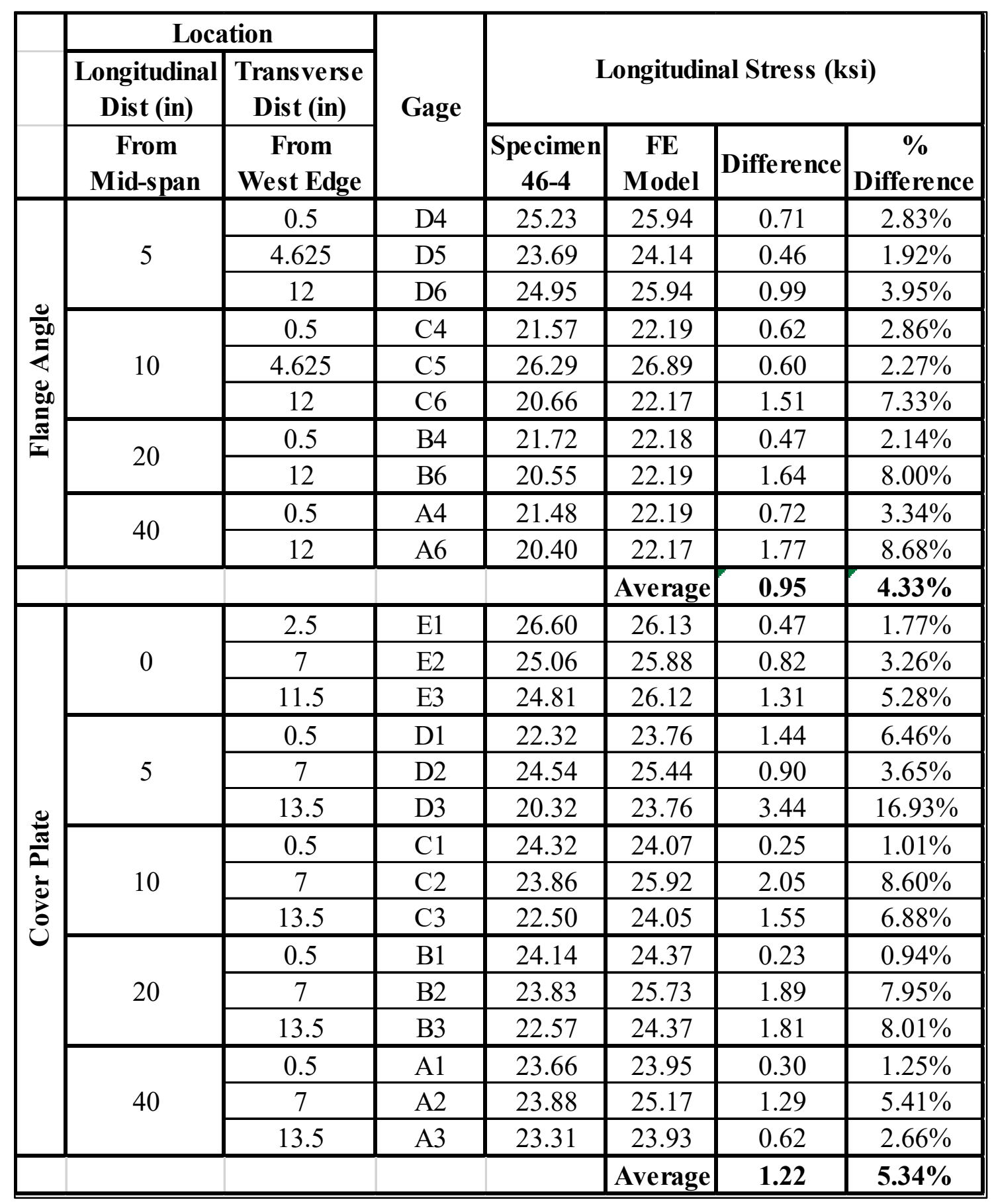




\subsubsection{Quarter Model Development}

Another model was created to validate the data obtained from specimens with hole notches (Specimens 46-1, 46-2, and 46-3). In order to simplify the finite element model, and reduce the computational time (from 252 hours to 112 hours), a quarter symmetry model was constructed. Figure 4-7 shows the experimental data plotted with the results from the FE quarter model, one hole away from mid-span (the location of the notches). Table 3-2 compares the stress from each of the gages on the bottom flange components with that obtained from the FE model at the same coordinates. The model showed good agreement with an average stress difference of $1.33 \mathrm{ksi}$ from the experimental data. In general, the model was more conservative than the experimental results with slightly higher stress values.

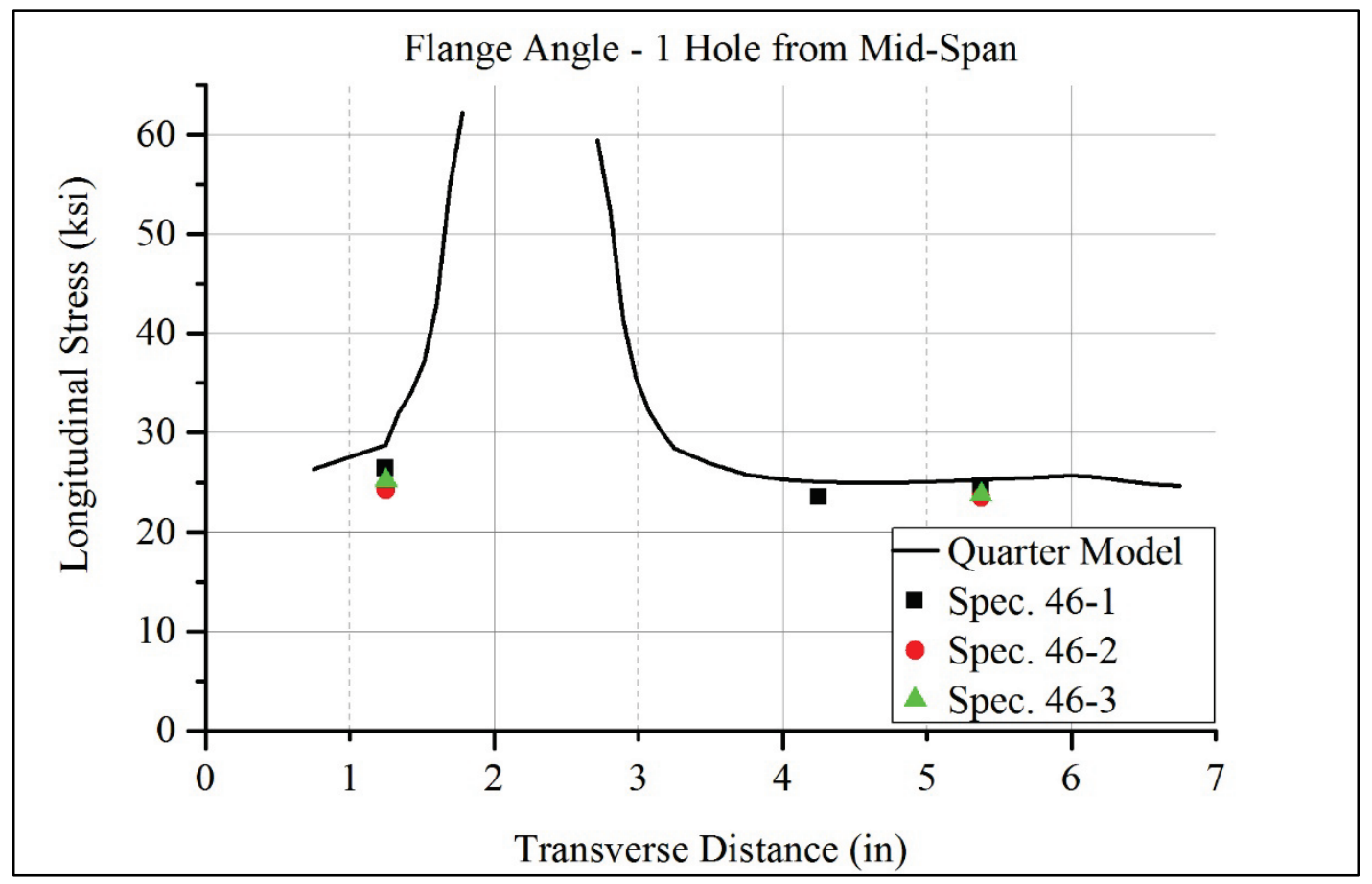

Figure 4-7 Stress comparison (FE quarter model vs. experimental data) 
Table 4-2 Stress comparison (FE quarter model vs. experimental data)

\begin{tabular}{|c|c|c|c|c|c|c|c|c|c|c|c|}
\hline & \multirow{3}{*}{\begin{tabular}{|c|} 
Loc \\
$\begin{array}{c}\text { Long. Dist } \\
\text { (in) }\end{array}$ \\
From \\
Mid-span
\end{tabular}} & \multirow{3}{*}{\begin{tabular}{|c|} 
ation \\
\begin{tabular}{|c|} 
Tran. Dist \\
(in)
\end{tabular} \\
From \\
West Edge
\end{tabular}} & \multicolumn{9}{|c|}{ Longitudinal Stress (ksi) } \\
\hline & & & \multicolumn{5}{|c|}{ Specimen } & \multirow{2}{*}{ Avg } & \multirow{2}{*}{$\begin{array}{c}\text { FE } \\
\text { Model }\end{array}$} & \multirow{2}{*}{ Diff. } & \multirow{2}{*}{$\begin{array}{c}\% \\
\text { Diff. }\end{array}$} \\
\hline & & & Gage & 46-1 & Gage & $46-2$ & $46-3$ & & & & \\
\hline \multirow{14}{*}{ 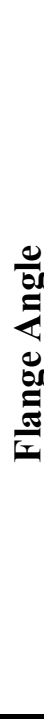 } & \multirow{4}{*}{5} & 0.5 & F5 & 26.45 & D4 & 24.27 & 25.15 & 25.29 & 28.75 & 3.46 & $13.70 \%$ \\
\hline & & 3.5 & F7 & 23.54 & & & & 23.54 & 25.06 & 1.52 & $6.44 \%$ \\
\hline & & 4.625 & F8 & 24.31 & D5 & 23.49 & 23.74 & 23.85 & 25.31 & 1.46 & $6.12 \%$ \\
\hline & & 12 & & & D6 & 24.34 & 25.22 & 24.78 & 28.75 & 3.97 & $16.04 \%$ \\
\hline & \multirow{4}{*}{10} & 0.5 & E5 & 22.82 & $\mathrm{C} 4$ & 21.84 & 22.01 & 22.23 & 22.77 & 0.54 & $2.45 \%$ \\
\hline & & 1.5 & E6 & 22.97 & & & & 22.97 & 24.01 & 1.03 & $4.50 \%$ \\
\hline & & 4.625 & & & $\mathrm{C} 5$ & 25.82 & 25.81 & 25.81 & 27.28 & 1.46 & $5.67 \%$ \\
\hline & & 12 & & & C6 & 21.98 & 21.87 & 21.93 & 22.77 & 0.85 & $3.85 \%$ \\
\hline & \multirow{3}{*}{20} & 0.5 & $\mathrm{C} 5$ & 22.42 & B4 & 21.28 & 20.41 & 21.37 & 22.17 & 0.80 & $3.74 \%$ \\
\hline & & 1.5 & $\mathrm{C} 6$ & 22.45 & & & & 22.45 & 23.42 & 0.97 & $4.33 \%$ \\
\hline & & 12 & & & B6 & 21.81 & 21.65 & 21.73 & 22.17 & 0.44 & $2.02 \%$ \\
\hline & \multirow{3}{*}{40} & 0.5 & A5 & 23.58 & A4 & 21.46 & 20.77 & 21.93 & 22.12 & 0.19 & $0.85 \%$ \\
\hline & & 1.5 & A6 & 23.29 & & & & 23.29 & 23.34 & 0.05 & $0.21 \%$ \\
\hline & & 12 & & & A6 & 22.05 & 19.64 & 20.84 & 22.12 & 1.28 & $6.13 \%$ \\
\hline & & & & & & & & & Average & 1.29 & $5.43 \%$ \\
\hline \multirow{17}{*}{$\frac{\pi}{0}$} & \multirow{2}{*}{0} & 0.5 & & & E1 & 30.68 & & 30.68 & 29.00 & 1.68 & $5.47 \%$ \\
\hline & & 1.5 & & & E2 & 27.75 & & 27.75 & 39.97 & 12.23 & $44.07 \%$ \\
\hline & \multirow{3}{*}{5} & 0.5 & F1 & 25.35 & D1 & 24.41 & 22.65 & 24.14 & 27.87 & 3.73 & $15.45 \%$ \\
\hline & & 4.25 & F3 & 21.60 & & & & 21.60 & 21.30 & 0.30 & $1.39 \%$ \\
\hline & & 7 & F4 & 22.51 & $\mathrm{D} 2$ & 21.81 & \begin{tabular}{|l|}
22.46 \\
\end{tabular} & 22.26 & 22.15 & 0.11 & $0.50 \%$ \\
\hline & \multirow{4}{*}{10} & 0.5 & E1 & 24.59 & C1 & 23.74 & 23.20 & 23.84 & 23.94 & 0.09 & $0.40 \%$ \\
\hline & & 2.25 & E2 & 23.94 & & & & 23.94 & 24.18 & 0.25 & $1.02 \%$ \\
\hline & & 7 & E4 & 24.28 & $\mathrm{C} 2$ & 23.34 & 22.69 & 23.44 & 24.33 & 0.89 & $3.82 \%$ \\
\hline & & 13.5 & & & C3 & 23.60 & 24.10 & 23.85 & 23.94 & 0.09 & $0.39 \%$ \\
\hline & \multirow{4}{*}{20} & 0.5 & $\mathrm{C} 1$ & 24.82 & B1 & 23.91 & 23.66 & 24.13 & 23.88 & 0.25 & $1.05 \%$ \\
\hline & & 2.25 & $\mathrm{C} 2$ & 24.43 & & & & 24.43 & 24.50 & 0.07 & $0.27 \%$ \\
\hline & & 7 & $\mathrm{C} 4$ & 24.96 & B2 & 23.97 & 23.70 & \begin{tabular}{|l|}
24.21 \\
\end{tabular} & 25.46 & 1.25 & $5.14 \%$ \\
\hline & & 13.5 & & & B3 & 23.78 & 23.25 & 23.52 & 23.88 & 0.36 & $1.54 \%$ \\
\hline & \multirow{4}{*}{40} & 0.5 & $\mathrm{~A} 1$ & 24.72 & $\mathrm{~A} 1$ & 23.75 & \begin{tabular}{|l|}
21.86 \\
\end{tabular} & 23.44 & 23.83 & 0.39 & $1.65 \%$ \\
\hline & & 2.25 & A2 & 24.18 & & & & 24.18 & 24.38 & 0.20 & $0.82 \%$ \\
\hline & & 7 & A4 & 24.76 & $\mathrm{~A} 2$ & 24.00 & & 24.38 & 25.32 & 0.94 & $3.86 \%$ \\
\hline & & 13.5 & & & $\mathrm{~A} 3$ & 23.98 & 23.20 & 23.59 & 23.83 & 0.24 & $1.01 \%$ \\
\hline & & & & & & & & & Average & 1.36 & $5.17 \%$ \\
\hline
\end{tabular}




\subsubsection{Axial Model Development}

A more simplified model was desired to further decrease the amount of time (from 112 hours to 2 hours) and computational power required to compute the stresses in built-up steel girders. A model was constructed with the intent of reducing the overall length of the model and therefore the number of elements. Similar model construction methods were used as those used in the full and quarter models. A model simulating a 46" specimen with a failed cover plate (at mid-span) was built so that the results could be benchmarked with experimental data.

The model was created as a quarter symmetry model to decrease the computational requirements. Two planes of symmetry were created, one plane along the longitudinal vertical centerline axis, and the other as a vertical transverse axis at the failure location (see Figure 4-8). Non-linear geometry was not used due to the observed minimal impact, as well as the decrease in time required to run each model. Implicit (standard) models were used. Each longitudinal component (top flange, web plate, flange angle, and cover plate) was extruded to a length of $8^{\prime}-0^{\prime \prime}$ (the length of approximately two beam heights) to allow adequate distance from the location of a mid-span failure to accurately describe the stress redistribution. 


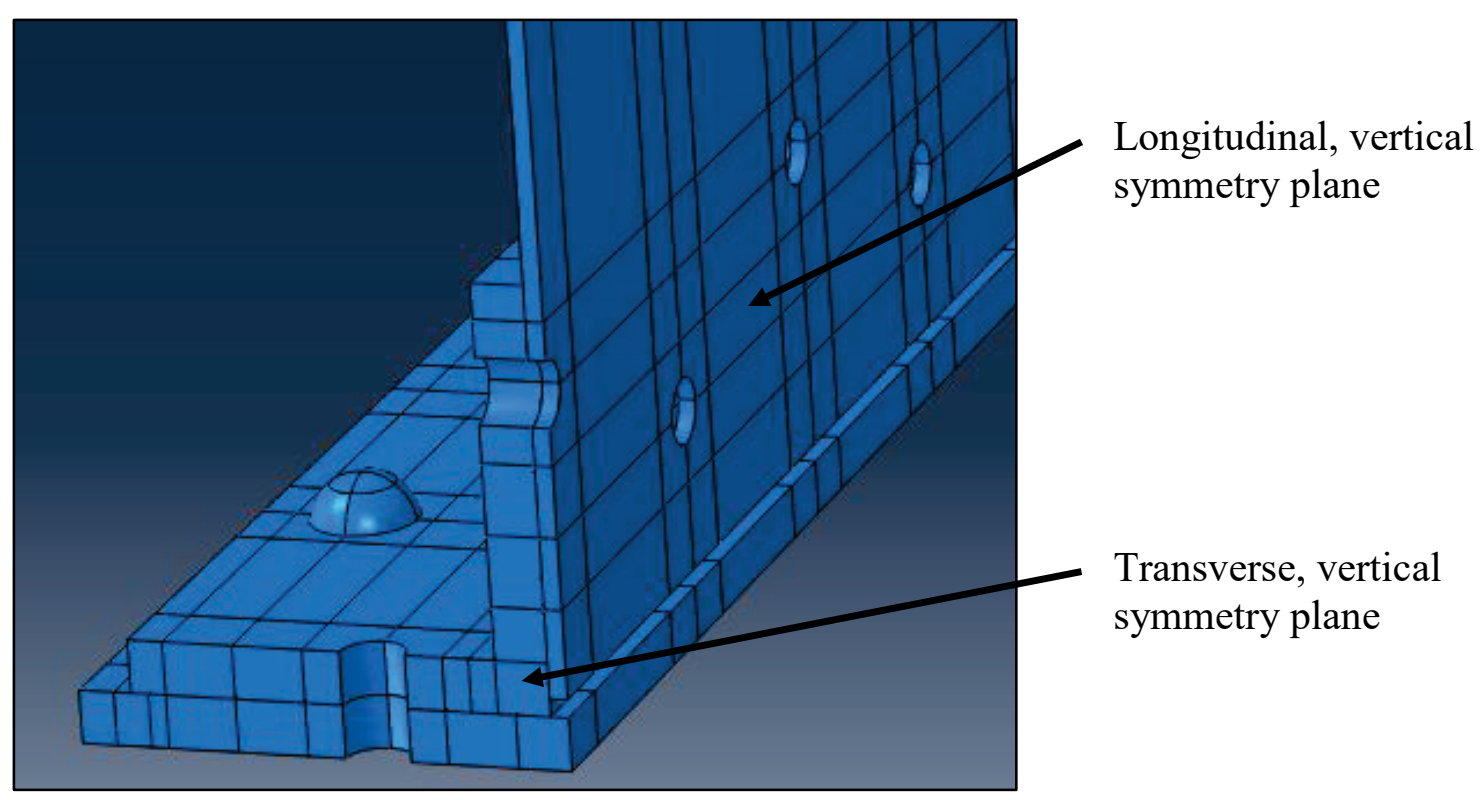

Figure 4-8 Axial model symmetry planes

A linear elastic steel material was used for all components. This was the result of comparing the results from full models having linear elastic materials, with those having plasticity in the form of the Ramberg-Osgood equation as described in Section 4.1.1. The longitudinal stress of the flange angle at the mid-span of two models were plotted to compare the behavior and are shown in Figure 4-9. The stresses matched very well between the two models except at the edge of the hole where the stress concentration results in significantly higher stresses. Due to the overall good correlation (within $6.6 \%$ overall, and $2.6 \%$ for the stresses below yield), further models were constructed with linear elastic material properties. This approach is also conservative in terms of estimating the amplification effects after component fracture occurs since local stresses are over predicted. 


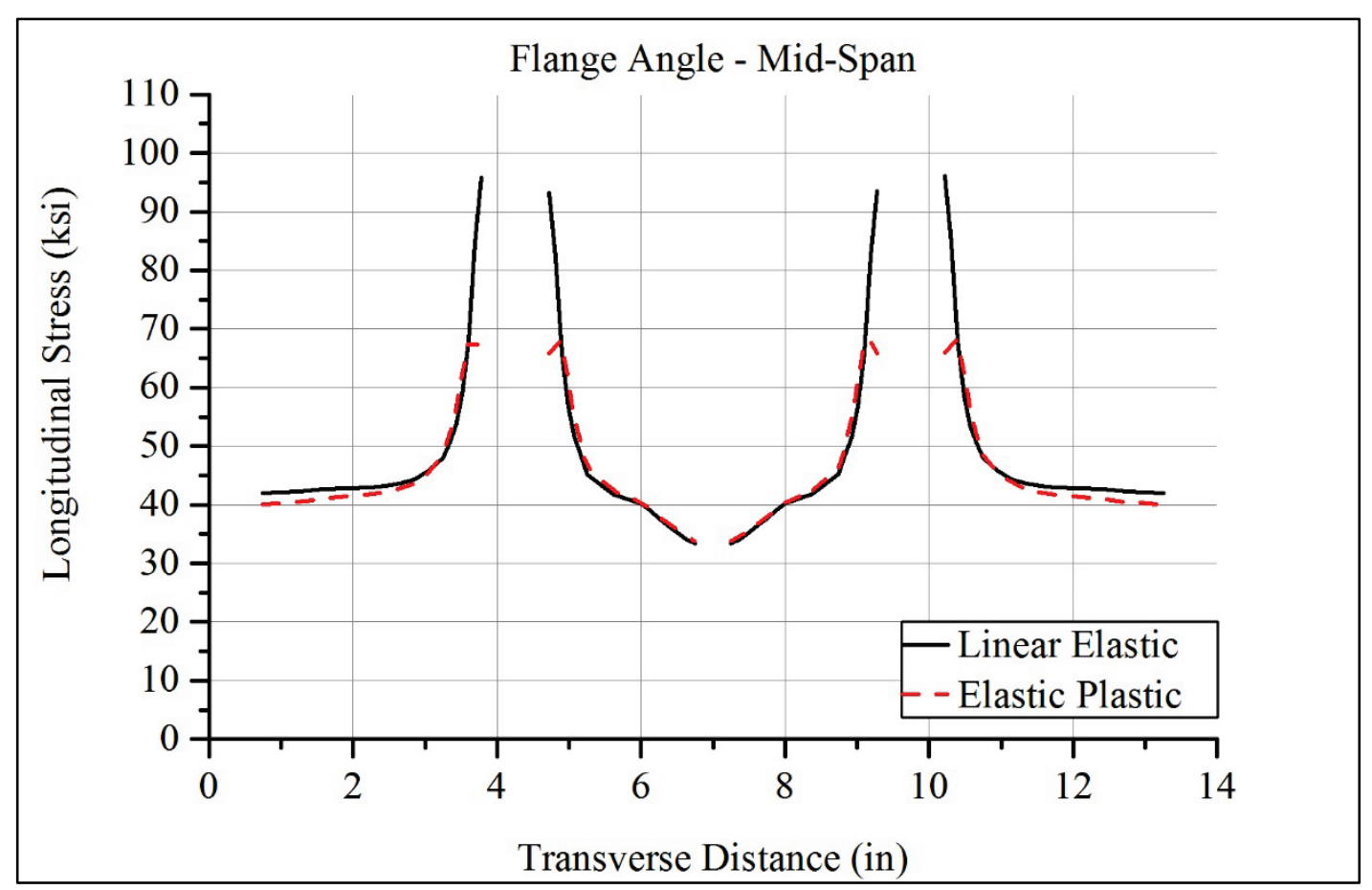

Figure 4-9 Full model - linear elastic vs. elastic plastic

It was found that the fastener pretension had minimal impact on the longitudinal stresses in the components near the area of interest. Consequently, no pretension was applied to the rivets. Rivets were modeled in the first four holes (connecting the horizontal flange of the flange angle to the cover plate) adjacent to the failure plane. This correlates with the work performed by Bonachera Martin 2014, in which four rivets were found to be the transfer length required for riveted plates with a discontinuity. All other rivets were simulated by using a nodal tie constraint around the hole at the intersection of adjoining components. Figure 4-10 shows the bottom flange cover plate with the web (the flange angle is hidden) and both the modeled rivets as well as the simulated rivets with nodal tie constraints. A global seed size of $0.125^{\prime \prime}$ was used for the rivet mesh. 


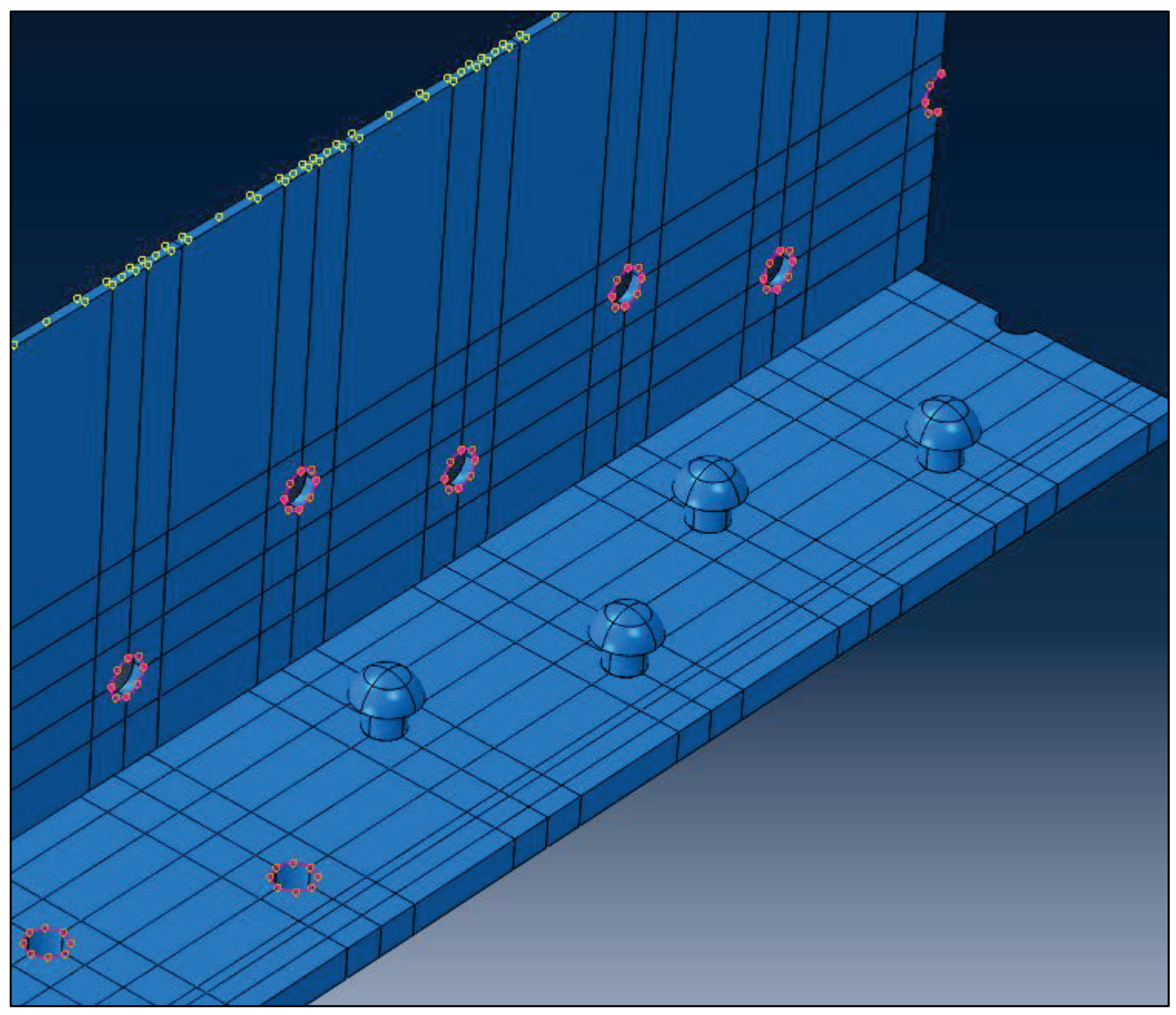

Figure 4-10 Axial model - modeled and simulated rivets

The meshing of each component was intended to correspond to the distance to the area of interest. Consequently, the top flange global mesh size was set to 2 " for the horizontal direction and 1 " for the vertical direction. The top flange was joined to web plate with a surface tie constraint. The web was divided into two sections joined with a surface tie constraint to maintain a more refined mesh near the location of interest while minimizing the number of elements needed to construct the model. The upper 34" portion had a global seed size of 2". The lower 12" portion, which was connected to the 
flange angle (and had proximity to the failure surface) was modeled with a global seed size of $0.5^{\prime \prime}$. The flange angle and cover plate were also given a global seed size of $0.5^{\prime \prime}$. Similar to the full model, the C3D8R elements (8-noded linear brick elements with reduced integration and hourglass control) were used.

'Hard Contact' normal behavior was used for the contact method. Hard contact prevents the penetration of the two surfaces modeled, but allows separation. No friction was included in this simplified model because it was found that its inclusion had little influence on the resulting longitudinal stress results. An axial stress was applied to the cross section of the beam (see Figure 4-11). The axial load had a trapezoidal shape in order to simulate a beam in bending. The magnitude of the stress was equal to $27.5 \mathrm{ksi}$ $\left(0.55 \mathrm{~F}_{\mathrm{y}}\right.$ of the test specimens $)$. 


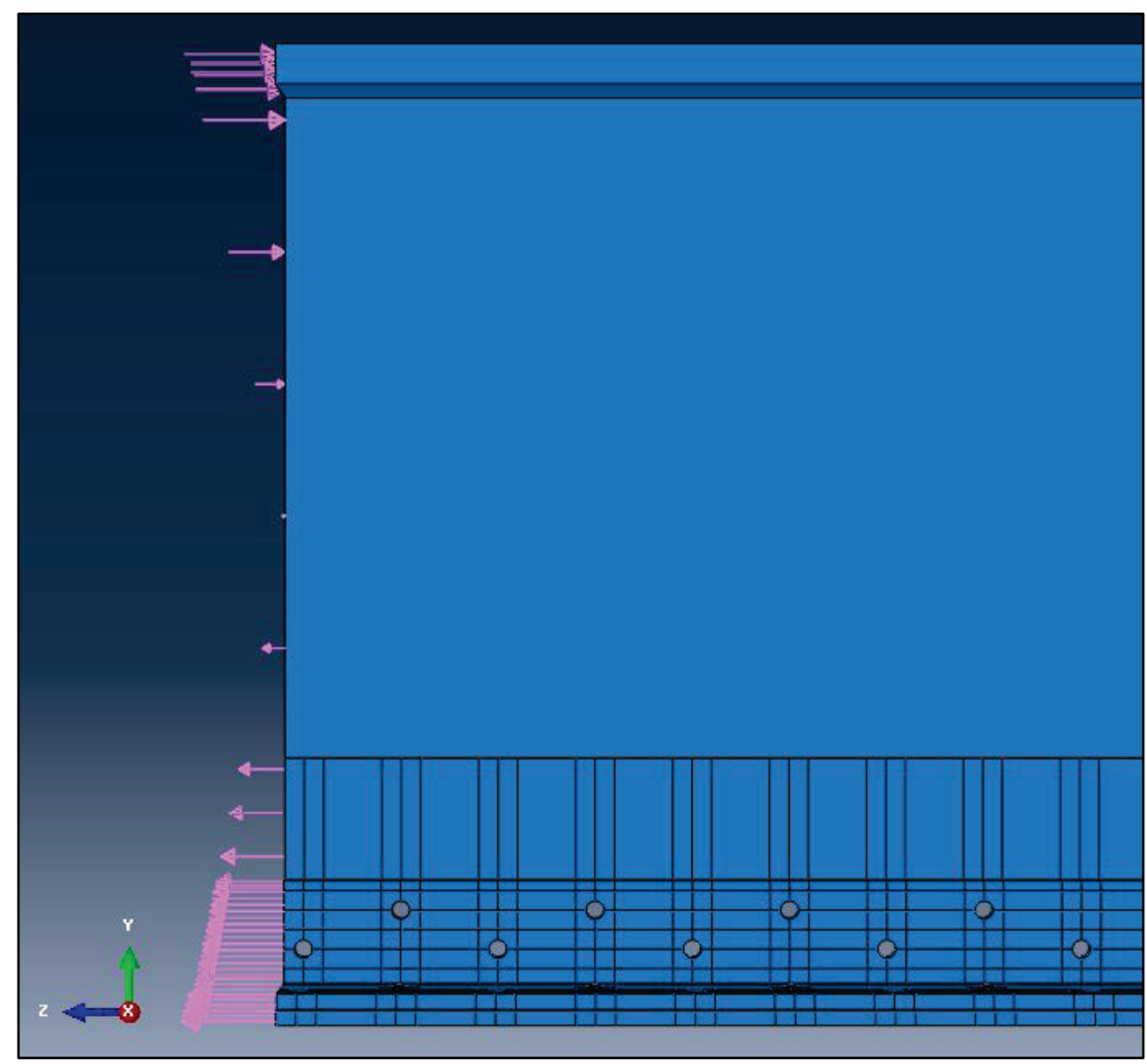

Figure 4-11 Axial model - trapezoidal load distribution

After the axial model was successfully created, the resulting longitudinal stresses were compared with the full model. The stress values were very nearly the same with an average of $2.0 \%$ difference. A mesh refinement study was performed with 4 additional models with increasing levels of refinement. Because the model constructed was of a beam with a failed cover plate, the most affected stress distributions (and therefore the point of interest) were in the flange angle near the failure. A 24" portion of the flange angle adjacent to the failed cover plate was refined to the levels shown in Table 4-3. The number of hole seeds describe the number of seeds at each quarter of the edge of the hole 
along a line extending from each quadrant of the hole to a $2^{\prime \prime} \times 2^{\prime \prime}$ square centered around the hole (as shown in Figure 4-12a).

Table 4-3 Axial model flange angle mesh refinement parameters

\begin{tabular}{|c|c|c|}
\hline Model & Global Mesh Size & \# of Hole Seeds \\
\hline Axial Model & $0.5^{\prime \prime}$ & 6 \\
\hline Refined 1 & $0.25^{\prime \prime}$ & 12 \\
\hline Refined 2 & $.1875^{\prime \prime}$ & 15 \\
\hline Refined 3 & $.125^{\prime \prime}$ & 18 \\
\hline Refined 4 & $.0625^{\prime \prime}$ & 21 \\
\hline
\end{tabular}

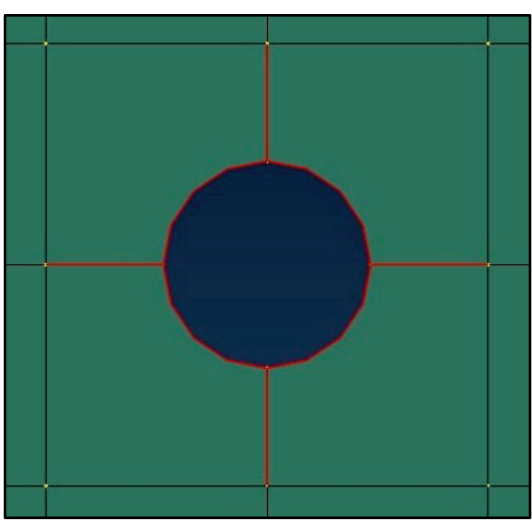

(a)

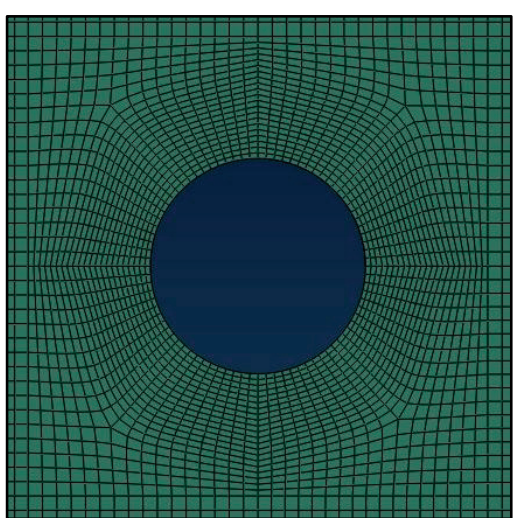

(b)

Figure 4-12 (a) Hole mesh seeding location, (b) Hole mesh 


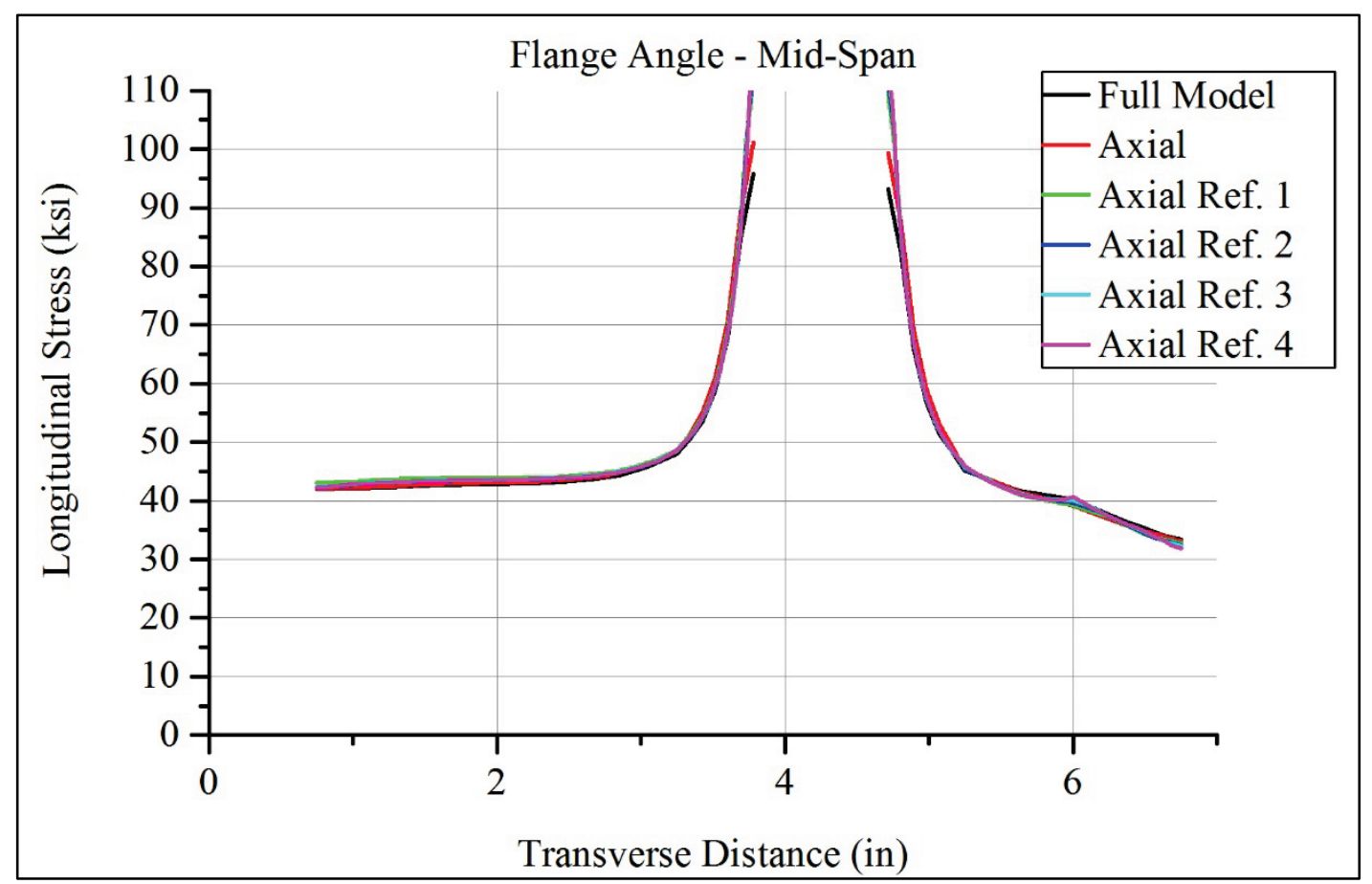

\section{Figure 4-13 Axial model (with refined versions) vs. full model}

In order to compare the results of the different models, a single equivalent netsection stress value of the partially failed cross-section was desired for each component at a cross-section. The trapezoidal rule was used to obtain the force in the component, and subsequently, the force was divided by the net area to obtain an equivalent net-section stress. A large stress gradient was observed through the thickness of a component in the FE model when a component in the same cross-section was partially or fully failed. In order to take into account the variation in stresses throughout the thickness, horizontal paths were created at evenly spaced increments at the point of interest and were compared. Figure 4-14 shows the flange angle of an axial model, with the plotted longitudinal stress (note the stress gradient). In addition, the horizontal paths used to determine stress profiles through the thickness of the component are shown (drawn as 
yellow lines in the image). The stress range of the plot is between $30 \mathrm{ksi}$ and $80 \mathrm{ksi}$ to highlight the stress concentration in the flange angle as well as the stress gradient through the thickness. The stress profile at each path was averaged in order to find a single stress value at each transverse point across the width of the horizontal leg of the flange angle. Next the trapezoidal rule was used to approximate the total force in the component while taking into account the distance from node-to-node (element width) in the FE model as follows:

$$
\sigma_{n e t}=\sum\left(x_{2}-x_{1}\right)\left[\frac{\sigma_{1}+\sigma_{2}}{2}\right]
$$

Where:

$$
\begin{aligned}
& \sigma_{\text {net }}=\text { Net-section stress } \\
& \mathrm{x}_{1}=\text { Distance to } 1^{\text {st }} \text { node from origin } \\
& \mathrm{x}_{2}=\text { Distance to } 2^{\text {nd }} \text { node from origin } \\
& \sigma_{1}=\text { Stress at node } 1 \\
& \sigma_{2}=\text { Stress at node } 2
\end{aligned}
$$

Lastly, the force in the component was divided by the net-area at the cross-section to determine an equivalent net-section stress. Figure 4-15 shows the stress profile at each of the paths through the thickness of the flange angle as well as the equivalent net-section stress calculated from the trapezoidal rule. 


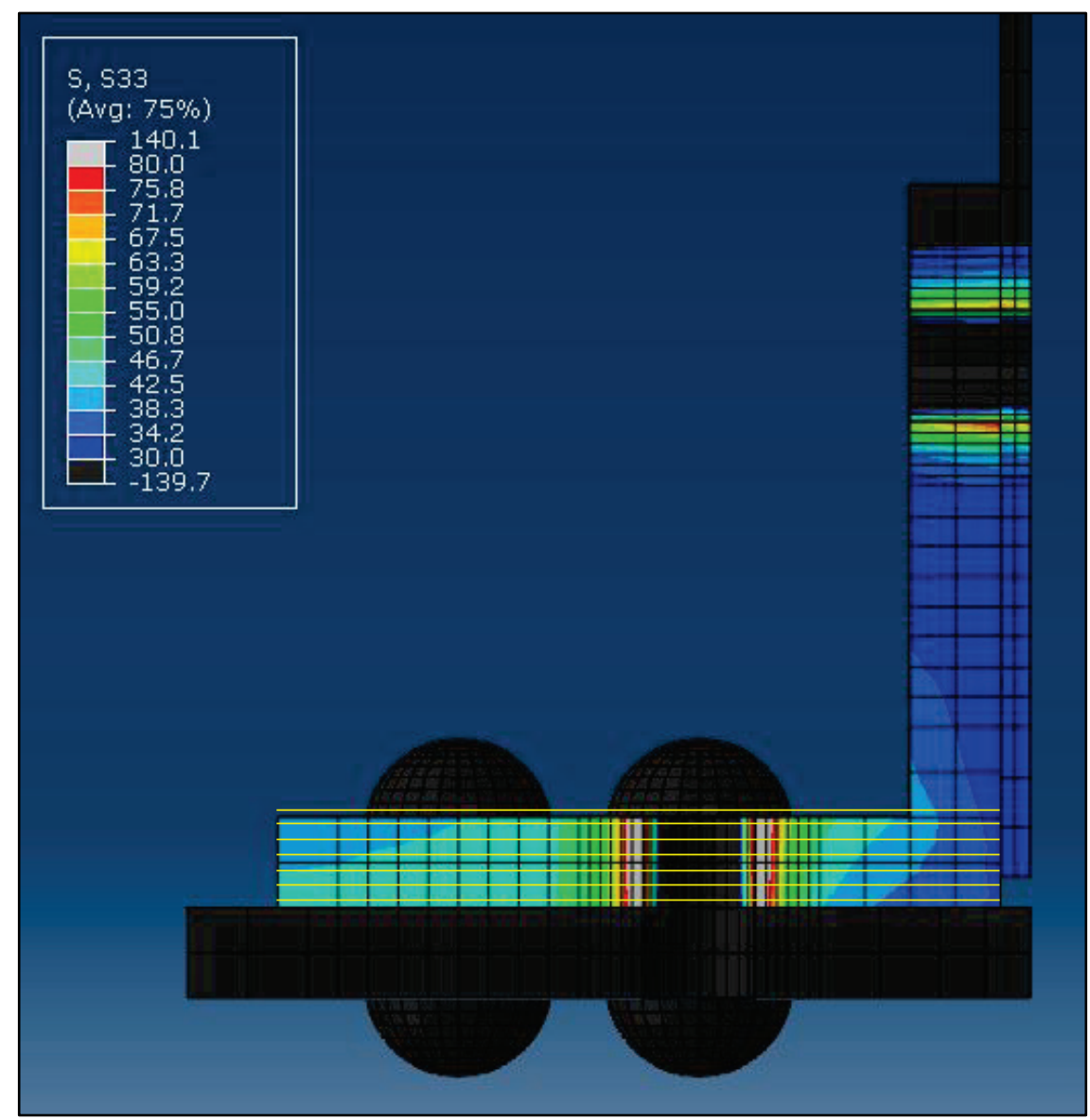

Figure 4-14 Axial model - stress paths through horizontal leg of flange angle 


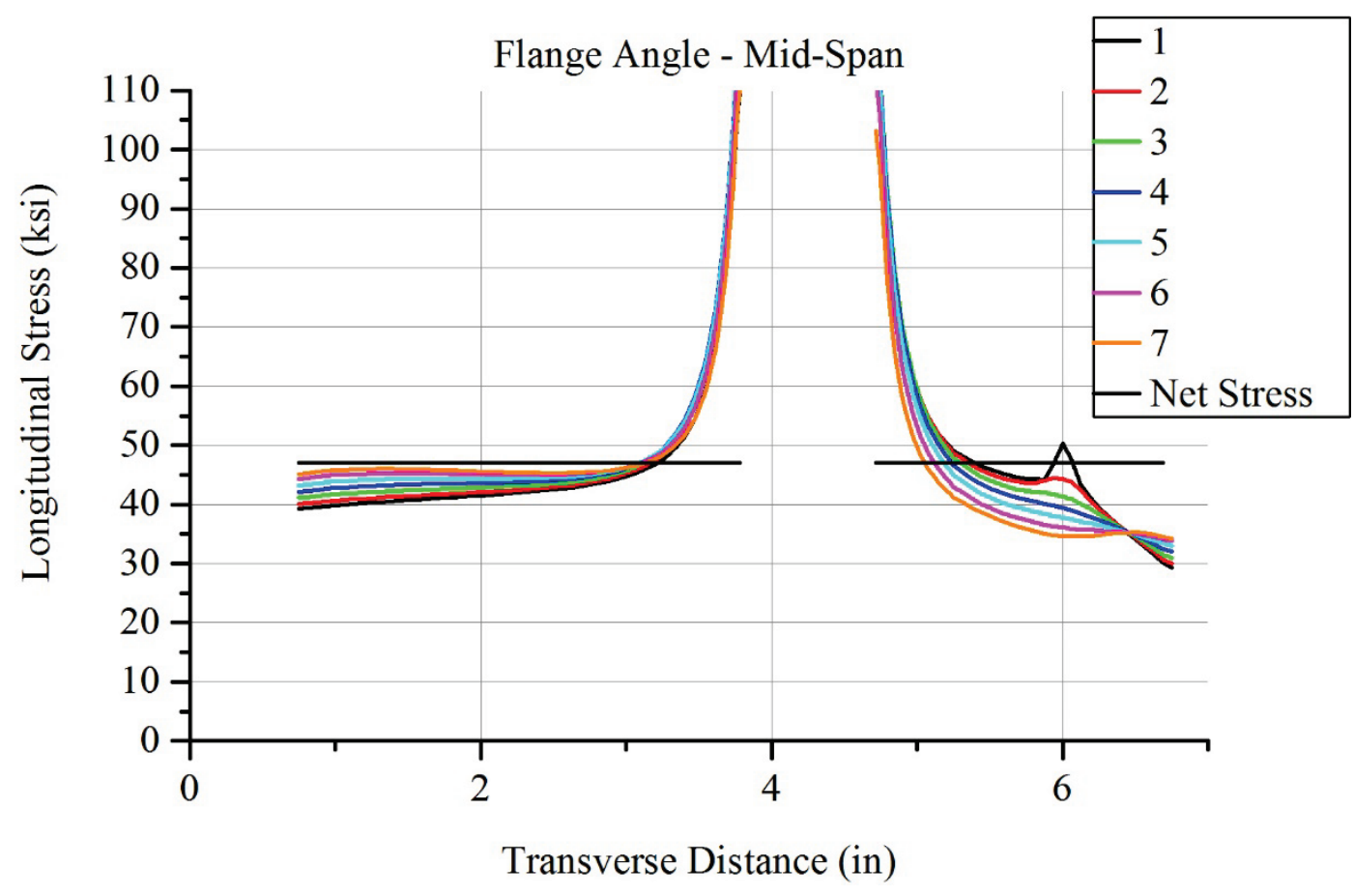

Figure 4-15 Axial model - stress gradient through flange angle thickness

The axial models produced good results which reduced the overall computational time and requirements which facilitated the performance of the parametric study (which required many models to be analyzed). Additionally, it was found that a linear elastic model was slightly conservative and also produced results which compared well with the experimental data. 


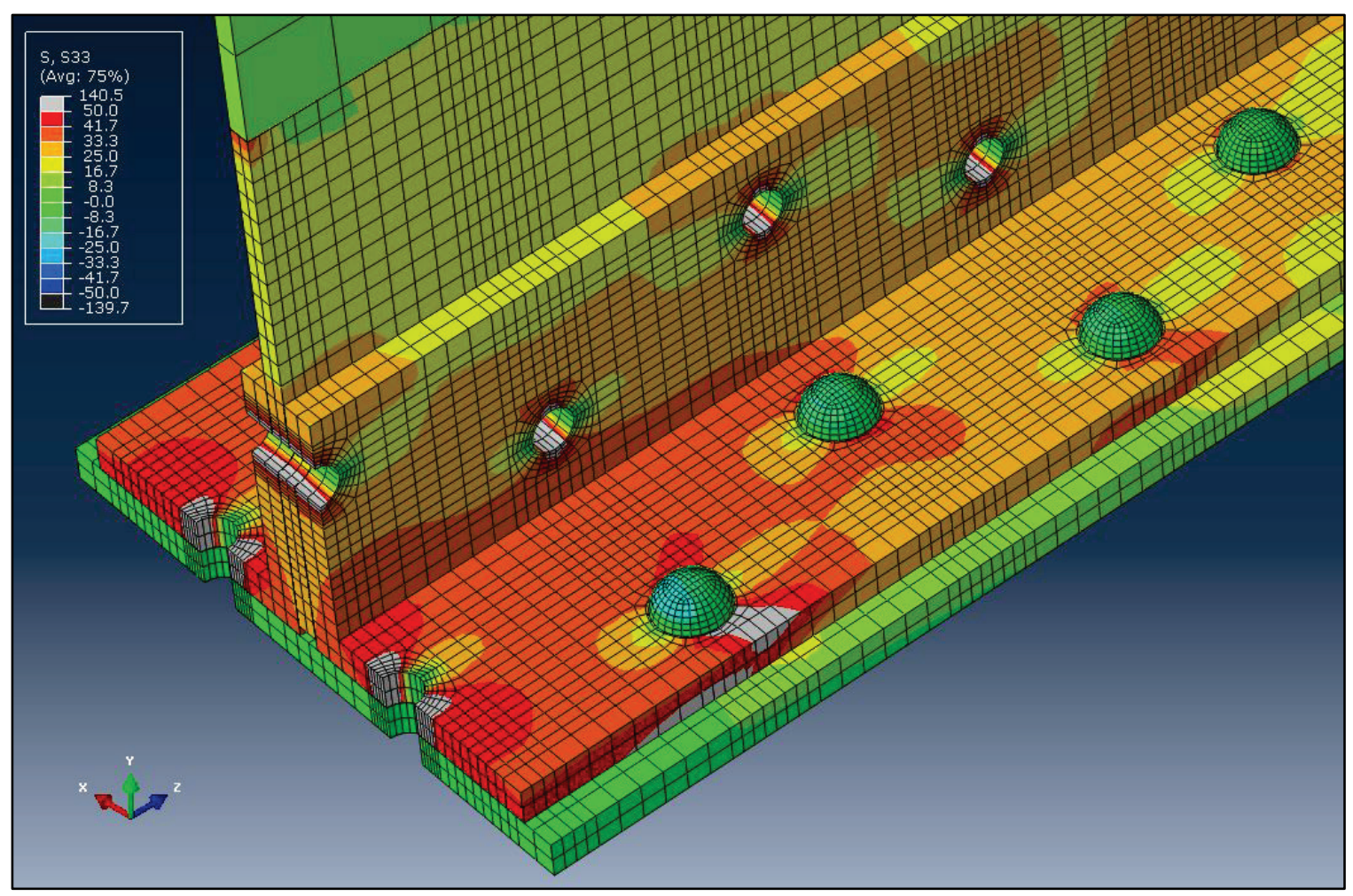

Figure 4-16 Typical axial model (failed cover plate)

\subsection{Analytical Parametric Study}

The goal of the analytical parametric study was to determine the relationships between various parameters to the resulting stresses in the net-section at the point of a failed (or partially failed) component through the use of FE models. The sensitivity of different parameters which were expected to affect the behavior of component stress concentrations resulting from the failure or partial failure of a component were investigated. The following parameters were included in the parametric study:

1. Non-symmetric failure of cross-section (i.e. flange angle failure or partial cover plate failure)

2. Tension flange unbraced length 


\section{Web height}

4. Cover plate quantity/area/geometry

Throughout the parametric study, if a parameter was found to have an insignificant affect (less than $5 \%$ change in longitudinal stresses) the parameter was not included in the remaining parametric study. This led to a streamlined parametric study by including only those parameters which had a large influence on the resulting stress distribution.

\subsubsection{Parametric Model Development}

The finite element model used in the parametric studies was based on the axial model developed in Section 4.1.3. An implicit (standard) model was used with beam components having a length of $120^{\prime \prime}$. The web plate was $0.5^{\prime \prime} \times 72^{\prime \prime}$, the flange angles were $8^{\prime \prime} \times 8^{\prime \prime} \times 1 "$, and the top and bottom cover plates were $20^{\prime \prime} \times 1 "$. Rivets were $1^{\prime \prime}$ diameter nominal, with a modeled diameter of 1-1/16" (due to the hole size and the tendency for rivets to expand and fill a hole during the driving process). The top flange, components (cover plate, flange angles, and upper 12" of the web plate) were modeled as a single shape and then extruded. Partitions were used in the top flange part to create boundaries at simulated component faces. No rivets were used for the upper cover plate because of the distance from the point of interest. The remaining $60^{\prime \prime}$ of the web plate was divided into two sections, a $12^{\prime \prime}$ strip at the bottom which had fastener holes and was connected to the bottom flange angles, and a 48 " middle portion which was tied to the upper and lower portion with a surface tie constraint. Following the findings from the development of the axial model (in Section 4.1.3), the first four rivets (on each side of the 
flange angle-to-cover plate connection) were modeled, and the remaining rivets were simulated with nodal tie constraints between each of the elements at the rivet holes.

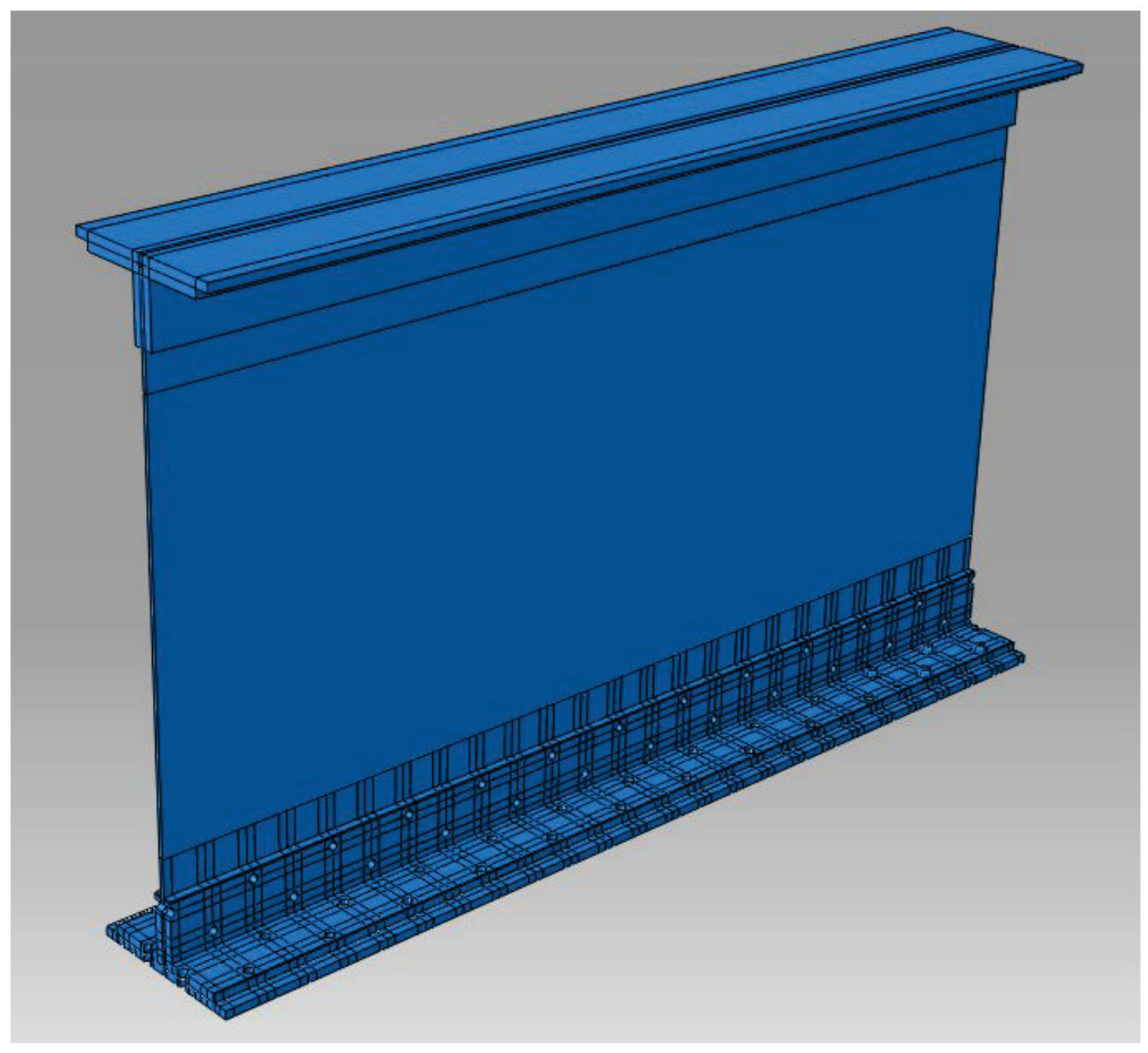

Figure 4-17 Parametric model

The material was defined as linear elastic $(E=29,000 \mathrm{ksi} ; v=0.3)$ and having a density of $7.4 \times 10^{-7}$ kips-s ${ }^{2} / \mathrm{in}^{4}$. Symmetry was applied at the vertical transverse plane at the failure location (point of interest) using a boundary condition. A simulated top flange bracing was applied using a boundary condition preventing displacement of the top flange cover plate in the transverse direction. The bottom flange was braced (using a 
nodal boundary condition) in the transverse direction at a distance of $120^{\prime \prime}$ from the failure (simulating an unbraced bottom flange length of $20^{\prime}-0^{\prime \prime}$.

The global seed size for the top flange part (including the upper web plate portion, top flange angles, and cover plate) was 2.0". A minimum of two elements were used through the height of each portion of the part. The middle portion of the web plate was meshed with a global seed size of 6.0". The bottom flange components (lower portion of the web plate, flange angles, and cover plate) were given a global seed size of $0.5^{\prime \prime}$. The holes were seeded with a total of 6 seeds per line portion as described in Section 4.1.3 and shown in Figure 4-12. The global seed size for the rivets was 0.125". 'Hard Contact' normal behavior was used as the contact method.

The components were given a 'Frictionless' tangential behavior based on previous results. A bending moment was simulated using an axial trapezoidal stress at the vertical cross section at the end of the model. The magnitude of the stress was equivalent to 0.55 $\mathrm{F}_{\mathrm{y}}(27.5 \mathrm{ksi})$ at the top and bottom (compression and tension, respectively) of the model. The stress distribution at the point of interest, the failure plane, was measured in each of the components. The stress was measured at five equal increments (six paths) through the thickness of each component and then averaged to minimize stress gradient concentrations at discrete locations through the thickness (as explained in Section 4.1.3).

The longitudinal stresses in the unfailed components were very similar at both the cross-section of the failure (mid-span for these models) and the first hole adjacent to the failure. This was expected because of the required stress transfer and the net-section at this location. Figure 4-18 shows the stress transfer in both the flange angles (a) and the cover plate (b) of a model with a fully failed cover plate (at the left side of the 
components shown). The longitudinal stresses are plotted from a range of $0 \mathrm{ksi}$ to $60 \mathrm{ksi}$ in order to illustrate the stress distribution between components. As is shown in the figure, the largest stresses in the flange angle are from the failure plane (left side) to the first row of rivets to the right of the failure.

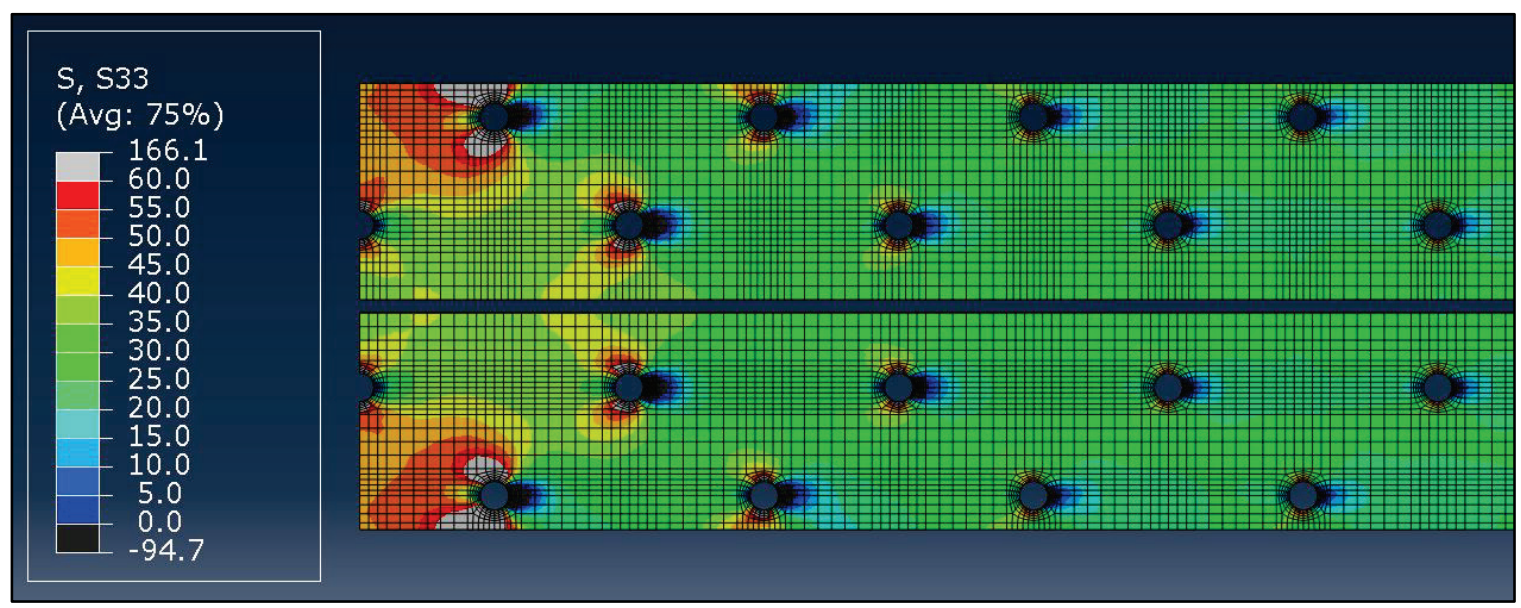

(a)

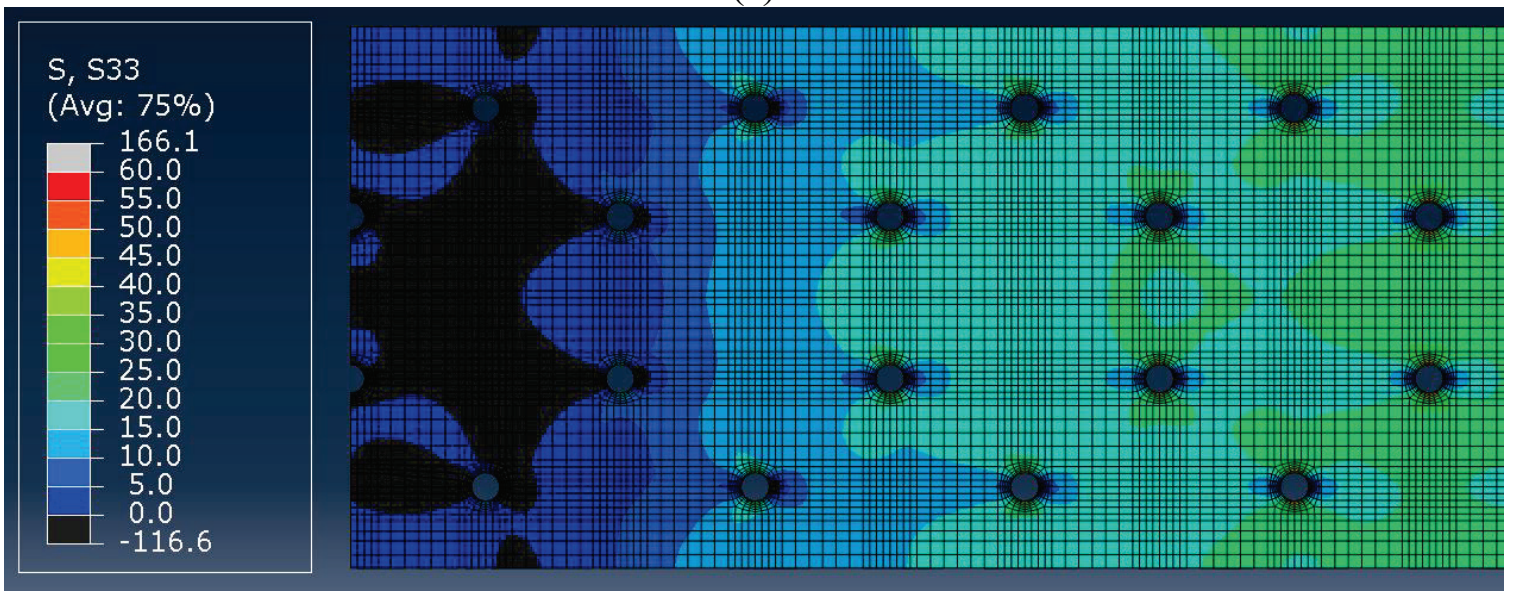

(b)

Figure 4-18 Stress transfer in (a) Flange angles, (b) Cover plate

\subsubsection{Non-symmetric Cross-section}

A built-up beam with a non-symmetrical cross-section could result from the failure of a flange angle or the partial failure of a cover plate (during the growth of a 
fatigue crack). To determine the influence of a non-symmetric cross-section on the longitudinal stress in a component adjacent to a failed, or partially failed, component (i.e., a cover plate), a series of models were constructed and analyzed with increasing percentages of a failure in the single cover plate. Additionally a model with a failed flange angle was compared (see Figure 4-19 for the model geometries). The built-up member size and geometry described in Section 4.1.3 was used for each of the models. It was expected that a larger non-symmetric influence would result when a portion of a cover plate was failed than when a flange angle was completely failed due to the proportional bottom flange area.
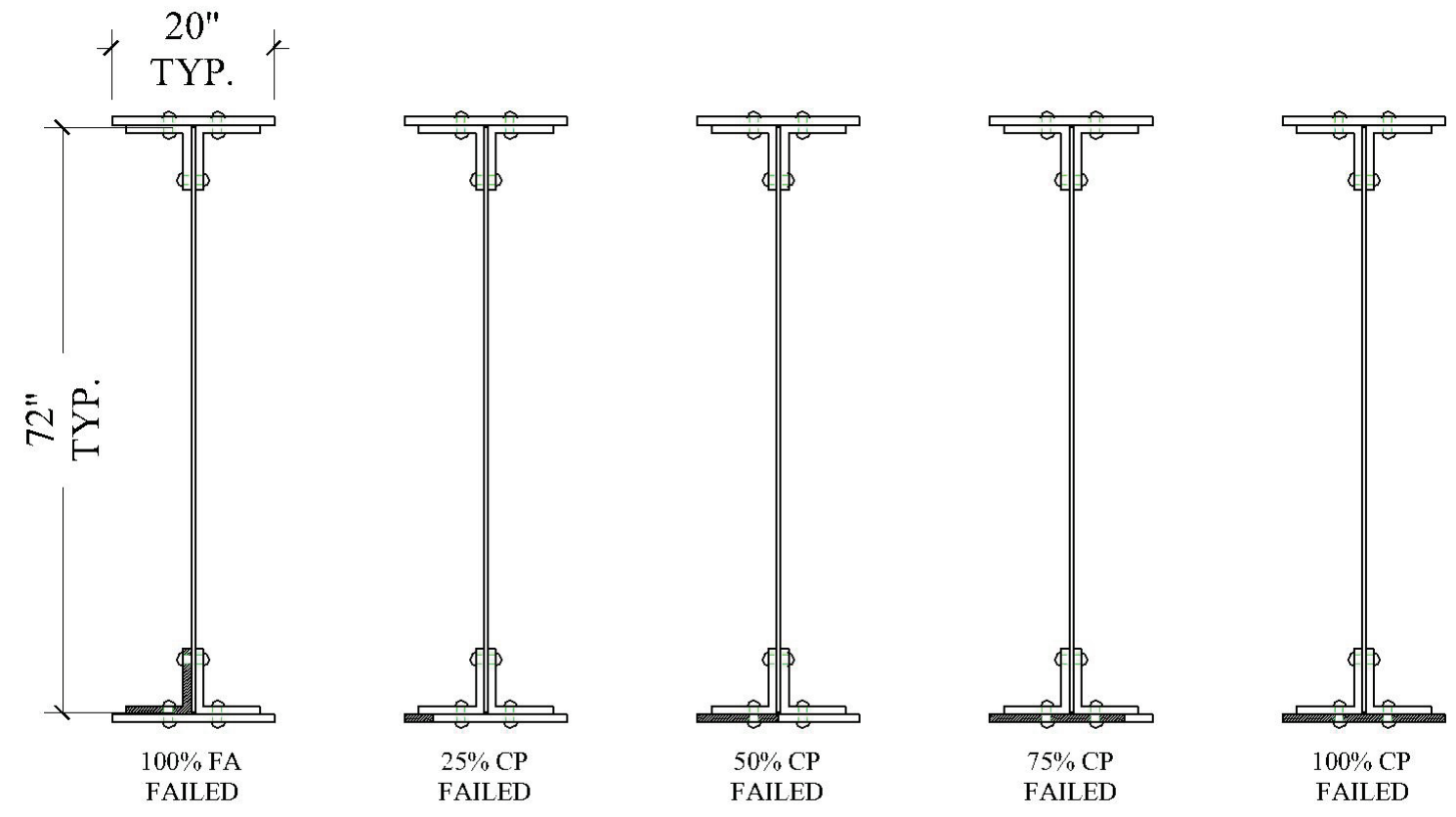

Figure 4-19 Non-symmetric cross-section models 


\subsubsection{Results}

The longitudinal stresses at the failure location (mid-span) and at the first hole were compared to determine which location was most critical. Table 4-4 shows a comparison between the net-section stresses of the partially failed cross section at each location for each of the different models used. The net-section stress reported is for a single flange angle (the one with the highest stresses). Since there was less than $1 \%$ difference between all models, the stresses at the failure plane were used for further comparison between the models.

Table 4-4 After-failure net-section stress comparison - failure plane vs. $1^{\text {st }}$ hole

\begin{tabular}{|c|c|c|c|}
\hline \multirow{2}{*}{ Model } & \multicolumn{3}{|c|}{ Net-section Stress (ksi) } \\
\cline { 2 - 4 } & Mid-span & 1st Hole & \% Diff \\
\hline No Failure & 26.89 & 27.09 & $0.7 \%$ \\
\hline 25\% CP Failed & 30.97 & 31.12 & $0.5 \%$ \\
\hline 50\% CP Failed & 43.07 & 43.15 & $0.2 \%$ \\
\hline 75\% CP Failed & 53.12 & 53.22 & $0.2 \%$ \\
\hline 100\% CP Failed & 48.86 & 49.22 & $0.7 \%$ \\
\hline 100\% FL Failed & 29.21 & 29.27 & $0.2 \%$ \\
\hline
\end{tabular}

Plots were made to compare the distribution of longitudinal stresses in each flange angle with the original stresses. Figure 4-20 shows the stresses in the original model (with no failure) compared to those in a model with the entire cover plate failed. The increase in the net-section stress (obtained through the trapezoidal rule as described in Section 4.1.3) was from $26.9 \mathrm{ksi}$ (approximately $0.55 \mathrm{~F}_{\mathrm{y}}$ ) to $48.9 \mathrm{ksi}$, an increase of $81.7 \%$. Due to the symmetry of the failed cross-section, the stresses have a similar distribution to the original stresses along the horizontal leg of the flange angle. 


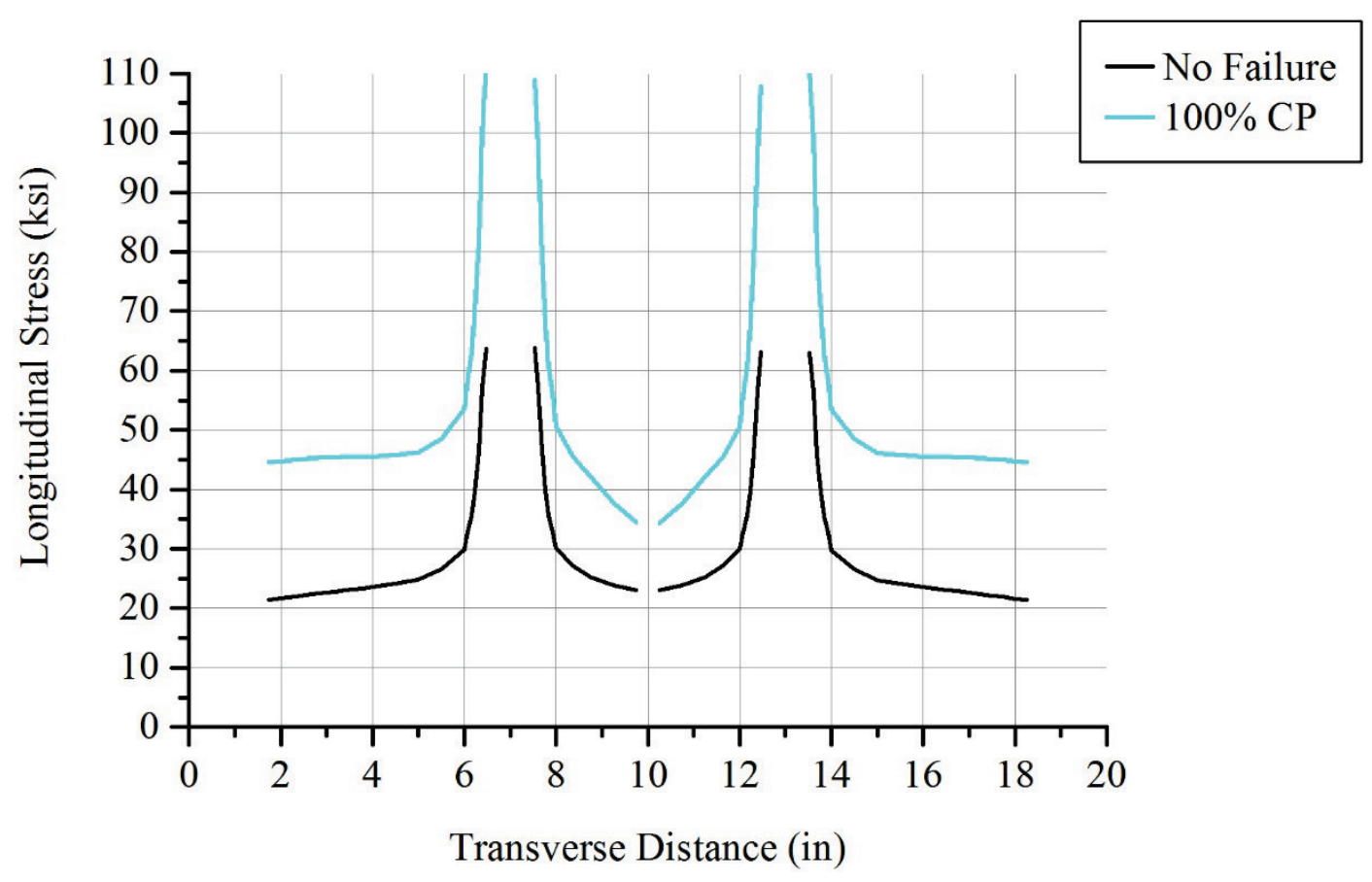

Figure 4-20 Stress comparison - No failure vs. $100 \%$ cover plate failure

A model was then analyzed for stress increases in a flange angle due to a nonsymmetric condition resulting from a complete failure of an adjacent flange angle. A modest stress increase of $8.6 \%$ (of the after failure net-section) resulted from this situation. The distribution of the stress can be seen in Figure 4-21. However, as will be discussed, the stresses for this condition were much lower than those produced by a partially failed cover plate. 


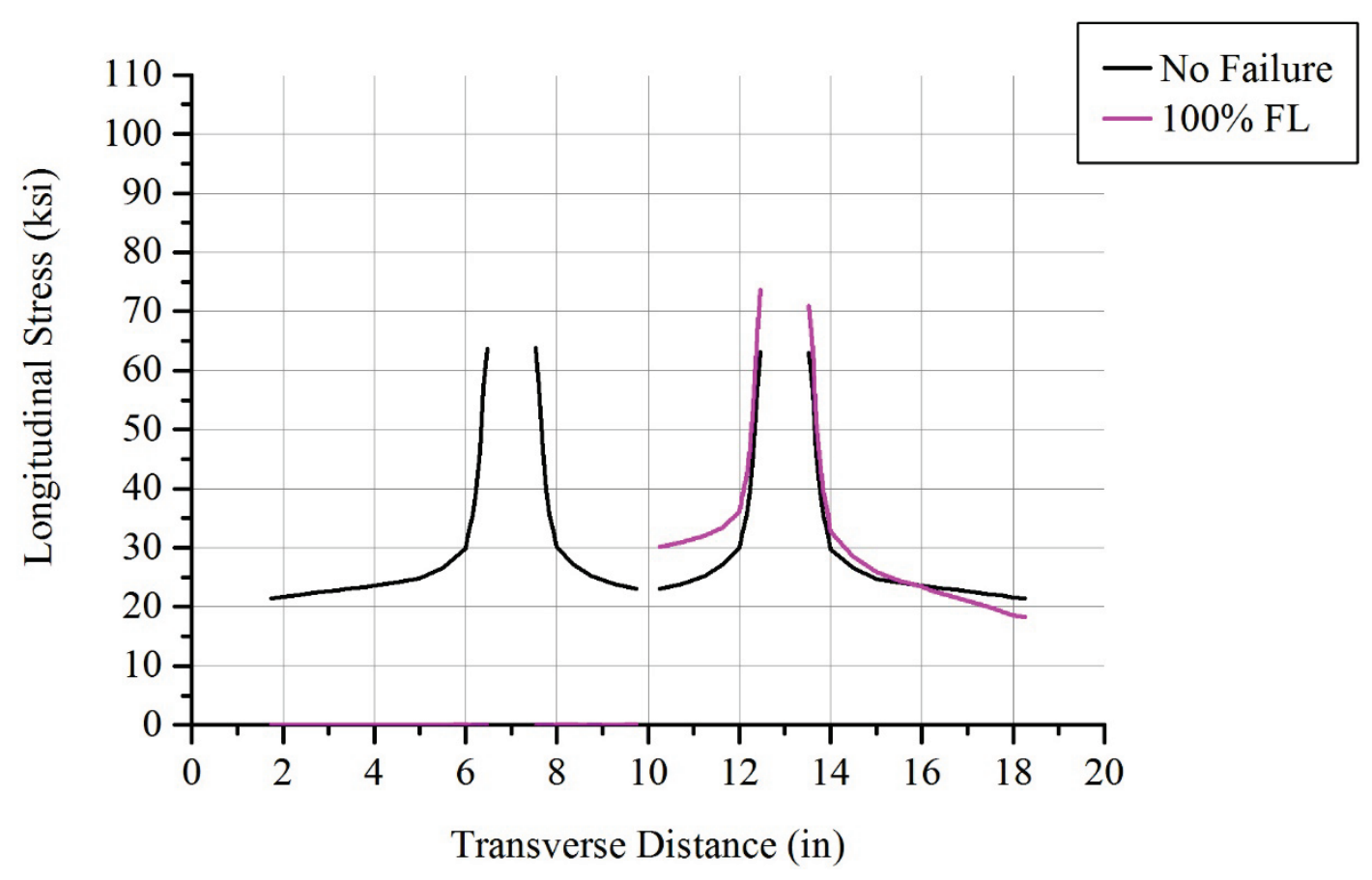

Figure 4-21 Stress comparison - No failure vs. $100 \%$ flange angle failure

The resulting stresses in the horizontal leg of the flange angle from models having three different amounts of cover plate degradation $(25 \%, 50 \%$, and $75 \%)$ are shown in Figure 4-22. As can be seen in the figure, the stress distribution results in an increase in longitudinal stresses in the flange angle above the cracked portion of the cover plate. Additional models (with partial flange failures of $60 \%, 85 \%$, and $95 \%$ ) were analyzed to characterize the increase in stress as influenced by the percentage of partial failure. Table 4-5 gives compares the resulting net-section stress (from the FE models) for each portion of cover plate failure. Figure 4-23 shows this information graphically. 


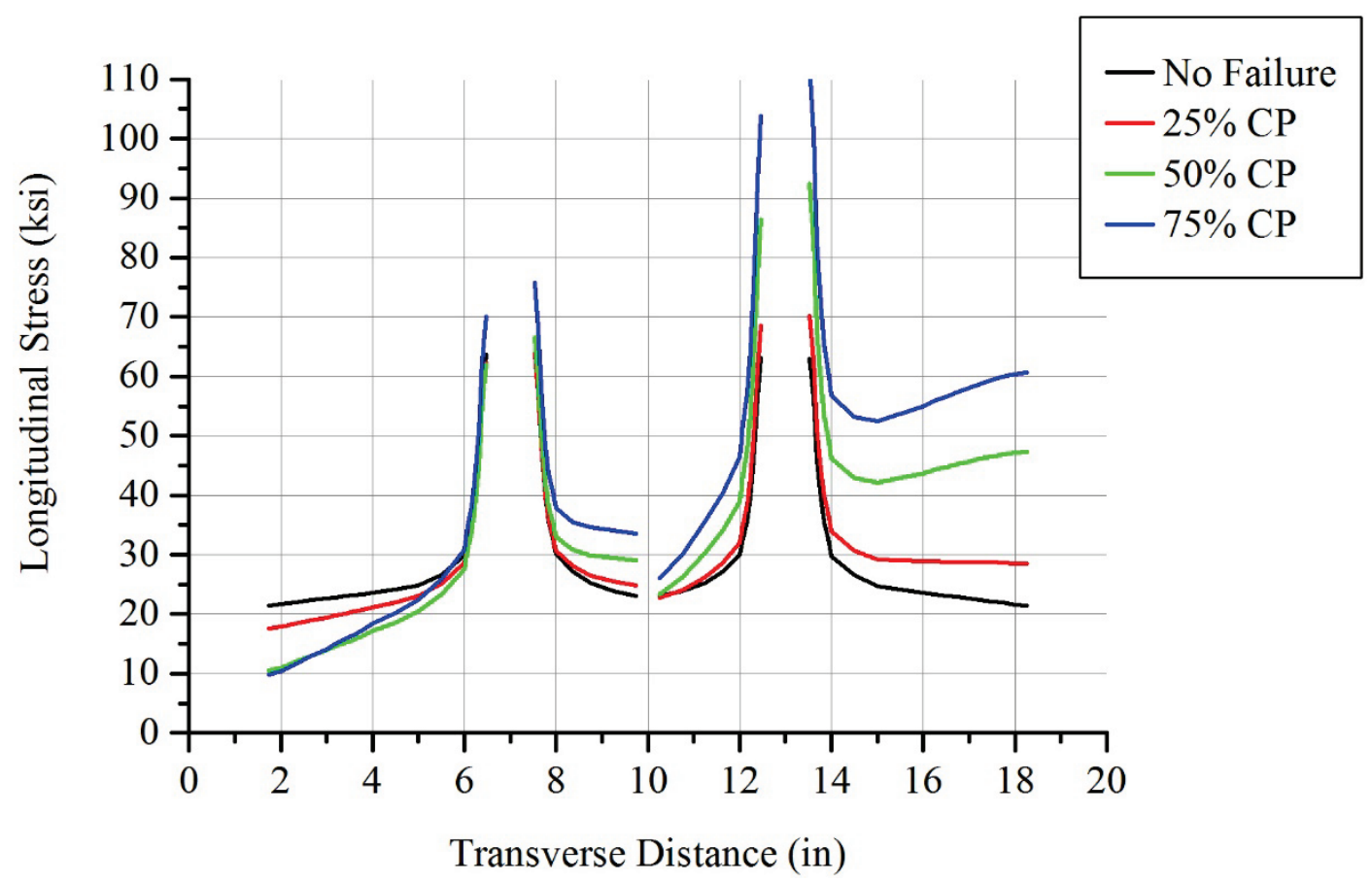

Figure 4-22 Stress comparison - No failure vs. $25 \%, 50 \%, 75 \%$ cover plate failure

Table 4-5 Out-of-plane stress redistribution (20" CP - partial cover plate failure)

\begin{tabular}{|c|c|c|c|c|}
\hline \multirow{2}{*}{ Model } & \multirow{2}{*}{$\begin{array}{c}\text { Gross \% } \\
\text { Failed }\end{array}$} & $\begin{array}{c}\text { Net } \% \\
\text { Failed }\end{array}$ & \multicolumn{2}{|c|}{$\begin{array}{c}\text { Net-s ection Stress } \\
\text { (ksi) }\end{array}$} \\
\cline { 4 - 5 } & & & Mid-span & $\%$ Diff \\
\hline No Failure & $\mathbf{0}$ & $\mathbf{0 \%}$ & 26.9 & $0.0 \%$ \\
\hline $\mathbf{2 5 \%}$ CP Failed & $\mathbf{2 5 \%}$ & $\mathbf{2 8 \%}$ & 31.0 & $15.2 \%$ \\
\hline $\mathbf{5 0 \%}$ CP Failed & $\mathbf{5 0 \%}$ & $\mathbf{5 0 \%}$ & 43.1 & $60.2 \%$ \\
\hline $\mathbf{6 0 \%}$ CP Failed & $\mathbf{6 0 \%}$ & $\mathbf{5 5 \%}$ & 48.3 & $79.6 \%$ \\
\hline $\mathbf{7 5 \%}$ CP Failed & $\mathbf{7 5 \%}$ & $\mathbf{7 2 \%}$ & 53.1 & $97.5 \%$ \\
\hline $\mathbf{8 5 \%}$ CP Failed & $\mathbf{8 5 \%}$ & $\mathbf{8 3} \%$ & 54.8 & $103.6 \%$ \\
\hline $\mathbf{9 5 \%}$ CP Failed & $\mathbf{9 5 \%}$ & $\mathbf{9 4 \%}$ & 54.6 & $103.1 \%$ \\
\hline $\mathbf{1 0 0 \%}$ CP Failed & $\mathbf{1 0 0 \%}$ & $\mathbf{1 0 0 \%}$ & 48.9 & $81.7 \%$ \\
\hline
\end{tabular}




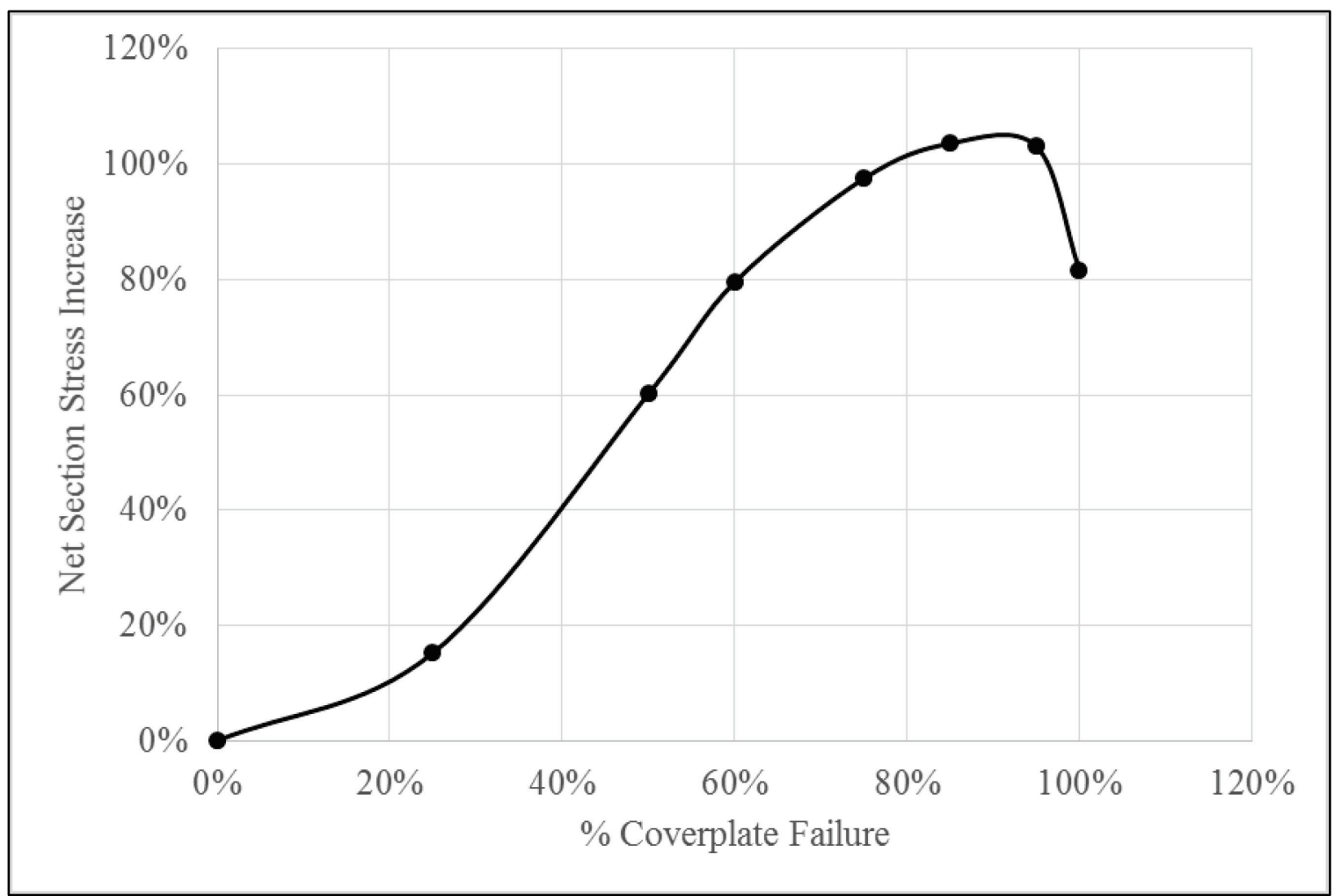

Figure 4-23 Out-of-plane stress redistribution (20" CP - partial cover plate failure)

The data indicates that with a fully failed cover plate, the stress increases $81.7 \%$ in the flange angles (at the plane of failure). With a partially failed cover plate, the outof-plane effects reach approximately the same level $(79.6 \%)$ when the cover plate is $60 \%$ failed. Eight additional models with a significantly larger top and bottom cover plate $\left(26^{\prime \prime} \times 1 "\right)$ were also constructed and analyzed. All other aspects of these models (including the remaining components) were identical to the previously analyzed models with $20^{\prime \prime} \times 1 "$ cover plates. The tabulated stress increases due to out-of-plane behavior are shown in Table 4-6 and the graphical representation of the data is shown in Figure 4-24. The data illustrates that, similarly to the $20^{\prime \prime}$ cover plate specimens, the stress increase in a single flange angle is equivalent to a fully failed cover plate model when about $60 \%$ of 
the cover plate has failed. The value increases until the crack is about $95 \%$ across the cover plate.

Table 4-6 Out-of-plane stress redistribution (26" CP - partial cover plate failure)

\begin{tabular}{|c|c|c|c|c|}
\hline \multirow{2}{*}{ Model } & \multirow{2}{*}{$\begin{array}{c}\text { Gros } \mathbf{\%} \\
\text { Failed }\end{array}$} & \multirow{2}{*}{$\begin{array}{c}\text { Net \% } \\
\text { Failed }\end{array}$} & \multicolumn{2}{|c|}{$\begin{array}{c}\text { Net-section Stress } \\
\text { (ksi) }\end{array}$} \\
\cline { 4 - 5 } & & & Mid-span & \% Diff \\
\hline No Failure & $\mathbf{0}$ & $\mathbf{0 \%}$ & 27.0 & $0.0 \%$ \\
\hline $\mathbf{2 5 \%}$ CP Failed & $\mathbf{2 5 \%}$ & $\mathbf{2 7 \%}$ & 32.0 & $18.7 \%$ \\
\hline $\mathbf{5 0 \%}$ CP Failed & $\mathbf{5 0 \%}$ & $\mathbf{5 0 \%}$ & 50.3 & $86.6 \%$ \\
\hline $\mathbf{5 8 \%}$ CP Failed & $\mathbf{5 8 \%}$ & $\mathbf{5 4 \%}$ & 56.6 & $109.9 \%$ \\
\hline $\mathbf{6 5 \%}$ CP Failed & $\mathbf{6 5 \%}$ & $\mathbf{6 2 \%}$ & 60.8 & $125.3 \%$ \\
\hline $\mathbf{7 5 \%}$ CP Failed & $\mathbf{7 5 \%}$ & $\mathbf{7 3 \%}$ & 64.8 & $140.2 \%$ \\
\hline $\mathbf{8 2 \%}$ CP Failed & $\mathbf{8 2 \%}$ & $\mathbf{8 0 \%}$ & 66.3 & $145.9 \%$ \\
\hline $\mathbf{9 8 \%}$ CP Failed & $\mathbf{9 8 \%}$ & $\mathbf{9 8 \%}$ & 65.3 & $142.0 \%$ \\
\hline $\mathbf{1 0 0 \%}$ CP Failed & $\mathbf{1 0 0 \%}$ & $\mathbf{1 0 0 \%}$ & 57.6 & $113.5 \%$ \\
\hline
\end{tabular}

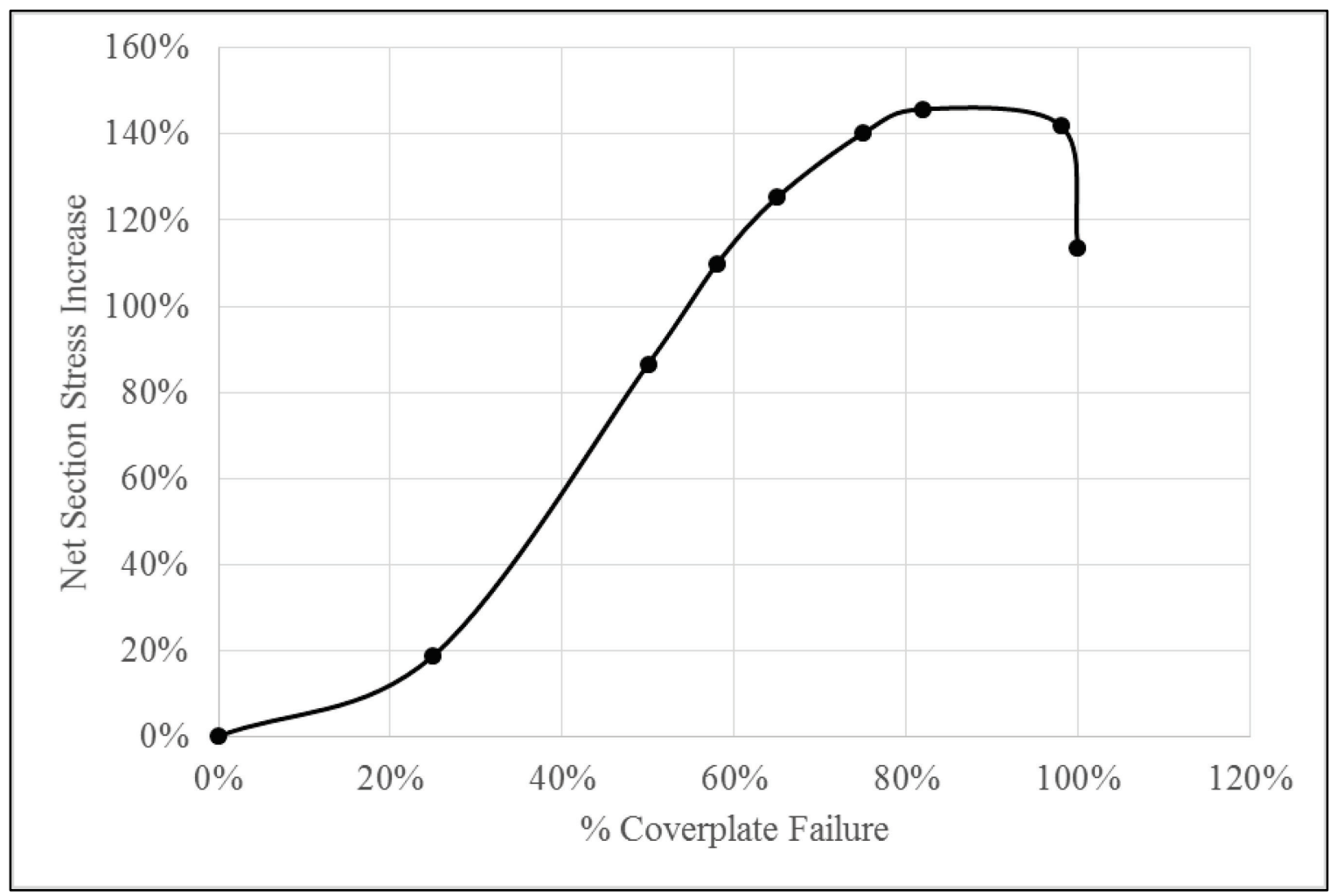

Figure 4-24 Out-of-plane stress redistribution (26" CP - partial cover plate failure) 


\subsubsection{Tension Flange Unbraced Length}

The impact of the bracing length of the tension (bottom) flange of a built-up girder was investigated to determine how much of an effect it plays on stress increases on remaining bottom flange components when a non-symmetric condition exists. Three different bottom flange unbraced lengths were used: 10'-0", 20'-0", and 30'-0". Because bottom flange bridge bracing is typically spaced in the range of $20^{\prime}-0^{\prime \prime}$ to $25^{\prime}-0^{\prime \prime}$ the models investigated unbraced lengths which were larger and smaller than this range to evaluate extreme limits.

In order to isolate the behavior of the unbraced length, a single built-up member size was used while only varying the bracing points for this sensitivity analysis study. The member geometry was very similar to that used in previous portions of this parametric study. The top and bottom flange were composed of $8^{\prime \prime} \times 8^{\prime \prime} \times 1^{\prime \prime}$ flange angles, with a single $20^{\prime \prime} \times 1 "$ cover plate. A $72^{\prime \prime} \times 1 / 2^{\prime \prime}$ web plate was used with a $75 \%$ failure at the midspan (plane of symmetry). Each component had a length of $15^{\prime}-0^{\prime \prime}$ (from the plane of symmetry). Figure 4-25 shows a drawing of each of the simulated beams. The bracing was simulated by restraining the transverse displacement of the vertical leg of the bottom flange angle at $1 / 2$ of each of the three unbraced lengths $\left(5^{\prime}, 10^{\prime}\right.$, and $\left.15^{\prime}\right)$ due to the symmetry of the model. 


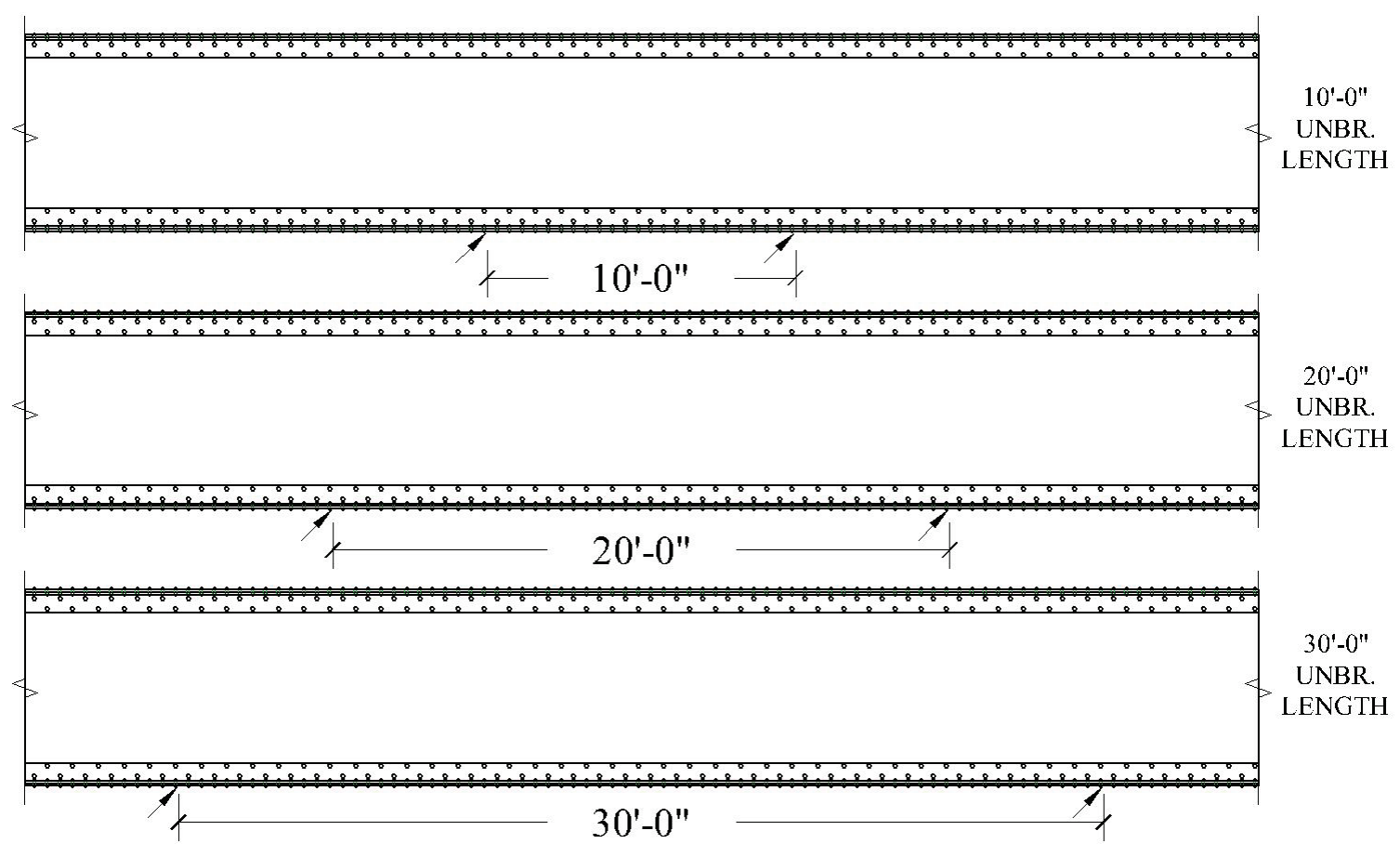

Figure 4-25 Unbraced length parameter model geometries

The models were analyzed for each of the unbraced lengths. For each model, the longitudinal stress in the flange angles directly above the partially failed cover plate was evaluated using the method described in Section 4.1.3. The resulting stresses in the highest stressed flange angle for all three models was $52.71 \mathrm{ksi}$. There was no increase or decrease in longitudinal stresses as a result of differing the bottom flange unbraced length.

\subsubsection{Web Height}

Due to the influence of a member's height on its section modulus, the web plate height was varied for a set of models to explore how much of an effect it plays on stress 
distribution in built-up girders. Four different web heights were used (24", 48", 72", and 96"). All other geometric dimensions and material properties of the models were held constant to isolate the specimen height parameter. Similar to previous models in the parametric study, $8^{\prime \prime} \times 8^{\prime \prime} \times 1$ " flange angles were constructed with $20^{\prime \prime} \times 1$ " cover plates and an unbraced bottom flange length of $20^{\prime}-0^{\prime \prime}$. Figure 4-26 shows each of the four model types.

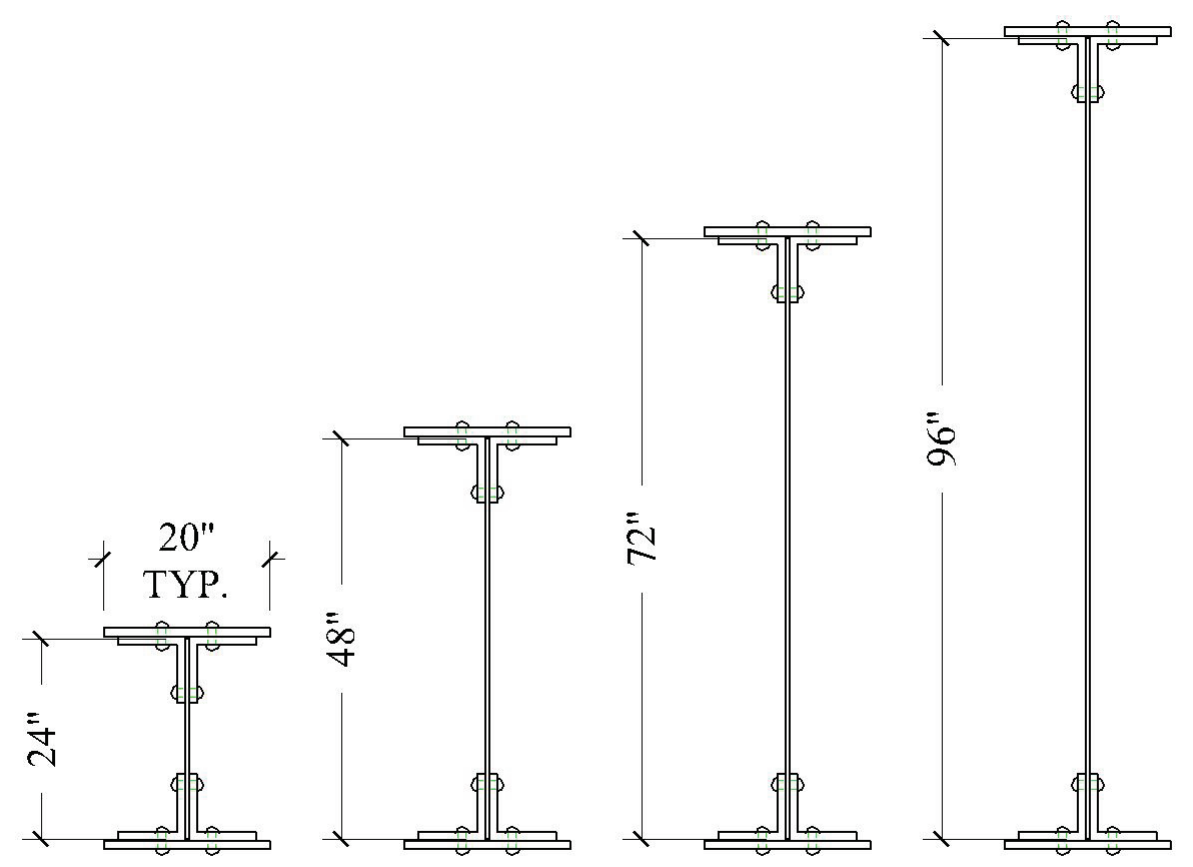

Figure 4-26 Web height parameter model geometries

Each of the four models was analyzed with a fully failed cover plate. The resulting longitudinal stresses showed little sign of being affected by the height of the specimen. A maximum of $2.8 \%(1.3 \mathrm{ksi})$ difference from the 72 " web height was recorded. Each of the four models were then analyzed with a $75 \%$ failed cover plate to assess the impact of a non-symmetric cross-section with varying web heights. The 
largest difference $(3.1 \%)$ was observed between the 24 " web height and the 72 " web height (1.6 ksi). Each of the recorded stresses can be seen in Table 4-7. Due to the minimal change in longitudinal stresses in the flange angles for models with fully and partially failed cover plates at various web heights, it was determined that the web height played little role in any stress distribution of partially failed built-up girders.

Table 4-7 Web height parameter stress redistribution

\begin{tabular}{|c|c|c|c|c|c|c|}
\hline \multicolumn{3}{|c|}{$\mathbf{1 0 0 \%}$ CP Failed } & \multicolumn{3}{c|}{ 75\% CP Failed } \\
\hline $\begin{array}{c}\text { Web } \\
\text { Height }\end{array}$ & $\begin{array}{c}\text { Stress } \\
\text { (ksi) }\end{array}$ & \% Diff & $\begin{array}{c}\text { Web } \\
\text { Height }\end{array}$ & $\begin{array}{c}\text { Stress } \\
\text { (ksi) }\end{array}$ & \% Diff \\
\hline $\mathbf{2 4 "}$ & 48.92 & $0.1 \%$ & & $\mathbf{2 4 "}$ & 51.61 & $3.1 \%$ \\
\hline $\mathbf{4 8 "}$ & 48.92 & $0.1 \%$ & & $\mathbf{4 8}^{\prime \prime}$ & 52.80 & $0.8 \%$ \\
\hline $\mathbf{7 2 "}$ & 48.86 & $0.0 \%$ & & $\mathbf{7 2}^{\prime \prime}$ & 53.22 & $0.0 \%$ \\
\hline $\mathbf{9 6 "}$ & 47.54 & $2.8 \%$ & & $\mathbf{9 6 "}$ & 52.12 & $2.1 \%$ \\
\hline
\end{tabular}

\subsubsection{Multiple Flange Components}

Due to the existence of girders with multiple cover plates (to meet bending stress demands), the effect of partial and complete failure of a single component was investigated. Models with varying quantities of cover plates were constructed. Similar to previous models, the geometry of each model consisted of $8^{\prime \prime} \times 8^{\prime \prime} \times 1$ " flange angles with a $72^{\prime \prime} \times 1 / 2^{\prime \prime}$ web plate and an unbraced bottom flange length of $20^{\prime}-00^{\prime \prime}$. The number of $20^{\prime \prime} \times 1 "$ cover plates was varied from 1 to 4 (see Figure 4-27). Fasteners in adjacent cover plates were simulated the same way as previously described for other models - the first four rivets were modeled physically modeled, and the remaining rivets were simulated using nodal tie constraints. 


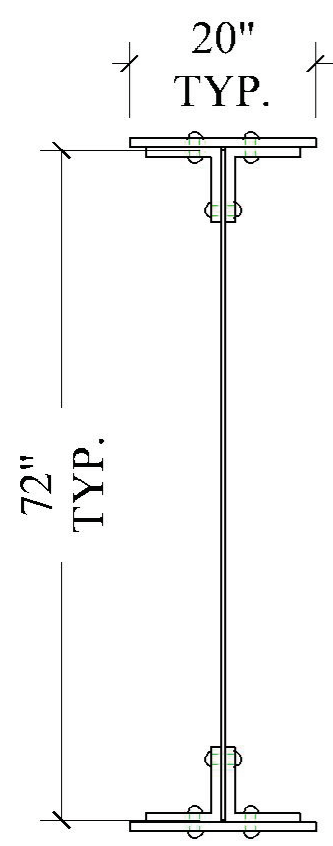

(1) COVER

PLATE

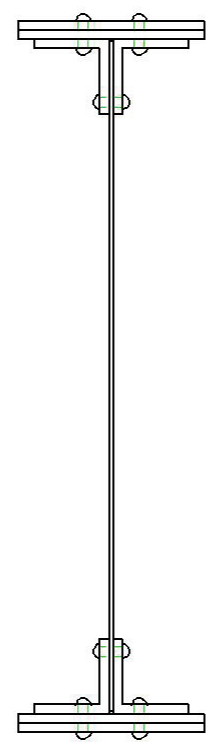

(2) COVER

PLATES

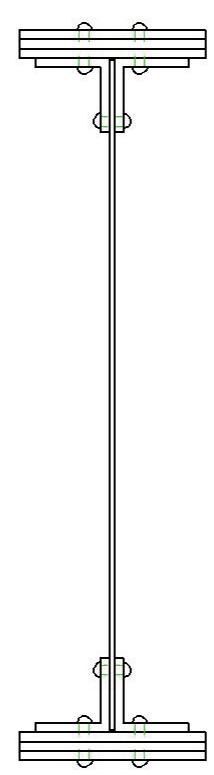

(3) COVER PLATES

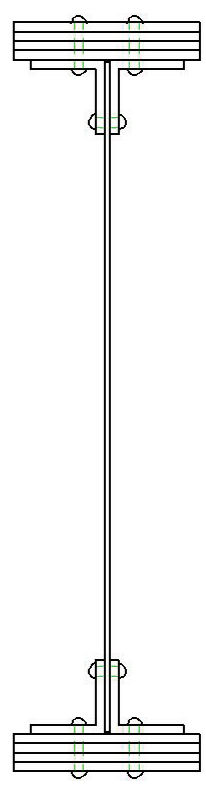

(4) COVER

PLATES

Figure 4-27 Cover plate quantity parameter model geometries

The four different geometries were modeled first with no failed components in order to obtain baseline stresses to compare stress distribution. Next, all four models were analyzed with a fully failed bottom cover plate and then with a $75 \%$ fully failed bottom cover plate. Longitudinal stresses were measured in each of the bottom flange components and then converted to an equivalent net-section stress using the trapezoidal rule as discussed in Section 4.1.3. Figure 4-28 shows the longitudinal stresses in a model with three cover plates (fully failed lower cover plate). 


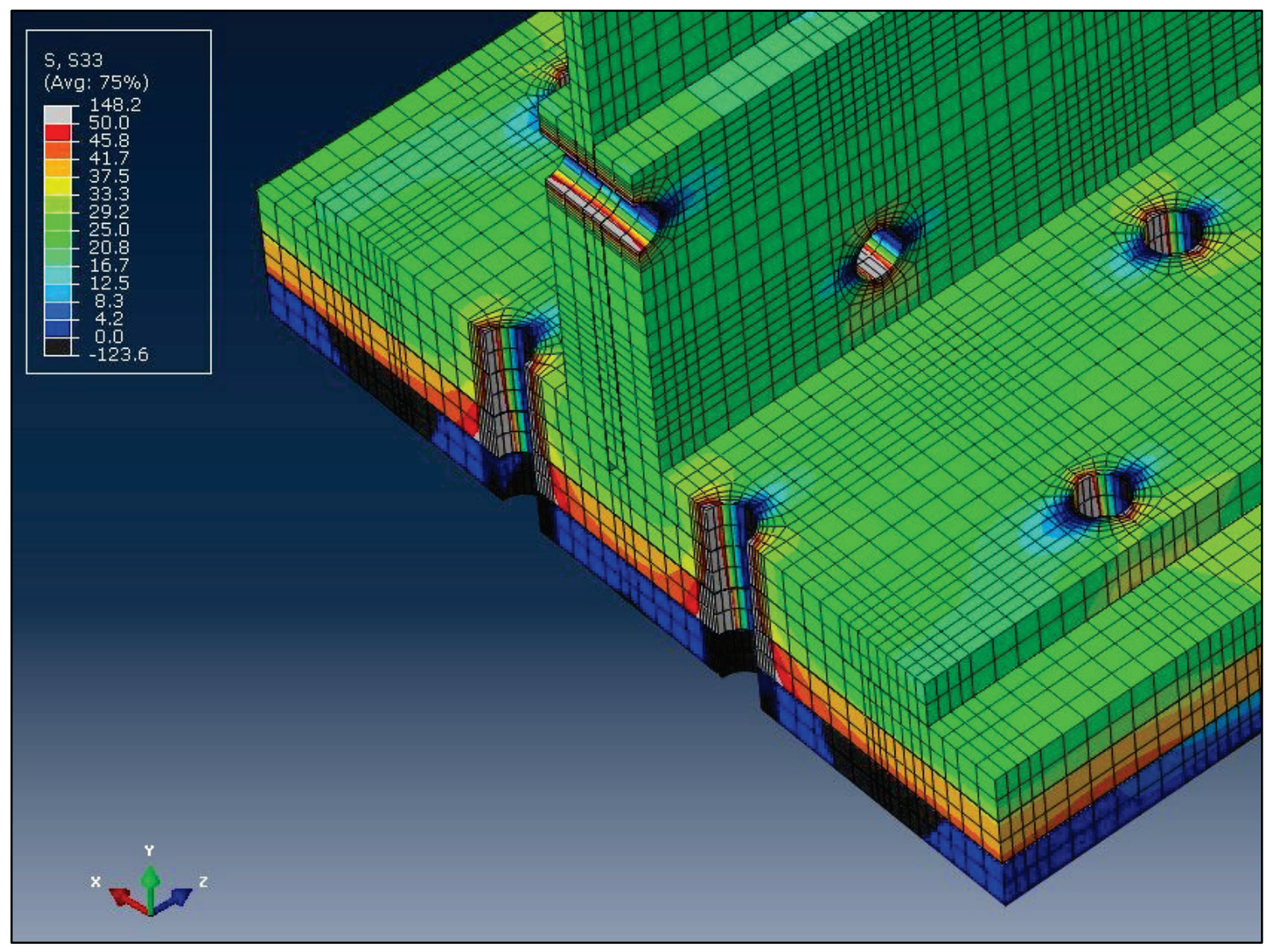

\section{Figure 4-28 Model with 3 cover plates - lower cover plate failed}

In each of the models, the component closest to the failed cover plate had the highest increase in stresses. Table 4-8 gives the net-section stresses of the partially failed cross-section of each component adjacent to the failed component (e.g. for the model with 4 cover plates, the reported stress is the net-section stress in the second to lowest cover plate). The after-failure net-section stresses are reported for both the models with a complete bottom cover plate failure, as well as the models with $75 \%$ bottom cover plate failure (non-symmetric cross-section). For all of the models except the model with one cover plate, the resulting stresses were higher when the cover plate was completely failed (rather than partially failed). This indicated that the non-symmetric cross-section did not 
result in significant stress increases in the stress redistribution when more than one cover plate was used. This is further illustrated in Figure 4-29 which shows the longitudinal stresses in the cover plate adjacent to the failed bottom cover plate for each of the three simulated cover plate conditions $(0 \%, 75 \%$, and $100 \%$ cover plate failure).

Table 4-8 Longitudinal stress in component adjacent to failed component

\begin{tabular}{|c|c|c|c|c|c|}
\hline \multirow{2}{*}{$\begin{array}{c}\text { \# of Cover } \\
\text { Plates }\end{array}$} & \multicolumn{5}{|c|}{$\%$ Bottom Cover Plate Failure } \\
\cline { 2 - 6 } & Stress (ksi) & Stress (ksi) & $\%$ Diff & Stress (ksi) & $\%$ Diff \\
\hline 1 & 26.9 & 53.12 & $98 \%$ & 48.9 & $82 \%$ \\
\hline 2 & 25.9 & 35.8 & $38 \%$ & 44.5 & $72 \%$ \\
\hline 3 & 26.6 & 35.9 & $35 \%$ & 44.4 & $67 \%$ \\
\hline 4 & 26.6 & 35.5 & $33 \%$ & 43.6 & $64 \%$ \\
\hline
\end{tabular}

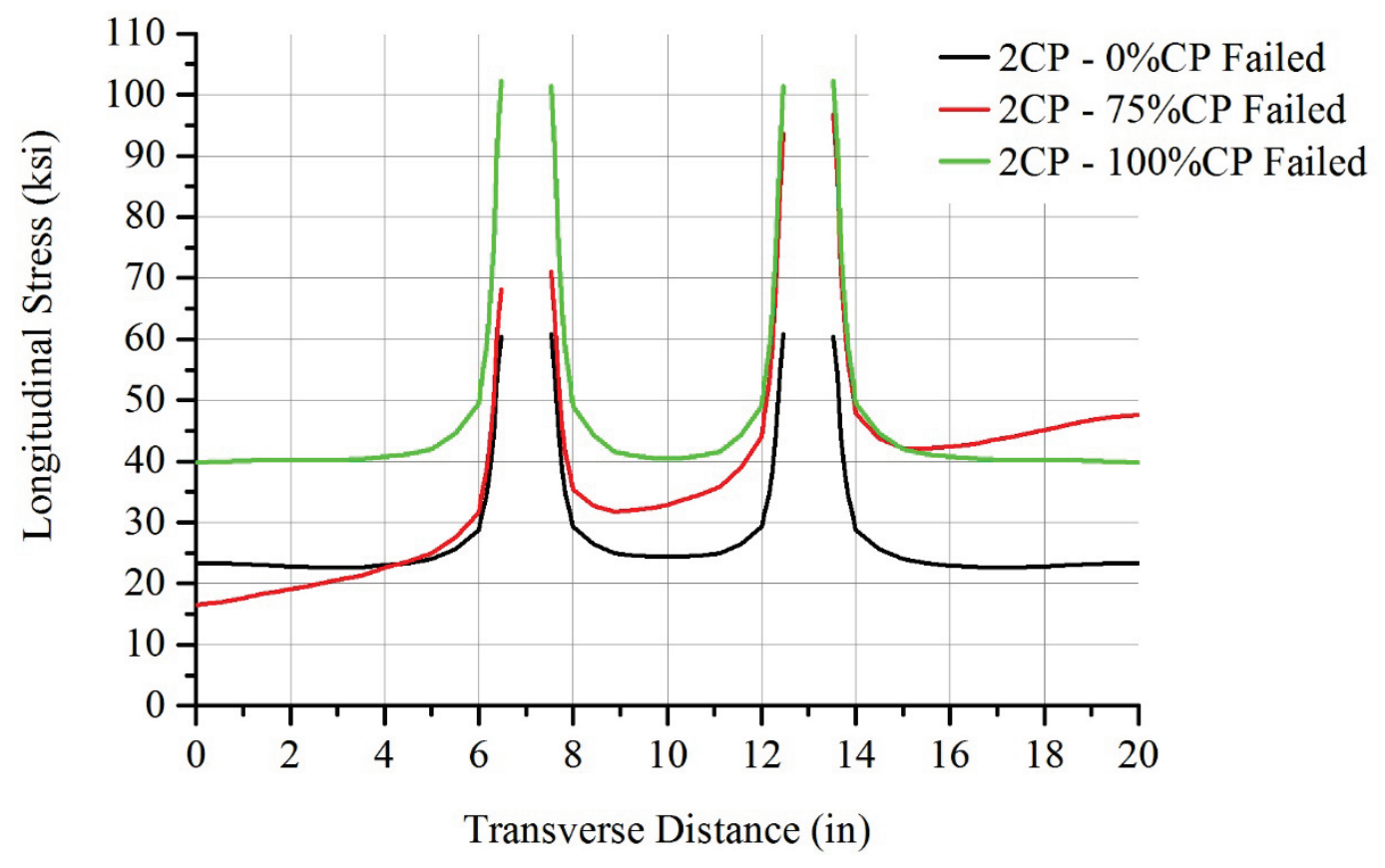

Figure 4-29 Model w/ two cover plates - stresses at 3 stages of cover plate failure 
In order to quantify the stress increase in adjacent components, the longitudinal stresses were measured in each of the bottom flange components of each of the models. The resulting component net-section stress increase of the partially failed cross-section was then plotted to determine the relationship between the proximity of each component to the amount of stress redistribution (see Figure 4-30). As shown in the graph, the majority of the stress $(64 \%-84 \%)$ of a failed component was distributed to the next closest component. Additionally, girders with a single cover plate experienced a significantly higher stress in the component adjacent to the failure than girders with more cover plates. Girders with more than one cover plate saw an increase of approximately $20 \%$ in the $2^{\text {nd }}$ closest component, and approximately $10 \%$ in the $3^{\text {rd }}$ and $4^{\text {th }}$ closest components.

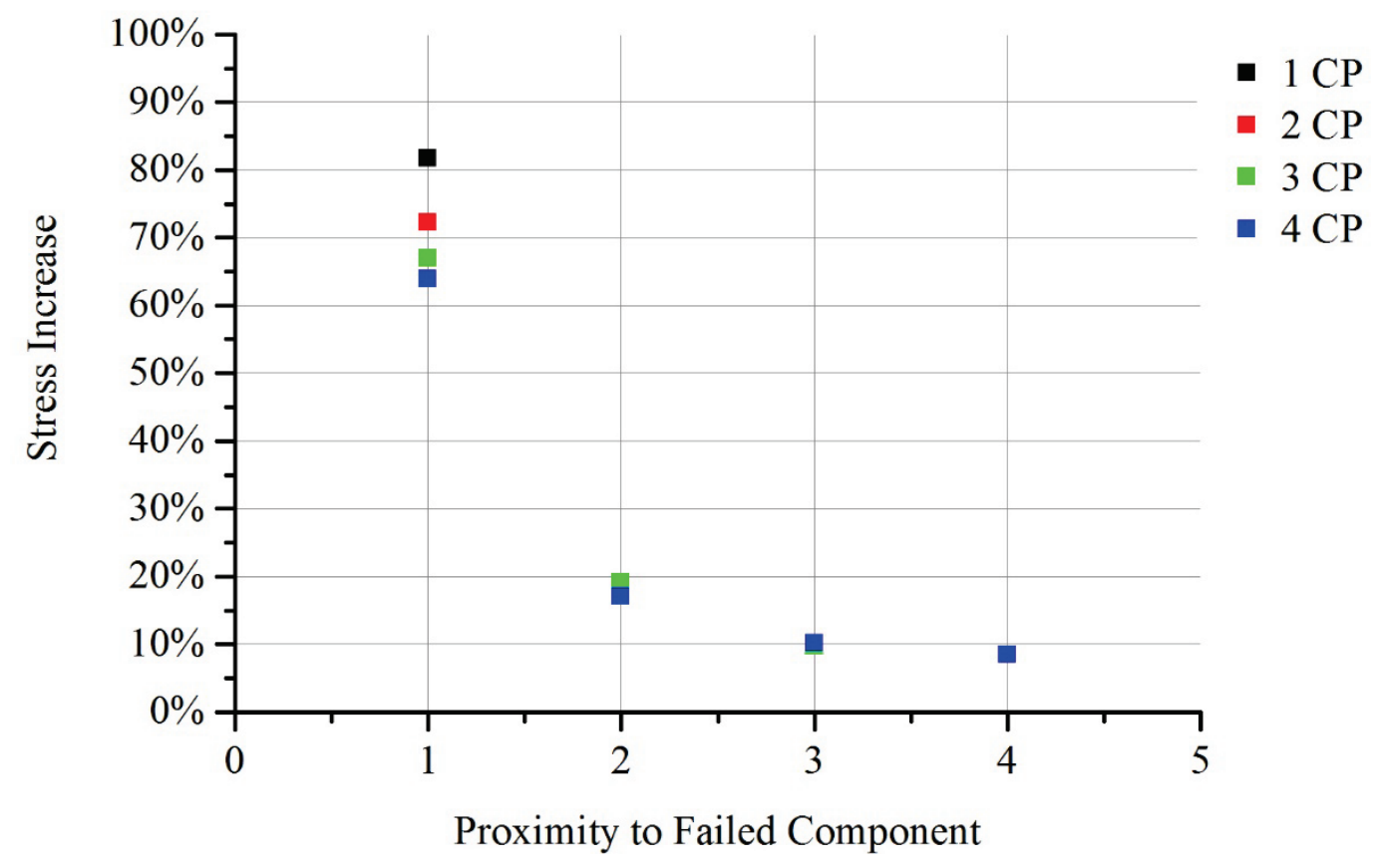

Figure 4-30 Stress increase in girders with multiple cover plates 
Due to the significance of this behavior, two more sets of models were constructed with similar geometries but with cover plate widths of $16^{\prime \prime}$ and 26". Each set consisted of models with 1, 2, 3, and 4 cover plates. The trends were then plotted along with those of the $20^{\prime \prime}$ cover plates (see Figure 4-31)

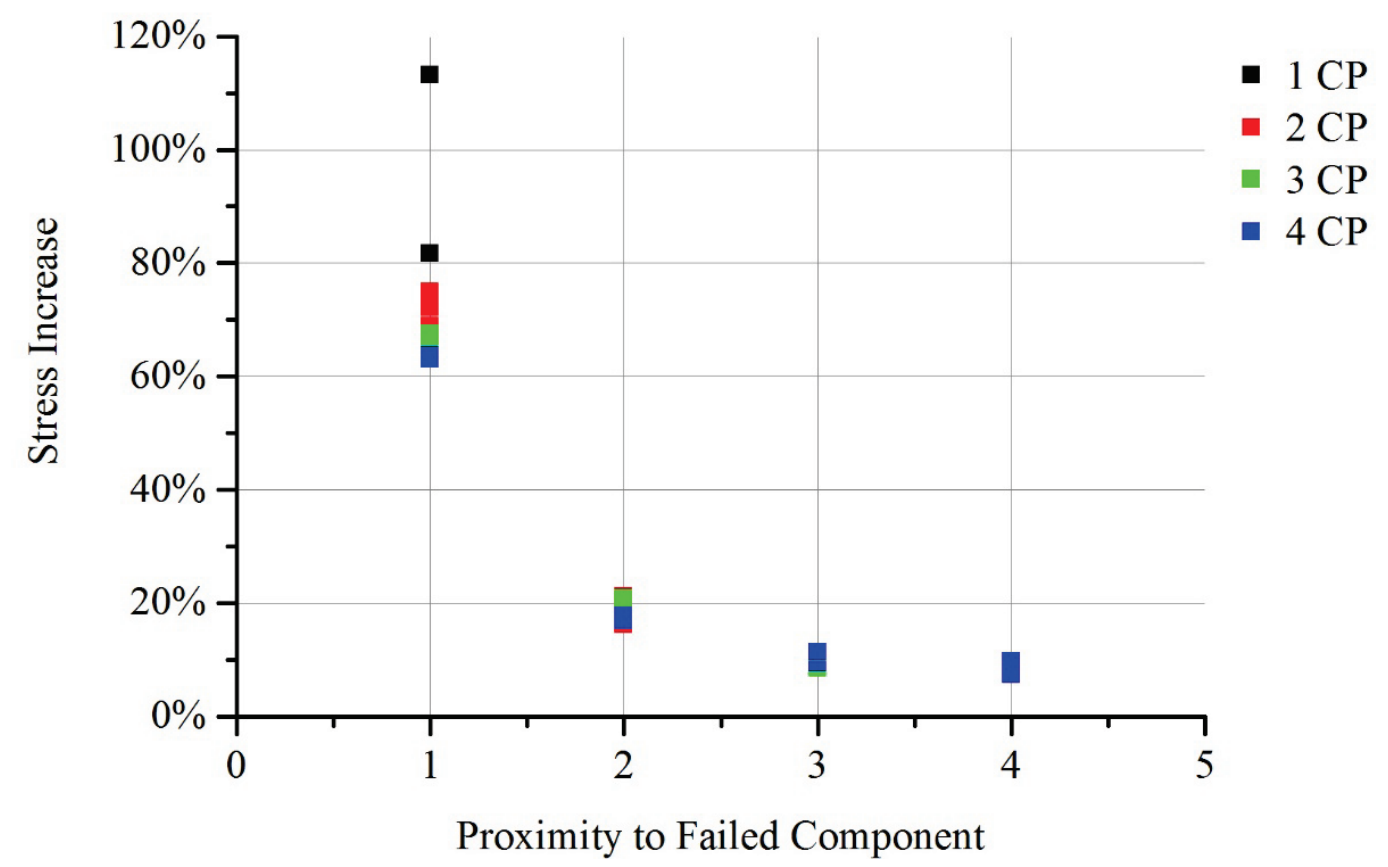

Figure 4-31 Stress increase in components of girders with multiple cover plates (16", 20", 26" cover plates)

The data indicated that, regardless of the number of cover plates, the largest effect on the longitudinal stresses was in the component most adjacent to the failed component. This indicated that a localized stress concentration, similar to one found in a partially cracked plate loaded in tension (see Figure 4-32) existed in the built-up girders with a single component failure. The resulting longitudinal stress increase in the first component was then compared to determine whether the number of cover plates in the model affected the stress increase of the adjacent most component. As is shown in Figure 
4-33, there largest stress increase typically occurs in components of models with a single cover plate.

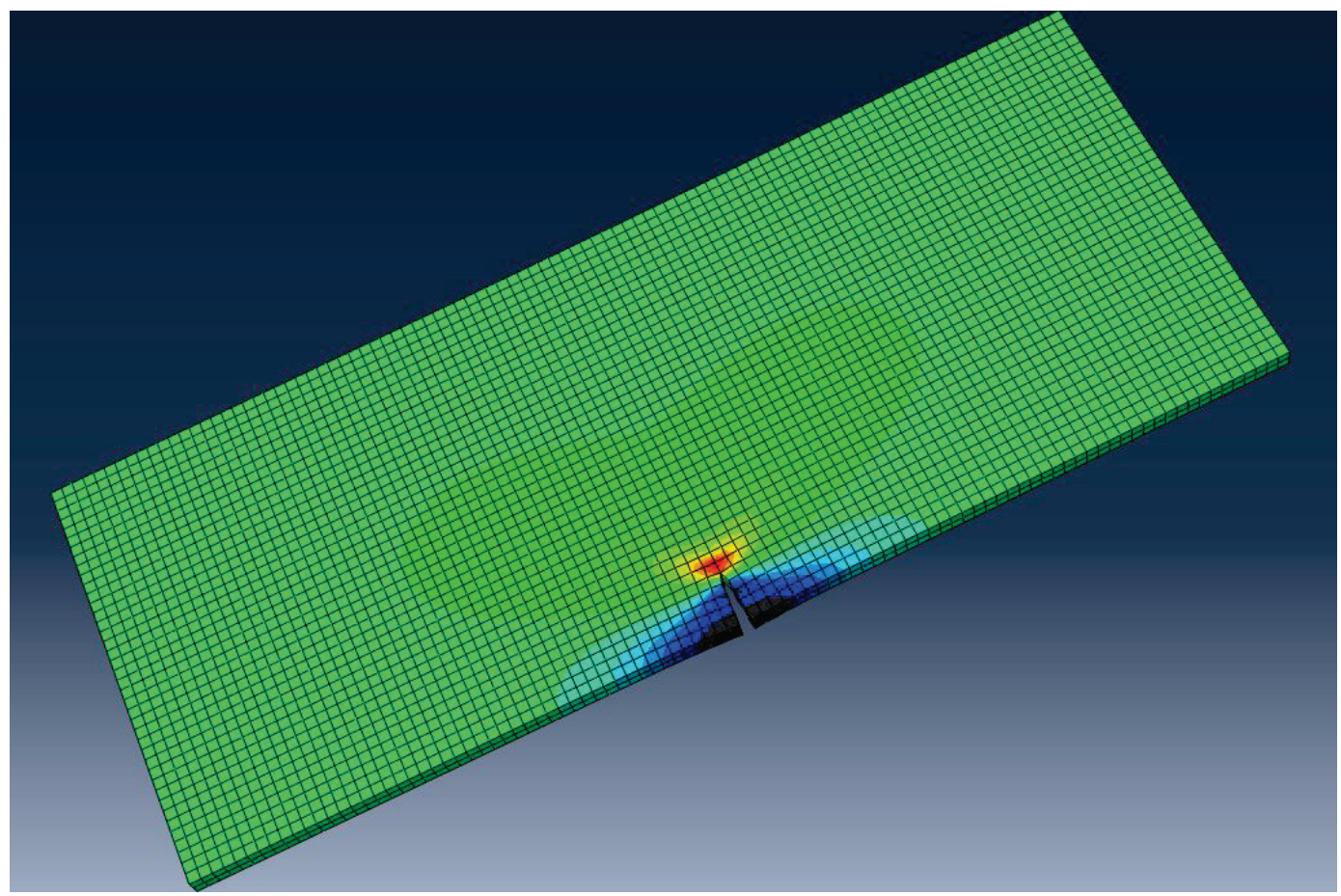

Figure 4-32 Stress concentration at cracked plate 


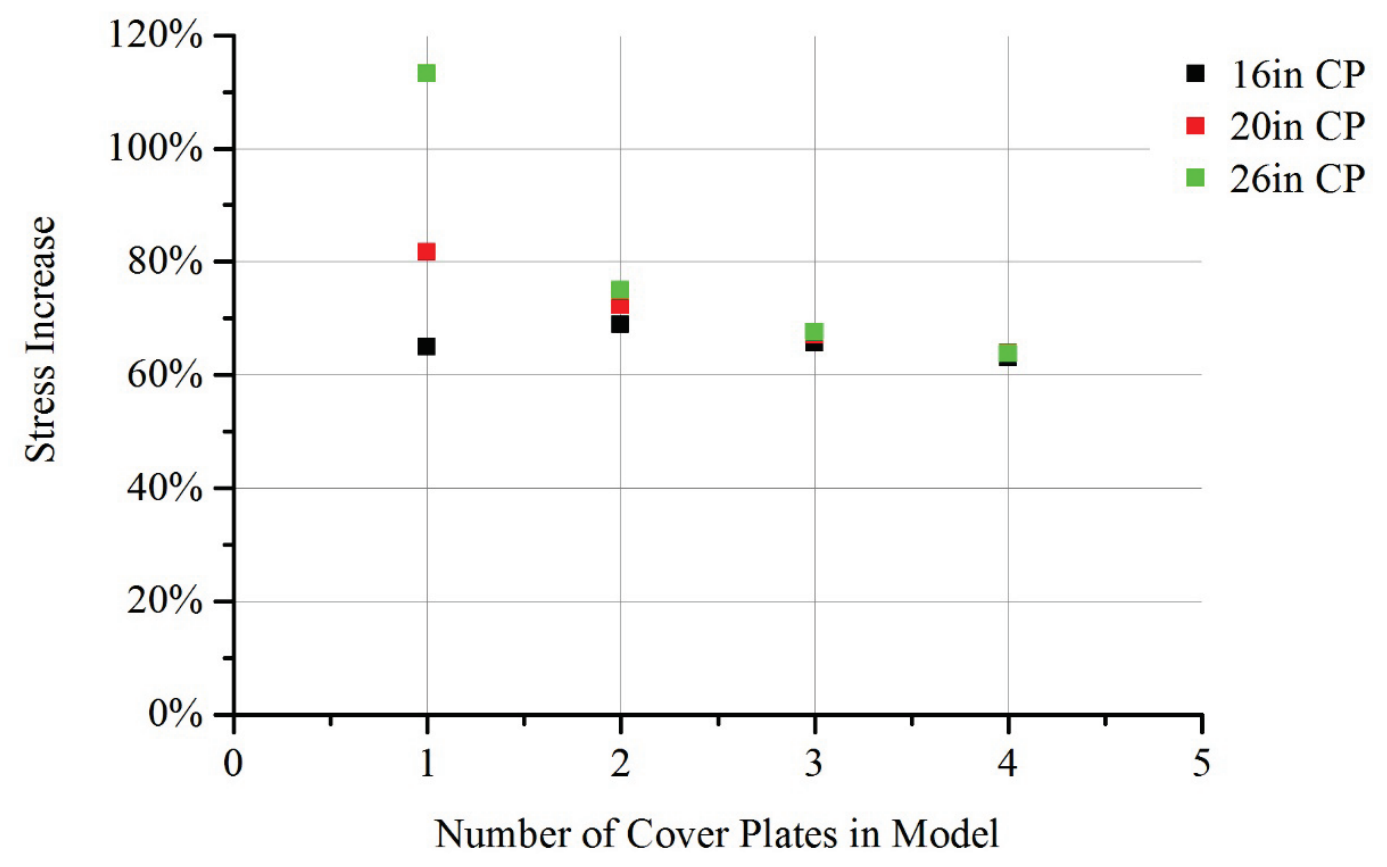

Figure 4-33 Stress increase in models with multiple cover plates

In order to determine a method by which a calculated after failure net-section stress could be amplified to reflect the true stress condition of a partially failed cross section, the calculated net-section stress was compared to the net-section stress from each of twelve different models with varying number of cover plates and cover plate widths. Three sets of models were made (16", 20", and 26" cover plate widths), with 1, 2, 3, and 4 cover plates. First, the after-failure net-section stress was obtained from the FE models (following the procedure described in Section 4.1.3). Next, the after-failure net-section stress was calculated using mechanics of materials (My/I). Then the FE net-section stress was divided by the calculated net-section stress. The resulting values for each of the sets of models can be seen in Table 4-9, along with a graph of these values corresponding to the number of cover plates used in each model in Figure 4-34. A line was fit to the upper bound of the data, in order to conservatively capture the influence of the multiple cover 
plates. The equation of the line was used as an amplification factor which can be used to conservatively determine the resulting stress in a partially failed cross section from the calculated net-section stress:

$$
\beta_{A F}=1+0.2\left(1+\frac{N}{4}\right)
$$

Where:

$$
\begin{aligned}
& \beta_{\mathrm{AF}}=\text { After-failure amplification factor } \\
& \mathrm{N}=\text { Number of cover plates }
\end{aligned}
$$


Table 4-9 Net-section stress comparison (FE model vs. calculated)

\begin{tabular}{|c|c|c|c|c|c|}
\hline \multicolumn{6}{|c|}{ 16" Cover Plates } \\
\hline \multirow{3}{*}{$\begin{array}{c}\# \text { of Cover } \\
\text { Plates }\end{array}$} & \multirow{3}{*}{$\begin{array}{c}\text { Proximity to } \\
\text { Failed } \\
\text { Comp. }\end{array}$} & \multicolumn{3}{|c|}{$\%$ Bottom Cover Plate Failure } & \\
\hline & & \multicolumn{2}{|c|}{\begin{tabular}{|l|} 
Net-section Stress (ksi) \\
\end{tabular}} & \multirow{2}{*}{$\operatorname{Diff}(\mathrm{ksi})$} & \multirow{2}{*}{ FE/Calc } \\
\hline & & FE Model & Calculated & & \\
\hline 1 & 1 & 44.2 & 37.9 & 6.3 & $117 \%$ \\
\hline 2 & 1 & 45.3 & 34.8 & 10.6 & $130 \%$ \\
\hline 3 & 1 & 44.4 & 33.1 & 11.4 & $134 \%$ \\
\hline 4 & 1 & 43.7 & 32.0 & 11.7 & $137 \%$ \\
\hline \multicolumn{6}{|c|}{ 20" Cover Plates } \\
\hline \multirow{3}{*}{$\begin{array}{c}\# \text { of Cover } \\
\text { Plates }\end{array}$} & \multirow{3}{*}{\begin{tabular}{|c|} 
Proximity to \\
Failed \\
Comp.
\end{tabular}} & \multicolumn{3}{|c|}{$\%$ Bottom Cover Plate Failure } & \\
\hline & & \multicolumn{2}{|c|}{ Net-section Stress (ksi) } & \multirow{2}{*}{$\begin{array}{c}\text { Difference } \\
\text { (ksi) }\end{array}$} & \multirow{2}{*}{ FE/Calc } \\
\hline & & \begin{tabular}{|l|} 
FE Model \\
\end{tabular} & Calculated & & \\
\hline 1 & 1 & 48.9 & 41.35 & 7.5 & $118 \%$ \\
\hline 2 & 1 & 45.8 & 36.36 & 9.4 & $126 \%$ \\
\hline 3 & 1 & 44.4 & 33.98 & 10.4 & $131 \%$ \\
\hline 4 & 1 & 43.6 & 32.59 & 11.1 & $134 \%$ \\
\hline \multicolumn{6}{|c|}{ 26" Cover Plates } \\
\hline \multirow{3}{*}{$\begin{array}{c}\# \text { of Cover } \\
\text { Plates }\end{array}$} & \multirow{3}{*}{$\begin{array}{c}\text { Proximity to } \\
\text { Failed } \\
\text { Comp. }\end{array}$} & \multicolumn{3}{|c|}{$\%$ Bottom Cover Plate Failure } & \\
\hline & & \multicolumn{2}{|c|}{ Net-section Stress (ksi) } & \multirow{2}{*}{ Diff(ksi) } & \multirow{2}{*}{ FE/Calc } \\
\hline & & \begin{tabular}{|l|} 
FE Model \\
\end{tabular} & Calculated & & \\
\hline 1 & 1 & 57.5 & 46.48 & 11.1 & $124 \%$ \\
\hline 2 & 1 & 46.2 & 38.32 & 7.8 & $120 \%$ \\
\hline 3 & 1 & 44.3 & 35.03 & 9.3 & $127 \%$ \\
\hline 4 & 1 & 43.4 & 33.25 & 10.2 & $131 \%$ \\
\hline
\end{tabular}




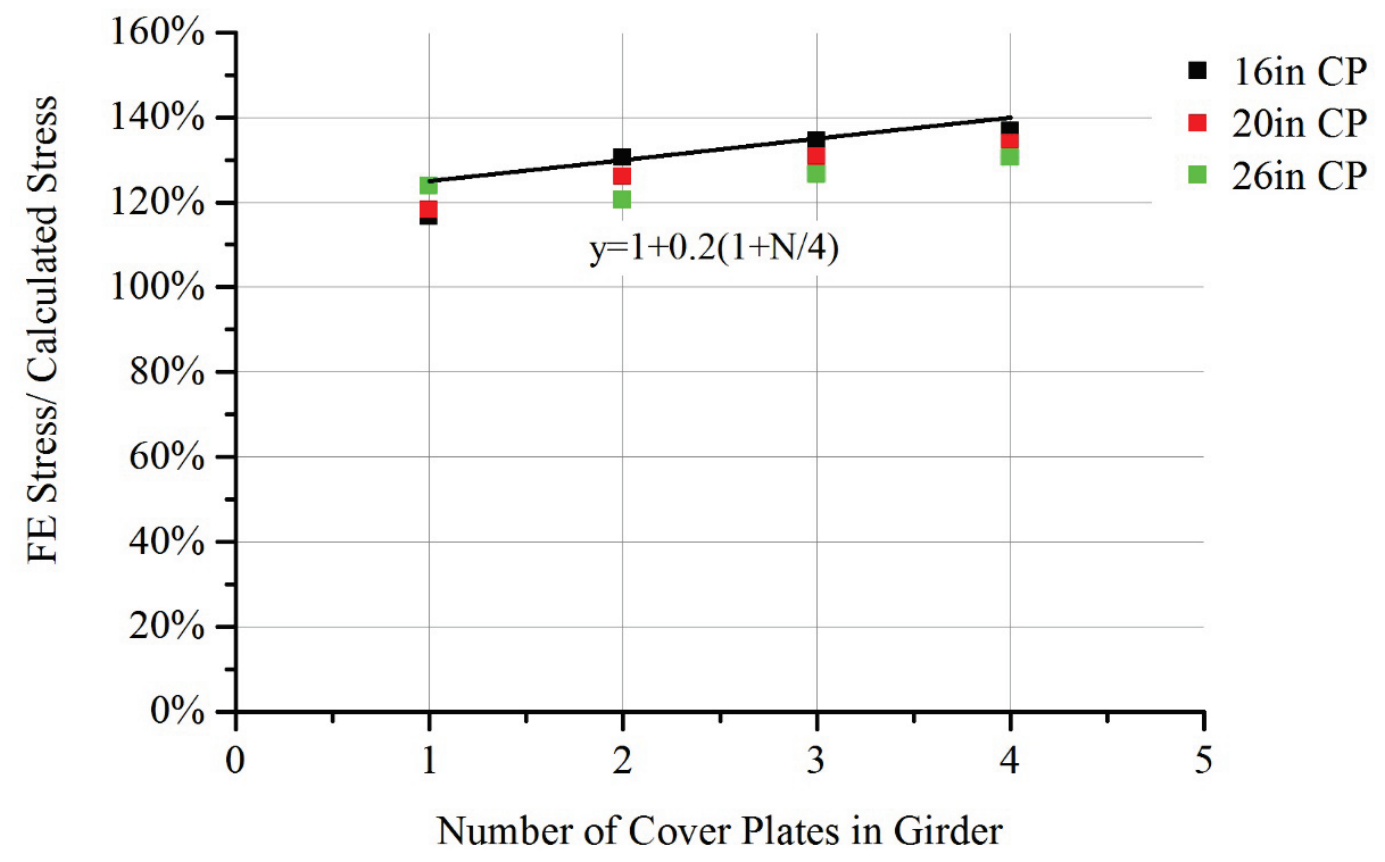

Figure 4-34 Net-section stress comparison (FE model vs. calculated)

The $\beta_{\mathrm{AF}}$ amplification factor increases when a member has more components because the net-section stress increase is more pronounced. This is a result of a member having more components. Therefore, the initial net-section stress (prior to a failure) is distributed linearly between all components. After a failure, while the calculated netsection stress (using $\sigma=\mathrm{My} / \mathrm{I}$ ) assumes a linear distribution to all components, the actual net-section stress (as observed in the FE models) is localized and primarily is redistributed to the adjacent most component.

In addition, three more models with single cover plates were analyzed. Two of the models consisted of the same geometry as described earlier except with a different width of cover plate $-22 "$ and $24 "$. The third model that was analyzed was the model used for benchmarking the experimental specimens as described in Section 4.1.3. Each of the models consisted of a bottom flange with two flange angles and a single cover 
plate. The resulting stress increase for each model is shown in Table 4-10, in addition to models previously constructed having a single cover plate. Based on the values shown, the $\beta_{\mathrm{AF}}$ factor of 1.25 (shown in Figure 4-34) was a conservative upper bound.

Table 4-10 FE stress vs. calculated stress

\begin{tabular}{|c|c|c|c|c|}
\hline Cover Plate & \% BF Area & \multicolumn{2}{|c|}{ Net-section Stress (ksi) } & \multirow{2}{*}{ \% Diff } \\
\cline { 3 - 4 } Width (in) & Reduction & FE Model & Calculated & \\
\hline 14 & $54 \%$ & 46.9 & 39.57 & $119 \%$ \\
\hline 16 & $50 \%$ & 44.2 & 37.92 & $117 \%$ \\
\hline 20 & $56 \%$ & 48.9 & 41.35 & $118 \%$ \\
\hline 22 & $59 \%$ & 51.1 & 43.06 & $119 \%$ \\
\hline 24 & $61 \%$ & 53.4 & 44.77 & $119 \%$ \\
\hline 26 & $63 \%$ & 57.5 & 46.48 & $124 \%$ \\
\hline
\end{tabular}

\subsubsection{Parametric Study Summary}

Many finite element models were analyzed to look at the influence of nonsymmetric cross-sections, unbraced length of a tension flange, the web height, and the quantity of cover plates on the stress redistribution of a partially failed built-up girder. Two of the parameters investigated (tension flange unbraced length, and web height) were found to have minimal influence on the stress redistribution. However, nonsymmetric cross-sections, as well as the quantity of cover plates appeared to influence the stresses significantly.

Nineteen different models with two different cover plate widths having a range of partially failed bottom flange cover plate or flange angle were analyzed to determine the effect of a non-symmetric cross-section on the longitudinal stress redistribution. The non-symmetric cross-section resulting from a flange angle or partially failed cover plate 
resulted in a stress increase in the remaining flange angles. It was found that a failed flange angle increased the stresses in the adjacent flange angle by $8.6 \%$, while a fully failed cover plate increased the stresses in the flange angles by $81.7 \%$. A partially failed cover plate was found to have the largest impact on the resulting stresses in a single flange angle (located directly above the failure plane). The resulting stresses in the flange angle when a cover plate was $60 \%$ failed was approximately equal to those of the flange angle when the cover plate was fully failed. Cover plate failure greater than $60 \%$ resulted in higher stresses in the flange angle until the cover plate was completely failed at which time, due to the symmetry of the cross-section, the stresses decreased in the flange angle (as shown in Figure 4-23 and Figure 4-24).

Thirty two different models with varying numbers of cover plates and failure percentages were analyzed to determine the effect of the number of cover plates on longitudinal stress redistribution. It was found that, the majority of the stress increase was experienced by the most adjacent component (approximately $60 \%$ to $80 \%$ depending on the number of bottom flange components). This resulted in a $20 \%-25 \%$ larger stress than that calculated from mechanics of materials based on the remaining net section. Components further from the failed component experienced a stress increase of $10 \%$ to $20 \%$. 


\section{CHAPTER 5 STRESS REDISTRIBUTION EVALUATION METHODOLOGY}

Based on the analytical parametric study, a methodology for determining the amount of longitudinal stress in components adjacent to a failed component was developed. This method was developed to aid in determining the remaining capacity when a component of a built-up steel girder fails. Prior to an evaluation using this method, certain criteria must be met:

1. This methodology is based on the research discussed, and therefore only applicable to built-up girders subjected to flexure.

2. Due to the sizes of components investigated, this method should be limited to members where the net-area of a potentially fractured component is less than or equal to $62 \%$ of the total net-area of tension flange. The area of the components should not include the vertical legs of any flange angles.

3. The initial fatigue life must be determined based on the AASHTO Category D fatigue curve. Currently, the Manual for Bridge Evaluation (AASHTO, 2011) indicates that the Category $\mathrm{C}$ curve should be used for evaluation purposes of the fatigue life of riveted connections due to their 'highly redundant' behavior. In the commentary to Section 7.2.1 of the MBE a discussion of initial cracking versus 'critical' crack length is used 
to justify the use of the Category $\mathrm{C}$ based on the redundancy of riveted members. The use of Category $\mathrm{C}$ assumes that although cracking has occurred, the redundancy inherent in the built up member allows one to utilize a higher fatigue category prior to member failure. However, if the proposed method (in this paper) is used, Category D should be used to determine the initial fatigue life in order to ensure that widespread fatigue damage (multiple cracks at the same location) is not present prior to this evaluation as it is critical that cracks do not exist in adjacent components.

4. The capacity of the partially failed section shall be evaluated to meet strength capacity.

5. Built-up members must have a minimum of 1 cover plate on the tension flange. Members having tension flanges composed of built-up flange angles only have not been evaluated as part of this research program. It is expected that, in most cases, due to the minimal amount of flange area when only angles are used, the cross section will not possess enough strength capacity to satisfy requirement \#3.

6. The after-failure section modulus $\left(\mathrm{S}_{\mathrm{X}-\mathrm{net}-\mathrm{AF}}\right)$ should be calculated using the net section of the remaining components at the failure plane and traditional mechanics of materials.

7. The after-failure net-section stress range, $\Delta \mathrm{f}_{\mathrm{AF}}$, is then calculated based upon the AASHTO fatigue truck (AASHTO, 2014, Article 3.6.1.4). The stress in a component adjacent to a failed component is calculated using: 


$$
\sigma_{n e t-A F}=\beta_{A F} \frac{M}{S_{x-n e t-A F}}
$$

Where:

$\sigma_{\text {net-AF }}=$ after failure net-section stress

$\beta_{A F}=1+0.2\left(1+\frac{N}{4}\right)=$ After-failure net section amplification factor as determined by the parametric study in Section 4.2 $\mathrm{M}=$ the applied moment

8. Three possible scenarios determine the remaining steps:

a. Case I: if $\Delta \mathrm{f}_{\mathrm{o}}$ (the original net-section stress range) was below the Category D CAFL (7 ksi) $\underline{\text { AND }} \Delta \mathrm{f}_{\mathrm{AF}}$ (the after-failure net-section stress range) is below the Category C CAFL (Category E' for punched holes)

i. This condition indicates that the partially failed member was, and still is in the 'infinite life' region of the S-N curve.

ii. If an infinite fatigue life is found for a member with a failed component, it should be acceptable to eliminate fracture critical (hands-on) inspections. The bridge can be inspected using the approach used for non-FCMs. Inspections would simply look for broken components during routine inspections.

b. Case II: if $\Delta \mathrm{f}_{\mathrm{o}}$ was below the Category D CAFL ( $\left.7 \mathrm{ksi}\right)$, but due to the reduced net-section, $\Delta \mathrm{f}_{\mathrm{AF}}$ is above the Category C CAFL for drilled holes, or Category E' CAFL for punched holes. 
i. This condition indicates that the partially failed member had 'infinite life' prior to the failure, but after failure is in the 'finite life' region of the S-N curve.

ii. Calculate a finite fatigue life after failure based on Section 7.2.5 of The Manual for Bridge Evaluation (AASHTO, 2011) and $\Delta \mathrm{f}_{\mathrm{AF}}$ since no prior fatigue damage should have occurred. The fatigue life would be assumed to start at the time of the first component failure.

iii. A hands-on fracture critical inspection interval should be based upon the estimated remaining finite fatigue life in the faulted state. The inspection interval should be less than the remaining finite fatigue life calculated in step ii (e.g., $75 \%$ of the life calculated in step ii). The fatigue life should be assumed to start at the time the inspection/evaluation is performed. This conservatively assumes that a fracture of a member component occurred immediately after the previous inspection.

c. Case III: if $\Delta \mathrm{f}_{\mathrm{o}}$ was above the Category D CAFL (7 ksi), and $\Delta \mathrm{f}_{\mathrm{AF}}$ is above the Category C CAFL for drilled holes, or the Category E' CAFL for punched holes.

i. This condition indicates that the partially failed member was, and still is in the 'finite life' region of the S-N curve. The girder must possess "positive" remaining fatigue life 
prior to the assumed failure of a component takes place. This is to ensure that there is effectively no probability of cracking in any of the remaining components.

ii. Calculate a finite fatigue life based on Section 7.2.5 of The Manual for Bridge Evaluation (AASHTO, 2011), $\Delta \mathrm{f}_{\mathrm{o}}$, and $\Delta \mathrm{f}_{\mathrm{AF}}$. Prior fatigue life should be factored into the remaining fatigue life using Miner's Rule:

$$
\sum \frac{n_{i}}{N_{i}}=1
$$

Where:

$n_{i}=$ Number of accumulated cycles at stress range $i$ $\mathrm{N}_{\mathrm{i}}=$ Number of possible cycles at stress range i correlating to CAFL of the applicable portion (e.g. Category D for initial accumulated cycles, and Category C (drilled holes) or Category E' (punched holes) for after-failure remaining life)

iii. A hands-on fracture critical inspection interval should be selected based upon the remaining finite fatigue life, and the owner's acceptance of risk. The inspection interval should be less than the remaining finite fatigue life calculated in step ii (e.g., $75 \%$ of the life calculated in step ii). The remaining finite fatigue life should be assumed to start at the time the inspection and evaluation is performed. 
This assumes a worst case scenario: that a fracture of a member component occurred immediately after the inspection occurred. During the subsequent inspection cycles, the fatigue life calculations must be updated to account for the fatigue life consumed during the inspection interval and to ensure positive life remains.

d. The revised inspection interval only applies to the built-up portion of the member. Any other details meeting the requirements for fracture critical inspection should be inspected as such.

e. Less rigorous routine inspections should still occur to evaluate the condition of the member (as well as other details of the bridge). 


\section{CHAPTER 6 CONCLUSIONS}

Built-up steel girders are acknowledged as having redundancy due to the multiple components, mechanically fasted together. Due to the fabrication methods of built-up steel girders, discontinuities between components prevent fracture propagation and fatigue crack growth through adjacent components. This has been observed as a byproduct of experimental testing as well as recorded anecdotal evidence. The purpose of this research was to evaluate the redundancy of built-up steel girders in terms of both fracture resilience and fatigue life of a member with a failed component.

\subsection{Summary of Primary Findings}

The primary findings of this research are as follows:

1. The fracture of an individual component is highly unlikely. This is due to the constraint created by fasteners in a stitch pattern along the length of a built-up steel girder. Further, load shedding to other uncracked components which occurs as a crack grows in a component results in the stress intensity factor at the crack tip being less than if the plate were loaded by itself. As a result, traditional linear elastic fracture mechanics calculations did not accurately predict the critical crack length of a cracked component. Three different 
methods were employed to attempt to initiate a fracture in a partially cracked component. In order to reliably create a fracture, the following three conditions were required (no single method worked on its own)

a. The specimen was loaded to the full design load resulting in an original net-section stress greater than the calculated critical stress for a given crack length.

b. Fasteners were required to be removed adjacent to the intended fracture plane to reduce the constraint.

c. Wedges were driven into notches in line with the crack to increase the stress concentration at the crack tip.

2. Fracture resilience of built-up steel girders was demonstrated. In only two cases representing unlikely scenarios did a fracture propagate into adjacent components. The first was a specimen with substantial fatigue cracks present in all components which was beyond remaining yield capacity at the point of component fracture. The second was a specimen with unrealistic proportioned components with remaining components which had experienced more than three times their expected fatigue life (fatigue cracks were found to exist at a rivet hole where the second fracture initiated in an angle). In all other cases, the fracture of a component of a built-up steel girder did not propagate into adjacent components.

3. The stress redistribution occurring when a cover plate was partially failed in fatigue was greater than $60 \%$. However, the crack length corresponding to this increase was significant (more than half the width of the plate). Because 
the fatigue crack growth rate is high when a crack reaches this length, it was determined that the stress increase would have little impact on the total fatigue life of adjacent components as most of the life is already consumed.

4. The unbraced length of a tension flange had no effect on the stress redistribution of a partially failed built-up girder.

5. The web height had no effect on the stress redistribution of a partially failed built-up girder.

6. The presence of more than one cover plate increases the remaining fatigue life of a built-up steel girder with a single component failed. This occurs due to the redistribution of stresses into multiple components. It was found that the majority of the stress is transferred from a failed component into the most adjacent non-failed component. This resulting longitudinal stress in a component adjacent to a failed component can be conservatively estimated by amplifying the calculated stress of the remaining cross-section obtained from mechanics of materials (My/I) with an amplification factor, $\beta_{\mathrm{AF}}$.

7. Substantial fatigue life remains in a built-up steel girder with a failed component. Twelve specimens were tested in fatigue after the failure of a single component. The results indicate that, based on the actual fatigue stress range (i.e., amplified by $\beta_{\mathrm{AF}}$ ), the AASHTO Category $\mathrm{C}$ fatigue curve is a reasonable lower bound for girders with drilled holes. The AASHTO Category D fatigue curve is a reasonable lower bound for specimens with drilled holes when the stress range is based solely on the calculated net- 
section stress range. Additionally, the AASHTO Category E' fatigue curve is a reasonable lower bound for girders with punched holes.

8. A methodology was developed to determine the remaining fatigue life of a built-up girder with a single component failed. The fatigue life was based on any prior fatigue damage (using Miner's Rule) and an adjusted net-section stress range which accounted for the localized stress increase adjacent to a component failure. Various cases of remaining fatigue life, from infinite to finite are addressed in the proposed evaluation procedures.

\subsection{Recommendations for Future Work}

The following are items suggested for future work which would increase the knowledge on the redundancy of partially failed built-up members and their ability to redistribute load:

1. Investigate the load redistribution of axially loaded members (e.g. truss members, tied arch tie girders, etc.)

2. Testing of partially failed cross-sections in bending at ultimate strength.

3. Evaluation (both experimentally and analytically) of members in bending with only two flange angles (no cover plates) which experience the failure of a single component. Due to the reduced total area, and the proportion of a failed component to the total tension flange component, it is expected that out-of-plane effects would be dramatically more evident. 
LIST OF REFERENCES 


\section{LIST OF REFERENCES}

AASHTO. (2010). AASHTO LRFD Bridge Design Specifications (5th Editio). Washington DC, USA.

AASHTO. (2011). The Manual for Bridge Evaluation Second Edition.

AASHTO. (2014). AASHTO LRFD Bridge Design Specifications (7th Editio). Washington DC, USA.

Adamson, D. E. J., \& Kulak, G. L. (1995). Fatigue Tests of Riveted Bridge Girders. Edmonton, Canada.

Åkesson, B. (2010). Fatigue Life of Riveted Steel Bridges. London: CRC Press. http://doi.org/10.1201/b10429

AREMA. (2012). AREMA - CHAPTER 15 - Steel Structures. In AREMA.

ASTM. (1964). A Guide for Fatigue Testing and Statistical Analysis of Fatigue Data. Philadelphia, PA.

Baker, K. A., \& Kulak, G. L. (1982). Fatigue Strength of Two Steel Details. Edmonton, Canada.

Baker, K. A., \& Kulak, G. L. (1985). Fatigue of Riveted Connection. Canadian Journal of Civil Engineering, 12(1), 184-191.

Baron, F., Larson, E. W. J., \& Kenworthy, K. J. (1955). The Effect of Certain Rivet Patterns on the Fatigue and Static Strengths of Joints.

Bonachera Martin, F. J. (2014). Detailed Finite Element Analysis and Preliminary Study of the Effects of Friction and Fastener Pre-Tension on the Mechanical Behavior of Fastened Built-Up Members. Purdue University.

Bowman, M. D., Fu, G., Zhou, Y. E., Connor, R. J., \& Godbole, A. A. (2012). NCHRP Report 721: Fatigue Evaluation of Steel Bridges. Washington DC, USA. Retrieved from http://trid.trb.org/view.aspx?id=1144251 
Brown, J. D., Lubitz, D. J., Cekov, Y. C., Frank, K. H., \& Keating, P. B. (2007). Evaluation of Influence of Hole Making Upon the Performance of Structural Steel Plates and Connections. Austin, TX.

Brühwiler, E., Smith, I. F. C., \& Hirt, M. a. (1990). Fatigue and Fracture of Riveted Bridge Members. Journal of Structural Engineering, 116(1), 198-214. http://doi.org/10.1061/(ASCE)0733-9445(1990)116:1(198)

Cha, H., Lyrenmann, L., Connor, R. J., \& Varma, A. H. (2014). Experimental and Numerical Evaluation of the Postfracture Redundancy of a Simple Span Truss Bridge. Journal of Bridge Engineering, http://doi.org/10.1061/(ASCE)BE.1943-5592.0000622.

Champion, D. J. (Ed.). (1914). Scientific Facts and other Valuable Information about Victor Boiler, Structural and Ship Rivets.

Connor, R. J., Dexter, R., \& Mahmoud, H. (2005). NCHRP Synthesis 354: Inspection and Management of Bridges with Fracture-Critical Details. Washington DC, USA. Retrieved from http://scholar.google.com/scholar?hl=en\&btnG=Search\&q=intitle:NCHRP+Synthesi s+354:+Inspection+and+Management + of + Bridges + with + FractureCritical+Details\#0

DiBattista, J. D., \& Kulak, G. L. (1995). Fatigue of Riveted Tension Members. Edmonton, Canada.

Diggelmann, L. M. (2012). Evaluation of Member and Structural Redundancy on the US421 Bridge Over the Ohio River. Purdue University.

Fasl, J. (2013). Estimating the remaining fatigue life of steel bridges using field measurements. University of Texas at Austin. Retrieved from http://repositories.lib.utexas.edu/handle/2152/20693

Federal Aid Highway Act of 1968, Pub. L. No. 90-495 (1968).

FHWA. (2012). Memorandum: Clarification of Requirements for Fracture Critical Members.

Fisher, J. W., Yen, B. T., Wang, D., \& Mann, J. E. (1987). NCHRP Report 302 - Fatigue and Fracture Evaluation for Rating Riveted Bridges. Washington DC, USA. Retrieved from http://scholar.google.com/scholar?hl=en\&btnG=Search\&q=intitle:NCHRP+302:+Fa tigue + and + Fracture + Evaluation + for + Rating + Riveted + Bridges $\# 0$

Friedman, D. (2009). Preservation Engineering: Early Steel Framing, (September), 0-2. 
Grandt Jr., A. F. (1975). Stress intensity factors for some through-cracked fastener holes. International Journal of Fracture, 11(2), 283-294. Retrieved from http://link.springer.com/article/10.1007/BF00038895

Hall, W., Mosborg, R., \& McDonald, V. (1957). Brittle Fracture Propagation in Wide Steel Plates. The Welding Journal, (January). Retrieved from http://www.shipstructure.org/pdf/131.pdf

Hechtman, R. A. (1948). A Study of the Effects of Heating and Driving Conditions on Hot-Driven Structural Steel Rivets. Was.

Lazar, R., \& Hall, W. (1957). Studies of Brittle Fracture Propagation in Six Foot Wide Structural Steel Plates. Urbana, IL. Retrieved from http://citeseerx.ist.psu.edu/viewdoc/download?doi=10.1.1.188.5199\&rep=rep1\&typ $\mathrm{e}=\mathrm{pdf}$

Lovejoy, S. C. (2001). Failure Analysis of the Fractured Flange on the N. FK. Molalla R. Bridge Clackamas County Bridge \# 06554. Salem, OR.

National Bridge Inspection Standards. (1971). Federal Register, 36(81), 7851-7852.

National Bridge Inspection Standards. (1988). Federal Register, 53, 32611.

National Center for Preservation Technology and Training. (2010). Preservation of Historic Iron and Steel in Bridges and Other Metal Structures. Washington DC, USA.

Newman, J. C. J. (1971). An Improved Method of Collocation for the Stress Analysis of Cracked Plates with Various Shaped Boundaries. NASA Technical Note. Washington DC, USA.

Niemann, T. L. (1999). Hastings Bridge Fracture Investigation. In The International Bridge Conference. Pittsburgh, PA.

OBEC. (2012). Dickey Prairie Road (North Fork Molalla River) Bridge. Retrieved December 7, 2014, from http://www.obec.com/bridge/dickey-prairie-roadbridge.html

Out, J. M. M. (1984). The Fatigue Strength of Weathered and Deteriorated Riveted Members. Lehigh University. Retrieved from http://preserve.lehigh.edu/engr-civilenvironmental-fritz-lab-reports/2281/?utm_source=preserve.lehigh.edu\%2Fengrcivil-environmental-fritz-labreports\%2F2281\&utm_medium=PDF\&utm_campaign=PDFCoverPages 
Out, J. M. M., Fisher, J. W., \& Yen, B. T. (1984). Fatigue Strength of Weathered and Deteriorated Riveted Members. Bethlehem, PA. Retrieved from $\mathrm{http} / / /$ preserve.lehigh.edu/cgi/viewcontent.cgi?article=3281\&context=engr-civilenvironmental-fritz-lab-reports

Parola, J. F., Chesson, E., \& Munse, W. H. (1965). Effect of Bearing Pressure on Fatigue Strength of Riveted Connections. University of Illinois Engineering Experiment Station Bulletin, 63(27), 1-57. Retrieved from http://trid.trb.org/view.aspx?id=106538

RCSC. (2009). Specification for Structural Joints Using High-Strength Bolts.

Reemsnyder, H. S. (1975). Fatigue Life Extension of Riveted Connections. Journal of the Structural Division, 101(12), 2591-2608.

Rolfe, S. T., \& Hall, W. J. (1958). Brittle Fracture Tests of Two Foot Wide Steel Plates with a Residual Cvompressive Strain in the Central Portion. Urbana, IL.

Seong, C. K. (1983). Fatigue Resistance of Riveted steel Truss Bridge Members and Joints. Lehigh University.

Tada, H., Paris, P. C., \& Irwin, G. R. (2000). The stress analysis of cracks handbook (3rd Editio). ASME Press. http://doi.org/10.1115/1.801535

The Lincoln Electric Company. (2012). Wearshield ME. Cleveland, OH.

The Lincoln Electric Company. (2014). Product and Procedure Selection: Guide to Hardfacing Materials and Procedures. Cleveland, $\mathrm{OH}$.

Vishay Micro-Measurements. (2005). Strain Gage Installations with M-Bond 200 Adhesive.

Webster, F. B. (Ed.). (1920). Shipbuilding Cyclopedia. New York: Simmons-Boardman Publishing Company.

Weibull, W. (1961). Fatigue Testing and Analysis of Results. Oxford: Pergamon Press.

Williamson, J. F. (2012). Wilson Dam Bascule Bridge Replacement Supplemental Environmental Assessment. Knoxville, TN. Retrieved from http://152.87.4.80/environment/reports/wilson_bascule/EA.pdf

Wilson, W. M., \& Thomas, F. P. (1938). Fatigue Tests of Riveted Joints. Urbana.

Wright, W. J. (2003). Fracture Initiation Resistance of I-Girders Fabricated from High Performance Steels. Lehigh University. Retrieved from 
http://scholar.google.com/scholar?hl=en\&btnG $=$ Search \&q=intitle:Fracture+initiatio $\mathrm{n}+$ resistance + of $+\mathrm{I}$-girders + fabricated + from + high-performance + steels $\# 0$

Zhou, Y. E. (1994). Fatigue Strength Evaluation of Riveted Bridge Members. Lehigh University. Retrieved from http://scholar.google.com/scholar?hl=en\&btnG=Search\&q=intitle:Fatigue+strength + evaluation + of + riveted + bridge + members $\# 1$ 
APPENDICES 
APPENDIX A WILSON DAM BASCULE BRIDGE DESIGN PLANS 


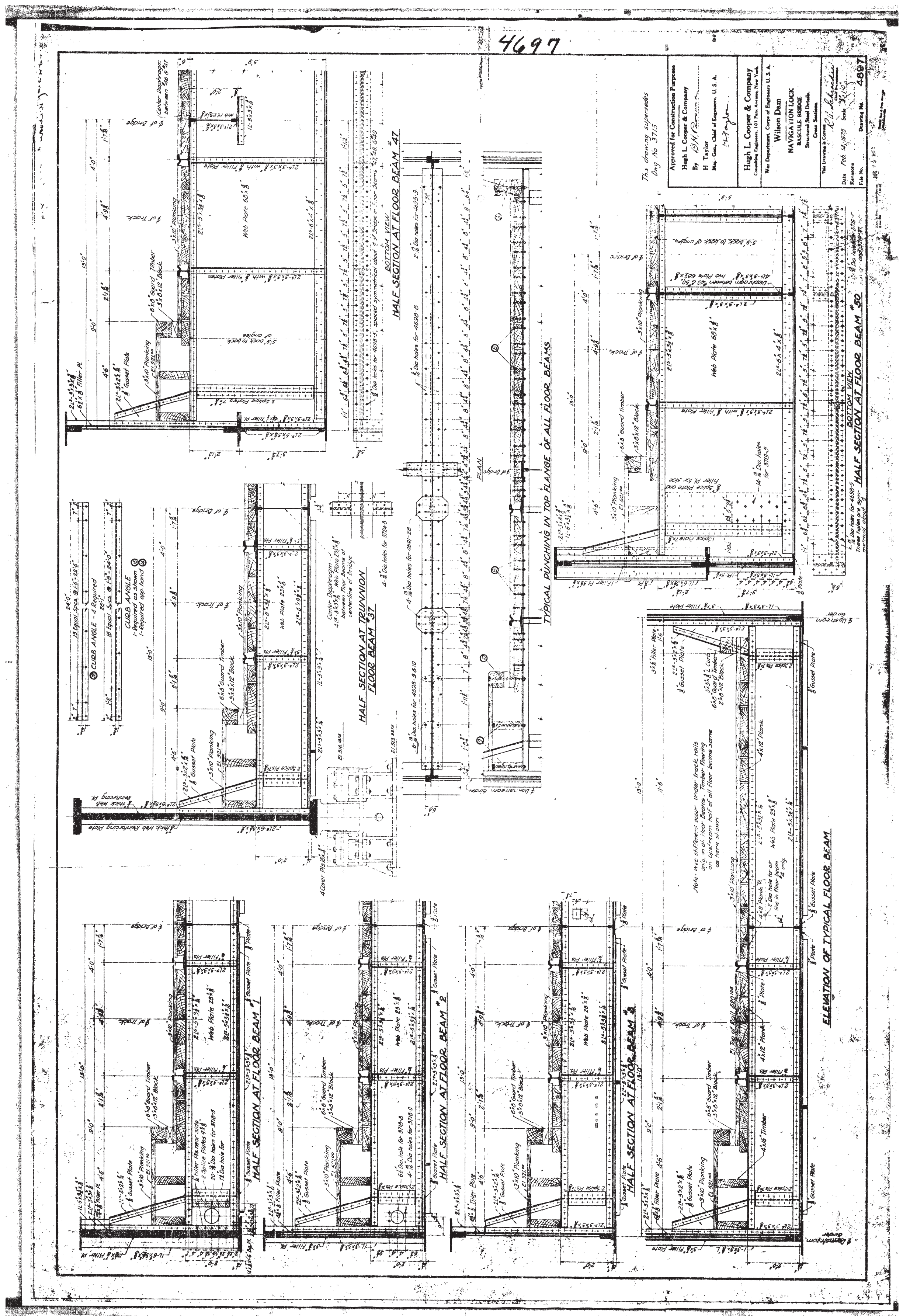




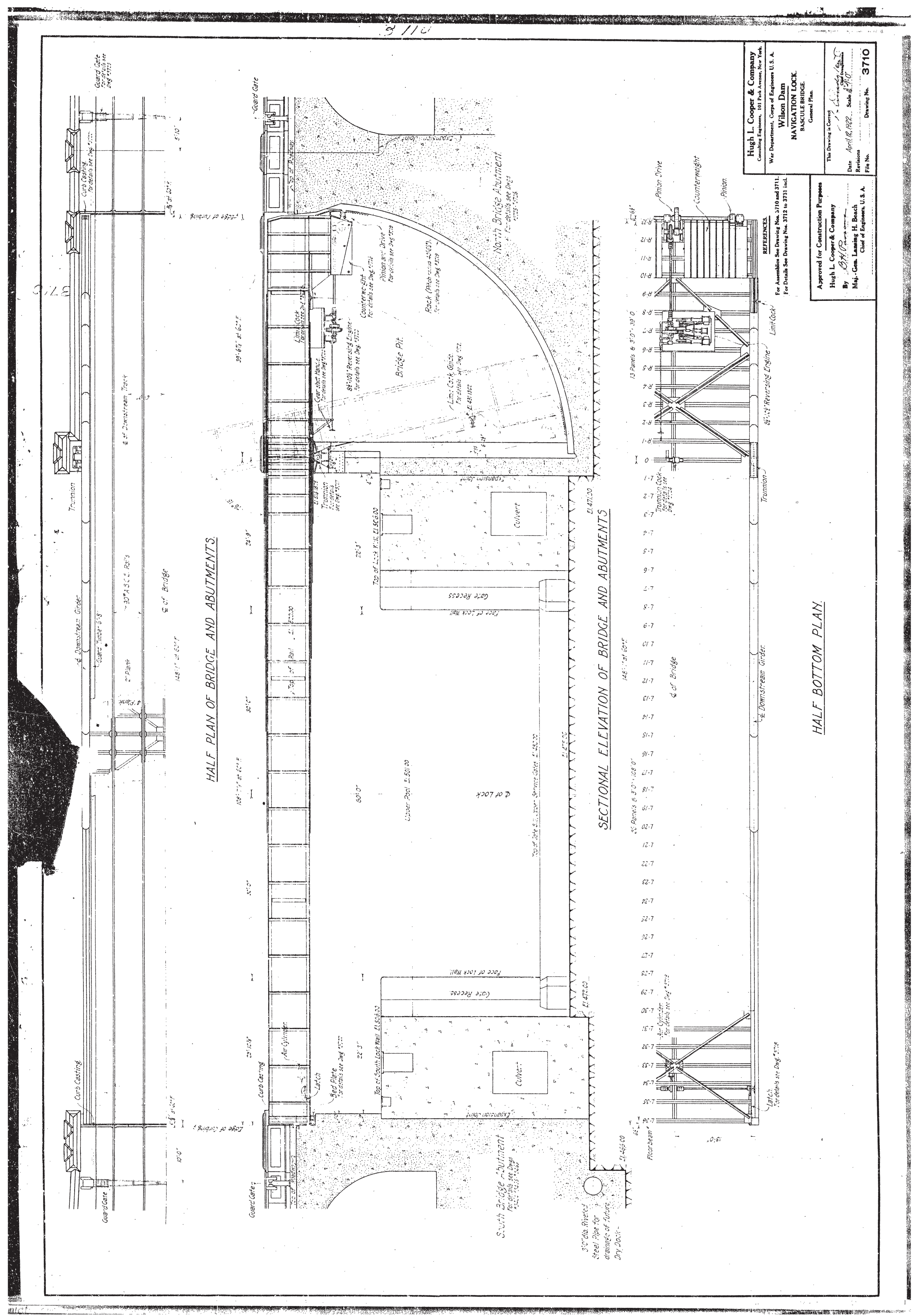




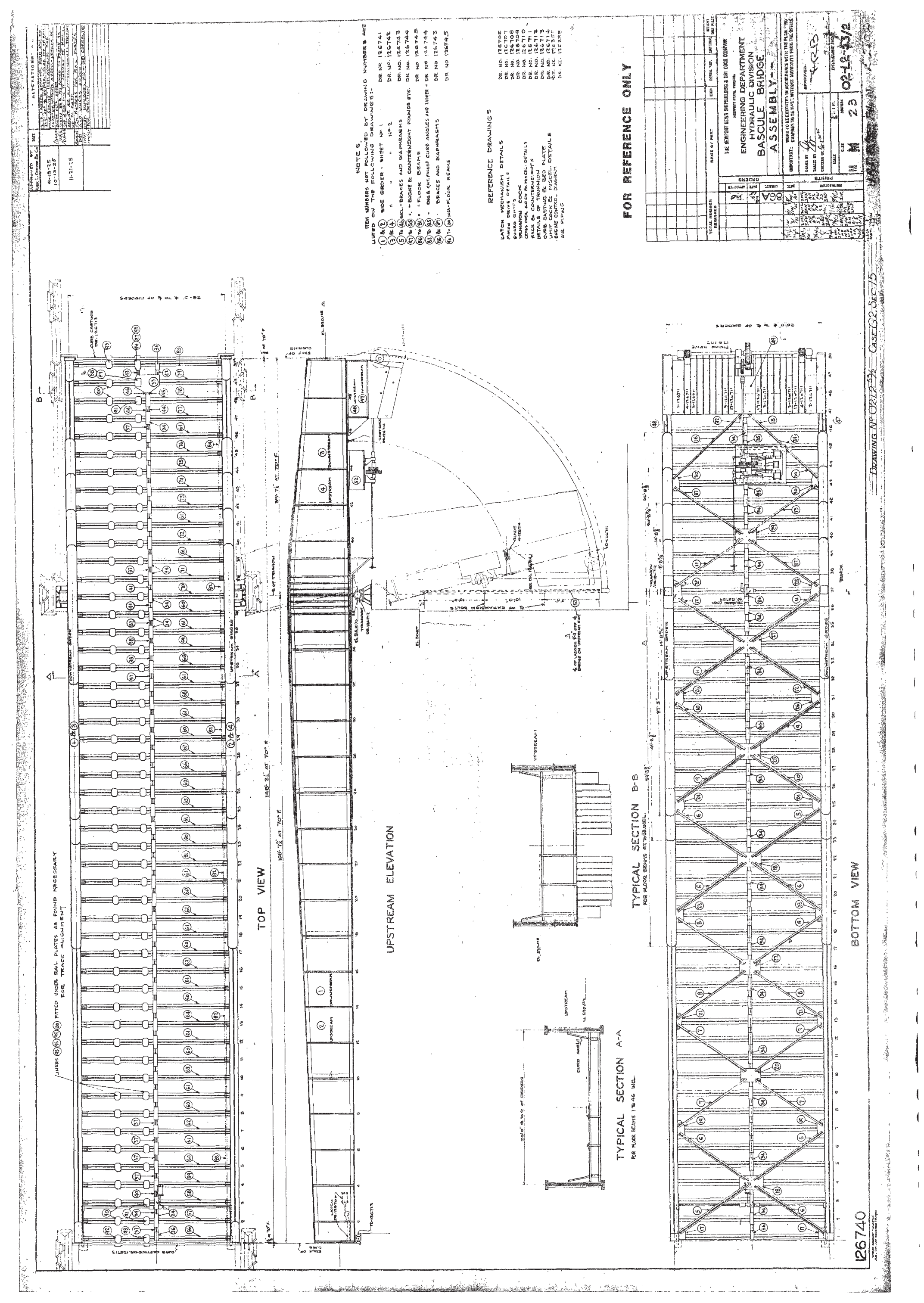




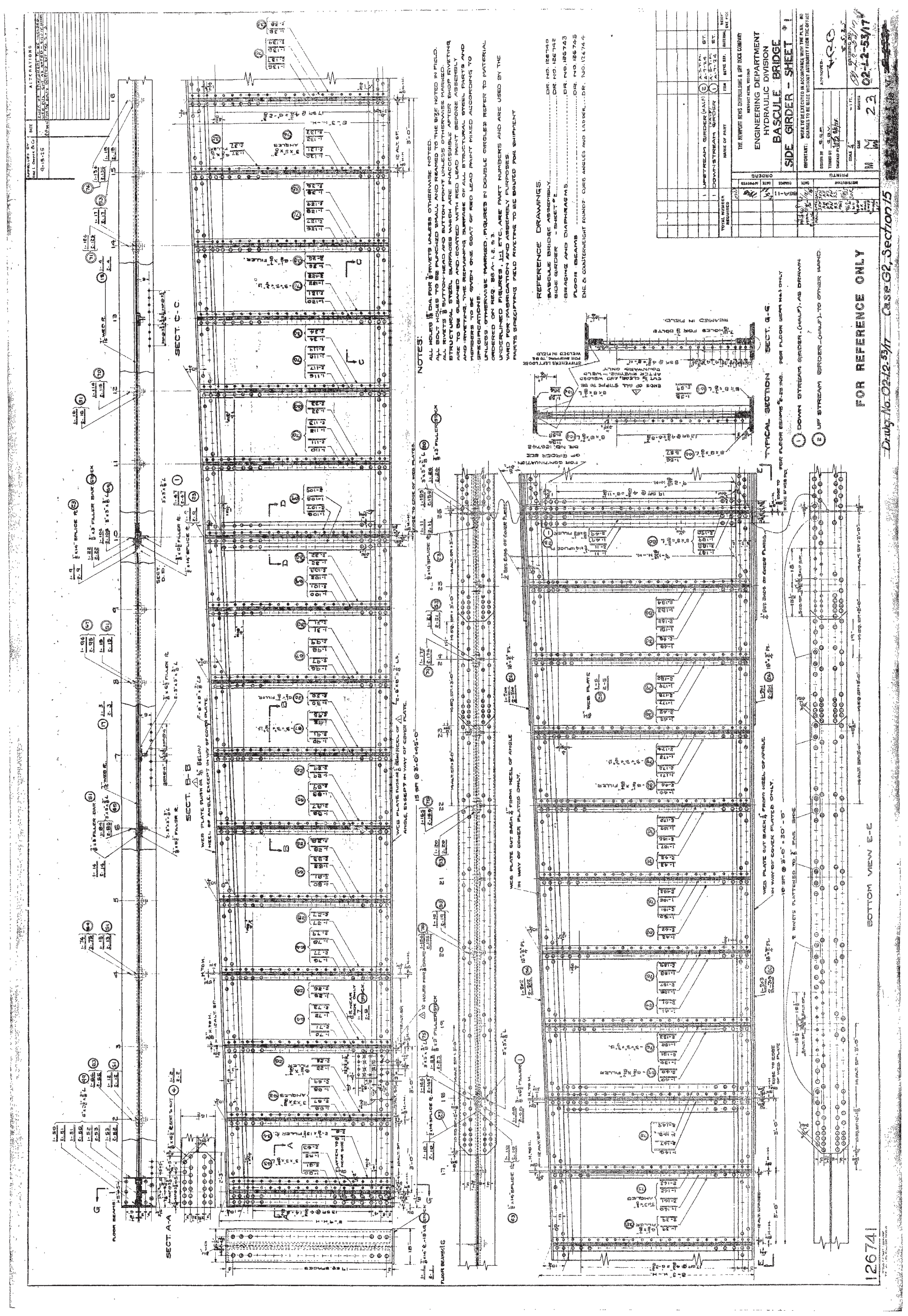




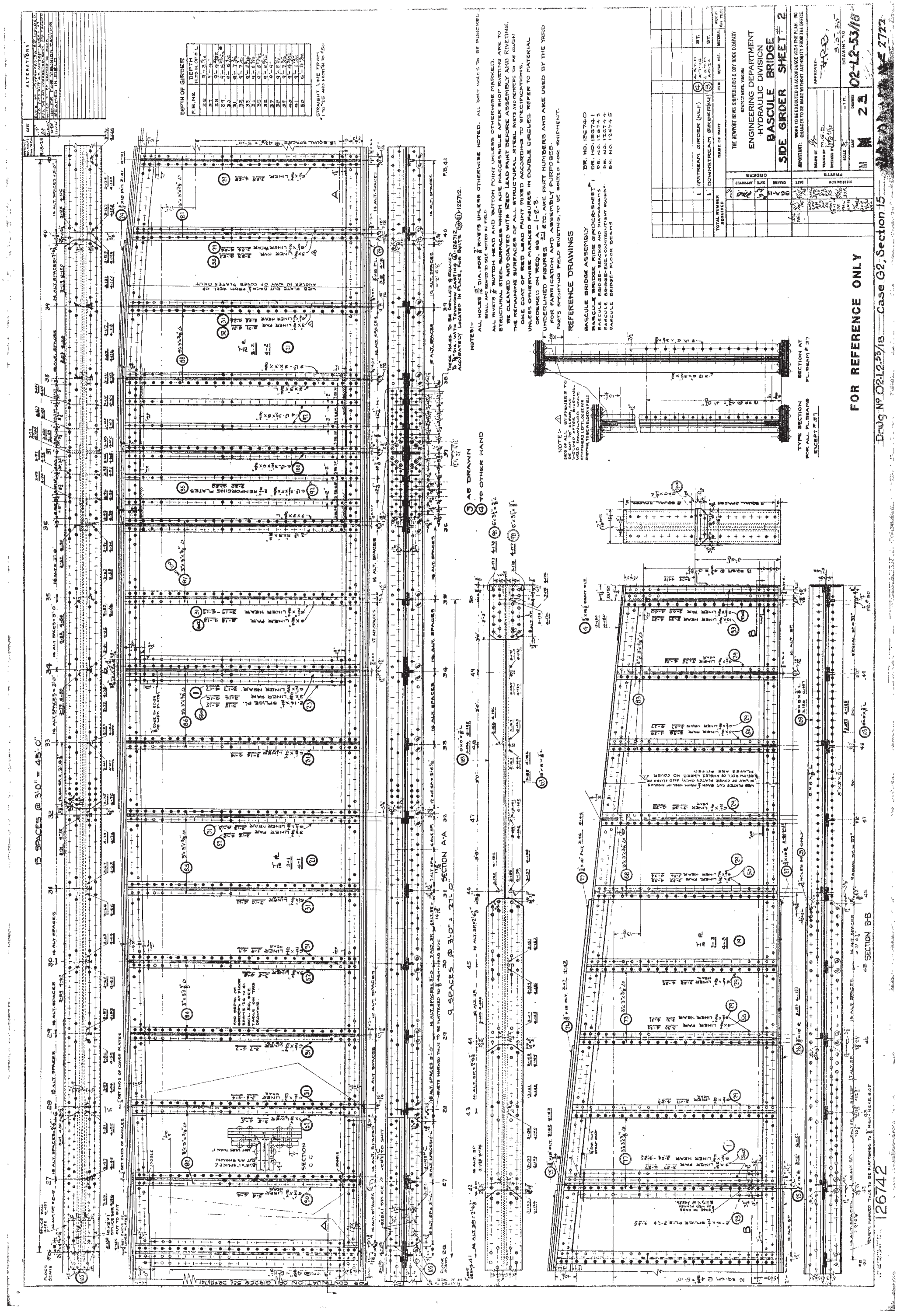


APPENDIX B HISTORICAL SPECIMEN DESIGN DRAWINGS 


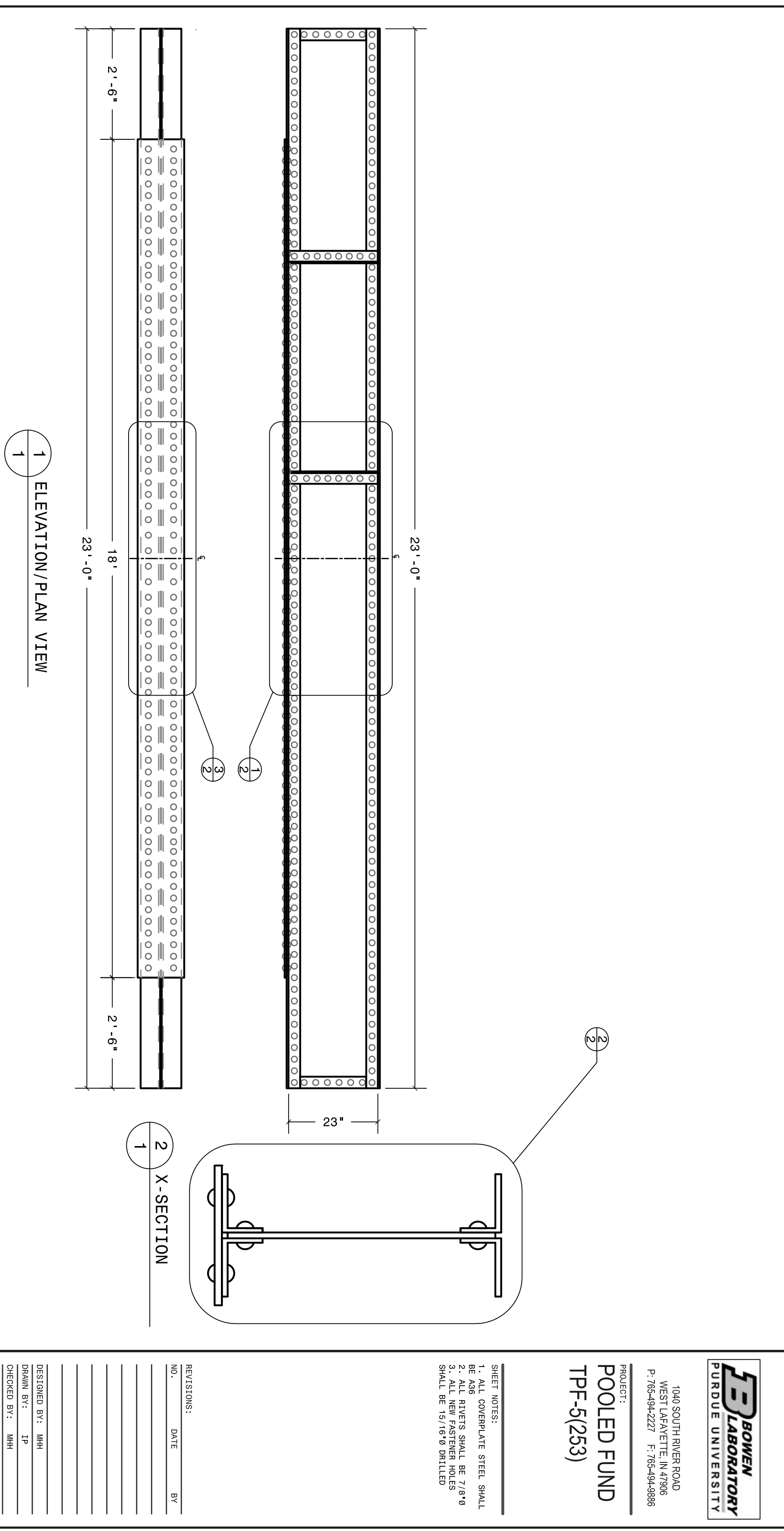



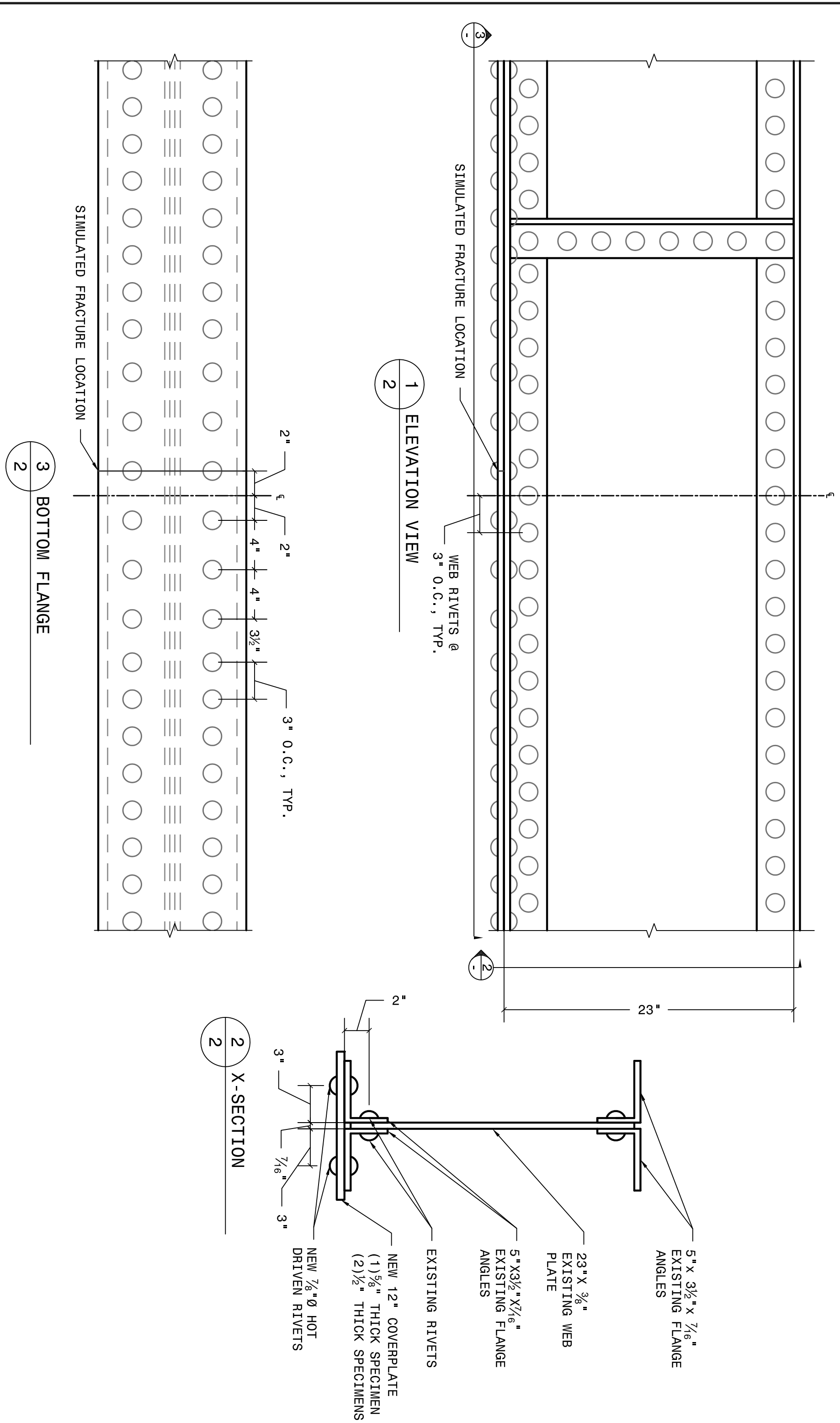

\begin{tabular}{|c|c|c|c|c|c|c|}
\hline $\begin{array}{l}\tilde{\mathrm{O}} \\
\stackrel{\mathrm{N}}{\mathrm{N}}\end{array}$ & 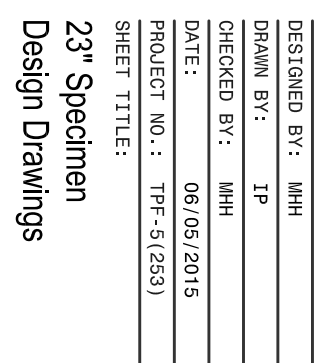 & $\mid$ & 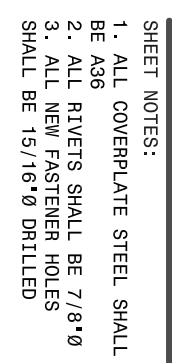 & 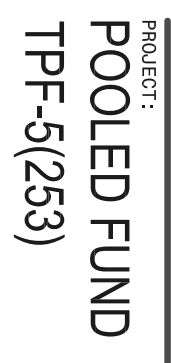 & 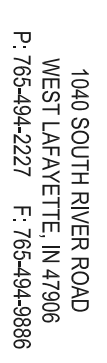 & 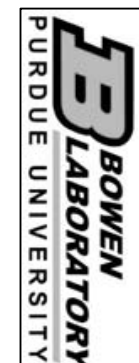 \\
\hline
\end{tabular}




\section{APPENDIX C FABRICATED SPECIMEN DESIGN DRAWINGS}




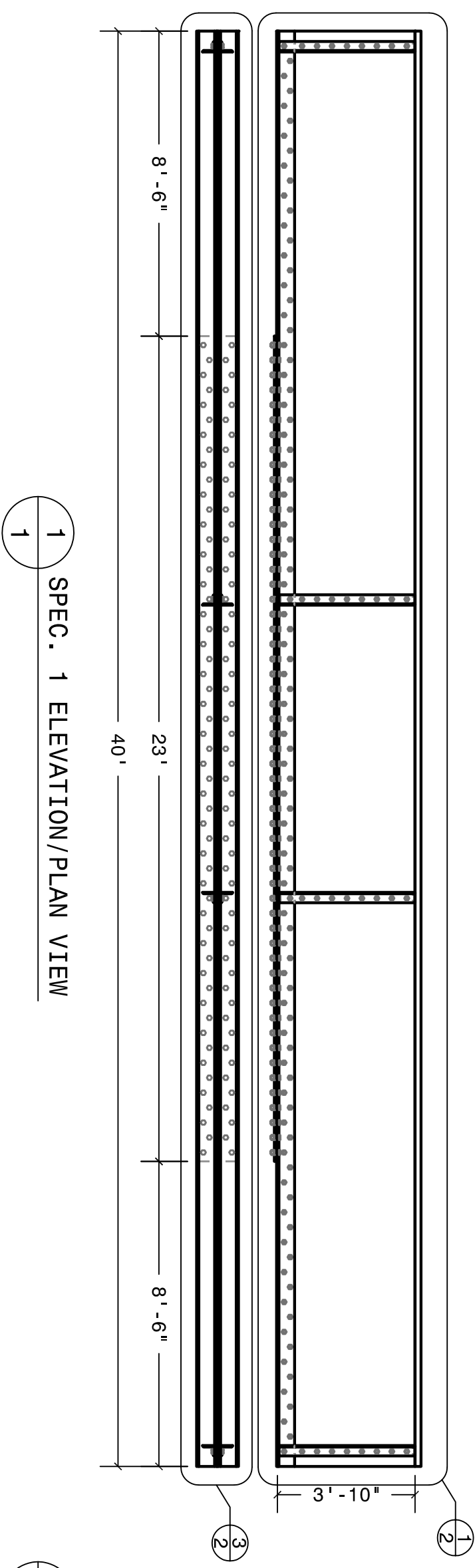

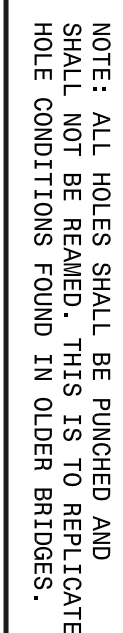

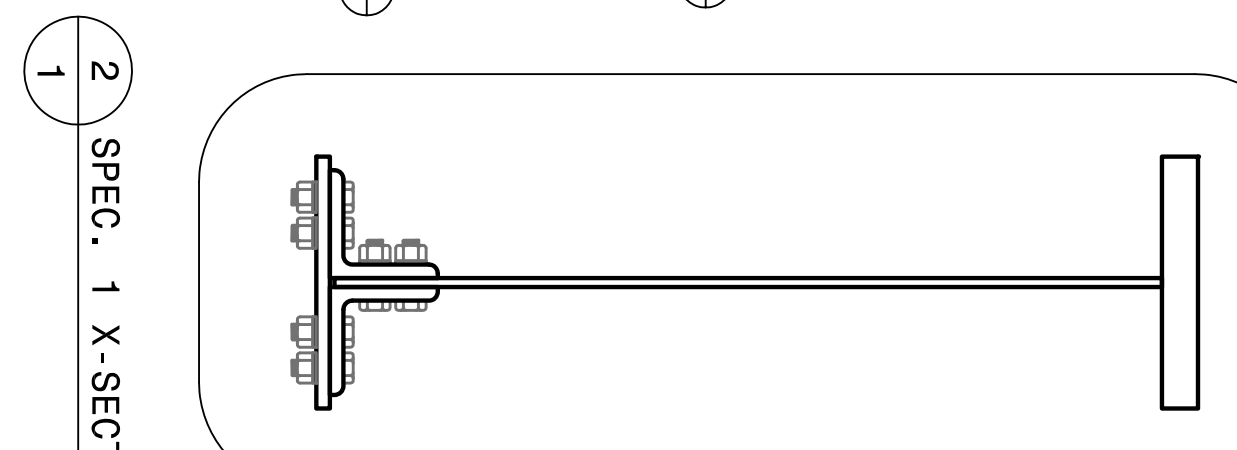

(v)

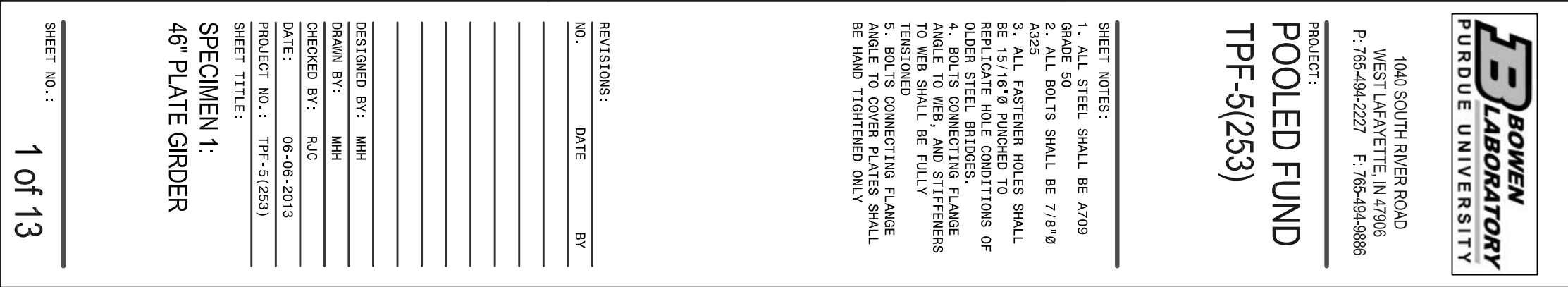




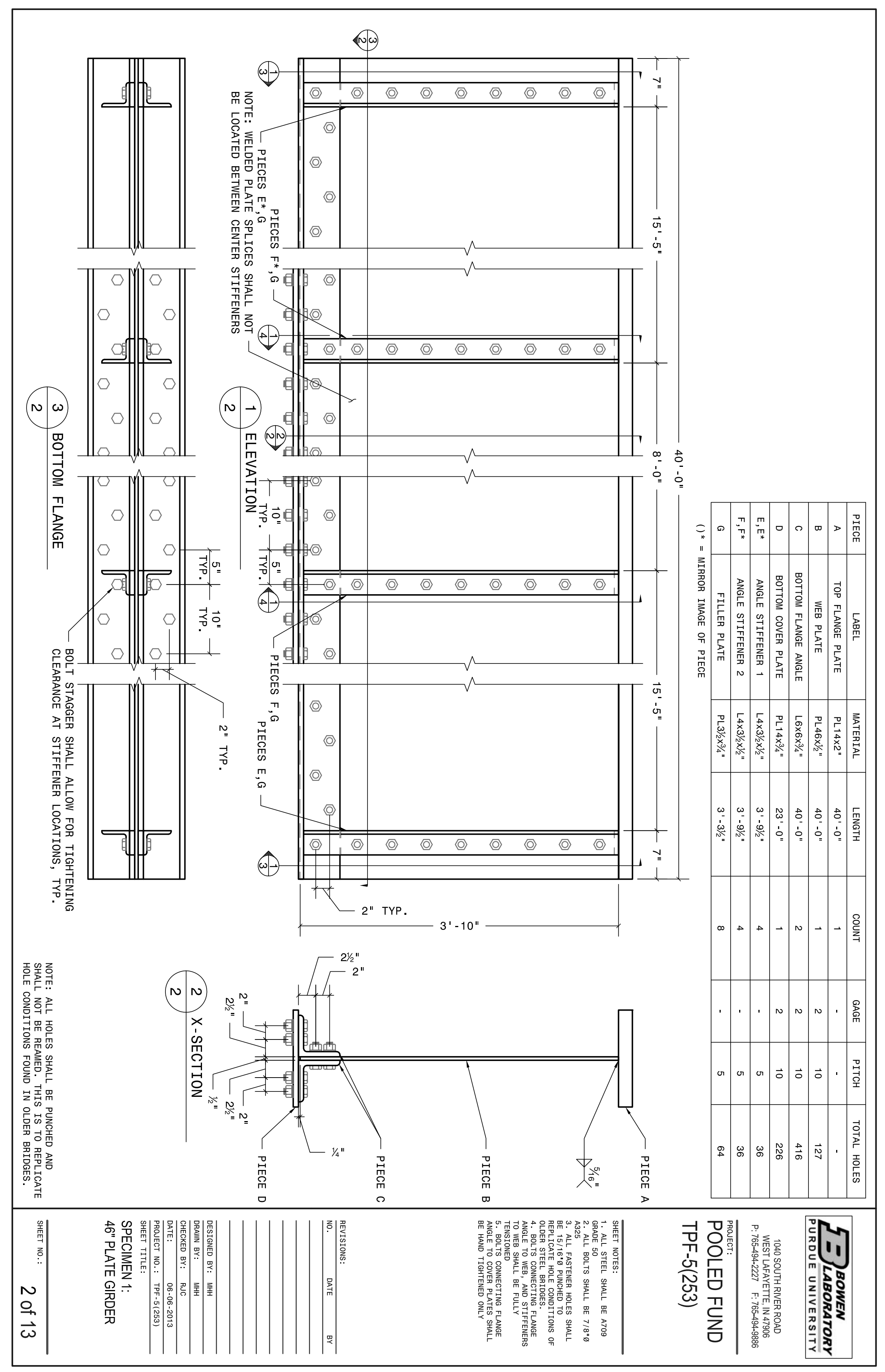



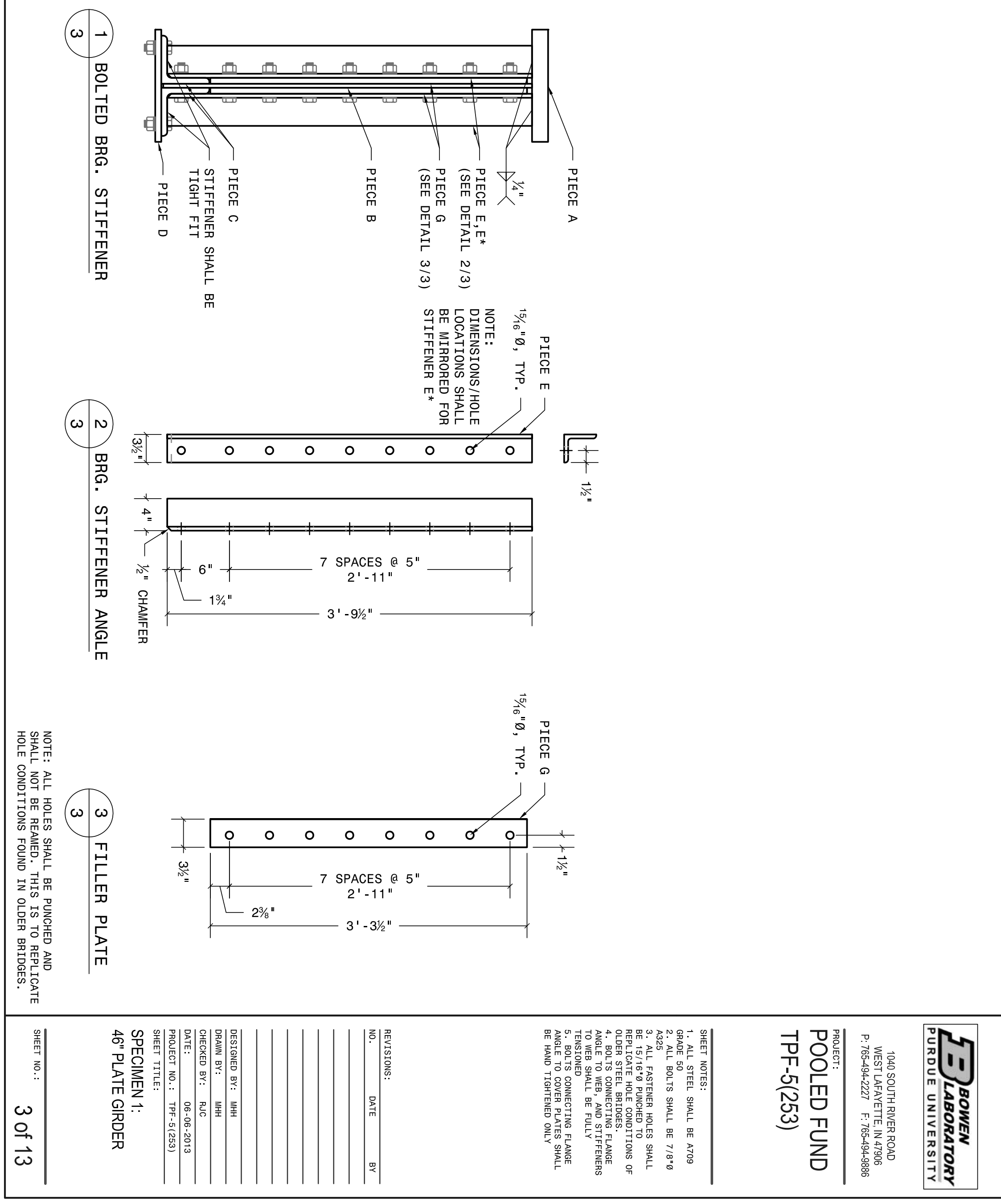


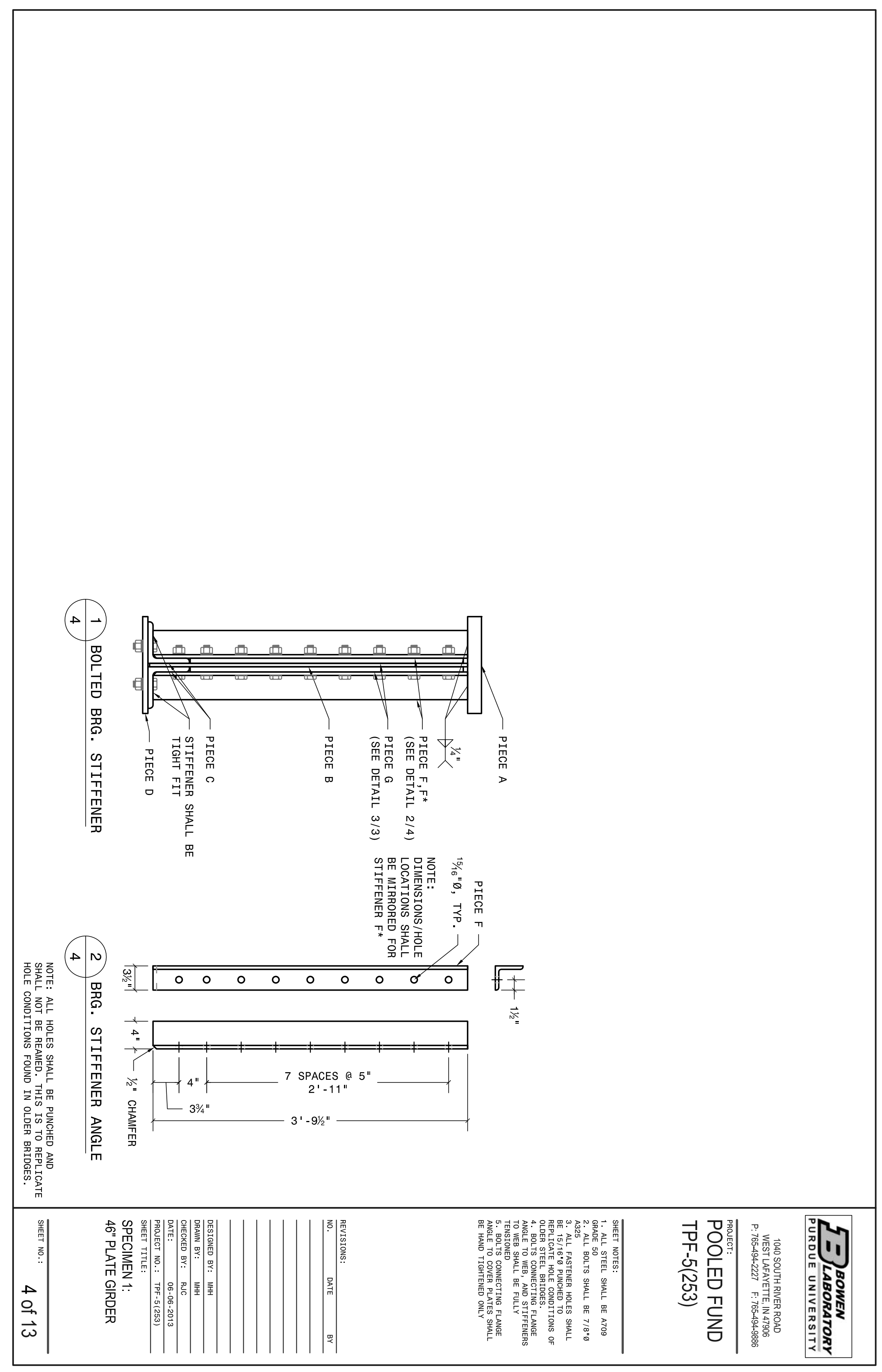




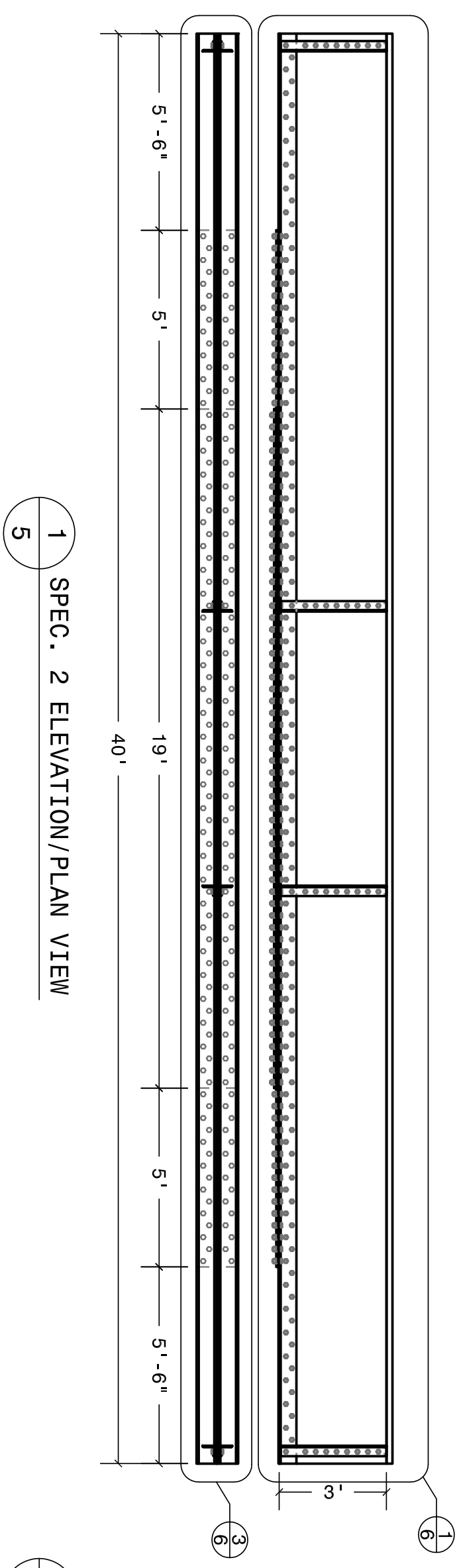

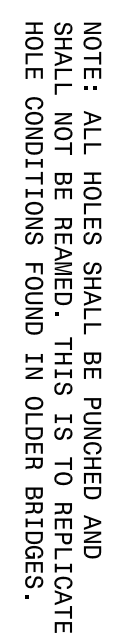
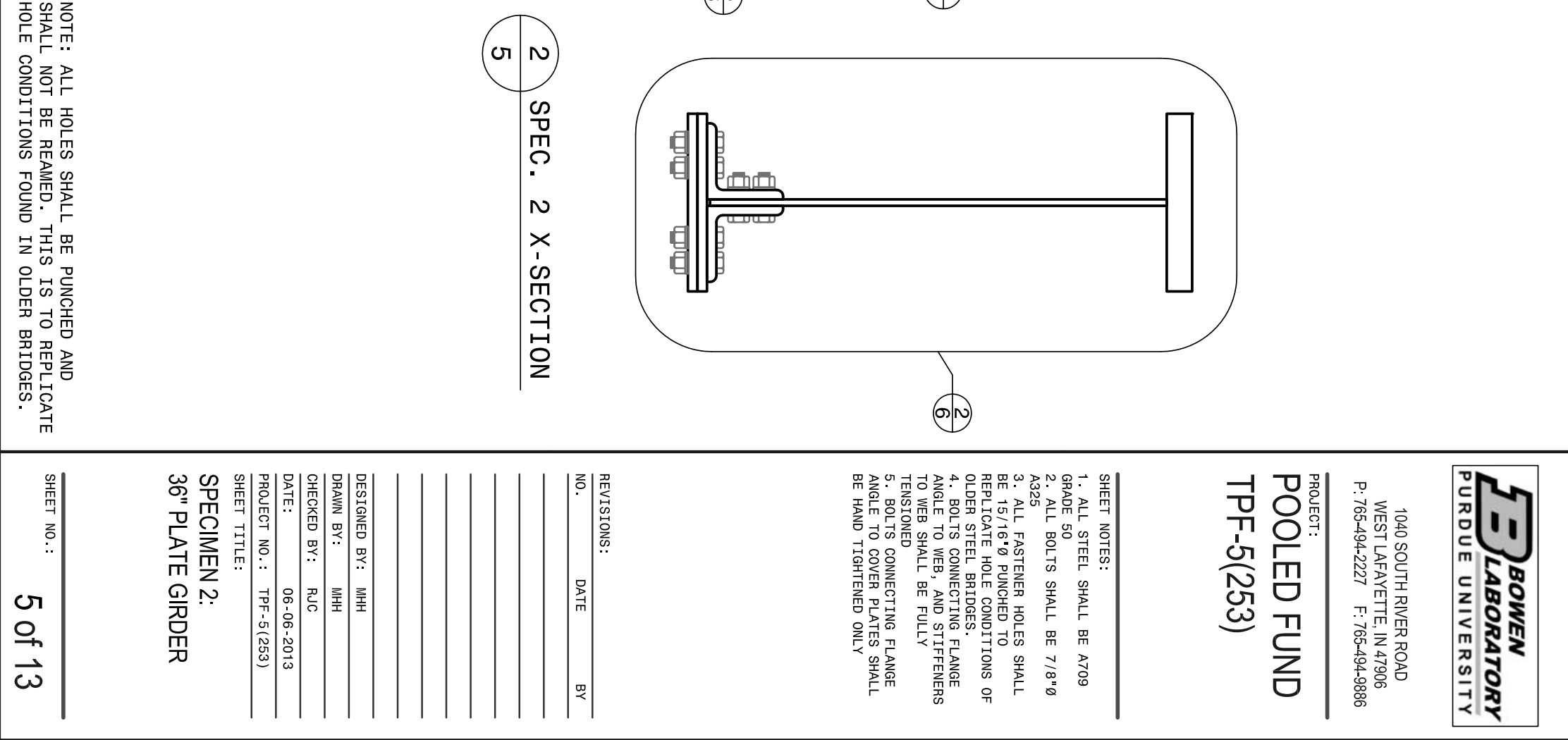


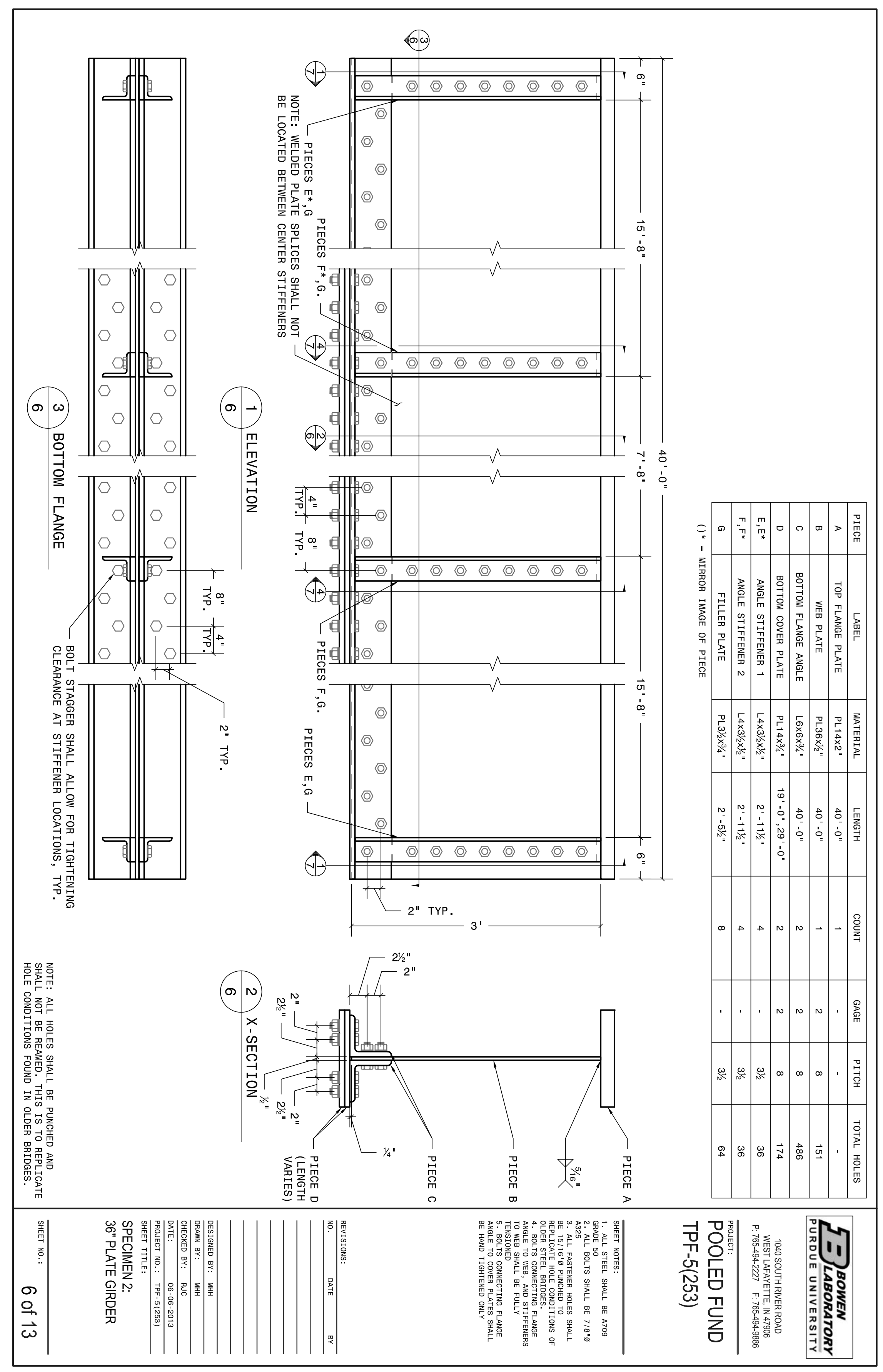



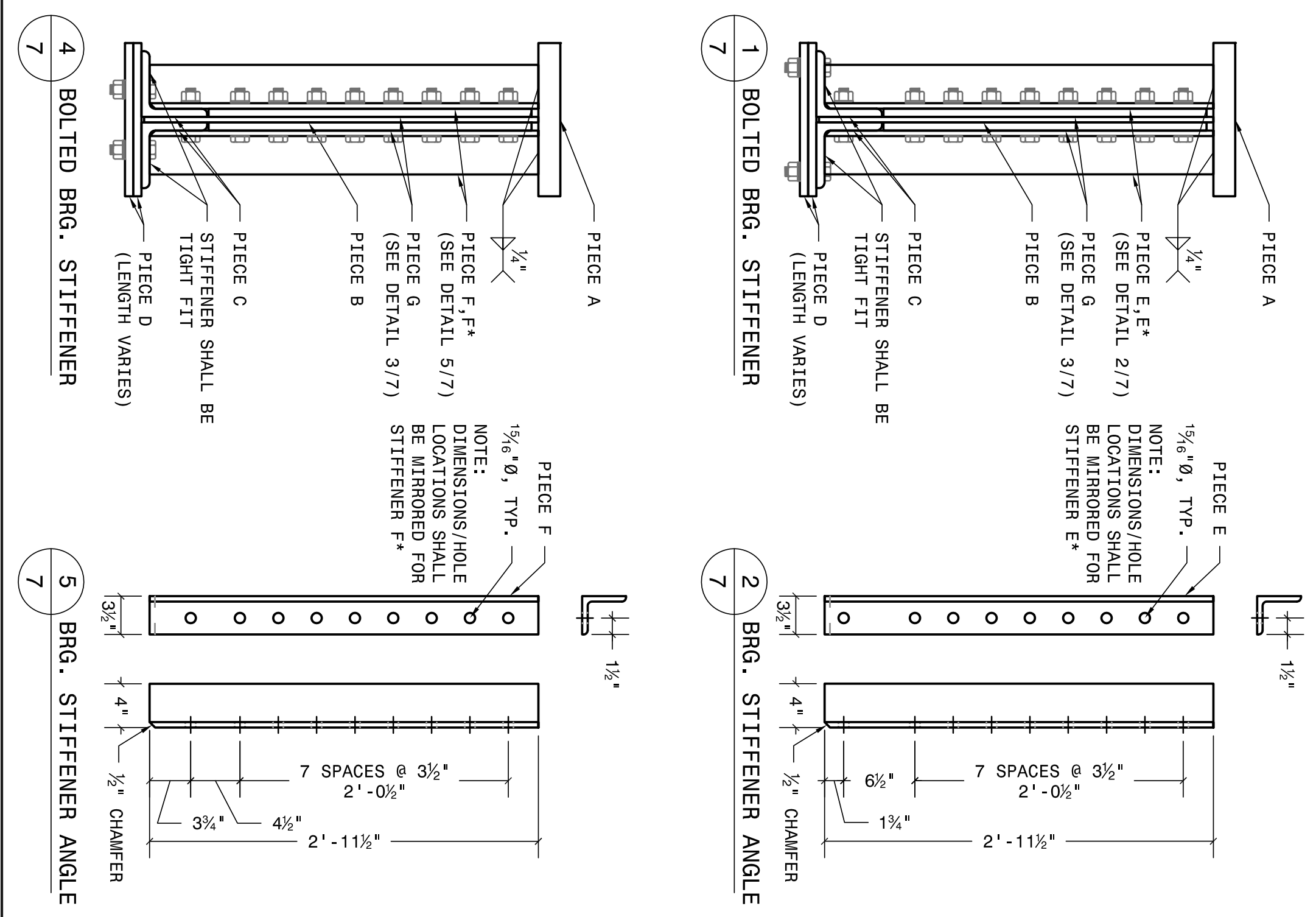

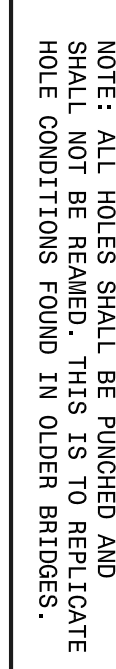
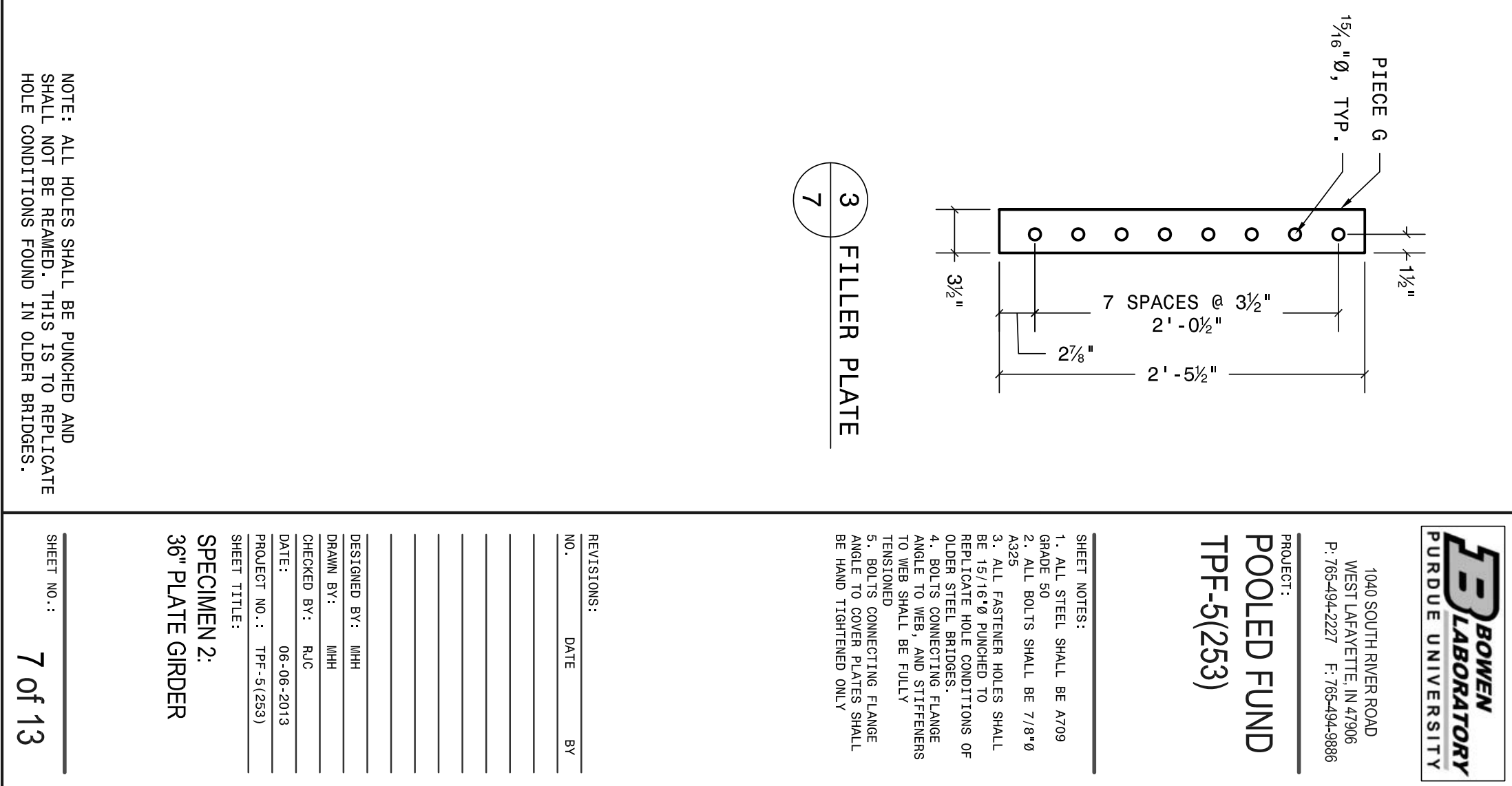


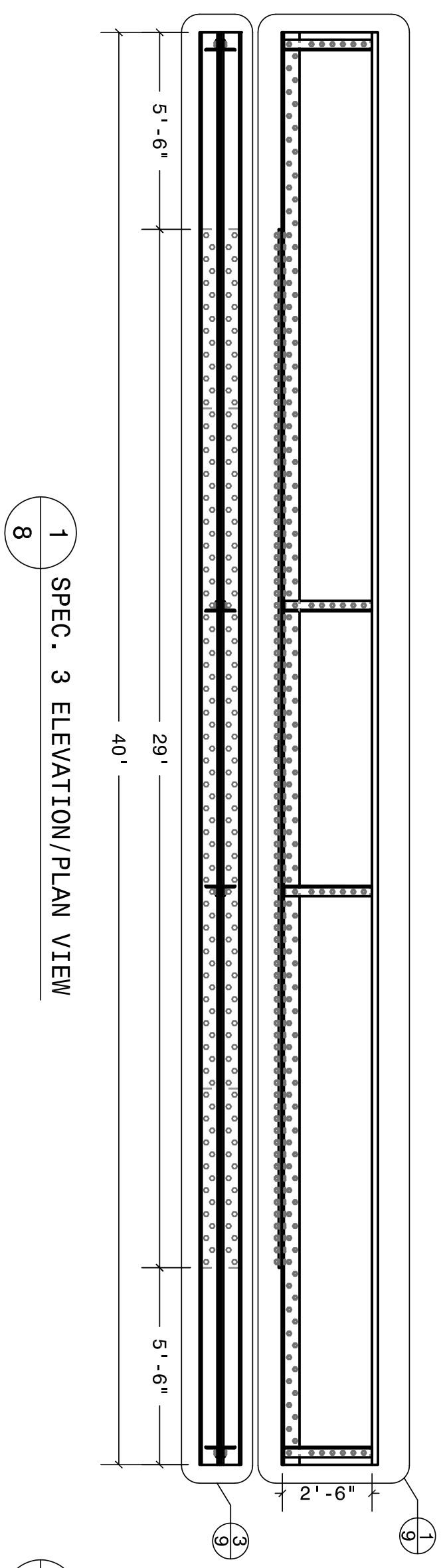

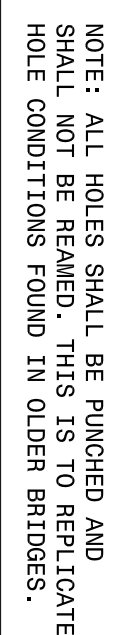
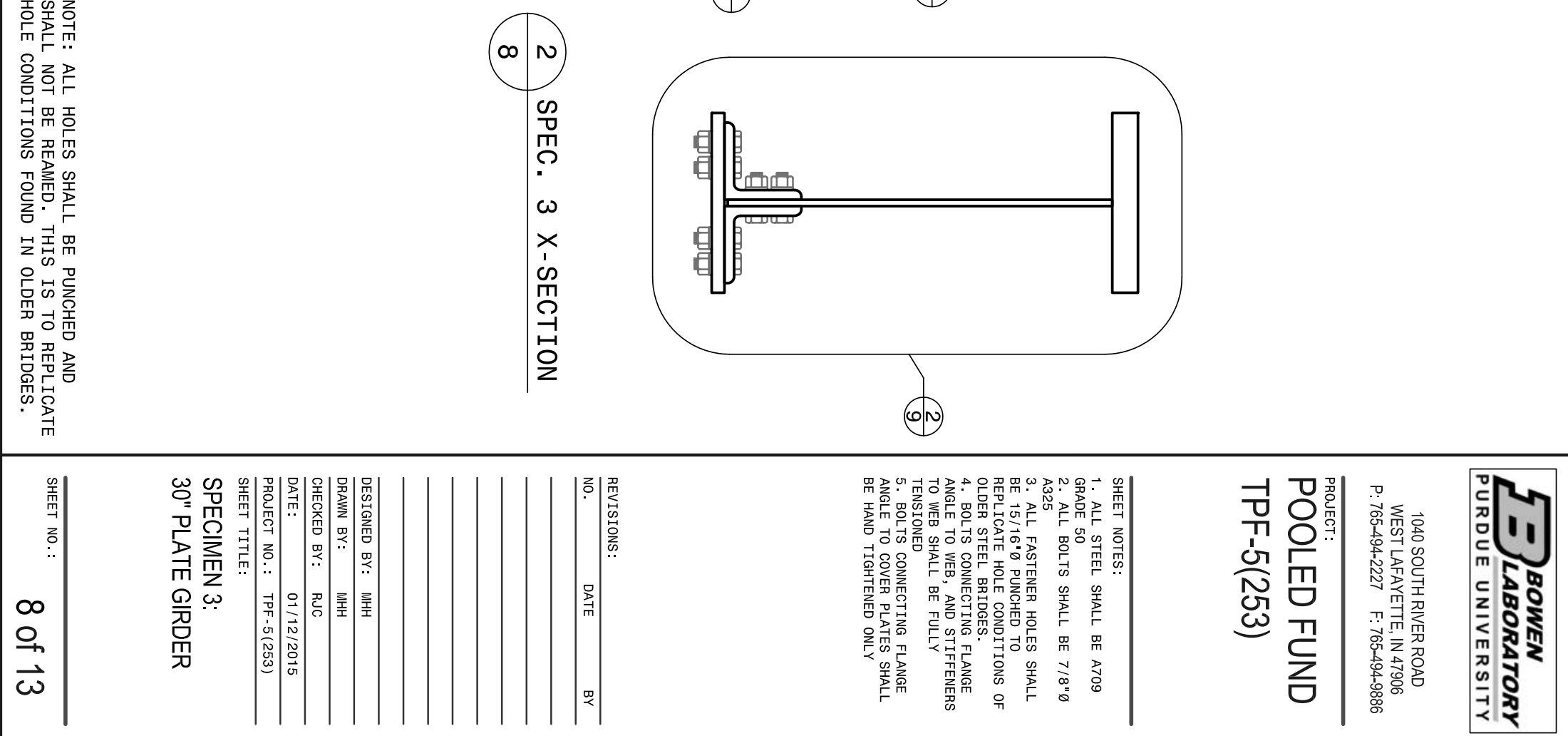


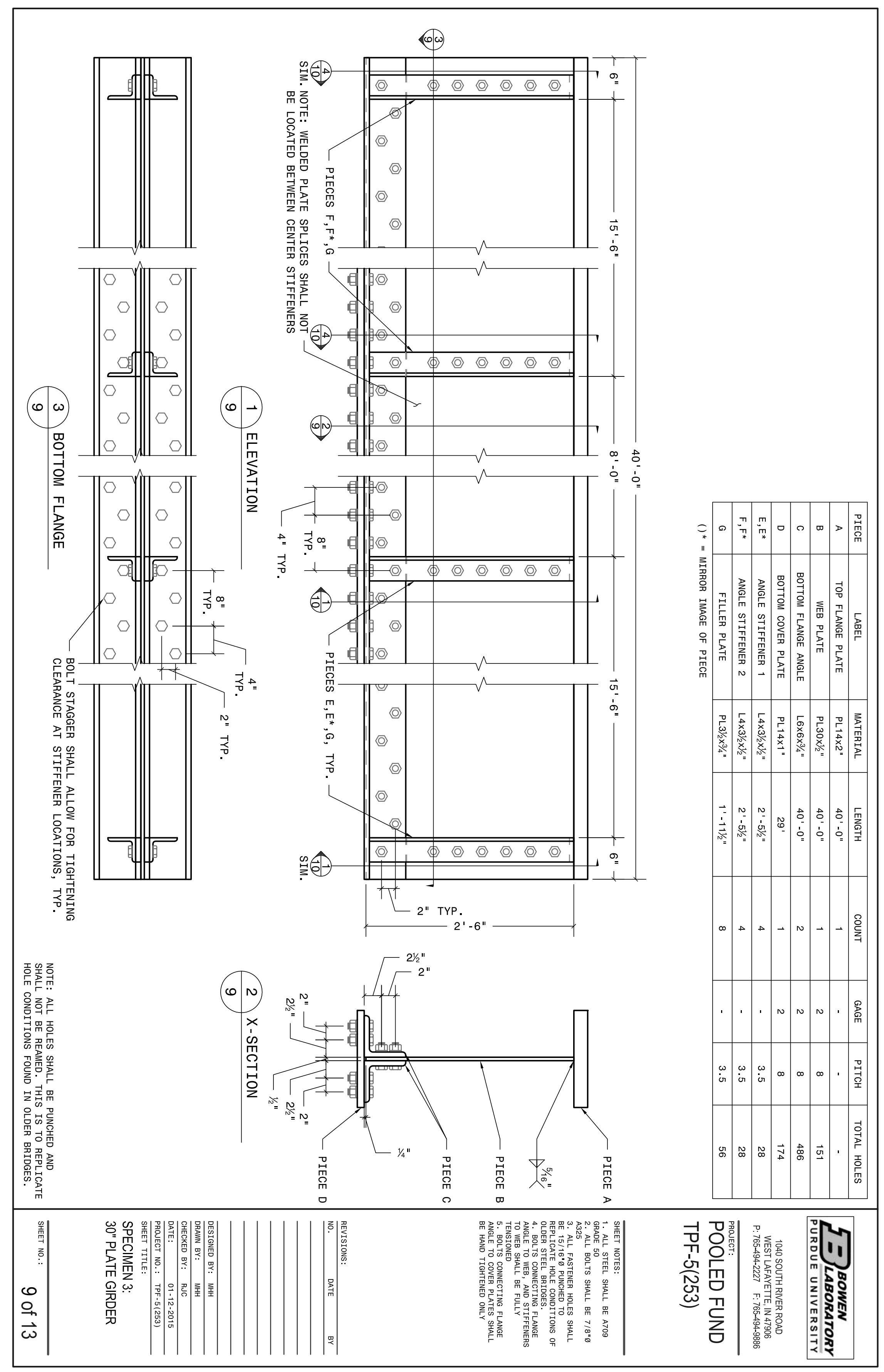




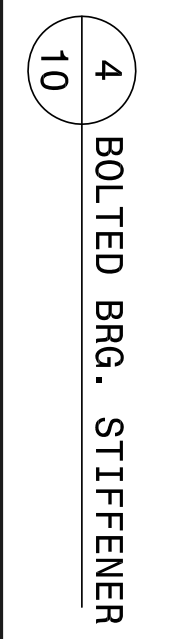
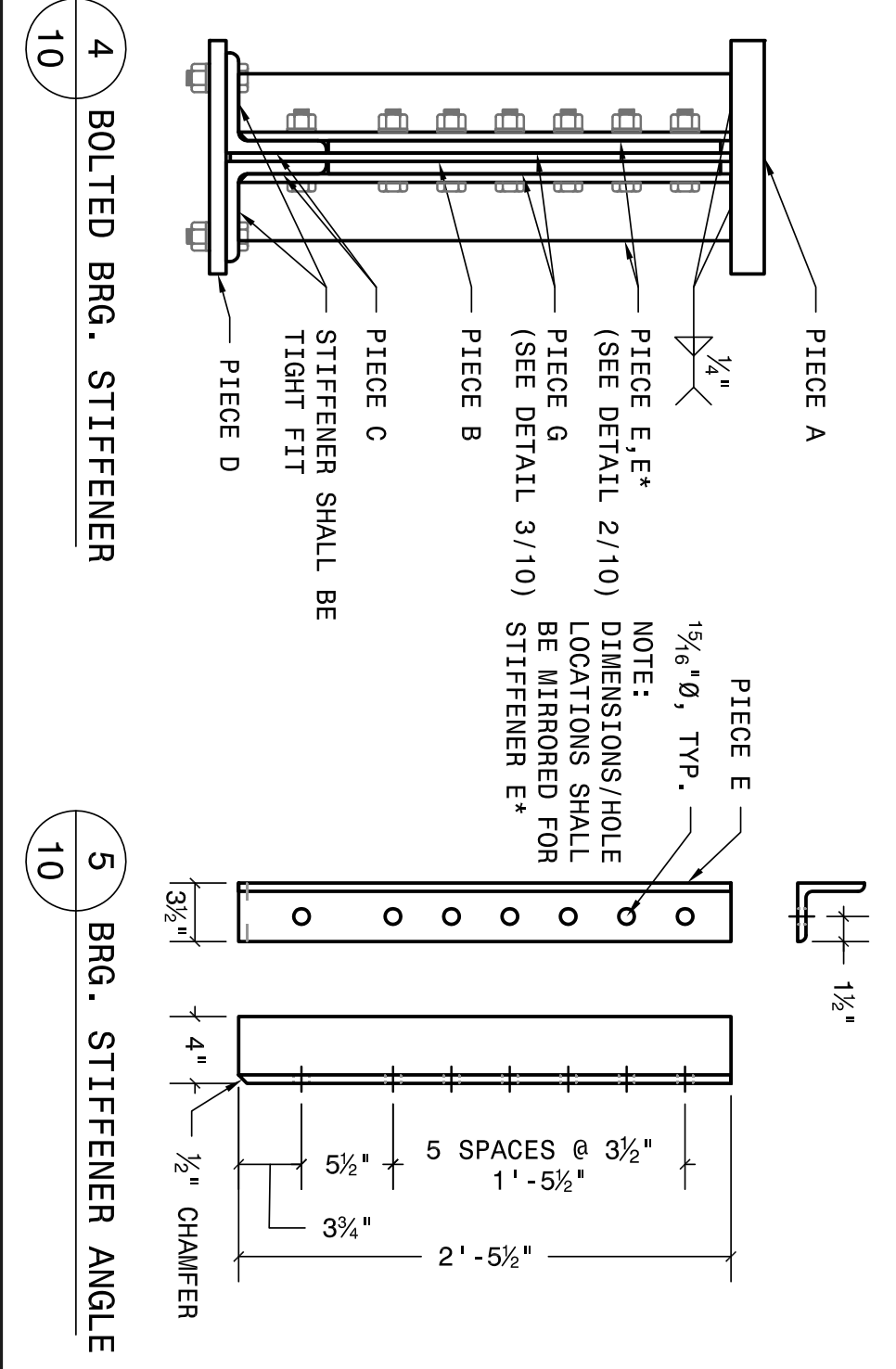

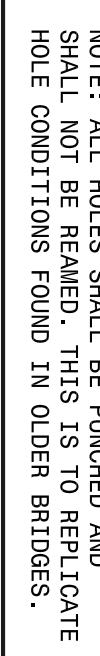

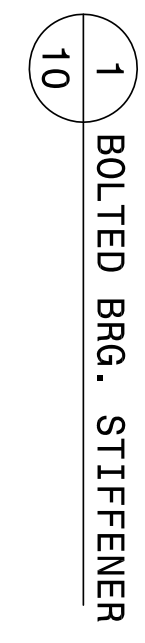
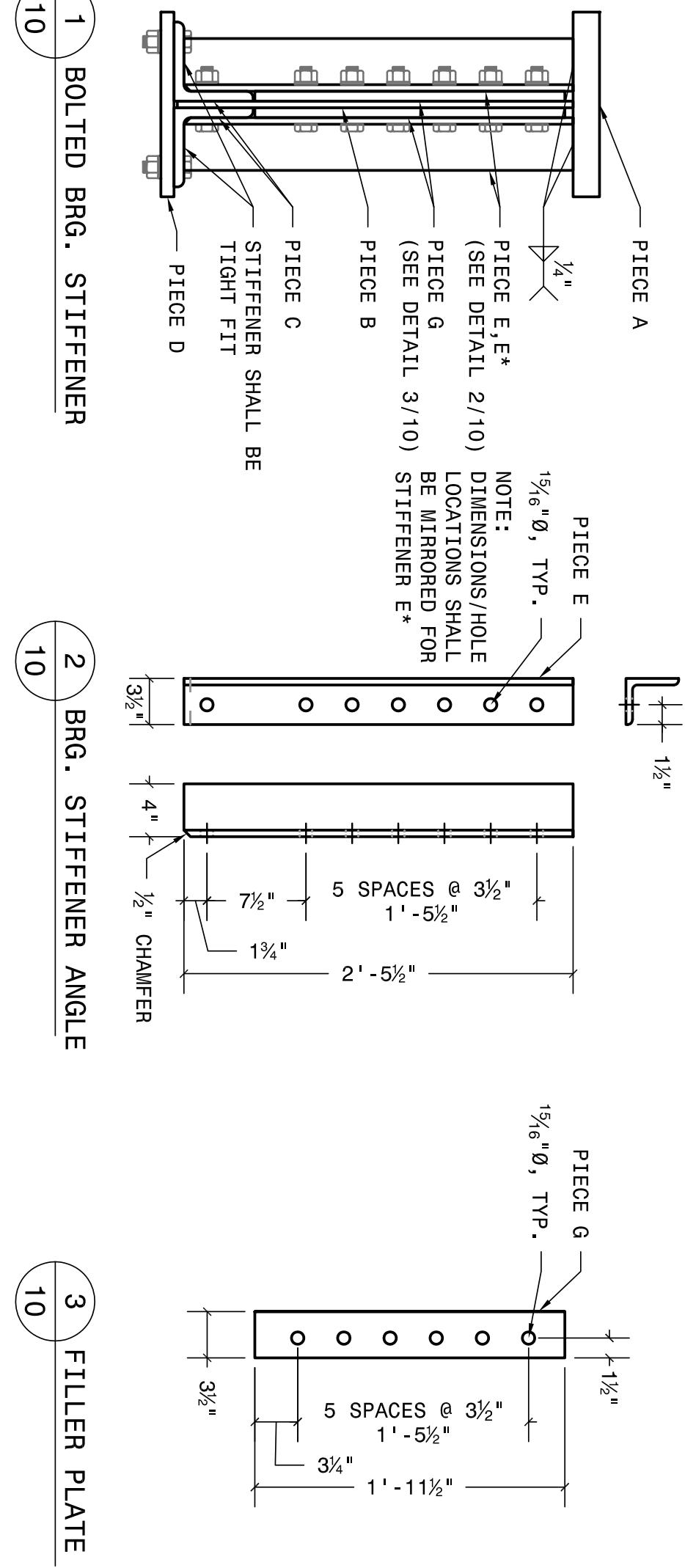
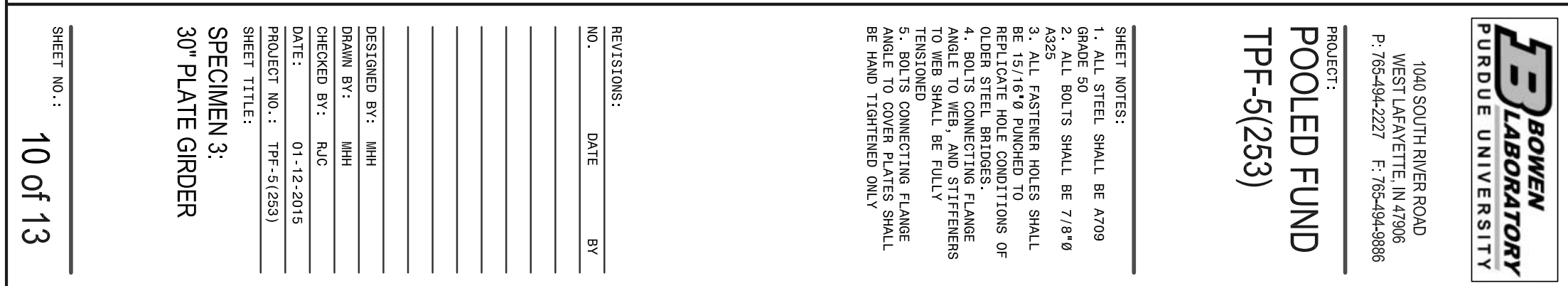


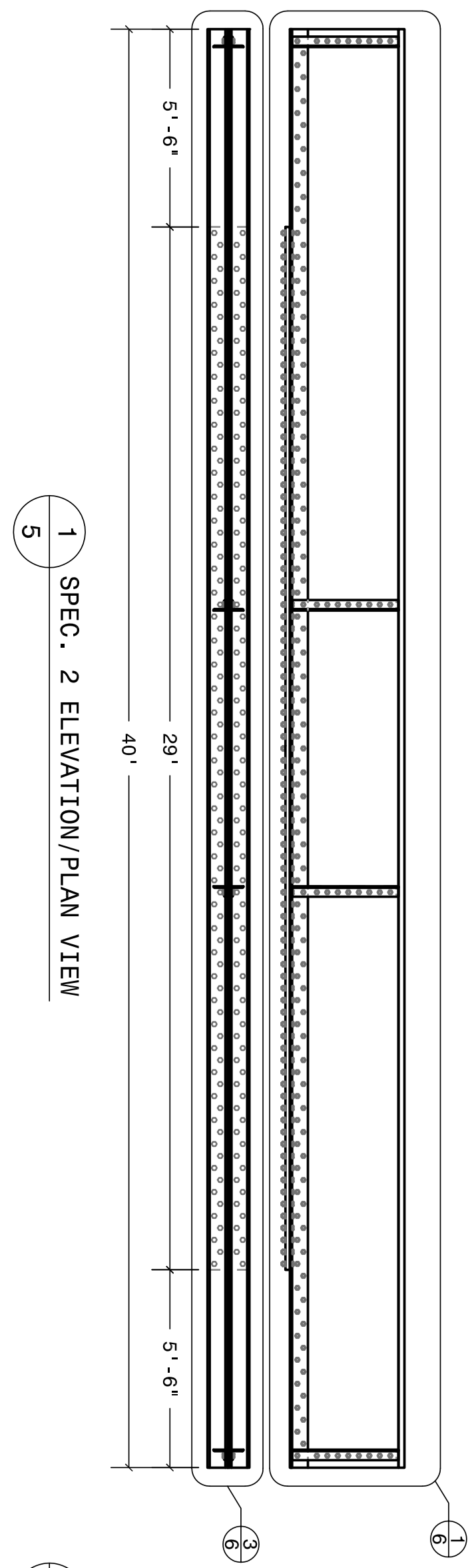

on

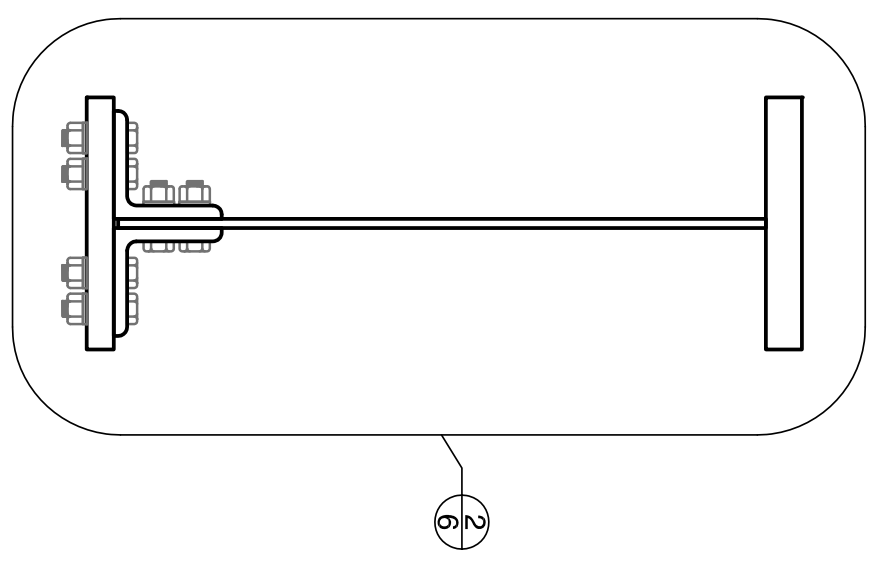

\begin{tabular}{|c|c|c|c|c|c|c|c|}
\hline $\begin{array}{l}\overrightarrow{\vec{a}} \\
\stackrel{\rightarrow}{a} \\
\vec{\omega}\end{array}$ & 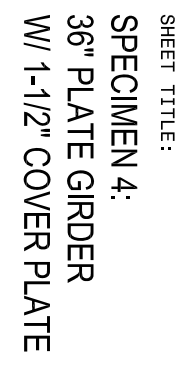 & 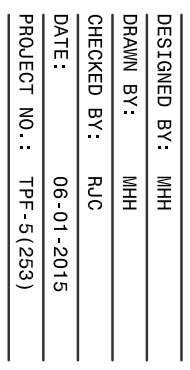 & $\mid$ & 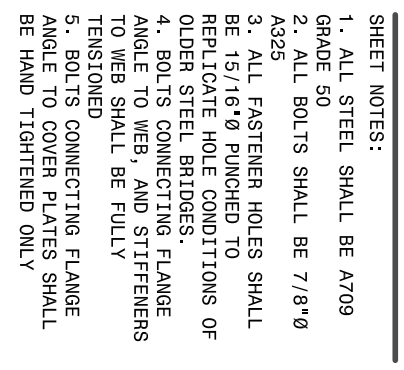 & 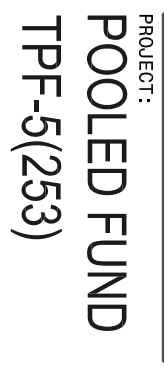 & 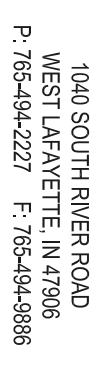 & 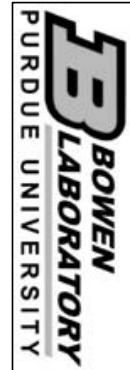 \\
\hline
\end{tabular}




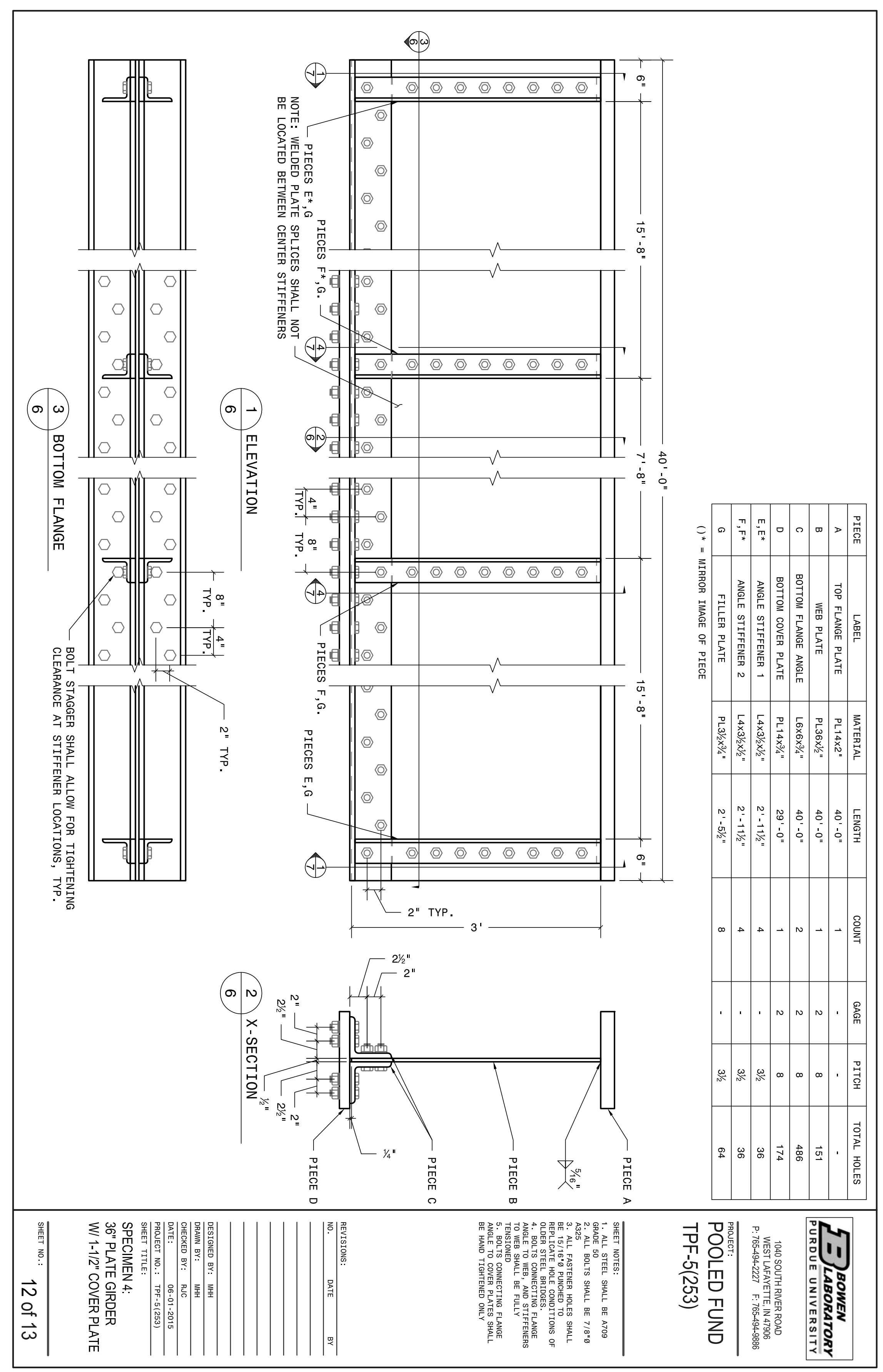



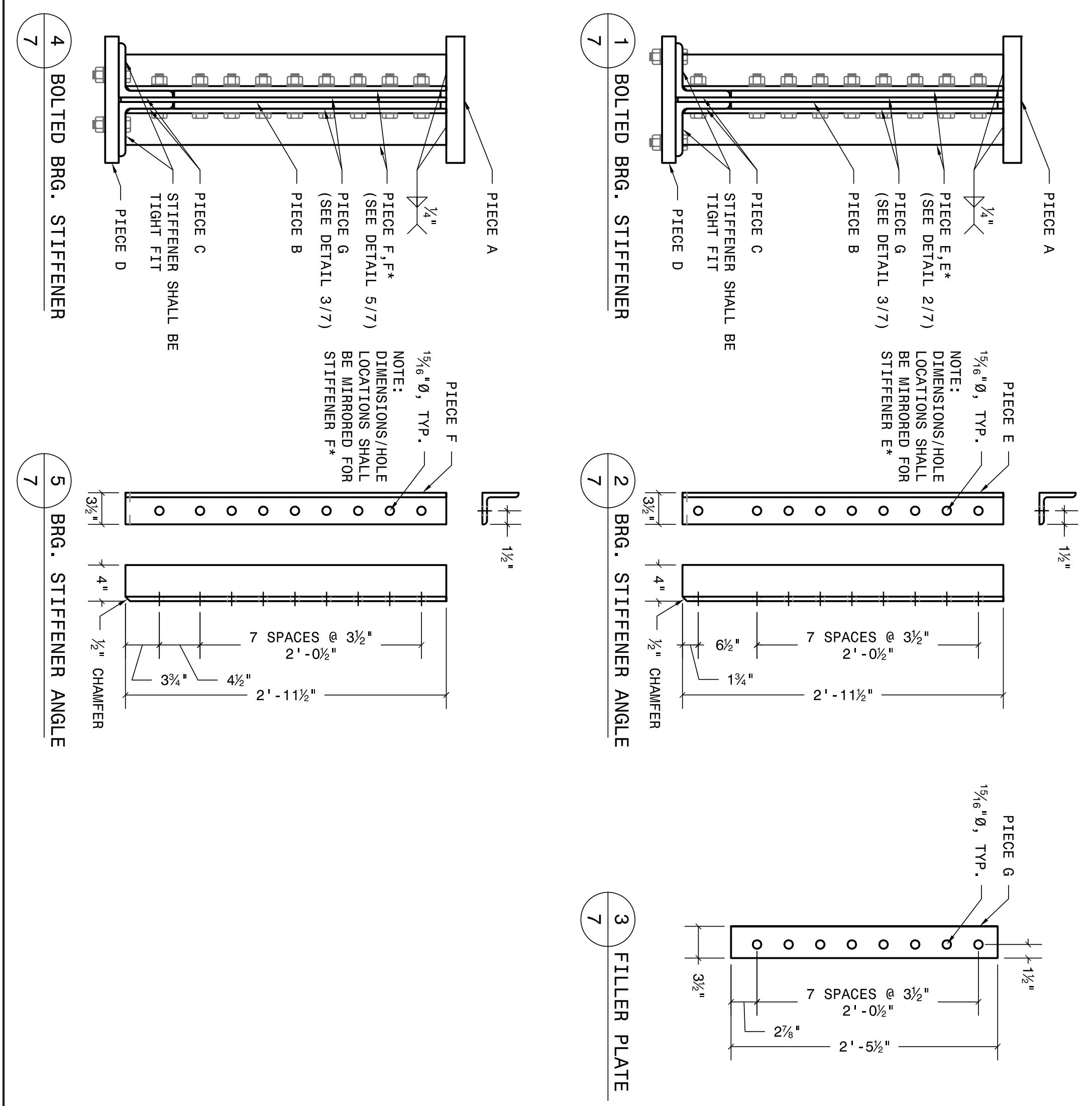

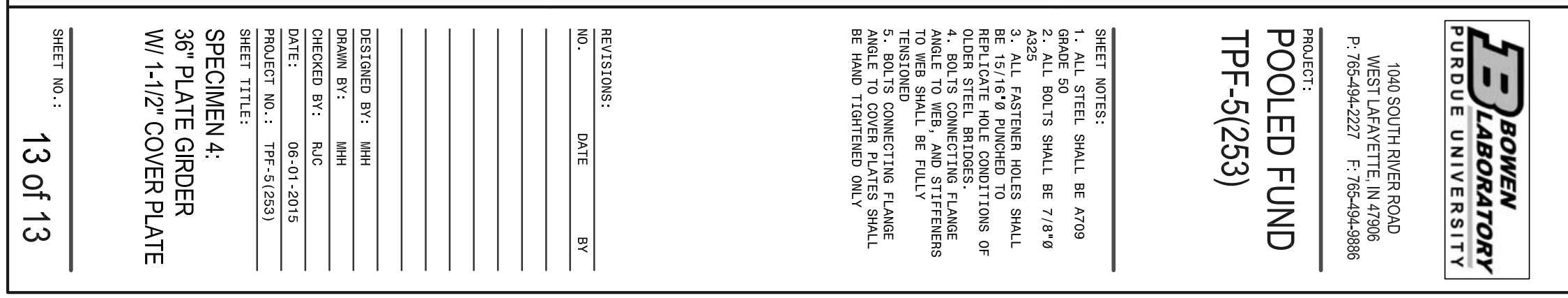




\section{APPENDIX D MATERIAL PROPERTIES}


Table D-1 Rivet material properties

\begin{tabular}{|c|c|c|}
\hline \multicolumn{3}{|c|}{ Rivets } \\
\hline \multicolumn{2}{|c|}{ Diameter } & 7/8" \\
\hline \multicolumn{2}{|l|}{ Heat } & 10216360 \\
\hline \multicolumn{2}{|l|}{ Grade } & C1018 \\
\hline \multicolumn{2}{|c|}{$\begin{array}{c}\text { Rockwell B } \\
\text { Hardness }\end{array}$} & 74.0 \\
\hline \multirow{16}{*}{$\begin{array}{l}\text { Chemical } \\
\text { Analysis }\end{array}$} & $\mathrm{Al}$ & 0.023 \\
\hline & B & 0.0001 \\
\hline & $\mathrm{C}$ & 0.16 \\
\hline & $\mathrm{Cr}$ & 0.07 \\
\hline & $\mathrm{Cu}$ & 0.09 \\
\hline & $\mathrm{Mn}$ & 0.67 \\
\hline & Mo & 0.01 \\
\hline & $\mathrm{N}$ & 0.007 \\
\hline & $\mathrm{Nb}$ & 0.001 \\
\hline & $\mathrm{Ni}$ & 0.05 \\
\hline & $\mathrm{P}$ & 0.01 \\
\hline & $\mathrm{S}$ & 0.011 \\
\hline & $\mathrm{Si}$ & 0.08 \\
\hline & $\mathrm{Sn}$ & 0.008 \\
\hline & $\mathrm{Ti}$ & 0.001 \\
\hline & $\mathrm{V}$ & 0.002 \\
\hline
\end{tabular}




\section{Specimen 23-1}

Table D-2 Specimen 23-1 material properties

\begin{tabular}{|c|c|c|c|c|}
\hline \multicolumn{5}{|c|}{ Specimen 23-1 } \\
\hline \multicolumn{2}{|c|}{ Component } & Web Plate & Flange Angle & Cover Plate \\
\hline \multicolumn{2}{|l|}{ Shape } & Plate & Angle & Plate \\
\hline \multicolumn{2}{|c|}{ Dimensions } & $23 " x 3 / 8 "$ & 5"x3-1/2"x1/2" & $5 / 8 " x 12 "$ \\
\hline \multicolumn{2}{|c|}{ Length } & $22^{\prime}-9 "$ & $22^{\prime}-9 "$ & $20^{\prime}-0^{\prime \prime}$ \\
\hline \multicolumn{2}{|c|}{ Heat No. } & N/A (Historical) & N/A (Historical) & 1015896 \\
\hline \multicolumn{2}{|l|}{ Grade } & & & A36 \\
\hline $\begin{array}{c}\text { Yield } \\
\text { Strength }\end{array}$ & ksi & 34.5 & 36.8 & 46.8 \\
\hline $\begin{array}{l}\text { Ultimate } \\
\text { Strength }\end{array}$ & ksi & 59.0 & 58.6 & 68.8 \\
\hline Elongation & $\%$ & 38 & 40 & 25.5 \\
\hline \multirow{15}{*}{$\begin{array}{l}\text { Chemical } \\
\text { Analysis }\end{array}$} & $\mathrm{Ni}$ & 0.01 & 0.01 & 0.14 \\
\hline & $\mathrm{Cr}$ & 0.02 & 0.02 & 0.18 \\
\hline & $\mathrm{MN}$ & 0.47 & 0.44 & 0.63 \\
\hline & $\mathrm{Si}$ & 0.01 & 0.01 & 0.21 \\
\hline & $\mathrm{C}$ & 0.2 & 0.21 & 0.11 \\
\hline & $\mathrm{S}$ & 0.03 & 0.026 & 0.045 \\
\hline & $\mathrm{P}$ & $<0.01$ & $<0.01$ & 0.017 \\
\hline & $\mathrm{Mo}$ & 0.01 & 0.01 & 0.045 \\
\hline & $\mathrm{Cu}$ & 0.03 & 0.02 & 0.31 \\
\hline & $\mathrm{V}$ & & & 0.003 \\
\hline & $\mathrm{Cb}$ & & & 0.001 \\
\hline & $\mathrm{Sn}$ & & & 0.011 \\
\hline & B & & & 0.0003 \\
\hline & $\mathrm{Ti}$ & & & 0.001 \\
\hline & $\mathrm{N}$ & & & 0.013 \\
\hline
\end{tabular}


Table D-3 Specimen 23-1 CVN data

\begin{tabular}{|c|c|c|c|c|c|c|}
\hline \multicolumn{7}{|c|}{ Specimen 23-1 } \\
\hline Component & \multicolumn{2}{|c|}{ Web Plate } & \multicolumn{2}{|c|}{ Flange Angle } & \multicolumn{2}{|c|}{ Cover Plate } \\
\hline Dimensions & \multicolumn{2}{|c|}{$23 " x 3 / 8 "$} & \multicolumn{2}{|c|}{ 5"x3-1/2"x1/2" } & \multicolumn{2}{|c|}{ 5/8"x12" } \\
\hline Heat No. & \multicolumn{2}{|c|}{ N/A (Historical) } & \multicolumn{2}{|c|}{ N/A (Historical) } & \multicolumn{2}{|c|}{1015896} \\
\hline Grade & & & & & \multicolumn{2}{|c|}{ A36 } \\
\hline \multirow{19}{*}{ CVN } & ${ }^{\circ} \mathrm{F}$ & Energy & ${ }^{\circ} \mathrm{F}$ & Energy & ${ }^{\circ} \mathrm{F}$ & Energy \\
\hline & & & -60 & 2.67 & -60 & 3 \\
\hline & & & -60 & 2.67 & -60 & 3 \\
\hline & & & -60 & 2.00 & -60 & 2.5 \\
\hline & & & -30 & 3.33 & -50 & 4 \\
\hline & & & -30 & 3.33 & -50 & 3 \\
\hline & & & -30 & 4.00 & -50 & 4.5 \\
\hline & & & -10 & 6.00 & -20 & 12 \\
\hline & & & -10 & 7.33 & -20 & 13.5 \\
\hline & & & -10 & 6.00 & -20 & 11.5 \\
\hline & & & 10 & 6.67 & 10 & 16 \\
\hline & & & 10 & 6.00 & 10 & 16.5 \\
\hline & & & 10 & 6.00 & 10 & 16.5 \\
\hline & & & 40 & 10.00 & 40 & 22 \\
\hline & & & 40 & 10.00 & 40 & 21.5 \\
\hline & & & 40 & 14.67 & 40 & 19 \\
\hline & & & 70 & 17.33 & 70 & 29.5 \\
\hline & & & 70 & 18.00 & 70 & 25.5 \\
\hline & & & 70 & 19.33 & 70 & 28.5 \\
\hline
\end{tabular}




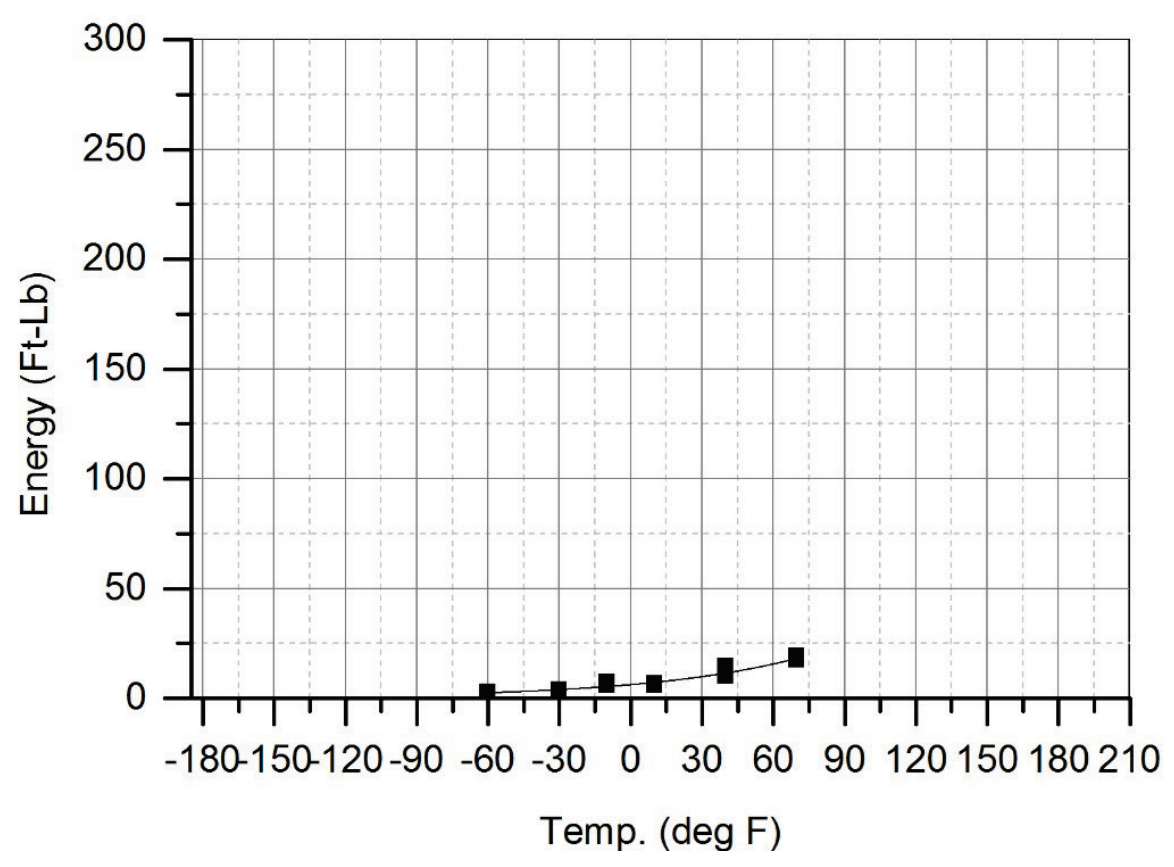

Figure D-1 CVN Data: Specimen 23-1 flange angles

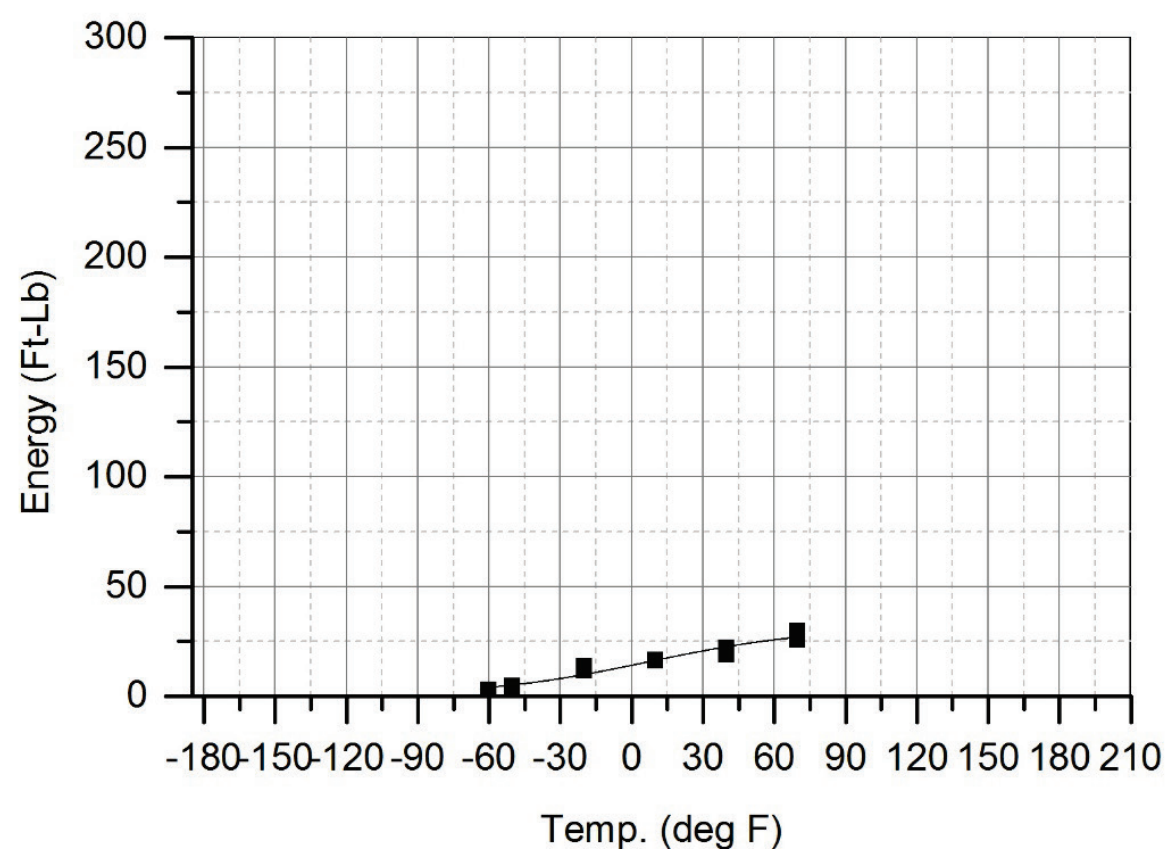

Figure D-2 CVN Data: Specimen 23-1 cover plate 


\section{Specimen 23-2}

Table D-4 Specimen 23-2 material properties

\begin{tabular}{|c|c|c|c|c|}
\hline \multicolumn{5}{|c|}{ Specimen 23-2 } \\
\hline \multicolumn{2}{|c|}{ Component } & Web Plate & Flange Angle & Cover Plate \\
\hline \multicolumn{2}{|l|}{ Shape } & Plate & Angle & Plate \\
\hline \multicolumn{2}{|c|}{ Dimensions } & $23 " x 3 / 8 "$ & 5"x3-1/2"x1/2" & 1/2"x12" \\
\hline \multicolumn{2}{|l|}{ Length } & $22^{\prime}-9^{\prime \prime}$ & $22^{\prime}-9^{\prime \prime}$ & $20^{\prime}-0^{\prime \prime}$ \\
\hline \multicolumn{2}{|c|}{ Heat No. } & N/A (Historical) & N/A (Historical) & G126358 \\
\hline \multicolumn{2}{|l|}{ Grade } & & & A36 \\
\hline $\begin{array}{c}\text { Yield } \\
\text { Strength }\end{array}$ & ksi & 34.5 & 36.8 & 53.2 \\
\hline $\begin{array}{l}\text { Ultimate } \\
\text { Strength }\end{array}$ & ksi & 59.0 & 58.6 & 76.0 \\
\hline Elongation & $\%$ & 38 & 40 & 23.6 \\
\hline \multirow{14}{*}{$\begin{array}{l}\text { Chemical } \\
\text { Analysis }\end{array}$} & $\mathrm{Ni}$ & 0.01 & 0.01 & 0.14 \\
\hline & $\mathrm{Cr}$ & 0.02 & 0.02 & 0.08 \\
\hline & $\mathrm{MN}$ & 0.47 & 0.44 & 0.9 \\
\hline & $\mathrm{Si}$ & 0.01 & 0.01 & 0.21 \\
\hline & $\mathrm{C}$ & 0.2 & 0.21 & 0.17 \\
\hline & $\mathrm{S}$ & 0.03 & 0.026 & 0.026 \\
\hline & $\mathrm{P}$ & $<0.01$ & $<0.01$ & 0.012 \\
\hline & Mo & 0.01 & 0.01 & 0.044 \\
\hline & $\mathrm{Cu}$ & 0.03 & 0.02 & 0.27 \\
\hline & $\mathrm{V}$ & & & 0.016 \\
\hline & $\mathrm{Nb}$ & & & 0.002 \\
\hline & $\mathrm{Sn}$ & & & 0.01 \\
\hline & $\mathrm{Al}$ & & & 0.001 \\
\hline & $\mathrm{N}$ & & & 0.01 \\
\hline
\end{tabular}


Table D-5 Specimen 23-2 CVN data

\begin{tabular}{|c|c|c|c|c|c|c|}
\hline \multicolumn{7}{|c|}{ Specimen 23-2 } \\
\hline Component & \multicolumn{2}{|c|}{ Web Plate } & \multicolumn{2}{|c|}{ Flange Angle } & \multicolumn{2}{|c|}{ Cover Plate } \\
\hline Dimensions & \multicolumn{2}{|c|}{$23 " x 3 / 8 "$} & \multicolumn{2}{|c|}{ 5"x3-1/2"x1/2" } & \multicolumn{2}{|c|}{$1 / 2 " x 12 "$} \\
\hline Heat No. & \multicolumn{2}{|c|}{ N/A (Historical) } & \multicolumn{2}{|c|}{ N/A (Historical) } & \multicolumn{2}{|c|}{ G126358 } \\
\hline Grade & & & & & \multicolumn{2}{|c|}{ A36 } \\
\hline \multirow{19}{*}{ CVN } & ${ }^{\circ} \mathrm{F}$ & Energy & ${ }^{\circ} \mathrm{F}$ & $\overline{\text { Energy }}$ & ${ }^{\circ} \mathrm{F}$ & $\overline{\text { Energy }}$ \\
\hline & & & -60 & 2.67 & -60 & 8.5 \\
\hline & & & -60 & 2.67 & -60 & 3 \\
\hline & & & -60 & 2.00 & -60 & 3 \\
\hline & & & -30 & 3.33 & -50 & 8 \\
\hline & & & -30 & 3.33 & -50 & 9 \\
\hline & & & -30 & 4.00 & -50 & 3 \\
\hline & & & -10 & 6.00 & -20 & 4.5 \\
\hline & & & -10 & 7.33 & -20 & 15 \\
\hline & & & -10 & 6.00 & -20 & 7 \\
\hline & & & 10 & 6.67 & 10 & 22 \\
\hline & & & 10 & 6.00 & 10 & 18 \\
\hline & & & 10 & 6.00 & 10 & 16.5 \\
\hline & & & 40 & 10.00 & 40 & 27.5 \\
\hline & & & 40 & 10.00 & 40 & 21.5 \\
\hline & & & 40 & 14.67 & 40 & 25.5 \\
\hline & & & 70 & 17.33 & 70 & 30.5 \\
\hline & & & 70 & 18.00 & 70 & 30.5 \\
\hline & & & 70 & 19.33 & 70 & 30 \\
\hline
\end{tabular}




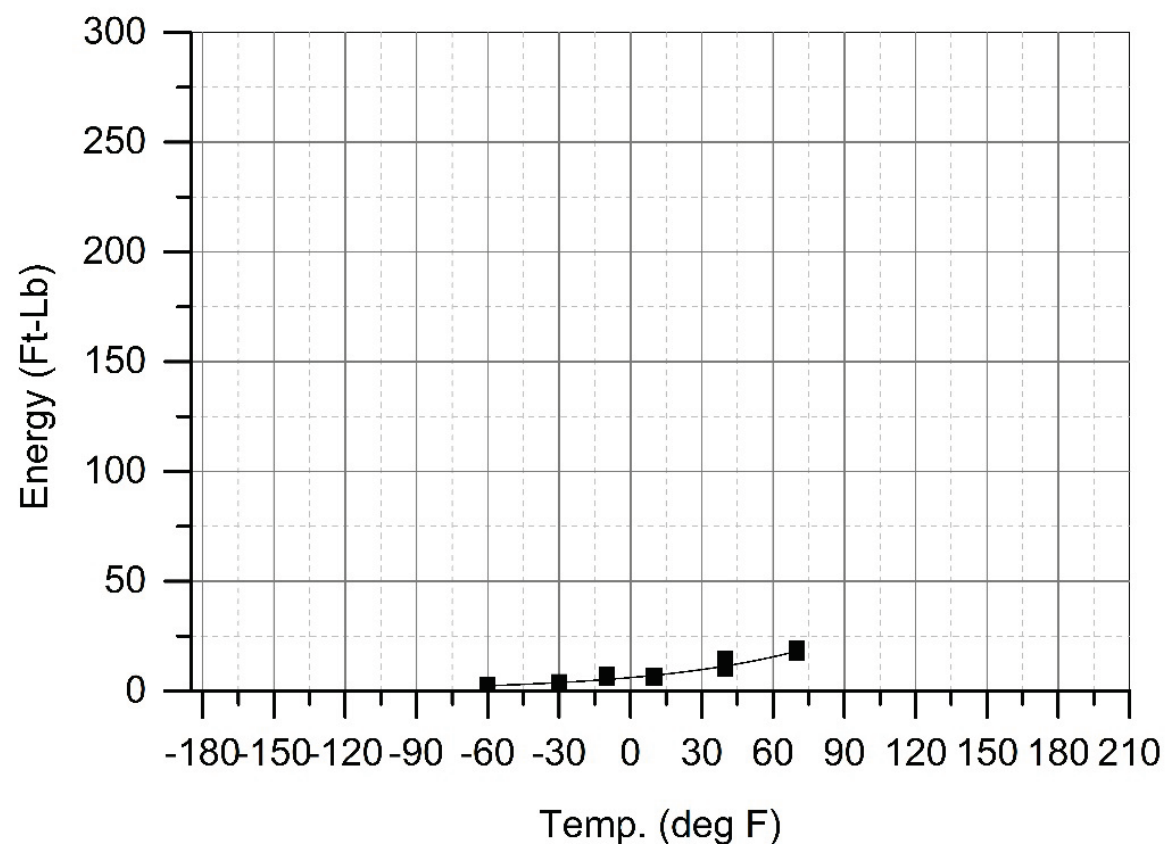

Figure D-3 CVN Data: Specimen 23-2 flange angles

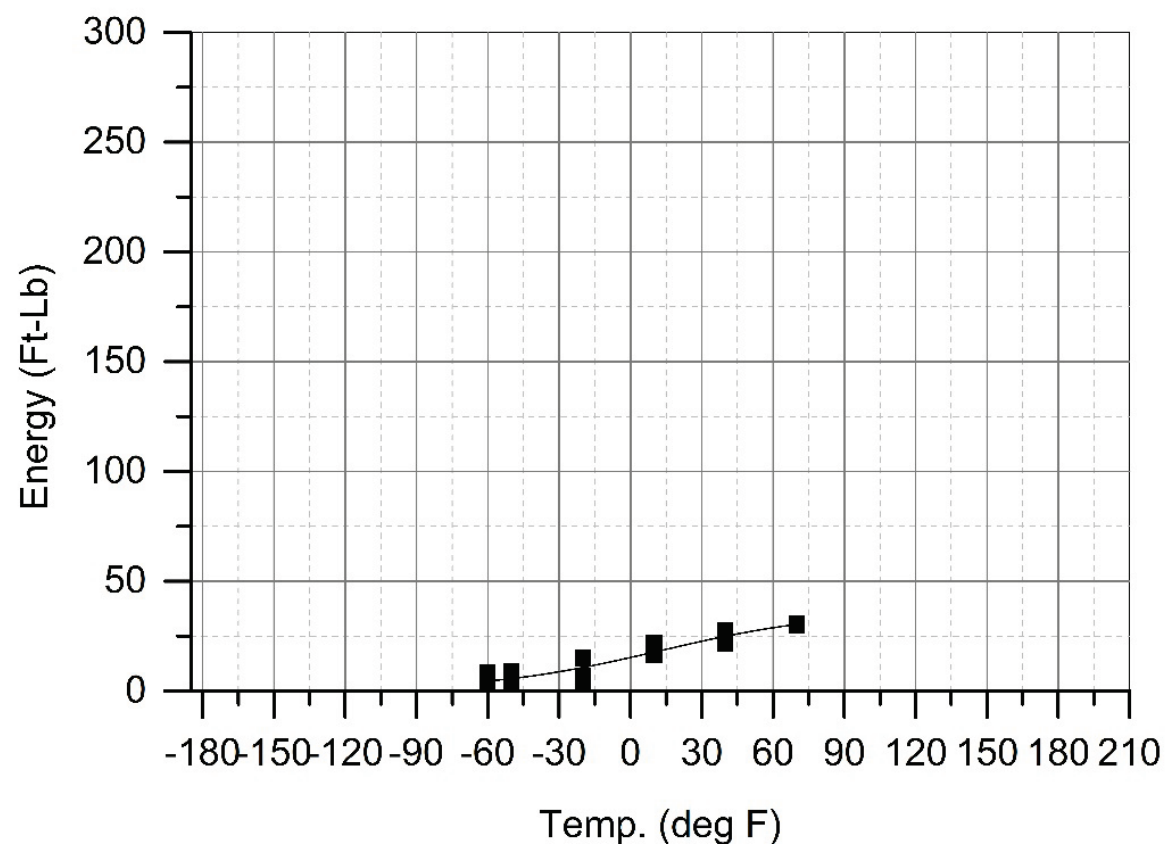

Figure D-4 CVN Data: Specimen 23-2 cover plate 


\section{Specimen 23-3}

Table D-6 Specimen 23-3 material properties

\begin{tabular}{|c|c|c|c|c|}
\hline \multicolumn{5}{|c|}{ Specimen 23-3 } \\
\hline \multicolumn{2}{|c|}{ Component } & Web Plate & Flange Angle & Cover Plate \\
\hline \multicolumn{2}{|l|}{ Shape } & Plate & Angle & Plate \\
\hline \multicolumn{2}{|c|}{ Dimensions } & $23 " x 3 / 8^{\prime \prime}$ & 5"x3-1/2"x1/2" & 1/2"x12" \\
\hline \multicolumn{2}{|l|}{ Length } & $22^{\prime}-9^{\prime \prime}$ & $22^{\prime}-9^{\prime \prime}$ & $20^{\prime}-0^{\prime \prime}$ \\
\hline \multicolumn{2}{|c|}{ Heat No. } & N/A (Historical) & N/A (Historical) & G126358 \\
\hline \multicolumn{2}{|l|}{ Grade } & & & A36 \\
\hline $\begin{array}{c}\text { Yield } \\
\text { Strength }\end{array}$ & ksi & 34.5 & 36.8 & 53.2 \\
\hline $\begin{array}{l}\text { Ultimate } \\
\text { Strength }\end{array}$ & ksi & 59.0 & 58.6 & 76.0 \\
\hline Elongation & $\%$ & 38 & 40 & 23.6 \\
\hline \multirow{14}{*}{$\begin{array}{l}\text { Chemical } \\
\text { Analysis }\end{array}$} & $\mathrm{Ni}$ & 0.01 & 0.01 & 0.14 \\
\hline & $\mathrm{Cr}$ & 0.02 & 0.02 & 0.08 \\
\hline & $\mathrm{MN}$ & 0.47 & 0.44 & 0.9 \\
\hline & $\mathrm{Si}$ & 0.01 & 0.01 & 0.21 \\
\hline & $\mathrm{C}$ & 0.2 & 0.21 & 0.17 \\
\hline & $\mathrm{S}$ & 0.03 & 0.026 & 0.026 \\
\hline & $\mathrm{P}$ & $<0.01$ & $<0.01$ & 0.012 \\
\hline & Mo & 0.01 & 0.01 & 0.044 \\
\hline & $\mathrm{Cu}$ & 0.03 & 0.02 & 0.27 \\
\hline & $\mathrm{V}$ & & & 0.016 \\
\hline & $\mathrm{Nb}$ & & & 0.002 \\
\hline & $\mathrm{Sn}$ & & & 0.01 \\
\hline & $\mathrm{Al}$ & & & 0.001 \\
\hline & $\mathrm{N}$ & & & 0.01 \\
\hline
\end{tabular}


Table D-7 Specimen 23-3 CVN data

\begin{tabular}{|c|c|c|c|c|c|c|}
\hline \multicolumn{7}{|c|}{ Specimen 23-3 } \\
\hline Component & \multicolumn{2}{|c|}{ Web Plate } & \multicolumn{2}{|c|}{ Flange Angle } & \multicolumn{2}{|c|}{ Cover Plate } \\
\hline Dimensions & \multicolumn{2}{|c|}{$23 " x 3 / 8 "$} & \multicolumn{2}{|c|}{ 5"x3-1/2"x1/2" } & \multicolumn{2}{|c|}{$1 / 2 " x 12 "$} \\
\hline Heat No. & \multicolumn{2}{|c|}{ N/A (Historical) } & \multicolumn{2}{|c|}{ N/A (Historical) } & \multicolumn{2}{|c|}{ G126358 } \\
\hline Grade & & & & & \multicolumn{2}{|c|}{ A36 } \\
\hline \multirow{19}{*}{ CVN } & ${ }^{\circ} \mathrm{F}$ & Energy & ${ }^{\circ} \mathrm{F}$ & $\overline{\text { Energy }}$ & ${ }^{\circ} \mathrm{F}$ & $\overline{\text { Energy }}$ \\
\hline & & & -60 & 2.67 & -60 & 8.5 \\
\hline & & & -60 & 2.67 & -60 & 3 \\
\hline & & & -60 & 2.00 & -60 & 3 \\
\hline & & & -30 & 3.33 & -50 & 8 \\
\hline & & & -30 & 3.33 & -50 & 9 \\
\hline & & & -30 & 4.00 & -50 & 3 \\
\hline & & & -10 & 6.00 & -20 & 4.5 \\
\hline & & & -10 & 7.33 & -20 & 15 \\
\hline & & & -10 & 6.00 & -20 & 7 \\
\hline & & & 10 & 6.67 & 10 & 22 \\
\hline & & & 10 & 6.00 & 10 & 18 \\
\hline & & & 10 & 6.00 & 10 & 16.5 \\
\hline & & & 40 & 10.00 & 40 & 27.5 \\
\hline & & & 40 & 10.00 & 40 & 21.5 \\
\hline & & & 40 & 14.67 & 40 & 25.5 \\
\hline & & & 70 & 17.33 & 70 & 30.5 \\
\hline & & & 70 & 18.00 & 70 & 30.5 \\
\hline & & & 70 & 19.33 & 70 & 30 \\
\hline
\end{tabular}




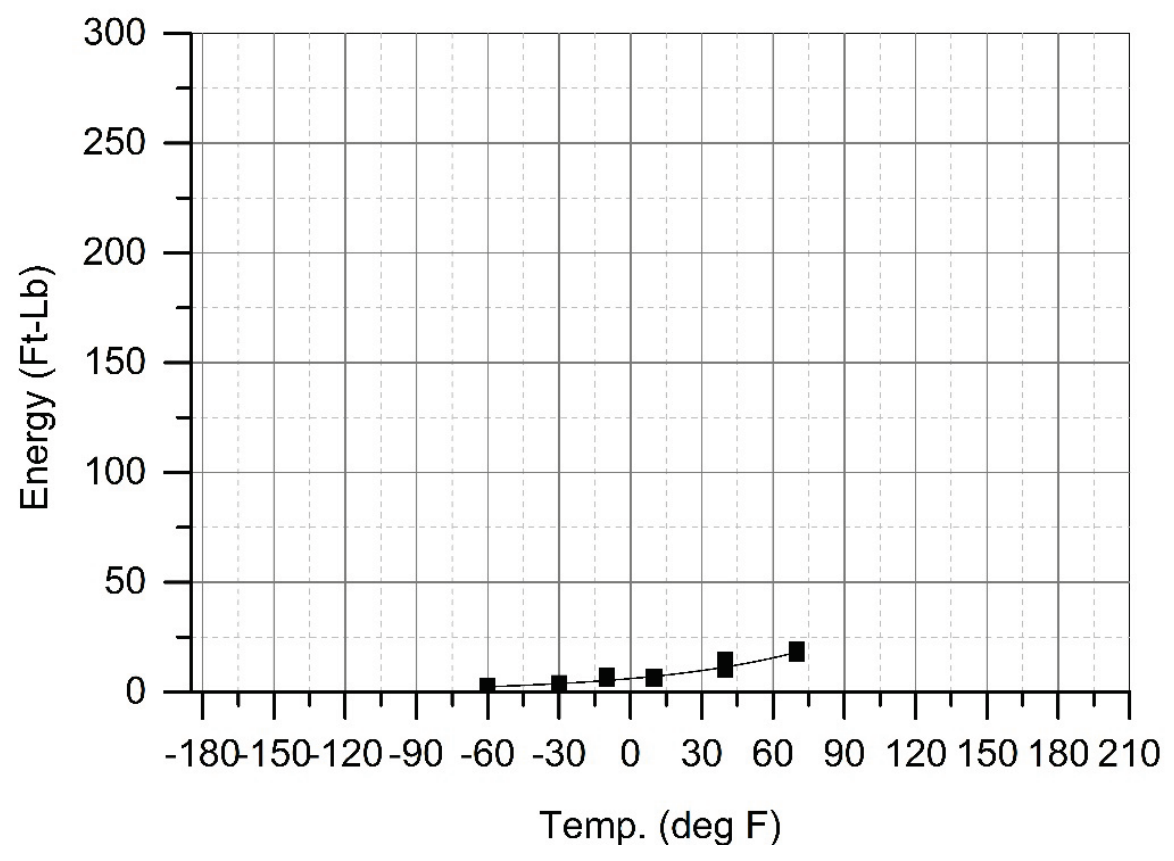

Figure D-5 CVN Data: Specimen 23-3 flange angles

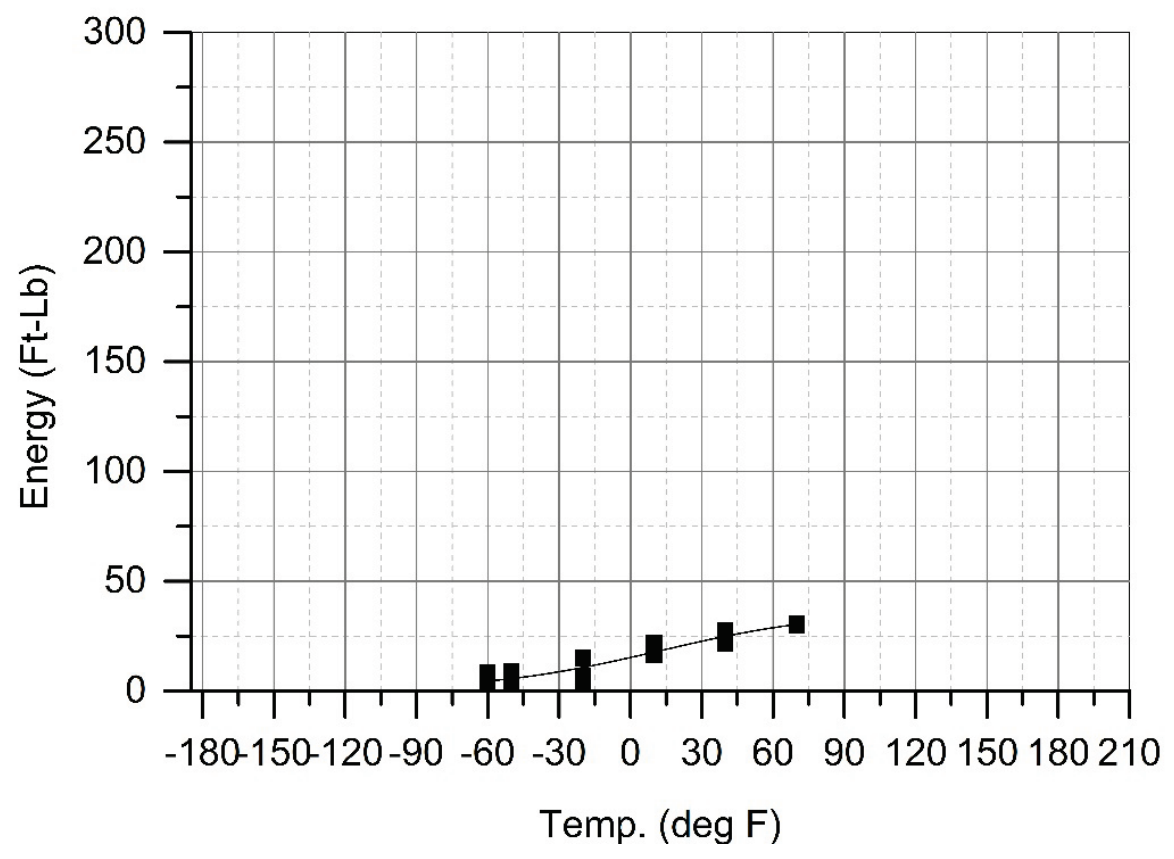

Figure D-6 CVN Data: Specimen 23-3 cover plate 


\section{Specimen 30-1}

Table D-8 Specimen 30-1 material properties

\begin{tabular}{|c|c|c|c|c|c|}
\hline \multicolumn{6}{|c|}{ Specimen 30-1 } \\
\hline \multicolumn{2}{|c|}{ Component } & Web Plate & Flange Angles & Cover Plate & $\begin{array}{c}\text { Cover Plate } \\
\text { Fuse } \\
\end{array}$ \\
\hline \multicolumn{2}{|l|}{ Shape } & Plate & Angle & Plate & Plate \\
\hline \multicolumn{2}{|c|}{ Dimensions } & $30 " x 0.5^{\prime \prime}$ & 6"x6"x0.75" & $14 " x 1 "$ & 14"x1" \\
\hline \multicolumn{2}{|l|}{ Length } & $40^{\prime}-0^{\prime \prime}$ & $40^{\prime}-0^{\prime \prime}$ & $24^{\prime}-11^{\prime \prime}$ & $4 "$ \\
\hline \multicolumn{2}{|c|}{ Heat No. } & H3011 & L91707 & NA (Donated) & NA (Historic) \\
\hline \multicolumn{2}{|l|}{ Grade } & A709 Gr 50W & $\mathrm{A} 588 \mathrm{~B}$ & A709 Gr 50W & Unknown \\
\hline $\begin{array}{c}\text { Yield } \\
\text { Strength }\end{array}$ & ksi & 59.0 & 57.8 & 56.5 & 31.4 \\
\hline $\begin{array}{l}\text { Ultimate } \\
\text { Strength }\end{array}$ & ksi & 79.0 & 75.5 & 75.5 & 60.6 \\
\hline Elongation & $\%$ & 36.0 & 26.0 & 31.0 & 32.4 \\
\hline \multirow{19}{*}{$\begin{array}{l}\text { Chemical } \\
\text { Analysis }\end{array}$} & $\mathrm{Al}$ & 0.035 & & 0.034 & \\
\hline & As & $<0.001$ & & 0.004 & \\
\hline & $\mathrm{B}$ & 0.0019 & & 0.0026 & \\
\hline & $\mathrm{C}$ & 0.09 & 0.12 & 0.066 & 0.28 \\
\hline & $\mathrm{Cb}$ & & 0 & & \\
\hline & $\mathrm{Co}$ & $<0.001$ & & 0.002 & \\
\hline & $\mathrm{Cr}$ & 0.5 & 0.62 & 0.096 & 0.03 \\
\hline & $\mathrm{Cu}$ & 0.41 & 0.31 & 0.41 & 0.02 \\
\hline & $\mathrm{Mn}$ & 0.91 & 0.95 & 1.32 & 0.43 \\
\hline & Mo & 0.043 & 0.048 & 0.087 & 0.01 \\
\hline & $\mathrm{Nb}$ & 0.001 & & 0.037 & \\
\hline & $\mathrm{Ni}$ & 0.2 & 0.12 & 0.057 & 0.01 \\
\hline & $\mathrm{P}$ & 0.003 & 0.013 & 0.011 & 0.012 \\
\hline & $\mathrm{S}$ & 0.009 & 0.040 & 0.007 & 0.034 \\
\hline & $\mathrm{Sb}$ & 0.004 & & 0.001 & \\
\hline & $\mathrm{Si}$ & 0.4 & 0.18 & 0.29 & $<0.005$ \\
\hline & $\mathrm{Sn}$ & 0.001 & 0.012 & 0.005 & \\
\hline & $\mathrm{Ti}$ & 0.001 & & 0.003 & \\
\hline & $\mathrm{V}$ & 0.034 & 0.044 & 0.065 & \\
\hline
\end{tabular}


Table D-9 Specimen 30-1 CVN data (1/2)

\begin{tabular}{|c|c|c|c|c|c|c|c|c|}
\hline \multicolumn{9}{|c|}{ Specimen 30-1 } \\
\hline Component & \multicolumn{2}{|c|}{ Web Plate } & \multicolumn{2}{|c|}{ Flange Angles } & \multicolumn{2}{|c|}{ Cover Plate } & \multicolumn{2}{|c|}{$\begin{array}{l}\text { Cover Plate } \\
\text { Fuse }\end{array}$} \\
\hline Dimensions & \multicolumn{2}{|c|}{$30 " x 0.5 "$} & \multicolumn{2}{|c|}{ 6"х6"х0.75" } & \multicolumn{2}{|c|}{ 14"x1" } & \multicolumn{2}{|c|}{$14 " x 1 "$} \\
\hline Heat No. & \multicolumn{2}{|c|}{ H3011 } & \multicolumn{2}{|c|}{ L91707 } & \multicolumn{2}{|c|}{ NA (Donated) } & \multirow{2}{*}{\multicolumn{2}{|c|}{ NA (Historic) }} \\
\hline Grade & \multicolumn{2}{|c|}{ A709 Gr 50W } & \multicolumn{2}{|c|}{ A588B } & \multicolumn{2}{|c|}{$\mathrm{A} 709 \mathrm{Gr} 50 \mathrm{~W}$} & & \\
\hline \multirow{32}{*}{$\mathrm{CVN}$} & ${ }^{\circ} \mathrm{F}$ & Energy & ${ }^{\circ} \mathrm{F}$ & Energy & ${ }^{\circ} \mathrm{F}$ & Energy & ${ }^{\circ} \mathrm{F}$ & Energy \\
\hline & -150 & 5 & -60 & 3.5 & -180 & 7 & -60 & 2.5 \\
\hline & -150 & 8 & -60 & 3 & -180 & 6 & -60 & 2 \\
\hline & $\begin{array}{l}-150 \\
\end{array}$ & 5 & -60 & 3 & -180 & 11 & -60 & 2 \\
\hline & -120 & 17 & -30 & 5.5 & -150 & 11 & -30 & 2.5 \\
\hline & -120 & 6 & -30 & 5 & -150 & 23 & -30 & 2 \\
\hline & -120 & 20 & -30 & 4.5 & -150 & 48 & -30 & 2.5 \\
\hline & -90 & 12 & 0 & 29 & -120 & 120 & 30 & 4 \\
\hline & -90 & 54 & 0 & 24.5 & -120 & 14 & 30 & 3 \\
\hline & -90 & 7 & 0 & 35 & -120 & 120 & 30 & 6.5 \\
\hline & -60 & 109 & 30 & 38 & -90 & 121 & 94 & 45 \\
\hline & -60 & 148.5 & 30 & 21 & -90 & 125 & 94 & 47 \\
\hline & -60 & 31 & 30 & 57.5 & -90 & 127 & 94 & 17.5 \\
\hline & -30 & 104 & 60 & 62 & -60 & 294.5 & 152 & 32 \\
\hline & -30 & 105.5 & 60 & 58.5 & -60 & 294 & 152 & 36 \\
\hline & -30 & 257.5 & 60 & 62 & -60 & 138 & 152 & 71 \\
\hline & 0 & 257 & 205 & 90 & -60 & 141 & 212 & 54 \\
\hline & 0 & 287 & 205 & 88.5 & -60 & 297.5 & 212 & 59 \\
\hline & 0 & 287.5 & 205 & 97 & -60 & 298 & 212 & 52.5 \\
\hline & & & & & -60 & 296 & & \\
\hline & & & & & -60 & 299 & & \\
\hline & & & & & -60 & 299 & & \\
\hline & & & & & -60 & 299 & & \\
\hline & & & & & $\begin{array}{l}-60 \\
\end{array}$ & 228 & & \\
\hline & & & & & $\begin{array}{l}-60 \\
\end{array}$ & 216 & & \\
\hline & & & & & -60 & 228 & & \\
\hline & & & & & -60 & 142 & & \\
\hline & & & & & -60 & 149 & & \\
\hline & & & & & -60 & 140 & & \\
\hline & & & & & -60 & 146 & & \\
\hline & & & & & -60 & 151 & & \\
\hline & & & & & -60 & 141 & & \\
\hline
\end{tabular}


Table D-10 Specimen 30-1 CVN data (2/2)

\begin{tabular}{|c|c|c|c|c|c|c|c|c|}
\hline \multicolumn{9}{|c|}{ Specimen 30-1 } \\
\hline Component & \multicolumn{2}{|c|}{ Web Plate } & \multicolumn{2}{|c|}{ Flange Angles } & \multicolumn{2}{|c|}{ Cover Plate } & \multicolumn{2}{|c|}{$\begin{array}{c}\text { Cover Plate } \\
\text { Fuse }\end{array}$} \\
\hline Dimensions & \multicolumn{2}{|c|}{$30 " x 0.5^{\prime \prime}$} & \multicolumn{2}{|c|}{ 6"x6"x0.75" } & \multicolumn{2}{|c|}{ 14"x1" } & \multicolumn{2}{|c|}{ 14"x1" } \\
\hline Heat No. & \multicolumn{2}{|c|}{ H3011 } & \multicolumn{2}{|c|}{ L91707 } & \multicolumn{2}{|c|}{ NA (Donated) } & \multicolumn{2}{|c|}{ NA (Historic) } \\
\hline Grade & \multicolumn{2}{|c|}{ A709 Gr 50W } & \multicolumn{2}{|c|}{ A588B } & \multicolumn{2}{|c|}{ A709 Gr 50W } & \multicolumn{2}{|c|}{ Unknown } \\
\hline \multirow{32}{*}{ CVN } & ${ }^{\circ} \mathrm{F}$ & Energy & ${ }^{\circ} \mathrm{F}$ & Energy & ${ }^{\circ} \mathrm{F}$ & Energy & ${ }^{\circ} \mathrm{F}$ & Energy \\
\hline & & & & & -60 & 141 & & \\
\hline & & & & & -60 & 142 & & \\
\hline & & & & & -60 & 149 & & \\
\hline & & & & & -60 & 128 & & \\
\hline & & & & & -60 & 131 & & \\
\hline & & & & & -60 & 190 & & \\
\hline & & & & & -60 & 157 & & \\
\hline & & & & & -60 & 175 & & \\
\hline & & & & & -60 & 160 & & \\
\hline & & & & & -60 & 170 & & \\
\hline & & & & & -60 & 205 & & \\
\hline & & & & & -60 & 196 & & \\
\hline & & & & & -60 & 194 & & \\
\hline & & & & & -60 & 240 & & \\
\hline & & & & & -60 & 238 & & \\
\hline & & & & & -60 & 278 & & \\
\hline & & & & & -60 & 279 & & \\
\hline & & & & & -60 & 210 & & \\
\hline & & & & & -60 & 205 & & \\
\hline & & & & & -60 & 292 & & \\
\hline & & & & & -30 & 135 & & \\
\hline & & & & & -30 & 131 & & \\
\hline & & & & & -30 & 151 & & \\
\hline & & & & & -30 & 299 & & \\
\hline & & & & & -30 & 299 & & \\
\hline & & & & & -30 & 299 & & \\
\hline & & & & & -30 & 249 & & \\
\hline & & & & & -30 & 289 & & \\
\hline & & & & & -30 & 303 & & \\
\hline & & & & & 60 & 197 & & \\
\hline & & & & & 60 & 204 & & \\
\hline
\end{tabular}




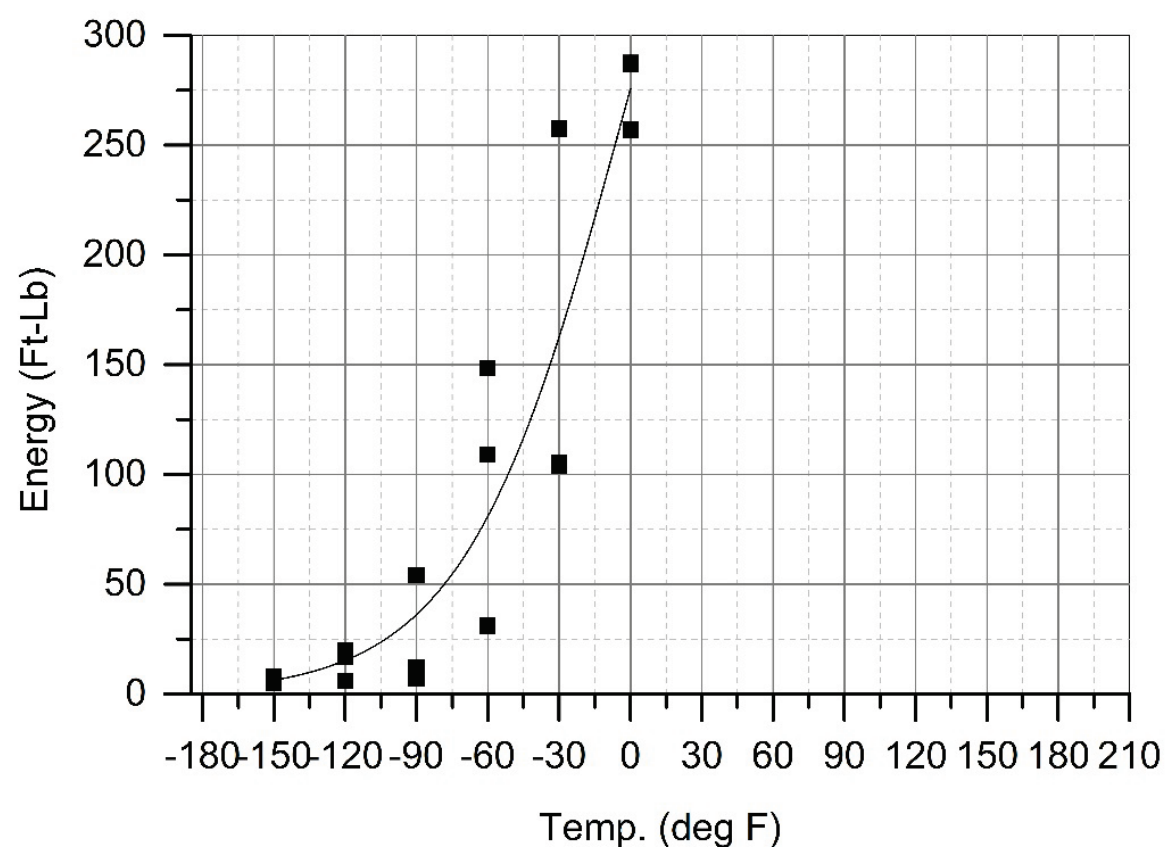

Figure D-7 CVN Data: Specimen 30-1 web plate

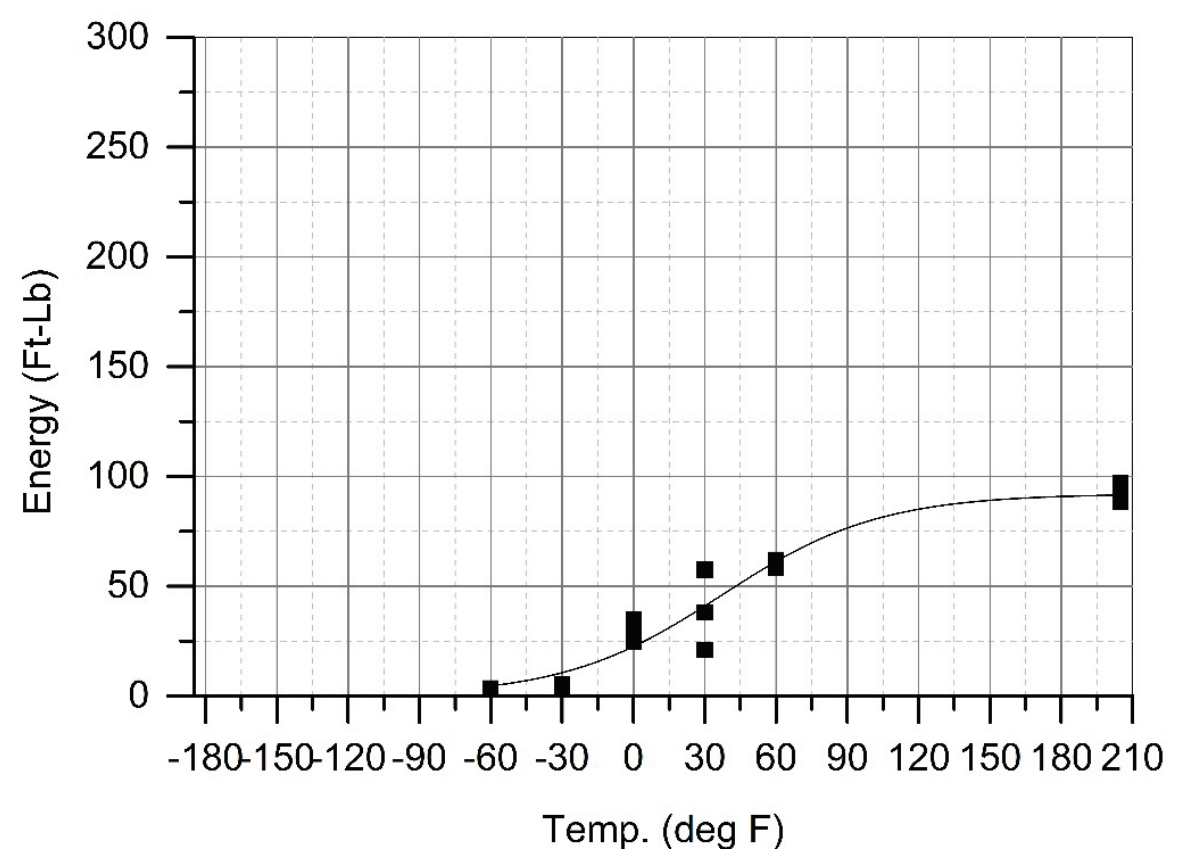

Figure D-8 CVN Data: Specimen 30-1 flange angles 


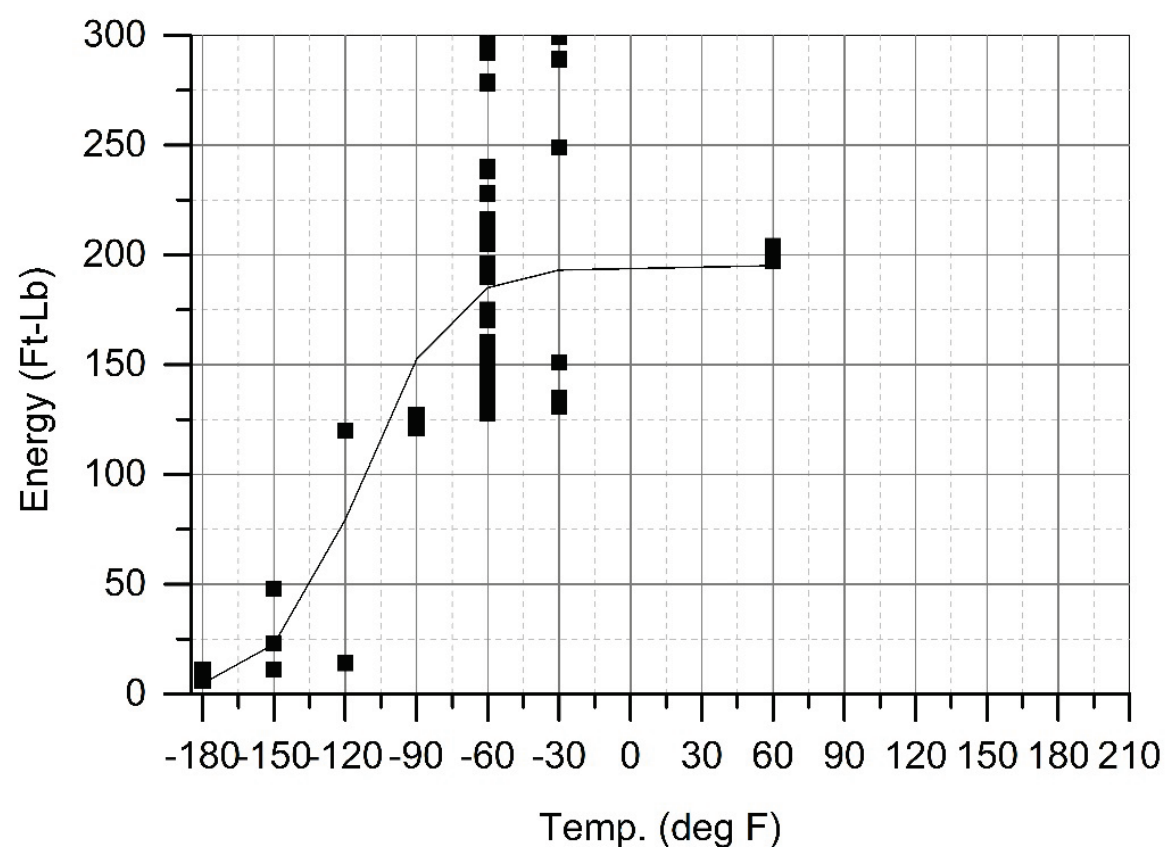

Figure D-9 CVN Data: Specimen 30-1 cover plate

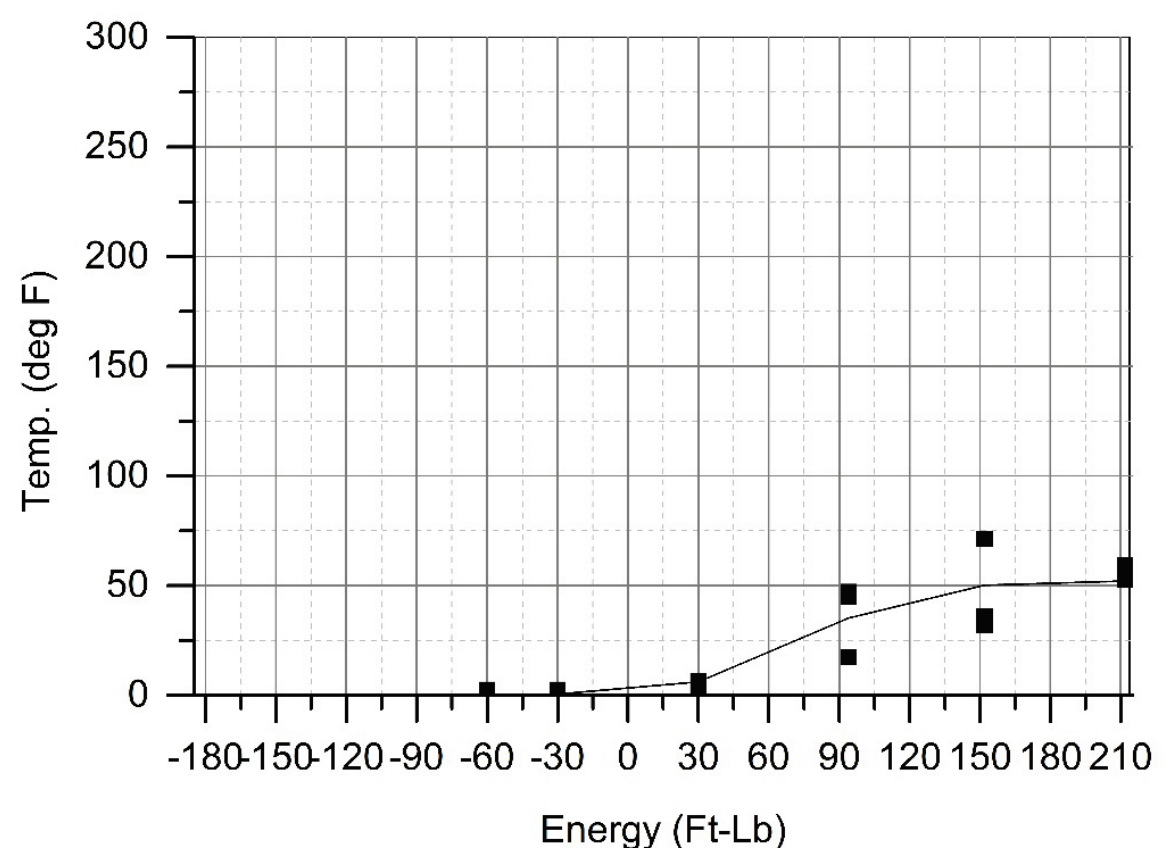

Figure D-10 CVN Data: Specimen 30-1 cover plate fuse 


\section{Specimen 36-1}

Table D-11 Specimen 36-1 material properties

\begin{tabular}{|c|c|c|c|c|c|}
\hline \multicolumn{6}{|c|}{ Specimen 36-1 } \\
\hline \multicolumn{2}{|c|}{ Component } & Web Plate & Flange Angles & $\begin{array}{c}\text { Upper Cover } \\
\text { Plate }\end{array}$ & $\begin{array}{c}\text { Lower Cover } \\
\text { Plate }\end{array}$ \\
\hline \multicolumn{2}{|l|}{ Shape } & Plate & Angle & Plate & Plate \\
\hline \multicolumn{2}{|c|}{ Dimensions } & $14 " x 3 / 4 "$ & 6"x6"x3/4" & $14 " x 3 / 4 "$ & $14 " x 3 / 4 "$ \\
\hline \multicolumn{2}{|l|}{ Length } & $40^{\prime}-0^{\prime \prime}$ & $40^{\prime}-0^{\prime \prime}$ & $23^{\prime}-0^{\prime \prime}$ & 19'-0" \\
\hline \multicolumn{2}{|c|}{ Heat No. } & H3011 & 1009182 & $2 \mathrm{H} 750$ & $2 \mathrm{H} 750$ \\
\hline \multicolumn{2}{|l|}{ Grade } & A709 Gr 50W & A588-05 Gr A & A709 Gr 50W & A709 Gr 50W \\
\hline $\begin{array}{c}\text { Yield } \\
\text { Strength }\end{array}$ & ksi & 59.0 & 59.5 & 64.5 & 64.5 \\
\hline $\begin{array}{l}\text { Ultimate } \\
\text { Strength }\end{array}$ & ksi & 79.0 & 75.9 & 81.5 & 81.5 \\
\hline Elongation & $\%$ & 36.0 & 22.0 & 21.0 & 21.0 \\
\hline \multirow{20}{*}{$\begin{array}{l}\text { Chemical } \\
\text { Analysis }\end{array}$} & $\mathrm{Al}$ & 0.035 & & 0.008 & 0.008 \\
\hline & As & $<0.001$ & & & \\
\hline & $\mathrm{B}$ & 0.0019 & 0.0005 & 0.0004 & 0.0004 \\
\hline & $\mathrm{C}$ & 0.09 & 0.11 & 0.12 & 0.12 \\
\hline & $\mathrm{Cb}$ & & 0.001 & 0 & 0 \\
\hline & $\mathrm{Co}$ & $<0.001$ & & & \\
\hline & $\mathrm{Cr}$ & 0.5 & 0.53 & 0.5514 & 0.5514 \\
\hline & $\mathrm{Cu}$ & 0.41 & 0.31 & 0.336 & 0.336 \\
\hline & $\mathrm{Mn}$ & 0.91 & 1 & 0.92 & 0.92 \\
\hline & Mo & 0.043 & 0.042 & 0.028 & 0.028 \\
\hline & $\mathrm{N}$ & & 0.0098 & 0.009 & 0.009 \\
\hline & $\mathrm{Nb}$ & 0.001 & & 0 & 0 \\
\hline & $\mathrm{Ni}$ & 0.2 & 0.12 & 0.158 & 0.158 \\
\hline & $\mathrm{P}$ & 0.003 & 0.009 & 0.009 & 0.009 \\
\hline & $\mathrm{S}$ & 0.009 & 0.027 & 0.013 & 0.013 \\
\hline & $\mathrm{Sb}$ & 0.004 & & & \\
\hline & $\mathrm{Si}$ & 0.4 & 0.34 & 0.4 & 0.4 \\
\hline & $\mathrm{Sn}$ & 0.001 & 0.012 & 0.029 & 0.029 \\
\hline & $\mathrm{Ti}$ & 0.001 & 0.001 & 0.002 & 0.002 \\
\hline & $\mathrm{V}$ & 0.034 & 0.04 & 0.04 & 0.04 \\
\hline
\end{tabular}


Table D-12 Specimen 36-1 CVN data

\begin{tabular}{|c|c|c|c|c|c|c|c|c|}
\hline & & & peci & en 36- & & & & \\
\hline Component & \multicolumn{2}{|c|}{ Web Plate } & \multicolumn{2}{|c|}{ Flange Angles } & \multicolumn{2}{|c|}{$\begin{array}{l}\text { Upper Cover } \\
\text { Plate }\end{array}$} & \multicolumn{2}{|c|}{$\begin{array}{l}\text { Lower Cover } \\
\text { Plate }\end{array}$} \\
\hline Dimensions & \multicolumn{2}{|c|}{ 14"x3/4" } & \multicolumn{2}{|c|}{ 6"x6"x3/4" } & \multicolumn{2}{|c|}{ 14"x3/4" } & \multicolumn{2}{|c|}{ 14"x3/4" } \\
\hline Heat No. & \multicolumn{2}{|c|}{ H3011 } & \multicolumn{2}{|c|}{1009182} & \multicolumn{2}{|c|}{$2 \mathrm{H} 750$} & \multicolumn{2}{|c|}{$2 \mathrm{H} 750$} \\
\hline Grade & \multicolumn{2}{|c|}{ A709 Gr 50W } & \multicolumn{2}{|c|}{ A588-05 Gr A } & \multicolumn{2}{|c|}{ A709 Gr 50W } & \multicolumn{2}{|c|}{ A709 Gr 50W } \\
\hline \multirow{19}{*}{$\mathrm{CVN}$} & ${ }^{\circ} \mathrm{F}$ & $\overline{\text { Energy }}$ & ${ }^{\circ} \mathrm{F}$ & $\overline{\text { Energy }}$ & ${ }^{\circ} \mathrm{F}$ & Energy & ${ }^{\circ} \mathrm{F}$ & $\overline{\text { Energy }}$ \\
\hline & -150 & 5 & -60 & 4 & -80 & 4.5 & -80 & 4.5 \\
\hline & -150 & 8 & -60 & 3.5 & -80 & 7 & -80 & 7 \\
\hline & -150 & 5 & -60 & 5 & -80 & 13.5 & -80 & 13.5 \\
\hline & -120 & 17 & -50 & 3.5 & -60 & 37.5 & -60 & 37.5 \\
\hline & -120 & 6 & -50 & 6.5 & -60 & 20 & -60 & 20 \\
\hline & -120 & 20 & -50 & 7.5 & -60 & 18.5 & -60 & 18.5 \\
\hline & -90 & 12 & -20 & 12.5 & -50 & 21.5 & -50 & 21.5 \\
\hline & -90 & 54 & -20 & 15 & -50 & 28.5 & -50 & 28.5 \\
\hline & -90 & 7 & -20 & 15 & -50 & 38.5 & -50 & 38.5 \\
\hline & -60 & 109 & 10 & 20 & -20 & 46.5 & -20 & 46.5 \\
\hline & -60 & 148.5 & 10 & 19 & -20 & 35.5 & -20 & 35.5 \\
\hline & -60 & 31 & 10 & 18.5 & -20 & 61.5 & -20 & 61.5 \\
\hline & -30 & 104 & 40 & 23 & 10 & 73.5 & 10 & 73.5 \\
\hline & -30 & 105.5 & 40 & 24 & 10 & 77.5 & 10 & 77.5 \\
\hline & -30 & 257.5 & 40 & 23 & 10 & 84.5 & 10 & 84.5 \\
\hline & 0 & 257 & 70 & 29 & 40 & 82 & 40 & 82 \\
\hline & 0 & 287 & 70 & 33.5 & 40 & 82 & 40 & 82 \\
\hline & 0 & 287.5 & 70 & 28 & 40 & 85.5 & 40 & 85.5 \\
\hline
\end{tabular}




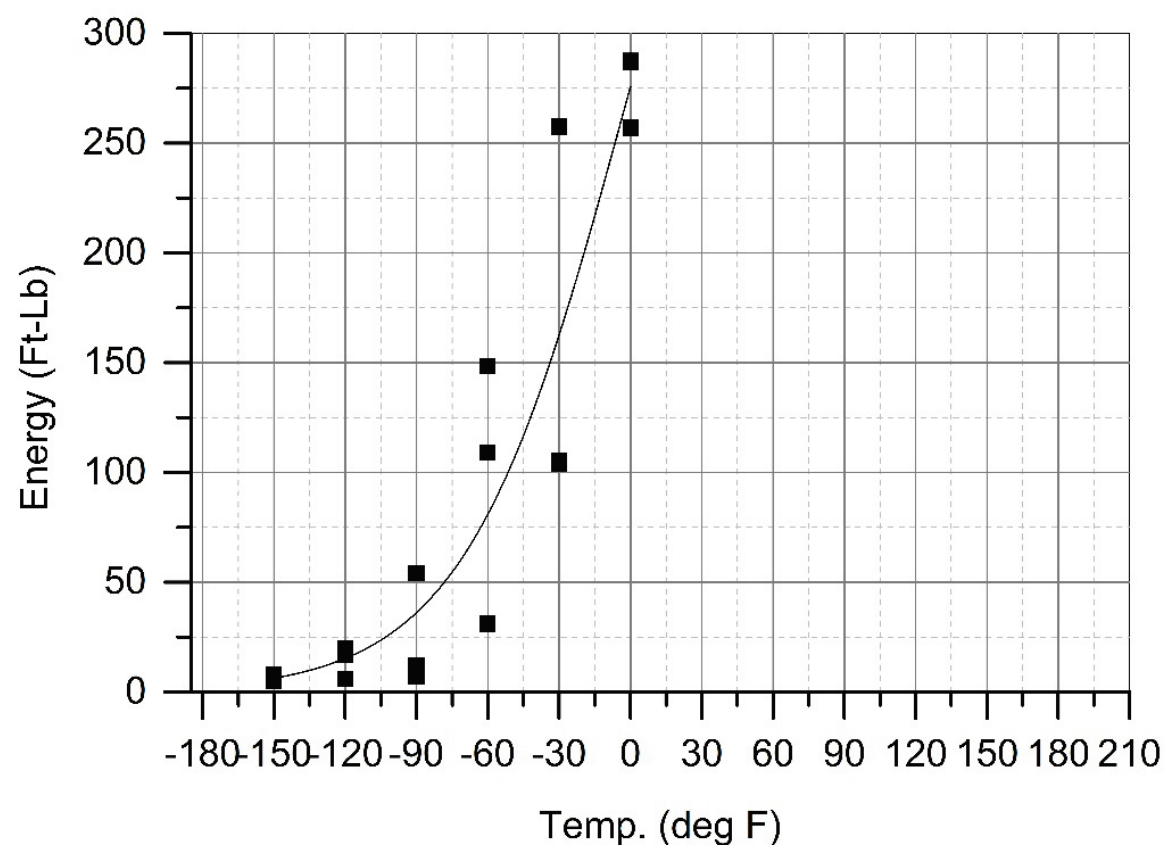

Figure D-11 CVN Data: Specimen 36-1 web plate

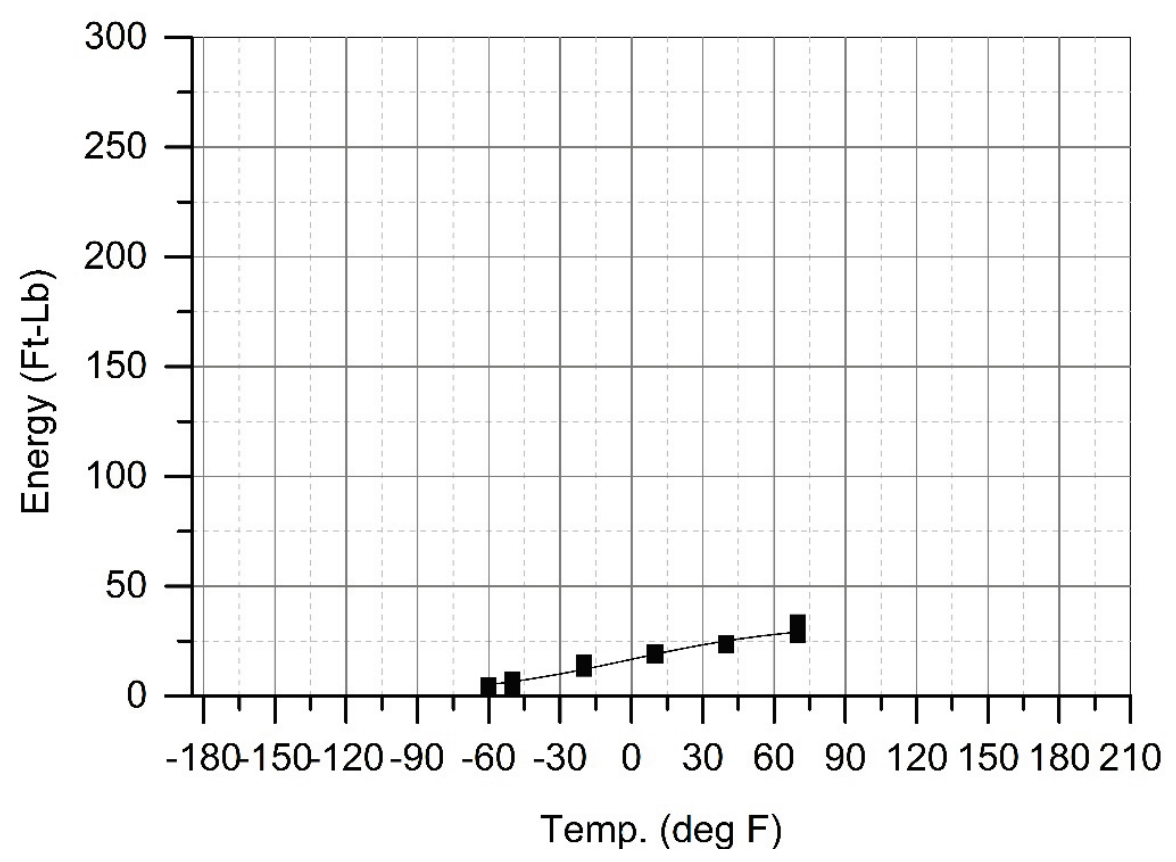

Figure D-12 CVN Data: Specimen 36-1 flange angles 


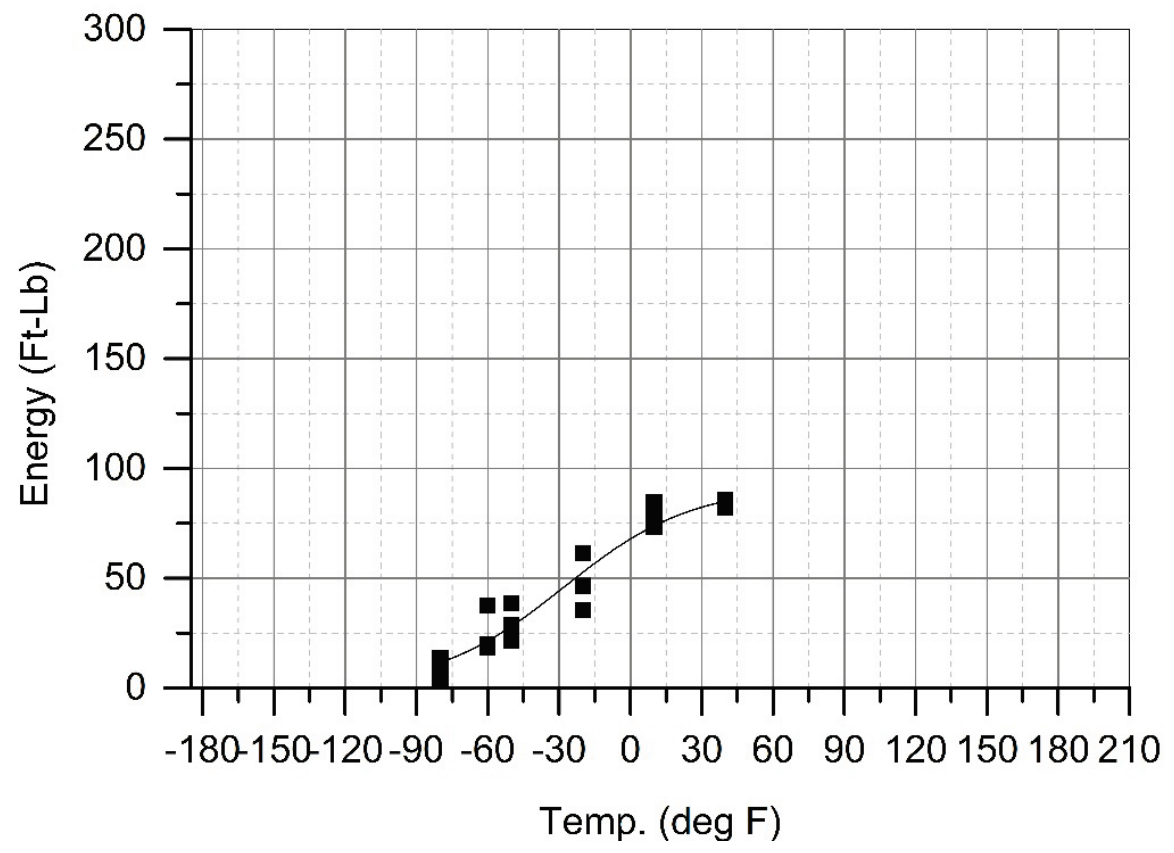

Figure D-13 CVN Data: Specimen 36-1 upper, lower cover plates 
Specimen 36-2

Table D-13 Specimen 36-2 material properties

\begin{tabular}{|c|c|c|c|c|c|}
\hline \multicolumn{6}{|c|}{ Specimen 36-2 } \\
\hline \multicolumn{2}{|c|}{ Component } & Web Plate & Flange Angles & $\begin{array}{l}\text { Upper Cover } \\
\text { Plate }\end{array}$ & $\begin{array}{l}\text { Lower Cover } \\
\text { Plate }\end{array}$ \\
\hline \multicolumn{2}{|l|}{ Shape } & Plate & Angle & Plate & Plate \\
\hline \multicolumn{2}{|c|}{ Dimensions } & $36 " \mathrm{x} 0.5^{\prime \prime}$ & 6"х6"x0.75" & $14 " \mathrm{x} 0.75 "$ & $14 " \mathrm{x} 0.75 "$ \\
\hline \multicolumn{2}{|c|}{ Length } & $40^{\prime}-0^{\prime \prime}$ & $40^{\prime}-0^{\prime \prime}$ & 29'-0" & $19^{\prime}-0 "$ \\
\hline \multicolumn{2}{|c|}{ Heat No. } & $\mathrm{H} 3011$ & 1009182 & $2 \mathrm{H} 750$ & $2 \mathrm{H} 750$ \\
\hline \multicolumn{2}{|l|}{ Grade } & A 709 Gr 50W & A588-05 Gr A & A 709 Gr $50 \mathrm{~W}$ & A709 Gr 50W \\
\hline $\begin{array}{c}\text { Yield } \\
\text { Strength }\end{array}$ & ksi & 59.0 & 59.5 & 64.5 & 64.5 \\
\hline $\begin{array}{l}\text { Ultimate } \\
\text { Strength } \\
\end{array}$ & ksi & 79.0 & 75.9 & 81.5 & 81.5 \\
\hline Elongation & $\%$ & 36.0 & 22.0 & 21.0 & 21.0 \\
\hline \multirow{20}{*}{$\begin{array}{c}\text { Chemical } \\
\text { Analysis }\end{array}$} & $\mathrm{Al}$ & 0.035 & & 0.008 & 0.008 \\
\hline & As & $<0.001$ & & & \\
\hline & $\mathrm{B}$ & 0.0019 & 0.0005 & 0.0004 & 0.0004 \\
\hline & $\mathrm{C}$ & 0.09 & 0.11 & 0.12 & 0.12 \\
\hline & $\mathrm{Cb}$ & & 0.001 & 0 & 0 \\
\hline & Co & $<0.001$ & & & \\
\hline & $\mathrm{Cr}$ & 0.5 & 0.53 & 0.5514 & 0.5514 \\
\hline & $\mathrm{Cu}$ & 0.41 & 0.31 & 0.336 & 0.336 \\
\hline & $\mathrm{Mn}$ & 0.91 & 1 & 0.92 & 0.92 \\
\hline & Mo & 0.043 & 0.042 & 0.028 & 0.028 \\
\hline & $\mathrm{N}$ & & 0.0098 & 0.009 & 0.009 \\
\hline & $\mathrm{Nb}$ & 0.001 & & 0 & 0 \\
\hline & \begin{tabular}{|l|}
$\mathrm{Ni}$ \\
\end{tabular} & 0.2 & 0.12 & 0.158 & 0.158 \\
\hline & $\mathrm{P}$ & 0.003 & 0.009 & 0.009 & 0.009 \\
\hline & $\mathrm{S}$ & 0.009 & 0.027 & 0.013 & 0.013 \\
\hline & \begin{tabular}{|l|}
$\mathrm{Sb}$ \\
\end{tabular} & 0.004 & & & \\
\hline & $\mathrm{Si}$ & 0.4 & 0.34 & 0.4 & 0.4 \\
\hline & $\mathrm{Sn}$ & 0.001 & 0.012 & 0.029 & 0.029 \\
\hline & $\mathrm{Ti}$ & 0.001 & 0.001 & 0.002 & 0.002 \\
\hline & $\mathrm{V}$ & 0.034 & 0.04 & 0.04 & 0.04 \\
\hline
\end{tabular}


Table D-14 Specimen 36-2 CVN data

\begin{tabular}{|c|c|c|c|c|c|c|c|c|}
\hline \multicolumn{9}{|c|}{ Specimen 36-2 } \\
\hline Component & \multicolumn{2}{|c|}{ Web Plate } & \multicolumn{2}{|c|}{ Flange Angles } & \multicolumn{2}{|c|}{$\begin{array}{l}\text { Upper Cover } \\
\text { Plate }\end{array}$} & \multicolumn{2}{|c|}{$\begin{array}{c}\text { Lower Cover } \\
\text { Plate }\end{array}$} \\
\hline Dimensions & \multicolumn{2}{|c|}{$36 " x 0.5 "$} & \multicolumn{2}{|c|}{ 6"x6"x0.75" } & \multicolumn{2}{|c|}{$14 " x 0.75^{\prime \prime}$} & \multicolumn{2}{|c|}{$14 " \mathrm{x} 0.75^{\prime \prime}$} \\
\hline Heat No. & \multicolumn{2}{|c|}{ H3011 } & \multicolumn{2}{|c|}{1009182} & \multicolumn{2}{|c|}{$2 \mathrm{H} 750$} & \multicolumn{2}{|c|}{$2 \mathrm{H} 750$} \\
\hline Grade & \multicolumn{2}{|c|}{ A709 Gr 50W } & \multicolumn{2}{|c|}{ A588-05 Gr A } & \multicolumn{2}{|c|}{ A709 Gr 50W } & \multicolumn{2}{|c|}{ A709 Gr 50W } \\
\hline \multirow{19}{*}{ CVN } & ${ }^{\circ} \mathrm{F}$ & Energy & ${ }^{\circ} \mathrm{F}$ & Energy & ${ }^{\circ} \mathrm{F}$ & Energy & ${ }^{\circ} \mathrm{F}$ & Energy \\
\hline & -150 & 5 & -60 & 4 & -80 & 4.5 & -80 & 4.5 \\
\hline & -150 & 8 & -60 & 3.5 & -80 & 7 & -80 & 7 \\
\hline & -150 & 5 & -60 & 5 & -80 & 13.5 & -80 & 13.5 \\
\hline & -120 & 17 & -50 & 3.5 & -60 & 37.5 & -60 & 37.5 \\
\hline & -120 & 6 & -50 & 6.5 & -60 & 20 & -60 & 20 \\
\hline & -120 & 20 & -50 & 7.5 & -60 & 18.5 & -60 & 18.5 \\
\hline & -90 & 12 & -20 & 12.5 & -50 & 21.5 & -50 & 21.5 \\
\hline & -90 & 54 & -20 & 15 & -50 & 28.5 & -50 & 28.5 \\
\hline & -90 & 7 & -20 & 15 & -50 & 38.5 & -50 & 38.5 \\
\hline & -60 & 109 & 10 & 20 & -20 & 46.5 & -20 & 46.5 \\
\hline & -60 & 148.5 & 10 & 19 & -20 & 35.5 & -20 & 35.5 \\
\hline & -60 & 31 & 10 & 18.5 & -20 & 61.5 & -20 & 61.5 \\
\hline & -30 & 104 & 40 & 23 & 10 & 73.5 & 10 & 73.5 \\
\hline & -30 & 105.5 & 40 & 24 & 10 & 77.5 & 10 & 77.5 \\
\hline & -30 & 257.5 & 40 & 23 & 10 & 84.5 & 10 & 84.5 \\
\hline & 0 & 257 & 70 & 29 & 40 & 82 & 40 & 82 \\
\hline & 0 & 287 & 70 & 33.5 & 40 & 82 & 40 & 82 \\
\hline & 0 & 287.5 & 70 & 28 & 40 & 85.5 & 40 & 85.5 \\
\hline
\end{tabular}




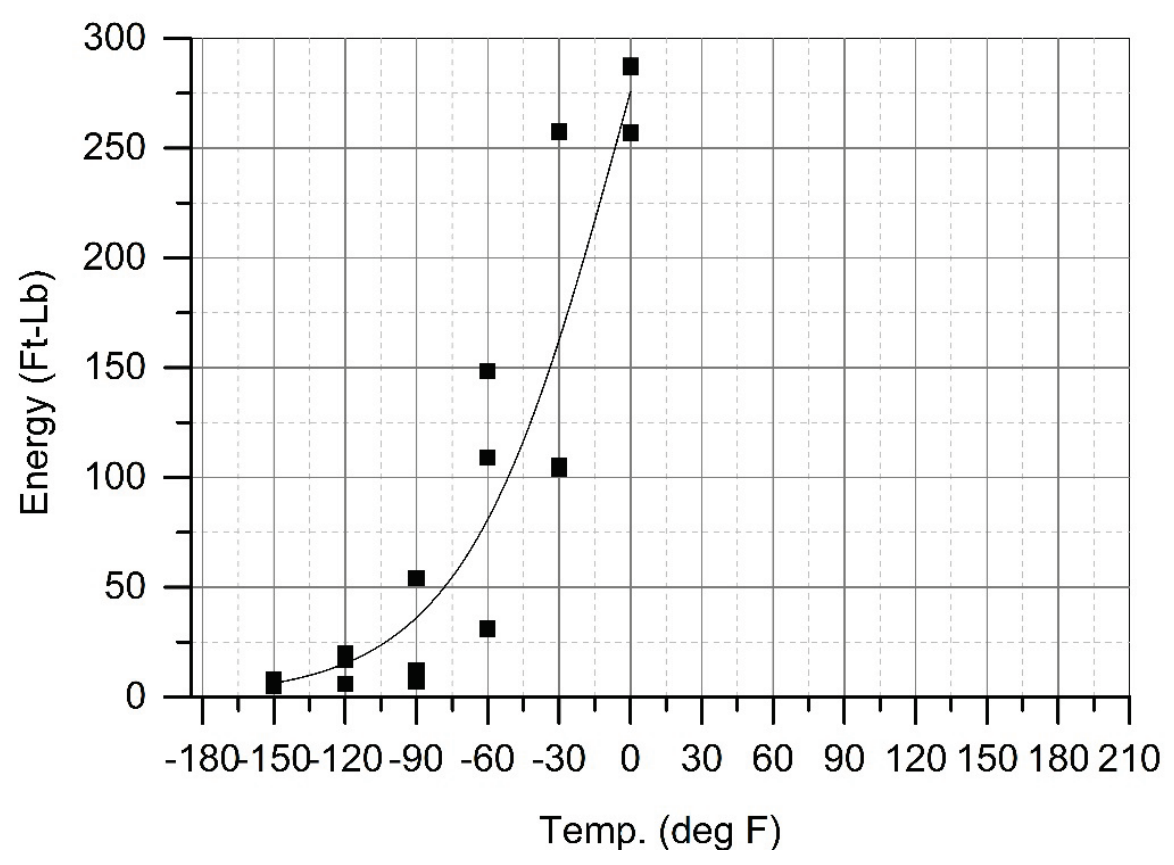

Figure D-14 CVN Data: Specimen 36-2 web plate

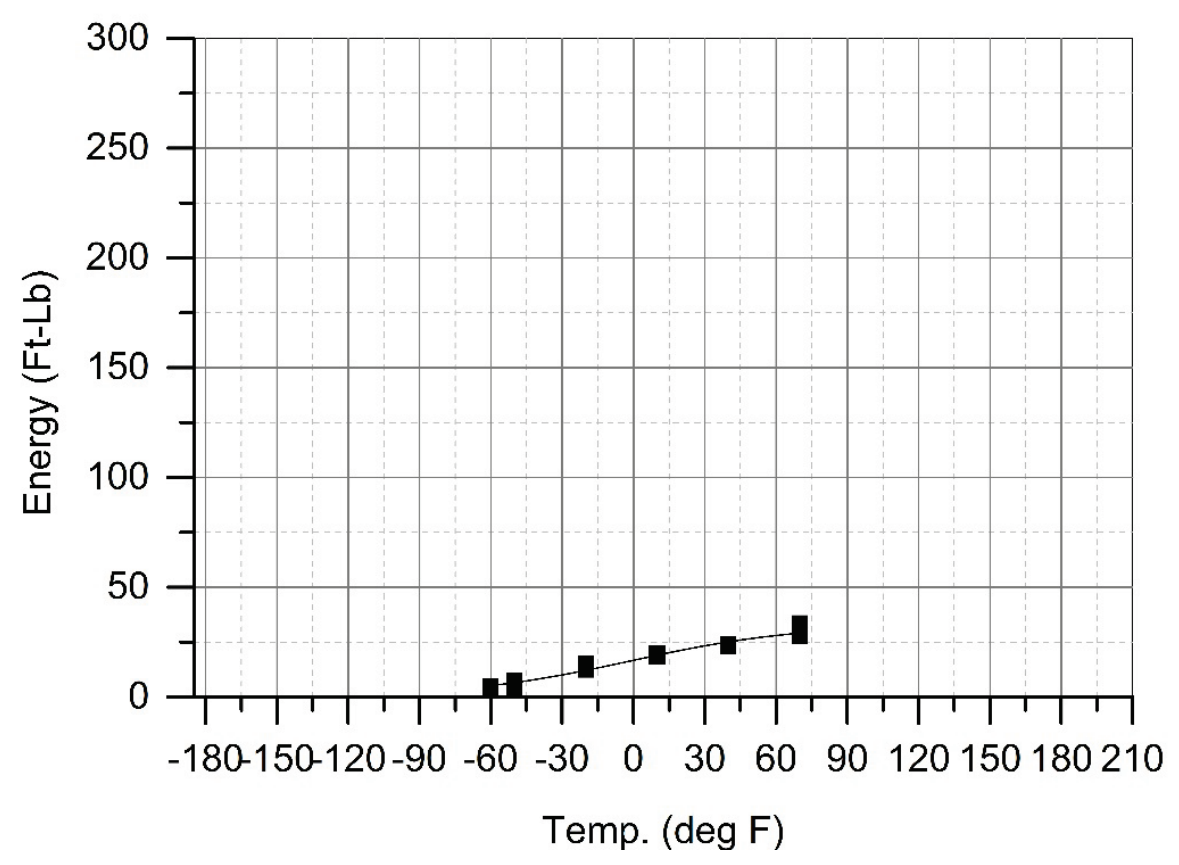

Figure D-15 CVN Data: Specimen 36-2 flange angles 


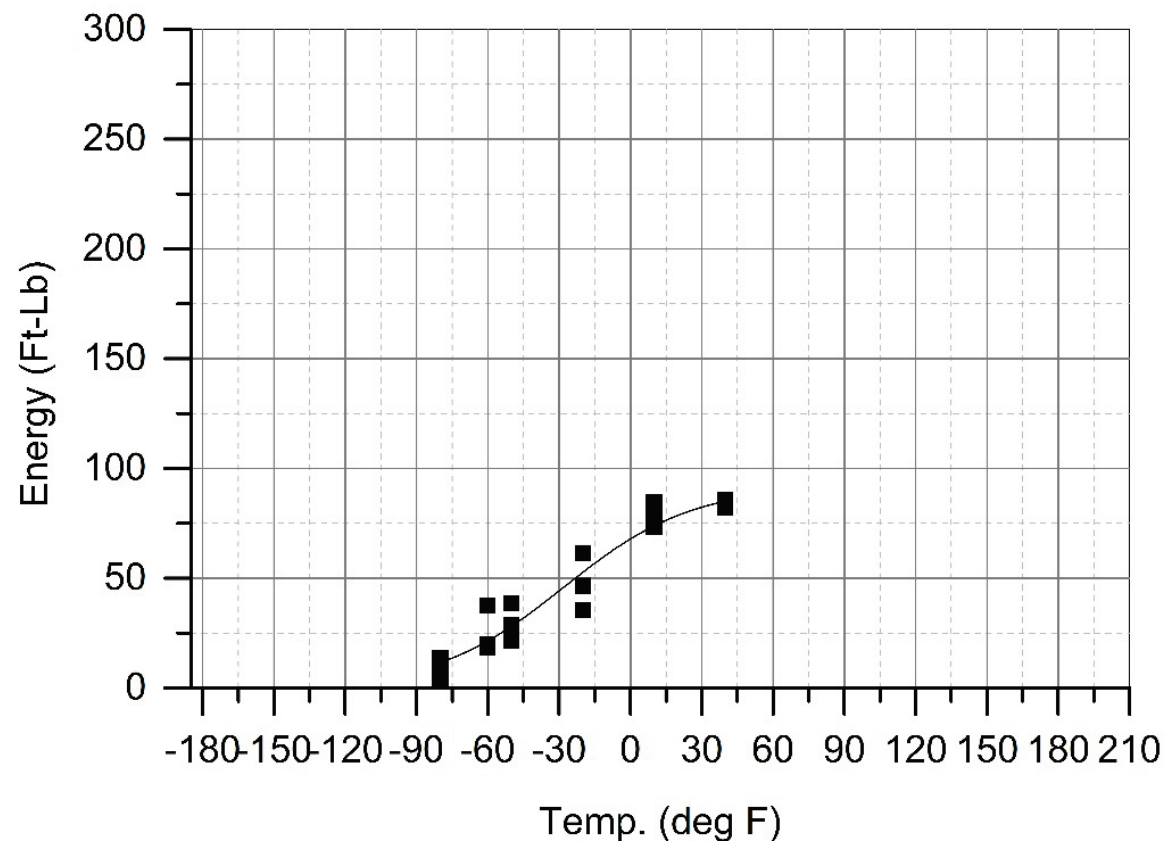

Figure D-16 CVN Data: Specimen 36-2 upper, lower cover plates 
Specimen 36-3

Table D-15 Specimen 36-3 material properties

\begin{tabular}{|c|c|c|c|c|c|}
\hline \multicolumn{6}{|c|}{ Specimen 36-3 } \\
\hline \multicolumn{2}{|c|}{ Component } & Web Plate & Flange Angles & $\begin{array}{c}\text { Upper Cover } \\
\text { Plate }\end{array}$ & $\begin{array}{l}\text { Lower Cover } \\
\text { Plate }\end{array}$ \\
\hline \multicolumn{2}{|l|}{ Shape } & Plate & Angle & Plate & Plate \\
\hline \multicolumn{2}{|c|}{ Dimensions } & $36 " \mathrm{x} 0.5^{\prime \prime}$ & 6"х6"x0.75" & $14 " \mathrm{x} 0.75 "$ & $14 " \mathrm{x} 0.75 "$ \\
\hline \multicolumn{2}{|c|}{ Length } & $40^{\prime}-0^{\prime \prime}$ & $40^{\prime}-0^{\prime \prime}$ & 29'-0" & 29'-0" \\
\hline \multicolumn{2}{|c|}{ Heat No. } & $\mathrm{H} 3011$ & 1009182 & $\mathrm{~A} 4 \mathrm{C} 245$ & $\mathrm{~A} 4 \mathrm{C} 245$ \\
\hline \multicolumn{2}{|l|}{ Grade } & $\mathrm{A} 709 \mathrm{Gr} 50 \mathrm{~W}$ & A588-05 Gr A & A572-50 & A572-50 \\
\hline $\begin{array}{c}\text { Yield } \\
\text { Strength }\end{array}$ & ksi & 59.0 & 59.5 & 59.0 & 59.0 \\
\hline $\begin{array}{l}\text { Ultimate } \\
\text { Strength }\end{array}$ & ksi & 79.0 & 75.9 & 81.0 & 81.0 \\
\hline Elongation & $\%$ & 36.0 & 22.0 & 26.0 & 26.0 \\
\hline \multirow{20}{*}{$\begin{array}{l}\text { Chemical } \\
\text { Analysis }\end{array}$} & $\mathrm{Al}$ & 0.035 & & 0.028 & 0.028 \\
\hline & As & $<0.001$ & & & \\
\hline & $\mathrm{B}$ & 0.0019 & 0.0005 & & \\
\hline & $\mathrm{C}$ & 0.09 & 0.11 & 0.06 & 0.06 \\
\hline & $\mathrm{Cb}$ & & 0.001 & 0.042 & 0.042 \\
\hline & Co & $<0.001$ & & & \\
\hline & $\mathrm{Cr}$ & 0.5 & 0.53 & 0.26 & 0.26 \\
\hline & $\mathrm{Cu}$ & 0.41 & 0.31 & 0.33 & 0.33 \\
\hline & $\mathrm{Mn}$ & 0.91 & 1 & 1.45 & 1.45 \\
\hline & Mo & 0.043 & 0.042 & 0.05 & 0.05 \\
\hline & $\mathrm{N}$ & & 0.0098 & & \\
\hline & $\mathrm{Nb}$ & 0.001 & & & \\
\hline & \begin{tabular}{|l|}
$\mathrm{Ni}$ \\
\end{tabular} & 0.2 & 0.12 & 0.18 & 0.18 \\
\hline & $\mathrm{P}$ & 0.003 & 0.009 & 0.011 & 0.011 \\
\hline & $\mathrm{S}$ & 0.009 & 0.027 & 0.001 & 0.001 \\
\hline & \begin{tabular}{|l|}
$\mathrm{Sb}$ \\
\end{tabular} & 0.004 & & & \\
\hline & \begin{tabular}{|l|}
$\mathrm{Si}$ \\
\end{tabular} & 0.4 & 0.34 & 0.24 & 0.24 \\
\hline & $\mathrm{Sn}$ & 0.001 & 0.012 & & \\
\hline & $\mathrm{Ti}$ & 0.001 & 0.001 & 0.011 & 0.011 \\
\hline & $\mathrm{V}$ & 0.034 & 0.04 & 0.057 & 0.057 \\
\hline
\end{tabular}


Table D-16 Specimen 36-3 CVN data

\begin{tabular}{|c|c|c|c|c|c|c|c|c|}
\hline \multicolumn{9}{|c|}{ Specimen 36-3 } \\
\hline Component & \multicolumn{2}{|c|}{ Web Plate } & \multicolumn{2}{|c|}{ Flange Angles } & \multicolumn{2}{|c|}{$\begin{array}{l}\text { Upper Cover } \\
\text { Plate }\end{array}$} & \multicolumn{2}{|c|}{$\begin{array}{c}\text { Lower Cover } \\
\text { Plate }\end{array}$} \\
\hline Dimensions & \multicolumn{2}{|c|}{$36 " x 0.5^{\prime \prime}$} & \multicolumn{2}{|c|}{ 6"х6"x0.75" } & \multicolumn{2}{|c|}{$14 " x 0.75^{\prime \prime}$} & \multicolumn{2}{|c|}{$14 " \mathrm{x} 0.75^{\prime \prime}$} \\
\hline Heat No. & \multicolumn{2}{|c|}{ H3011 } & \multicolumn{2}{|c|}{1009182} & \multicolumn{2}{|c|}{$\mathrm{A} 4 \mathrm{C} 245$} & \multicolumn{2}{|c|}{ A $4 C 245$} \\
\hline Grade & \multicolumn{2}{|c|}{ A709 Gr 50W } & \multicolumn{2}{|c|}{ A588-05 Gr A } & \multicolumn{2}{|c|}{ A572-50 } & \multicolumn{2}{|c|}{ A $572-50$} \\
\hline \multirow{22}{*}{$\mathrm{CVN}$} & ${ }^{\circ} \mathrm{F}$ & Energy & ${ }^{\circ} \mathrm{F}$ & Energy & ${ }^{\circ} \mathrm{F}$ & Energy & ${ }^{\circ} \mathrm{F}$ & Energy \\
\hline & -150 & 5 & -60 & 4 & -120 & 7 & -120 & 7 \\
\hline & -150 & 8 & -60 & 3.5 & -120 & 8 & -120 & 8 \\
\hline & -150 & 5 & -60 & 5 & -120 & 9 & -120 & 9 \\
\hline & -120 & 17 & -50 & 3.5 & -90 & 22 & -90 & 22 \\
\hline & -120 & 6 & -50 & 6.5 & -90 & 10 & -90 & 10 \\
\hline & -120 & 20 & -50 & 7.5 & -90 & 17 & -90 & 17 \\
\hline & -90 & 12 & -20 & 12.5 & -60 & 37.5 & -60 & 37.5 \\
\hline & -90 & 54 & -20 & 15 & -60 & 38 & -60 & 38 \\
\hline & -90 & 7 & -20 & 15 & -60 & 62.5 & -60 & 62.5 \\
\hline & -60 & 109 & 10 & 20 & -30 & 125 & -30 & 125 \\
\hline & -60 & 148.5 & 10 & 19 & -30 & 72.5 & -30 & 72.5 \\
\hline & -60 & 31 & 10 & 18.5 & -30 & 105 & -30 & 105 \\
\hline & -30 & 104 & 40 & 23 & 0 & 218 & 0 & 218 \\
\hline & -30 & 105.5 & 40 & 24 & 0 & 133 & 0 & 133 \\
\hline & -30 & 257.5 & 40 & 23 & 0 & 143.5 & 0 & 143.5 \\
\hline & 0 & 257 & 70 & 29 & 30 & 246 & 30 & 246 \\
\hline & 0 & 287 & 70 & 33.5 & 30 & 244 & 30 & 244 \\
\hline & 0 & 287.5 & 70 & 28 & 30 & 187.5 & 30 & 187.5 \\
\hline & & & & & 60 & 272 & 60 & 272 \\
\hline & & & & & 60 & 282.5 & 60 & 282.5 \\
\hline & & & & & 60 & 283 & 60 & 283 \\
\hline
\end{tabular}




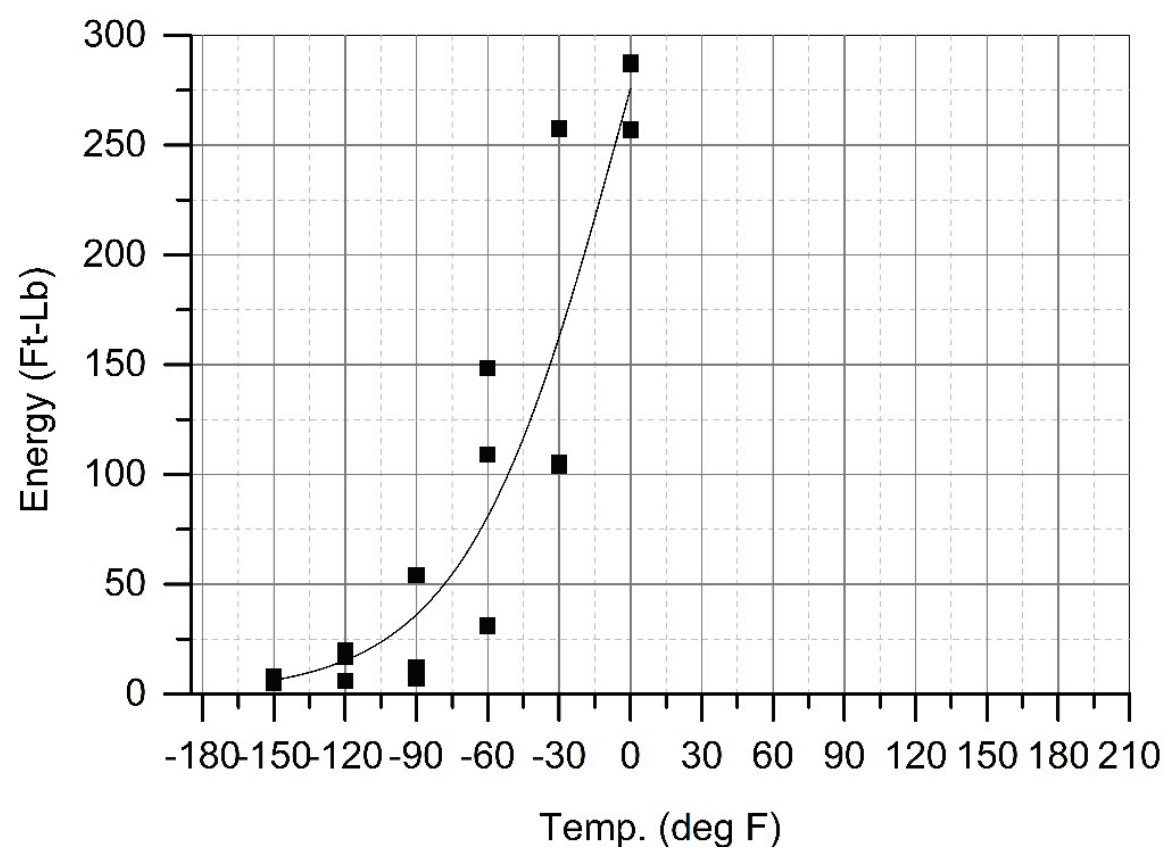

Figure D-17 CVN Data: Specimen 36-3 web plate

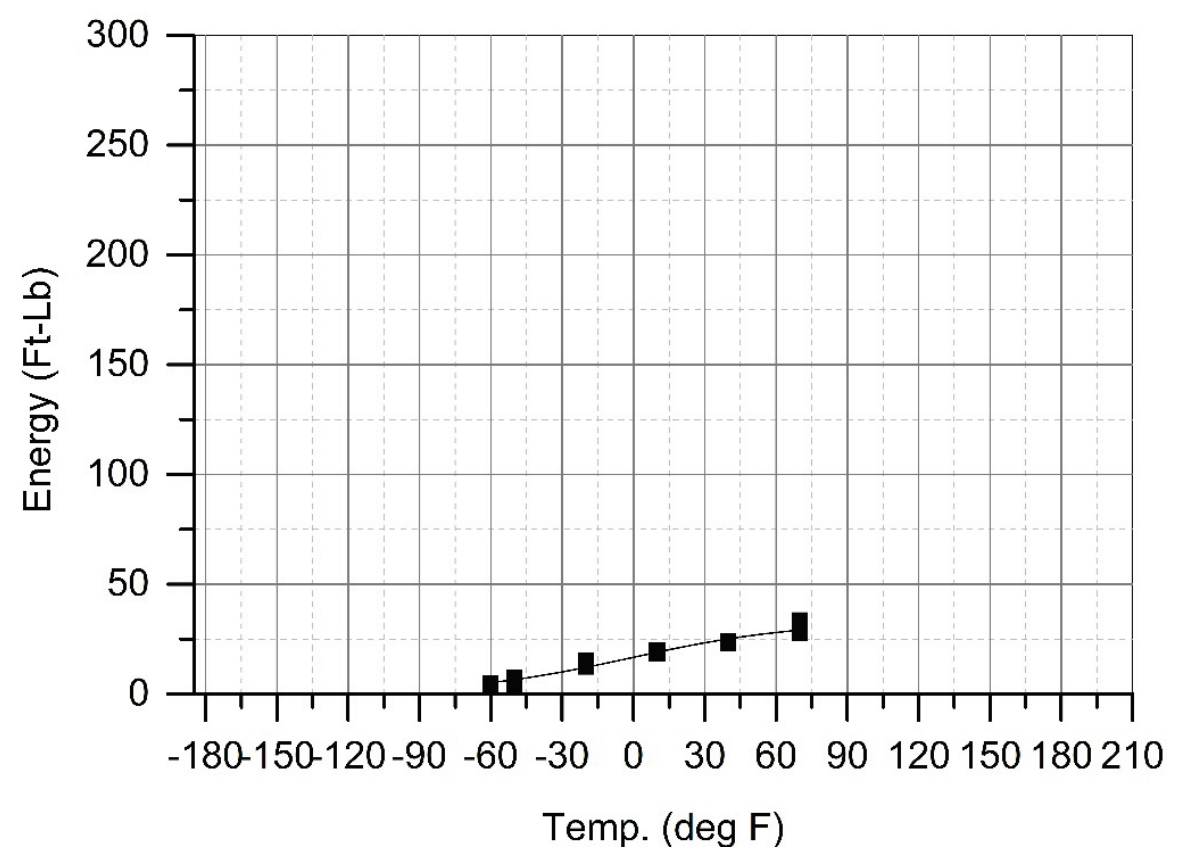

Figure D-18 CVN Data: Specimen 36-3 flange angles 


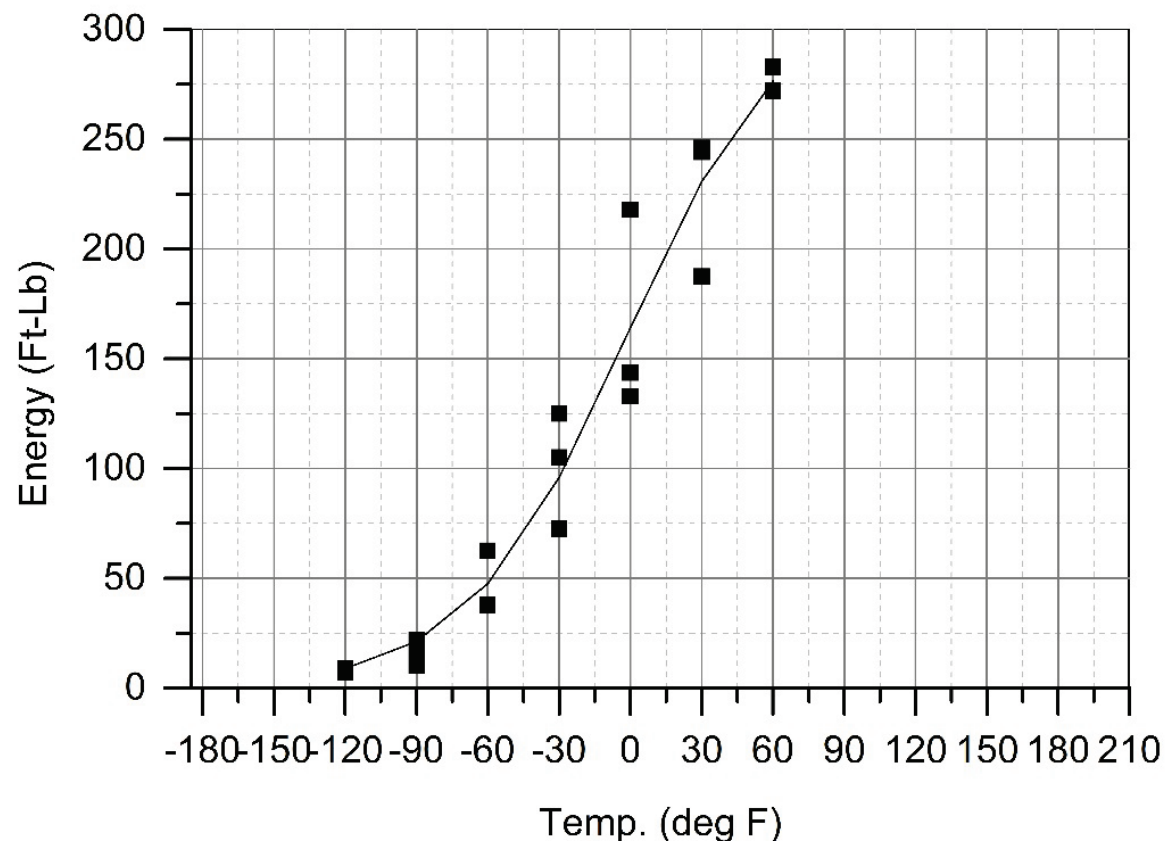

Figure D-19 CVN Data: Specimen 36-3 upper, lower cover plates 


\section{Specimen 36-4}

Table D-17 Specimen 36-4 material properties

\begin{tabular}{|c|c|c|c|c|c|}
\hline \multicolumn{6}{|c|}{ Specimen 36-4 } \\
\hline \multicolumn{2}{|c|}{ Component } & Web Plate & Flange Angles & $\begin{array}{c}\text { Upper Cover } \\
\text { Plate }\end{array}$ & $\begin{array}{c}\text { Lower Cover } \\
\text { Plate }\end{array}$ \\
\hline \multicolumn{2}{|l|}{ Shape } & Plate & Angle & Plate & Plate \\
\hline \multicolumn{2}{|c|}{ Dimensions } & $36 " x 0.5^{\prime \prime}$ & 6"x6"x0.75" & $14 " \mathrm{x} 0.75^{\prime \prime}$ & $14 " \mathrm{x} 0.75^{\prime \prime}$ \\
\hline \multicolumn{2}{|l|}{ Length } & $40^{\prime}-0^{\prime \prime}$ & $40^{\prime}-0^{\prime \prime}$ & $29^{\prime}-0^{\prime \prime}$ & 19'-0" \\
\hline \multicolumn{2}{|c|}{ Heat No. } & C6470 & 1030128 & $\mathrm{~A} 4 \mathrm{C} 245$ & $2 \mathrm{H} 750$ \\
\hline \multicolumn{2}{|l|}{ Grade } & A709-Gr 50 & 6-12/A529-05 Gr & A572-50 & A709 Gr 50W \\
\hline $\begin{array}{c}\text { Yield } \\
\text { Strength }\end{array}$ & ksi & 59.0 & 53.1 & 59.0 & 64.5 \\
\hline $\begin{array}{l}\text { Ultimate } \\
\text { Strength }\end{array}$ & $\mathrm{ksi}$ & 80.1 & 74.2 & 81.0 & 81.5 \\
\hline Elongation & $\%$ & 23.0 & 23.5 & 26.0 & 21.0 \\
\hline \multirow{16}{*}{$\begin{array}{l}\text { Chemical } \\
\text { Analysis }\end{array}$} & $\mathrm{Al}$ & 0.012 & & 0.028 & 0.008 \\
\hline & $\mathrm{B}$ & & 0.0003 & & 0.0004 \\
\hline & $\mathrm{C}$ & 0.12 & 0.16 & 0.06 & 0.12 \\
\hline & $\mathrm{Cb}$ & 0.001 & 0.000 & 0.042 & 0 \\
\hline & $\mathrm{Cr}$ & 0.53 & 0.17 & 0.26 & 0.5514 \\
\hline & $\mathrm{Cu}$ & 0.28 & 0.28 & 0.33 & 0.336 \\
\hline & $\mathrm{Mn}$ & 0.98 & 0.76 & 1.45 & 0.92 \\
\hline & Mo & 0.05 & 0.034 & 0.05 & 0.028 \\
\hline & $\mathrm{N}$ & & 0.0070 & & 0.009 \\
\hline & $\mathrm{Ni}$ & 0.14 & 0.12 & 0.18 & 0.158 \\
\hline & $\mathrm{P}$ & 0.007 & 0.016 & 0.011 & 0.009 \\
\hline & $\mathrm{S}$ & 0.002 & 0.033 & 0.001 & 0.013 \\
\hline & $\mathrm{Si}$ & 0.37 & 0.17 & 0.24 & 0.4 \\
\hline & $\mathrm{Sn}$ & & 0.013 & & 0.029 \\
\hline & $\mathrm{Ti}$ & & 0.001 & 0.011 & 0.002 \\
\hline & $\mathrm{V}$ & 0.039 & 0.024 & 0.057 & 0.04 \\
\hline
\end{tabular}


Table D-18 Specimen 36-4 CVN data

\begin{tabular}{|c|c|c|c|c|c|c|c|c|}
\hline \multicolumn{9}{|c|}{ Specimen 36-4 } \\
\hline Component & \multicolumn{2}{|c|}{ Web Plate } & \multicolumn{2}{|c|}{ Flange Angles } & \multicolumn{2}{|c|}{$\begin{array}{l}\text { Upper Cover } \\
\text { Plate }\end{array}$} & \multicolumn{2}{|c|}{$\begin{array}{l}\text { Lower Cover } \\
\text { Plate }\end{array}$} \\
\hline Dimensions & \multicolumn{2}{|c|}{$36 " x 0.5 "$} & \multicolumn{2}{|c|}{ 6"х6"х0.75" } & \multicolumn{2}{|c|}{ 14"x0.75" } & \multicolumn{2}{|c|}{ 14"x0.75" } \\
\hline Heat No. & \multicolumn{2}{|c|}{$\overline{C 6470}$} & \multicolumn{2}{|c|}{1030128} & \multicolumn{2}{|c|}{$\mathrm{A} 4 \mathrm{C} 245$} & \multicolumn{2}{|c|}{$2 \mathrm{H} 750$} \\
\hline Grade & \multicolumn{2}{|c|}{ A709-Gr 50} & \multicolumn{2}{|c|}{ A36-12/A529-05 } & \multicolumn{2}{|c|}{ A572-50 } & \multicolumn{2}{|c|}{ A709 Gr 50W } \\
\hline \multirow{25}{*}{$\mathrm{CVN}$} & ${ }^{\circ} \mathrm{F}$ & Energy & ${ }^{\circ} \mathrm{F}$ & Energy & ${ }^{\circ} \mathrm{F}$ & Energy & ${ }^{\circ} \mathrm{F}$ & Energy \\
\hline & -120 & 4.00 & -60 & 2 & -120 & 7 & -80 & 4.5 \\
\hline & -120 & 6.00 & -60 & 3.5 & -120 & 8 & -80 & 7 \\
\hline & -120 & 4.00 & -60 & 2 & -120 & 9 & -80 & 13.5 \\
\hline & -90 & 7.00 & -30 & 3 & -90 & 22 & -60 & 37.5 \\
\hline & -90 & 6.00 & -30 & 3.5 & $\begin{array}{l}-90 \\
\end{array}$ & 10 & -60 & 20 \\
\hline & -90 & 6.00 & -30 & 2 & -90 & 17 & -60 & 18.5 \\
\hline & -60 & 10.00 & 0 & 4.5 & -60 & 37.5 & -50 & 21.5 \\
\hline & -60 & 6.00 & 0 & 6 & -60 & 38 & -50 & 28.5 \\
\hline & -60 & 6.00 & 0 & 4 & -60 & 62.5 & -50 & 38.5 \\
\hline & -30 & 11.00 & 30 & 9 & -30 & 125 & -20 & 46.5 \\
\hline & -30 & 10.50 & 30 & 7 & -30 & 72.5 & -20 & 35.5 \\
\hline & -30 & 15.50 & 30 & 6 & -30 & 105 & -20 & 61.5 \\
\hline & 0 & 16.00 & 60 & 18 & 0 & 218 & 10 & 73.5 \\
\hline & 0 & 25.00 & 60 & 7 & 0 & 133 & 10 & 77.5 \\
\hline & 0 & 17.50 & 60 & 12.5 & 0 & 143.5 & 10 & 84.5 \\
\hline & 30 & 25.50 & & & 30 & 246 & 40 & 82 \\
\hline & 30 & 30.50 & & & 30 & 244 & 40 & 82 \\
\hline & 30 & 30.00 & & & 30 & 187.5 & 40 & 85.5 \\
\hline & 60 & 28.00 & & & 60 & 272 & & \\
\hline & 60 & 32 & & & 60 & 282.5 & & \\
\hline & 60 & 30.5 & & & 60 & 283 & & \\
\hline & 205 & 64 & & & & & & \\
\hline & 205 & 70 & & & & & & \\
\hline & 205 & 66 & & & & & & \\
\hline
\end{tabular}




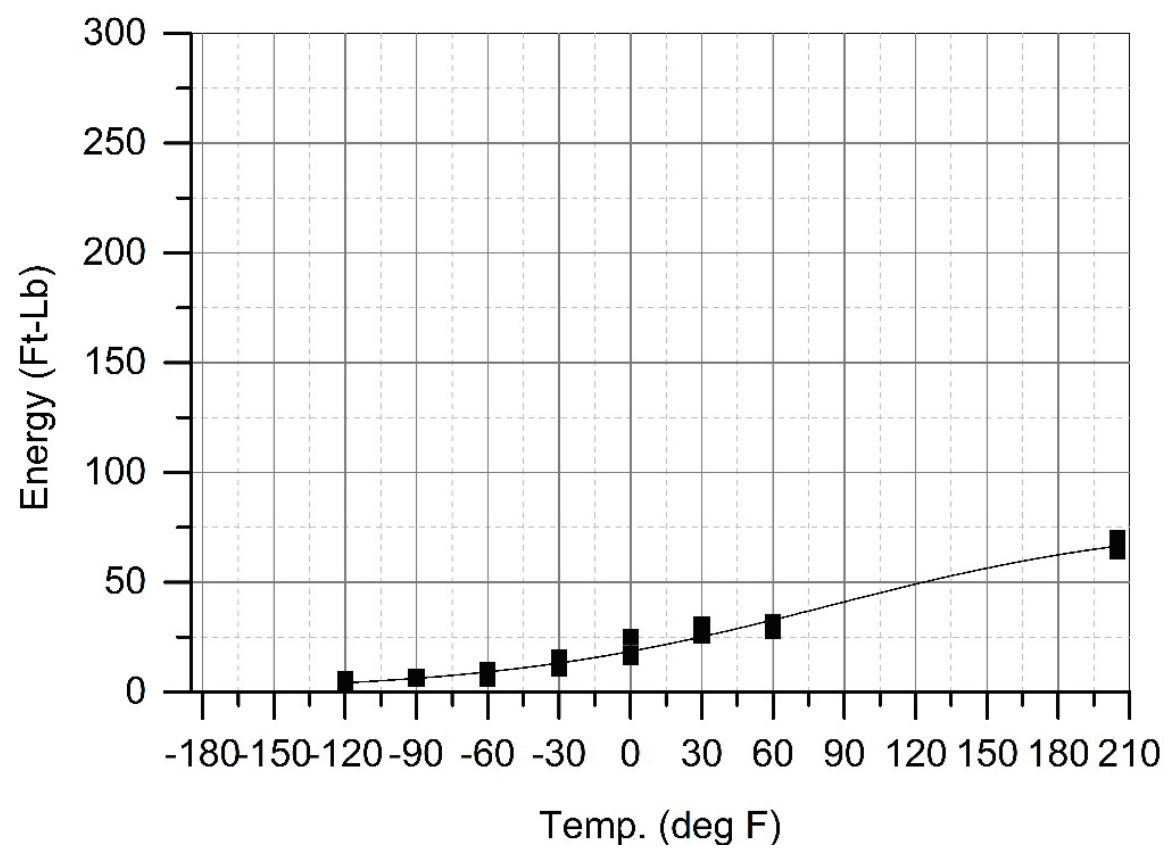

Figure D-20 CVN Data: Specimen 36-4 web plate

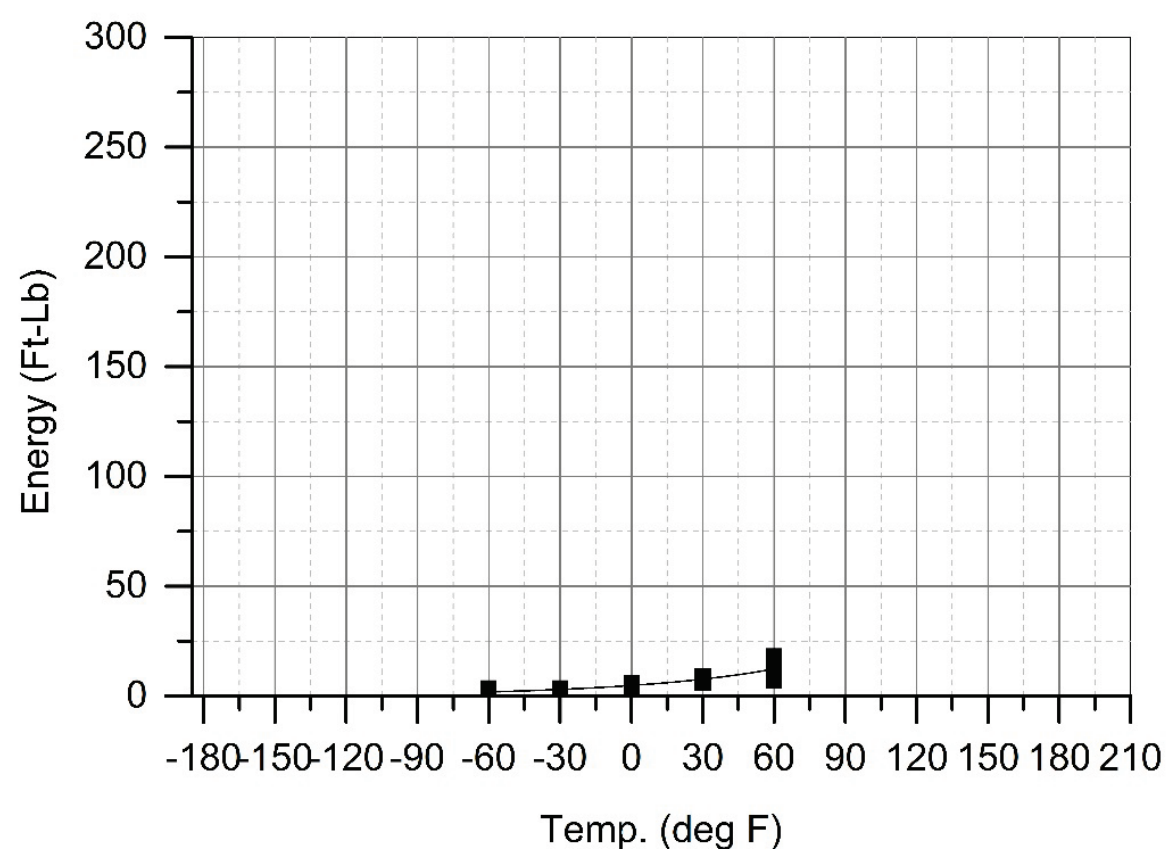

Figure D-21 CVN Data: Specimen 36-4 flange angles 


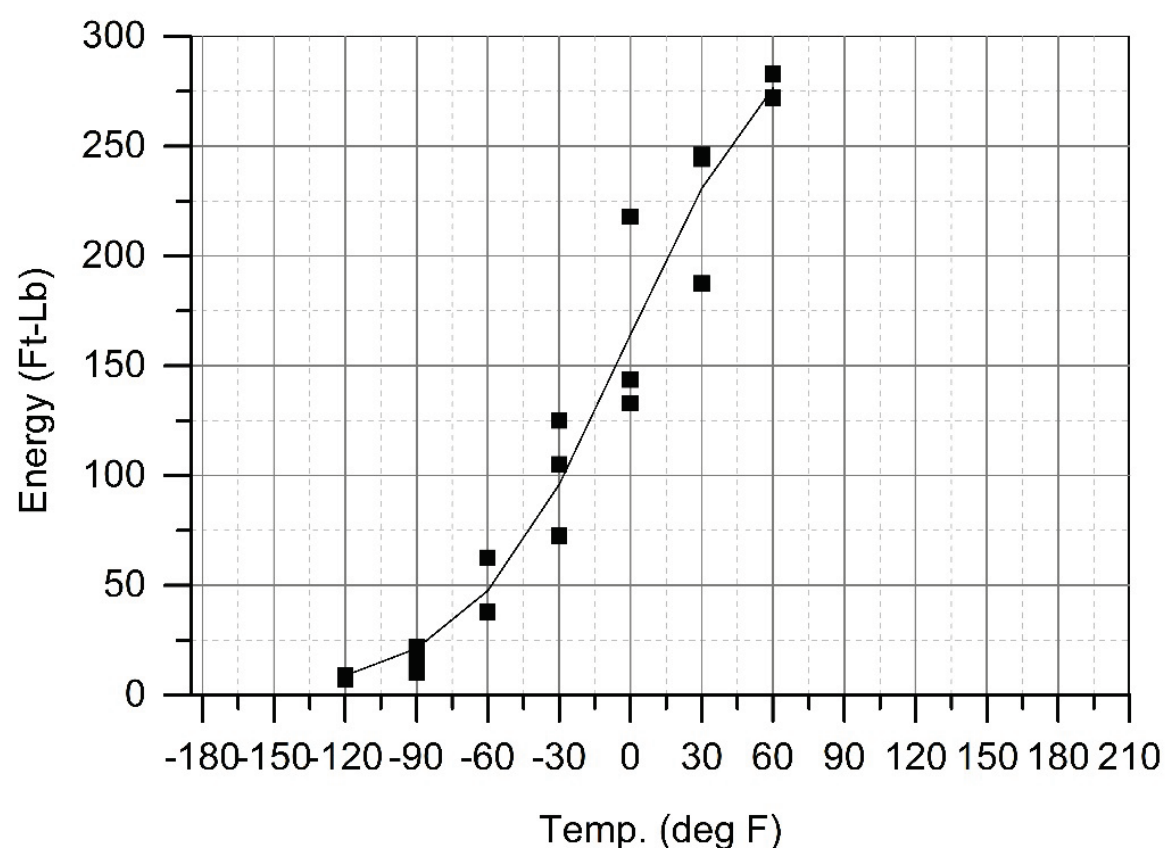

Figure D-22 CVN Data: Specimen 36-4 upper cover plate

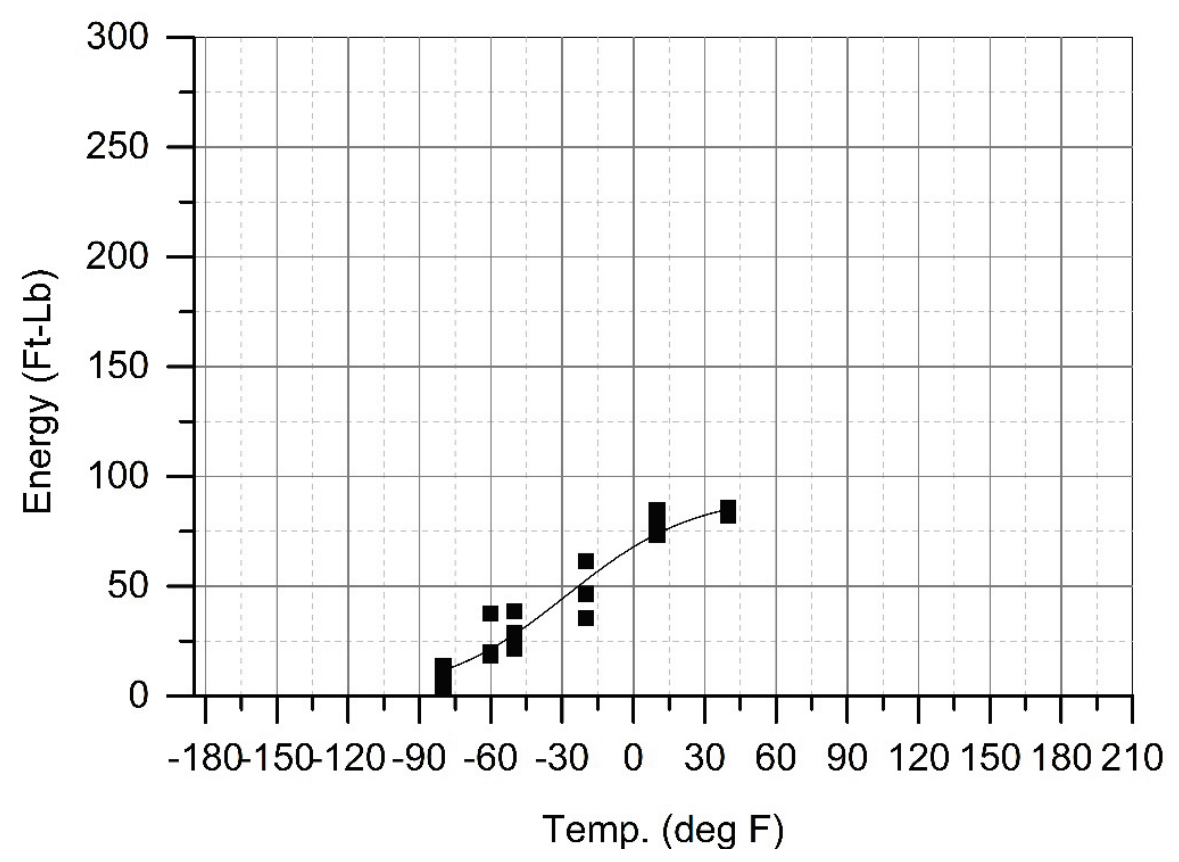

Figure D-23 CVN Data: Specimen 36-4 lower cover plate 


\section{Specimen 36-5}

Table D-19 Specimen 36-5 material properties

\begin{tabular}{|c|c|c|c|c|}
\hline \multicolumn{5}{|c|}{ Specimen 36-5 } \\
\hline \multicolumn{2}{|c|}{ Component } & Web Plate & Flange Angles & Cover Plate \\
\hline \multicolumn{2}{|l|}{ Shape } & Plate & Angle & Plate \\
\hline \multicolumn{2}{|c|}{ Dimensions } & $36 " x 0.5 "$ & 6"x6"x0.75" & $14 " x 1.5 "$ \\
\hline \multicolumn{2}{|l|}{ Length } & $40^{\prime}-0^{\prime \prime}$ & $40^{\prime}-0^{\prime \prime}$ & $29^{\prime}-4.5^{\prime \prime}$ \\
\hline \multicolumn{2}{|l|}{ Heat No. } & H3011 & 1009182 & 3507723 \\
\hline \multicolumn{2}{|l|}{ Grade } & A709 Gr 50W & A588-05 Gr A & A572-50 \\
\hline $\begin{array}{c}\text { Yield } \\
\text { Strength }\end{array}$ & ksi & 59.0 & 59.5 & 53.5 \\
\hline $\begin{array}{l}\text { Ultimate } \\
\text { Strength }\end{array}$ & ksi & 79.0 & 75.9 & 81.5 \\
\hline Elongation & $\%$ & 36.0 & 22.0 & 29.0 \\
\hline \multirow{20}{*}{$\begin{array}{l}\text { Chemical } \\
\text { Analysis }\end{array}$} & $\mathrm{Al}$ & 0.035 & & 0.03 \\
\hline & As & $<0.001$ & & 0.005 \\
\hline & $\mathrm{B}$ & 0.0019 & 0.0005 & 0.0023 \\
\hline & $\mathrm{C}$ & 0.09 & 0.11 & 0.15 \\
\hline & $\mathrm{Cb}$ & & 0.001 & \\
\hline & $\mathrm{Co}$ & $<0.001$ & & 0.002 \\
\hline & $\mathrm{Cr}$ & 0.5 & 0.53 & 0.092 \\
\hline & $\mathrm{Cu}$ & 0.41 & 0.31 & 0.36 \\
\hline & $\mathrm{Mn}$ & 0.91 & 1 & 1.14 \\
\hline & $\mathrm{Mo}$ & 0.043 & 0.042 & 0.066 \\
\hline & $\mathrm{N}$ & & 0.0098 & \\
\hline & $\mathrm{Nb}$ & 0.001 & & $<0.001$ \\
\hline & $\mathrm{Ni}$ & 0.2 & 0.12 & 0.081 \\
\hline & $\mathrm{P}$ & 0.003 & 0.009 & 0.009 \\
\hline & $\mathrm{S}$ & 0.009 & 0.027 & 0.007 \\
\hline & $\mathrm{Sb}$ & 0.004 & & 0.0002 \\
\hline & $\mathrm{Si}$ & 0.4 & 0.34 & 0.21 \\
\hline & $\mathrm{Sn}$ & 0.001 & 0.012 & 0.007 \\
\hline & $\mathrm{Ti}$ & 0.001 & 0.001 & 0.001 \\
\hline & $\mathrm{V}$ & 0.034 & 0.04 & 0.043 \\
\hline
\end{tabular}


Table D-20 Specimen 36-5 CVN data (1/3)

\begin{tabular}{|c|c|c|c|c|c|c|}
\hline \multicolumn{7}{|c|}{ Specimen 36-5 } \\
\hline Component & \multicolumn{2}{|c|}{ Web Plate } & \multicolumn{2}{|c|}{ Flange Angles } & \multicolumn{2}{|c|}{ Cover Plate } \\
\hline Dimensions & \multicolumn{2}{|c|}{$36 " x 0.5 "$} & \multicolumn{2}{|c|}{ 6"x6"x0.75" } & \multicolumn{2}{|c|}{$14 " x 1.5 "$} \\
\hline Heat No. & \multicolumn{2}{|c|}{ H3011 } & \multicolumn{2}{|c|}{1009182} & \multicolumn{2}{|c|}{3507723} \\
\hline Grade & \multicolumn{2}{|c|}{ A709 Gr 50W } & \multicolumn{2}{|c|}{ A588-05 Gr A } & \multicolumn{2}{|c|}{ A572-50 } \\
\hline \multirow{31}{*}{$\mathrm{CVN}$} & ${ }^{\circ} \mathrm{F}$ & Energy & ${ }^{\circ} \mathrm{F}$ & Energy & ${ }^{\circ} \mathrm{F}$ & Energy \\
\hline & -150 & 5 & -60 & 4 & 8 & -150 \\
\hline & -150 & 8 & -60 & 3.5 & 6 & -150 \\
\hline & -150 & 5 & -60 & 5 & 11 & -150 \\
\hline & -120 & 17 & -50 & 3.5 & 9 & -120 \\
\hline & -120 & 6 & -50 & 6.5 & 11 & -120 \\
\hline & -120 & 20 & -50 & 7.5 & 5 & -120 \\
\hline & -90 & 12 & -20 & 12.5 & 22 & -120 \\
\hline & -90 & 54 & -20 & 15 & 5 & -120 \\
\hline & -90 & 7 & -20 & 15 & 5 & -120 \\
\hline & -60 & 109 & 10 & 20 & 6 & -120 \\
\hline & -60 & 148.5 & 10 & 19 & 5 & -120 \\
\hline & -60 & 31 & 10 & 18.5 & 4 & -120 \\
\hline & -30 & 104 & 40 & 23 & 13 & -90 \\
\hline & -30 & 105.5 & 40 & 24 & 26 & -90 \\
\hline & -30 & 257.5 & 40 & 23 & 34 & -90 \\
\hline & 0 & 257 & 70 & 29 & 18 & -90 \\
\hline & 0 & 287 & 70 & 33.5 & 11 & -90 \\
\hline & 0 & 287.5 & 70 & 28 & 14 & -90 \\
\hline & & & & & 13 & -90 \\
\hline & & & & & 13 & -90 \\
\hline & & & & & 31 & -90 \\
\hline & & & & & 48.5 & -60 \\
\hline & & & & & 53 & -60 \\
\hline & & & & & 30 & -60 \\
\hline & & & & & 8 & -60 \\
\hline & & & & & 23 & -60 \\
\hline & & & & & 77 & -60 \\
\hline & & & & & 46.5 & -60 \\
\hline & & & & & 48.5 & -60 \\
\hline & & & & & 27 & -60 \\
\hline
\end{tabular}


Table D-21 Specimen 36-5 CVN data (2/3)

\begin{tabular}{|c|c|c|c|c|c|c|}
\hline \multicolumn{7}{|c|}{ Specimen 36-5 } \\
\hline Component & \multicolumn{2}{|c|}{ Web Plate } & \multicolumn{2}{|c|}{ Flange Angles } & \multicolumn{2}{|c|}{ Cover Plate } \\
\hline Dimensions & \multicolumn{2}{|c|}{$36 " x 0.5 "$} & \multicolumn{2}{|c|}{ 6"x6"x0.75" } & \multicolumn{2}{|c|}{$14 " x 1.5 "$} \\
\hline Heat No. & \multicolumn{2}{|c|}{ H3011 } & \multicolumn{2}{|c|}{1009182} & \multicolumn{2}{|c|}{3507723} \\
\hline Grade & \multicolumn{2}{|c|}{ A709 Gr 50W } & \multicolumn{2}{|c|}{ A588-05 Gr A } & \multicolumn{2}{|c|}{ A572-50 } \\
\hline \multirow{31}{*}{$\mathrm{CVN}$} & ${ }^{\circ} \mathrm{F}$ & Energy & ${ }^{\circ} \mathrm{F}$ & Energy & ${ }^{\circ} \mathrm{F}$ & Energy \\
\hline & & & & & 55.5 & -30 \\
\hline & & & & & 66.5 & -30 \\
\hline & & & & & 72.5 & -30 \\
\hline & & & & & 70 & -30 \\
\hline & & & & & 81.5 & -30 \\
\hline & & & & & 46.5 & -30 \\
\hline & & & & & 67 & -30 \\
\hline & & & & & 68.5 & -30 \\
\hline & & & & & 85 & -30 \\
\hline & & & & & 92.5 & 0 \\
\hline & & & & & 75 & 0 \\
\hline & & & & & 73 & 0 \\
\hline & & & & & 83.5 & 0 \\
\hline & & & & & 16 & 0 \\
\hline & & & & & 84.5 & 0 \\
\hline & & & & & 87 & 0 \\
\hline & & & & & 98 & 0 \\
\hline & & & & & 97 & 0 \\
\hline & & & & & 109.5 & 30 \\
\hline & & & & & 110 & 30 \\
\hline & & & & & 123.5 & 30 \\
\hline & & & & & 85.5 & 30 \\
\hline & & & & & 106 & 30 \\
\hline & & & & & 54 & 30 \\
\hline & & & & & 112.5 & 30 \\
\hline & & & & & 101 & 30 \\
\hline & & & & & 92.5 & 30 \\
\hline & & & & & 139 & 60 \\
\hline & & & & & 114.5 & 60 \\
\hline & & & & & 130 & 60 \\
\hline
\end{tabular}


Table D-22 Specimen 36-5 CVN data (3/3)

\begin{tabular}{|c|c|c|c|c|c|c|}
\hline \multicolumn{7}{|c|}{ Specimen 36-5 } \\
\hline Component & \multicolumn{2}{|c|}{ Web Plate } & \multicolumn{2}{|c|}{ Flange Angles } & \multicolumn{2}{|c|}{ Cover Plate } \\
\hline Dimensions & \multicolumn{2}{|c|}{$36 " x 0.5 "$} & \multicolumn{2}{|c|}{ 6"x6"x0.75" } & \multicolumn{2}{|c|}{$14 " x 1.5 "$} \\
\hline Heat No. & \multicolumn{2}{|c|}{ H3011 } & \multicolumn{2}{|c|}{1009182} & \multicolumn{2}{|c|}{3507723} \\
\hline Grade & \multicolumn{2}{|c|}{ A709 Gr 50W } & \multicolumn{2}{|c|}{ A588-05 Gr A } & \multicolumn{2}{|c|}{ A572-50 } \\
\hline \multirow{10}{*}{$\mathrm{CVN}$} & ${ }^{\circ} \mathrm{F}$ & Energy & ${ }^{\circ} \mathrm{F}$ & Energy & ${ }^{\circ} \mathrm{F}$ & Energy \\
\hline & & & & & 125.5 & 60 \\
\hline & & & & & 131 & 60 \\
\hline & & & & & 121 & 60 \\
\hline & & & & & 143 & 60 \\
\hline & & & & & 133.5 & 60 \\
\hline & & & & & 128 & 60 \\
\hline & & & & & 176 & 205 \\
\hline & & & & & 158 & 205 \\
\hline & & & & & 167.5 & 205 \\
\hline
\end{tabular}

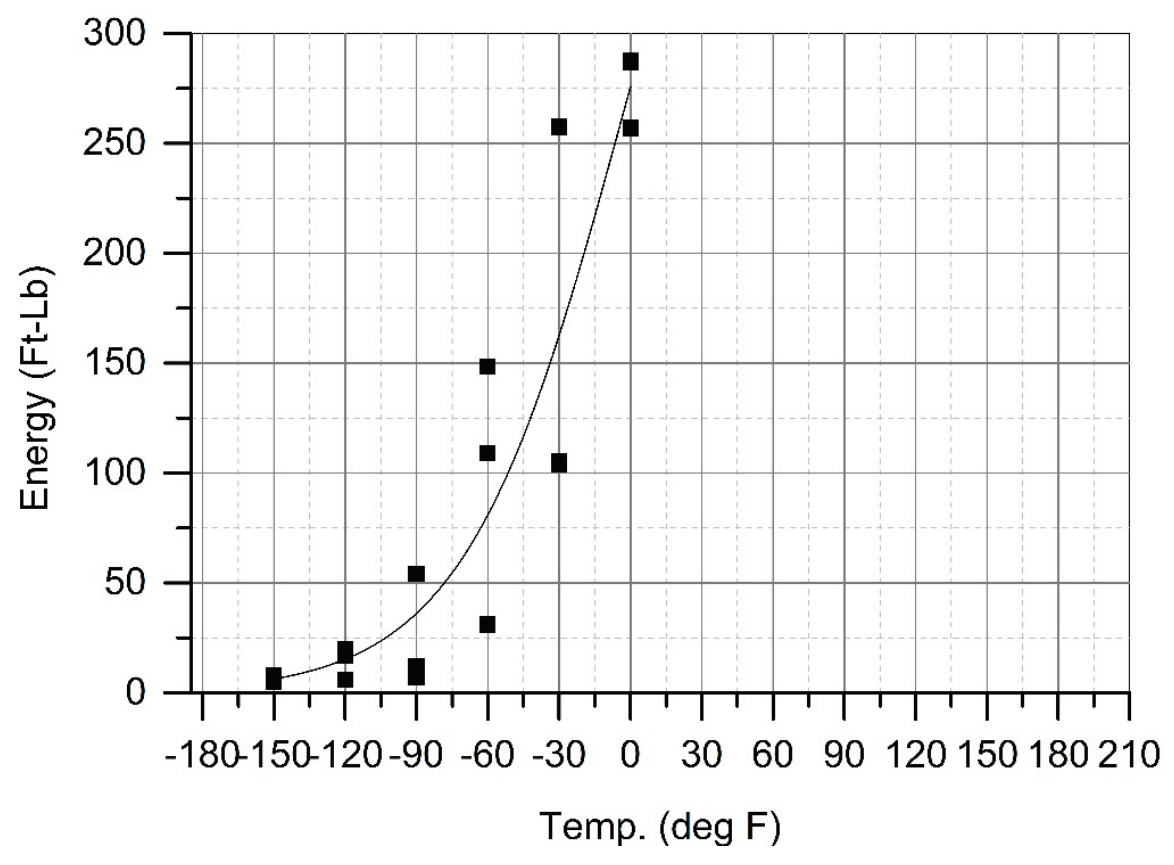

Figure D-24 CVN Data: Specimen 36-5 web plate 


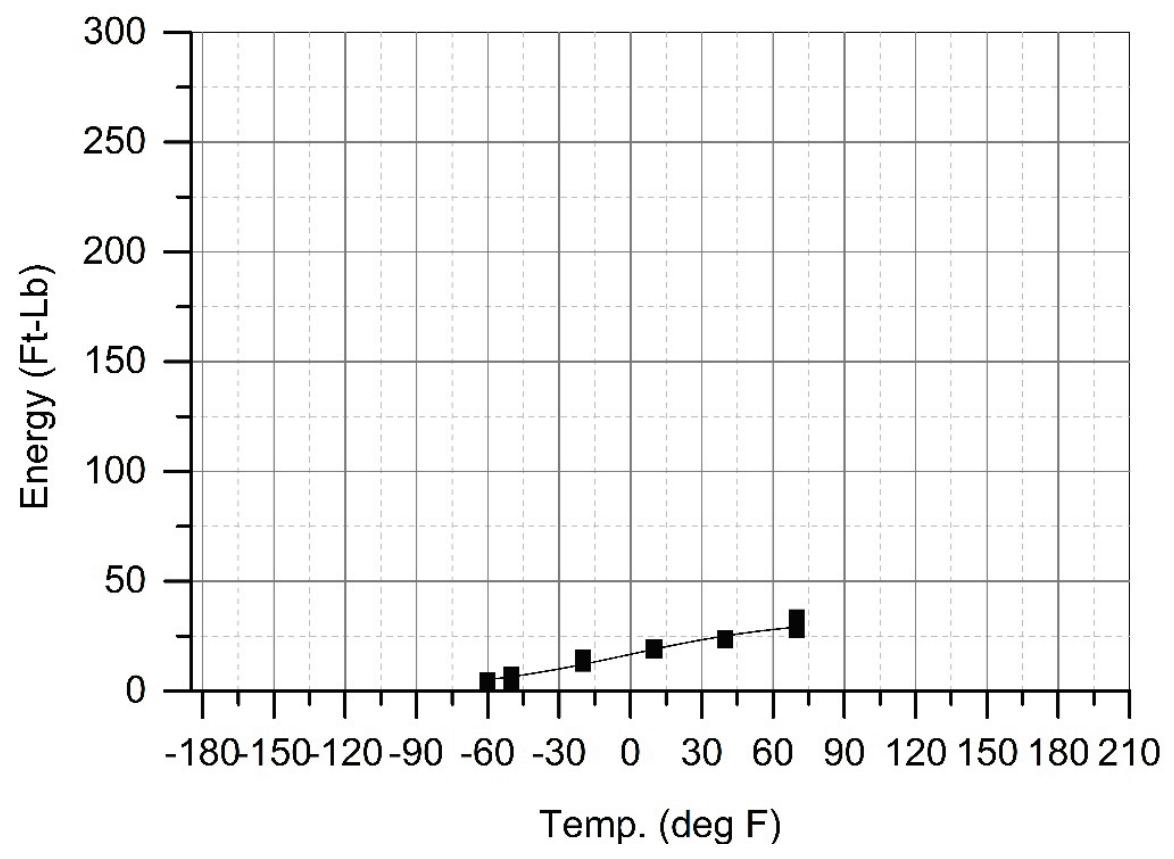

Figure D-25 CVN Data: Specimen 36-5 flange angles

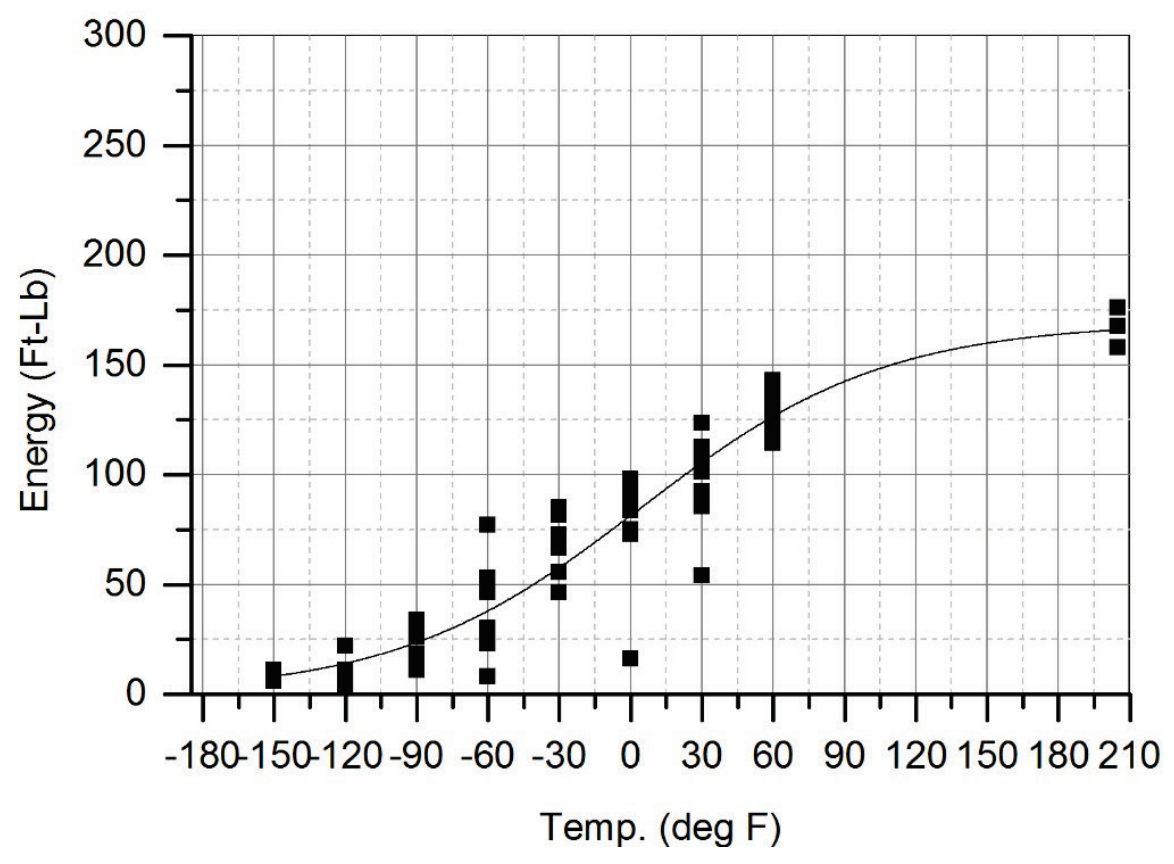

Figure D-26 CVN Data: Specimen 36-5 cover plate 


\section{Specimen 36-6}

Table D-23 Specimen 36-6 material properties

\begin{tabular}{|c|c|c|c|c|}
\hline \multicolumn{5}{|c|}{ Specimen 36-6 } \\
\hline \multicolumn{2}{|c|}{ Component } & Web Plate & Flange Angles & Cover Plate \\
\hline \multicolumn{2}{|l|}{ Shape } & Plate & Angle & Plate \\
\hline \multicolumn{2}{|c|}{ Dimensions } & $46 " x 0.5 "$ & 6"x6"x0.75" & $14 " x 1.5 "$ \\
\hline \multicolumn{2}{|c|}{ Length } & $40^{\prime}-0^{\prime \prime}$ & $40^{\prime}-0^{\prime \prime}$ & $29^{\prime}-4.5^{\prime \prime}$ \\
\hline \multicolumn{2}{|c|}{ Heat No. } & C6470 & L91707 & 3507723 \\
\hline \multicolumn{2}{|l|}{ Grade } & A709-Gr 50 & A588B & A572-50 \\
\hline $\begin{array}{c}\text { Yield } \\
\text { Strength }\end{array}$ & ksi & 59.0 & 57.8 & 53.5 \\
\hline $\begin{array}{l}\text { Ultimate } \\
\text { Strength }\end{array}$ & ksi & 80.1 & 75.5 & 81.5 \\
\hline Elongation & $\%$ & 23.0 & 26.0 & 29.0 \\
\hline \multirow{20}{*}{$\begin{array}{l}\text { Chemical } \\
\text { Analysis }\end{array}$} & $\mathrm{Al}$ & 0.012 & & 0.03 \\
\hline & As & & & 0.005 \\
\hline & $\mathrm{B}$ & & & 0.0023 \\
\hline & $\mathrm{C}$ & 0.12 & 0.12 & 0.15 \\
\hline & $\mathrm{Cb}$ & 0.001 & 0 & \\
\hline & $\mathrm{Co}$ & & & 0.002 \\
\hline & $\mathrm{Cr}$ & 0.53 & 0.62 & 0.092 \\
\hline & $\mathrm{Cu}$ & 0.28 & 0.31 & 0.36 \\
\hline & $\mathrm{Mn}$ & 0.98 & 0.95 & 1.14 \\
\hline & Mo & 0.05 & 0.048 & 0.066 \\
\hline & $\mathrm{N}$ & & & \\
\hline & $\mathrm{Nb}$ & & & $<0.001$ \\
\hline & $\mathrm{Ni}$ & 0.14 & 0.12 & 0.081 \\
\hline & $\mathrm{P}$ & 0.007 & 0.013 & 0.009 \\
\hline & $\mathrm{S}$ & 0.002 & 0.040 & 0.007 \\
\hline & $\mathrm{Sb}$ & & & 0.0002 \\
\hline & $\mathrm{Si}$ & 0.37 & 0.18 & 0.21 \\
\hline & $\mathrm{Sn}$ & & 0.012 & 0.007 \\
\hline & $\mathrm{Ti}$ & & & 0.001 \\
\hline & $\mathrm{V}$ & 0.039 & 0.044 & 0.043 \\
\hline
\end{tabular}


Table D-24 Specimen 36-6 CVN data (1/3)

\begin{tabular}{|c|c|c|c|c|c|c|}
\hline \multicolumn{7}{|c|}{ Specimen 36-6 } \\
\hline Component & \multicolumn{2}{|c|}{ Web Plate } & \multicolumn{2}{|c|}{ Flange Angles } & \multicolumn{2}{|c|}{ Cover Plate } \\
\hline Dimensions & \multicolumn{2}{|c|}{$46 " x 0.5 "$} & \multicolumn{2}{|c|}{ 6"x6"x0.75" } & \multicolumn{2}{|c|}{$14 " \mathrm{n} 1.5^{\prime \prime}$} \\
\hline Heat No. & \multicolumn{2}{|c|}{ C6470 } & \multicolumn{2}{|c|}{ L91707 } & \multicolumn{2}{|c|}{3507723} \\
\hline Grade & \multicolumn{2}{|c|}{ A709-Gr 50} & \multicolumn{2}{|c|}{ A588B } & \multicolumn{2}{|c|}{ A572-50 } \\
\hline \multirow{31}{*}{$\mathrm{CVN}$} & ${ }^{\circ} \mathrm{F}$ & Energy & ${ }^{\circ} \mathrm{F}$ & Energy & ${ }^{\circ} \mathrm{F}$ & Energy \\
\hline & -120 & 4.00 & -60 & 3.5 & 8 & -150 \\
\hline & -120 & 6.00 & -60 & 3 & 6 & -150 \\
\hline & -120 & 4.00 & -60 & 3 & 11 & -150 \\
\hline & -90 & 7.00 & -30 & 5.5 & 9 & -120 \\
\hline & -90 & 6.00 & -30 & 5 & 11 & -120 \\
\hline & -90 & 6.00 & -30 & 4.5 & 5 & -120 \\
\hline & -60 & 10.00 & 0 & 29 & 22 & -120 \\
\hline & -60 & 6.00 & 0 & 24.5 & 5 & -120 \\
\hline & -60 & 6.00 & 0 & 35 & 5 & -120 \\
\hline & -30 & 11.00 & 30 & 38 & 6 & -120 \\
\hline & -30 & 10.50 & 30 & 21 & 5 & -120 \\
\hline & -30 & 15.50 & 30 & 57.5 & 4 & -120 \\
\hline & 0 & 16.00 & 60 & 62 & 13 & -90 \\
\hline & 0 & 25.00 & 60 & 58.5 & 26 & -90 \\
\hline & 0 & 17.50 & 60 & 62 & 34 & -90 \\
\hline & 30 & 25.50 & 205 & 90 & 18 & -90 \\
\hline & 30 & 30.50 & 205 & 88.5 & 11 & -90 \\
\hline & 30 & 30.00 & 205 & 97 & 14 & -90 \\
\hline & 60 & 28.00 & & & 13 & -90 \\
\hline & 60 & 32 & & & 13 & -90 \\
\hline & 60 & 30.5 & & & 31 & -90 \\
\hline & 205 & 64 & & & 48.5 & -60 \\
\hline & 205 & 70 & & & 53 & -60 \\
\hline & 205 & 66 & & & 30 & -60 \\
\hline & & & & & 8 & -60 \\
\hline & & & & & 23 & -60 \\
\hline & & & & & 77 & -60 \\
\hline & & & & & 46.5 & -60 \\
\hline & & & & & 48.5 & -60 \\
\hline & & & & & 27 & -60 \\
\hline
\end{tabular}


Table D-25 Specimen 36-6 CVN data (2/3)

\begin{tabular}{|c|c|c|c|c|c|c|}
\hline \multicolumn{7}{|c|}{ Specimen 36-6 } \\
\hline Component & \multicolumn{2}{|c|}{ Web Plate } & \multicolumn{2}{|c|}{ Flange Angles } & \multicolumn{2}{|c|}{ Cover Plate } \\
\hline Dimensions & \multicolumn{2}{|c|}{$46 " x 0.5 "$} & \multicolumn{2}{|c|}{ 6"x6"x0.75" } & \multicolumn{2}{|c|}{ 14"x1.5" } \\
\hline Heat No. & \multicolumn{2}{|c|}{ C6470 } & \multicolumn{2}{|c|}{ L91707 } & \multicolumn{2}{|c|}{3507723} \\
\hline Grade & \multicolumn{2}{|c|}{ A709-Gr 50} & \multicolumn{2}{|c|}{ A588B } & \multicolumn{2}{|c|}{ A572-50 } \\
\hline \multirow{31}{*}{$\mathrm{CVN}$} & ${ }^{\circ} \mathrm{F}$ & Energy & ${ }^{\circ} \mathrm{F}$ & Energy & ${ }^{\circ} \mathrm{F}$ & Energy \\
\hline & & & & & 55.5 & -30 \\
\hline & & & & & 66.5 & -30 \\
\hline & & & & & 72.5 & -30 \\
\hline & & & & & 70 & -30 \\
\hline & & & & & 81.5 & -30 \\
\hline & & & & & 46.5 & -30 \\
\hline & & & & & 67 & -30 \\
\hline & & & & & 68.5 & -30 \\
\hline & & & & & 85 & -30 \\
\hline & & & & & 92.5 & 0 \\
\hline & & & & & 75 & 0 \\
\hline & & & & & 73 & 0 \\
\hline & & & & & 83.5 & 0 \\
\hline & & & & & 16 & 0 \\
\hline & & & & & 84.5 & 0 \\
\hline & & & & & 87 & 0 \\
\hline & & & & & 98 & 0 \\
\hline & & & & & 97 & 0 \\
\hline & & & & & 109.5 & 30 \\
\hline & & & & & 110 & 30 \\
\hline & & & & & 123.5 & 30 \\
\hline & & & & & 85.5 & 30 \\
\hline & & & & & 106 & 30 \\
\hline & & & & & 54 & 30 \\
\hline & & & & & 112.5 & 30 \\
\hline & & & & & 101 & 30 \\
\hline & & & & & 92.5 & 30 \\
\hline & & & & & 139 & 60 \\
\hline & & & & & 114.5 & 60 \\
\hline & & & & & 130 & 60 \\
\hline
\end{tabular}


Table D-26 Specimen 36-6 CVN data (3/3)

\begin{tabular}{|c|c|c|c|c|c|c|}
\hline \multicolumn{7}{|c|}{ Specimen 36-6 } \\
\hline Component & \multicolumn{2}{|c|}{ Web Plate } & \multicolumn{2}{|c|}{ Flange Angles } & \multicolumn{2}{|c|}{ Cover Plate } \\
\hline Dimensions & \multicolumn{2}{|c|}{$46 " \mathrm{x} 0.5^{\prime \prime}$} & \multicolumn{2}{|c|}{ 6"х6"х0.75" } & \multicolumn{2}{|c|}{$14 " x 1.5 "$} \\
\hline Heat No. & \multicolumn{2}{|c|}{ C6470 } & \multicolumn{2}{|c|}{ L91707 } & \multicolumn{2}{|c|}{3507723} \\
\hline Grade & \multicolumn{2}{|c|}{ A709-Gr 50} & \multicolumn{2}{|c|}{ A588B } & \multicolumn{2}{|c|}{ A572-50 } \\
\hline \multirow{10}{*}{ CVN } & ${ }^{\circ} \mathrm{F}$ & Energy & ${ }^{\circ} \mathrm{F}$ & Energy & ${ }^{\circ} \mathrm{F}$ & Energy \\
\hline & & & & & 125.5 & 60 \\
\hline & & & & & 131 & 60 \\
\hline & & & & & 121 & 60 \\
\hline & & & & & 143 & 60 \\
\hline & & & & & 133.5 & 60 \\
\hline & & & & & 128 & 60 \\
\hline & & & & & 176 & 205 \\
\hline & & & & & 158 & 205 \\
\hline & & & & & 167.5 & 205 \\
\hline
\end{tabular}

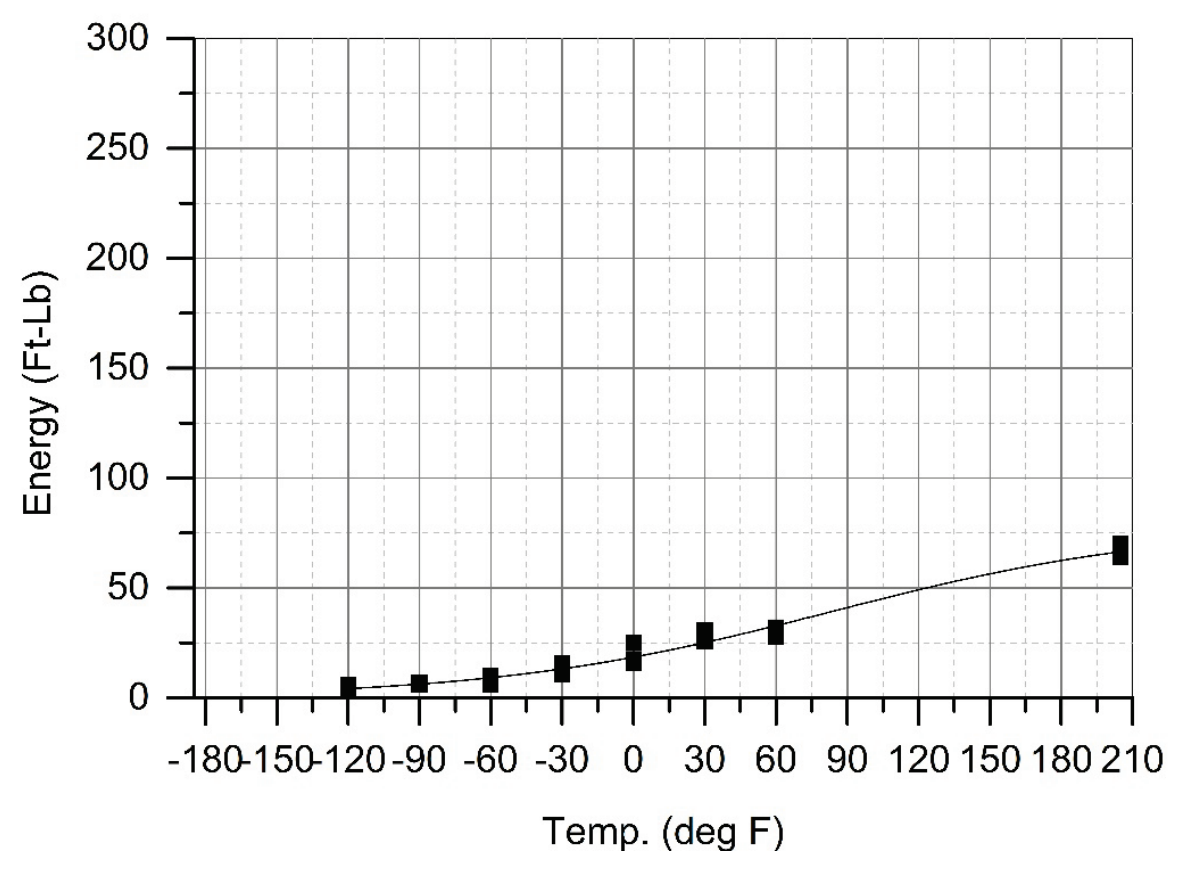

Figure D-27 CVN Data: Specimen 36-6 web plate 


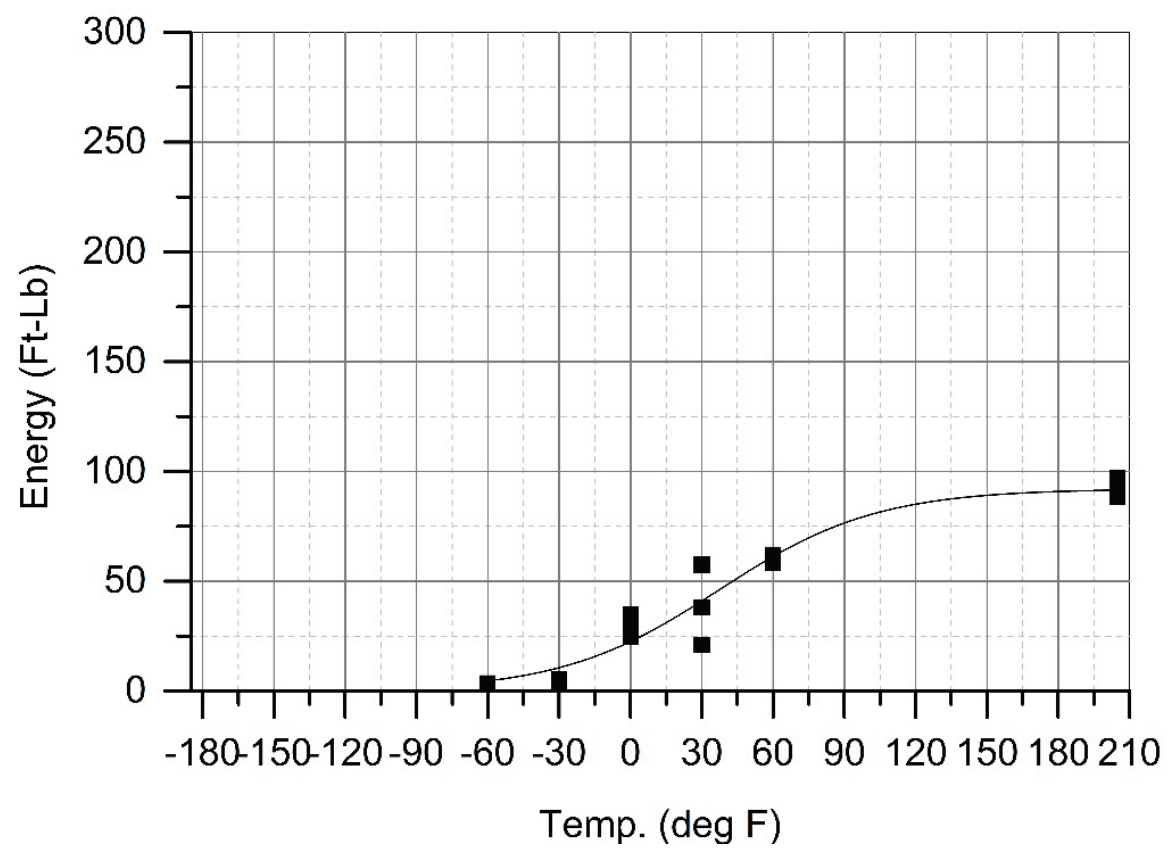

Figure D-28 CVN Data: Specimen 36-6 flange angles

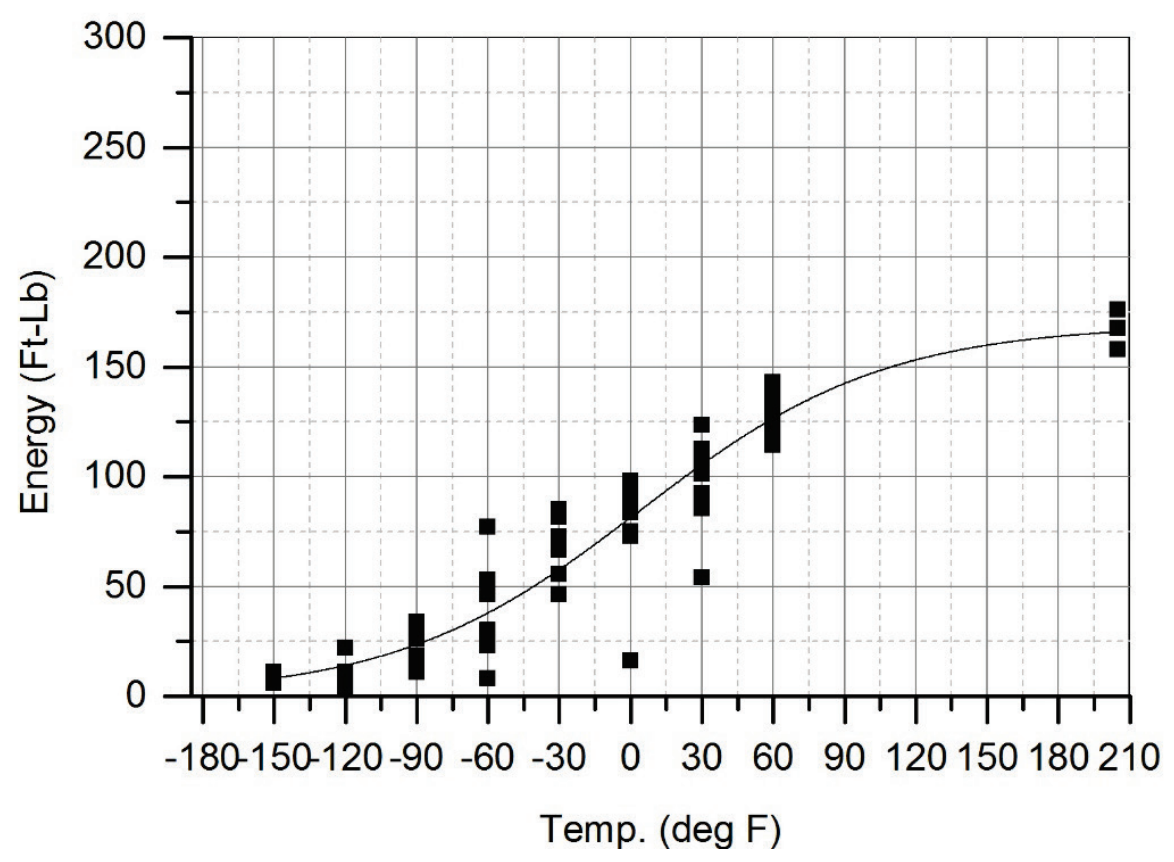

Figure D-29 CVN Data: Specimen 36-6 cover plate 


\section{Specimen 46-1}

Table D-27 Specimen 46-1 material properties

\begin{tabular}{|c|c|c|c|c|}
\hline \multicolumn{5}{|c|}{ Specimen 46-1 } \\
\hline \multicolumn{2}{|c|}{ Component } & Web Plate & Flange Angles & Cover Plate \\
\hline \multicolumn{2}{|l|}{ Shape } & Plate & Angle & Plate \\
\hline \multicolumn{2}{|c|}{ Dimensions } & $46 " \mathrm{x} 0.5^{\prime \prime}$ & 6"x6"x0.75" & $14 " x 0.75^{\prime \prime}$ \\
\hline \multicolumn{2}{|c|}{ Length } & $40^{\prime}-0^{\prime \prime}$ & $40^{\prime}-0^{\prime \prime}$ & $23^{\prime}-0^{\prime \prime}$ \\
\hline \multicolumn{2}{|c|}{ Heat No. } & C6470 & 1009182 & $2 \mathrm{H} 750$ \\
\hline \multicolumn{2}{|l|}{ Grade } & A709-Gr 50 & A588-05 Gr A & A709 Gr 50W \\
\hline $\begin{array}{c}\text { Yield } \\
\text { Strength }\end{array}$ & ksi & 59.0 & 59.5 & 64.5 \\
\hline $\begin{array}{l}\text { Ultimate } \\
\text { Strength }\end{array}$ & ksi & 80.1 & 75.9 & 81.5 \\
\hline Elongation & $\%$ & 23.0 & 22.0 & 21.0 \\
\hline \multirow{16}{*}{$\begin{array}{l}\text { Chemical } \\
\text { Analysis }\end{array}$} & $\mathrm{Al}$ & 0.012 & & 0.008 \\
\hline & $\mathrm{B}$ & & 0.0005 & 0.0004 \\
\hline & $\mathrm{C}$ & 0.12 & 0.11 & 0.12 \\
\hline & $\mathrm{Cb}$ & 0.001 & 0.001 & 0 \\
\hline & $\mathrm{Cr}$ & 0.53 & 0.53 & 0.5514 \\
\hline & $\mathrm{Cu}$ & 0.28 & 0.31 & 0.336 \\
\hline & $\mathrm{Mn}$ & 0.98 & 1 & 0.92 \\
\hline & Mo & 0.05 & 0.042 & 0.028 \\
\hline & $\mathrm{N}$ & & 0.0098 & 0.009 \\
\hline & $\mathrm{Ni}$ & 0.14 & 0.12 & 0.158 \\
\hline & $\mathrm{P}$ & 0.007 & 0.009 & 0.009 \\
\hline & $\mathrm{S}$ & 0.002 & 0.027 & 0.013 \\
\hline & $\mathrm{Si}$ & 0.37 & 0.34 & 0.4 \\
\hline & $\mathrm{Sn}$ & & 0.012 & 0.029 \\
\hline & $\mathrm{Ti}$ & & 0.001 & 0.002 \\
\hline & $\mathrm{V}$ & 0.039 & 0.04 & 0.04 \\
\hline
\end{tabular}


Table D-28 Specimen 46-1 CVN data

\begin{tabular}{|c|c|c|c|c|c|c|}
\hline \multicolumn{7}{|c|}{ Specimen 46-1 } \\
\hline Component & \multicolumn{2}{|c|}{ Web Plate } & \multicolumn{2}{|c|}{ Flange Angles } & \multicolumn{2}{|c|}{ Cover Plate } \\
\hline Dimensions & \multicolumn{2}{|c|}{ 46"x0.5" } & \multicolumn{2}{|c|}{ 6"х6"х0.75" } & \multicolumn{2}{|c|}{$14 " x 0.75 "$} \\
\hline Heat No. & \multicolumn{2}{|c|}{ C6470 } & \multicolumn{2}{|c|}{1009182} & \multicolumn{2}{|c|}{$2 \mathrm{H} 750$} \\
\hline Grade & \multicolumn{2}{|c|}{ A709-Gr 50} & \multicolumn{2}{|c|}{ A588-05 Gr A } & \multicolumn{2}{|c|}{ A709 Gr 50W } \\
\hline \multirow{25}{*}{$\mathrm{CVN}$} & ${ }^{\circ} \mathrm{F}$ & Energy & ${ }^{\circ} \mathrm{F}$ & Energy & ${ }^{\circ} \mathrm{F}$ & Energy \\
\hline & -120 & 4.00 & -60 & 4 & -80 & 4.5 \\
\hline & -120 & 6.00 & -60 & 3.5 & -80 & 7 \\
\hline & -120 & 4.00 & -60 & 5 & -80 & 13.5 \\
\hline & -90 & 7.00 & -50 & 3.5 & -60 & 37.5 \\
\hline & -90 & 6.00 & -50 & 6.5 & -60 & 20 \\
\hline & -90 & 6.00 & -50 & 7.5 & -60 & 18.5 \\
\hline & -60 & 10.00 & -20 & 12.5 & -50 & 21.5 \\
\hline & -60 & 6.00 & -20 & 15 & -50 & 28.5 \\
\hline & -60 & 6.00 & -20 & 15 & -50 & 38.5 \\
\hline & -30 & 11.00 & 10 & 20 & -20 & 46.5 \\
\hline & -30 & 10.50 & 10 & 19 & -20 & 35.5 \\
\hline & -30 & 15.50 & 10 & 18.5 & -20 & 61.5 \\
\hline & 0 & 16.00 & 40 & 23 & 10 & 73.5 \\
\hline & 0 & 25.00 & 40 & 24 & 10 & 77.5 \\
\hline & 0 & 17.50 & 40 & 23 & 10 & 84.5 \\
\hline & 30 & 25.50 & 70 & 29 & 40 & 82 \\
\hline & 30 & 30.50 & 70 & 33.5 & 40 & 82 \\
\hline & 30 & 30.00 & 70 & 28 & 40 & 85.5 \\
\hline & 60 & 28.00 & & & & \\
\hline & 60 & 32 & & & & \\
\hline & 60 & 30.5 & & & & \\
\hline & 205 & 64 & & & & \\
\hline & 205 & 70 & & & & \\
\hline & 205 & 66 & & & & \\
\hline
\end{tabular}




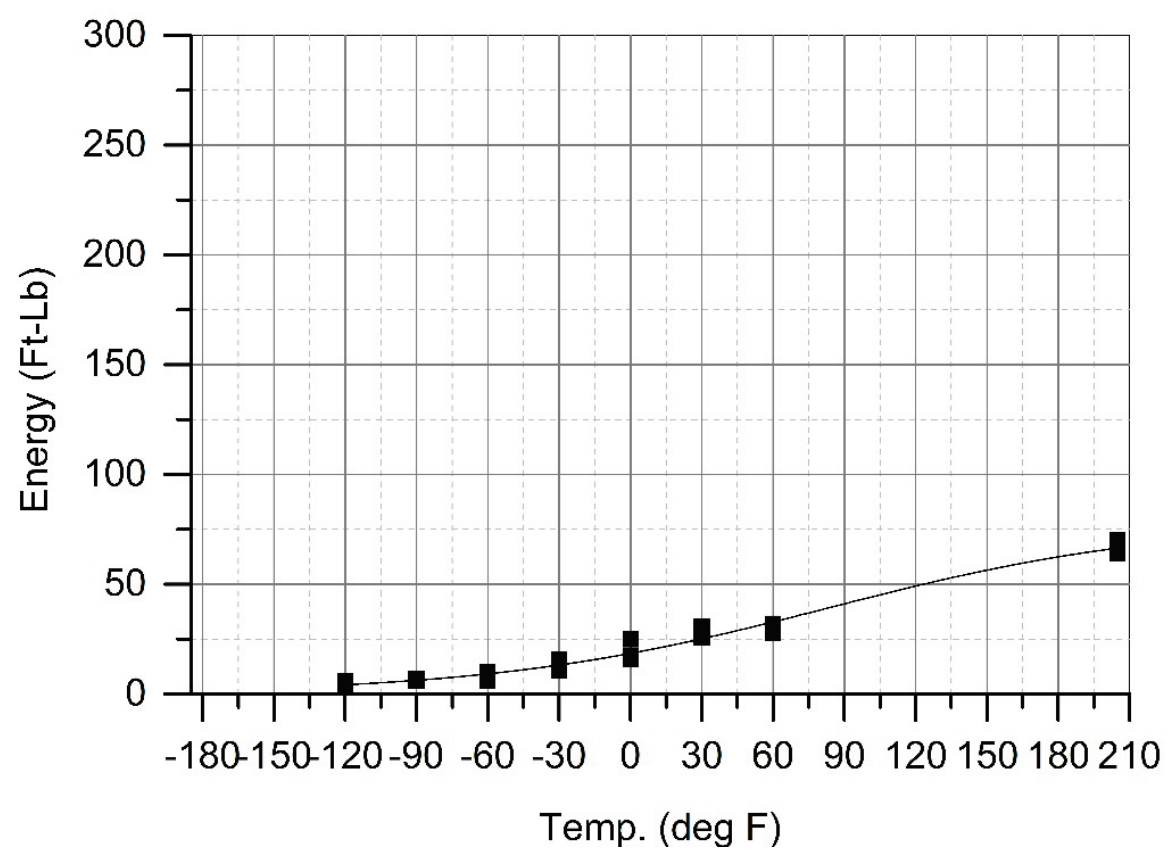

Figure D-30 CVN Data: Specimen 46-1 web plate

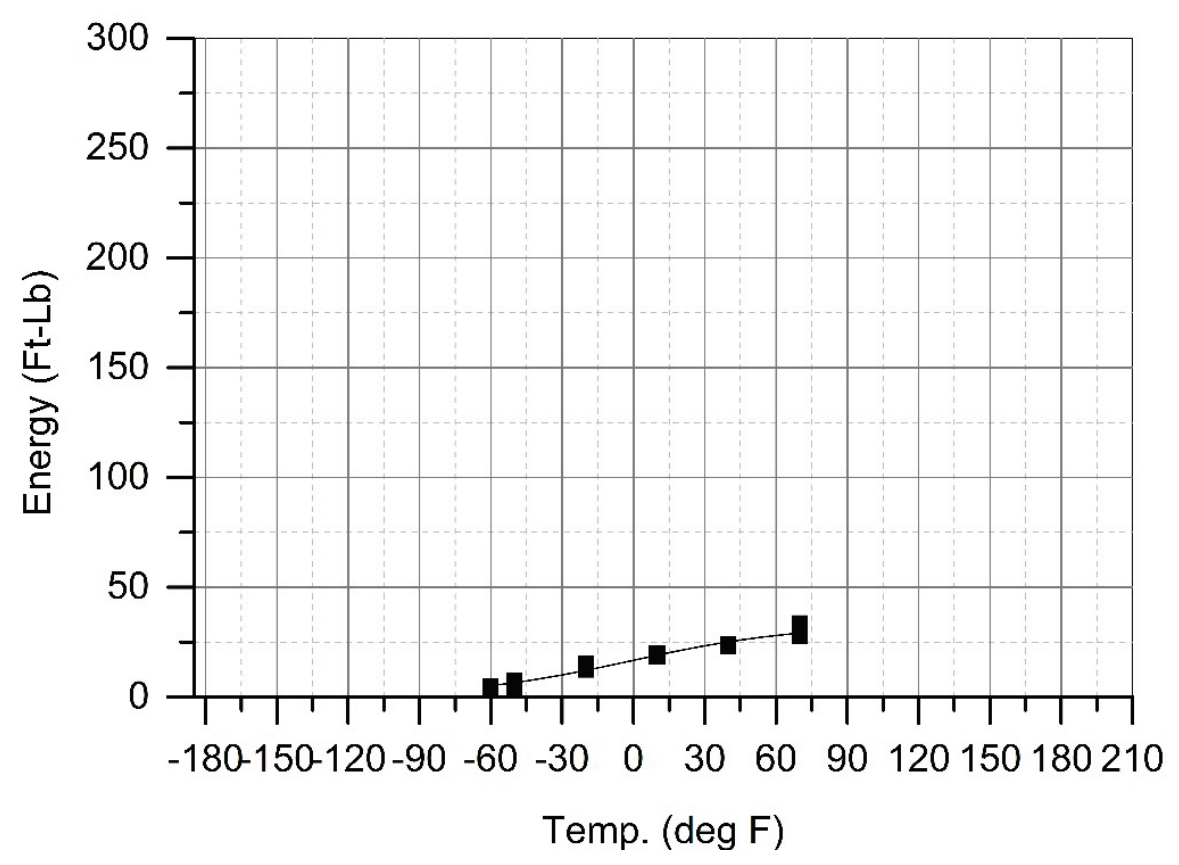

Figure D-31 CVN Data: Specimen 46-1 flange angles 


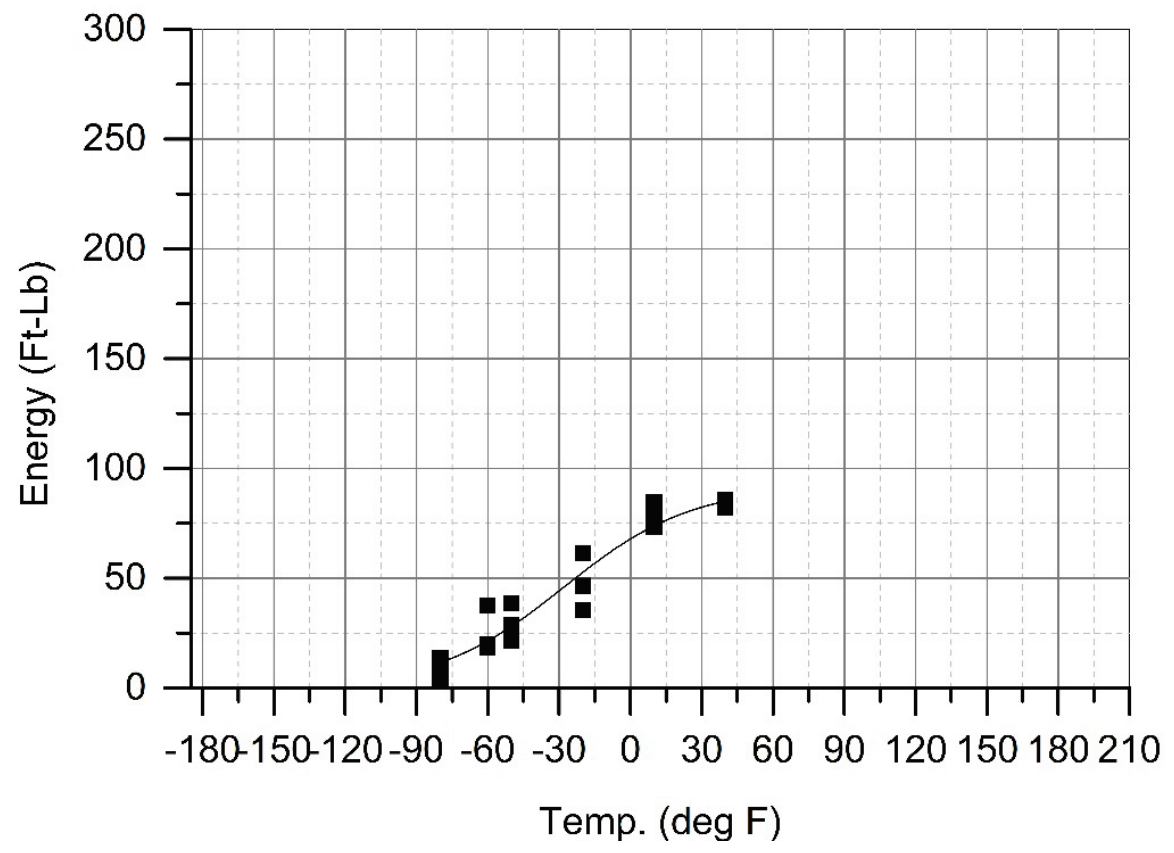

Figure D-32 CVN Data: Specimen 46-1 cover plate 


\section{Specimen 46-2}

Table D-29 Specimen 46-2 material properties

\begin{tabular}{|c|c|c|c|c|}
\hline \multicolumn{5}{|c|}{ Specimen 46-2 } \\
\hline \multicolumn{2}{|c|}{ Component } & Web Plate & Flange Angles & Cover Plate \\
\hline \multicolumn{2}{|l|}{ Shape } & Plate & Angle & Plate \\
\hline \multicolumn{2}{|c|}{ Dimensions } & $46 " \mathrm{x} 0.5^{\prime \prime}$ & 6"x6"x0.75" & $14 " \mathrm{x} 0.75^{\prime \prime}$ \\
\hline \multicolumn{2}{|c|}{ Length } & $40^{\prime}-0^{\prime \prime}$ & $40^{\prime}-0^{\prime \prime}$ & $23^{\prime}-0^{\prime \prime}$ \\
\hline \multicolumn{2}{|c|}{ Heat No. } & C6470 & 1009182 & $2 \mathrm{H} 750$ \\
\hline \multicolumn{2}{|l|}{ Grade } & A709-Gr 50 & A588-05 Gr A & A709 Gr 50W \\
\hline $\begin{array}{c}\text { Yield } \\
\text { Strength }\end{array}$ & ksi & 59.0 & 59.5 & 64.5 \\
\hline $\begin{array}{l}\text { Ultimate } \\
\text { Strength }\end{array}$ & ksi & 80.1 & 75.9 & 81.5 \\
\hline Elongation & $\%$ & 23.0 & 22.0 & 21.0 \\
\hline \multirow{16}{*}{$\begin{array}{l}\text { Chemical } \\
\text { Analysis }\end{array}$} & $\mathrm{Al}$ & 0.012 & & 0.008 \\
\hline & $\mathrm{B}$ & & 0.0005 & 0.0004 \\
\hline & $\mathrm{C}$ & 0.12 & 0.11 & 0.12 \\
\hline & $\mathrm{Cb}$ & 0.001 & 0.001 & 0 \\
\hline & $\mathrm{Cr}$ & 0.53 & 0.53 & 0.5514 \\
\hline & $\mathrm{Cu}$ & 0.28 & 0.31 & 0.336 \\
\hline & $\mathrm{Mn}$ & 0.98 & 1 & 0.92 \\
\hline & Mo & 0.05 & 0.042 & 0.028 \\
\hline & $\mathrm{N}$ & & 0.0098 & 0.009 \\
\hline & $\mathrm{Ni}$ & 0.14 & 0.12 & 0.158 \\
\hline & $\mathrm{P}$ & 0.007 & 0.009 & 0.009 \\
\hline & $\mathrm{S}$ & 0.002 & 0.027 & 0.013 \\
\hline & $\mathrm{Si}$ & 0.37 & 0.34 & 0.4 \\
\hline & $\mathrm{Sn}$ & & 0.012 & 0.029 \\
\hline & $\mathrm{Ti}$ & & 0.001 & 0.002 \\
\hline & $\mathrm{V}$ & 0.039 & 0.04 & 0.04 \\
\hline
\end{tabular}


Table D-30 Specimen 46-2 CVN data

\begin{tabular}{|c|c|c|c|c|c|c|}
\hline \multicolumn{7}{|c|}{ Specimen $46-2$} \\
\hline Component & \multicolumn{2}{|c|}{ Web Plate } & \multicolumn{2}{|c|}{ Flange Angles } & \multicolumn{2}{|c|}{ Cover Plate } \\
\hline Dimensions & \multicolumn{2}{|c|}{$46 " \mathrm{x} 0.5^{\prime \prime}$} & \multicolumn{2}{|c|}{ 6"x6"x0.75" } & \multicolumn{2}{|c|}{$14 " x 0.75 "$} \\
\hline Heat No. & \multicolumn{2}{|c|}{$\mathrm{C} 6470$} & \multicolumn{2}{|c|}{1009182} & \multicolumn{2}{|c|}{$2 \mathrm{H} 750$} \\
\hline Grade & \multicolumn{2}{|c|}{ A709-Gr 50} & \multicolumn{2}{|c|}{ A588-05 Gr A } & \multicolumn{2}{|c|}{ A709 Gr 50W } \\
\hline \multirow{25}{*}{ CVN } & ${ }^{\circ} \mathrm{F}$ & Energy & ${ }^{\circ} \mathrm{F}$ & Energy & ${ }^{\circ} \mathrm{F}$ & Energy \\
\hline & -120 & 4.00 & -60 & 4 & -80 & 4.5 \\
\hline & -120 & 6.00 & -60 & 3.5 & -80 & 7 \\
\hline & -120 & 4.00 & -60 & 5 & -80 & 13.5 \\
\hline & -90 & 7.00 & -50 & 3.5 & -60 & 37.5 \\
\hline & -90 & 6.00 & -50 & 6.5 & -60 & 20 \\
\hline & -90 & 6.00 & -50 & 7.5 & -60 & 18.5 \\
\hline & -60 & 10.00 & -20 & 12.5 & -50 & 21.5 \\
\hline & -60 & 6.00 & -20 & 15 & -50 & 28.5 \\
\hline & -60 & 6.00 & -20 & 15 & -50 & 38.5 \\
\hline & -30 & 11.00 & 10 & 20 & -20 & 46.5 \\
\hline & -30 & 10.50 & 10 & 19 & -20 & 35.5 \\
\hline & -30 & 15.50 & 10 & 18.5 & -20 & 61.5 \\
\hline & 0 & 16.00 & 40 & 23 & 10 & 73.5 \\
\hline & 0 & 25.00 & 40 & 24 & 10 & 77.5 \\
\hline & 0 & 17.50 & 40 & 23 & 10 & 84.5 \\
\hline & 30 & 25.50 & 70 & 29 & 40 & 82 \\
\hline & 30 & 30.50 & 70 & 33.5 & 40 & 82 \\
\hline & 30 & 30.00 & 70 & 28 & 40 & 85.5 \\
\hline & 60 & 28.00 & & & & \\
\hline & 60 & 32 & & & & \\
\hline & 60 & 30.5 & & & & \\
\hline & 205 & 64 & & & & \\
\hline & 205 & 70 & & & & \\
\hline & 205 & 66 & & & & \\
\hline
\end{tabular}




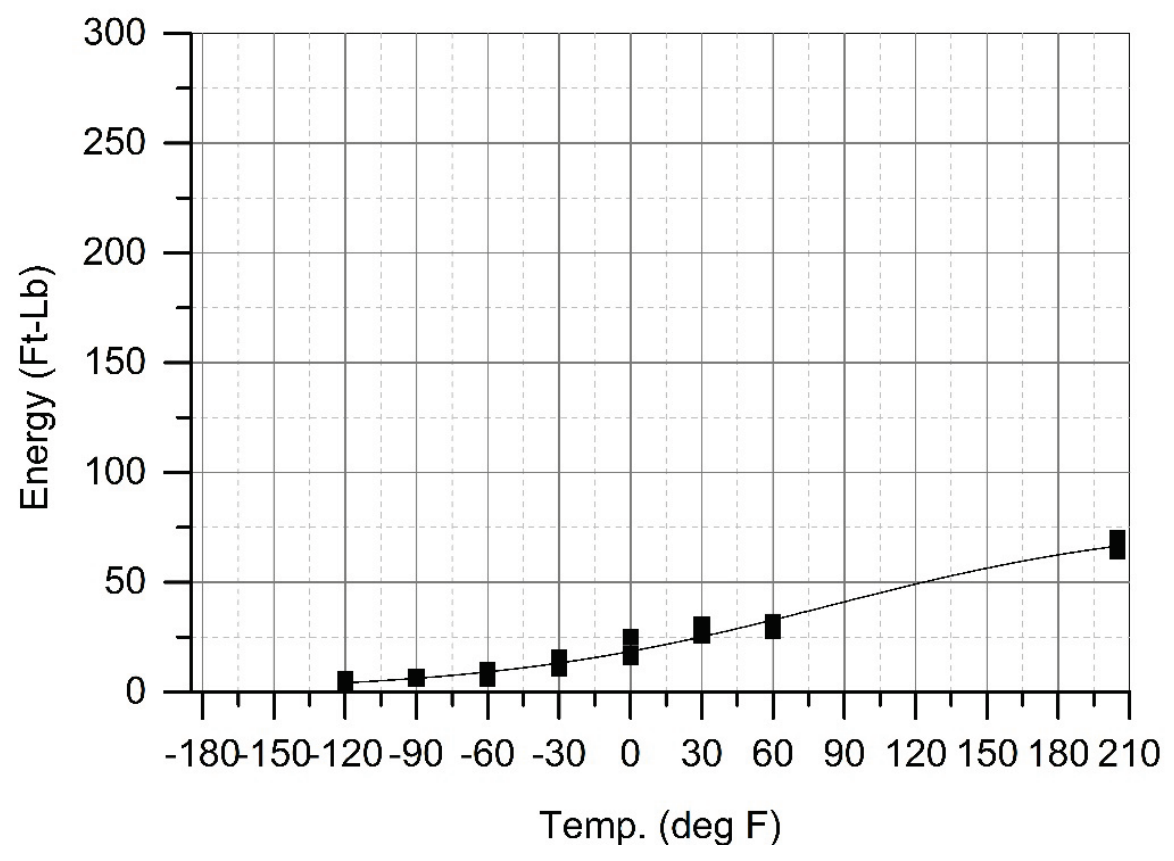

Figure D-33 CVN Data: Specimen 46-2 web plate

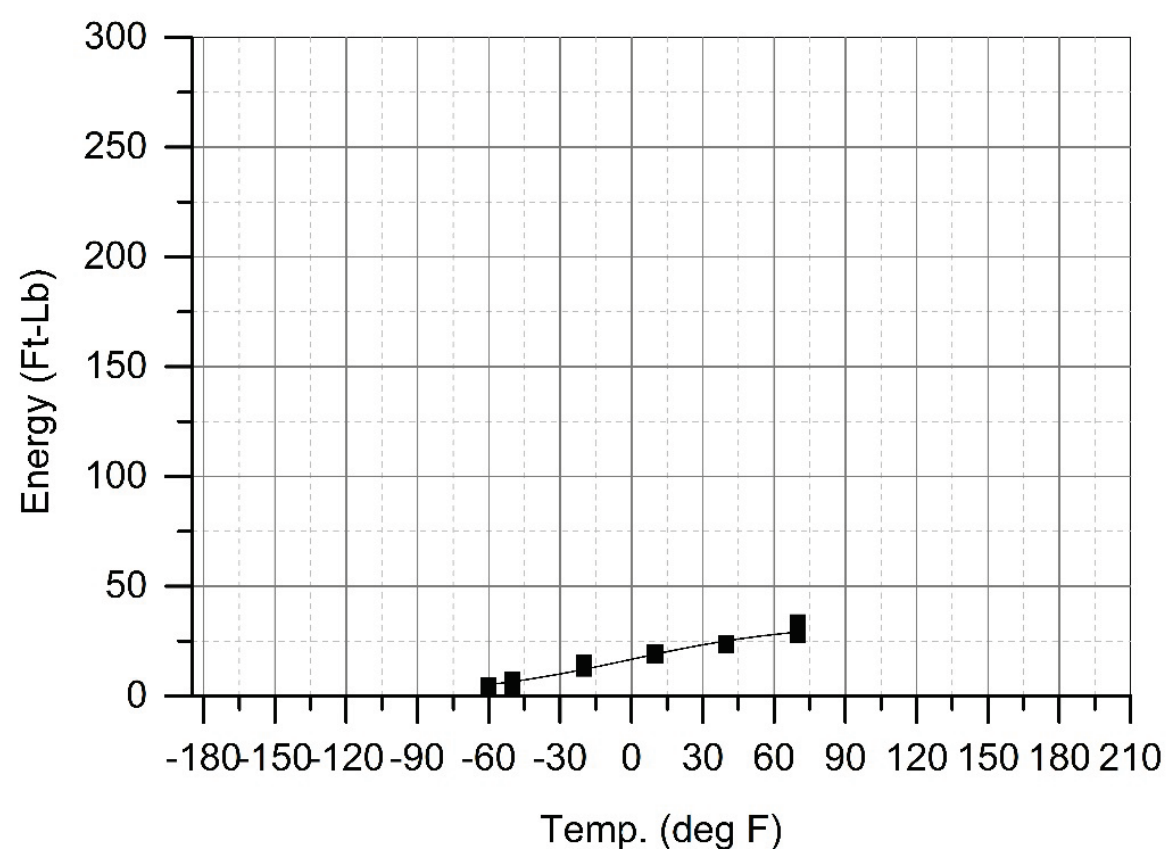

Figure D-34 CVN Data: Specimen 46-2 flange angles 


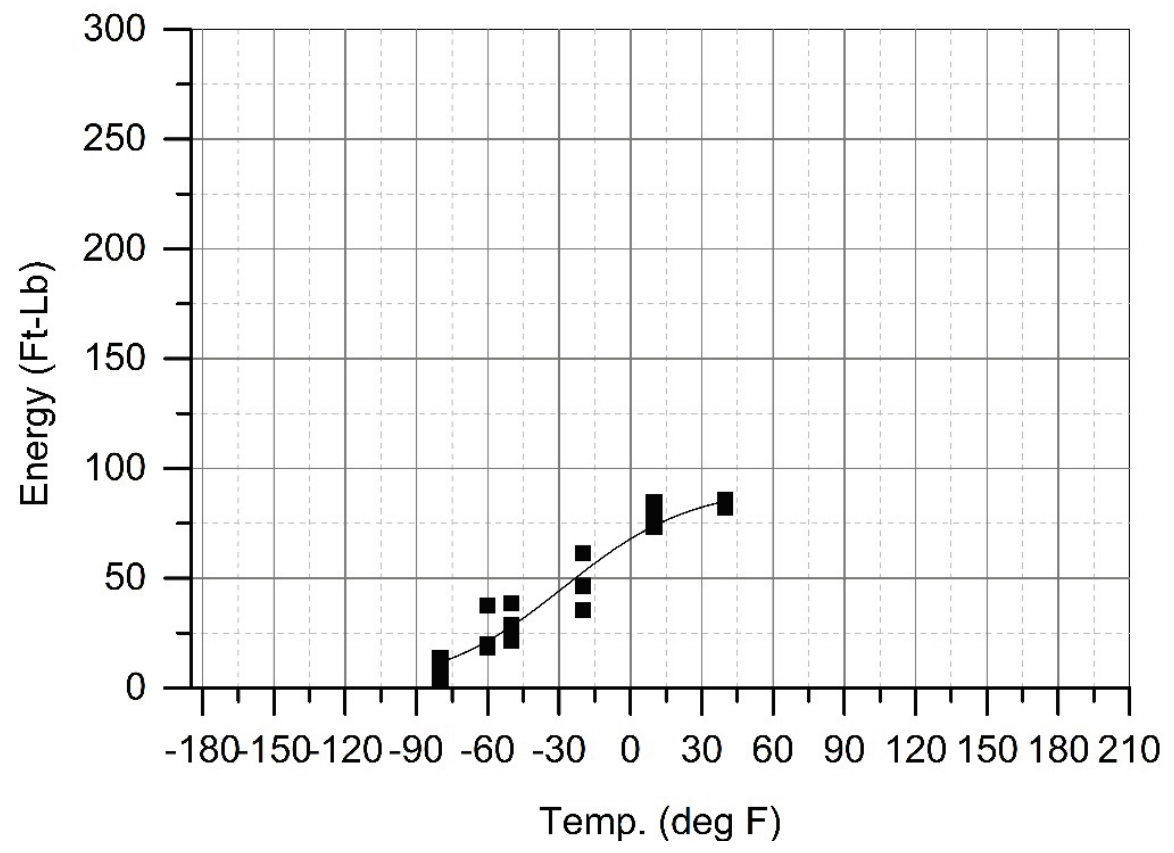

Figure D-35 CVN Data: Specimen 46-2 cover plate 


\section{Specimen 46-3}

Table D-31 Specimen 46-3 material properties

\begin{tabular}{|c|c|c|c|c|}
\hline \multicolumn{5}{|c|}{ Specimen 46-3 } \\
\hline \multicolumn{2}{|c|}{ Component } & Web Plate & Flange Angles & Cover Plate \\
\hline \multicolumn{2}{|l|}{ Shape } & Plate & Angle & Plate \\
\hline \multicolumn{2}{|c|}{ Dimensions } & $46 " x 0.5^{\prime \prime}$ & 6"x6"x0.75" & 14"x0.75" \\
\hline \multicolumn{2}{|c|}{ Length } & $40^{\prime}-0^{\prime \prime}$ & $40^{\prime}-0^{\prime \prime}$ & $23^{\prime}-0^{\prime \prime}$ \\
\hline \multicolumn{2}{|c|}{ Heat No. } & C6470 & 10735 & 2505978 \\
\hline \multicolumn{2}{|l|}{ Grade } & A709 Gr 50 & A709 Gr50 & A709 Gr 50 \\
\hline $\begin{array}{c}\text { Yield } \\
\text { Strength }\end{array}$ & ksi & 59.0 & 53.0 & 57.5 \\
\hline $\begin{array}{l}\text { Ultimate } \\
\text { Strength }\end{array}$ & $\mathrm{ksi}$ & 80.1 & 75.3 & 80.8 \\
\hline Elongation & $\%$ & 23.0 & 28.0 & 19.8 \\
\hline \multirow{16}{*}{$\begin{array}{l}\text { Chemical } \\
\text { Analysis }\end{array}$} & $\mathrm{Al}$ & 0.012 & & 0.031 \\
\hline & $\mathrm{B}$ & & & 0.0002 \\
\hline & $\mathrm{C}$ & 0.12 & 0.13 & 0.17 \\
\hline & $\mathrm{Cb}$ & 0.001 & & \\
\hline & $\mathrm{Co}$ & & 0.000 & \\
\hline & $\mathrm{Cr}$ & 0.53 & 0.13 & 0.09 \\
\hline & $\mathrm{Cu}$ & 0.28 & 0.36 & 0.27 \\
\hline & $\mathrm{Mn}$ & 0.98 & 0.99 & 1.19 \\
\hline & $\mathrm{Mo}$ & 0.05 & 0.045 & 0.02 \\
\hline & $\mathrm{Nb}$ & & & 0.001 \\
\hline & $\mathrm{Ni}$ & 0.14 & 0.13 & 0.1 \\
\hline & $\mathrm{P}$ & 0.007 & 0.019 & 0.010 \\
\hline & $\mathrm{S}$ & 0.002 & 0.04 & 0.001 \\
\hline & $\mathrm{Si}$ & 0.37 & 0.22 & 0.23 \\
\hline & $\mathrm{Sn}$ & & & 0.011 \\
\hline & $\mathrm{V}$ & 0.039 & 0.024 & 0.042 \\
\hline
\end{tabular}


Table D-32 Specimen 46-3 CVN data

\begin{tabular}{|c|c|c|c|c|c|c|}
\hline \multicolumn{7}{|c|}{ Specimen $46-3$} \\
\hline Component & \multicolumn{2}{|c|}{ Web Plate } & \multicolumn{2}{|c|}{ Flange Angles } & \multicolumn{2}{|c|}{ Cover Plate } \\
\hline Dimensions & \multicolumn{2}{|c|}{$46 " x 0.5^{\prime \prime}$} & \multicolumn{2}{|c|}{ 6"х6"х0.75" } & \multicolumn{2}{|c|}{ 14"x0.75" } \\
\hline Heat No. & \multicolumn{2}{|c|}{ C6470 } & \multicolumn{2}{|c|}{10735} & \multicolumn{2}{|c|}{2505978} \\
\hline Grade & \multicolumn{2}{|c|}{ A709 Gr 50} & \multicolumn{2}{|c|}{ A709 Gr50 } & \multicolumn{2}{|c|}{ A709 Gr 50} \\
\hline \multirow{25}{*}{$\mathrm{CVN}$} & ${ }^{\circ} \mathrm{F}$ & Energy & ${ }^{\circ} \mathrm{F}$ & Energy & ${ }^{\circ} \mathrm{F}$ & Energy \\
\hline & -120 & 4.00 & -60 & 3 & -120 & 5 \\
\hline & -120 & 6.00 & -60 & 3 & -120 & 2 \\
\hline & -120 & 4.00 & -60 & 2 & -120 & 3 \\
\hline & -90 & 7.00 & -30 & 4 & -90 & 6 \\
\hline & -90 & 6.00 & -30 & 6.5 & -90 & 6 \\
\hline & -90 & 6.00 & -30 & 8 & -90 & 7 \\
\hline & -60 & 10.00 & 0 & 30.5 & -60 & 18 \\
\hline & -60 & 6.00 & 0 & 29.5 & -60 & 10 \\
\hline & -60 & 6.00 & 0 & 24 & -60 & 8 \\
\hline & -30 & 11.00 & 30 & 34.5 & -30 & 34 \\
\hline & -30 & 10.50 & 30 & 21 & -30 & 10.5 \\
\hline & -30 & 15.50 & 30 & 47 & -30 & 67 \\
\hline & 0 & 16.00 & 60 & 50 & 0 & 70 \\
\hline & 0 & 25.00 & 60 & 40 & 0 & 17 \\
\hline & 0 & 17.50 & 60 & 48 & 0 & 63.5 \\
\hline & 30 & 25.50 & & & 30 & 74 \\
\hline & 30 & 30.50 & & & 30 & 85 \\
\hline & 30 & 30.00 & & & 30 & 92 \\
\hline & 60 & 28.00 & & & 60 & 109.5 \\
\hline & 60 & 32 & & & 60 & 100 \\
\hline & 60 & 30.5 & & & 60 & 95 \\
\hline & 205 & 64 & & & & \\
\hline & 205 & 70 & & & & \\
\hline & 205 & 66 & & & & \\
\hline
\end{tabular}




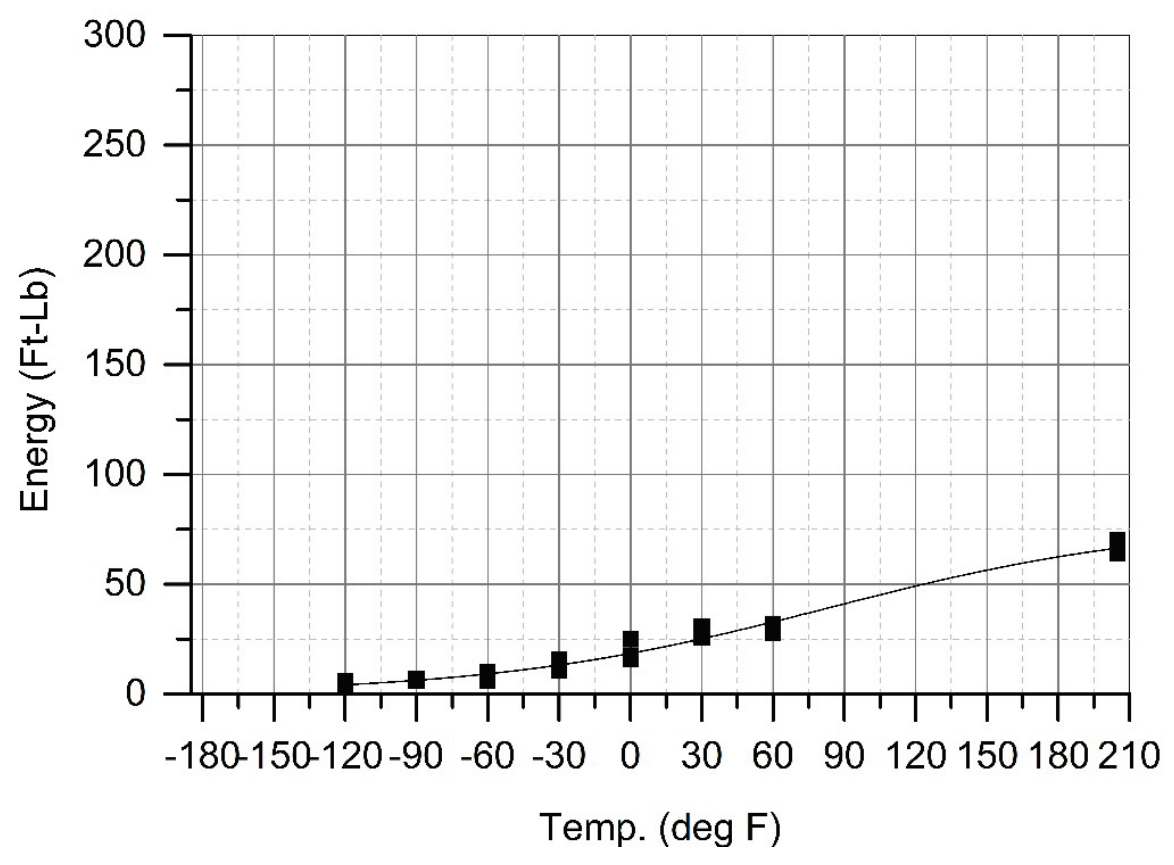

Figure D-36 CVN Data: Specimen 46-3 web plate

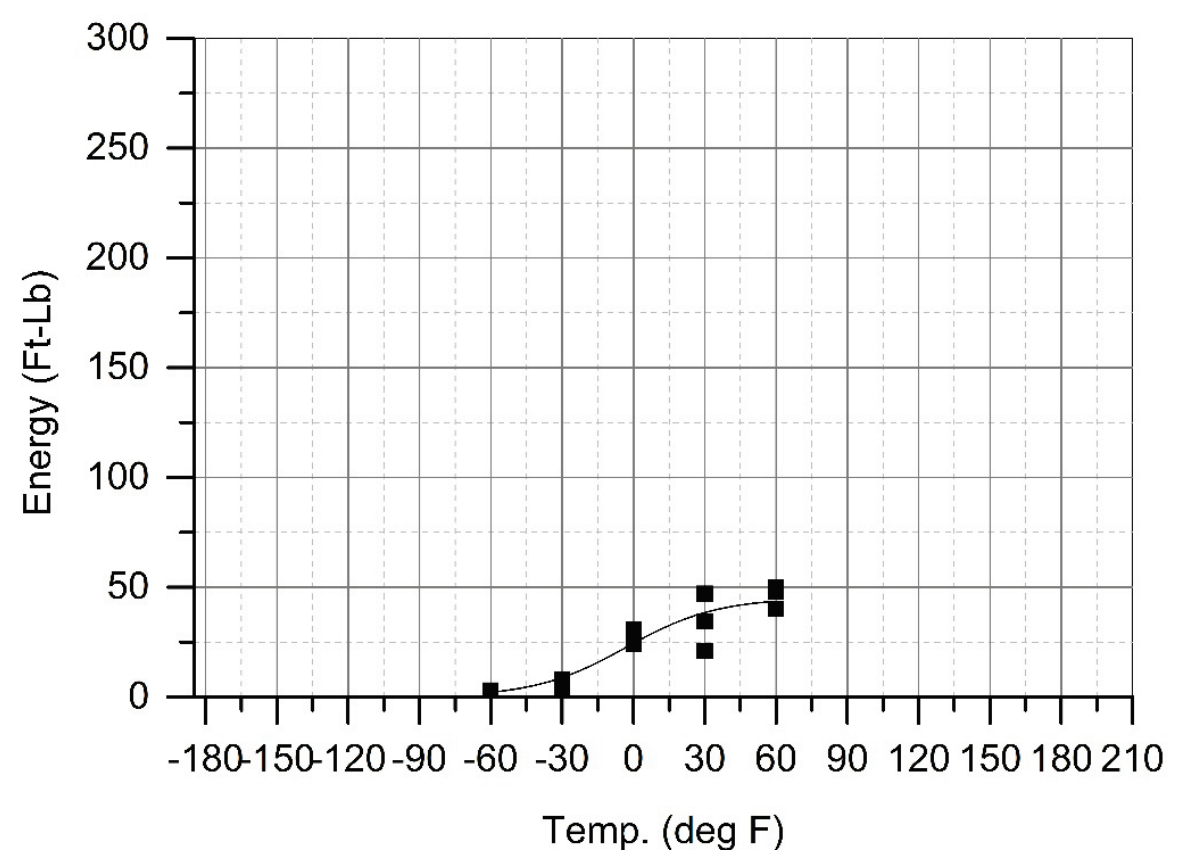

Figure D-37 CVN Data: Specimen 46-3 flange angles 


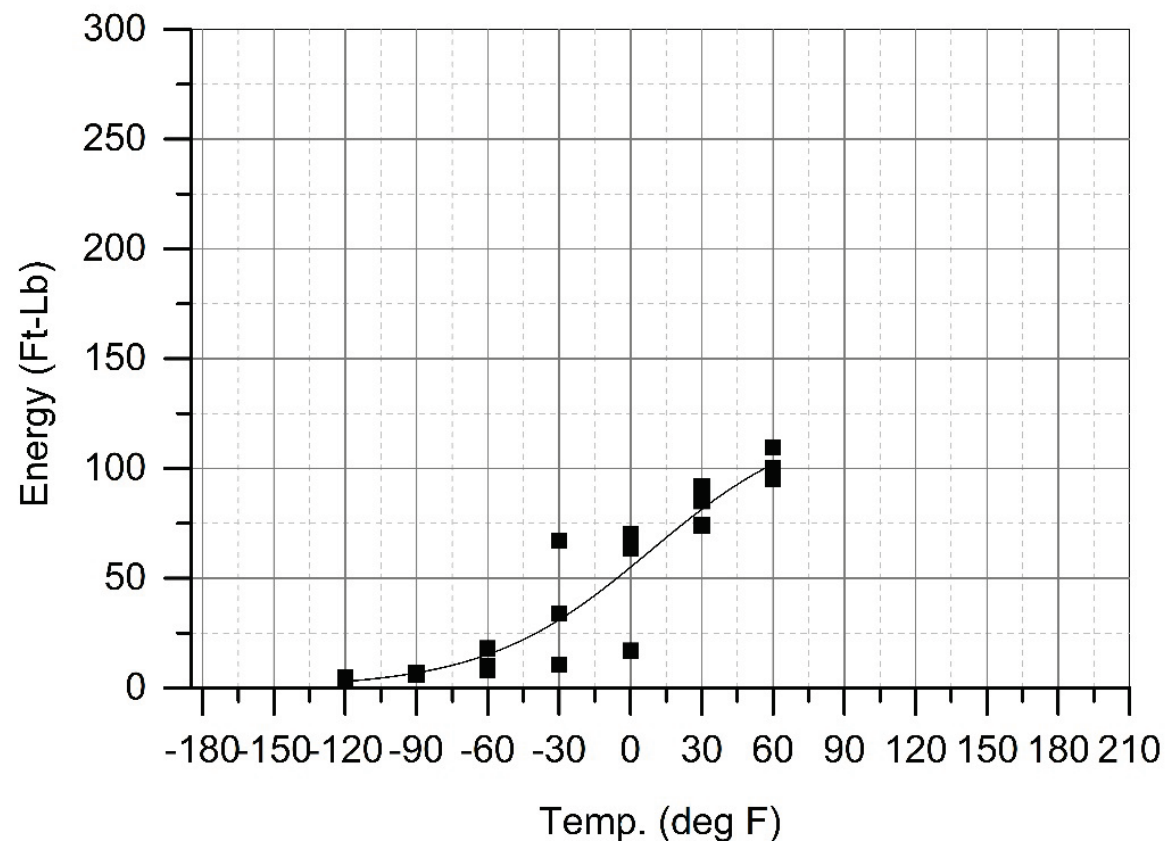

Figure D-38 CVN Data: Specimen 46-3 cover plate 


\section{Specimen 46-4}

Table D-33 Specimen 46-4 material properties

\begin{tabular}{|c|c|c|c|c|}
\hline \multicolumn{5}{|c|}{ Specimen $46-4$} \\
\hline \multicolumn{2}{|c|}{ Component } & Web Plate & Flange Angles & Cover Plate \\
\hline \multicolumn{2}{|l|}{ Shape } & Plate & Angle & Plate \\
\hline \multicolumn{2}{|c|}{ Dimensions } & $46 " \mathrm{x} 0.5^{\prime \prime}$ & 6"х6"х0.75" & $14 " \times 0.75 "$ \\
\hline \multicolumn{2}{|c|}{ Length } & $40^{\prime}-0^{\prime \prime}$ & $40^{\prime}-0^{\prime \prime}$ & $23^{\prime}-0^{\prime \prime}$ \\
\hline \multicolumn{2}{|c|}{ Heat No. } & C6470 & L91707 & $161 \mathrm{P} 72400$ \\
\hline \multicolumn{2}{|l|}{ Grade } & A709-Gr 50 & A588B & A709-05 Gr 50 \\
\hline $\begin{array}{c}\text { Yield } \\
\text { Strength }\end{array}$ & ksi & 59.0 & 57.8 & 56.6 \\
\hline $\begin{array}{l}\text { Ultimate } \\
\text { Strength }\end{array}$ & ksi & 80.1 & 75.5 & 80.9 \\
\hline Elongation & $\%$ & 23.0 & 26.0 & 23.0 \\
\hline \multirow{14}{*}{$\begin{array}{c}\text { Chemical } \\
\text { Analysis }\end{array}$} & $\mathrm{Al}$ & 0.012 & & 0.033 \\
\hline & $\mathrm{C}$ & 0.12 & 0.12 & 0.18 \\
\hline & $\mathrm{Cb}$ & 0.001 & 0 & 0.001 \\
\hline & $\mathrm{Cr}$ & 0.53 & 0.62 & 0.13 \\
\hline & $\mathrm{Cu}$ & 0.28 & 0.31 & 0.018 \\
\hline & $\mathrm{Mn}$ & 0.98 & 0.95 & 1.23 \\
\hline & Mo & 0.05 & 0.048 & 0.004 \\
\hline & $\mathrm{N}$ & & & 0.004 \\
\hline & $\mathrm{Ni}$ & 0.14 & 0.12 & 0.02 \\
\hline & $\mathrm{P}$ & 0.007 & 0.013 & 0.006 \\
\hline & $\mathrm{S}$ & 0.002 & 0.040 & 0.005 \\
\hline & $\mathrm{Si}$ & 0.37 & 0.18 & 0.273 \\
\hline & $\mathrm{Sn}$ & & 0.012 & \\
\hline & $\mathrm{V}$ & 0.039 & 0.044 & 0.055 \\
\hline
\end{tabular}


Table D-34 Specimen 46-4 CVN data

\begin{tabular}{|c|c|c|c|c|c|c|}
\hline \multicolumn{7}{|c|}{ Specimen $46-4$} \\
\hline Component & \multicolumn{2}{|c|}{ Web Plate } & \multicolumn{2}{|c|}{ Flange Angles } & \multicolumn{2}{|c|}{ Cover Plate } \\
\hline Dimensions & \multicolumn{2}{|c|}{$46 " x 0.5^{\prime \prime}$} & \multicolumn{2}{|c|}{ 6"х6"х0.75" } & \multicolumn{2}{|c|}{$14 " x 0.75 "$} \\
\hline Heat No. & \multicolumn{2}{|c|}{ C6470 } & \multicolumn{2}{|c|}{ L91707 } & \multicolumn{2}{|c|}{$161 P 72400$} \\
\hline Grade & \multicolumn{2}{|c|}{ A709-Gr 50} & \multicolumn{2}{|c|}{ A588B } & \multicolumn{2}{|c|}{ A709-05 Gr 50} \\
\hline \multirow{25}{*}{$\mathrm{CVN}$} & ${ }^{\circ} \mathrm{F}$ & $\overline{\text { Energy }}$ & ${ }^{\circ} \mathrm{F}$ & $\overline{\text { Energy }}$ & ${ }^{\circ} \mathrm{F}$ & Energy \\
\hline & -120 & 4.00 & -60 & 3.5 & -120 & 5 \\
\hline & -120 & 6.00 & -60 & 3 & -120 & 4 \\
\hline & -120 & 4.00 & -60 & 3 & -120 & 4 \\
\hline & -90 & 7.00 & -30 & 5.5 & -90 & 23 \\
\hline & -90 & 6.00 & -30 & 5 & -90 & 11 \\
\hline & -90 & 6.00 & -30 & 4.5 & -90 & 11 \\
\hline & -60 & 10.00 & 0 & 29 & -60 & 53 \\
\hline & -60 & 6.00 & 0 & 24.5 & -60 & 5 \\
\hline & -60 & 6.00 & 0 & 35 & -60 & 43 \\
\hline & -30 & 11.00 & 30 & 38 & -30 & 39 \\
\hline & -30 & 10.50 & 30 & 21 & -30 & 77.5 \\
\hline & -30 & 15.50 & 30 & 57.5 & -30 & 46 \\
\hline & 0 & 16.00 & 60 & 62 & 0 & 85 \\
\hline & 0 & 25.00 & 60 & 58.5 & 0 & 45 \\
\hline & 0 & 17.50 & 60 & 62 & 0 & 91.5 \\
\hline & 30 & 25.50 & 205 & 90 & 30 & 100 \\
\hline & 30 & 30.50 & 205 & 88.5 & 30 & 94 \\
\hline & 30 & 30.00 & 205 & 97 & 30 & 112 \\
\hline & 60 & 28.00 & & & 60 & 126 \\
\hline & 60 & 32 & & & 60 & 120 \\
\hline & 60 & 30.5 & & & 60 & 134.5 \\
\hline & 205 & 64 & & & & \\
\hline & 205 & 70 & & & & \\
\hline & 205 & 66 & & & & \\
\hline
\end{tabular}




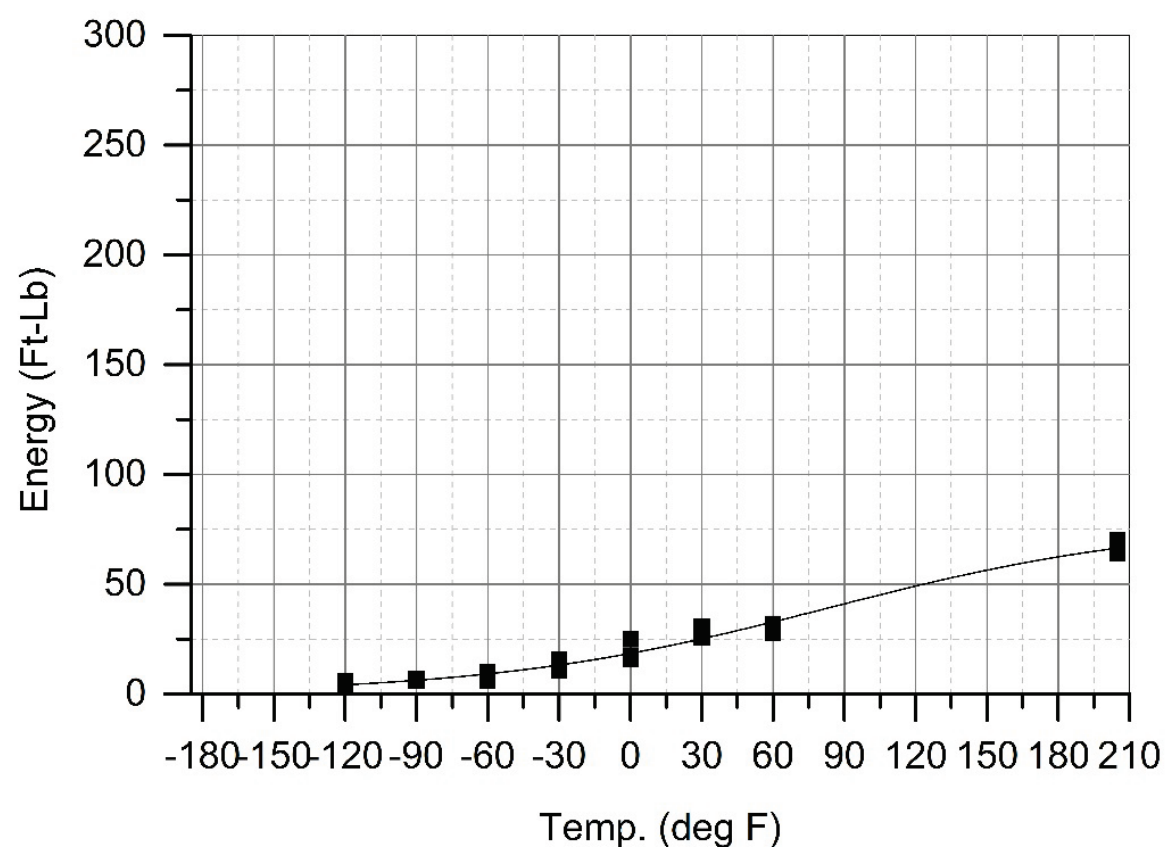

Figure D-39 CVN Data: Specimen 46-4 web plate

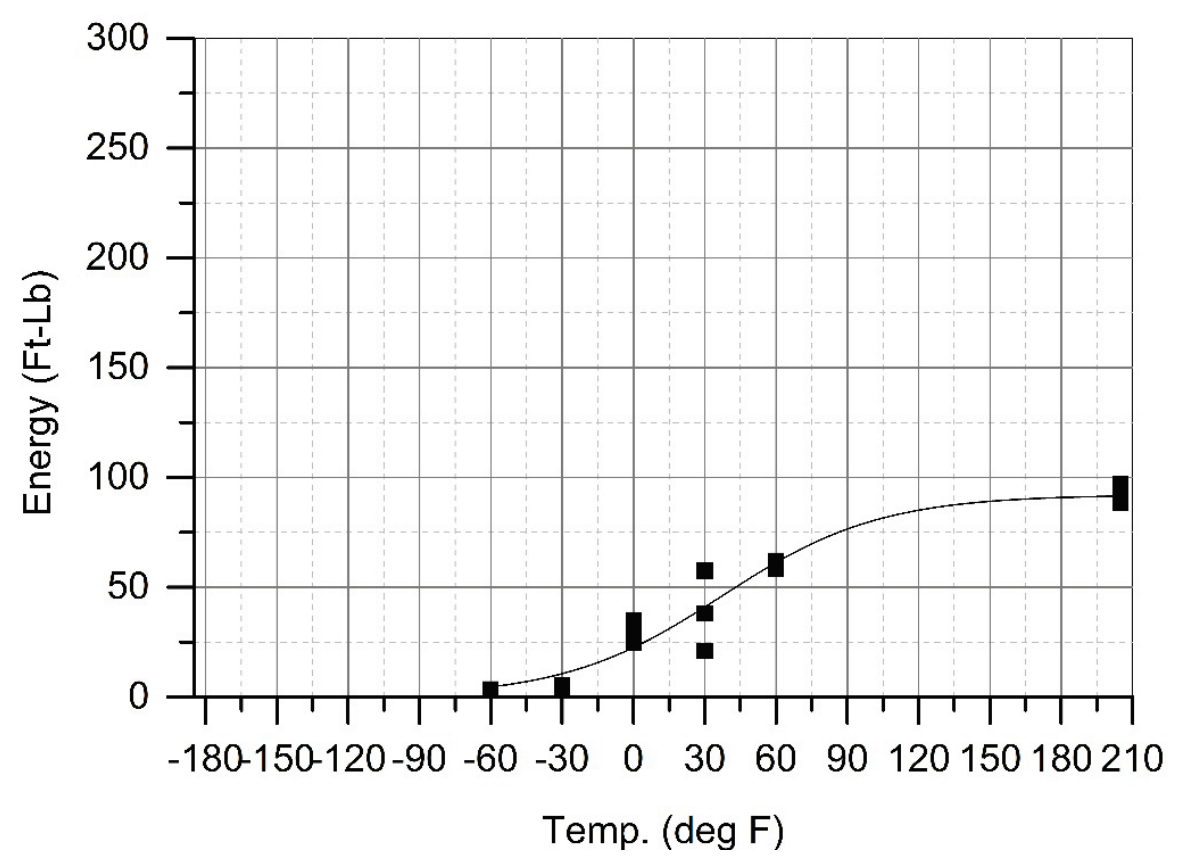

Figure D-40 CVN Data: Specimen 46-4 flange angles 


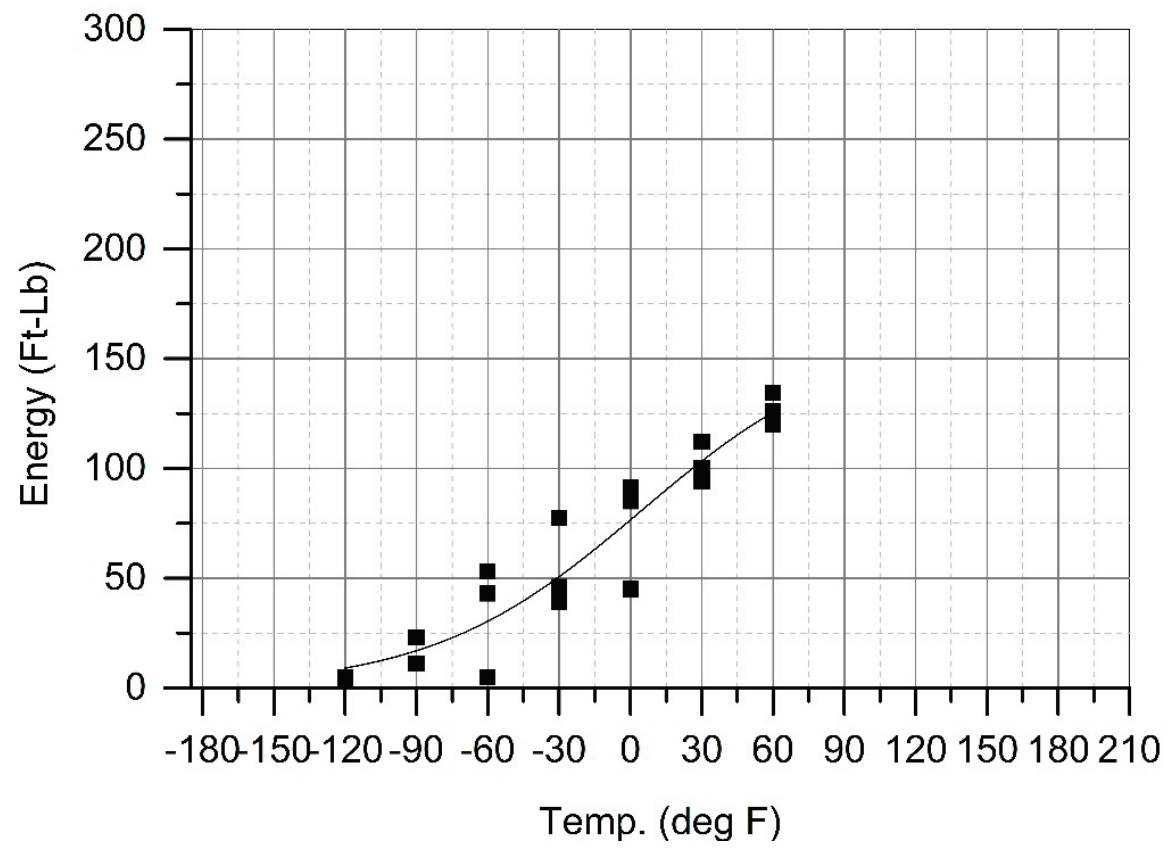

Figure D-41 CVN Data: Specimen 46-4 cover plate 


\section{Specimen 46-5}

Table D-35 Specimen 46-5 material properties

\begin{tabular}{|c|c|c|c|c|}
\hline \multicolumn{5}{|c|}{ Specimen 46-5 } \\
\hline \multicolumn{2}{|c|}{ Component } & Web Plate & Flange Angles & Cover Plate \\
\hline \multicolumn{2}{|l|}{ Shape } & Plate & Angle & Plate \\
\hline \multicolumn{2}{|c|}{ Dimensions } & $46 " x 0.5^{\prime \prime}$ & 6"x6"x0.75" & $14 " x 0.75 "$ \\
\hline \multicolumn{2}{|c|}{ Length } & $40^{\prime}-0^{\prime \prime}$ & $40^{\prime}-0 "$ & $23^{\prime}-0^{\prime \prime}$ \\
\hline \multicolumn{2}{|c|}{ Heat No. } & C6470 & L91707 & $161 \mathrm{P} 72400$ \\
\hline \multicolumn{2}{|l|}{ Grade } & A709-Gr 50 & A588B & A709-05 Gr 50 \\
\hline $\begin{array}{c}\text { Yield } \\
\text { Strength }\end{array}$ & ksi & 59.0 & 57.8 & 56.6 \\
\hline $\begin{array}{l}\text { Ultimate } \\
\text { Strength }\end{array}$ & ksi & 80.1 & 75.5 & 80.9 \\
\hline Elongation & $\%$ & 23.0 & 26.0 & 23.0 \\
\hline \multirow{14}{*}{$\begin{array}{l}\text { Chemical } \\
\text { Analysis }\end{array}$} & $\mathrm{Al}$ & 0.012 & & 0.033 \\
\hline & $\mathrm{C}$ & 0.12 & 0.12 & 0.18 \\
\hline & $\mathrm{Cb}$ & 0.001 & 0 & 0.001 \\
\hline & $\mathrm{Cr}$ & 0.53 & 0.62 & 0.13 \\
\hline & $\mathrm{Cu}$ & 0.28 & 0.31 & 0.018 \\
\hline & $\mathrm{Mn}$ & 0.98 & 0.95 & 1.23 \\
\hline & Mo & 0.05 & 0.048 & 0.004 \\
\hline & $\mathrm{N}$ & & & 0.004 \\
\hline & $\mathrm{Ni}$ & 0.14 & 0.12 & 0.02 \\
\hline & $\mathrm{P}$ & 0.007 & 0.013 & 0.006 \\
\hline & $\mathrm{S}$ & 0.002 & 0.040 & 0.005 \\
\hline & $\mathrm{Si}$ & 0.37 & 0.18 & 0.273 \\
\hline & $\mathrm{Sn}$ & & 0.012 & \\
\hline & $\mathrm{V}$ & 0.039 & 0.044 & 0.055 \\
\hline
\end{tabular}


Table D-36 Specimen 46-5 CVN data

\begin{tabular}{|c|c|c|c|c|c|c|}
\hline \multicolumn{7}{|c|}{ Specimen $46-5$} \\
\hline Component & \multicolumn{2}{|c|}{ Web Plate } & \multicolumn{2}{|c|}{ Flange Angles } & \multicolumn{2}{|c|}{ Cover Plate } \\
\hline Dimensions & \multicolumn{2}{|c|}{$46 " \mathrm{x} 0.5^{\prime \prime}$} & \multicolumn{2}{|c|}{ 6"х6"х0.75" } & \multicolumn{2}{|c|}{$14 " x 0.75 "$} \\
\hline Heat No. & \multicolumn{2}{|c|}{ C6470 } & \multicolumn{2}{|c|}{ L91707 } & \multicolumn{2}{|c|}{$161 P 72400$} \\
\hline Grade & \multicolumn{2}{|c|}{ A709-Gr 50} & \multicolumn{2}{|c|}{ A588B } & \multicolumn{2}{|c|}{ A $709-05$ Gr 50} \\
\hline \multirow{25}{*}{ CVN } & ${ }^{\circ} \mathrm{F}$ & Energy & ${ }^{\circ} \mathrm{F}$ & Energy & ${ }^{\circ} \mathrm{F}$ & Energy \\
\hline & -120 & 4.00 & -60 & 3.5 & -120 & 5 \\
\hline & -120 & 6.00 & -60 & 3 & -120 & 4 \\
\hline & -120 & 4.00 & -60 & 3 & -120 & 4 \\
\hline & -90 & 7.00 & -30 & 5.5 & -90 & 23 \\
\hline & -90 & 6.00 & -30 & 5 & -90 & 11 \\
\hline & -90 & 6.00 & -30 & 4.5 & -90 & 11 \\
\hline & -60 & 10.00 & 0 & 29 & -60 & 53 \\
\hline & -60 & 6.00 & 0 & 24.5 & -60 & 5 \\
\hline & -60 & 6.00 & 0 & 35 & -60 & 43 \\
\hline & -30 & 11.00 & 30 & 38 & -30 & 39 \\
\hline & -30 & 10.50 & 30 & 21 & -30 & 77.5 \\
\hline & -30 & 15.50 & 30 & 57.5 & -30 & 46 \\
\hline & 0 & 16.00 & 60 & 62 & 0 & 85 \\
\hline & 0 & 25.00 & 60 & 58.5 & 0 & 45 \\
\hline & 0 & 17.50 & 60 & 62 & 0 & 91.5 \\
\hline & 30 & 25.50 & 205 & 90 & 30 & 100 \\
\hline & 30 & 30.50 & 205 & 88.5 & 30 & 94 \\
\hline & 30 & 30.00 & 205 & 97 & 30 & 112 \\
\hline & 60 & 28.00 & & & 60 & 126 \\
\hline & 60 & 32 & & & 60 & 120 \\
\hline & 60 & 30.5 & & & 60 & 134.5 \\
\hline & 205 & 64 & & & & \\
\hline & 205 & 70 & & & & \\
\hline & 205 & 66 & & & & \\
\hline
\end{tabular}




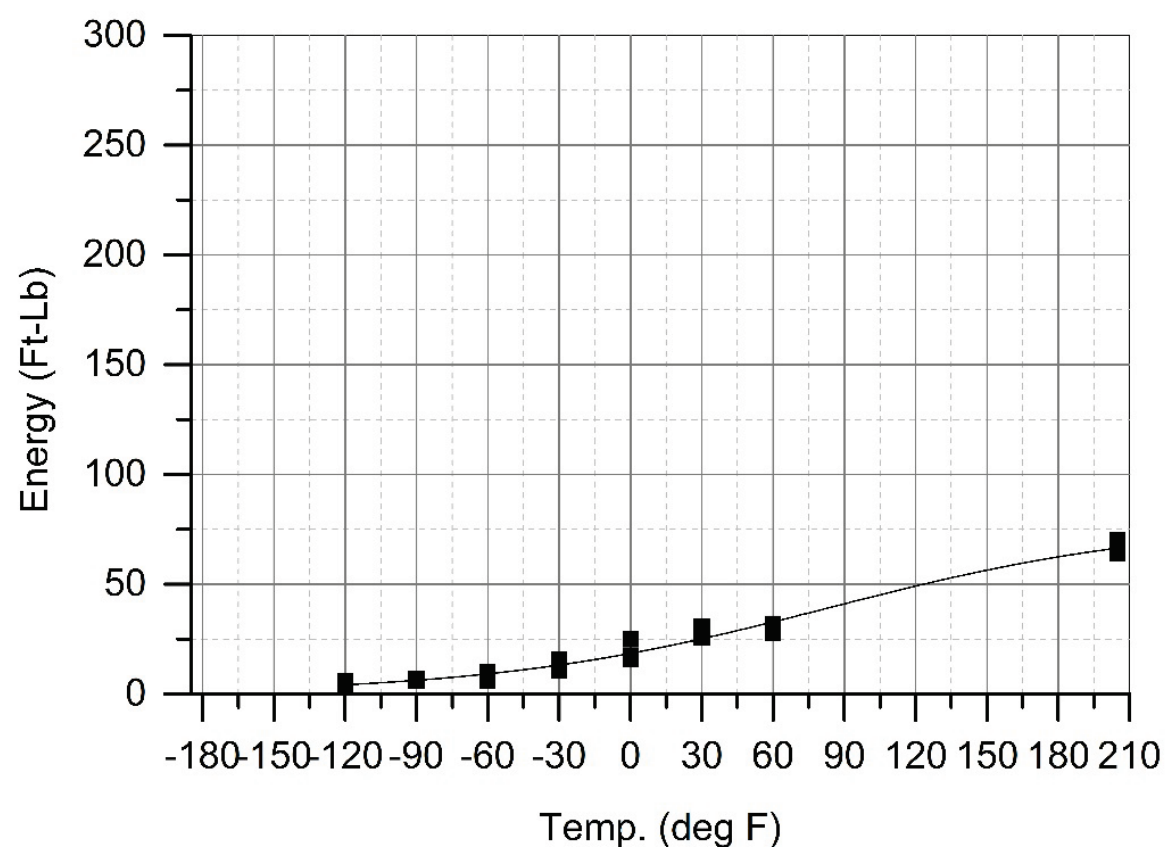

Figure D-42 CVN Data: Specimen 46-5 web plate

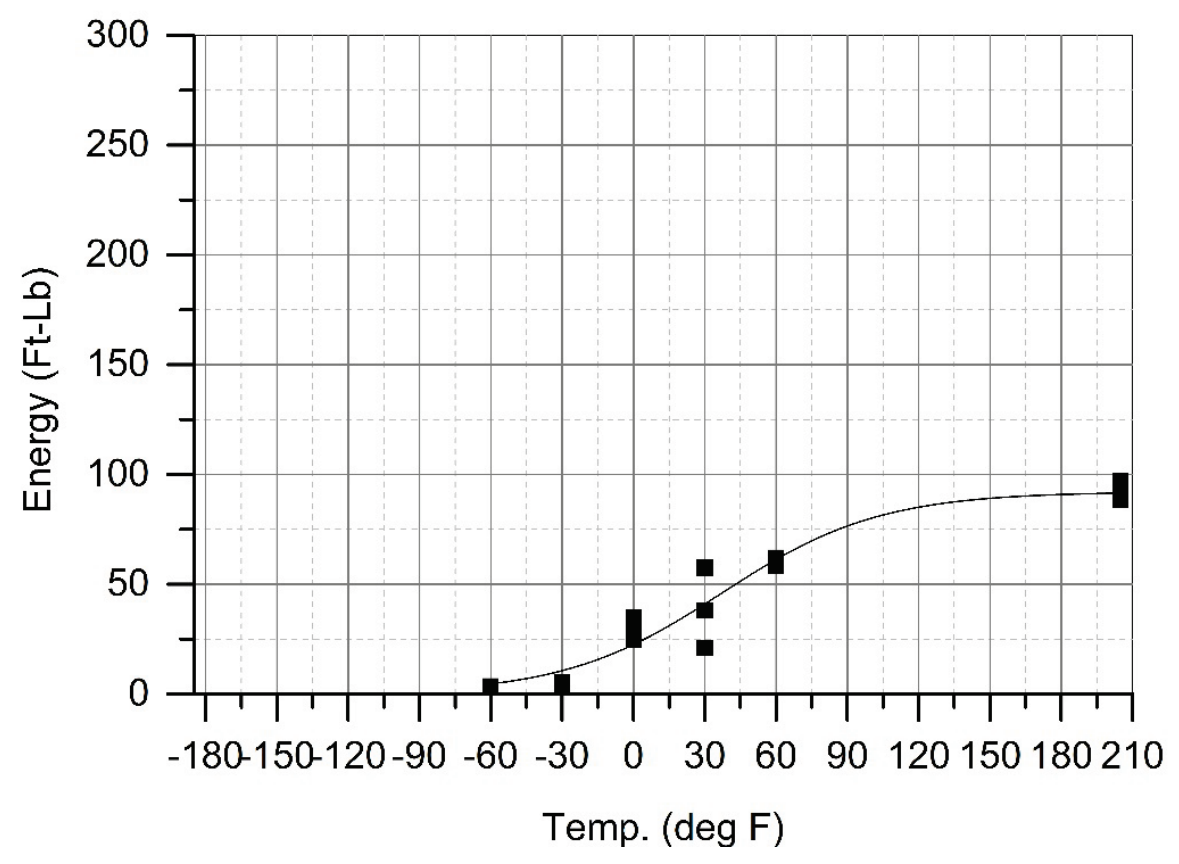

Figure D-43 CVN Data: Specimen 46-5 flange angles 


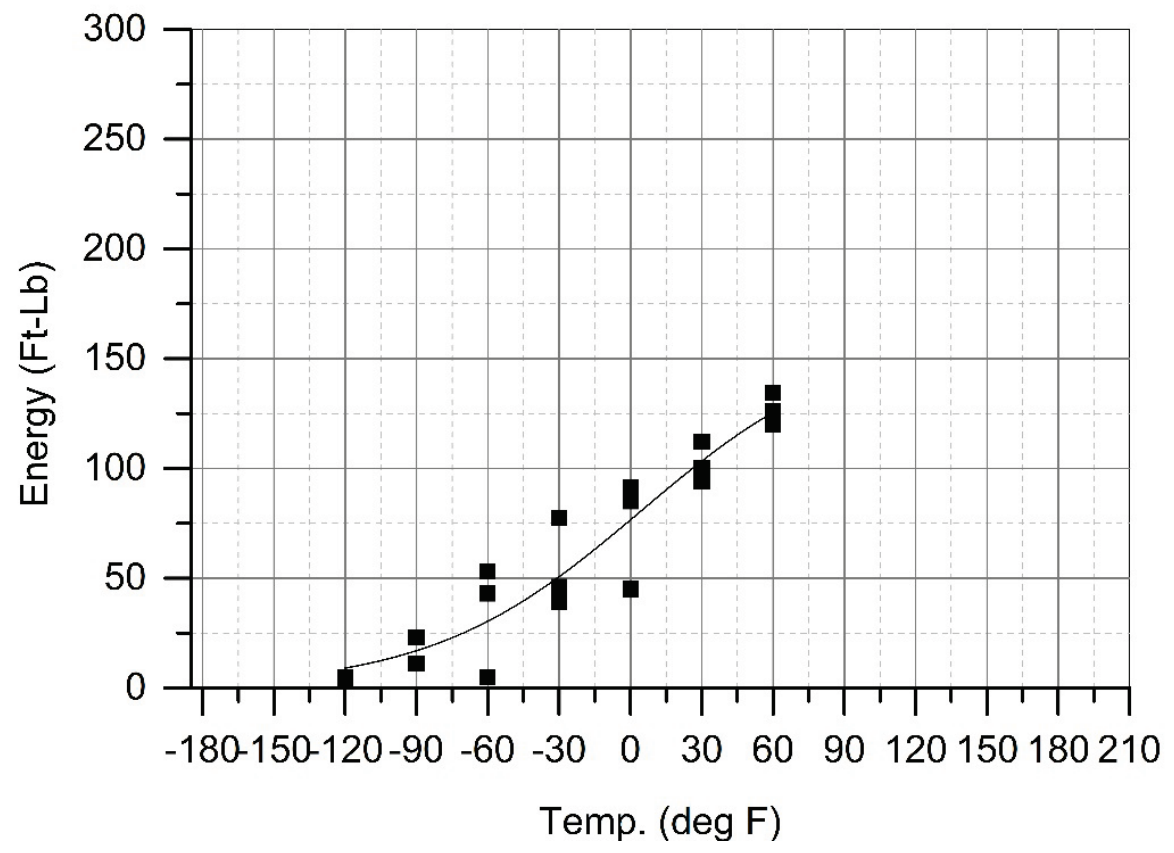

Figure D-44 CVN Data: Specimen 46-5 cover plate 


\section{APPENDIX E STRAIN GAGE DRAWINGS}




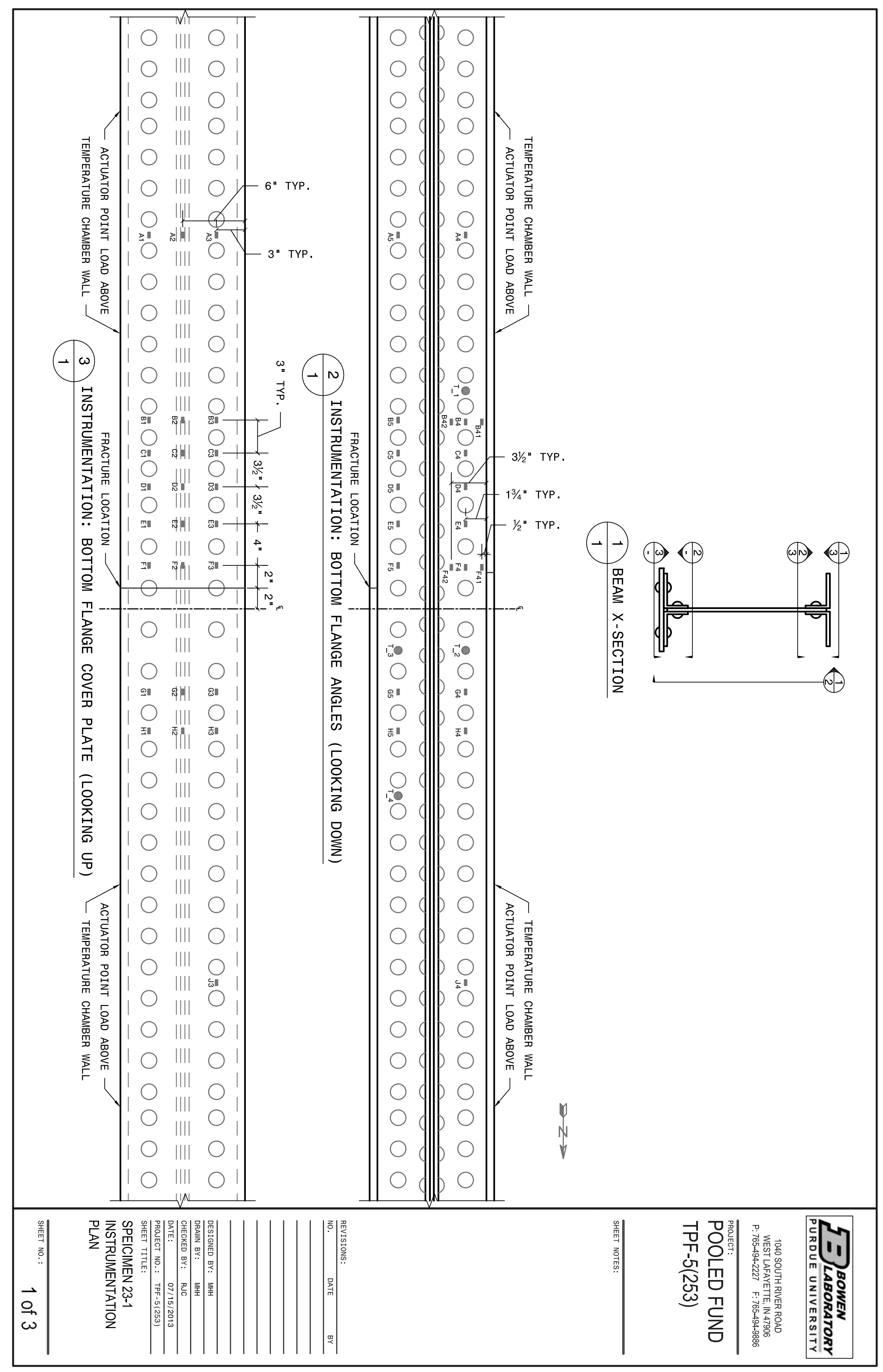



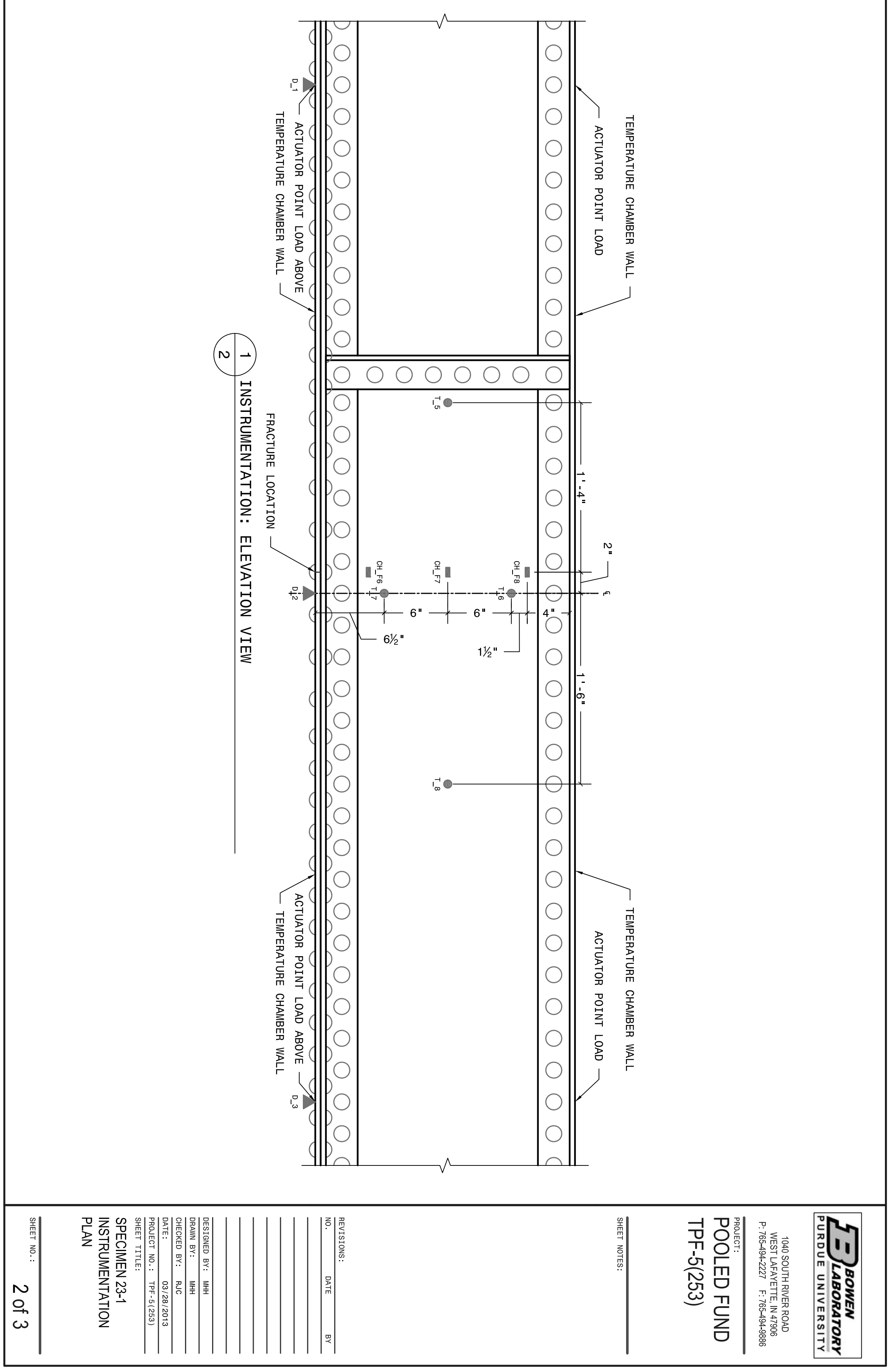


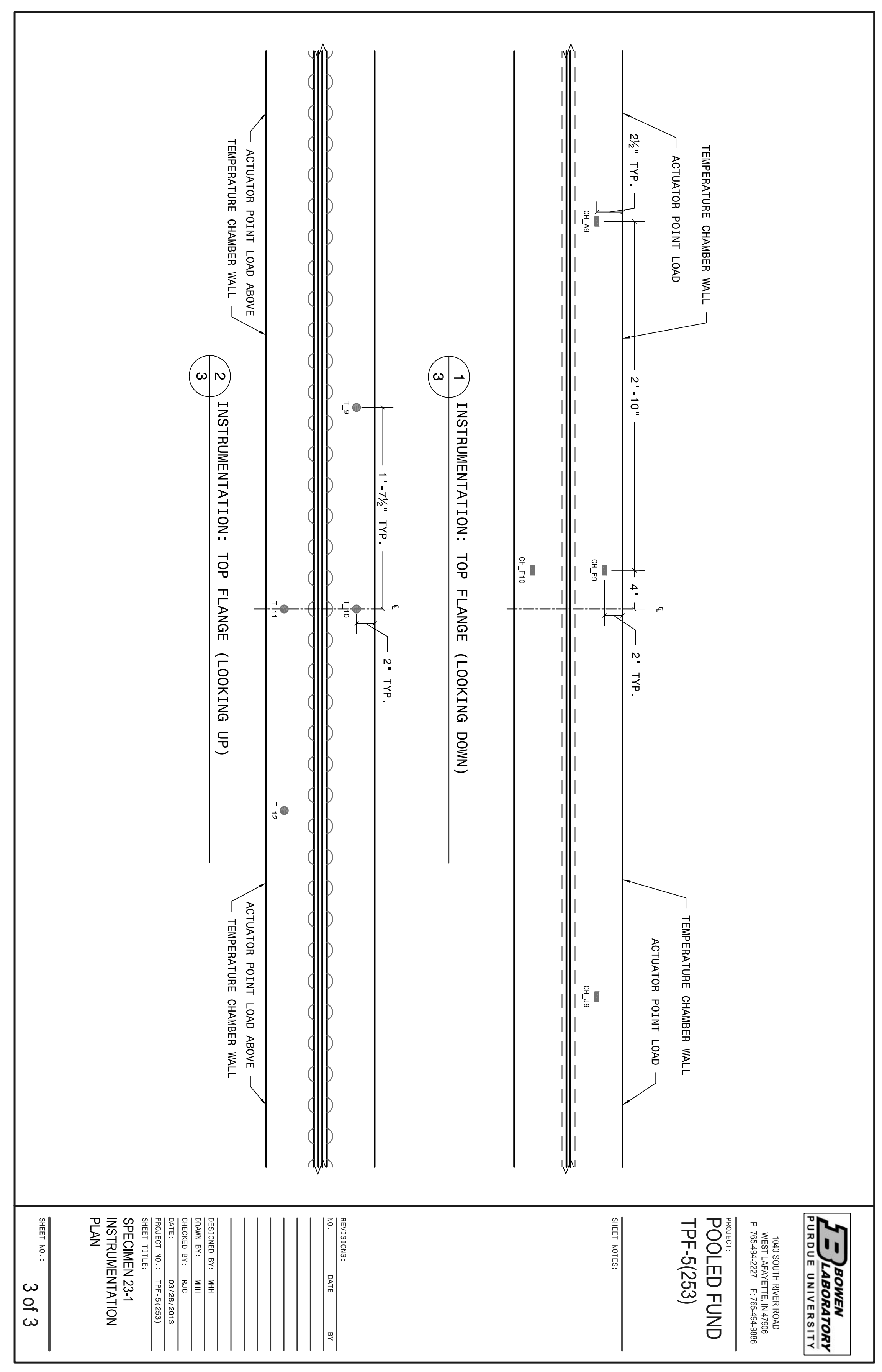




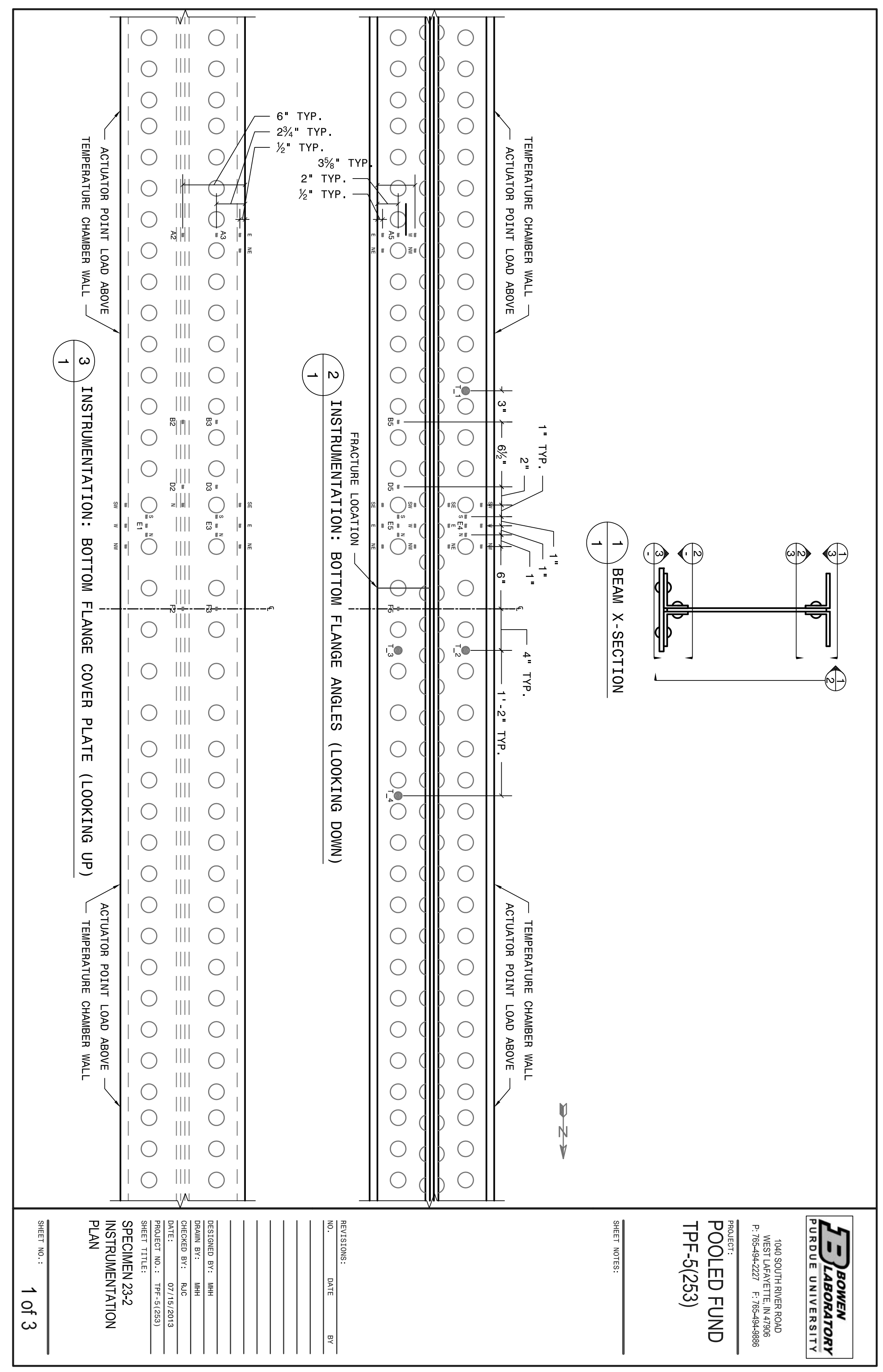



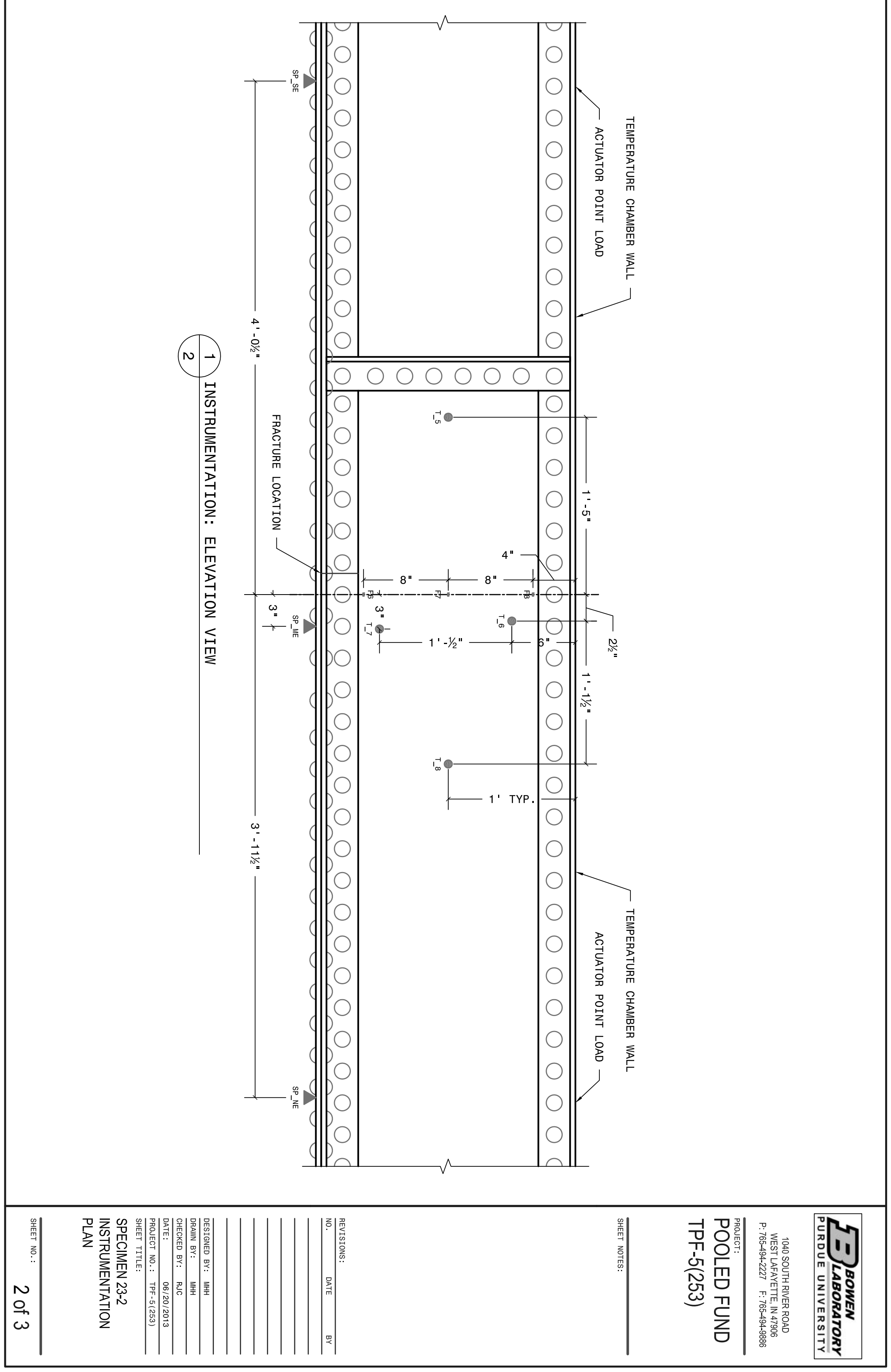


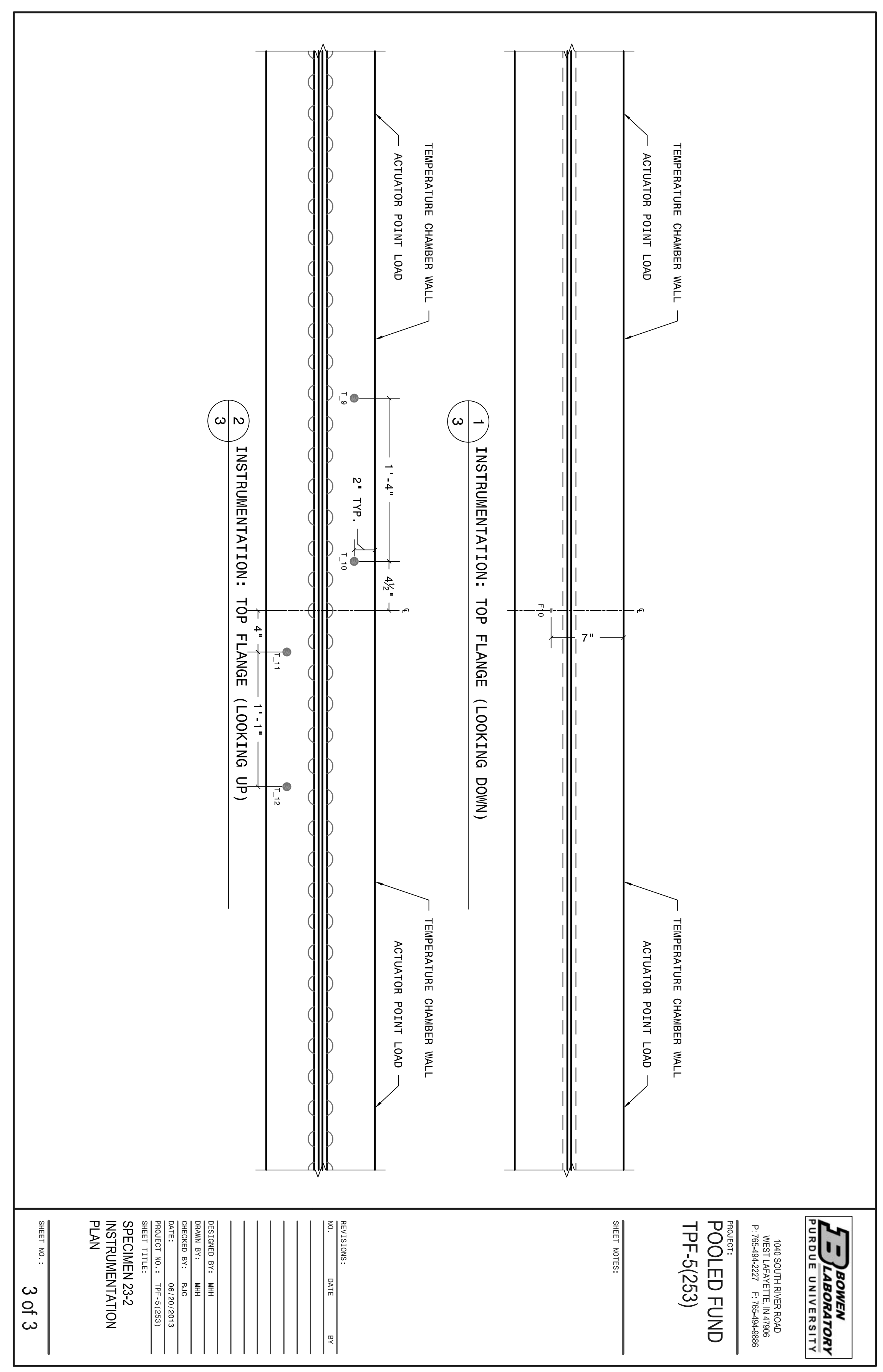




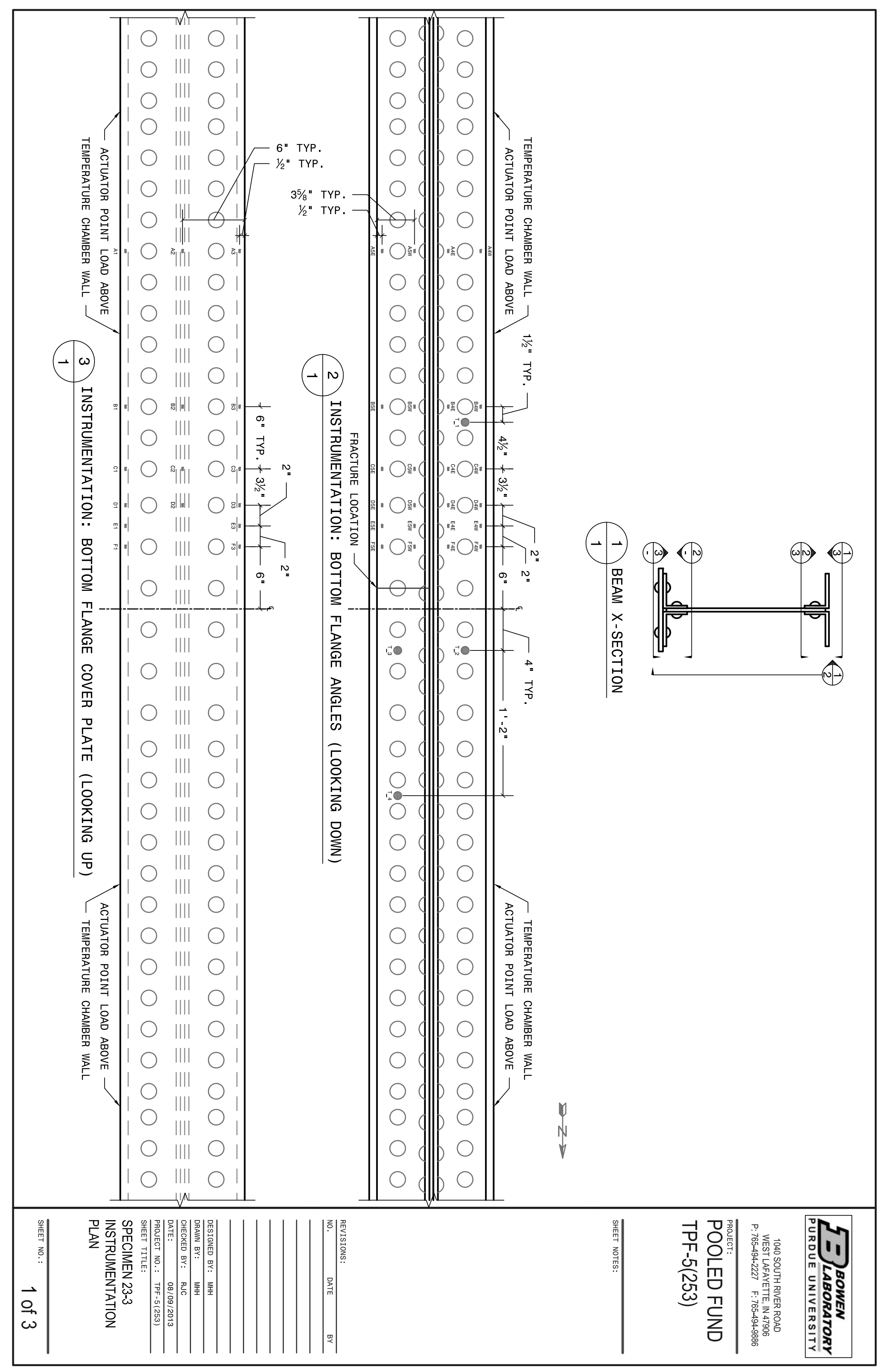



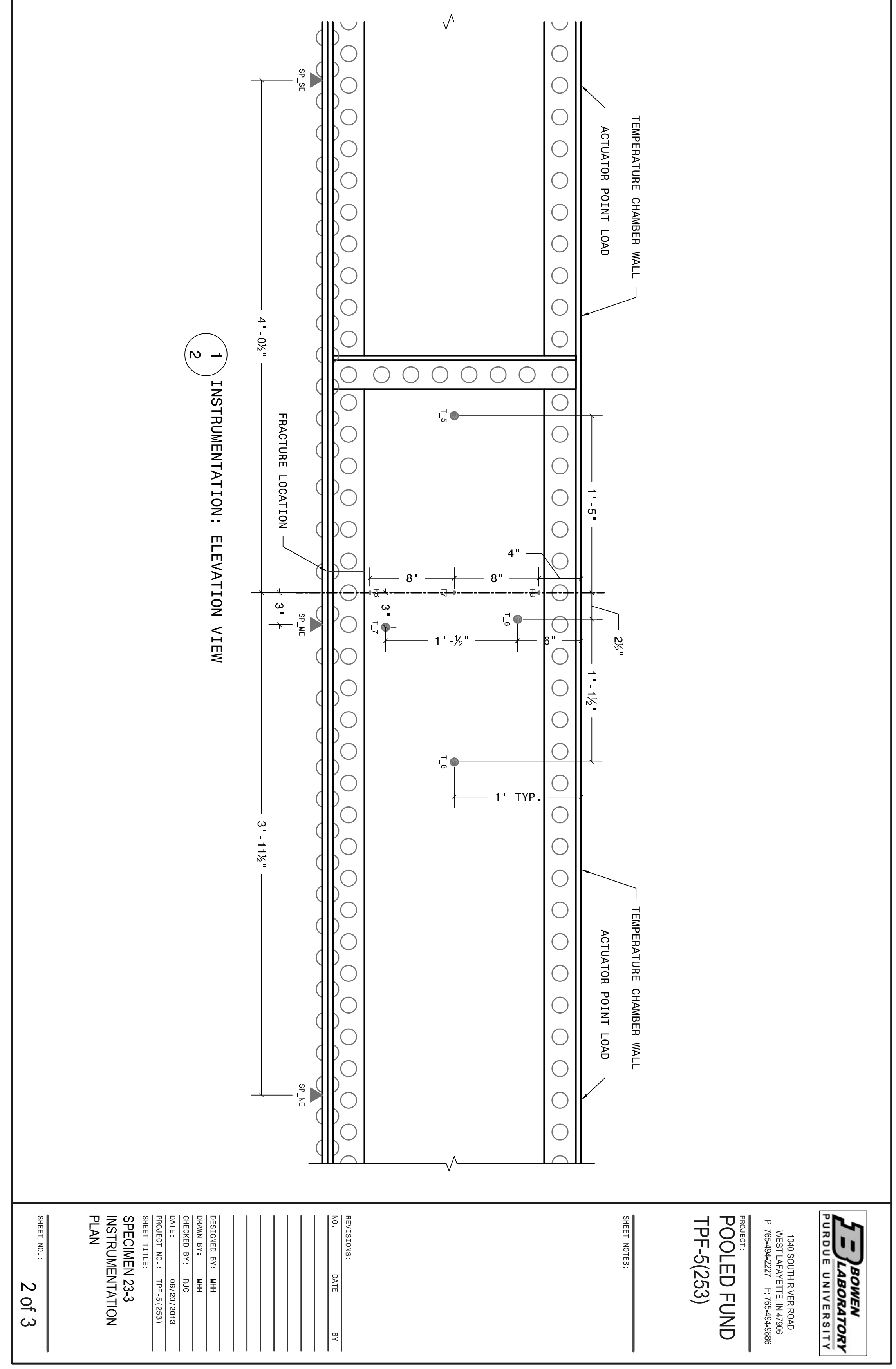


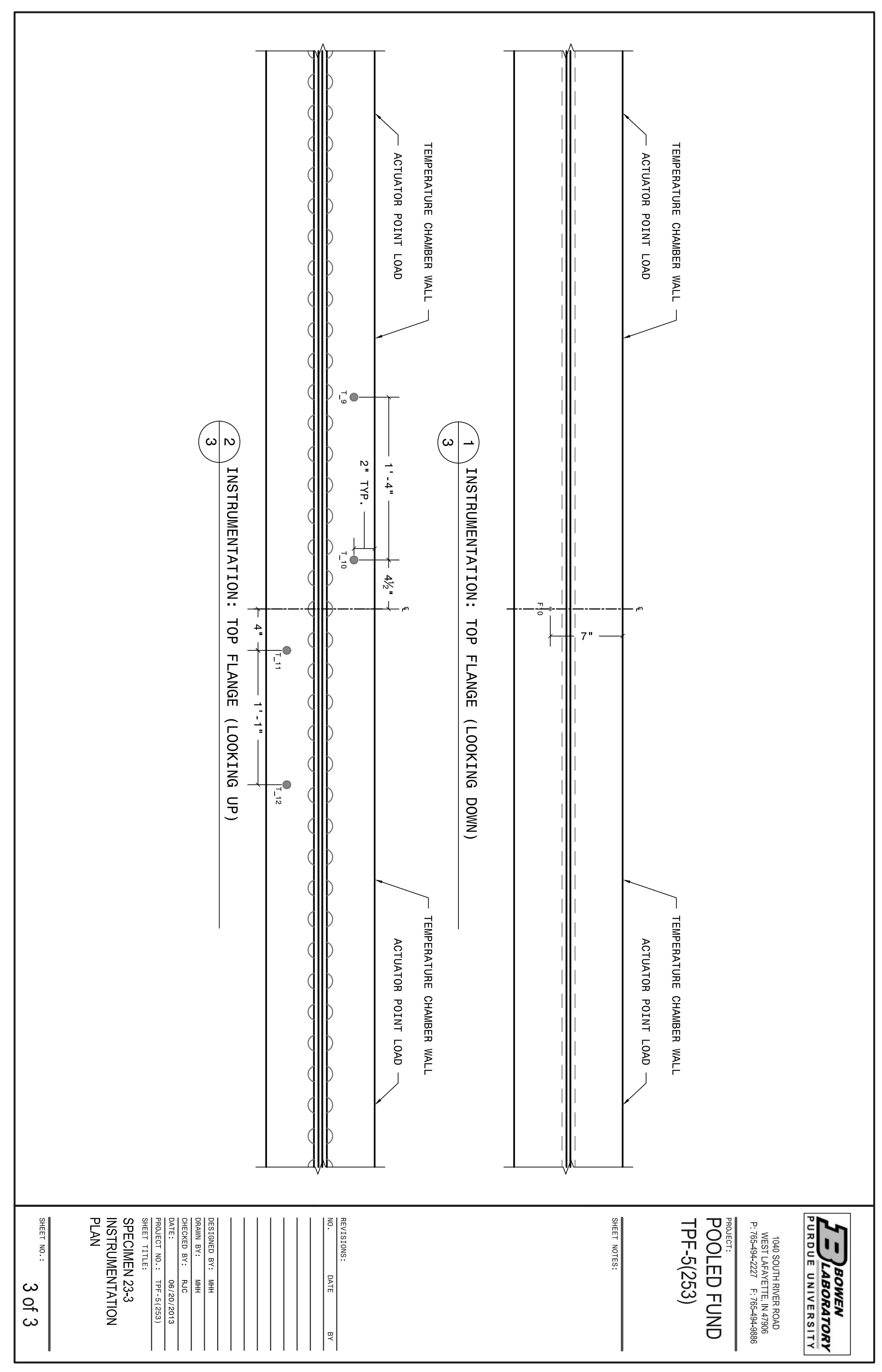




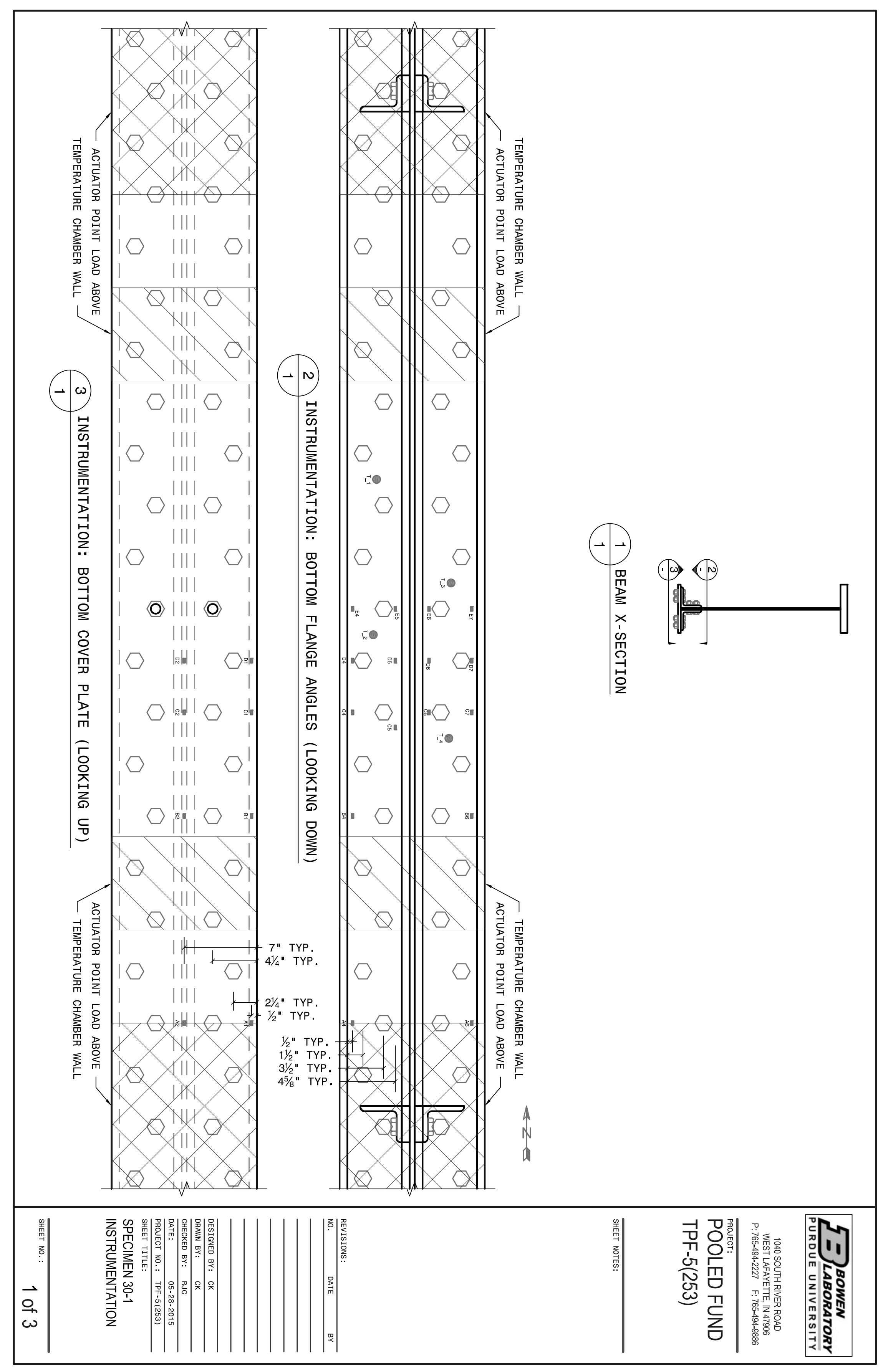




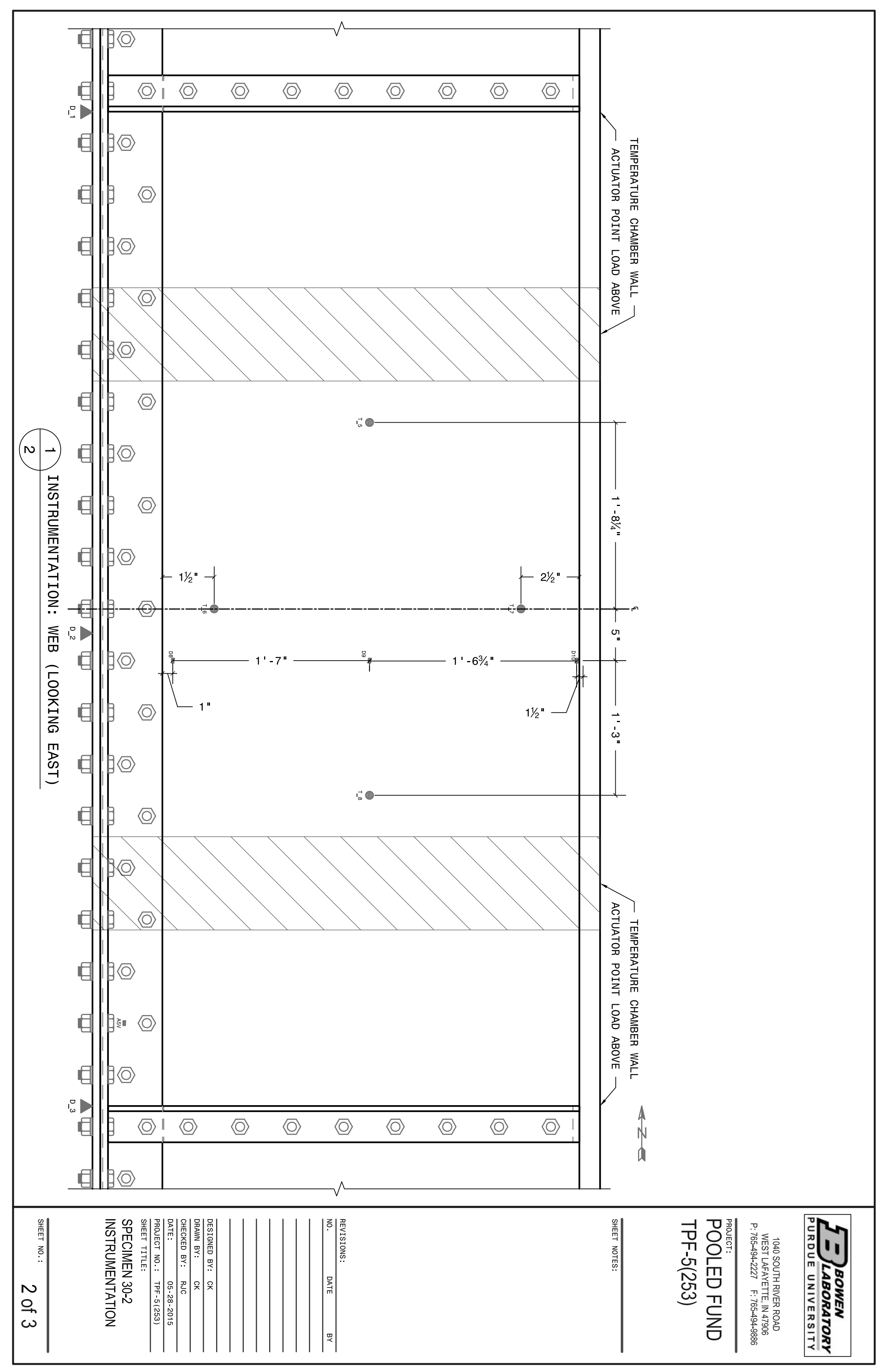




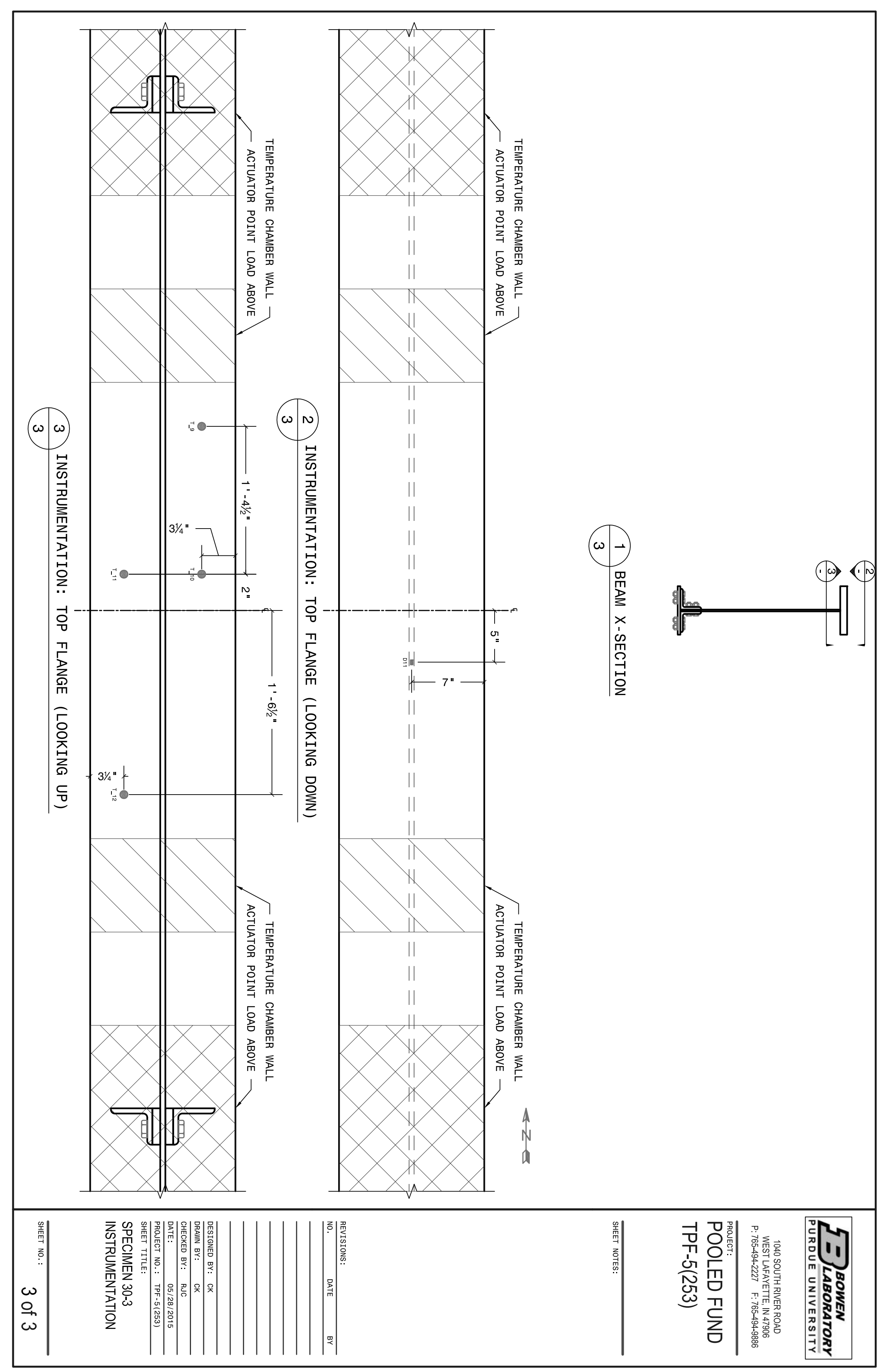




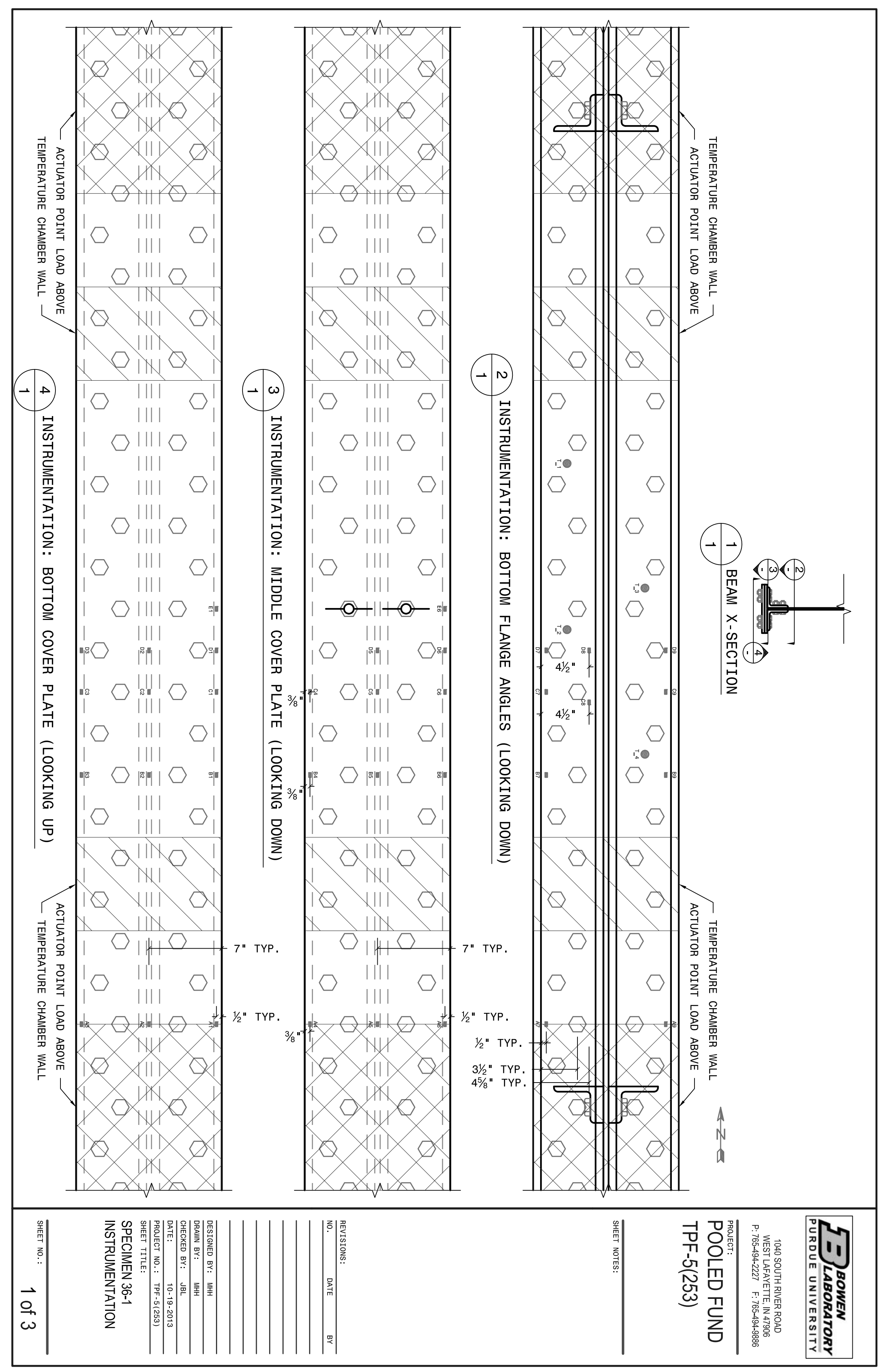




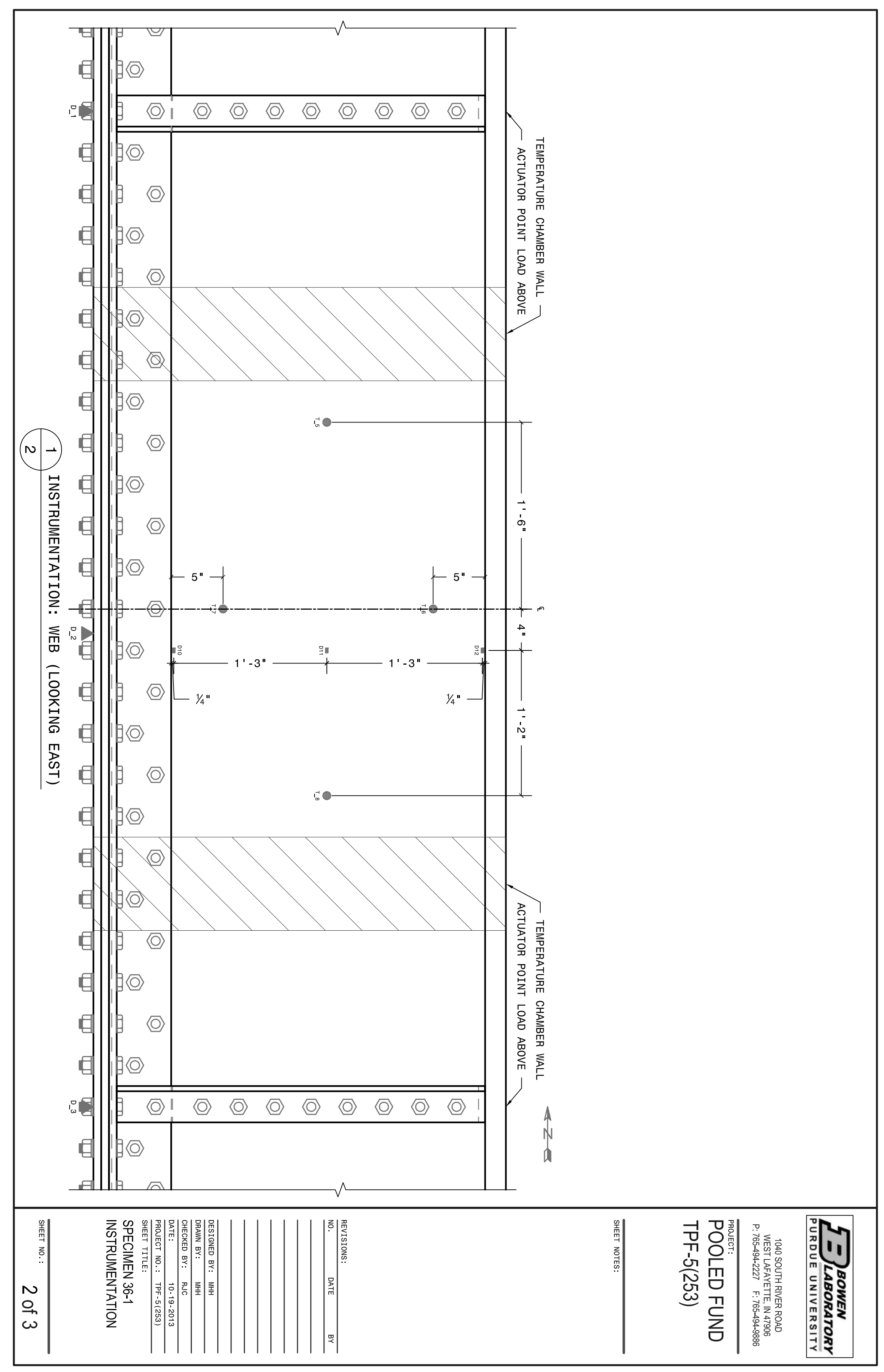




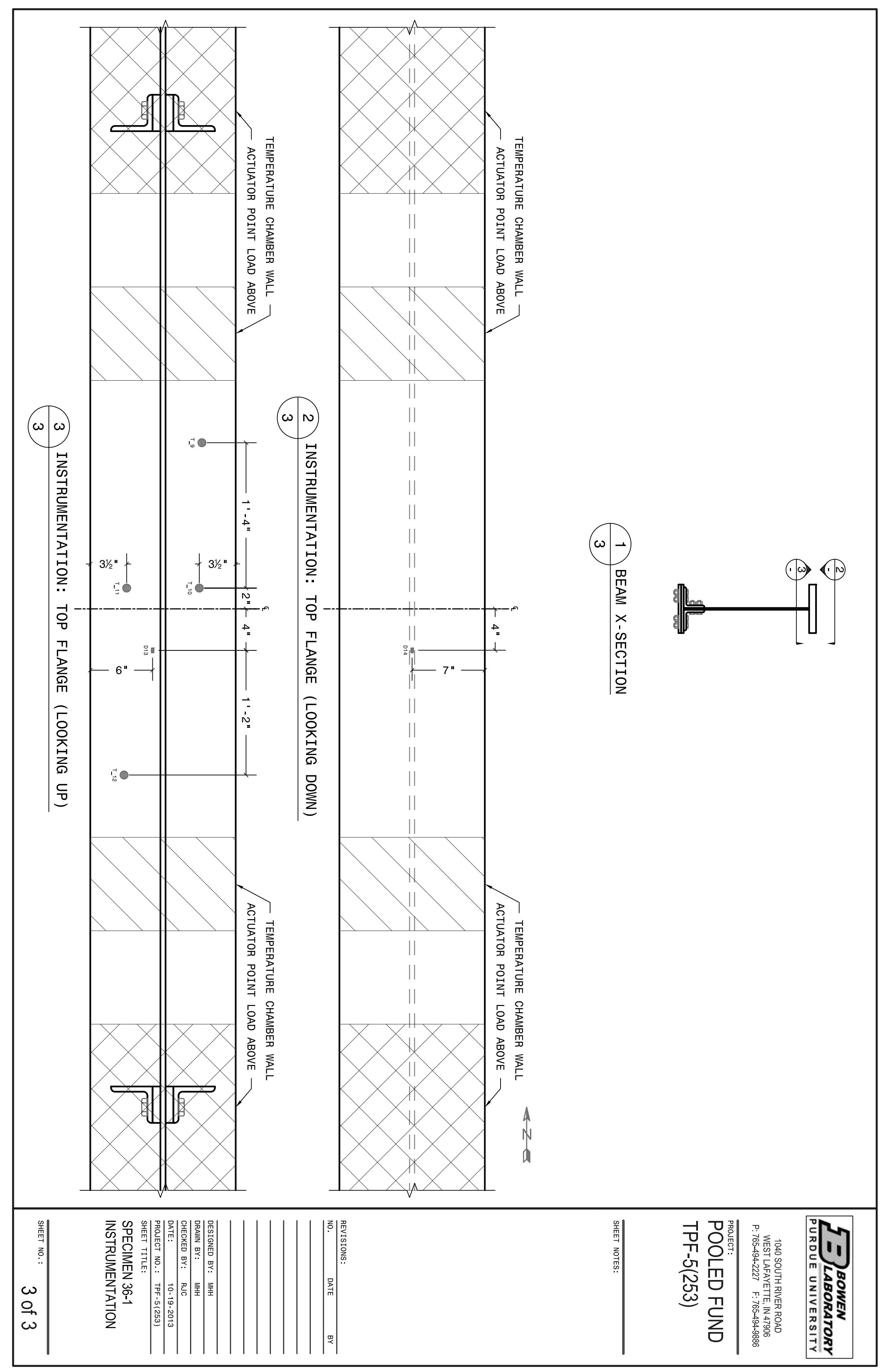




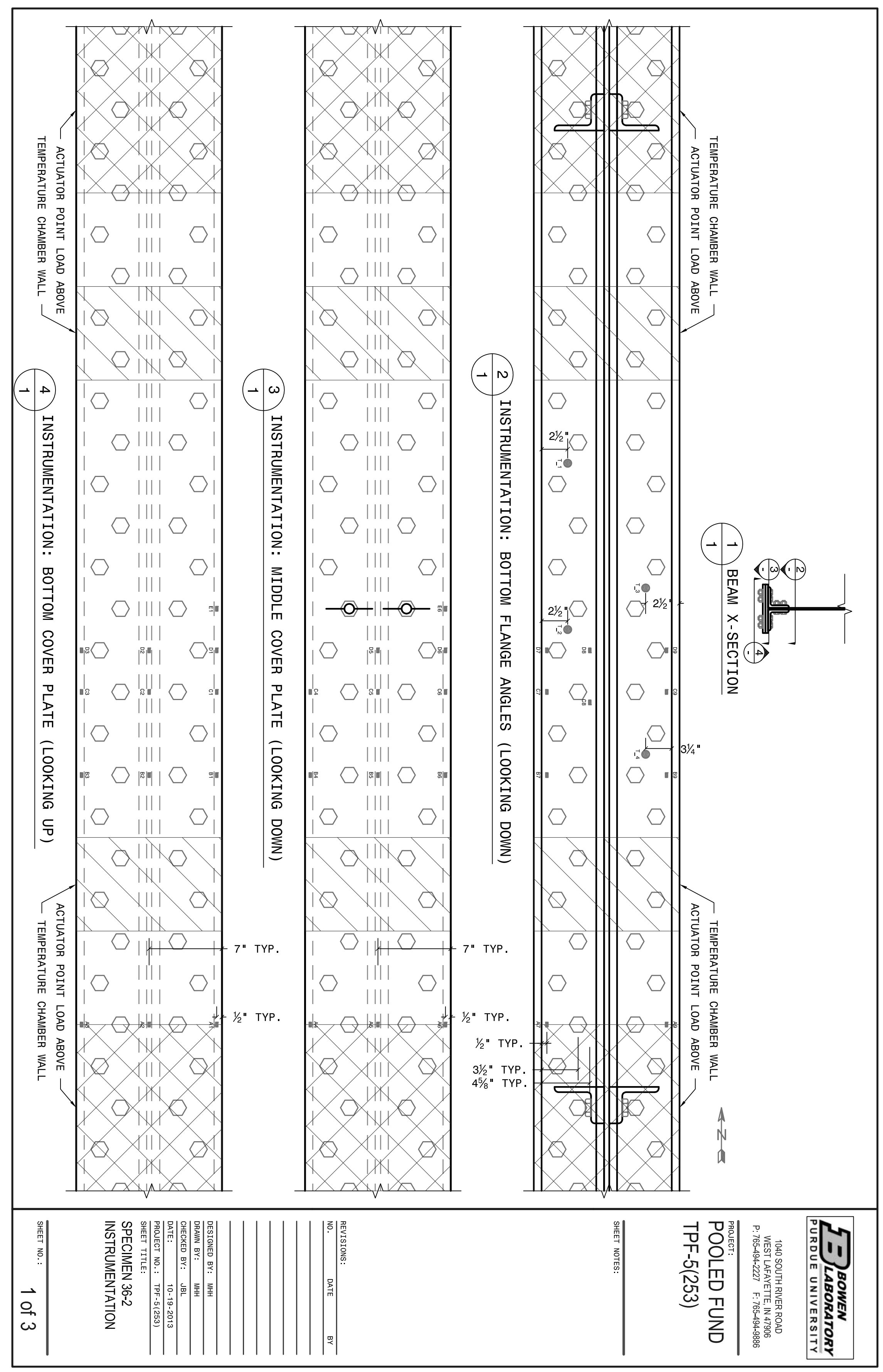




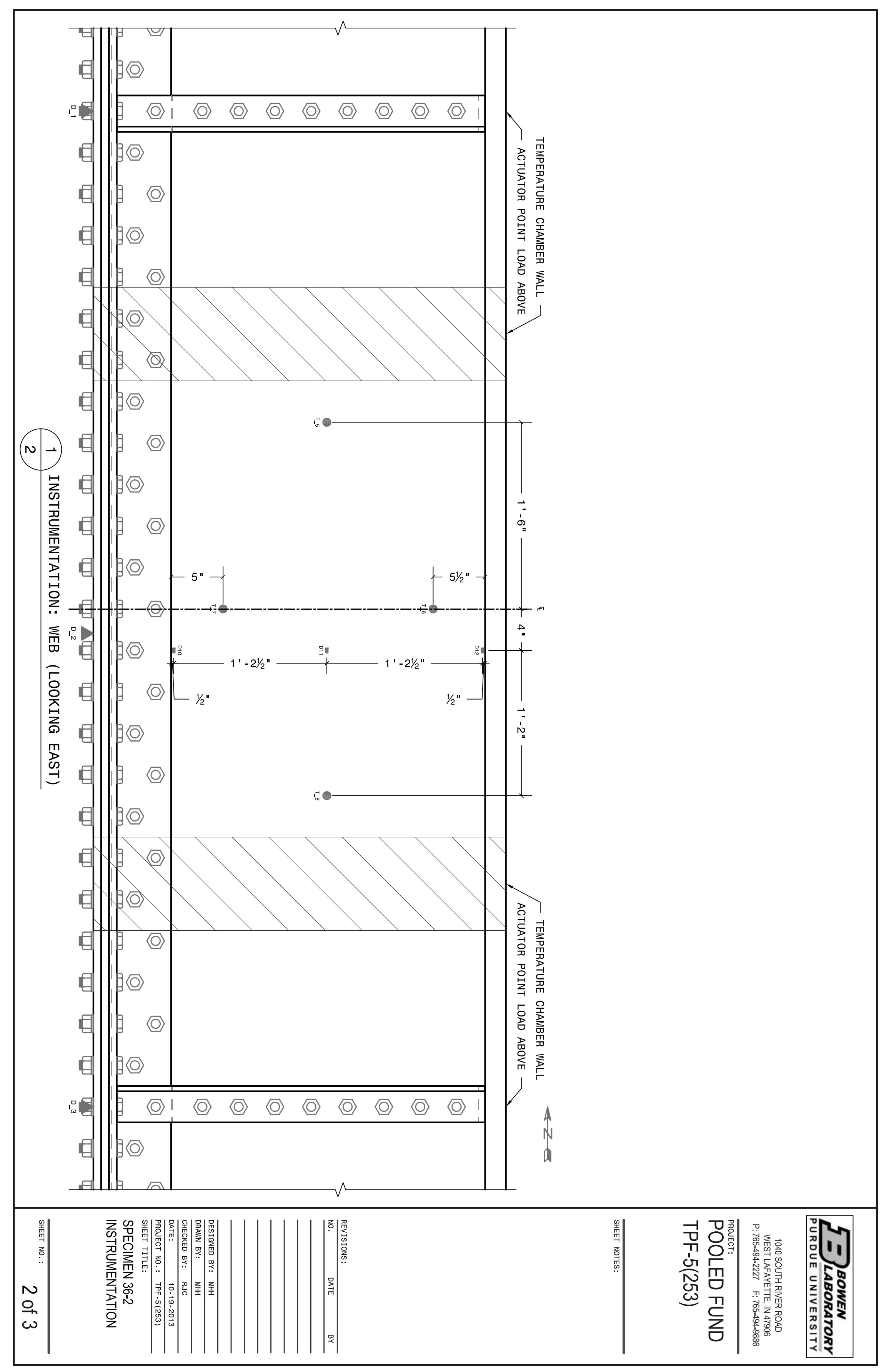




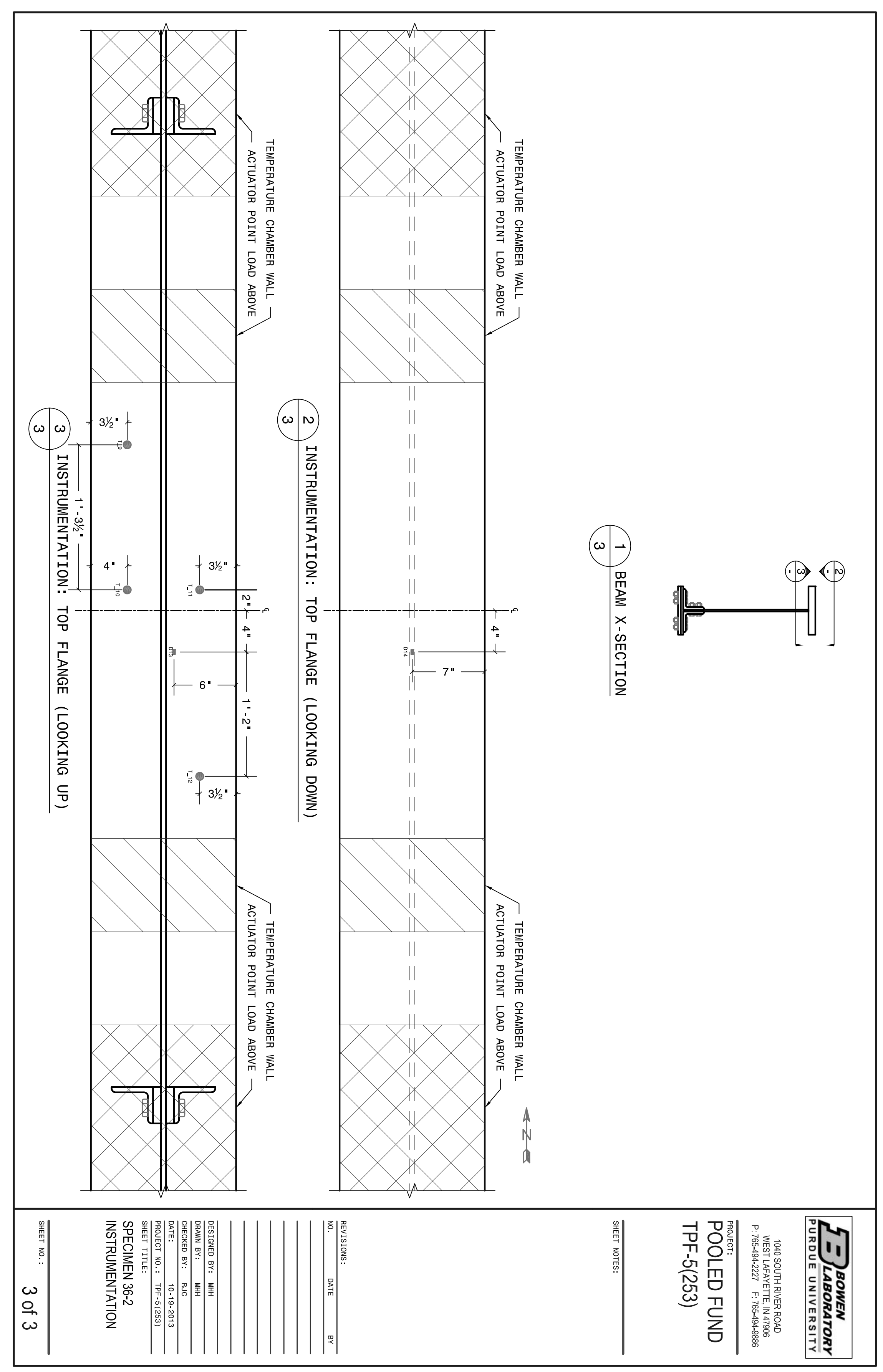




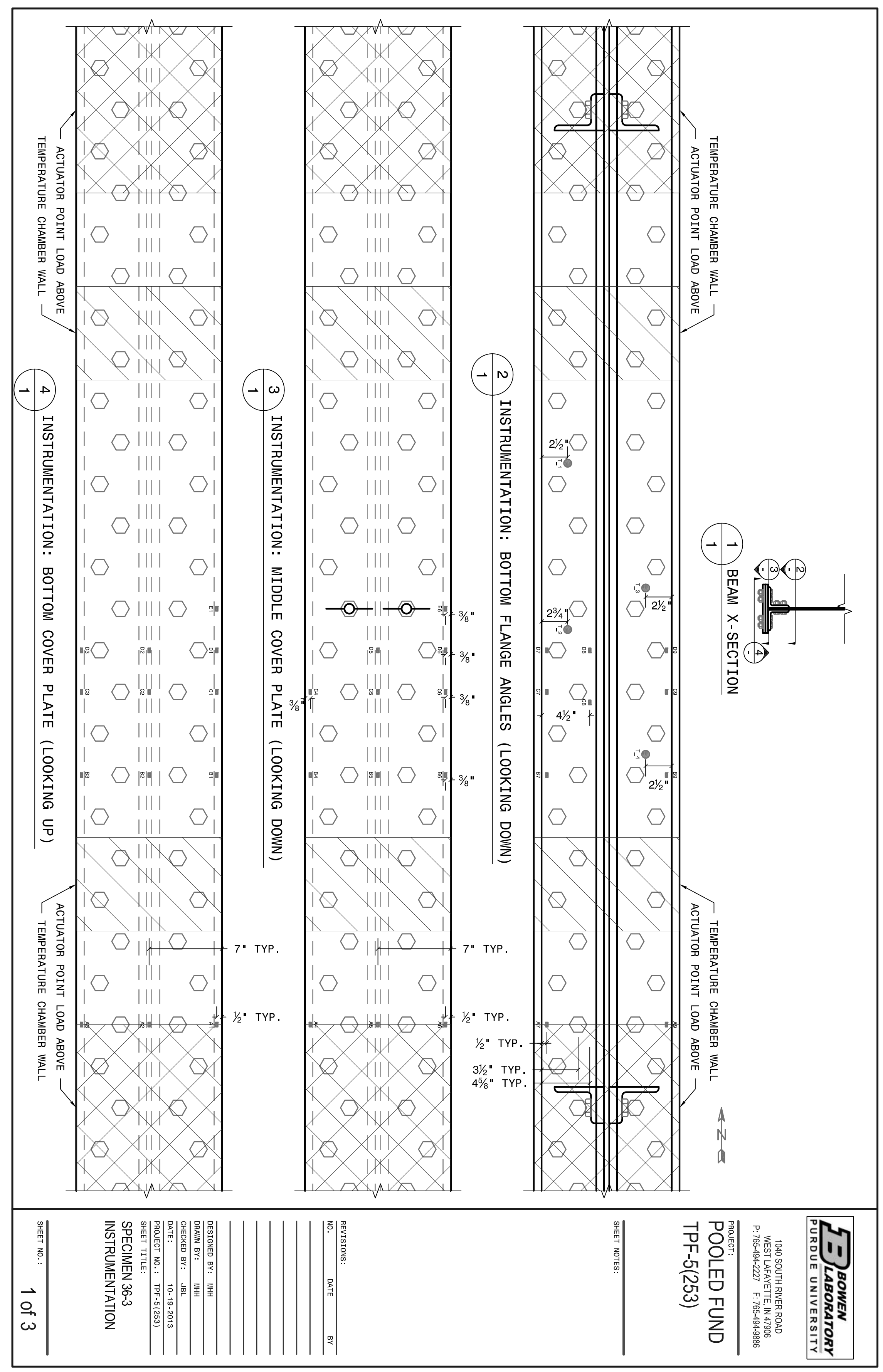




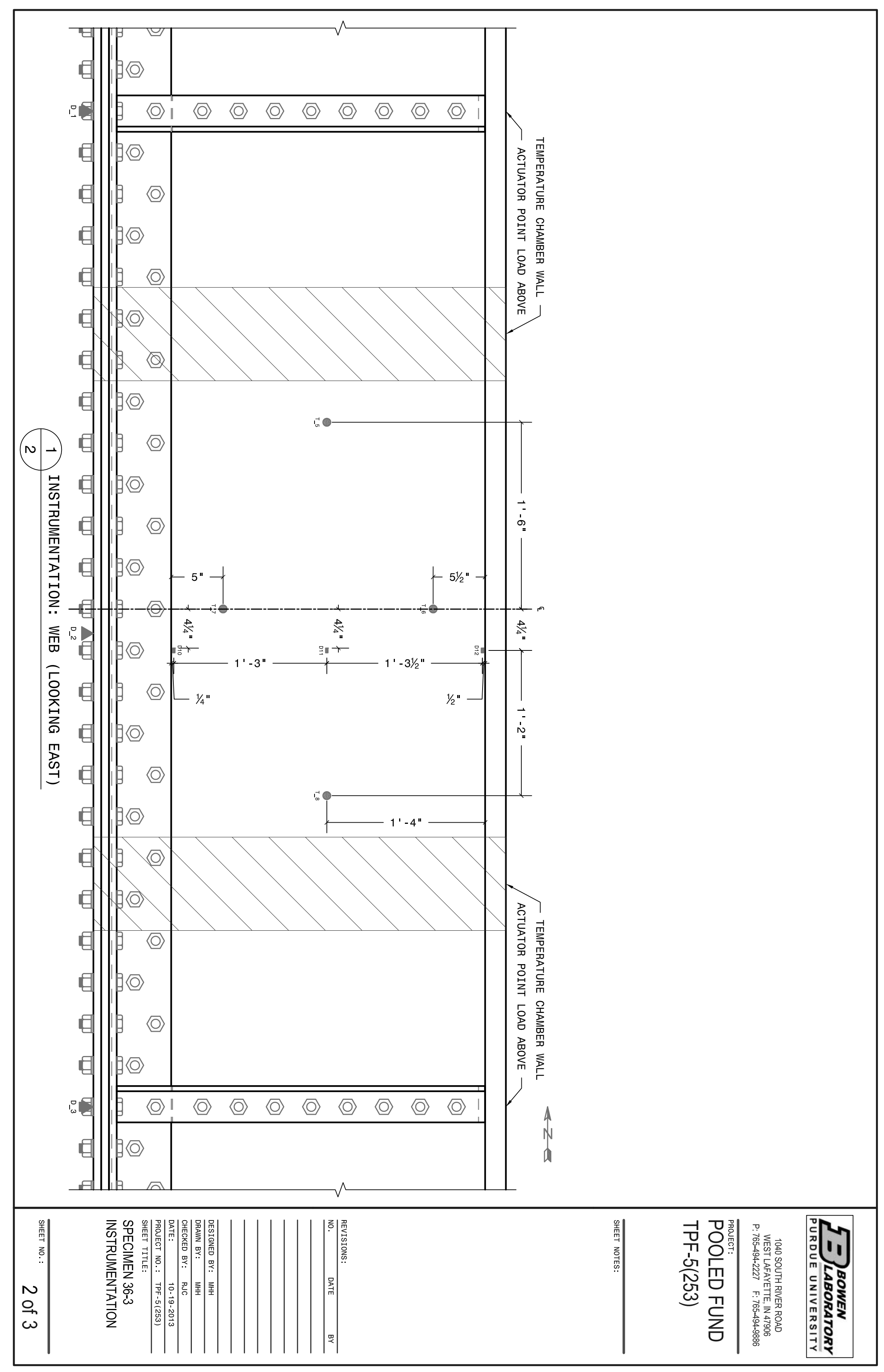




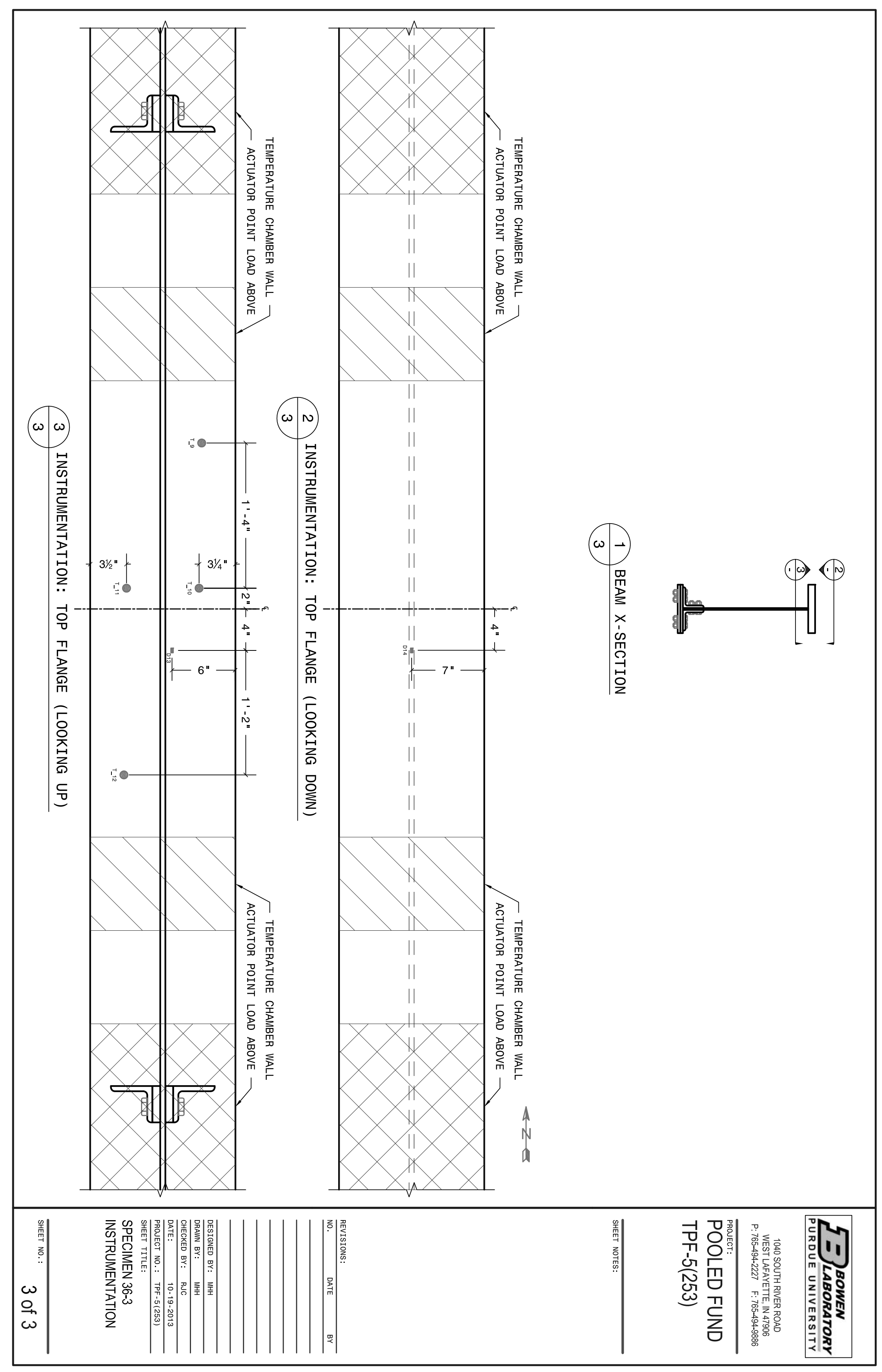




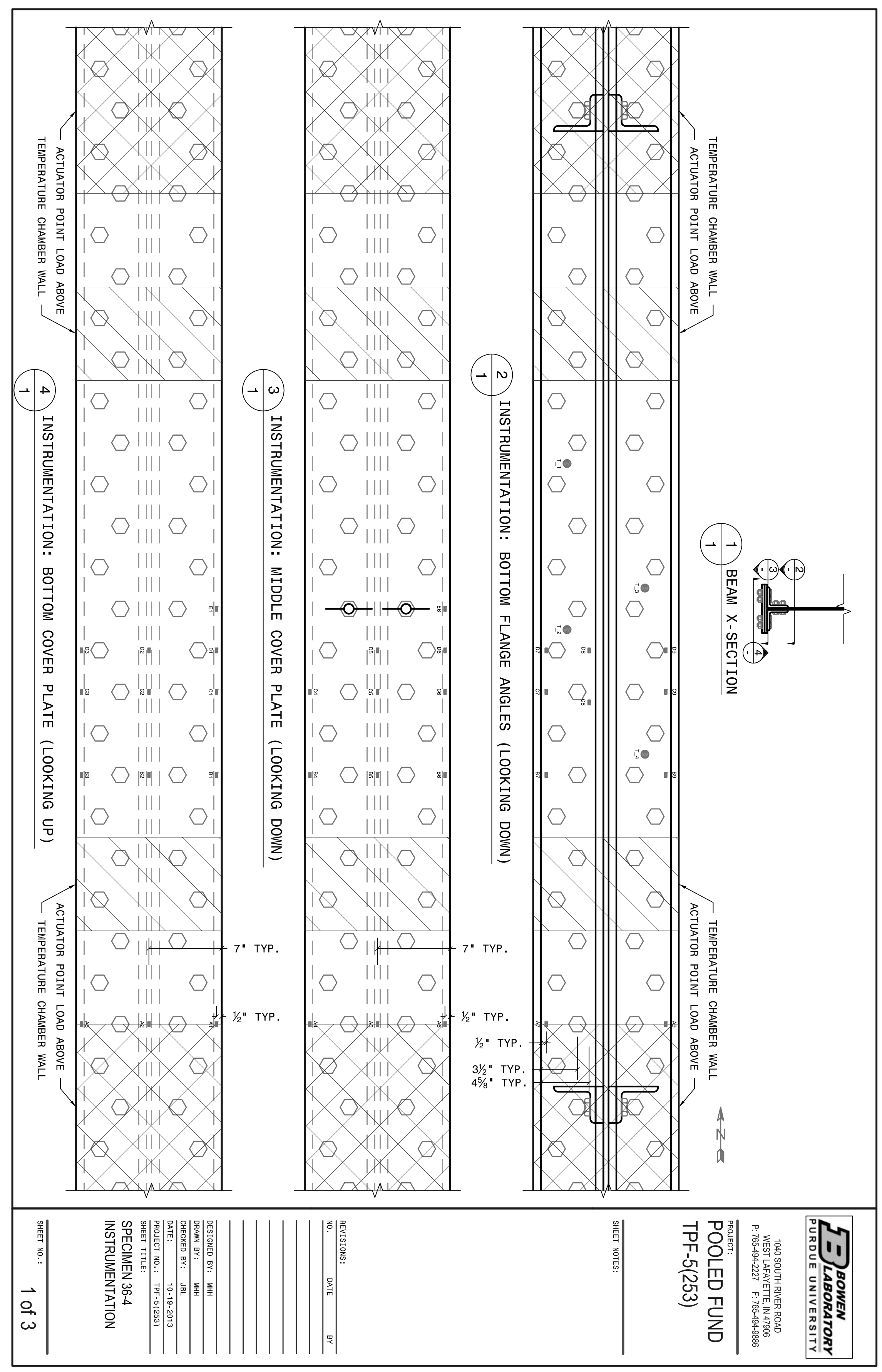




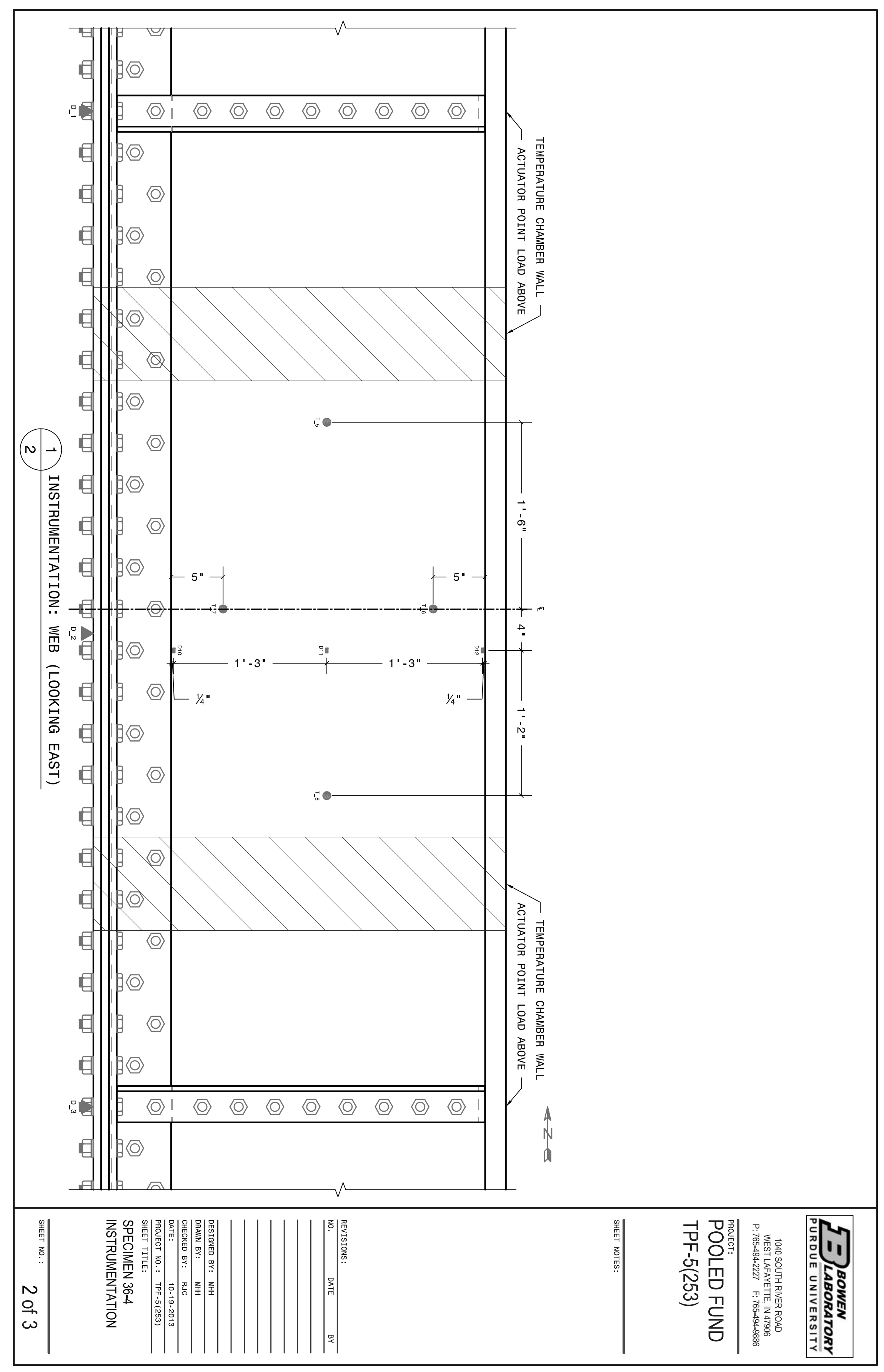




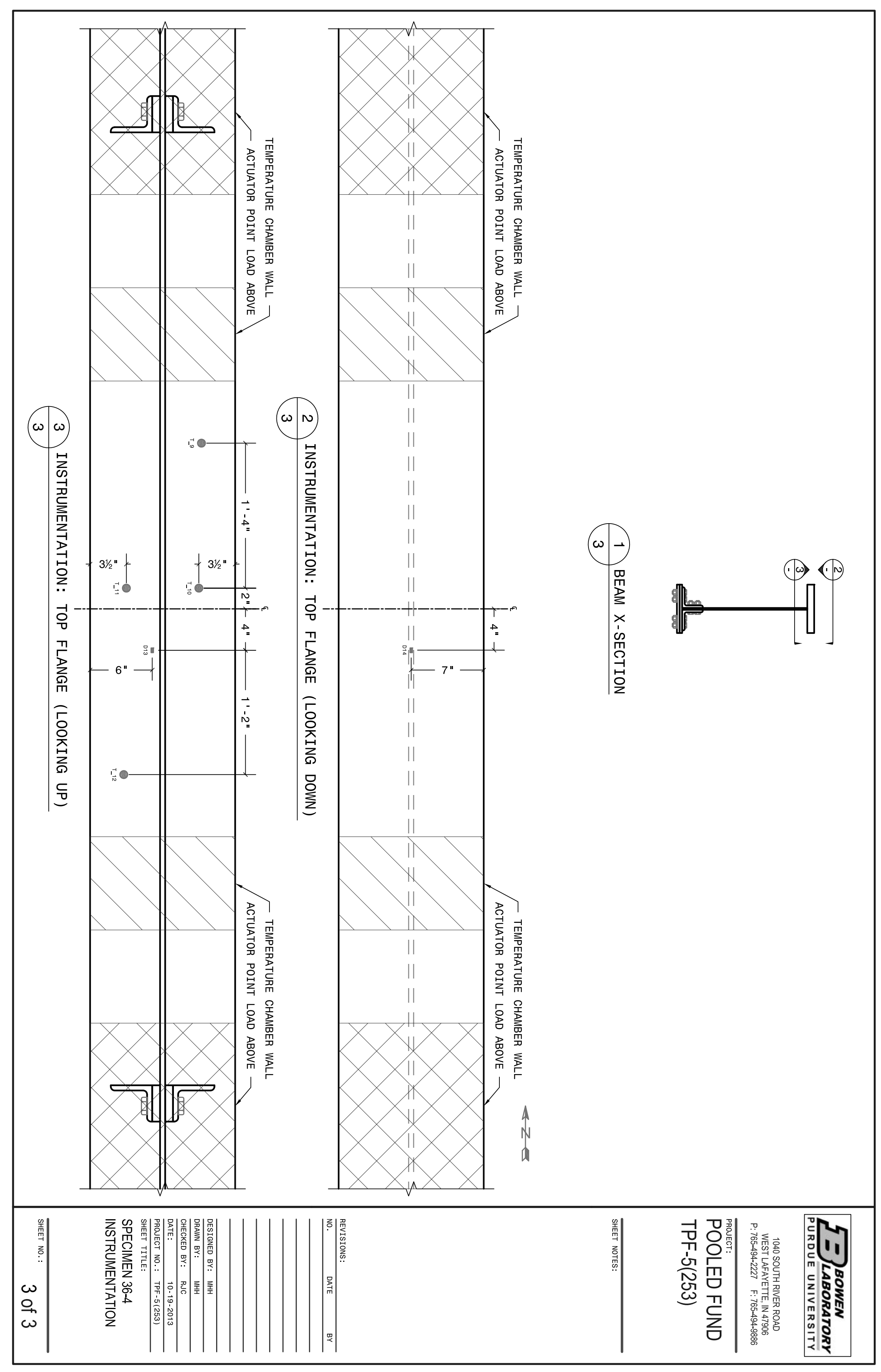




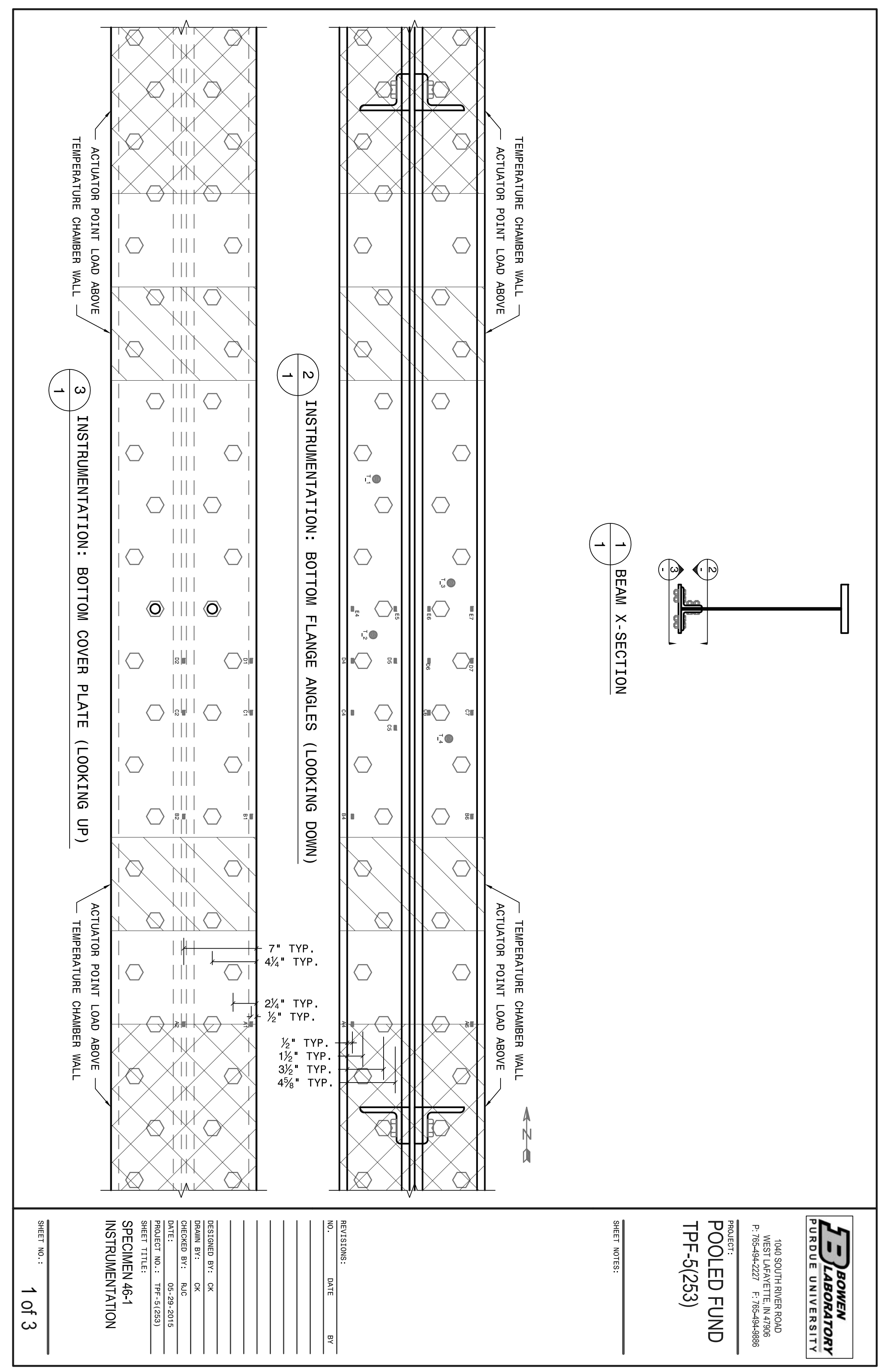




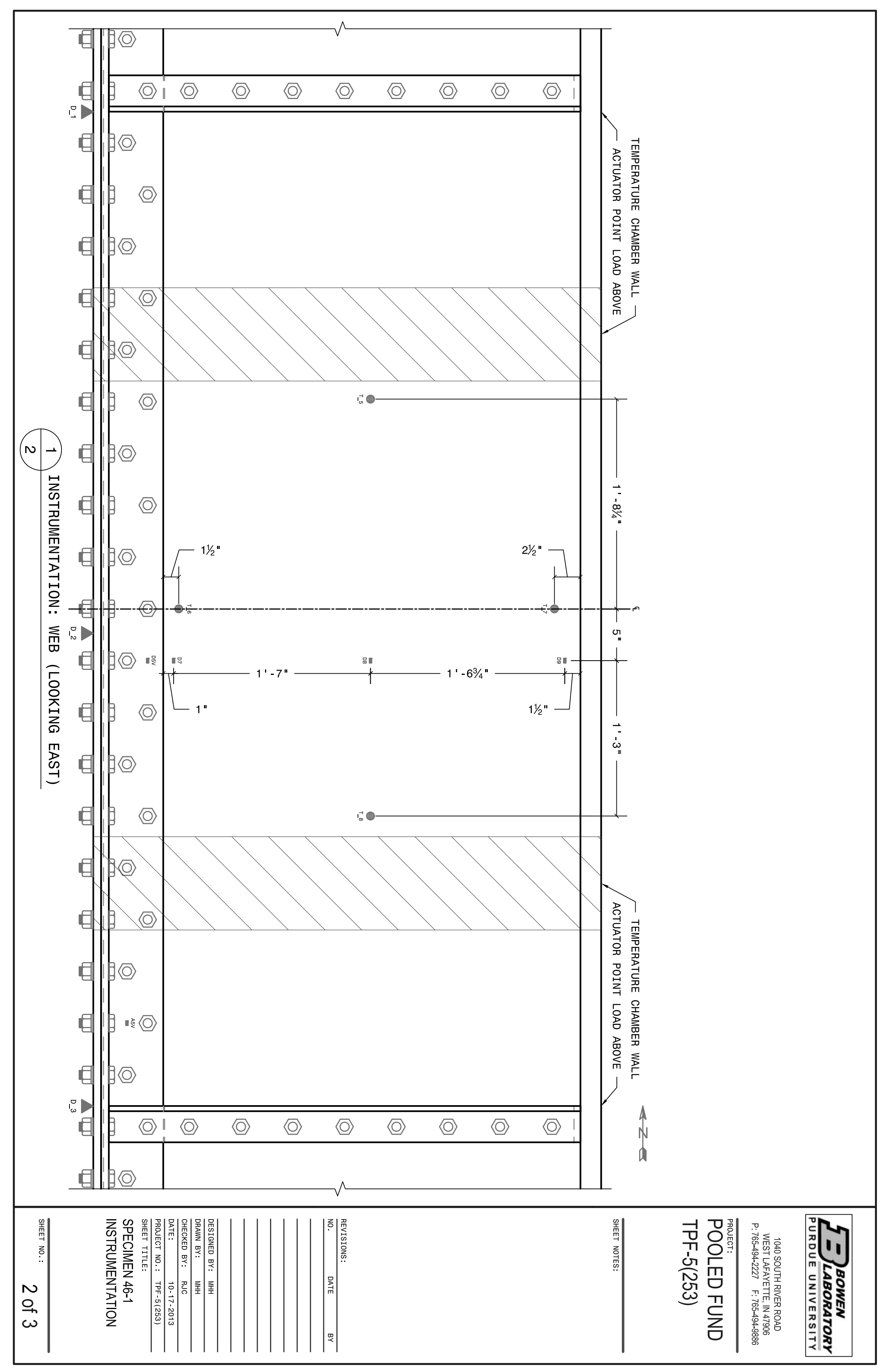




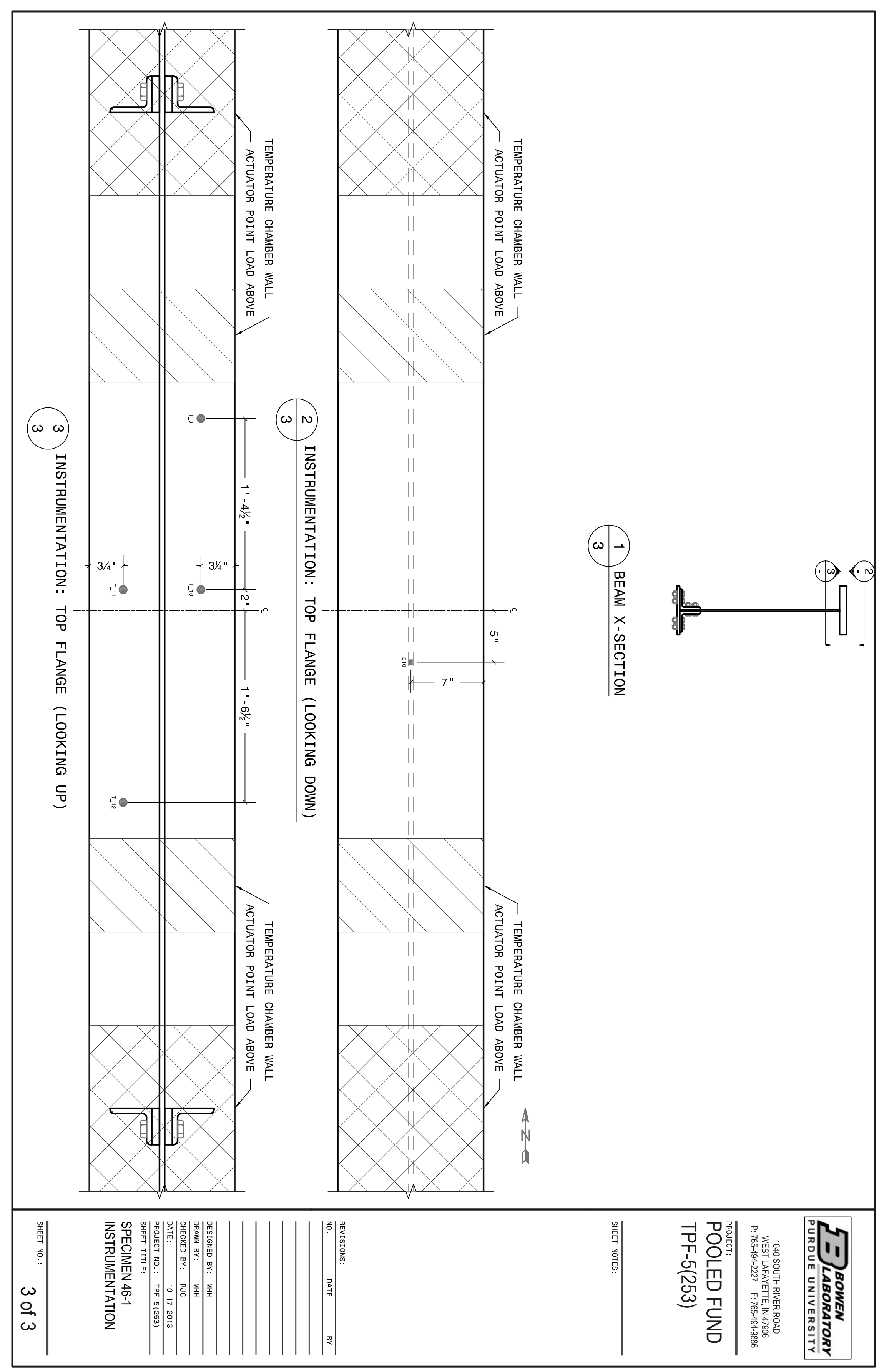




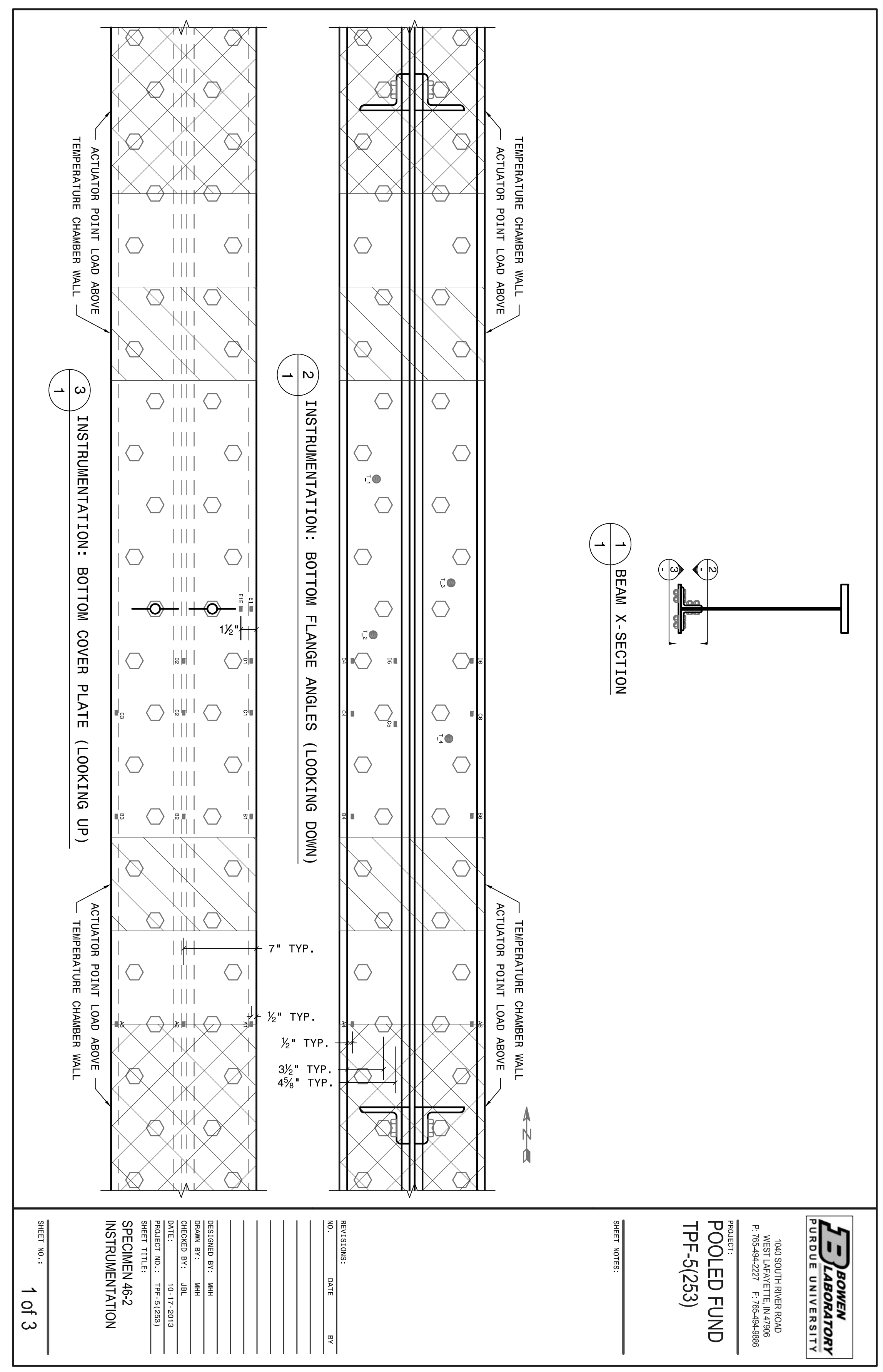




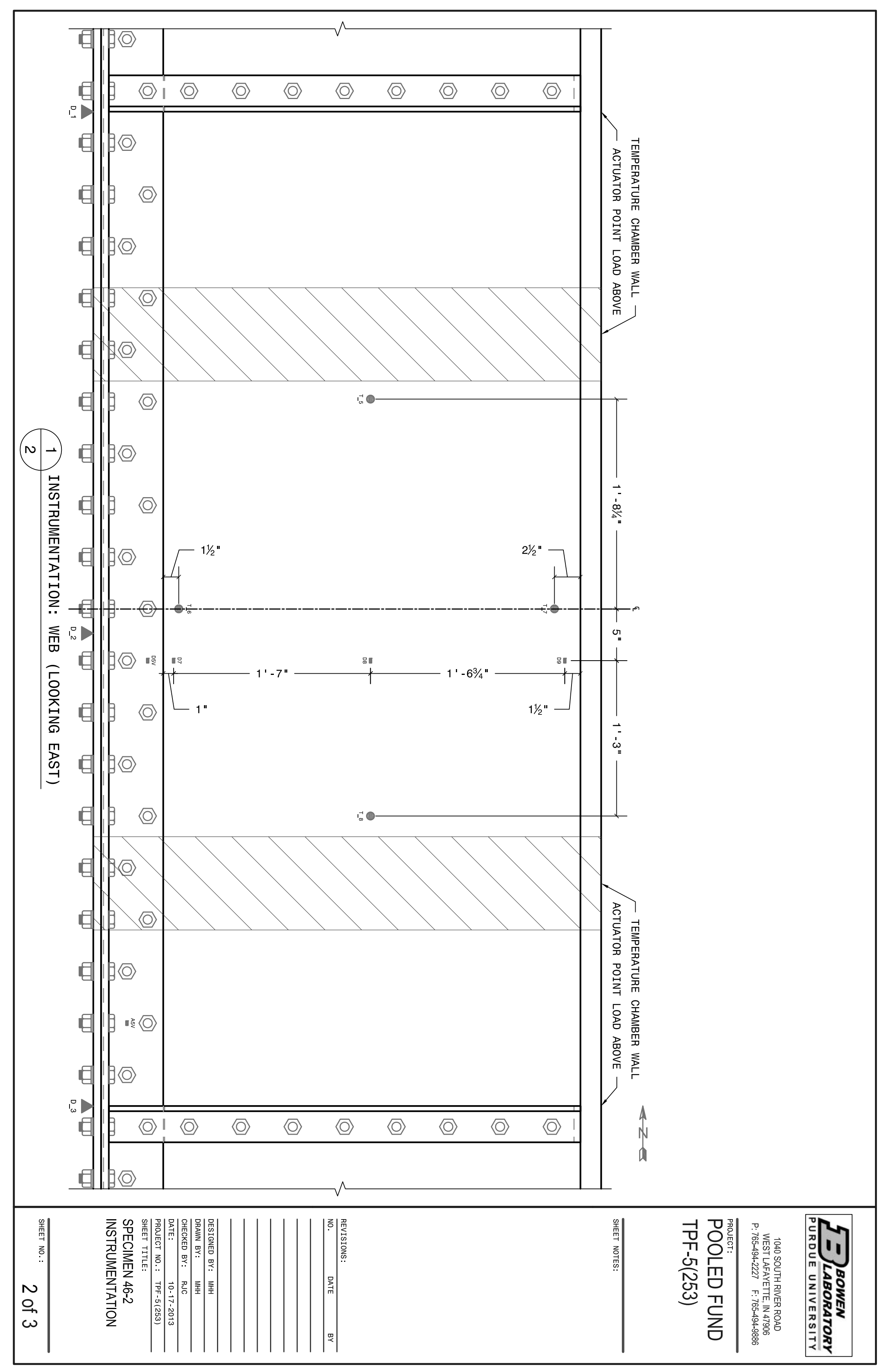




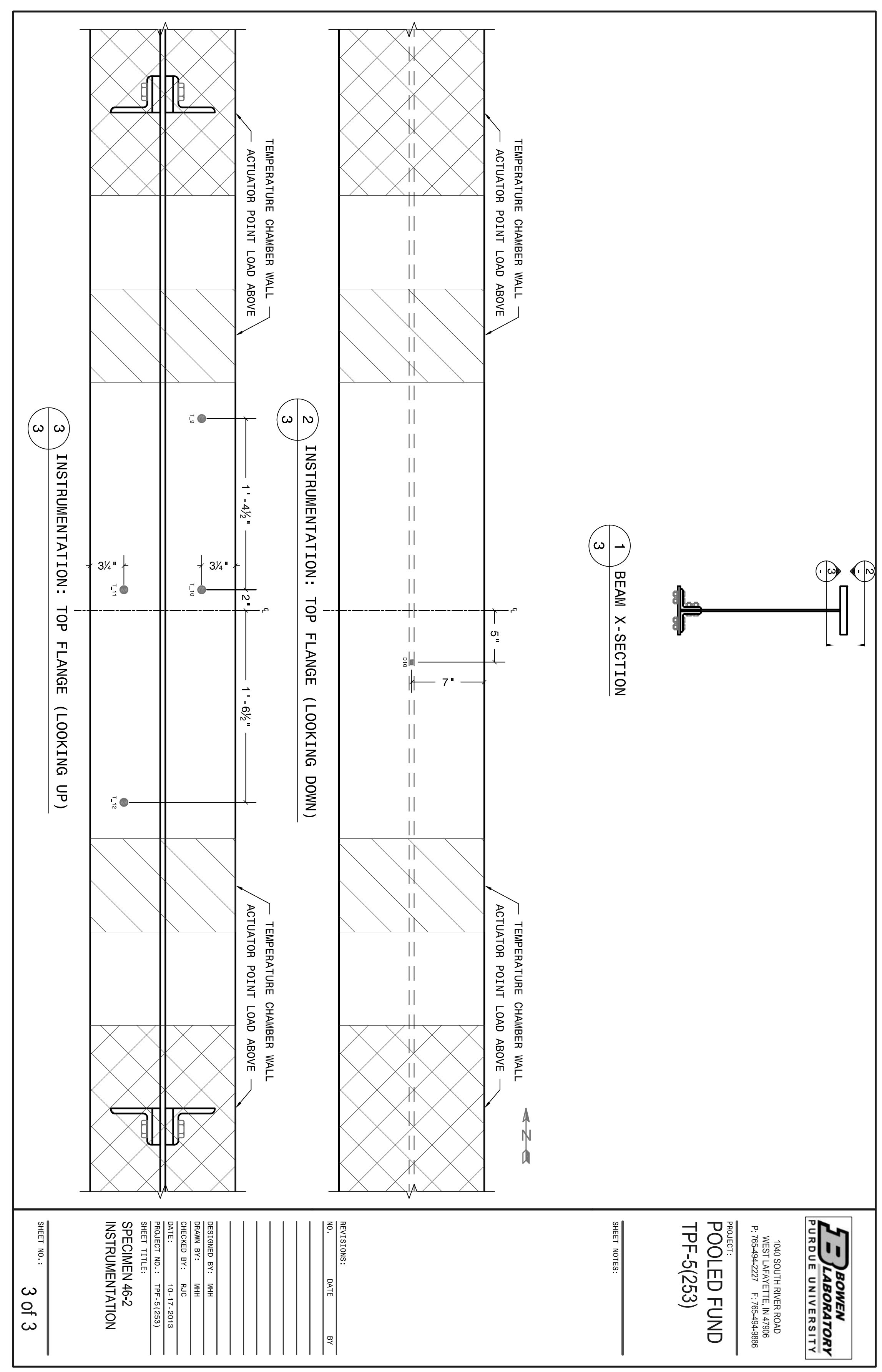




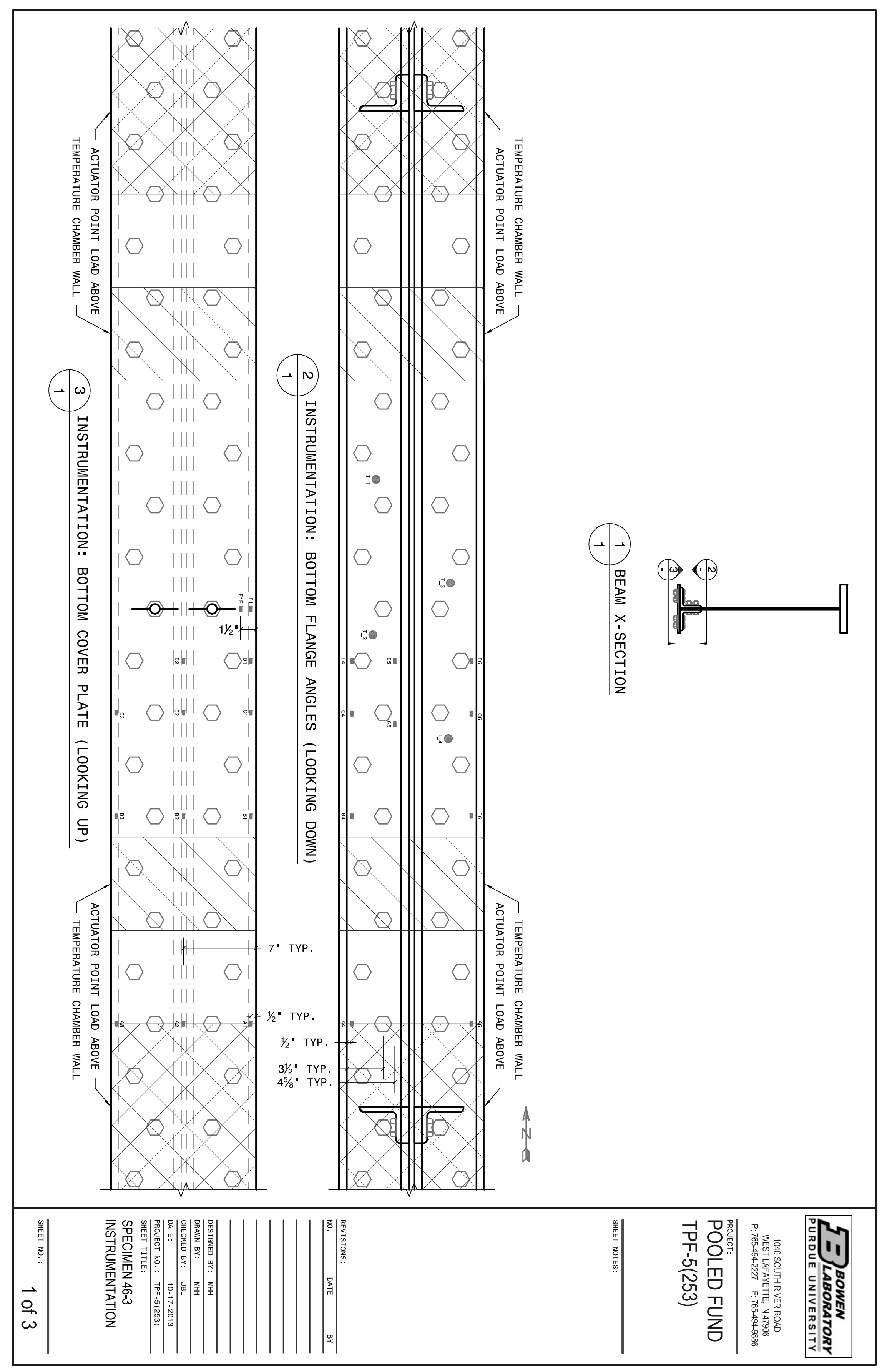




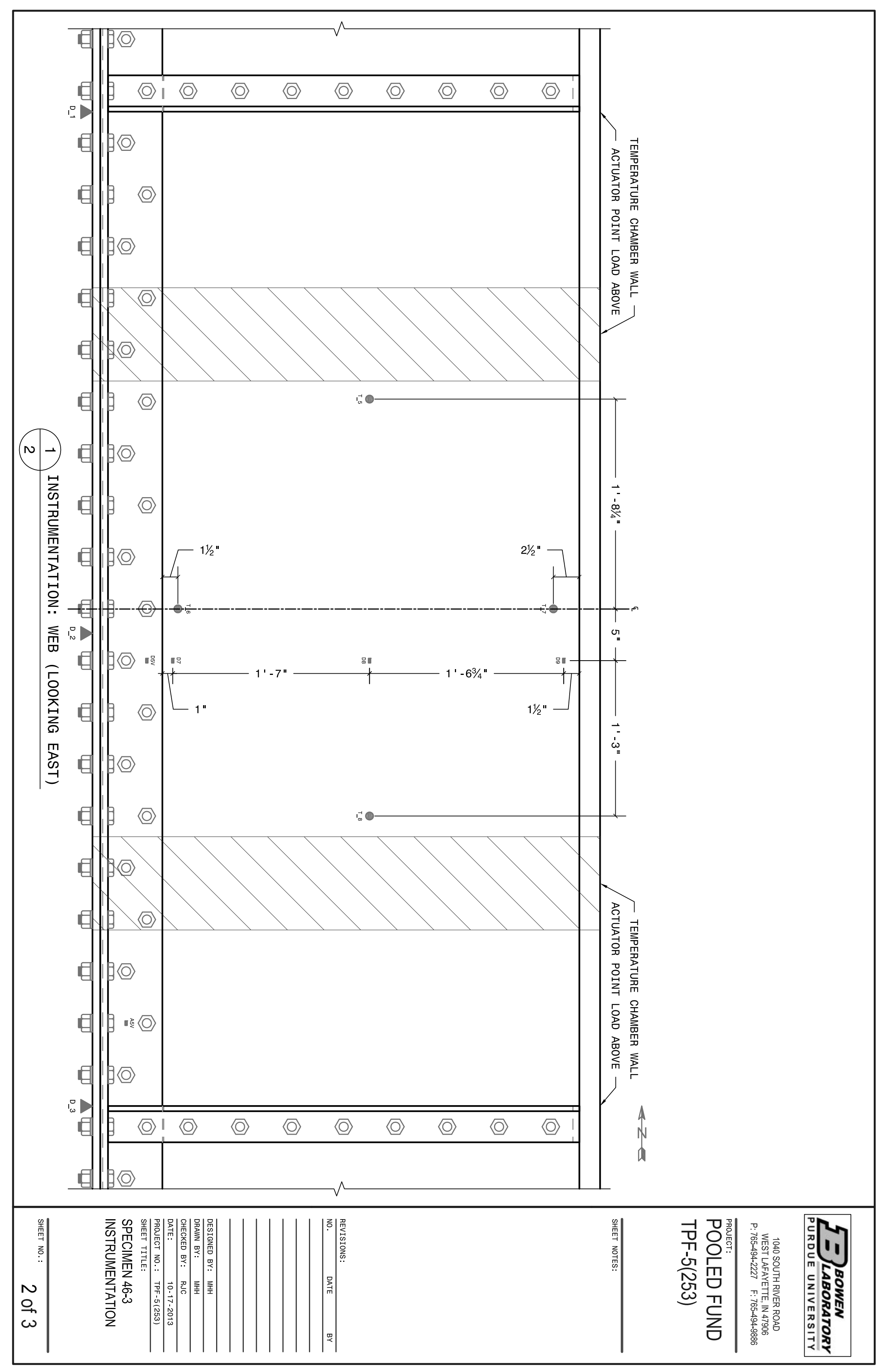




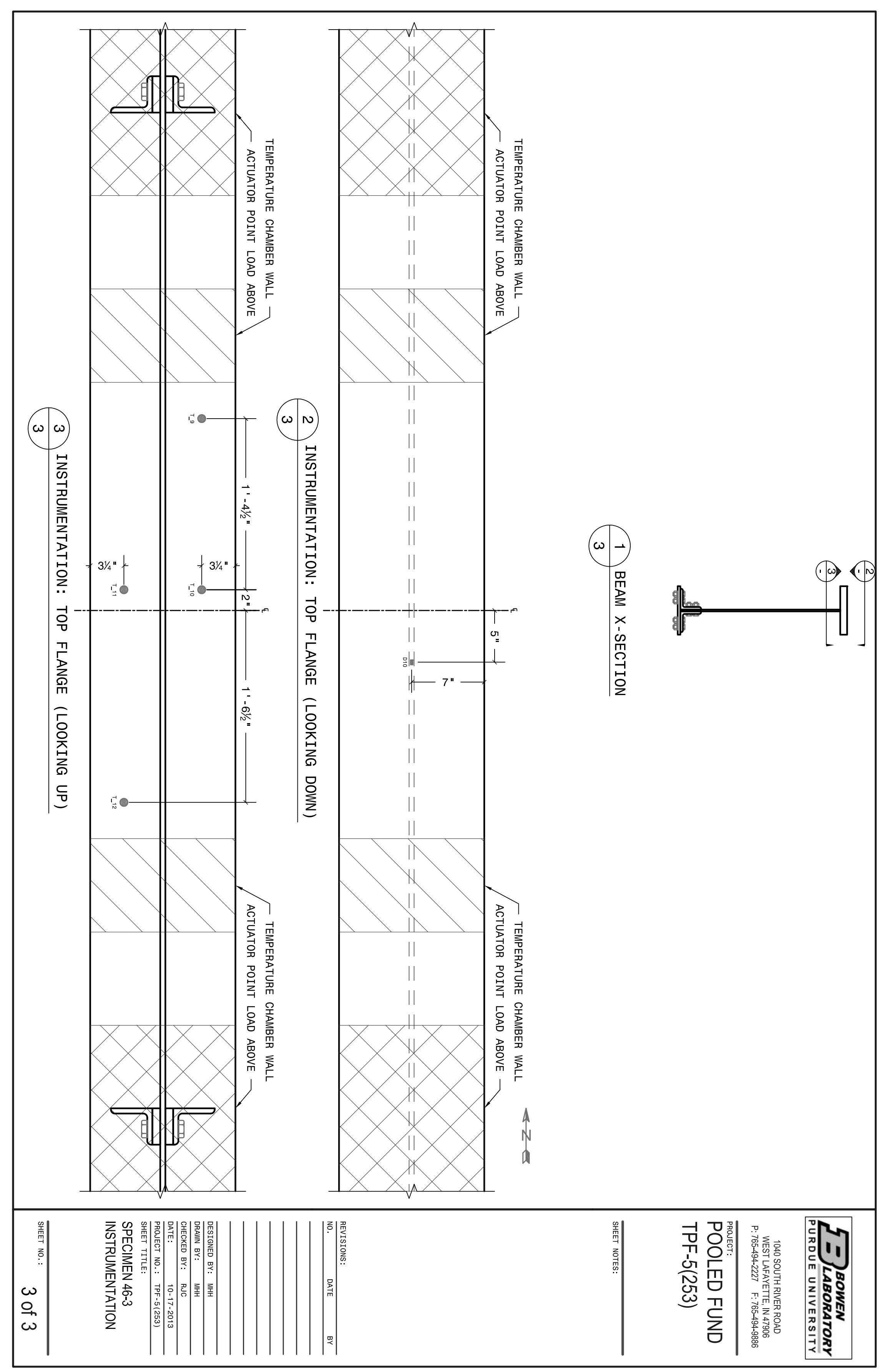




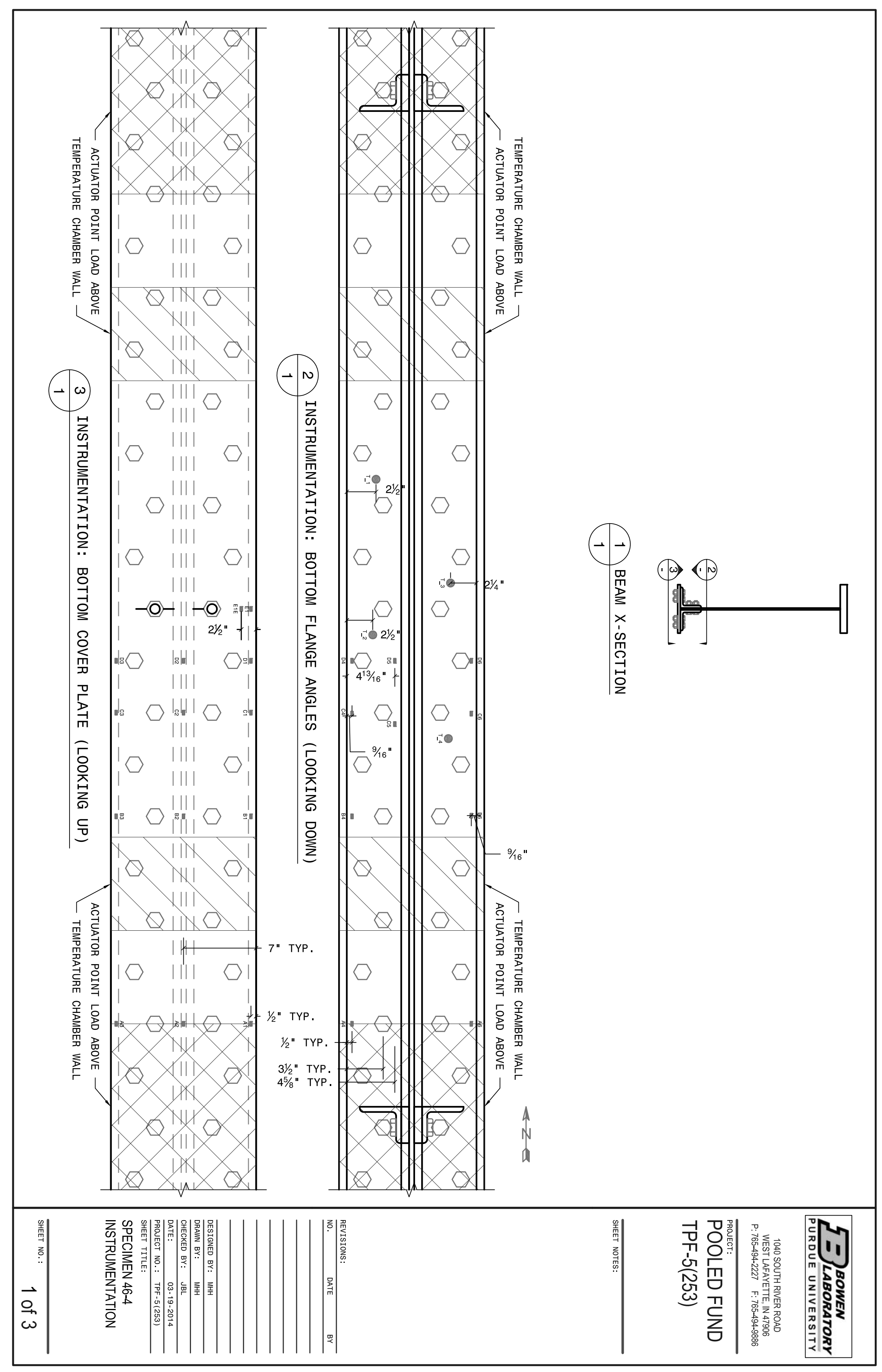




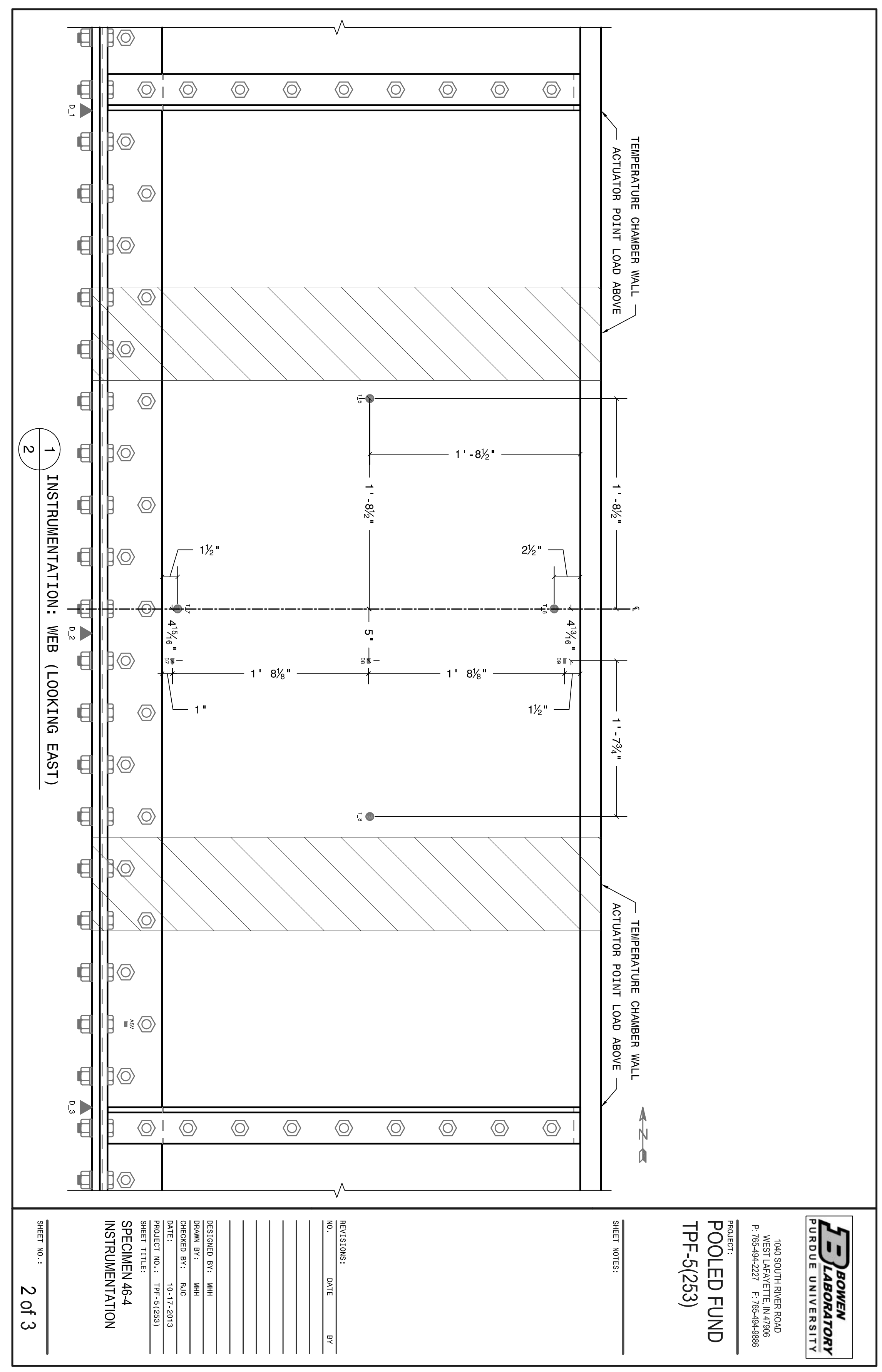




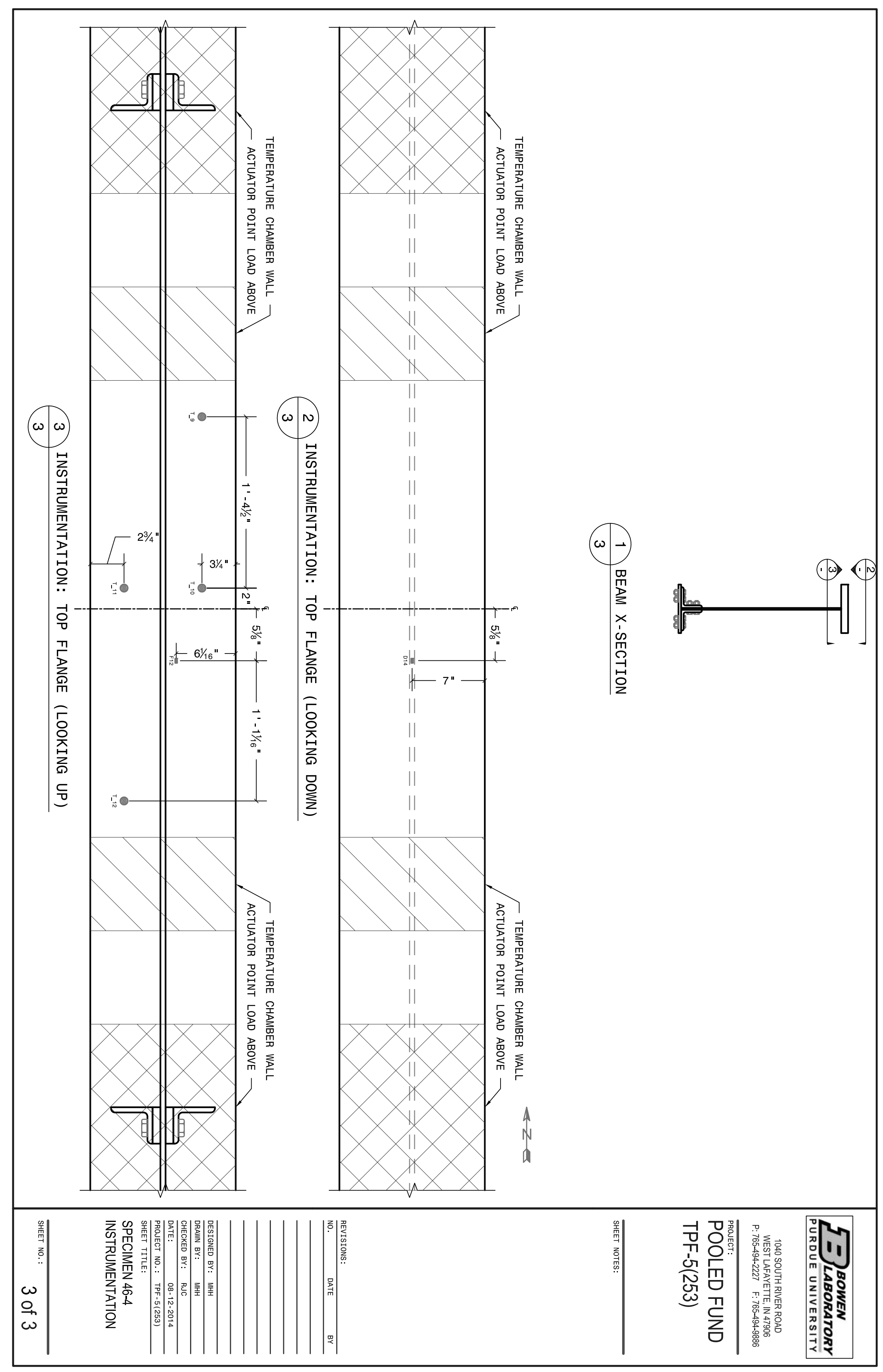




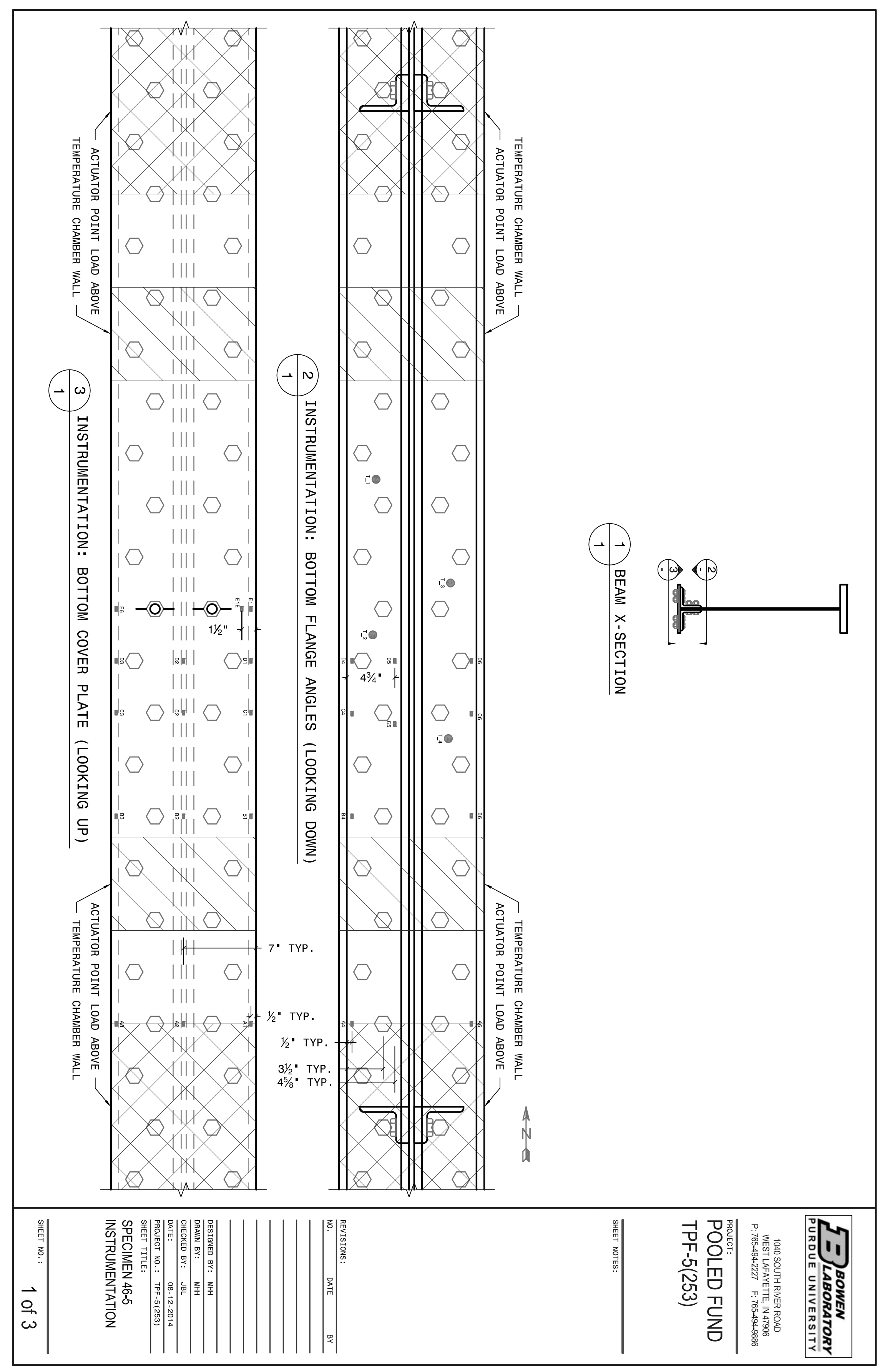




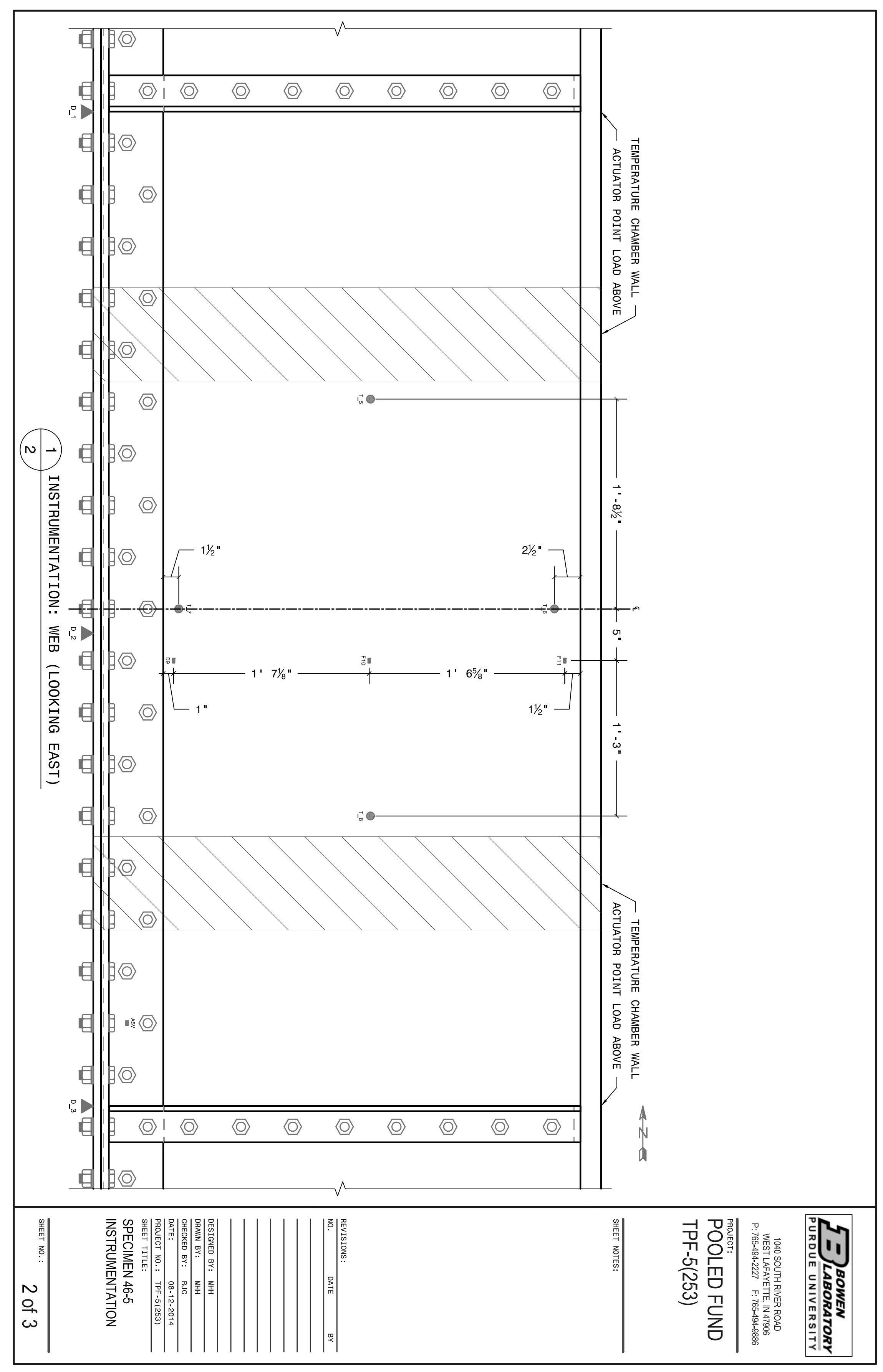




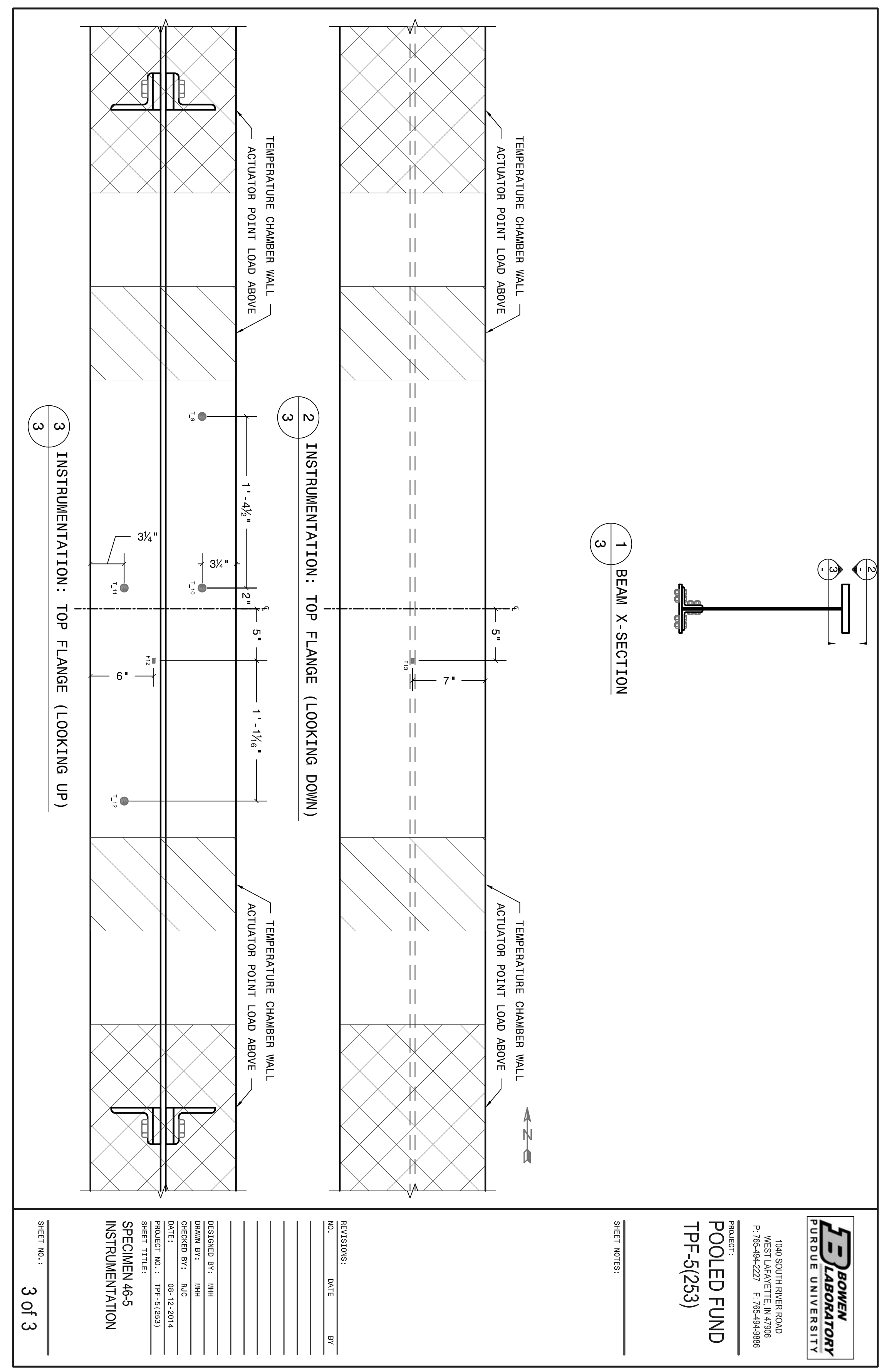




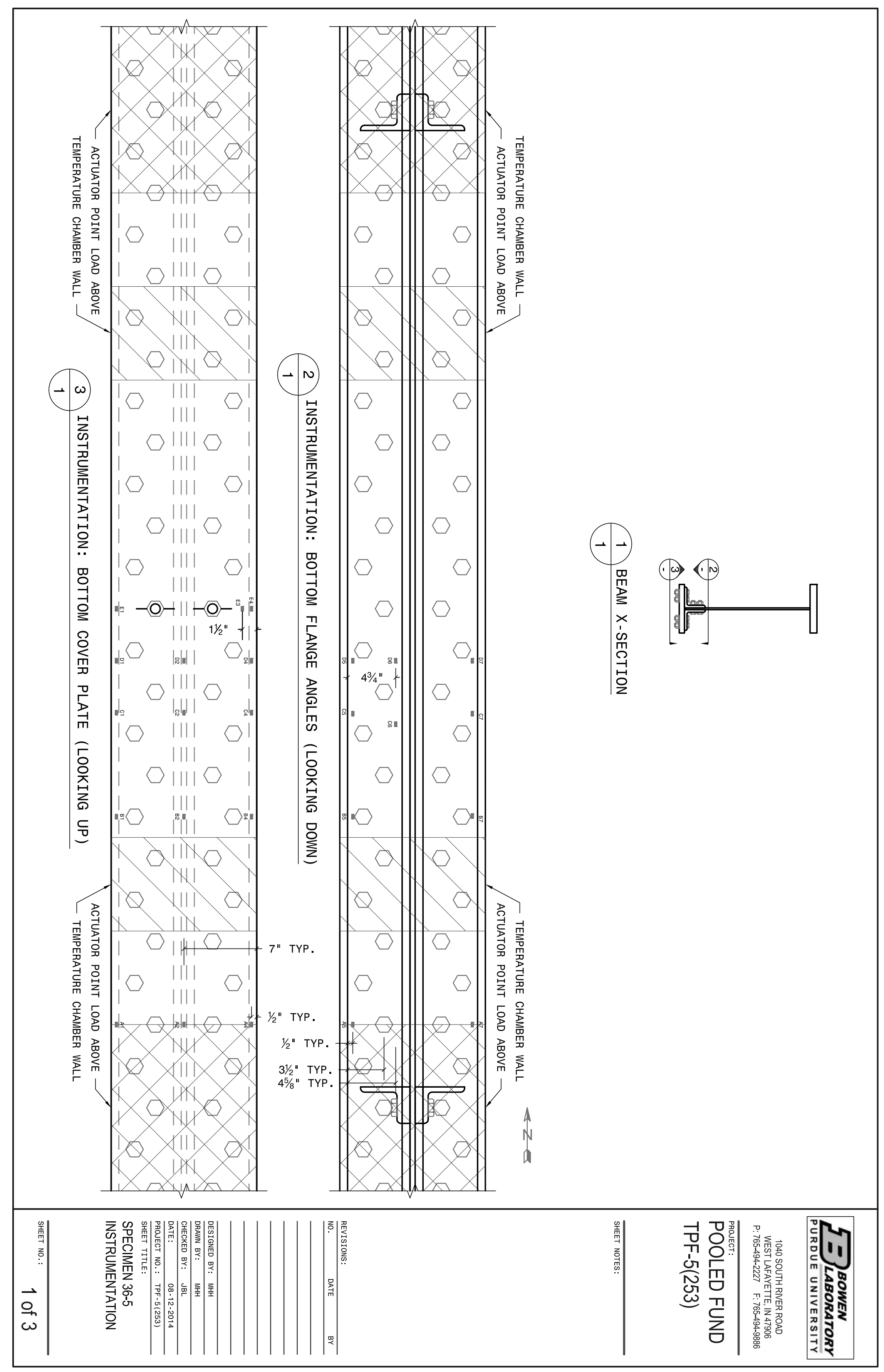




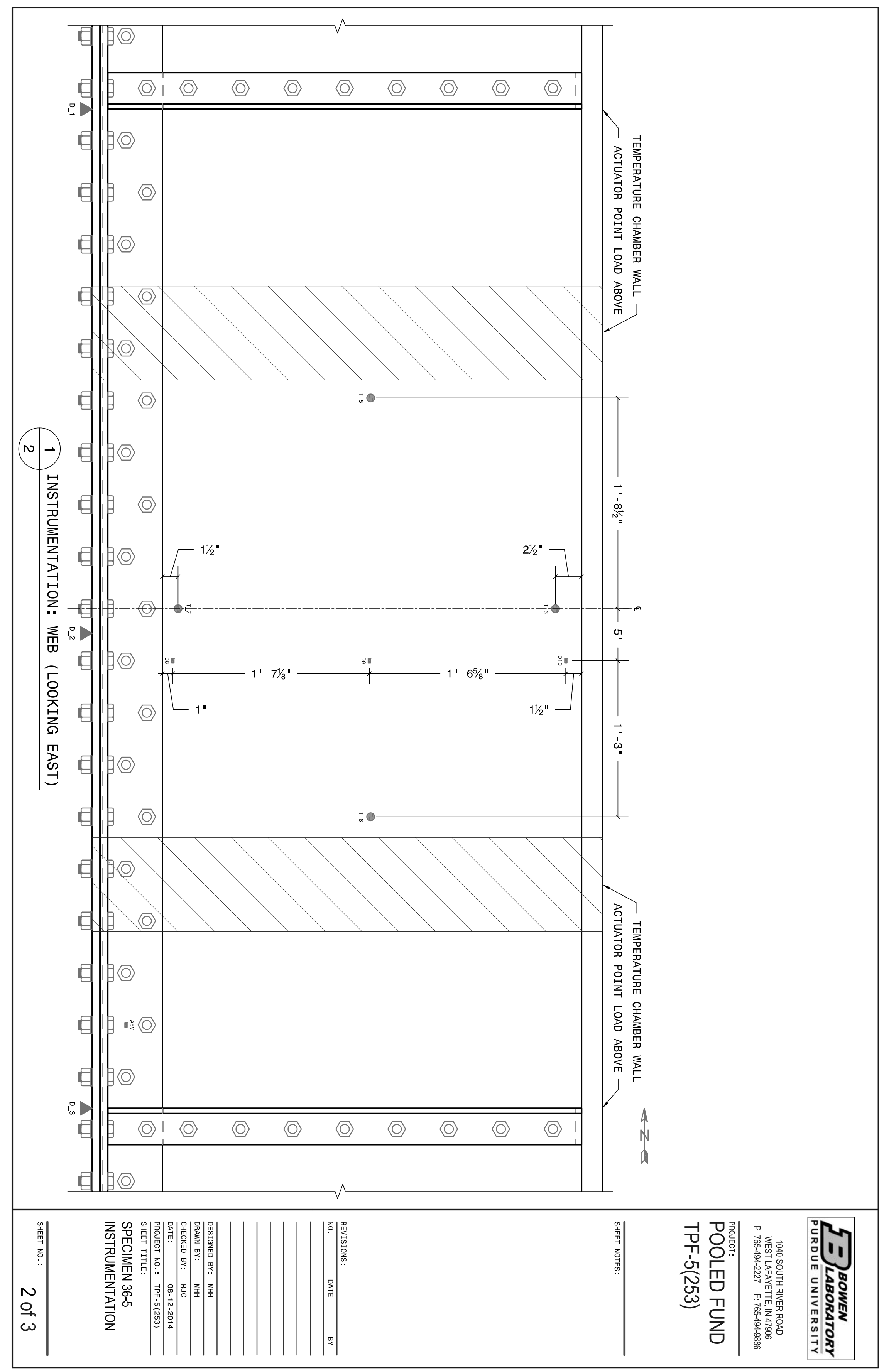




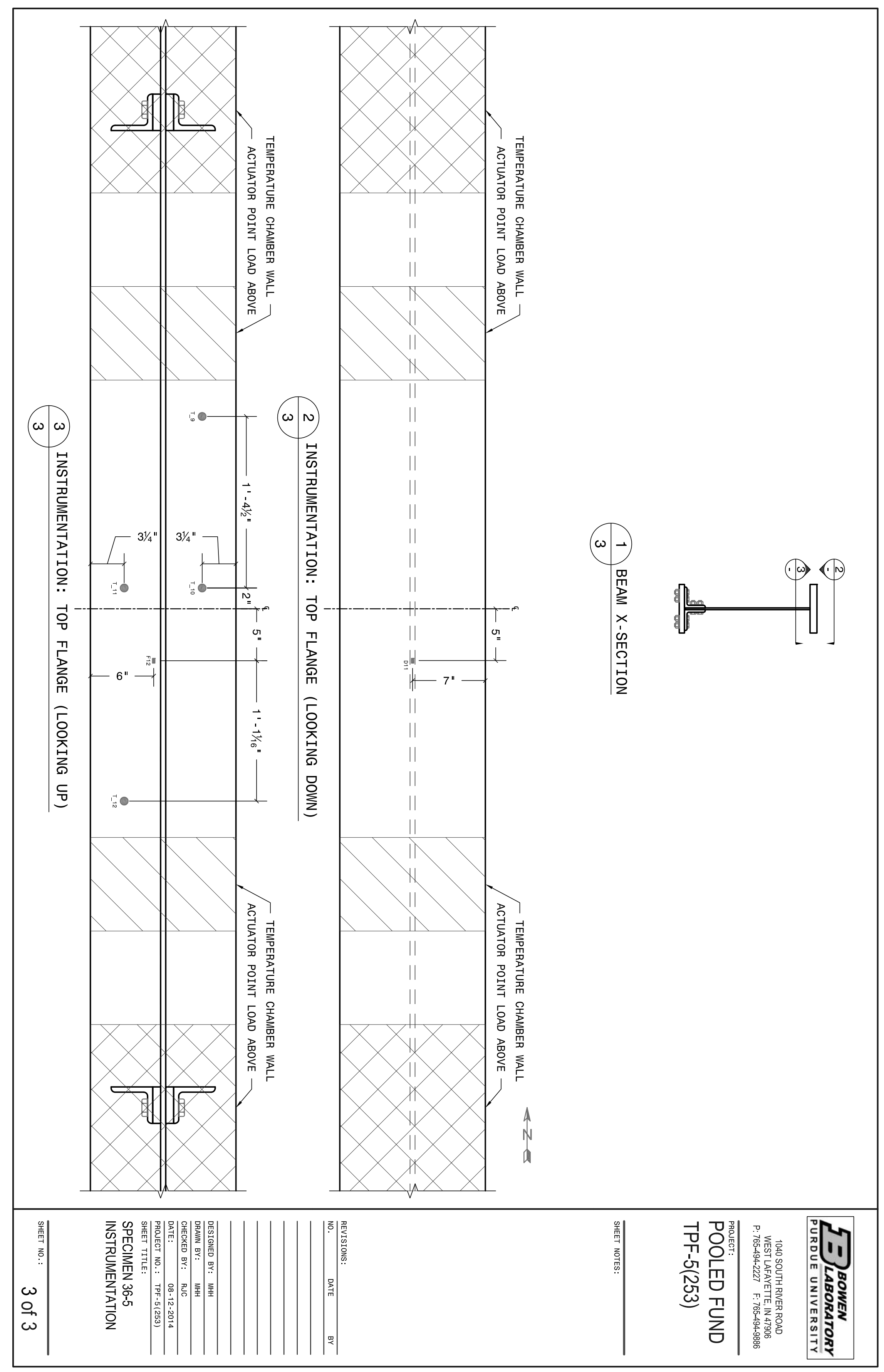




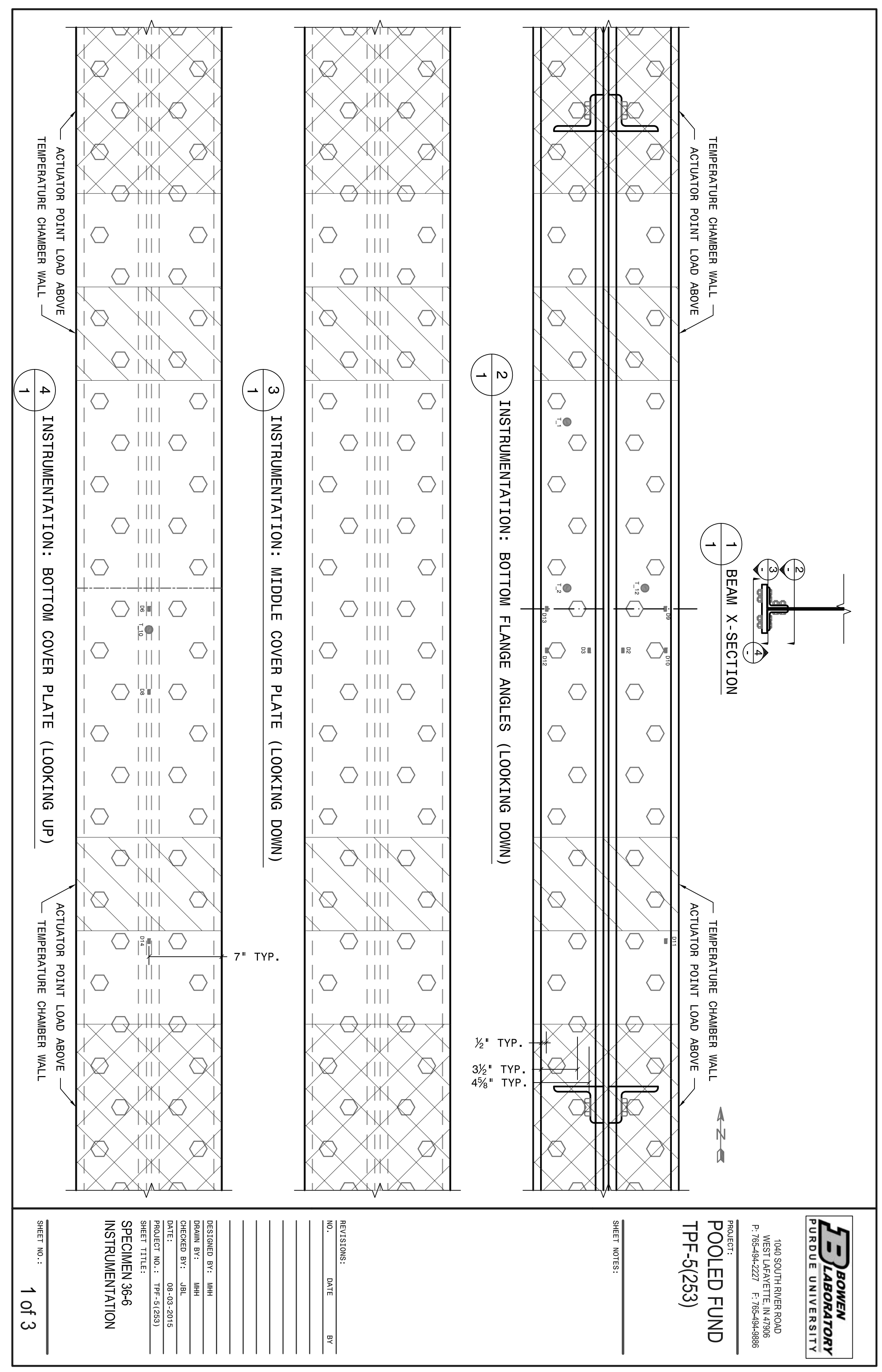




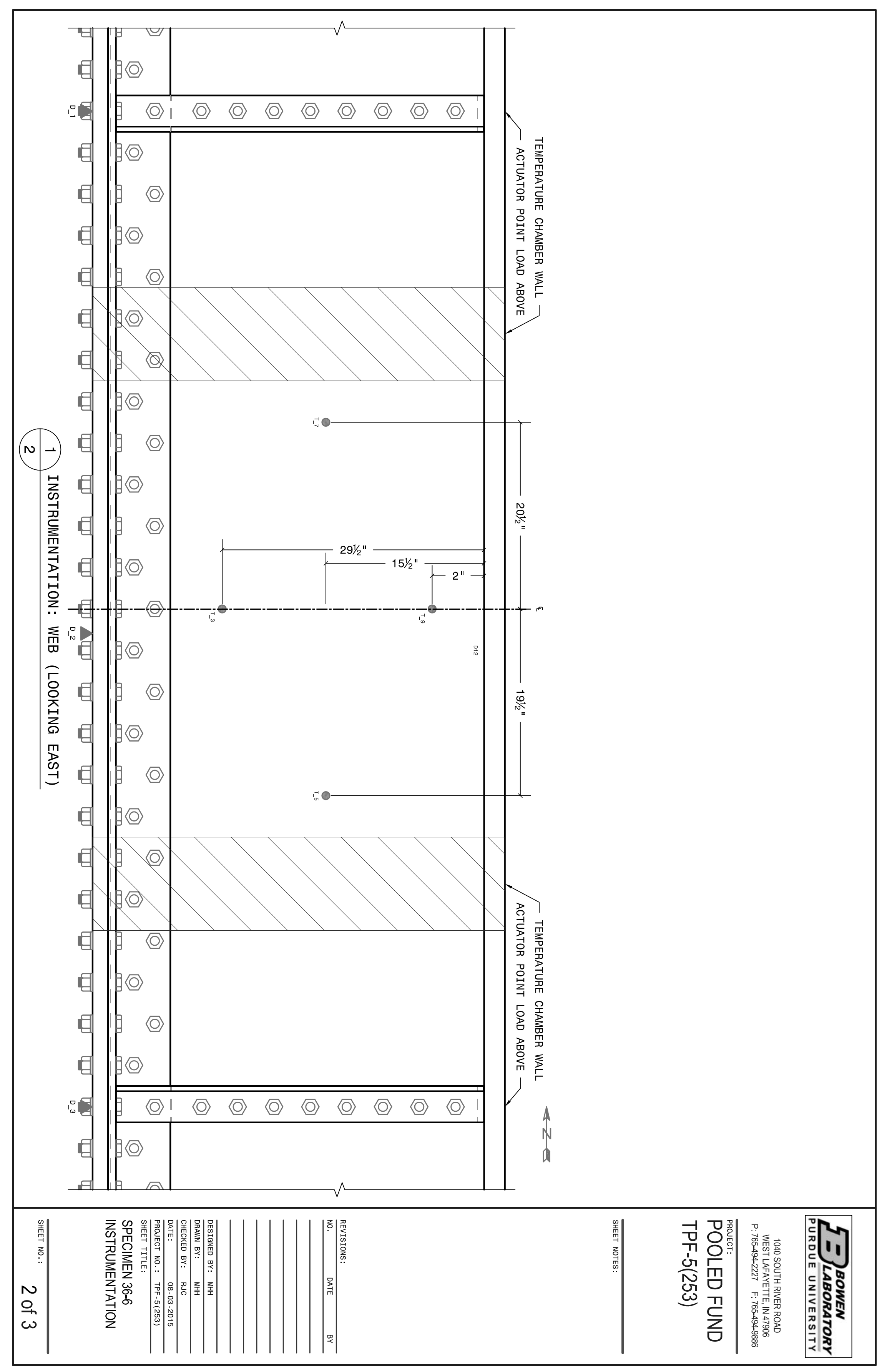




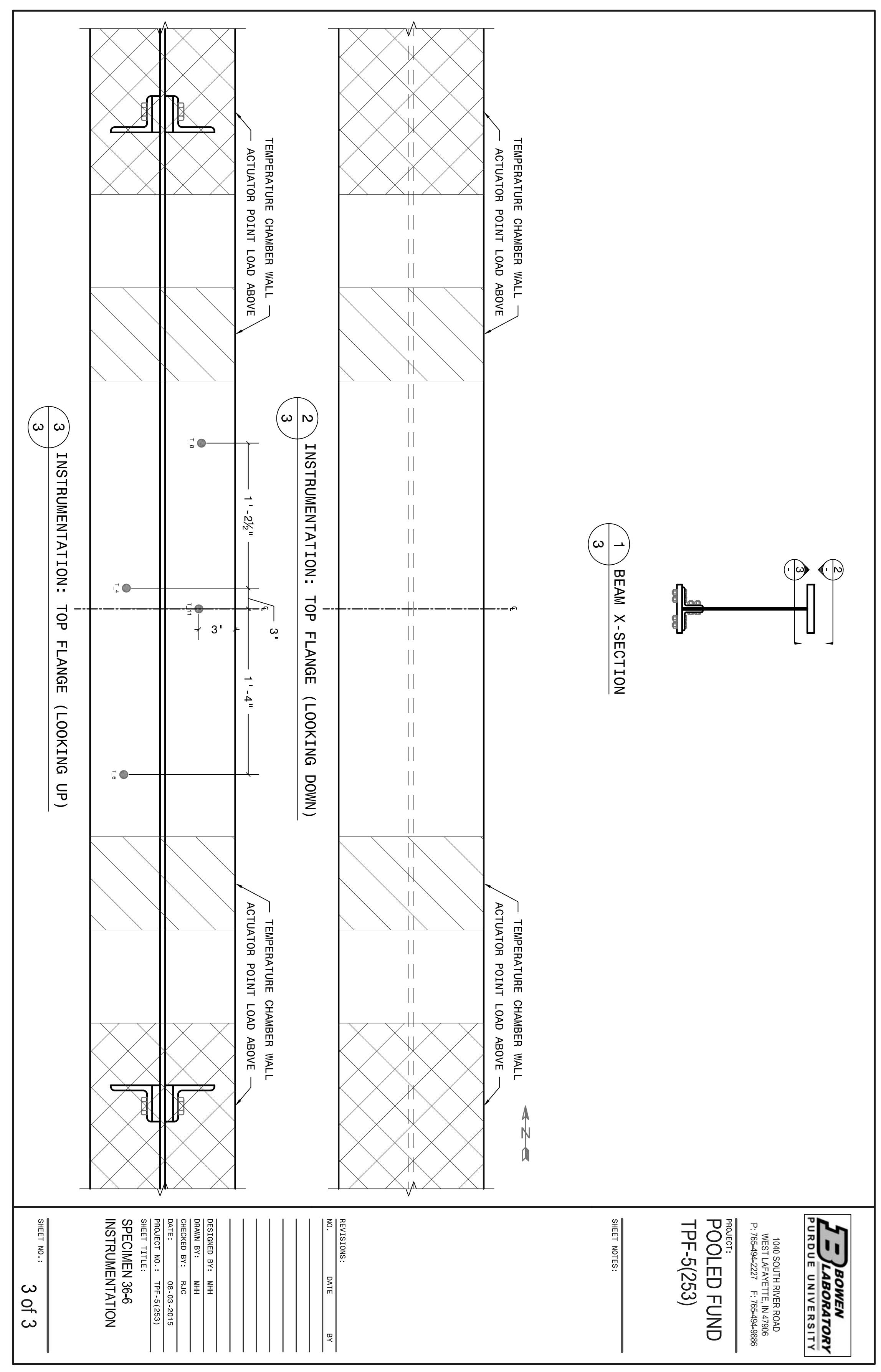


APPENDIX F TABULAR DATA FOR PLASTIC MATERIAL DEFINITION 
Table F-1 Tabular data for material definition

\begin{tabular}{|c|c|c|c|}
\hline \multicolumn{4}{|c|}{ Isotropic Plastic Hardening } \\
\hline $\begin{array}{l}\text { Yield Stress } \\
\quad(\mathrm{ksi})\end{array}$ & Plastic Strain & $\begin{array}{l}\text { Yield Stress } \\
\quad(\mathrm{ksi})\end{array}$ & Plastic Strain \\
\hline 63 & 0 & 82 & 0.027177 \\
\hline 63 & 0.002 & 83 & 0.030642 \\
\hline 64 & 0.002337 & 84 & 0.034499 \\
\hline 65 & 0.002725 & 85 & 0.038786 \\
\hline 66 & 0.00317 & 86 & 0.043547 \\
\hline 67 & 0.003679 & 87 & 0.048827 \\
\hline 68 & 0.00426 & 88 & 0.054676 \\
\hline 69 & 0.004922 & 89 & 0.061147 \\
\hline 70 & 0.005675 & 90 & 0.068298 \\
\hline 71 & 0.006531 & 91 & 0.076193 \\
\hline 72 & 0.007501 & 92 & 0.084898 \\
\hline 73 & 0.008598 & 93 & 0.094488 \\
\hline 74 & 0.009837 & 94 & 0.10504 \\
\hline 75 & 0.011235 & 95 & 0.11664 \\
\hline 76 & 0.01281 & 96 & 0.12938 \\
\hline 77 & 0.014579 & 97 & 0.143356 \\
\hline 78 & 0.016566 & 98 & 0.158675 \\
\hline 79 & 0.018792 & 99 & 0.175451 \\
\hline 80 & 0.021284 & 100 & 0.193804 \\
\hline 81 & 0.024069 & & \\
\hline
\end{tabular}

